Article

\title{
Glassfrogs of Ecuador: Diversity, Evolution, and Conservation
}

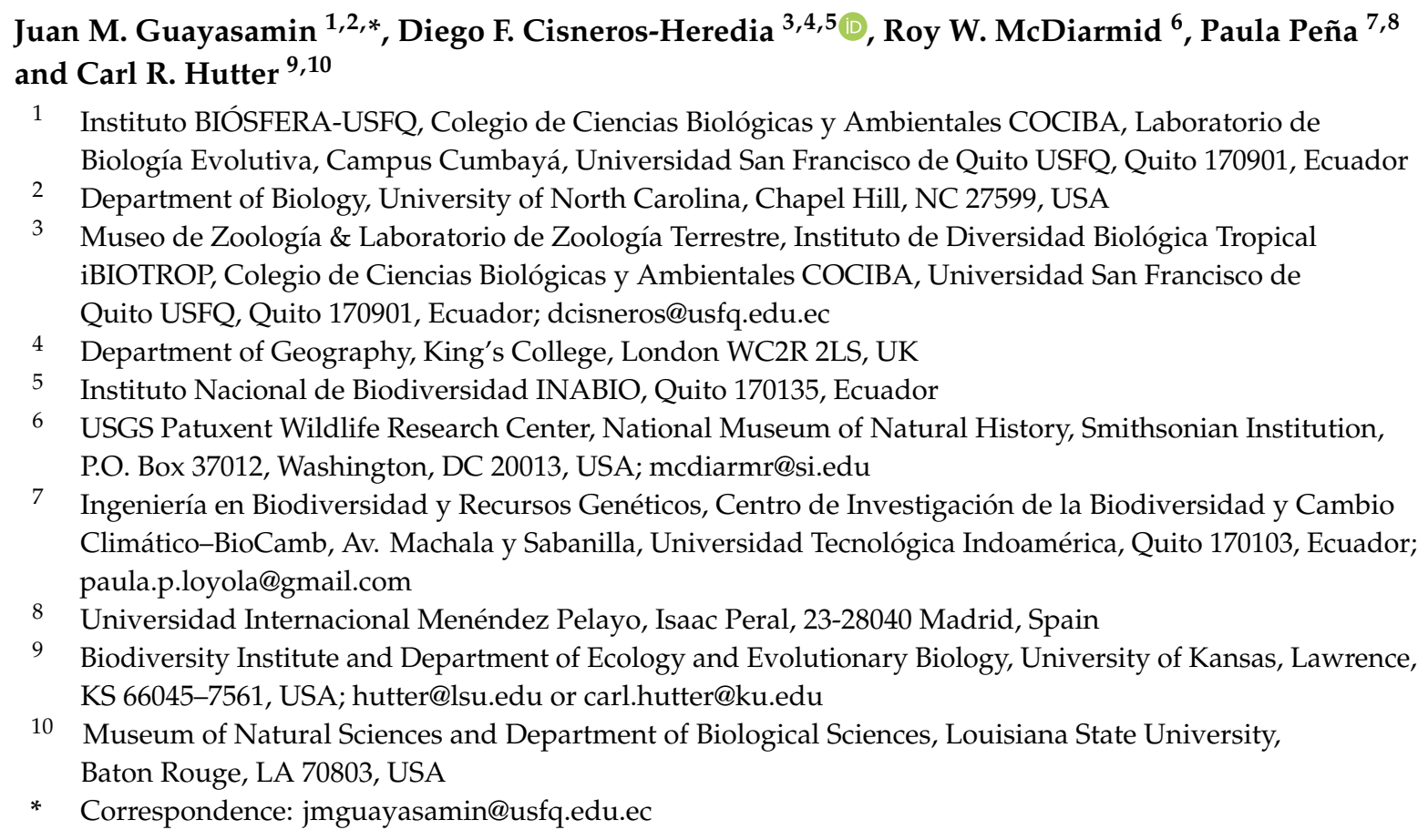

Received: 30 December 2019; Accepted: 6 May 2020; Published: 2 June 2020

Abstract: Glassfrogs (family: Centrolenidae) represent a fantastic radiation ( 150 described species) of Neotropical anurans that originated in South America and dispersed into Central America. In this study, we review the systematics of Ecuadorian glassfrogs, providing species accounts of all 60 species, including three new species described herein. For all Ecuadorian species, we provide new information on the evolution, morphology, biology, conservation, and distribution. We present a new molecular phylogeny for Centrolenidae and address cryptic diversity within the family. We mploy a candidate species system and designate 24 putative new species that require further study to determine their species status. We find that, in some cases, currently recognized species lack justification; specifically, we place Centrolene gemmata and Centrolene scirtetes under the synonymy of Centrolene lynchi; C. guanacarum and C. bacata under the synonymy of Centrolene sanchezi; Cochranella phryxa under the synonymy of Cochranella resplendens; and Hyalinobatrachium ruedai under the synonymy of Hyalinobatrachium munozorum. We also find that diversification patterns are mostly congruent with allopatric speciation, facilitated by barriers to gene flow (e.g., valleys, mountains, linearity of the Andes), and that niche conservatism is a dominant feature in the family. Conservation threats are diverse, but habitat destruction and climate change are of particular concern. The most imperiled glassfrogs in Ecuador are Centrolene buckleyi, C. charapita, C. geckoidea, C. medemi, C. pipilata, Cochranella mache, Nymphargus balionotus, N. manduriacu, N. megacheirus, and N. sucre, all of which are considered Critically Endangered. Lastly, we identify priority areas for glassfrog conservation in Ecuador.

Keywords: anura; biogeography; centrolenidae; systematics; taxonomy 


\section{Introduction}

The Neotropical family Centrolenidae Taylor 1951 is a monophyletic taxon that contains about 150 species classified into 12 genera [1] (Figure 1). Historical biogeographic evidence in a phylogenetic context suggests that the group originated in South America and subsequently dispersed to Central America [2,3]. Centrolenids share a unique morphology and behavior that makes them readily identifiable; some of the most evident traits include a green dorsum in most species (Figure 2), completely or partially translucent venter (Figure 3), out-of-water deposition of eggs along streams (Figure 4), and forward-directed eyes (Figure 2A). Other interesting features that have evolved within Centrolenidae include parental care [4] (Figure 5), fighting behavior [5] (Figure 6), and humeral spines in males of some species [6] (Figure 7).
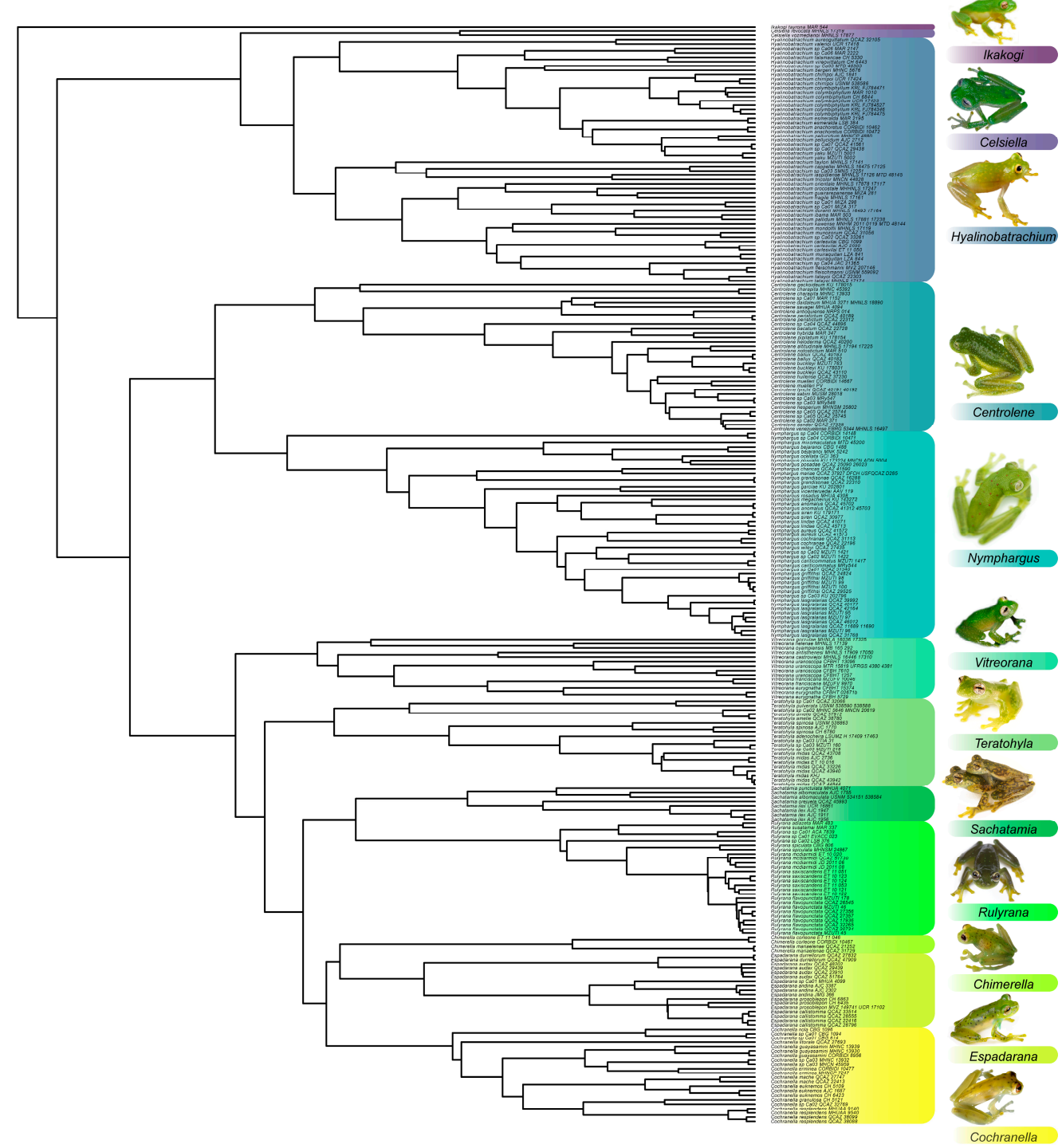

Figure 1. Relationships among glassfrog genera as inferred herein, using maximum likelihood criterium. Taxonomy sensu Guayasamin et al. [1]. Taxon sampling includes 113 named glassfrog species, 24 putative new species, and 49 outgroup taxa (not shown). The dataset contains complete or partial sequences of 10 genes representing $6513 \mathrm{bp}$ of data (mitochondrial: 12S rRNA, 16S rRNA, ND1; nuclear: BDNF, C-MYC exon 2, CXCR4, NCX1, POMC, RAG1, SLC8A3). Sequences were generated in previous studies, as well as this one (see Table S2). Relationships within each genus are shown in additional figures and follow the same methodology. 
A

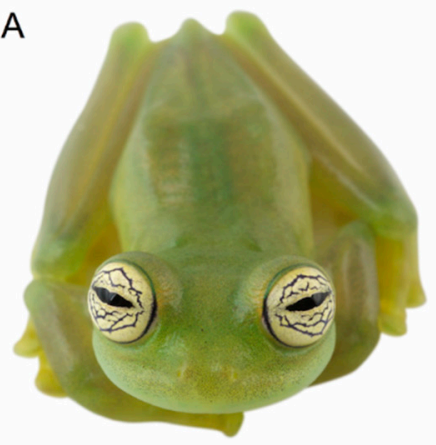

B

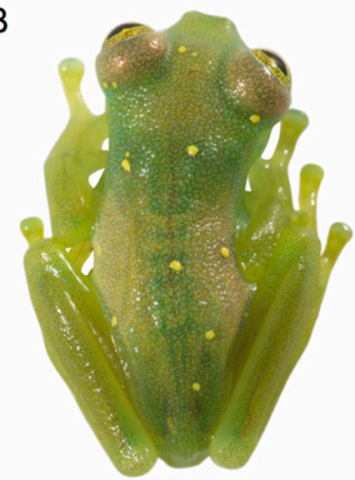

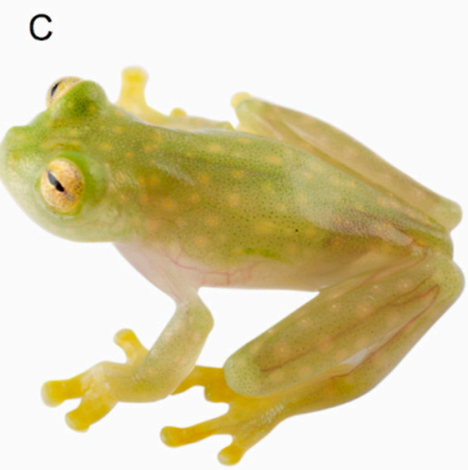
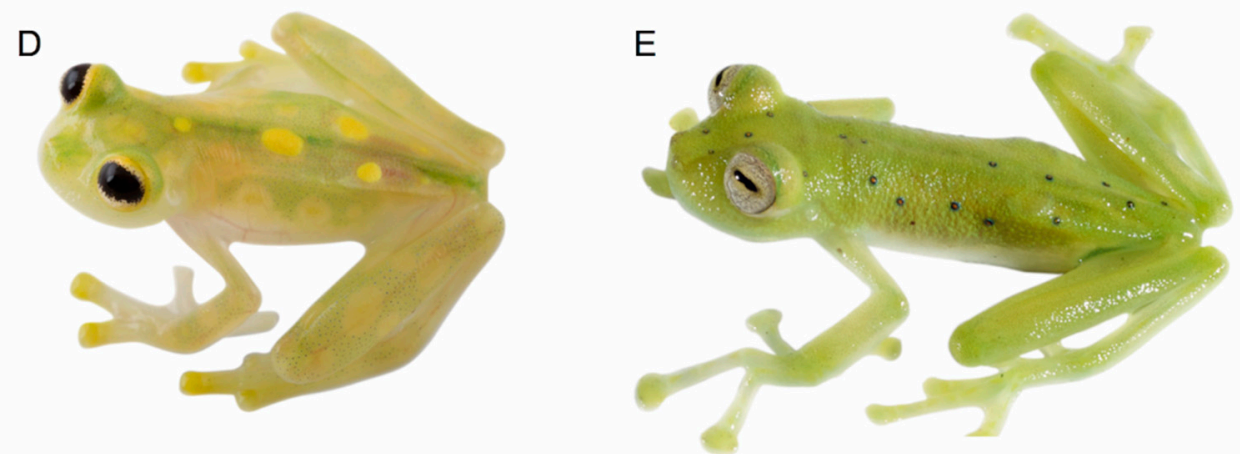

E

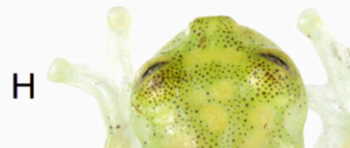

$\mathrm{F}$
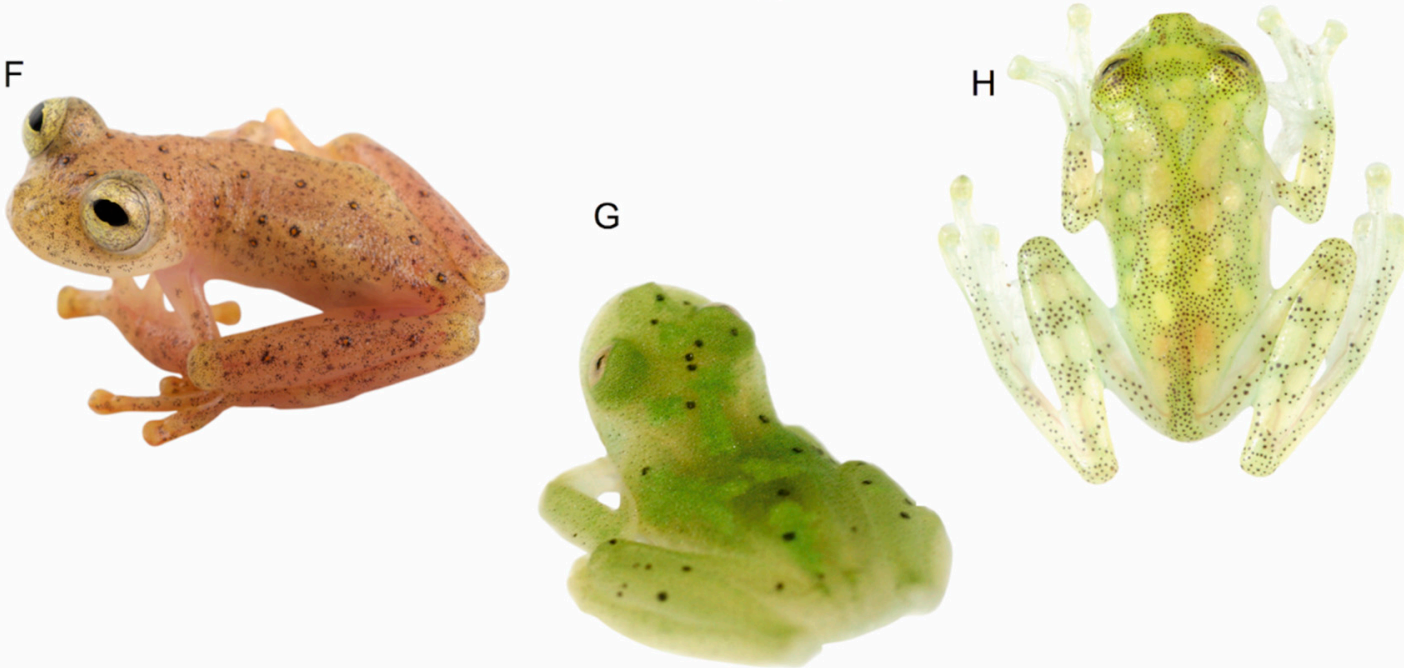

Figure 2. Dorsal color patterns in glassfrogs. (A) Uniform; Sachatamia ilex, QCAZ 47193. (B) With small and well-defined yellow spots; Nymphargus humboldti sp. nov., QCAZ 41084. (C) With small and diffuse yellow spots; Hyalinobatrachium fleischmanni, QCAZ 45386. (D) With large yellow spots; H. aureoguttatum, QCAZ 45365. (E) With small ocelli, N. cochranae, QCAZ 31113. (F) With ocelli and dark flecks; N. anomalus, QCAZ 47507. (G) With irregular light-green marks and small well-defined black spots, H. iaspidiense, QCAZ 38438. (H) With green reticulation; H. cf. valerioi, ZSFQ 0544 (photo by Jose Vieira). All photographs by Luis A. Coloma, except when noted.

The monophyly of Centrolenidae is well supported by morphological [7-9] and molecular $[2,8,10-14]$ studies. Osteological characters shared by all glassfrogs (Figure 8 ) include a dilated medial process on Metacarpal III [7], T-shaped terminal phalanges [15], intercalary element between distal and penultimate phalanges [15], and complete or partial fusion of tibiale and fibulare [15,16]. The diversity of glassfrogs is growing and in constant revision (e.g., [1,6,17-21]). Centrolenid species richness is concentrated in mountain chains, where humidity is high, and streams provide suitable 
reproductive habitats. Therefore, it is no surprise that the Andes, by far, is the center of diversity and endemism for the group and that Colombia and Ecuador maintain the highest species richness.

In 1973, John D. Lynch and William E. Duellman [22] provided the first review of the glassfrogs of Ecuador, and they reported the presence of 20 species and suggested the occurrence of an additional one. Only 47 years later, the species richness of this family has tripled, reaching the incredible number of 60 species in Ecuador. Since Lynch and Duellman's pioneering work, our understanding of centrolenid biology [23-25], morphology [6,9,17], systematics $[1,6,17,26,27]$, biogeography $[3,28]$, and evolution $[2,19,25]$ has improved substantially. Still, there are novel challenges and conspicuous gaps that need to be filled.

Herein, we provide a new review of Ecuadorian glassfrogs, bringing an update of what is known about the group, highlighting issues pending resolution, and providing a framework that we hope will facilitate further research, particularly with species identification, discovery, and conservation. We employ a candidate species system (e.g., [29]) to identify putative undescribed species to be investigated and to streamline the species discovery process. These tasks are particularly urgent in the current global amphibian extinction phenomenon [30-33].

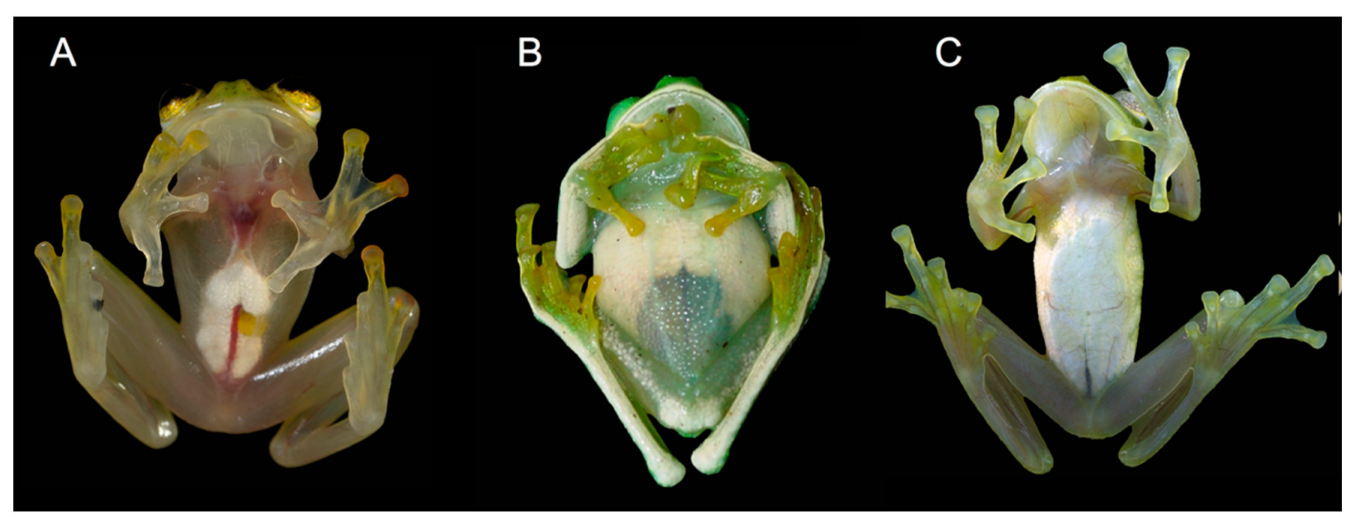

Figure 3. Ventral transparency in glassfrogs. (A) Complete transparency of parietal peritoneum and pericardium; H. aureoguttatum. (B) Partial transparency: parietal peritoneum is transparent only posteriorly; N. posadae. (C) Venter opaque (no ventral transparency): ventral parietal peritoneum and the urinary bladder peritoneum are opaque (white); N. gradisonae. Photos by Martín Bustamante.

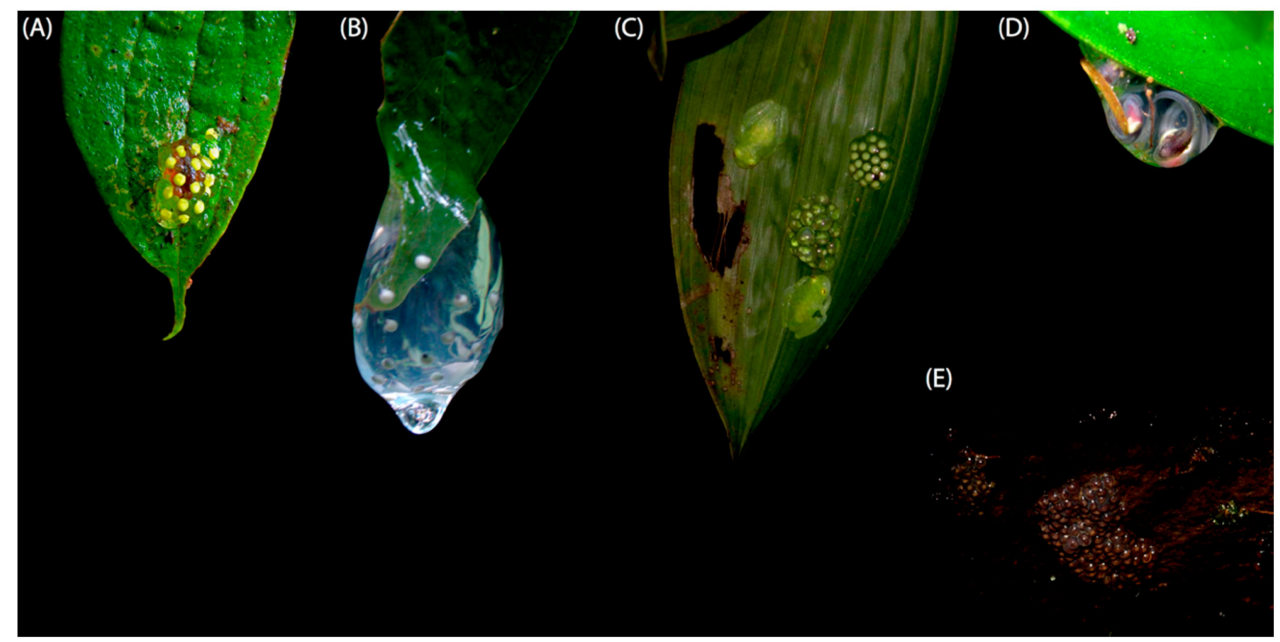

Figure 4. Egg deposition sites in glassfrogs. (A) On upper side of leaves (C. sanchezi). (B) On tip of leave (N. wileyi). (C) On underside of leaves (H. cappellei, photo by C. Barrio-Amorós). (D) On the margin of underside of leaves (Teratohyla spinosa, photo by R. Puschendorf). (E) On rocks (e.g., Sachatamia albomaculata, photo by R. Puschendorf). Figure modified from Guayasamin et al. [1]. 


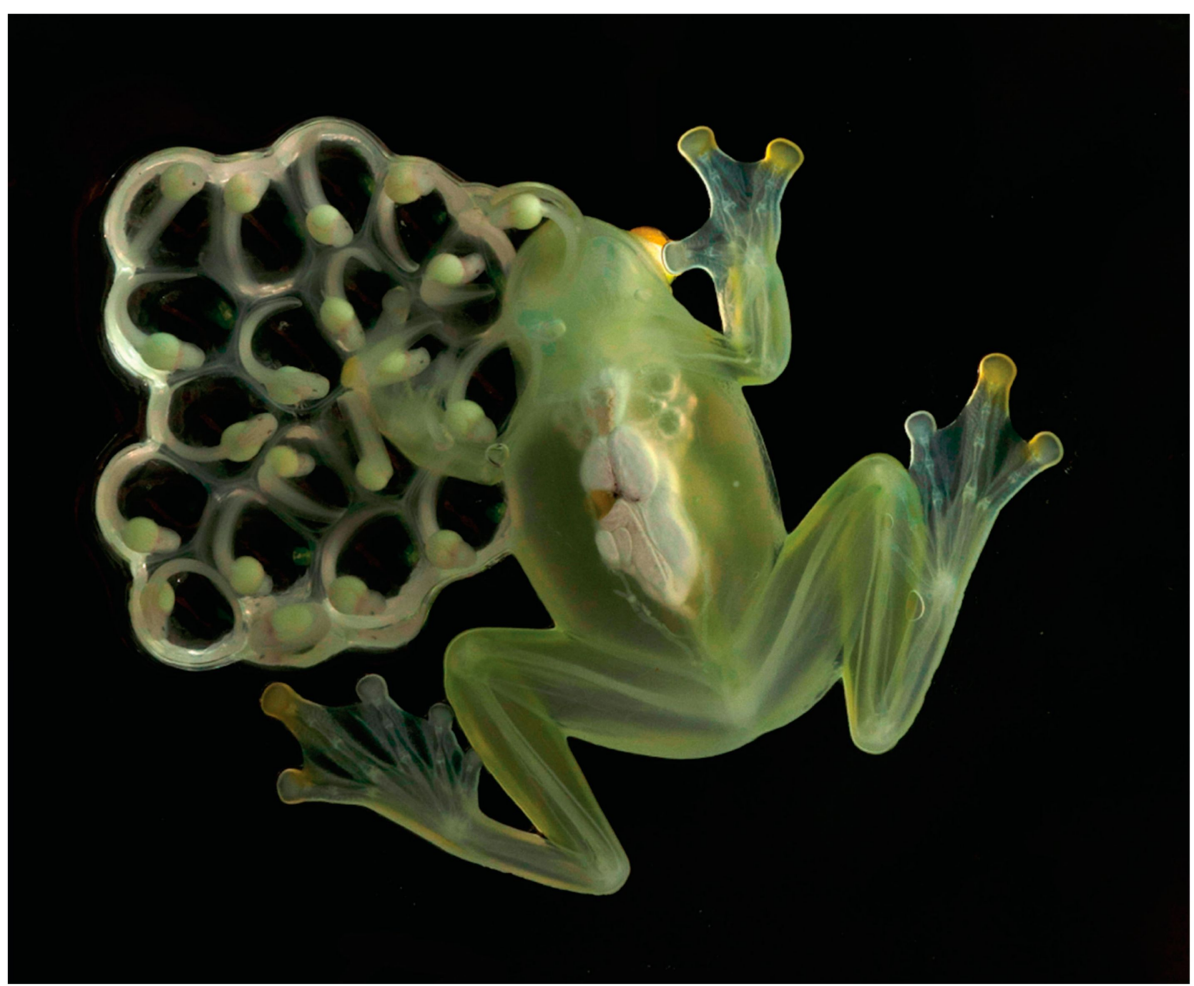

Figure 5. Parental care in glassfrogs. Adult male of Hyalinobatrachium aureoguttatum, with egg clutch. Photo by Luis A. Coloma.

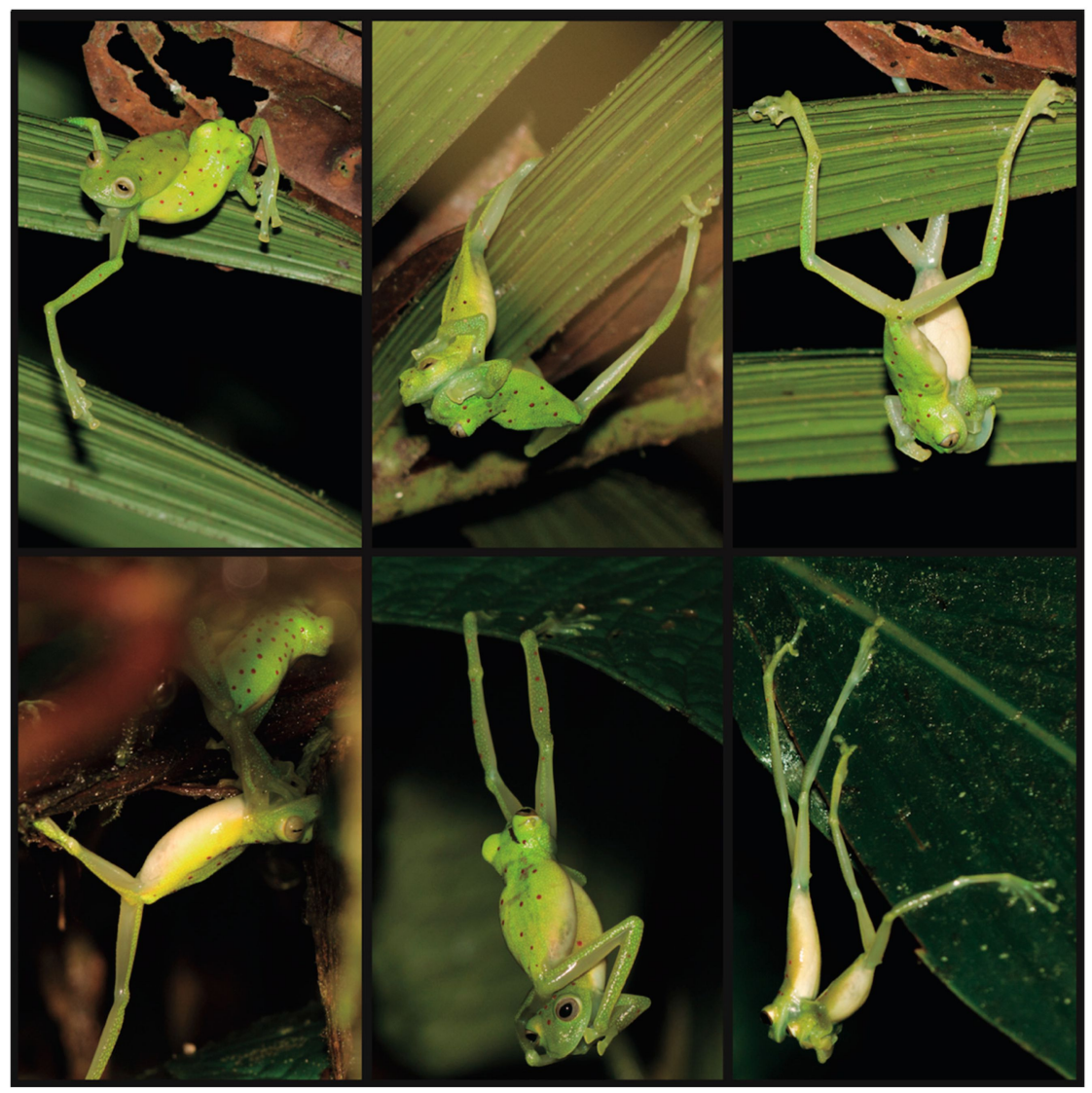

Figure 6. Combat behavior in glassfrogs. Note diversity of positions. Illustrated species: Nymphargus grandisonae. Photos by Carl R. Hutter. 


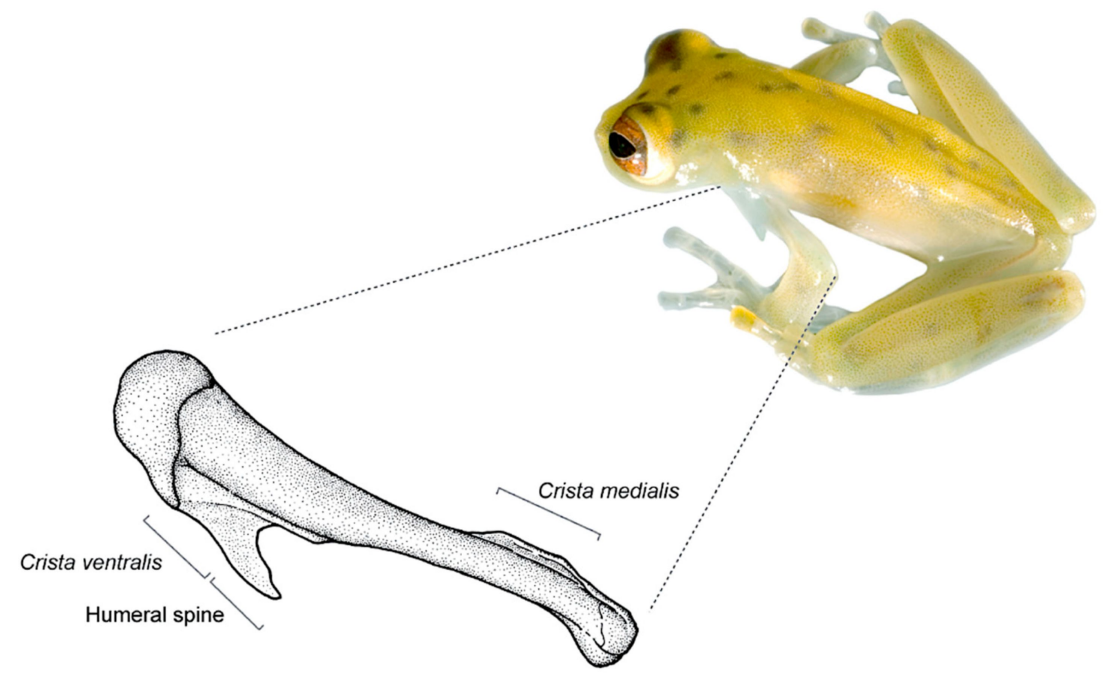

Figure 7. Humeral spine in Cochranella litoralis. Note that the humeral spine is formed by the prolongation of the crista ventralis. Photo by Luis A. Coloma; drawing by Linda Trueb.

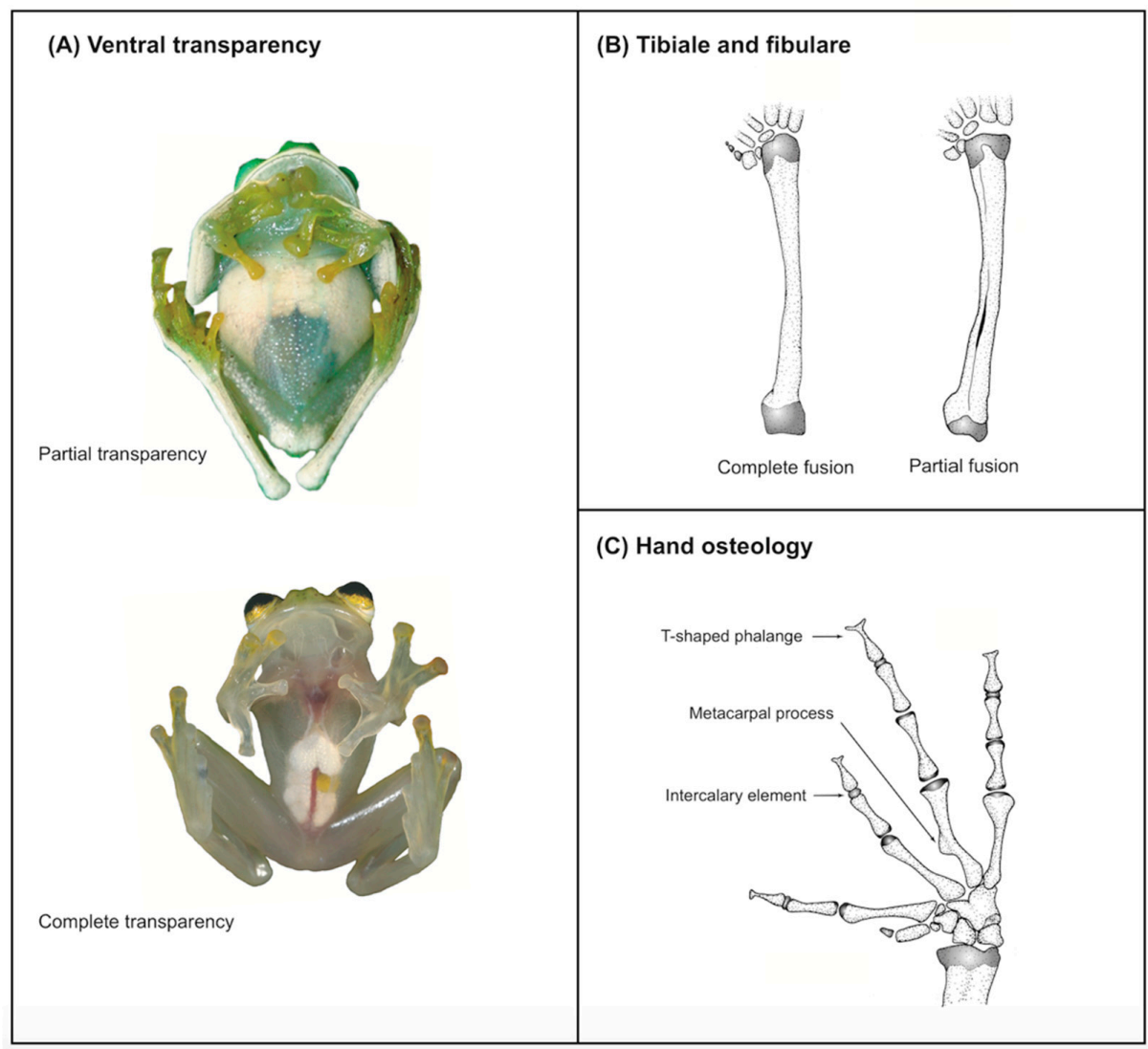

Figure 8. Synapomorphies of Centrolenidae. (A) Partial (Nymphargus posadae, QCAZ 25090) and complete ventral transparency (Hyalinobatrachium aureoguttatum, QCAZ 32070). (B) Partial (N. wileyi, QCAZ 26029) and complete fusion between tibiale and fibulare (H. munozorum, KU 155497). (C) Presence of medial process on Metacarpal III and intercalary element (Teratohyla spinosa, KU 32935). The presence of $\mathrm{T}$ or Y-shaped terminal phalanges is a synapomorphy of Allocentroleniae (Allophrynidae + Centrolenidae). Photos in (A) by M. Bustamante. Modified from Guayasamin et al. [1]. 


\section{Methods}

\subsection{Taxonomy and Species Concept}

Throughout this work, we use the name Centrolenidae as originally intended by Taylor [15]. The taxonomic arrangement below the family level (i.e., subfamily and genus) follows the proposal by Guayasamin et al. [1]. We use quotations to denote species with uncertain phylogenetic position to differentiate them from monophyletic clades (e.g., "Centrolene", "Cochranella"), as proposed by Guayasamin et al. [1]. An updated taxonomy for all the species in Centrolenidae is provided in Table S1.

For recognizing species, we adhered to the evolutionary species concept first proposed by Simpson [34,35], modified by Wiley [36] and de Queiroz [37,38]. This concept incorporates important theoretical factors such as lineage independence, identity, and evolutionary tendencies, and provides a flexible framework when reproductive isolation is difficult to test (e.g., allopatric populations). Evidence supporting the validity of a species can come from different sources (e.g., morphology, DNA, behavior, ecology), and no trait alone can be considered a biological property that a species must have in order to be recognized [37]. In other words, under the evolutionary species concept, the only necessary property for an entity to be a recognized as a species is that it corresponds to a temporal segment of a metapopulation lineage evolving separately from other lineages [37,38]. Evidence for independent evolution is gathered from different data sources, where integrative taxonomy plays a fundamental role when assessing what represents (or not) a distinctive species (e.g., [39,40]).

\subsection{Characters and Terminology}

For general terminology and descriptions of morphological characters we follow the proposals by Lynch and Duellman [22] and Cisneros-Heredia and McDiarmid [17]. We illustrate some of the most relevant traits for glassfrog identification, including dorsal color pattern (Figure 2), skin texture (Figure 9), and snout shape (Figure 10). To facilitate comparison with previous literature dealing with anurans, fingers are numbered preaxially to postaxially from I-IV. However, we stress that from an evolutionary perspective, anuran fingers should be numbered from II-V, to reflect the loss of Digit I in anurans [41-43]. Webbing formulae follow the method of Savage and Heyer [44], as modified by Guayasamin et al. [20] (Figure 11). Larval characters follow the terminology recommended by McDiarmid and Altig [45]. The morphology of nuptial excrescences and prepollical spines (Figure 12) follows the types proposed by Flores [46], with the additions and modifications detailed in Cisneros-Heredia and McDiarmid [17] and Guayasamin et al. [1]. Other key traits in centrolenid taxonomy are humeral spines (Figure 7, Figure 13, and Figure 14), ventral transparency (Figure 8), peritoneum and pericardium (with or without iridophores; Figure 13), enlarged subcloacal warts on thighs below vent (Figure 15), and tubercles on the external edge of arm, hand, and foot (Figure 16).
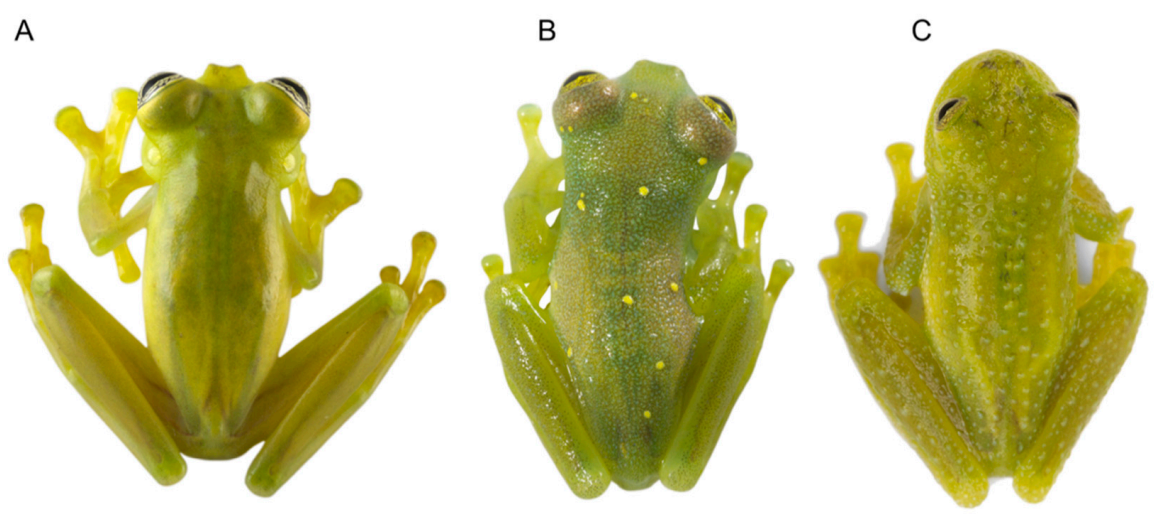

Figure 9. Skin texture in glassfrogs. (A) Smooth; Sachatamia ilex, QCAZ 47193. (B) Shagreen; Nymphargus humboldti sp. nov., ZSFQ 0833. (C) Pustular; Centrolene heloderma, QCAZ 40200. All photographs by Luis A. Coloma, except (B) by Jose Vieira/Tropical Herping. 
When discussing parental care, we adopt the terminology by Delia et al. [25]. Egg brooding refers to a specific form of ventral contact where the parent positions its body over the egg clutch; this behavior reduces embryonic mortality by protecting embryos from dehydration and, possibly, by preventing fungal development and predation [25]. Parental care is divided into the following behaviors [25]: (i) Short-term maternal care, where brooding is provided for a few hours just after oviposition; (ii) prolonged male care, where parental care is provided for several weeks; and (iii) prolonged female care, where parental care is provided for several weeks (only observed in Ikakogi tayrona [47]).

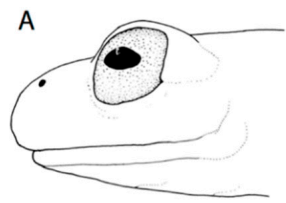

D

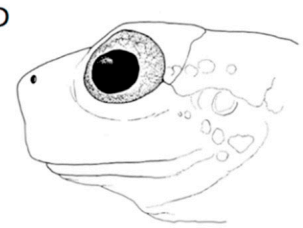

B

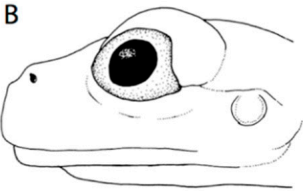

$\mathrm{E}$

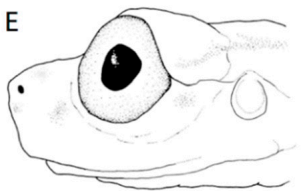

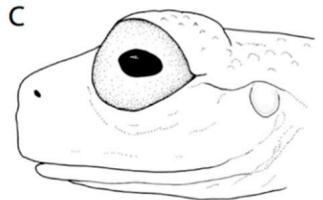

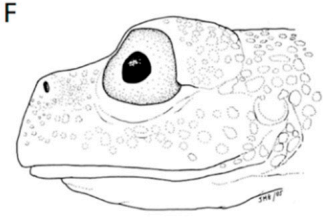

Figure 10. Snout shape in Glassfrogs. (A) Round, Hyalinobatrachium munozorum, KU 118054. (B) Bluntly round, Centrolene ballux, KU 164725. (C) Truncate, Nymphargus megacheirus, KU 143269. (D) Slightly protruding, "Centrolene" medemi, KU 164493. (E) Protruding, "Cochranella" balionota, KU 164708. (F) Sloping, Nymphargus grandisonae, KU 164688. Drawings by Juan M. Guayasamin.

Morphometrics-morphological variables were measured with digital callipers to the nearest $0.1 \mathrm{~mm}$, as follows: (1) Snout-vent length $(\mathrm{SVL})=$ distance from tip of snout to posterior margin of vent; (2) tibia length (TL) = length of flexed leg from knee to heel; (3) foot length (FL) = distance from proximal margin of outer metatarsal tubercle to tip of Toe IV; (4) head length (HL) = distance from tip of snout to posterior angle of jaw articulation; (5) head width $(\mathrm{HW})=$ width of head measured at level of jaw articulations; (6) interorbital distance $(\mathrm{IOD})=$ distance between upper eyelids, representing the width of the underlying frontoparietals; (7) upper eyelid width (UE) = greatest transverse width of upper eyelid; (8) internarial distance (IN) = distance between nostrils; (9) eye-nostril distance $(\mathrm{EN})=$ distance from posterior margin of nostril to anterior margin of eye; (10) snout-eye distance $(\mathrm{SE})=$ distance from tip of snout to anterior margin of eye; (11) horizontal eye diameter (ED) $=$ distance between anterior and posterior borders of eye; (12) tympanum diameter (TD) = distance between anterior and posterior margins of tympanic annulus; (13) eye-tympanum distance (ET) $=$ distance from posterior border of eye to anterior margin of tympanic annulus; (14) radio-ulna length $($ RUL) $=$ length of flexed forearm from elbow to proximal border of palmar tubercle; (15) hand length (HDL) = distance from the proximal margin of palmar tubercle to tip of Finger III; (16) Finger-I length $(\mathrm{F} 1 \mathrm{~L})=$ distance from outer margin of palmar tubercle to tip of Finger I; (17) Finger-II length $(\mathrm{F} 2 \mathrm{~L})=$ distance from outer margin of palmar tubercle to tip of Finger II; (18) disc of Finger III $(3 \mathrm{DW})=$ greatest width of disc of Finger III; and (19) Finger-III width (F3W) = width of Finger III measured at the level of distal subarticular tubercle, including lateral fringes and excluding webbing. For comparing different body sizes (SVL) among glassfrogs, we considered the average size of males and categorized them according to the following criteria: Minute (SVL $<22 \mathrm{~mm}$ ), small (SVL 22-25 mm), medium (SVL 25-30 mm), large (SVL 30-50 mm), and giant (SVL > 50). Eye diameter was divided into small (eye diameter $<10 \% \mathrm{SVL}$ ), moderate size (eye diameter 10\%-15\% SVL), and large (eye diameter $>15 \%$ SVL). Tympanum was considered to be very small (tympanum $<20 \%$ of eye diameter), small (tympanum $20 \%-30 \%$ of eye diameter), moderate (tympanum $31 \%-40 \%$ of eye diameter), large (tympanum diameter $41 \%-50 \%$ of eye diameter), and very large (tympanum diameter $>50 \%$ of eye diameter. 


\section{A - Webbing Formula}

IV

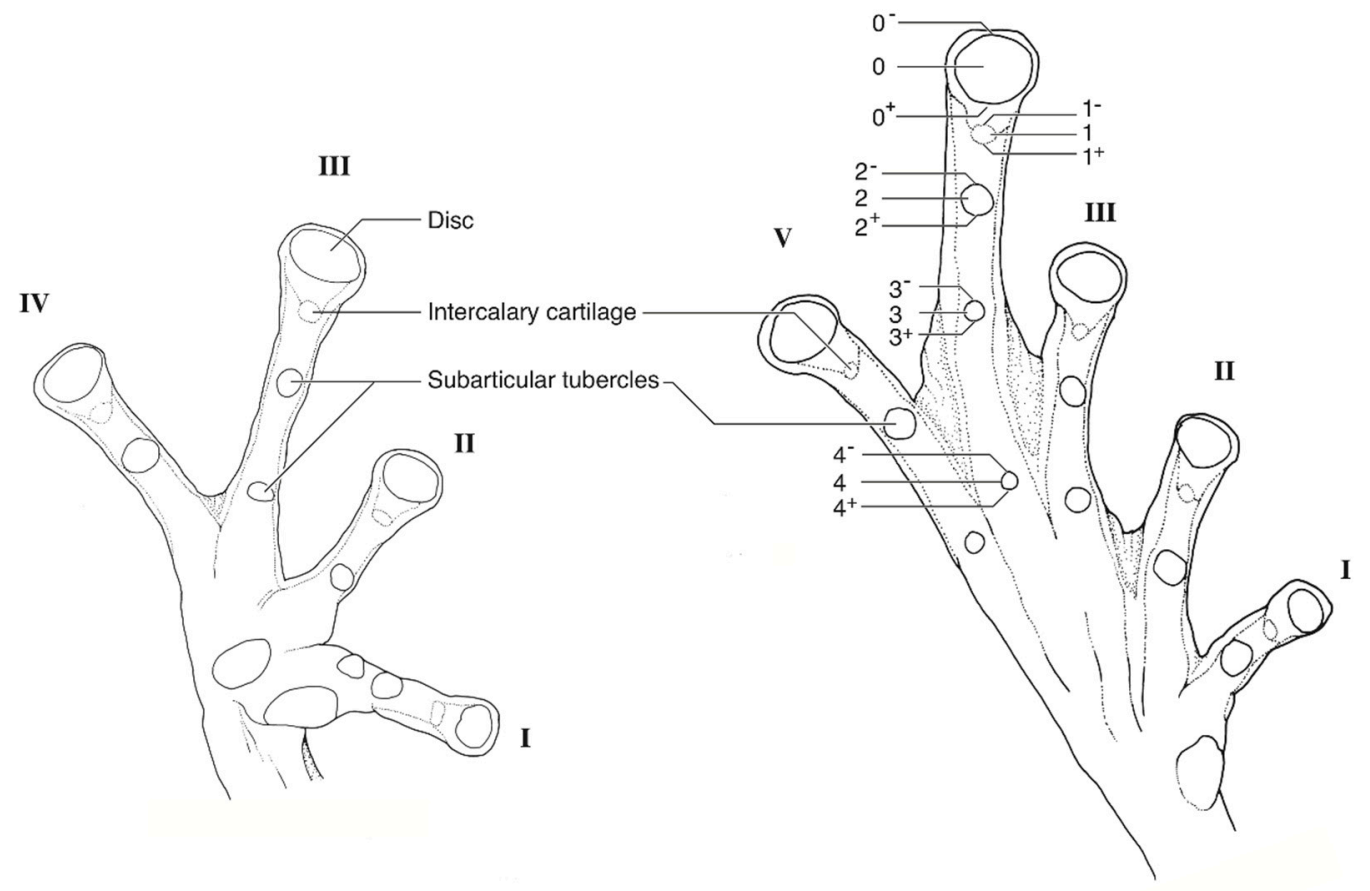

B - Types of hand webbing

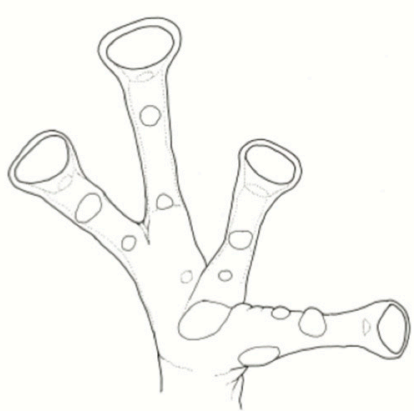

Absent

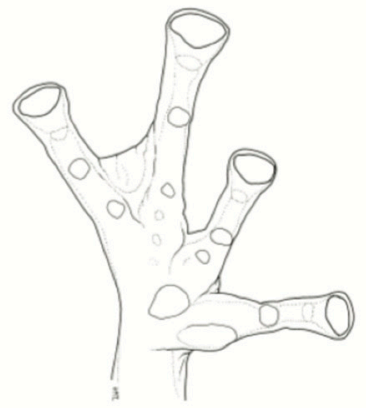

Moderate

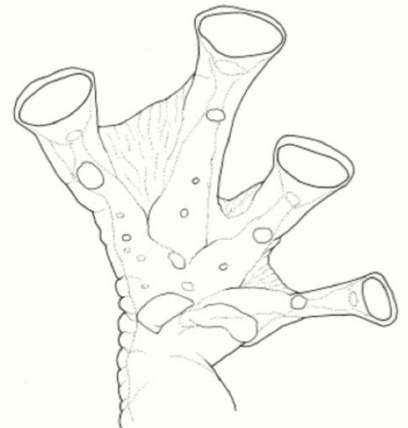

Extensive

Figure 11. Webbing in glassfrogs. (A) Terminology used for webbing formula in hands and feet (see Guayasamin et al. [20]; modified from Savage and Heyer [44]). Roman numerals (I, II, III, IV, V) represent fingers or toes. Arabic numerals represent the number of phalanges completely or partially free of webbing. We use $\mathbf{0}^{-}$to indicate that webbing reaches the distal margin of the disc; 0 indicates that webbing reaches the middle of the disc; $\mathbf{0}^{+}$indicates that webbing reaches the proximal margin of the disc; $\mathbf{1}^{-}$indicates that webbing reaches the distal margin of the intercalary cartilage; $\mathbf{1}$ indicates that the webbing the middle of the intercalary cartilage; $\mathbf{1}^{+}$indicates that the webbing the proximal margin of the intercalary cartilage; $2^{-}$indicates that webbing reaches the distal margin of the distal subarticular tubercle; $\mathbf{2}$ indicates that webbing reaches the middle of the distal subarticular tubercle; $\mathbf{2}^{\mathbf{-}}$ indicates that webbing reaches the proximal margin of the distal subarticular tubercle. For example, webbing formula in the illustrated foot is absent between Toes I and II (lateral fringes are not considered as webbing); II $1^{2 / 3}-3^{+}$III $1^{2 / 3}-3^{-}$IV $3^{-}-2$ V. Figure modified from Guayasamin et al. (2006). (B) Simplified type of hand webbing. Absent: Nymphargus cochranae, QCAZ 31113. Moderate: Chimerella mariaelenae, QCAZ 22363. Extensive: Centrolene geckoidea, KU 164490. Drawings by Juan M. Guayasamin. 


\section{A - Exposure of Prepollex}

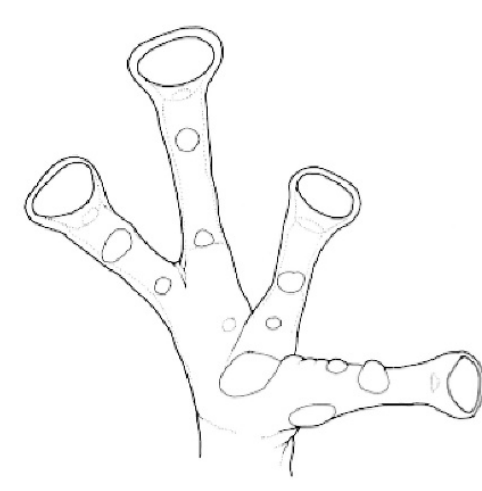

Concealed (hidden)

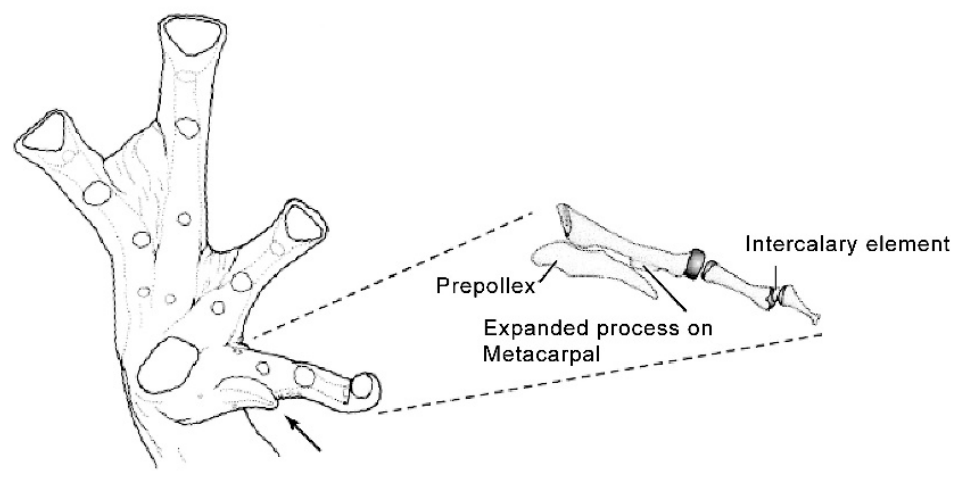

Distinct (visible)

\section{B - Nuptial pad morphology}

Type I

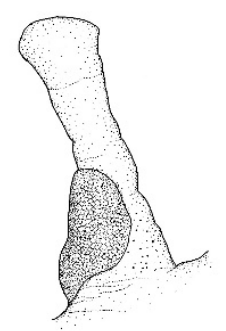

Type II

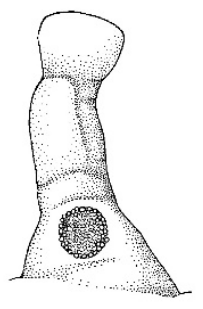

Type III

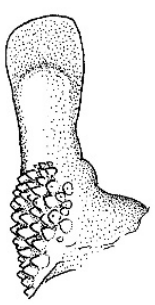

Type IV

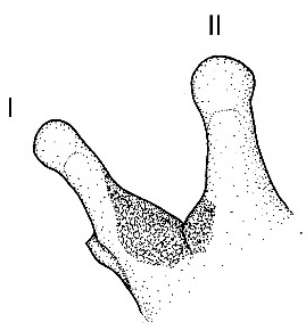

Type V

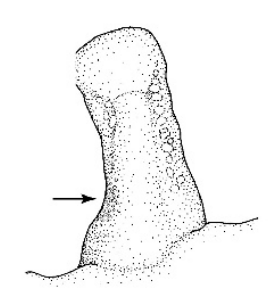

Figure 12. Prepollex and nuptial pad morphology in glassfrogs. (A) Condition of the prepollex. Concealed, Nymphargus cochranae, QCAZ 31113. Distinct, Teratohyla spinosa, KU 164668. (B) Nuptial pad morphology. Type I: Large to medium-size nuptial excrescence present on the dorsal, lateral, and/or ventral sides of the thumb; Cochranella posadae, QCAZ 26023. Type II: Small circular or squarish nuptial excrescence present on the dorsal or dorsolateral face of the thumb; Centrolene lynchi, MCZ 97846 (figure modified from Flores 1985). Type III: Medium-size spinous nuptial excrescence extending from the lateral side of the thumb to its dorsomedial surface; Nymphargus armatus, UVC 9400 (modified from Lynch and Ruiz-Carranza 1996). Type IV: Large nuptial excrescence formed by a granular pad that extends from the side of the thumb to its dorsomedial surface, and on the proximal dorsolateral surface of finger II; Cochranella litoralis, ICN 13821. Type V: Medium-size diffuse nuptial excrescence formed by glandular clusters and individual glands; a pad as such is absent; Hyalinobatrachium aureoguttatum, QCAZ 27429. Type VI (not illustrated): Nuptial excrescences formed by a combination of clustered and individual glands that sparse along the flanks of the body (see text). 


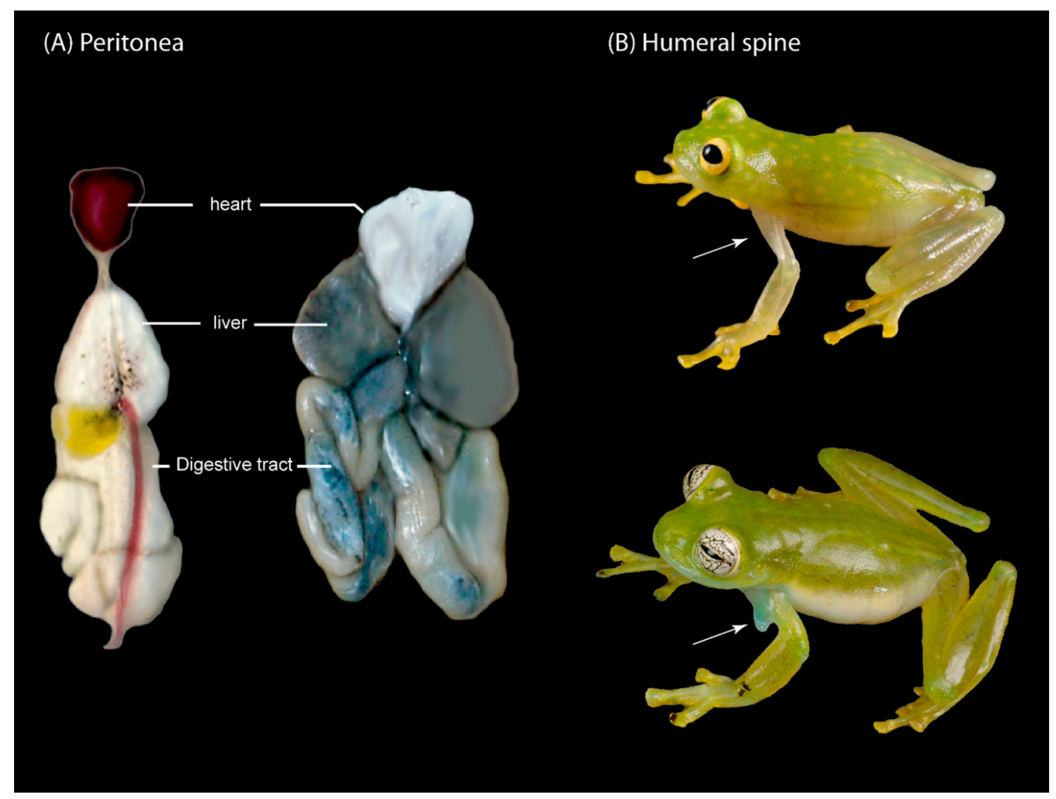

Figure 13. Peritonea and humeral spines in Centrolenidae. (A,Left): Pericardium lacking iridophores, hepatic, and visceral peritonea with iridophores (Hyalinobatrachium aureoguttatum). (A,Right): Pericardium with iridophores, hepatic, and visceral peritonea lacking iridophores (Centrolene buckleyi). (B,Top): Absence of humeral spine (H. fleischmanni). (B,Bottom): Presence of humeral spine in males (Espadarana callistomma). Figure modified from Guayasamin et al. [1].
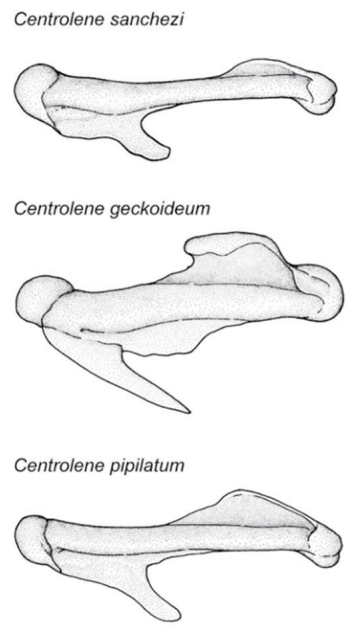

Chimerella mariaelenae
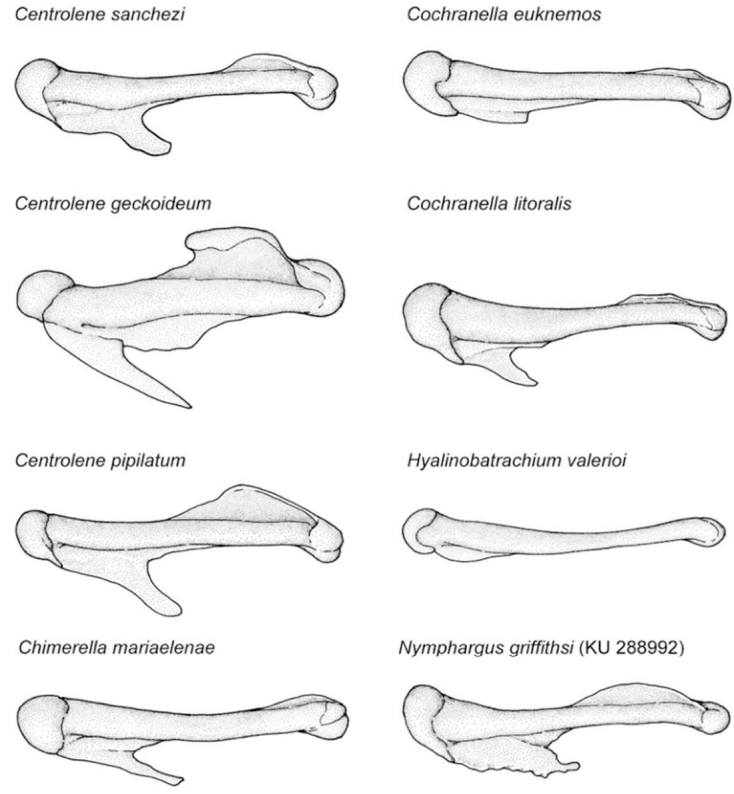

Nymphargus cochranae

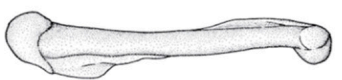

Nymphargus megacheirus
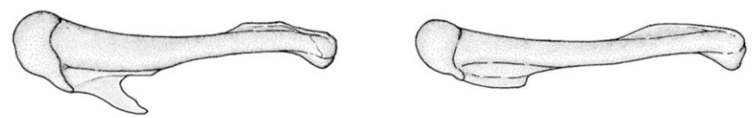

Hyalinobatrachium valerioi

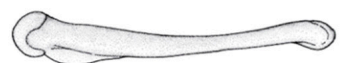

Sachatamia albomaculata

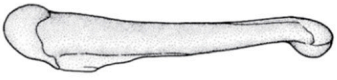

Sachatamia ilex

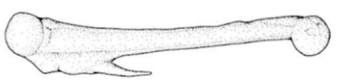

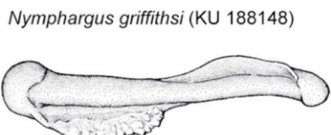

Teratohyla spinosa

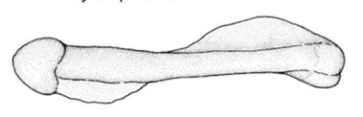

Figure 14. Variation of humeral spines, crista medialis, and crista ventralis, in adult males of Centrolenidae (modified from Guayasamin et al. [1]). Illustrated specimens are: Centrolene sanchezi, KU 170116; C. geckoidea, ICN 5598; C. pipilata, KU 143286; Cochranella euknemos, KU 77534; Cochranella litoralis, QCAZ 27693; Teratohyla spinosa, KU 32935; Nymphargus griffithsi, KU 288992, 188148; N. cochranae, KU 123218; N. megacheirus, KU 143271; Sachatamia albomaculata, KU 65185; S. ilex, LACM 72910; Chimerella mariaelenae, QCAZ 21252; H. valerioi, KU 178091. 


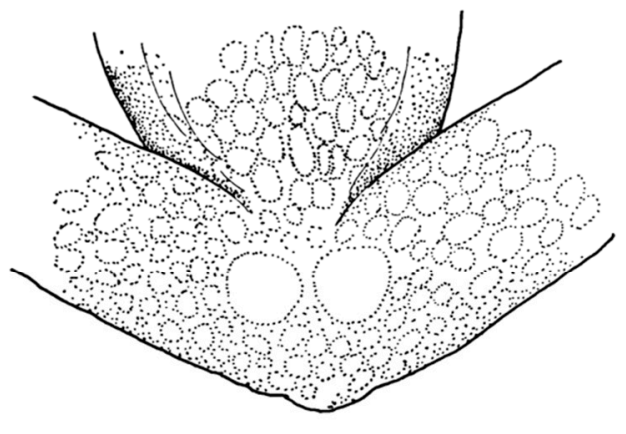

(A) Enlarged tubercles present

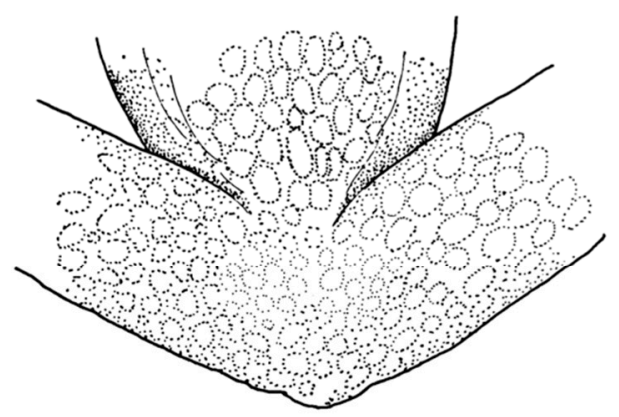

(B) Enlarged tubercles absent

Figure 15. Ventral surfaces of tights in glassfrogs. (A) With enlarged subcloacal warts. (B) Lacking enlarged warts. Illustrations by Juan M. Guayasamin.

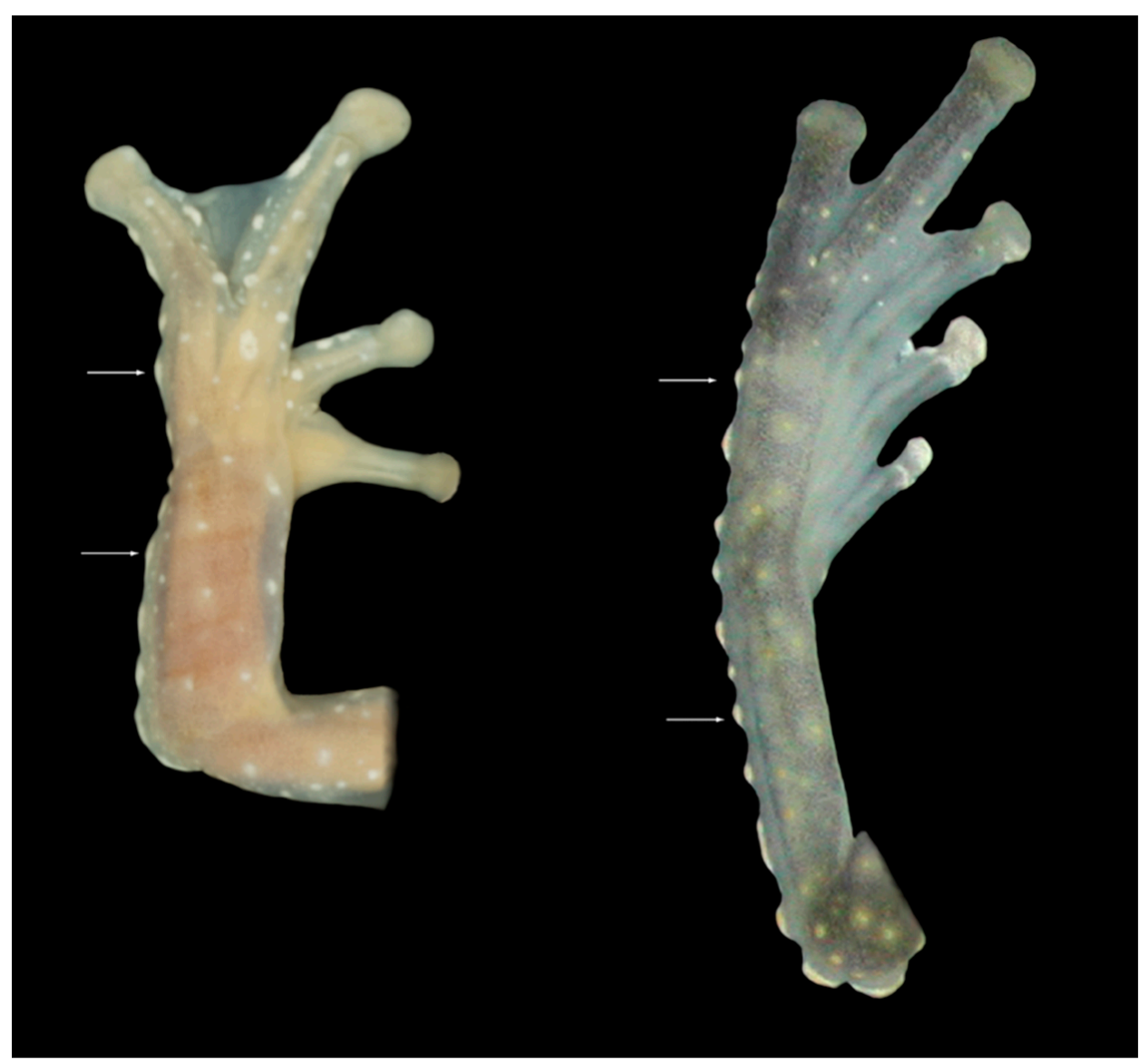

(A)

(B)

Figure 16. Tubercles on limbs. (A) Tubercles on ventrolateral edge of Finger IV and arm, Cochranella resplendens, KU 118053. (B) Tubercles on ventrolateral edge of Toe V and tarsus, C. mache, QCAZ 22412. Photos by Martín Bustamante.

Vocalizations - Calls were recorded in the field by different researchers (see Acknowledgments) using an Olympus Linear PCM Recorder LS-10 tape recorder and a Sennheiser K6-ME67 directional microphone. Recordings obtained by us are stored at the Laboratorio de Biología Evolutiva of the Universidad San Francisco de Quito (LBE). Sounds were recorded in PCM format at a sampling frequency of $44.1 \mathrm{kHz}$. Audiospectograms and oscillograms were generated in the $\mathrm{R}$ package 
SeeWave [48]. Frequency information was obtained through fast Fourier transformation, with a 50\% window overlap (Hanning window size of 1024 and a frequency window of $43.1 \mathrm{~Hz}$ ). The following call variables were measured: Call duration, duration between calls, number of notes per call, note duration, duration between notes, dominant frequency, first harmonic, second harmonic [49-51] (Table 1). A call is defined as the sound produced in a single exhalation of air. Calls and notes were divided into two categories, tonal and pulsed, based on distinct morphology. Tonal calls/notes have non-peaked amplitude sustained throughout the duration of the note. Pulsed calls/notes are characterized by having at least one clear amplitude peak. Pulses were defined as a visible increase and decrease of amplitude peaks on the oscillogram within a single note, and notes were defined by a single and complete amplitude rise from and return to the base frequency of the background noise. For a review on the use of bioacoustics in taxonomy and specific variable definitions, see Köhler et al. [52].

Table 1. Definitions of call variables [51].

\begin{tabular}{|c|c|}
\hline Call Variables & Definition \\
\hline Call type & $\begin{array}{l}\text { Calls tonal or pulsed; pulsed defined as having amplitude modulation } \\
\text { (Dautel et al. [50]) }\end{array}$ \\
\hline Call/note interval & Measured time between a call/note \\
\hline Call duration & $\begin{array}{l}\text { Call measured from the start of the amplitude rise away from the background } \\
\text { noise to return to the background noise }\end{array}$ \\
\hline Call rate & $\begin{array}{l}\text { (Total number of calls-1)/time measured from start of the first call to the } \\
\text { beginning of the last call }\end{array}$ \\
\hline Call rise time & Time from start of call to the point at maximum amplitude \\
\hline Number of pulses & Total number of pulses per call \\
\hline Pulse/note rate & $\begin{array}{c}\text { (Total number of pulses/notes-1)/time from beginning of first pulse/note to the } \\
\text { beginning of the final pulse }\end{array}$ \\
\hline Pulse length & $\begin{array}{l}\text { Time from start to end of one pulse; measured for pulses at the beginning, } \\
\text { middle, and end of call }\end{array}$ \\
\hline Pulse/note rise time & Time from start of a pulse/note to the point of maximum amplitude \\
\hline Pulse/note shape & $\begin{array}{l}\text { (Pulse rise time/pulse length); unitless variable that describes the overall shape } \\
\text { of the amplitude envelope of the pulse. Right or left skewed pulses will have a } \\
\text { rise time near the start or end of the call, respectively. This parameter allows } \\
\text { comparison of pulses/notes with differing lengths. }\end{array}$ \\
\hline $\begin{array}{l}\text { Pulse/note amplitude to call } \\
\text { peak amplitude ratio }\end{array}$ & $\begin{array}{c}\text { Maximum amplitude of pulses/notes compared to the peak amplitude of the } \\
\text { call. Measured between the start, middle, and end of call. Describes amplitude } \\
\text { distribution and modulation throughout call. }\end{array}$ \\
\hline $\begin{array}{l}\text { Pulse/note amplitude } \\
\text { change throughout call }\end{array}$ & $\begin{array}{l}\text { Ratio of pulse/notes amplitude compared between the middle and beginning of } \\
\text { call, the end and beginning of call, and the end and middle of call }\end{array}$ \\
\hline $\begin{array}{l}\text { Lower frequency of the } \\
\text { fundamental frequency }\end{array}$ & Lower limit of the fundamental frequency \\
\hline $\begin{array}{l}\text { Upper frequency of the } \\
\text { fundamental frequency }\end{array}$ & Upper limit of the fundamental frequency \\
\hline Dominant frequency & Frequency of call, which contains the greatest concentration of energy \\
\hline Frequency modulation & $\begin{array}{l}\text { Dominant frequency of the last } 0.020 \mathrm{~s} \text { of call subtracted from the dominant } \\
\text { frequency of the first } 0.020 \text { of call }\end{array}$ \\
\hline Harmonic frequencies & Measured harmonic frequencies \\
\hline Power, percent of max & $\begin{array}{l}\text { Measure for harmonic frequencies, percent of power in harmonic compared to } \\
\text { max power of call }\end{array}$ \\
\hline
\end{tabular}

Specimens examined -We examined ethanol-preserved specimens from the following herpetological collections: Centro de Biodiversidad y Genética, Cochabamba, Bolivia (CBG); Círculo Herpetológico de Panamá (CHP); Centro Jambatu de Investigación y Conservación de Anfibios, San Rafael, Ecuador (CJ); División de Herpetología, Museo Ecuatoriano de Ciencias Naturales, Quito, Ecuador (DHMECN); Field Museum, Division of Amphibians and Reptiles, Chicago, USA (FMNH); Instituto de Ciencias 
Naturales, Universidad Nacional de Colombia, Bogotá, Colombia (ICN); University of Kansas, Museum of Natural History, Division of Herpetology, Lawrence, Kansas, USA (KU); Natural History Museum of Los Angeles County, Section of Herpetology, Los Angeles, California, USA (LACM); Museum of Comparative Zoology, Harvard University, Cambridge, Massachusetts, USA (MCZ); Museo de Historia Natural La Salle, Caracas, Venezuela (MHNLS); Museo de Zoología, Universidad Tecnológica Indoamérica, Quito, Ecuador (MZUTI); Museo de Zoología, Pontificia Universidad Católica del Ecuador, Quito, Ecuador (QCAZ); Colección de Herpetología, Escuela de Biología, Universidad de Costa Rica, San José, Costa Rica (UCR); Museo de Vertebrados, Universidad del Valle, Cali, Colombia (UVC); and Museo de Zoología, Universidad San Francisco de Quito, Ecuador (ZSFQ). When specimens were not available for direct comparison, we relied on descriptions in the literature. Sexual maturity of specimens was determined by the presence of vocal slits and nuptial pads in males and by the presence of eggs or convoluted oviducts in females.

\subsection{Evolutionary Relationships}

Taxon and gene sampling-we combined genetic sequences available from previous work (mostly $[2,3,19])$ and new sequences generated during this study (Table S2). Genomic extraction, amplification, and sequencing are as described in Guayasamin et al. [2] and Castroviejo-Fisher et al. [3]. The final dataset contains complete or partial sequences of 10 genes representing $6513 \mathrm{bp}$ of data (mitochondrial: 12S rRNA, 16S rRNA, ND1; nuclear: BDNF, C-MYC exon 2, CXCR4, NCX1, POMC, RAG1, SLC8A3). We sampled 49 outgroup taxa from a large range of families within Hyloidea (Table S2), and include all three species from Allophrynidae, the sister group to Centrolenidae [2,12]. Finally, ingroup taxon sampling includes 251 terminals, representing 113 named species, and 24 putative new species. The percentage of named species sampled (i.e., matrix completeness) for each marker is as follows: $12 \mathrm{~S}=90 \% ; 16 \mathrm{~S}=94 \%$; BDNF $=55 \%$; C-MYC exon $261 \%$; CXCR4 $=61 \%$; NCX1 $=59 \%$; $\mathrm{ND} 1=81 \%$; POMC $=61 \%$; RAG1 $=62 \%$; and SLC8A3 $=60 \%$ (complete marker statistics can be found in Table S3). For most species of Ecuadorian glassfrogs, we obtained a total of $\sim 2733 \mathrm{bp}$ from the following mitochondrial markers: 12S rRNA ( 907 bp), 16S rRNA ( 864 bp), and ND1 ( 960 bp). See Table S2 for genes sequenced for each species and GenBank Accession Numbers.

Candidate species-to assist in identifying putative new species for future study, we employed the candidate species designation system of Vieites et al. [29]. Prior to this study, divergent centrolenid lineages have been designated in inconsistent ways (using sp. or aff. or museum numbers), which can result in confusion in identifying and studying tentative new species. Given the increasing number of putative new species in Centrolenidae, establishing candidate species aims to better organize and maintain the growing discovery of undescribed lineages. Importantly, designating a divergent lineage as a putative new species does not necessarily mean it is a new species; rather, the system is meant to identify these lineages for future study, incorporating multiple lines of evidence (i.e., morphology, bioacoustics, biogeography, or nuclear genes) in order to determine their species status.

Candidate species are typically identified through evidence from genetic distances or phylogenetic lineage divergence through widely used genetic markers that provide a basis for comparison (i.e., 12S, 16S, CO1; [29,53]). In this study, we used the mitochondrial genetic markers 12S, 16S, and ND1 and integrated evidence from genetic distances and phylogenetic relationships to identify candidate species. We first used a threshold of 3\% in identifying divergent lineages, which is a threshold that most named centrolenid species exceed (this study). Putative new species were then numbered using a scheme of "sp_CaXX", with numbering beginning at 01 for each genus. Finally, we note that Vieites et al. [29] also uses "unconfirmed" and "confirmed" designations, whereas "confirmed" candidate species have additional evidence (morphology or calls) for their status as species and are simply awaiting detailed analyses and subsequent description. We did not use these designations, as most putative new centrolenid species are supported only through mitochondrial genetic divergence.

Phylogenetics - the analyzed dataset contains complete or partial sequences of 10 genes representing 6513 bp of data (mitochondrial: 12S rRNA, 16S rRNA, ND1; nuclear: BDNF, C-MYC exon 2, CXCR4, 
NCX1, POMC, RAG1, SLC8A3). See Tables S2 and S3 for details. Analyses were conducted using maximum likelihood (ML) and Bayesian (BA) criteria. We did not perform searches under the parsimony criterion because of its limitations under certain conditions (long branch attraction; [54,55]) and lack of theoretical support for transition/transversion bias and variation in substitution rates among different nucleotide sites [56]. The 12S and 16S rRNA sequence data were aligned using MAFFT 7.4 [57], using the Q-INS-i algorithm that takes RNA secondary structure into consideration. Protein coding genes were also aligned in MAFFT using the AUTO function and manually inspected for accuracy and open reading frames.

Maximum likelihood was run in the IQ-TREE v1.5.5 software [58]. The data were automatically partitioned, and the best model was implemented using ModelFinder within IQ-TREE [59], which groups partitions with the same model and similar rates and simultaneously searches model and tree space. Node support was assessed via 100 ultra-fast bootstrap replicates [60].

For Bayesian phylogenetic analyses and divergence dating, we used BEAST v2.4.5 [61]. We used a single secondary calibration point using ages estimated from Hutter et al. [62], which estimates divergence dates for Hyloidea using 18 genetic markers and 8 fossil/geographic calibrations. We used median age of Centrolenidae with a normal distribution to capture the $95 \%$ confidence interval from this study (Mean = 33.4 Myr; Sigma =6). We used a single uncorrelated lognormal relaxed clock prior linked across all partitions. We partitioned data by codon position for protein-coding genes and used the Bayesian bModelTest package within BEAST to select the best model for each partition. We estimated the relaxed clock rate using an initial value of $1 \mathrm{e}-9$ and a broad prior (in our case, a gamma distribution with a shape parameter of 0.001 and scale parameter of 1000). We used a Yule speciation process for the tree prior. We ran Markov chain Monte Carlo (MCMC) searches for a total of 100 million generations, sampling every 10,000 generations. Stationarity was assessed by examining the standard deviation of the split frequencies and by plotting the $-\ln L$ per generation, using Tracer v1.5 [63]; trees generated before stationarity were discarded as "burn-in", which was $20 \%$ of trees.

Species conservation status-global and local (Ecuador) conservation status of glassfrogs follow the categorization and criteria established by the International Union for Conservation of Nature (IUCN) [64] (Figure 17), including rate of decline, population size, area of geographic distribution, and degree of distribution fragmentation. The following categories were used: (i) Not Evaluated: The species has not yet been evaluated against the criteria, (ii) Data Deficient: There is inadequate information to make a direct or indirect assessment of its risk of extinction based on its distribution and/or population status, (iii) Least Concern: The species is widespread and abundant and not under immediate risk of extinction, (iv) Near Threatened: For species that are not currently threatened, but are close to qualifying for or are likely to qualify for a threatened category in the near future, (v) Vulnerable: A taxon is Vulnerable when it is considered to be facing a high risk of extinction in the wild (Criteria A to $\mathrm{E}$ for Vulnerable), (vi) Endangered: When the species is considered to be facing a very high risk of extinction in the wild (Criteria A to E for Endangered), (vii) Critically Endangered: When the species is considered to be facing an extremely high risk of extinction in the wild (Criteria A to E for Critically Endangered), (viii) Extinct in the Wild: When the species is known only to survive in cultivation, in captivity, or as a naturalized population, outside its historical range. A taxon is presumed Extinct in the Wild when exhaustive surveys in known and/or expected habitats, at appropriate times, throughout its historic range have failed to record an individual, (ix) Extinct: When there is no reasonable doubt that the last individual of the species has died. A taxon is presumed Extinct when exhaustive surveys in known and/or expected habitats, at appropriate times (diurnal, seasonal, annual), throughout its historic range have failed to record an individual. 


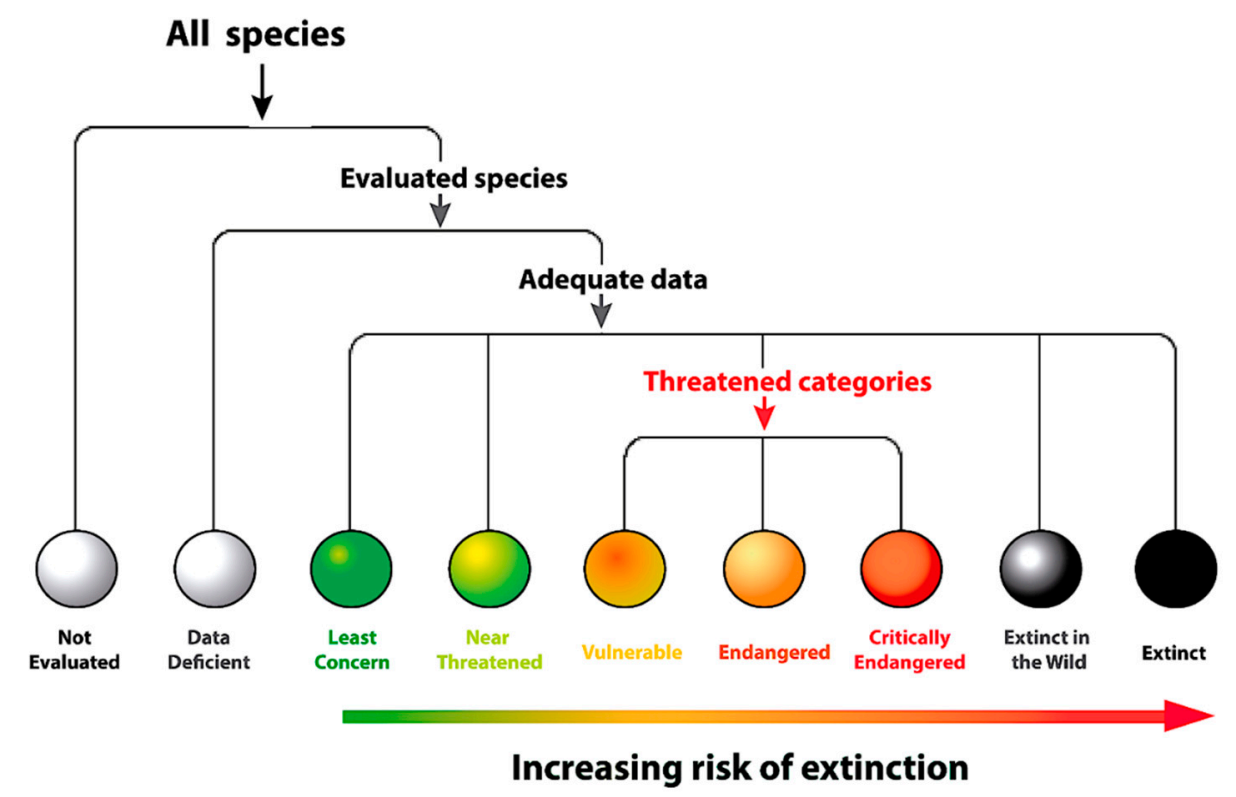

Figure 17. International Union for Conservation of Nature (IUCN) categories of species conservation status.

\subsection{Biogeographic Regions of Ecuador}

In this study, we applied biogeographic regions of continental Ecuador as a simplification of vegetation types [65,66] (Figure 18). This system has the virtue of combining the characteristics of the vegetation and the historic isolation between the western and eastern slopes of the Andes and the eastern and western lowlands. Mean annual precipitation and mean annual temperature for each of the recognized regions are shown in Table 2. We also summarized the land cover of Ecuador, illustrating which ecosystems have suffered intensive deforestation and which are still preserved (Table 3, Figure 18).

Dry Shrub - characterized by a combination of warm and extremely dry conditions. Annual precipitation can be as low as $60 \mathrm{~mm}$ in the westernmost locality (Salinas, Santa Elena Province). This region covers an area of $8033 \mathrm{~km}^{2}$ and is restricted to the coastal margin of central Ecuador (Figure 18). In some areas, grasses introduced for raising livestock have replaced native plants. In the drier habitats, xerophytic plants are dominant, especially cacti and other thorny plants [67].

Western Deciduous Forest - this forest occurs at an elevation of 50-300 $\mathrm{m}$ in central and northern Ecuador (100-400 m in southern Ecuador) and covers $25,673 \mathrm{~km}^{2}$ (10.3\% of Ecuadorian territory, Figure 18). Conditions are drier and the terrain has lower tree densities than in evergreen forests. The trees are generally shorter than $20 \mathrm{~m}$ with an understory that can be dense with abundant herbaceous plants. Some tree species lose their leaves during the dry season [67]. More than half of the land cover of this habitat type has been converted for agriculture and grazing cattle.

Chocoan Tropical Rainforest - this rainforest is the second largest biogeographic region in Ecuador, with $31,732 \mathrm{~km}^{2}$ at elevations ranging from sea level to $300 \mathrm{~m}$ (Figure 18). It has a closed canopy with trees that can reach $30 \mathrm{~m}$ in height and with an understory dominated by ferns and Araceae [67]. Tree diversity is high, with more than 100 species/ha with diameter at breast height $>10 \mathrm{~cm}$, but lower than in the Amazonian Tropical Rainforest [68]. Habitat destruction rate in this region is the highest in Ecuador and only $18.3 \%$ of its natural vegetation remains.

Western Foothill Forest-this forest covers $15,305 \mathrm{~km}^{2}$ on the western Andean slopes with an elevational range of 300-1300 m (400-1000 $\mathrm{m}$ in southern Ecuador). Plant endemism is high, especially between latitudes $0^{\circ}$ and $3^{\circ} \mathrm{S}$ [67]. This forest is structurally similar to its counterpart from the eastern Andean slope, although the amphibian communities are highly differentiated. 
Land Use in Ecuador

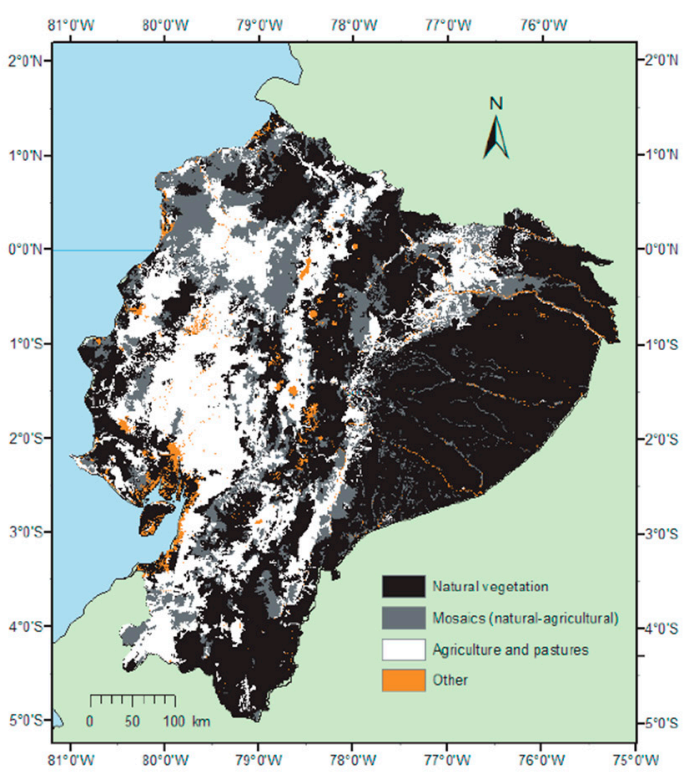

Biogeographic Regions

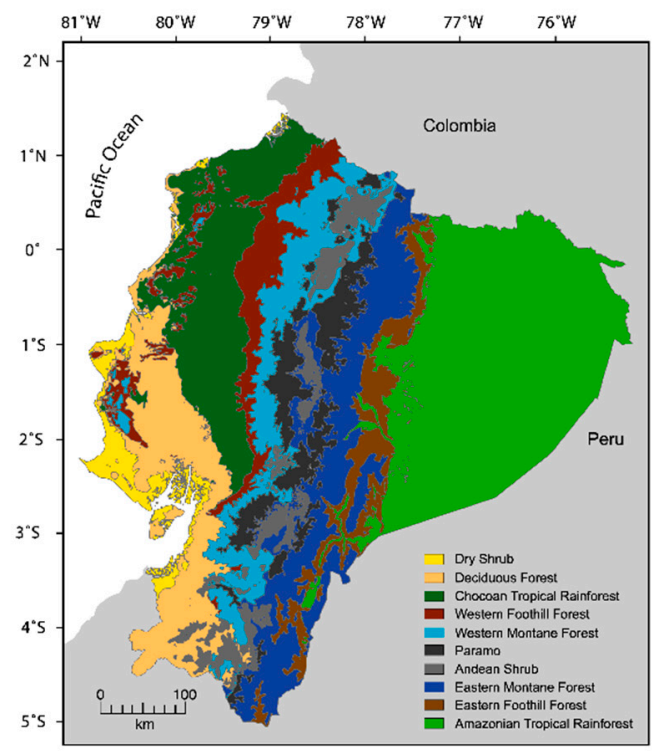

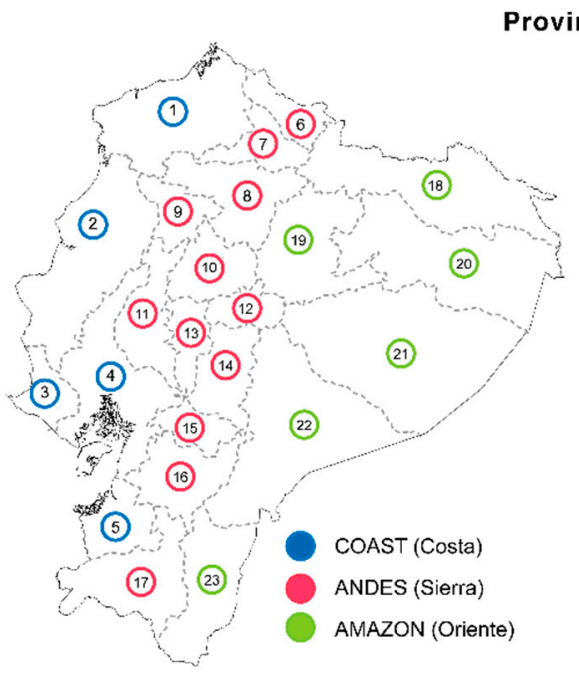
(1) Esmeraldas
(2) Manabi
(3) Santa Elena
(4) Guayas
(5) El Oro
(6) Carchi
(7) Imbabura
(8) Pichincha
(9) Sto. Domingo de los Tsáchilas
(10) Cotopaxi
(11) Los Ríos
(12) Tungurahua
(13) Bolivar
(14) Chimborazo

(15) Cañar

(16) Azuay

(17) Loja

(18) Sucumbios

(19) Napo

(20) Orellana

(21) Pastaza

(22) Morona Santiago

Figure 18. Land use, biogeographic regions, and provinces of Ecuador. Land cover: Modified from Ron et al. [66]; "Mosaics" are mixtures of natural vegetation and either agricultural land or pastures. "Other" includes urban areas, shrimp farms, lakes, rivers, glaciers, and sand banks. Biogeographic regions: Shown as a simplification of vegetation types (Sierra et al. [65], as modified by Ron et al. [66]). Provinces: Provinces are divided into three broad geographic regions: Coast, Andes, and Amazon. 
Table 2. Glassfrog diversity and climate in the Ecuadorian biogeographic regions, as defined in Figure $14[65,66]$. Note that any given species can occur in more than one biogeographic region.

\begin{tabular}{cccccc}
\hline $\begin{array}{c}\text { Biogeographic } \\
\text { Region }\end{array}$ & $\begin{array}{c}\text { Area of the } \\
\text { Region } \mathbf{k m}^{\mathbf{2}} \mathbf{)}\end{array}$ & $\begin{array}{c}\text { Mean Annual } \\
\text { Temperature } \\
\mathbf{(} \mathbf{C})\end{array}$ & $\begin{array}{c}\text { Mean Annual } \\
\text { Precipitation } \\
(\mathbf{m m})\end{array}$ & $\begin{array}{c}\text { No. of } \\
\text { Glassfrog } \\
\text { Species }\end{array}$ & $\begin{array}{c}\text { Density } \\
\left(\text { Species/1000 } \mathbf{k m}^{\mathbf{2}} \mathbf{)}\right.\end{array}$ \\
\hline Dry Shrub & 8033 & $24.8 \pm 0.66$ & $500 \pm 393$ & 0 & 0 \\
\hline Deciduous Forest & 25,673 & $24.3 \pm 1.32$ & $843 \pm 316$ & 3 & 0.38 \\
\hline $\begin{array}{c}\text { Chocoan Tropical } \\
\text { Rainforest }\end{array}$ & 31,737 & $25.1 \pm 0.59$ & $2086 \pm 665$ & 12 & 0.98 \\
\hline $\begin{array}{c}\text { Western Foothill } \\
\text { Forest }\end{array}$ & 15,305 & $22.4 \pm 1.71$ & $2,218 \pm 907$ & 15 & 0.65 \\
\hline $\begin{array}{c}\text { Western Montane } \\
\text { Forest }\end{array}$ & 21,576 & $15.0 \pm 4.04$ & $1187 \pm 610$ & 14 & 0.06 \\
\hline Páramo & 15,976 & $7.3 \pm 2.30$ & $803 \pm 277$ & 1 & 0.09 \\
\hline Andean Shrub & 11,266 & $15.8 \pm 2.70$ & $817 \pm 215$ & 1 & 0.63 \\
\hline $\begin{array}{c}\text { Eastern Montane } \\
\text { Forest }\end{array}$ & 31,555 & $15.8 \pm 4.13$ & $1691 \pm 799$ & 20 & 1.21 \\
\hline $\begin{array}{c}\text { Eastern Foothill } \\
\text { Forest }\end{array}$ & 13,133 & $21.7 \pm 0.91$ & $2923 \pm 1023$ & 16 & 0.14 \\
\hline $\begin{array}{c}\text { Amazonian } \\
\text { Tropical Rainforest }\end{array}$ & 73,909 & $24.9 \pm 0.81$ & $3349 \pm 555$ & 10 & 0.24 \\
\hline Total: Continental & 248,163 & & 60 & \\
\hline
\end{tabular}

Table 3. Land cover (as percentage) in Ecuadorian biogeographic regions [66] (Figure 15). Mosaics: Mixtures of natural vegetation and either agricultural land or pastures. Other: Includes urban areas, shrimp farms, lakes, rivers, glaciers, and sand banks.

\begin{tabular}{ccccc}
\hline Biogeographic Region & Natural Vegetation & $\begin{array}{c}\text { Mosaics } \\
\text { (Natural-Agricultural) }\end{array}$ & $\begin{array}{c}\text { Agriculture } \\
\text { and Pastures }\end{array}$ & Other \\
\hline Dry Shrub & 53.1 & 9.9 & 13.8 & 23.2 \\
\hline Deciduous Forest & 26.7 & 17.4 & 51.6 & 4.3 \\
\hline Chocoan Tropical Rainforest & 18.3 & 23.8 & 60.0 & 1.9 \\
\hline Western Foothill Forest & 40.3 & 20.6 & 38.2 & 0.9 \\
\hline Western Montane Forest & 35.8 & 28.5 & 34.6 & 1.1 \\
\hline Páramo & 78.9 & 7.0 & 6.7 & 7.4 \\
\hline Andean Shrub & 29.1 & 7.2 & 53.7 & 10.0 \\
\hline Eastern Montane Forest & 69.4 & 16.0 & 14.2 & 3.4 \\
\hline Eastern Foothill Forest & 59.3 & 15.6 & 24.4 & 0.7 \\
\hline Amazonian Tropical Rainforest & 76.2 & 10 & 9.5 & 4.3 \\
\hline
\end{tabular}

Western Montane Forest - this evergreen forest covers $21,576 \mathrm{~km}^{2}$ at an elevational range between $1300-3400 \mathrm{~m}$ (1000-3000 m in southern Ecuador; Figure 18). The canopy is generally below $25 \mathrm{~m}$ with a high abundance of epiphytic plants (especially mosses, ferns, orchids, and bromeliads). At intermediate elevations, especially during the afternoon, the forests become misty and receive horizontal precipitation from low, overhanging clouds. Western Montane Forest is restricted to narrow stretches between the basin of the Mira River (close to the Colombian border) and the basins of the Chanchán and Chimbo rivers $\left(2^{\circ} \mathrm{S}\right)$. It is replaced by drier habitats (principally Andean Shrub) south of $4^{\circ} \mathrm{S}$, close to the border with Peru. Only 35\% of its natural vegetation remains unaltered (Table 3).

Páramo - this is the vegetation type that reaches the highest elevation and covers 15,976 ha $(6.1 \%$ of the territory; Figure 18). Depending on the region, its lower limit lies between 3000 and $3600 \mathrm{~m}$. Short herbaceous plants generally forming tight clumps dominate the vegetation. The plants are adapted to cold temperatures and to low availability of water. Open grassy areas predominate but are 
mixed with small patches of forest or shrubs [69]. At higher elevations, the vegetation is restricted to sparse clumps on otherwise bare land. Because of the occurrence of frequent freezes, agriculture is limited, and this has ameliorated anthropogenic habitat degradation. In this region, only $21.1 \%$ of the natural vegetation has been cleared or severely fragmented, the lowest proportion for any region (Table 3). However, the Páramo is the region with the highest proportion of endangered amphibians.

Andean Shrub - this biogeographic region lies between 1400 and $3000 \mathrm{~m}$ and has an area of $11,266 \mathrm{~km}^{2}$; it is found in the inter-Andean basins between the Cordillera Occidental and Cordillera Oriental (Figure 18). As a result of rain shadow effects from both mountain chains, the Andean Shrub has a relatively low precipitation (Table 2). Although originally dominated by shrubs, most of the vegetation has been replaced by crops, pastures, or forests of exotic trees (Eucalyptus and Pinus; [69]). In dry valleys (e.g., Chota, Guayllabamba, and Patate) the native vegetation is spiny. Andean Shrub is almost unrepresented in the Ecuadorian National System of Protected Areas. Habitat degradation is severe; more than half the land cover is devoted to agriculture or to raising cattle (Table 3).

Eastern Montane Forest-this forest covers $31,555 \mathrm{~km}^{2}$ between $1300 \mathrm{~m}$ and $3600 \mathrm{~m}$ on the eastern Andean slopes (Figure 18). The vegetation is structurally similar to that from the Western Montane Forest. Above $2900 \mathrm{~m}$, the soil of the forest is covered by moss and the trees are irregularly shaped [69].

Eastern Foothill Forest-this evergreen forest covers $13,133 \mathrm{~km}^{2}$ between elevations of $600 \mathrm{~m}$ and $1300 \mathrm{~m}$ (Figure 18), and is a mixture of tree species from the Andes and the lowlands of the Amazon Basin [68]. The canopy reaches up to $30 \mathrm{~m}$ in height and encloses a dense sub-canopy and understory. Tree diversity is lower (130 species/ha, $>10 \mathrm{~cm}$ DBH) [68] than in the Amazonian Tropical Forest. Average annual precipitation is the second highest of all regions $(2833 \mathrm{~mm})$.

Amazonian Tropical Rainforest-the Amazonian Tropical Rainforest is the most extensive biogeographic region in Ecuador with a total area of $73,909 \mathrm{~km}^{2}(29.8 \%$ of the Ecuadorian continental territory; Figure 18). It is restricted to elevations below $600 \mathrm{~m}$ and has the highest average annual precipitation of any region $(3349 \mathrm{~mm})$. The dominant forest type, Terra Firme, is characterized by well-drained soils. The canopy is $10-30 \mathrm{~m}$ high, punctuated with emergent trees up to $40 \mathrm{~m}$ (and rarely $50 \mathrm{~m}$ ); small gaps created by fallen trees $[68,70]$ are common. Tree diversity is high with 200-300 species of trees/ha (>10 cm DBH) [68,70]. Other vegetation types in this region include Várzea forest (flooded with white water), Igapó forest (flooded with black water), riparian woodland forest, river island scrub, and Mauritia flexuosa palm swamps $[68,71]$. At the local scale $\left(\leq 100 \mathrm{~km}^{2}\right)$, amphibian diversity reaches its global peak in the Amazonian Tropical Rainforest of Ecuador [72,73].

\subsection{Potential Distribution}

Estimating the distribution of a species is challenging, since biotic, abiotic, and historic factors come into play. As an approximation to species distributions and being aware of the associated caveats $[74,75]$, we modelled the ecological niche of all species for which we had at least 10 independent localities ( $>1 \mathrm{~km}$ apart). Given that our ecological models did not include variables such as biotic interactions, random extinction, vagility, influence of diseases or introduced species, we used our results only as proxy, and are fully aware that predicted areas might be, in most cases, overestimated; nevertheless, models are useful for conservations assessments. Locality data were obtained from the following museums: AMNH, BMNH, FHGO, KU, QCAZ, MECN, MZUTI, ZSFQ, and USNM. All specimens were directly examined by Juan M. Guayasamin or Diego F. Cisneros-Heredia.

We used all 19 climatic variables from the WorldClim database (www.worldclim.org). These bioclimatic variables are derived from monthly temperature and rainfall values [76]. A correlation analysis was used to determine independent variables for the distribution of each species. The potential distributions of centrolenid species were estimated using default settings in Maxent v. 3.3.3k [77,78]. We used $70 \%$ of the presence records as training data, and the other $30 \%$ was used to evaluate the model. Maxent was run 10 times to obtain the ecological model for each species. In order to evaluate models, we employed the area under the curve (AUC), a value that is an indicator of model performance [77,79]. The AUC value was calculated in Maxent and ranges between 0.5 (random classification) and 1 
(perfect fit). We discarded models that had AUC values below 0.7 [80]. Maxent continuous models were reclassified in order to obtain a binary map of potential presence or absence, using the maximum training sensitivity plus specificity threshold $($ MTS $+S)$, a method that has been shown to produce highly accurate predictions [81,82]. The potential distribution models were edited using ArcMap v.10 to obtain more realistic estimates of species distributions by removing areas predicted as present that are located in inaccessible biogeographic regions (e.g., species restricted to the Amazon basin predicted as present in the Chocó and vice versa; species from the Pacific slope of the Andes predicted as present in the Amazonian slope and vice versa).

Impacts of human activities to species - in order to build a layer of human impact (LHI) for Ecuador, we used shape files containing information on land use, roads, human settlements, human population density, mining, and oil exploration and concession shape files (ESRI, 2003). The original shape files were converted to raster files in ArcMap v. 10; we then calculated Euclidean distances in each raster file to compute buffer areas around specific features (i.e., roads, oil fields), giving values according to the intensity of human impact and distance from the specific human activity (Table 4). In the case of population density, the intensity value was equal to the logarithmic scale of the population density value for each grid cell. We obtained raster layers with buffer zones and intensity values for each of the impacts, which were added using the map calculator tool (ArcMap v. 10) to obtain a single map summarizing all considered threats.

Table 4. Intensity values and distance of influence of human activities.

\begin{tabular}{|c|c|c|c|}
\hline Human Impact & Class & $\begin{array}{c}\text { Intensity Values } \\
(\mathbf{0 - 1 0 0 )}\end{array}$ & Distance of Influence (m) \\
\hline \multirow{5}{*}{ Roads } & 1st Order & 50 & \multirow{5}{*}{ 0-1000 } \\
\hline & 2nd Order & 25 & \\
\hline & 3rd Order & 17 & \\
\hline & Railroad & 17 & \\
\hline & Trails & 10 & \\
\hline Population density & - & Logarithmic scale & $0-7000$ \\
\hline \multirow{3}{*}{$\begin{array}{l}\text { Agriculture/Animal } \\
\text { husbandry }\end{array}$} & Monoculture & 60 & 0-2000 \\
\hline & Mixed crops & 50 & $0-1000$ \\
\hline & $\begin{array}{c}\text { Mosaic (crops } \\
\text { plus forest remnants) }\end{array}$ & 40 & 0-1000 \\
\hline \multirow{4}{*}{ Oil } & Active oil fields & 70 & $0-3000$ \\
\hline & Oil concession & $\begin{array}{l}\text { Present: } 20 \\
\text { Future: } 20\end{array}$ & 0-3000 (future) \\
\hline & Oil exploration & $\begin{array}{l}\text { Present: } 0 \\
\text { Future: } 20\end{array}$ & 3000 (future) \\
\hline & $\begin{array}{l}\text { Oil exploration- } \\
\text { without operator }\end{array}$ & $\begin{array}{l}\text { Present: } 0 \\
\text { Future: } 20\end{array}$ & 3000 (future) \\
\hline \multirow{2}{*}{ Mining Industry } & Active mines & $\begin{array}{l}\text { Present: } 30 \\
\text { Future: } 30\end{array}$ & 10,000 \\
\hline & Mine concession & $\begin{array}{l}\text { Present: } 0 \\
\text { Future: } 30\end{array}$ & 10,000 (future) \\
\hline
\end{tabular}

\subsection{Registration of New Nomenclatural Acts}

According to the International Commission on Zoological Nomenclature (ICZN), which produces the International Code of Zoological Nomenclature, the electronic publication of this article in portable document format (PDF) represents a published work. Therefore, the new species name contained 
in the PDF is effectively published under the International Code of Zoological Nomenclature from the electronic edition alone. This publication and the nomenclatural acts contained in it have been registered in ZooBank, the online official register for the ICZN. The ZooBank Life Science Identifiers (LSIDs) can be accessed and viewed through standard web browsers by appending the LSID to the prefix http://zoobank.org/. The online version of this work is archived and available from the following digital repositories: Diversity, CLOCKSS, and e-Helvetica.

\section{Results}

\subsection{Phylogenetic Systematics}

The relationships among glassfrog genera are shown in Figure 19. We also included a tree for each genus that occurs in Ecuador. These trees are the source of evidence for generic placement and comments on the evolutionary relationships among species discussed below and are summarized in Table S1. Each genus was well supported and congruent with the trees estimated by Guayasamin et al. [1,2], Castroviejo-Fisher et al. [3], and Twomey et al. [19], with only a few differences resulting from our improved taxon sampling. There was significant support (ML: Greater than $95 \%$ bootstrap [BS]; BA: Greater than 0.95 posterior probability [PP]) for all genera.

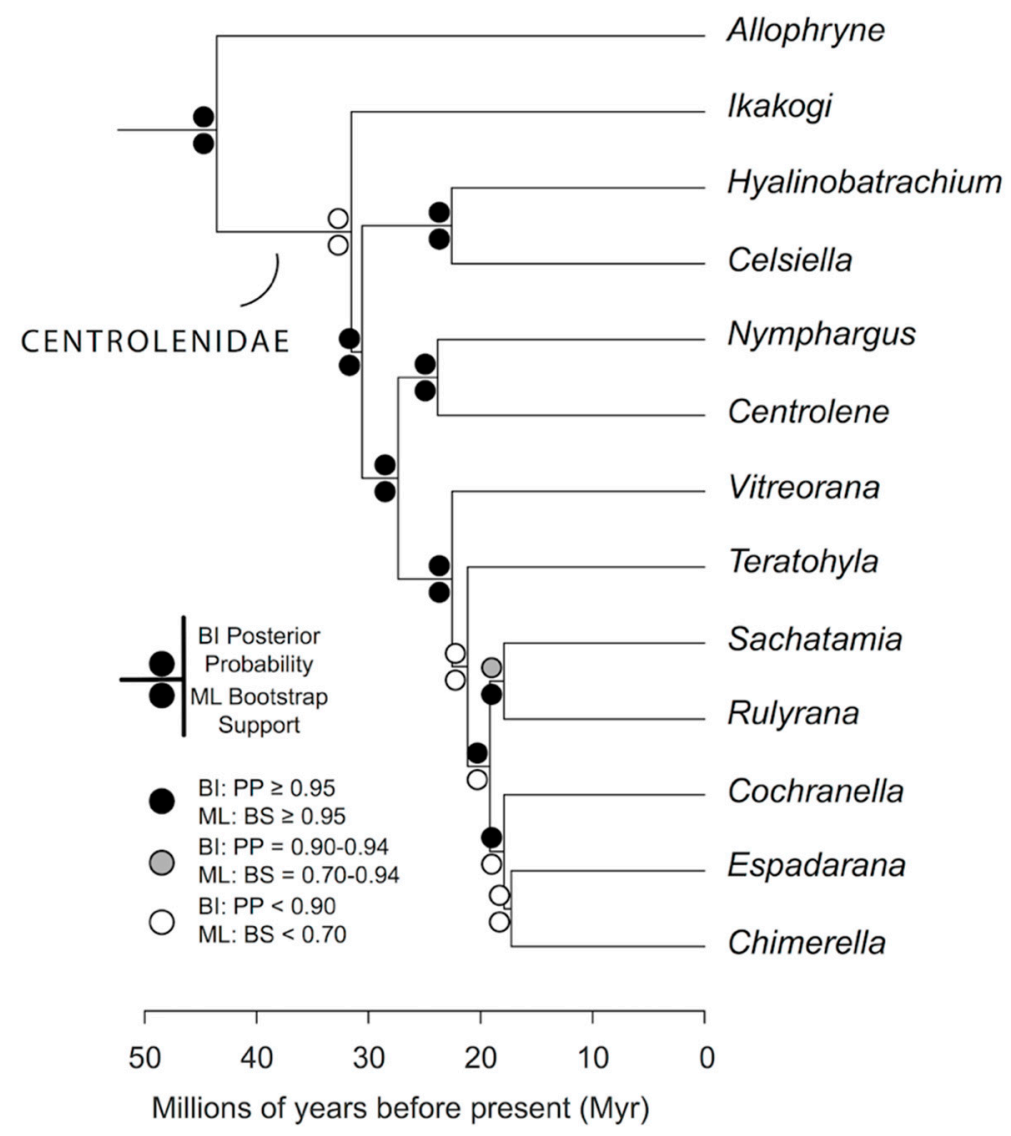

Figure 19. Evolutionary relationships among glassfrog genera (family: Centrolenidae) under maximum likelihood and Bayesian criteria.

\subsection{Potential Distribution}

The area of the potential distribution of each glassfrog species is summarized in Table S5. AUCs associated to each model are reported in Table S4. The species with the largest area of potential distribution was Cochranella resplendens $\left(77,792 \mathrm{~km}^{2}\right)$, whereas the species with the most restricted 
predicted distribution was Centrolene heloderma $\left(1067 \mathrm{~km}^{2}\right)$. The areas with the highest impacts were the interandean valleys and the Pacific lowlands; these were also areas with the highest population density. In terms of distribution and range extensions, agriculture and ranching were the activities that had the highest impact on habitats. Other activities with high impact values are related to mining and the oil industry.

\section{Species Accounts}

Genus Centrolene Jiménez de la Espada, 1872 [83]

Etymology: The name Centrolene is derived from the Greek words kéntron (point or spur) and ōlénē (elbow, forearm), alluding to the humeral spine found in males of this genus [84]. Although the name Centrolene has been used as neuter in gender for almost 150 years, now, because of an intricate game of words and nomenclatural regulations, it is considered to be feminine [85], creating nomenclatural instability that, in our opinion, was unnecessary. Centrolene is the type genus for the family Centrolenidae.

Centrolene ballux (Duellman and Burrowes 1989 [86]; Figures 20-23)

Centrolenella ballux Duellman and Burrowes, 1989 [86]. Holotype: KU 164725.

Type locality: “14 km (by road) west of Chiriboga (00¹8' S, 7849' W), $1960 \mathrm{~m}$, Provincia de

Pichincha, Ecuador" (now in Provincia de Santo Domingo de los Tsáchilas).

Centrolene ballux-Ruiz-Carranza and Lynch, 1991 [6].

"Centrolene" ballux - Guayasamin, Castroviejo-Fisher, Trueb, Ayarzagüena, Rada, and Vilà, 2009 [1].

Common names: English: Gold-dust Glassfrog. Spanish: Rana de Cristal Polvo de Oro.

Etymology: The specific name ballux is Latin; it means "gold dust" and is used in reference to the minute gold flecks on the dorsum [86].

Identification: On the Pacific versant of the Ecuadorian Andes, only Nymphargus buenaventura and some populations of N. griffithsi are similar to Centrolene ballux in having a green dorsum with small light spots (Figure 20), but they differ by possessing basal webbing between outer fingers (moderate webbing in C. ballux), concealed prepollex (distinct in C. ballux), and lacking humeral spines (present in males of C. ballux). The Colombian "Centrolene" robledoi resembles C. ballux; both lack vomerine teeth, have a small series of white spots on flanks, and have a similar webbing and snout shape. However, C. robledoi has small dark spots on its dorsum (absent in C. ballux), concealed prepollex (distinct in C. ballux), and is slightly larger than C. ballux (males, SVL 19.9-24.4 $\mathrm{mm}$ in C. robledoi; 19.2-22.2 $\mathrm{mm}$ in C. ballux). Centrolene peristicta and C. lynchi are sympatric with C. ballux in several localities, but the two species can be distinguished by having dorsal dark and light minute spots (only light spots present in C. ballux; Figure 20).

Diagnosis: (1) Vomers lacking teeth; (2) snout bluntly rounded to truncated in dorsal and lateral profiles (Figure 21); (3) tympanum oriented almost vertically, ED/TD = 31\%-34\%; tympanic annulus visible except for dorsal border covered by supratympanic fold; tympanic membrane partially pigmented, differentiated from surrounding skin; (4) dorsal surfaces shagreen with small warts; (5) pair of enlarged subcloacal tubercles (Figure 15); (6) anterior two-thirds of ventral parietal peritoneum white, posterior third transparent (condition P3); silvery white pericardium; no iridophores in peritonea covering intestines, stomach, testes, kidneys, gall bladder, and urinary bladder (condition V1); (7) liver tetralobed, lacking iridophores (condition H0); (8) humeral spines present in adult males; (9) no webbing between Fingers I and II, webbing between Fingers II and III basal or absent; webbing formula for outer fingers: III $\left(2^{1 / 4}-2^{3 / 4}\right)-\left(2-2^{+}\right)$IV (Figure $\left.21 C\right)$; (10) webbing formula on foot: I $1-\left(2-2^{+}\right)$II $1-\left(2-2^{+}\right)$III $\left(1-1^{+}\right)-\left(2-2^{1 / 3}\right)$ IV $2^{1 / 2}-\left(1-1^{1 / 3}\right) \mathrm{V} ;(11)$ ulnar fold low, white; inner tarsal fold 
low; outer tarsal fold absent, but small white tubercles evident along ventrolateral margin of tarsus; (12) distinct prepollex, clearly separated from Finger I; in males, nuptial pad Type I; (13) Finger II slightly longer than Finger I (Finger I 91.4\%-98.0\% of Finger II); (14) disc of Finger III of moderate size, about $47.4 \%-59.3 \%$ of eye diameter; (15) in life, dorsum green with small white warts; upper lip white; bones green; (16) in preservative, dorsal surfaces lavender with small white and/or unpigmented spots, particularly evident on limbs; (17) iris whitish cream with dark-grey thin reticulation and pale yellow hue around pupil; (18) melanophores mostly absent from fingers and toes, except for a few on Toes IV and V and on base of Finger IV; (19) males call from the upper side of leaves; call emitted sporadically and consisting of a single short note (328.5-420.4 ms) with 7-9 pulses; mean dominant frequency at peak amplitude $4833 \mathrm{~Hz} \pm 14$ (range 444-464); notes are frequency modulated (Márquez et al. 1996); (20) fighting behavior unknown; (21) eggs deposited on the upper sides of leaves; short-term maternal care unknown; long-term parental care absent; (22) tadpoles undescribed; (23) minute body size; SVL 19.2-22.2 $\mathrm{mm}(\overline{\mathrm{X}}=20.6 \pm 0.911, n=25)$ in males; SVL 21.0-23.3 mm $(n=3)$ in females.

A
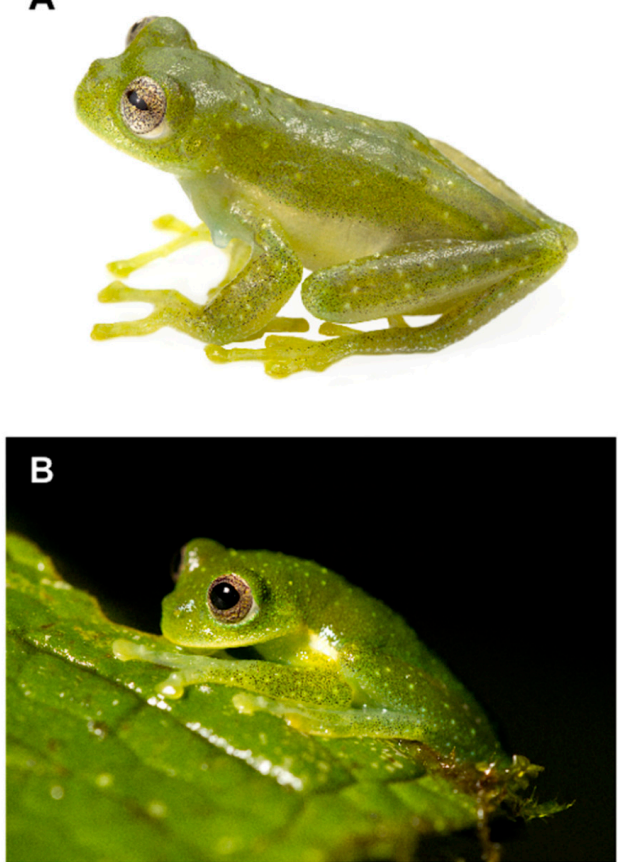

C

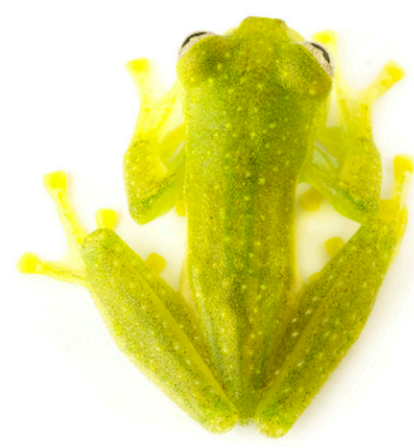

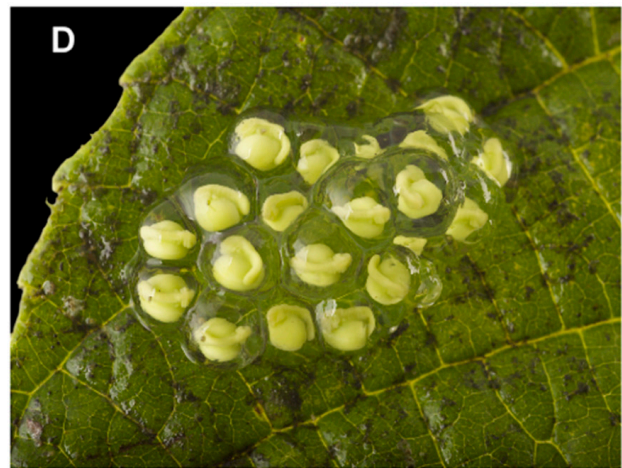
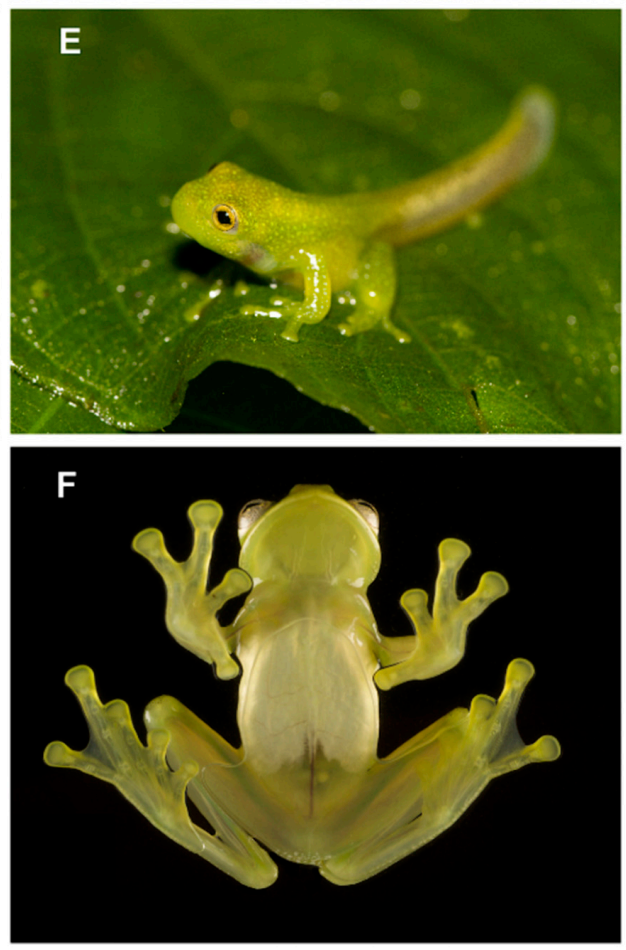

Figure 20. Centrolene ballux in life from Reserva Las Gralarias, Pichincha province, Ecuador. (A,B) Adult males. (C) Adult male in dorsal view, QCAZ 40199. (D) Egg clutch on upper side of leaf. (E) Metamorph. (F) Adult female in ventral view, QCAZ 40196. Photos by Carl R. Hutter (B,D,E), Luis A. Coloma (C,F), and Alejandro Arteaga/Tropical Herping (A). 
A
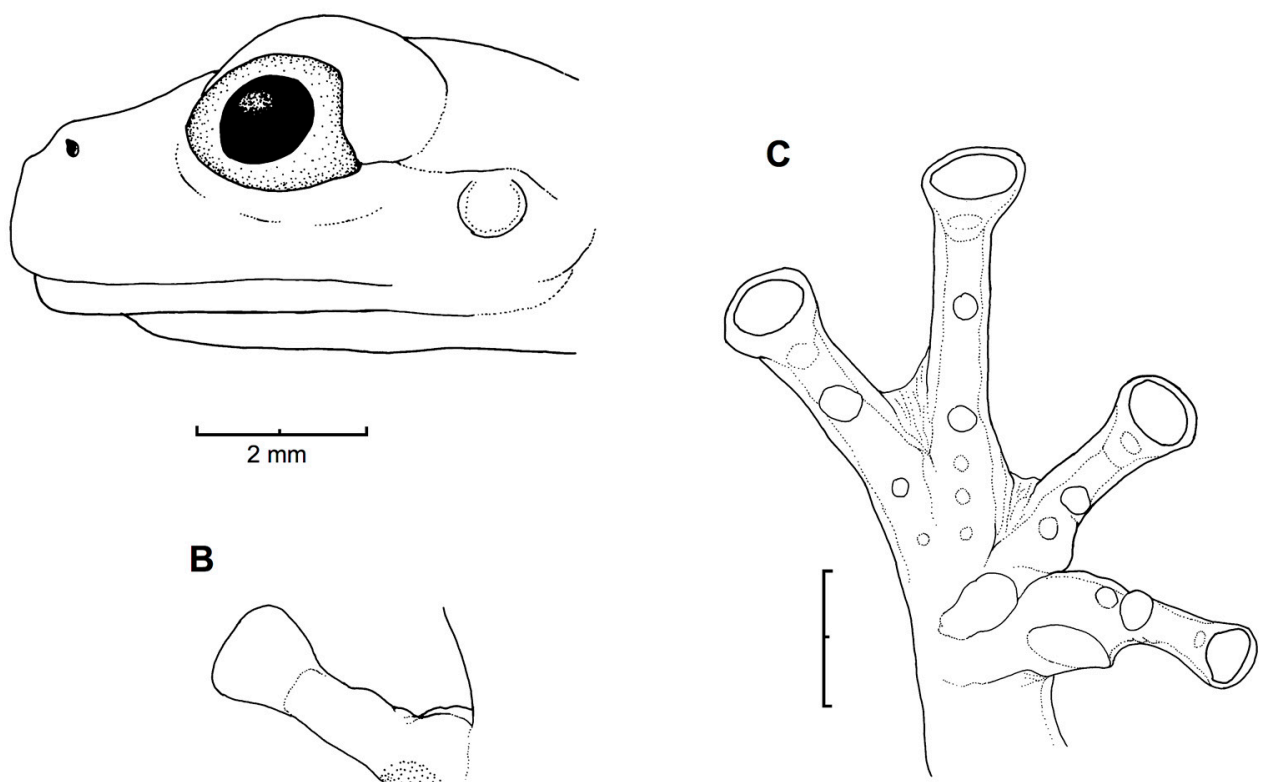

B

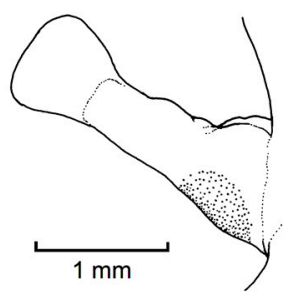

Figure 21. Centrolene ballux. (A) Head in lateral view, KU 164725. (B) Finger I and nuptial pad in dorsal view, KU 200275, adult male. (C) Hand in ventral view, KU 164725. Illustrations by Juan M. Guayasamin.

Color in life (Figure 20): Dorsum lime green with small greenish-white to yellowish-white warts; fingers and toes yellowish green; anterior two-thirds of ventral parietal peritoneum white; visceral peritoneum lacking iridophores; pericardium silvery white; bones green; upper lip yellowish white to white; iris cream white with fine black reticulations.

Color in ethanol: Dorsal surfaces of head, body, and limbs lavender with small white and/or unpigmented warts; hands and Toes I-III mostly unpigmented; margin of upper lip white; ulnar fold white; small tubercles on outer ventrolateral margin of tarsus white; small white tubercles posterior to cloacal opening; ventral surfaces cream. Anterior two-thirds of the ventral parietal peritoneum white, posterior third transparent; silvery white pericardium; no iridophores in peritonea covering intestines, stomach, testes, kidneys, gall bladder, and urinary bladder.

Biology and ecology: Individuals are active at night on the upper surfaces of leaves of bushes and trees 50-800 cm above and along small streams, or on ferns over roadside ditches (Arteaga et al. 2013). The reproductive activity of Centrolene ballux occurs in the rainy season (December-April [87]). One male (IND-AN 1725) was on a leaf $5 \mathrm{~cm}$ below another leaf on which there was a clutch of 18 eggs [86]. Another clutch found at La Planada had 13 eggs. Near Chiriboga, a gravid female (KU 164729) with green eggs and five adult males were found along a stream on 8 May 1975. At Reserva Las Gralarias, on March 2009, a clutch with 21 embryos was found on the upper side of a leaf, which was hidden by another leaf; an adult male was observed nearby (ca. $100 \mathrm{~cm}$ from the clutch). Centrolene ballux is relatively abundant at Reserva Las Gralarias, where it maintains reproductive populations along several streams (Ballux Creek, Five-frog Creek, Heloderma Creek, Chalguayacu River, Kathy's Creek; [88]). It is unknown if females provide short-term parental care to egg clutches; males do not exhibit parental care [25].

Call (Figure 22): The advertisement call of Centrolene ballux was described from Las Palmeras, Ecuador, by Márquez et al. [89]. The call was emitted sporadically and consisted of a single short note (328.5-420.4 ms, $n=2)$ with 7-9 pulses, the first $4-5$ being repeated at short, regular intervals, 
and the last three pulses being emitted at longer intervals (mean pulses per second $=21.0 \pm 0.1$, range 21.3-21.4). The dominant frequency was high (mean dominant frequency at peak amplitude $4833 \mathrm{~Hz} \pm 14$ ). The notes were frequency modulated (dominant frequency at the beginning of note is lower than at its end). Recordings obtained at Reserva Las Gralarias, Ecuador, match this description.

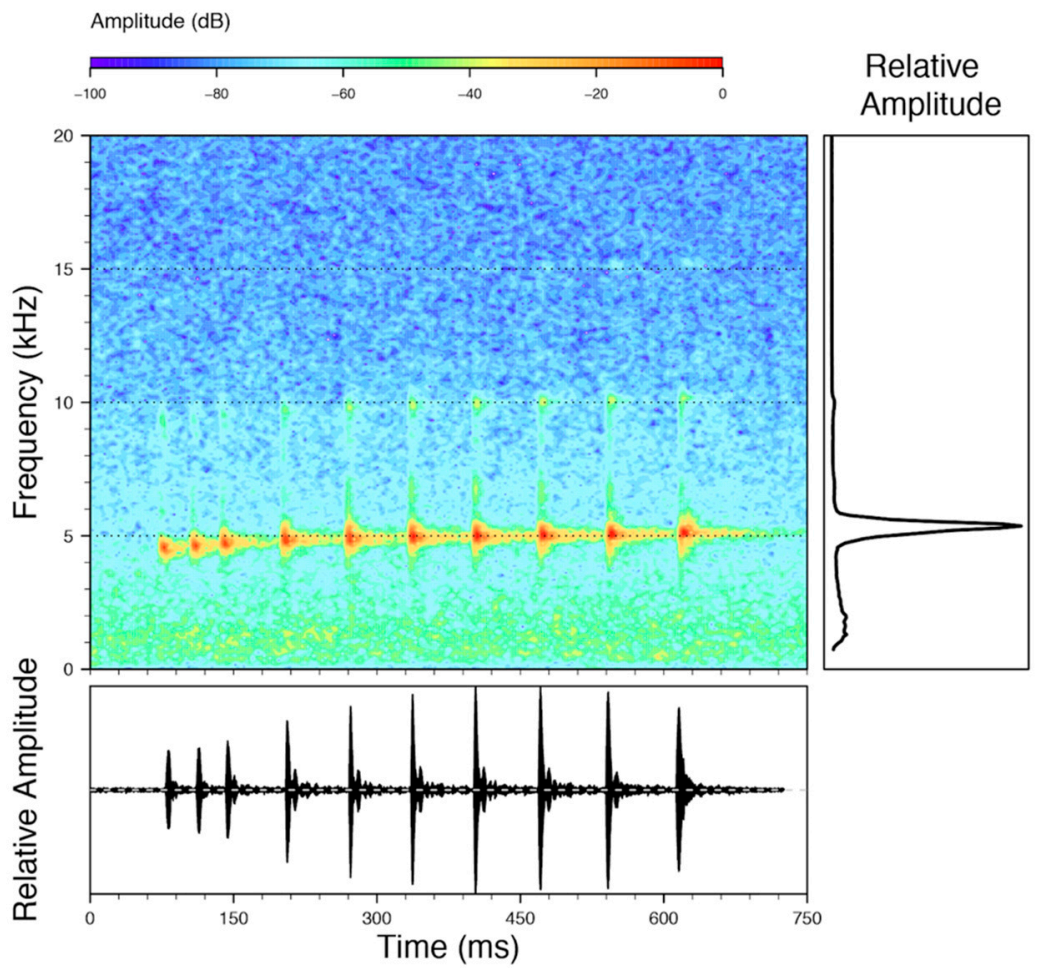

Figure 22. Call of Centrolene ballux from Reserva Las Gralarias, Pichincha province, Ecuador.

Tadpole: Not described.

Distribution (Figure 23): Centrolene ballux is known from six localities in the cloud forests of Carchi, Imbabura, Pichincha, and Santo Domingo de los Tsáchilas provinces (Ecuador) and one in the department of Nariño (Colombia) on the Pacific slopes of the Cordillera Occidental of the Andes at elevation between 1780 and 2340 m [86,87,89] (Specimens Examined). The species inhabits the Western Montane Forest ecoregion. In Ecuador, it has a potential distribution of $4752 \mathrm{~km}^{2}$.

Conservation status: Globally, Centrolene ballux is currently listed as Endangered by the IUCN [90]. In Ecuador, the most recent records of the species are from Reserva Las Gralarias (March 2018) and Reserva Río Manduriacu (2008) [21]. In Colombia, the last published record is from Reserva La Planada on April-June 1986 [86]. Recent surveys at Quebrada Zapadores and Las Palmeras (= Río Guajalito) have been unsuccessful in finding this species [91] (DFCH unpubl. data). During the rainy seasons (December-April) of 2011-2018, reproductive populations were observed in four streams at Reserva Las Gralarias. The species has a very restricted distribution, with only five known localities in Ecuador, in an area where forest fragmentation is common. At Reserva Las Gralarias, the amphibian chytrid fungus Batrachochytrium dendrobatidis infects $C$. ballux with a relatively high prevalence, but no recent declines have been recorded [92].

Evolutionary relationships (Figure 24): Centrolene ballux and C. buckleyi are sister species.

Specimens examined: Centrolene ballux: Ecuador: Provincia de Carchi: ca. $5 \mathrm{~km}$ W La Gruel (0.916667 N, 78.13333 W; 2340 m), KU 202798. Provincia de Pichincha: Reserva Las Gralarias (0.00806 S, 78.72433 W, 1852 m), QCAZ 40195-99; Quebrada Zapadores, 5 km ESE of Chiriboga on Chiriboga-Quito road $(0.245278$ S, 78.7261 W, 2010 m), KU 164733. Provincia de Santo Domingo de los Tsáchilas: 14 km we'st of Chiriboga on Chiriboga-Santo Domingo road (0.265278 S, 78.8478 W, 1960 m), KU 164725 (holotype), 164726-32 (paratypes). 
Localities from the Literature: Provincia de Pichincha: Las Palmeras (=Bosque Protector Río Guajalito) (0.283 S, 78.75 W; $1800 \mathrm{~m})$ [89].

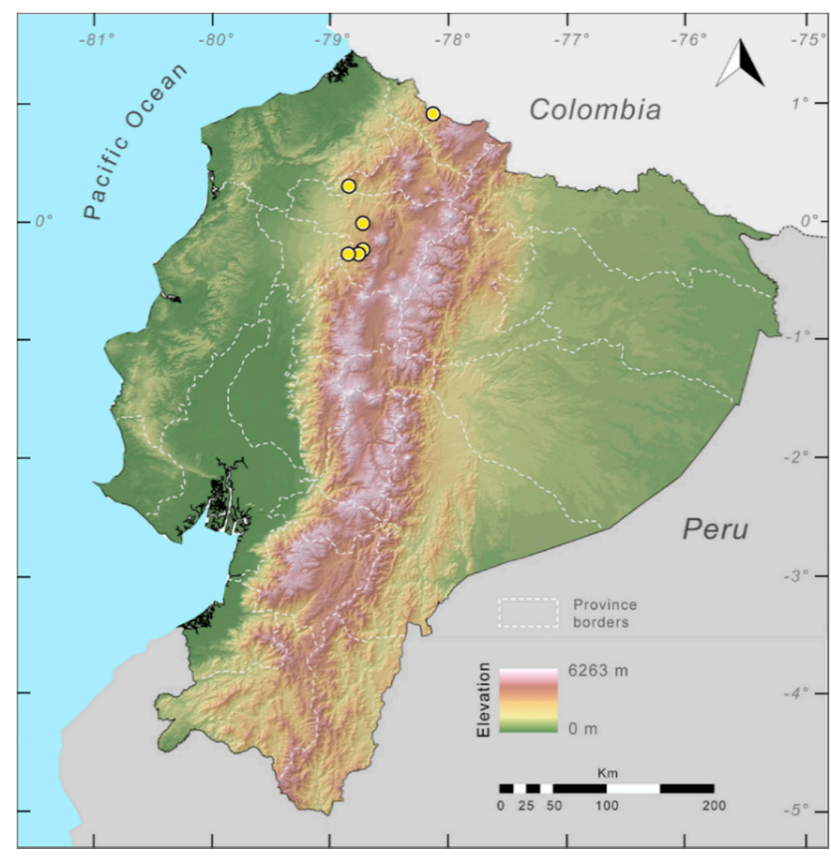

Figure 23. Distribution of Centrolene ballux in Ecuador (yellow dots).

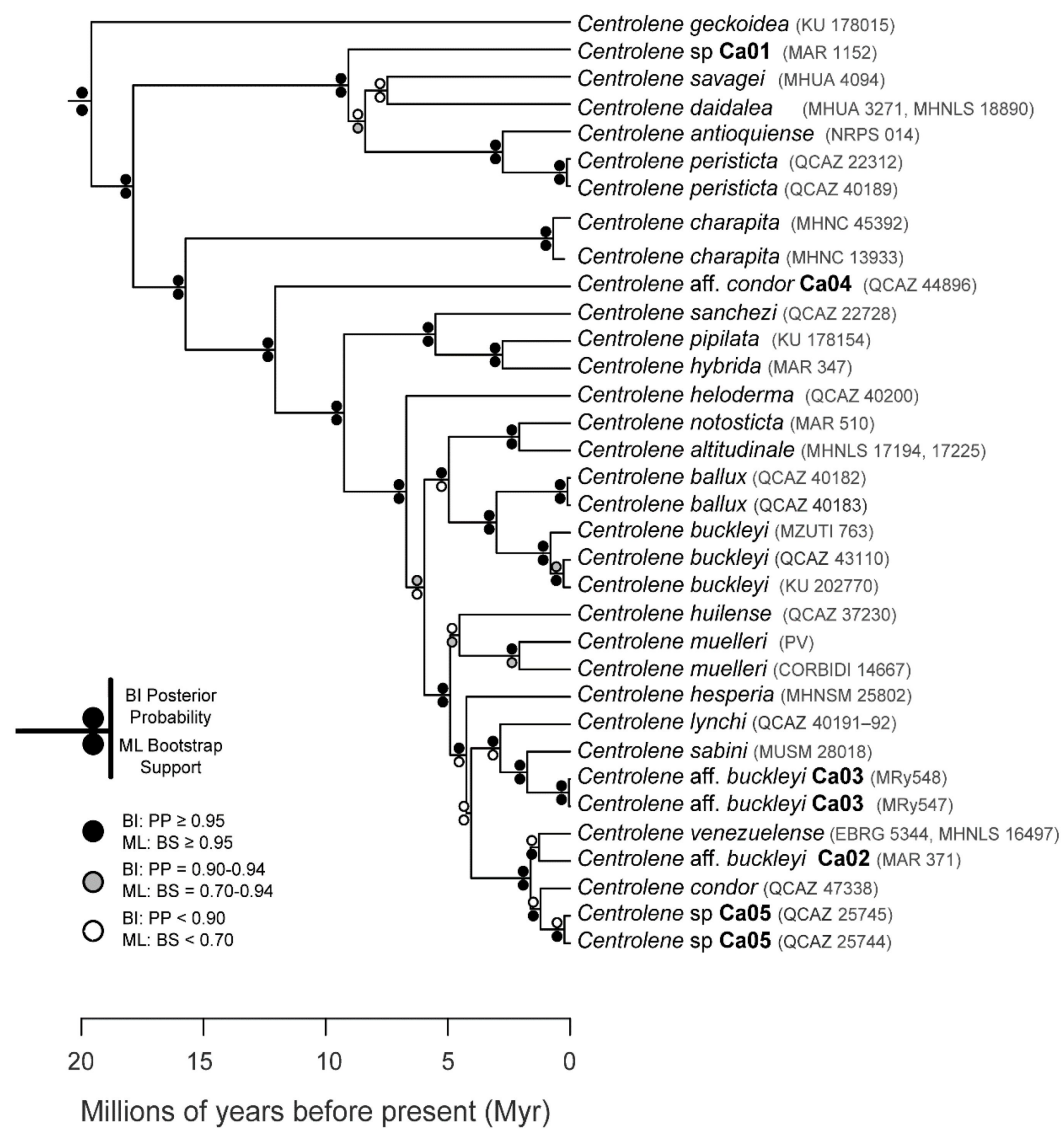

Figure 24. Evolutionary relationships among species in the genus Centrolene, inferred using maximum likelihood and Bayesian criteria. 
Centrolene buckleyi (Boulenger 1882 [93]; Figures 25-28)

Hylella buckleyi Boulenger, 1882 [93]. Syntypes: BM 78.1.25.16 (Intac), 80.12.5.201 (Pallatanga). See comments below on type material. Neotype: KU 202770.

Neotype locality: Isla Wolf of Laguna Cuicocha $\left(0^{\circ} 18^{\prime} 07^{\prime \prime} \mathrm{N}, 78^{\circ} 22^{\prime} 00^{\prime \prime} \mathrm{W} ; 3070 \mathrm{~m}\right)$, Provincia Imbabura, Ecuador, collected on 28 February 1984 by W. E. Duellman.

Centrolenella buckleyi-Noble, 1920 [94].

Cochranella buckleyi-Taylor, 1951 [15]. Rivero, 1961.

Centrolenella buckleyi buckleyi-Rivero, 1968 [95].

Centrolenella johnelsi Cochran and Goin, 1970 [96]. Holotype: MLS 432. Type locality: "San Pedro, N of Medellín, Antioquia, Colombia". Synonymy by Ruiz-Carranza and Lynch, 1991 [6].

Centrolene buckleyi-Ruiz-Carranza and Lynch, 1991 [6].

Common names: English: Buckley's Glassfrog. Spanish: Rana de Cristal de Buckley.

Etymology: The specific name buckleyi was used to recognize Mr. Buckley, who collected the type series of the species.

Identification: Centrolene buckleyi is one of the few species of glassfrogs found in the highlands of Ecuador (2050-3070 m). It is easily recognized by the presence of a large humeral spine (in adult males), white upper lip, inclined snout in lateral profile, and reduced webbing between fingers (Figures 25 and 26). In life, dorsal surfaces are uniform green, but some individuals have small whitish warts. Centrolene heloderma and C. condor can be confused with C. buckleyi; however, C. heloderma has a pustular dorsal skin (shagreen in C. buckleyi) and C. condor has small light and dark spots on the dorsum (dark spots absent in C. buckleyi). Similar species from other countries include Centrolene hesperia, C. lemniscata (Peru), C. altitudinalis, and C. venezuelensis (Venezuela). We note that, as currently defined, C. buckleyi is a species complex that requires further taxonomic studies.

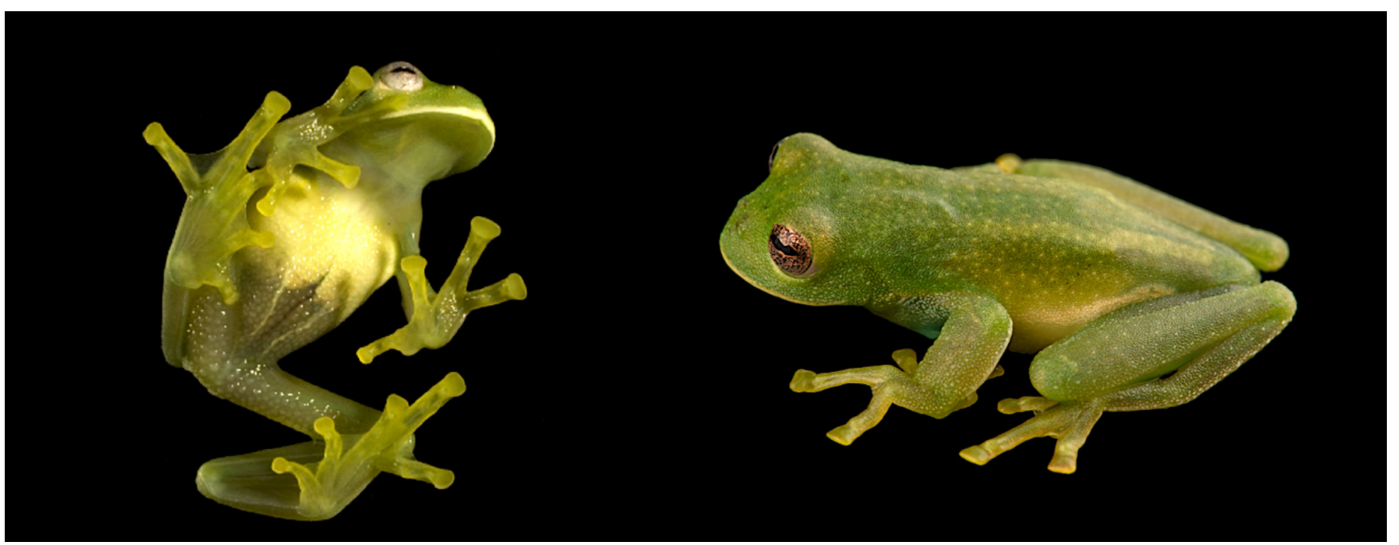

Figure 25. Centrolene buckleyi in life. (Left): Adult male from locality near Oyacachi, Napo province, 3012 m, MZUTI 763, photo by Eduardo Toral. (Right): Adult male from Guarumales, Zamora Chinchipe province, 2070 m, CJ-11364, photo by Diego Acosta-López.

Comments on type material: The description of Centrolene buckleyi was based on two specimens housed at The Natural History Museum, London (formerly British Museum of Natural History). As noted by Goin [97] and Lynch and Duellman [22], one syntype (BMNH 80.12.5.201; from Pallatanga, Provincia de Chimborazo, Ecuador) is now almost completely macerated in ethanol and almost no bones remain, and the other (BMNH 78.1.25.16; from Intac, Imbabura province, Ecuador) is missing and recent searches by Jeff Streicher and DFCH were unsuccessful. Both localities are on the western versant of the Andes of Ecuador, on the slopes of the Cordillera Occidental. Because Centrolene buckleyi represents a species complex [20,98] (Figure 24), we here designate a neotype for Centrolene buckleyi (KU 202770, adult female) collected from Laguna de Cuicocha (near the syntype locality of Intac = Intag), 
thereby allowing clear comparisons among populations that might represent independent lineages. The morphological characteristics of the neotype fully correspond to those mentioned by Boulenger [93] in the original description of the species. Additionally, mitochondrial sequences of the neotype are included in the phylogeny shown in Figure 24. The designation of the neotype is justified on the Article 75.3 of the International Code of Zoological Nomenclature [99].

Diagnosis: (1) Vomers lacking teeth; (2) snout round in dorsal aspect, slightly sloping to sloping in lateral profile (Figure 26); (3) tympanum partially or completely hidden under skin, when visible oriented almost vertically, its diameter is $29.0 \%-38.6 \%$ of eye diameter; supratympanic fold moderately heavy; tympanic membrane slightly thinner than skin around tympanum; (4) dorsal skin finely shagreen, males with spicules; (5) pair of round subcloacal warts (Figure 26); (6) anterior half to two-thirds of venter covered by white parietal peritoneum, posterior portion translucent (condition P2-P3); silvery white pericardium; translucent peritoneum covering intestines, stomach, testes, kidneys, gall bladder, and urinary bladder (condition V1); (7) liver with four or five lobes, lacking iridophores (condition H0); (8) in males, humeral spines present; (9) webbing absent between Fingers I, II, and III; reduced webbing between outer fingers: III $\left(2^{1 / 4}-3^{-}\right)-\left(2^{+}-2^{1 / 2}\right)$ IV (Figure 26$) ;(10)$ webbing formula on foot: I $\left(1^{1 / 2}-2^{-}\right)-\left(2-2^{1 / 4}\right)$ II $\left(1^{-}-1^{+}\right)-\left(2^{+}-2^{1 / 2}\right)$ III $\left(1^{+}-1^{2 / 3}\right)-\left(2^{1 / 3}-3\right)$ IV $\left(2^{2 / 3}-3\right)-\left(1^{2 / 3}-2^{-}\right)$V; (11) ulnar fold low, ventrolateral margin of arm white; inner tarsal fold evident; outer tarsal fold absent, external ventrolateral margin of tarsus white; (12) concealed prepollex; in males, nuptial pad Type I; (13) Finger II slightly longer than Finger I (Finger I 86.5\%-98.7\% of Finger II); (14) disc of Finger III of moderate size, about $54.2 \%-64.5 \%$ of eye diameter; (15) in life, dorsum uniform green that may have scattered whitish warts; upper lip white, usually continuing as a white line across the flanks; bones green; (16) in preservative, pericardium and anterior half to two-thirds of ventral parietal peritoneum white, visceral peritoneum translucent, peritoneum around kidneys translucent; (17) iris grey-white with thin black reticulation and a horizontal brown stripe; (18) melanophores mostly absent from fingers and toes, except for a few on Toes IV and V and on base of outer fingers; (19) males call from the upper sides of leaves; two call descriptions available (see Call section); (20) males fight upside down, grasping one another venter to venter; (21) eggs deposited on the upper sides of leaves; females provide short-term parental care; prolonged parental care is absent; (22) tadpoles unknown; egg clutches deposited within male's territory, but parental care has not been reported; (23) medium body size, SVL in males 26.5-30.9 mm ( $\bar{X}=29.0 ; n=25)$, in females $29.3-34.4 \mathrm{~mm}(\bar{X}=31.2 ; n=9)$.

A

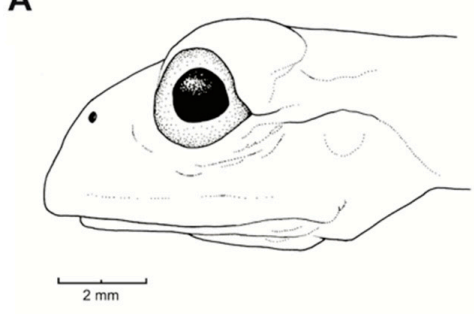

C

B
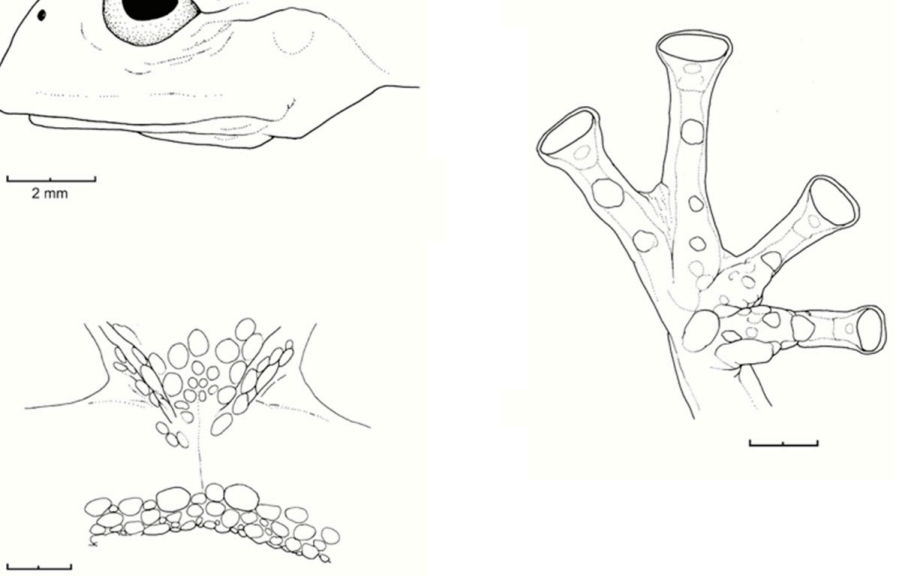

Figure 26. Centrolene buckleyi. (A) Head in lateral view, adult female, KU 178035. (B) Venter and thighs in ventral view, adult female, KU 178040. (C) Hand in ventral view, adult female, KU 178055. Illustrations by Juan M. Guayasamin. 
Description of Neotype: Adult female, SVL 32.6 mm (KU 202770; Figure 27). Head wider than long; head length $28.5 \%$ of SVL; snout rounded in dorsal profile, sloping in lateral profile; canthus indistinct; loreal region slightly concave; upper lip white, slightly flared; nostril protuberant, closer to eye than to tip of snout, directed dorsolaterally; internarinal area barely depressed. Eye small (diameter $14 \%$ of SVL), directed anterolaterally; transverse diameter of disc of Finger III 50.9\% of eye diameter. Supratympanic fold conspicuous; tympanum not visible externally. Vomers lacking teeth, choanae large, round; tongue ovoid, ventral posterior half not attached to floor of mouth and posterior margin notched; vocal slits extending posterolaterally from the posterolateral base of tongue to angle of jaws.

Humeral spine absent; ulnar fold evident, white; relative length of fingers: III > IV > II > I; webbing between Fingers I, II, and III absent, basal webbing for outer fingers: III $2^{2 / 3}-2^{+}$IV; discs and disc pads expanded, elliptical; subarticular tubercles large, round, simple; numerous fleshy supernumerary tubercles present; palmar tubercle elliptical, simple. Length of tibia 51.5\% of SVL; inner tarsal fold evident; outer tarsal fold absent, ventrolateral margin of tarsi white; feet about three-fourths webbed; webbing formula on foot I $1^{1 / 2}-2$ II $1-2^{+}$III $1^{1 / 2}-3$ IV $3-1^{2 / 3} \mathrm{~V}$; discs on toes elliptical; disc on Toe IV narrower that disc on Finger IV; inner metatarsal tubercle large, ovoid; outer metatarsal tubercle not evident; subarticular tubercles small, round; numerous fleshy supernumerary tubercles evident.

Skin on dorsal surfaces of head, body, and lateral surface of head and flanks shagreen, lacking spicules; throat smooth; venter and lower flanks areolate; cloacal opening directed posteriorly at upper level of thighs; small, white tubercles located immediately posterior to cloacae. In ventral view, pair of enlarged subcloacal tubercles not evident.

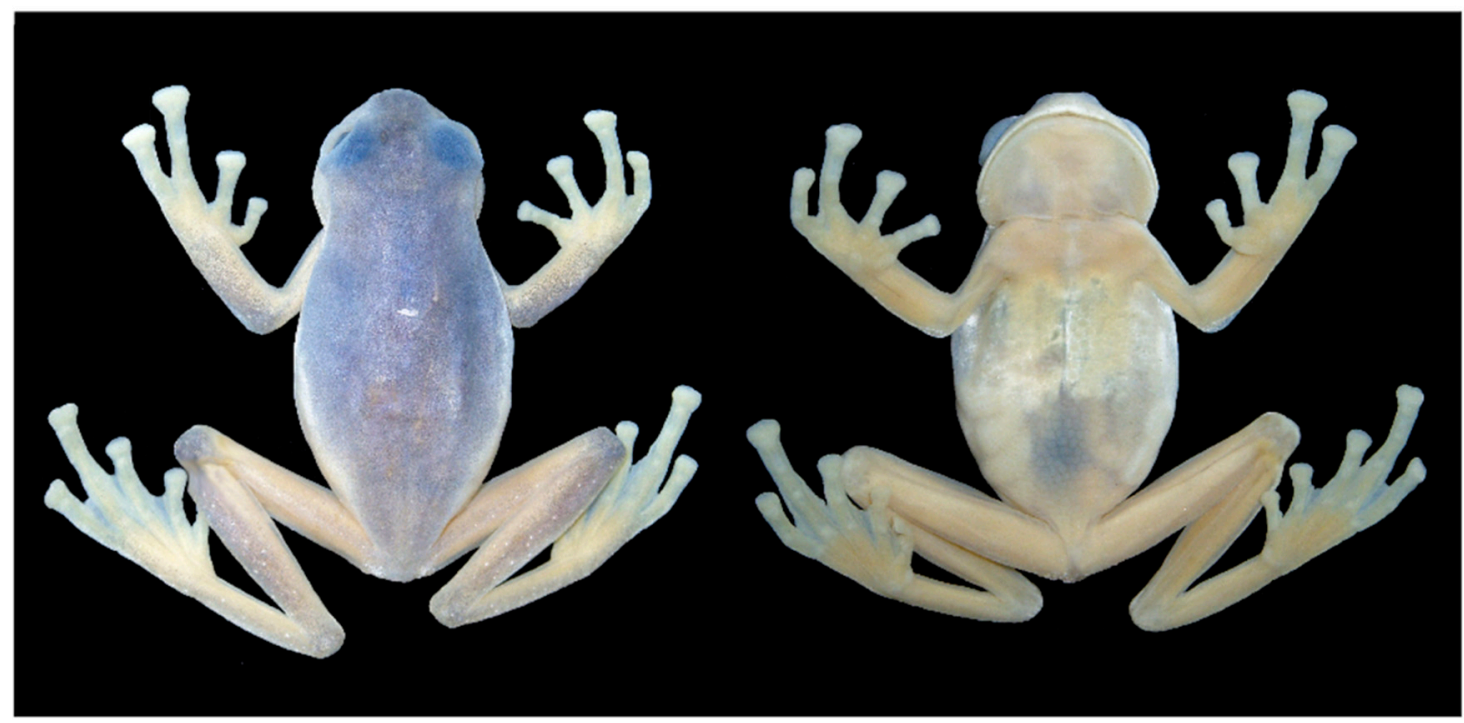

Figure 27. Centrolene buckleyi, adult female, neotype, KU 220770. Ecuador, Imbabura province, Isla Grande, Lago Cuicocha, 3070 m. Photos by Juan M. Guayasamin.

Color in life (Figure 25): Dorsal surfaces bright to dark green, sharply demarcated laterally from lower white flanks; throat and most of venter pale green; parietal peritoneum yellowish white; edge of upper lip white; ventrolateral borders of arms and tarsus white; small, white warts posterior to cloacal opening; bones green; grey-white iris with thin black reticulation and a horizontal brown stripe. Some individuals have whitish warts on dorsum (QCAZ 22388, 26031-32) or small white spots on legs and forearms (KU 202770)

Color in ethanol (Figure 27): Dorsum of head and body uniform lavender or with minute whitish or unpigmented spots; limbs cream with slight lavender tone and with or without small white spots; conspicuous white border on the upper lip; dorsally, all fingers, Toes I-III, and most of Toe IV unpigmented; ventrolateral borders of arms and tarsus white; cloacal region mostly unpigmented, except for several white warts posterior to cloacal opening; males with cream nuptial pad on Finger I. 
Three specimens (QCAZ 26031-32, KU 178042) were dissected to observe coloration of internal organs: Anterior half to two-thirds of ventral parietal peritoneum white; pericardium white; hepatic peritoneum transparent; peritonea covering viscera and kidneys translucent to opaque.

Biology and ecology: During the day, Centrolene buckleyi has been found in terrestrial and arboreal bromeliads near and away from streams in secondary forest and pastures (J. D. Lynch, W. E. Duellman field notes). During the night, Centrolene buckleyi were active on terrestrial bromeliads and vegetation 30-160 cm above streams, lakes, and marshes in primary and secondary forests ([20,22], this work). Lynch and Duellman [22] suggested that C. buckleyi might breed in the same situations as other centrolenids-rapid, mountain streams-but also in bromeliads or in ciénegas; they based this statement on the observation of an egg clutch (KU 170221) on the inner leaf of bromeliad in an area where C. buckleyi was abundant. Males fight dangling upside down while holding onto vegetation with their hind limbs, grasping one another venter to venter (Bolívar et al. 1999). A male (QCAZ 22388) was found on the upper side of a leaf close to another leaf with a clutch of eggs, approximately $160 \mathrm{~cm}$ above a stream [20]. Females provide short-term parental care to egg clutches; males do not exhibit parental care [25].

Call (Figure 28): Two descriptions of the call of Centrolene buckleyi are available in the literature $[20,100]$. The differences between these calls, combined with the non-monophyly of C. buckleyi (Figure 24), clearly show that Centrolene buckleyi, as currently recognized, represents a species complex [20,98]. Below we describe a call from the highlands of Ecuador (MZUTI 763; see Examined Specimens); although the call presented herein is not from the neotype locality, genetically, it clusters together with samples from the type locality; thus, apparently corresponding to the same species. Calls are produced in series, every $45-67 \mathrm{~s}$ (mean $=53 \pm 9.9 ; n=10$ ). Each call has a single, highly pulsed note, with a duration of $0.248-0.288 \mathrm{~s}$ (mean $=0.264 \pm 13.7 ; n=10$; Figure 23). Calls have a slight frequency modulation, with an initial dominant frequency at $2816-2941 \mathrm{~Hz}$ (mean $=2893 \pm 38$; $n=10$ ) and a final dominant frequency at $3222-3255 \mathrm{~Hz}$ (mean $=3229 \pm 12 ; n=10)$. First harmonics are at $5385-6393 \mathrm{~Hz}$.

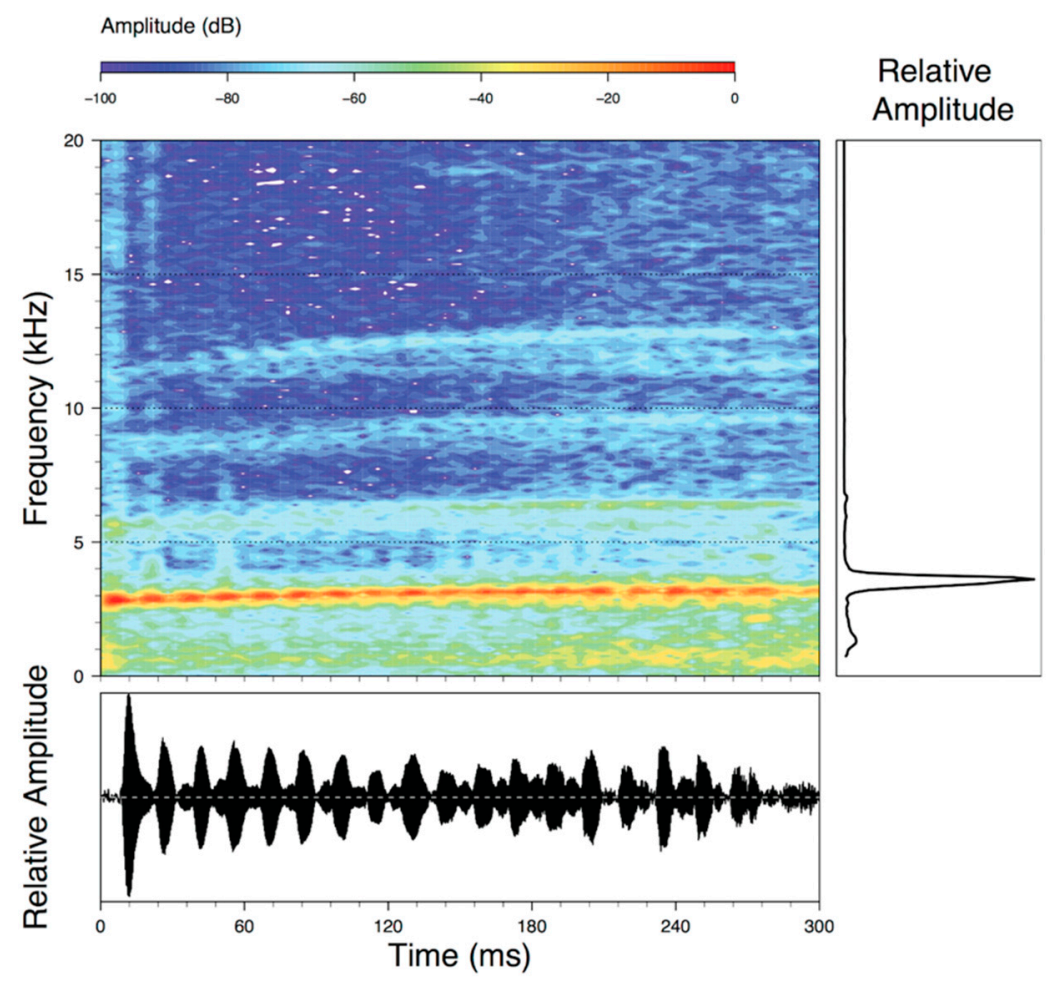

Figure 28. Call of Centrolene buckleyi, MZUTI 763. Recorded at páramo wetland nearby Oyacachi, 3012 m, Napo province, Ecuador. 
Tadpole: Not described.

Distribution (Figure 29): The Centrolene buckleyi species complex occurs through the Andes of Colombia and Ecuador to Huacambamba in the Departamento de Piura in northern Peru at elevations between 2450 and $3300 \mathrm{~m}([17,101,102]$, this work). Records below $2450 \mathrm{~m}$ are considered dubious. In Ecuador, Centrolene buckleyi is found along the Cordillera Oriental and Cordillera Occidental of the Andes, and inhabits the Western Montane Forest, Andean Shrub, Páramo, and Eastern Montane Forest ecoregions, with a potential distribution of $44,586 \mathrm{~km}^{2}$.

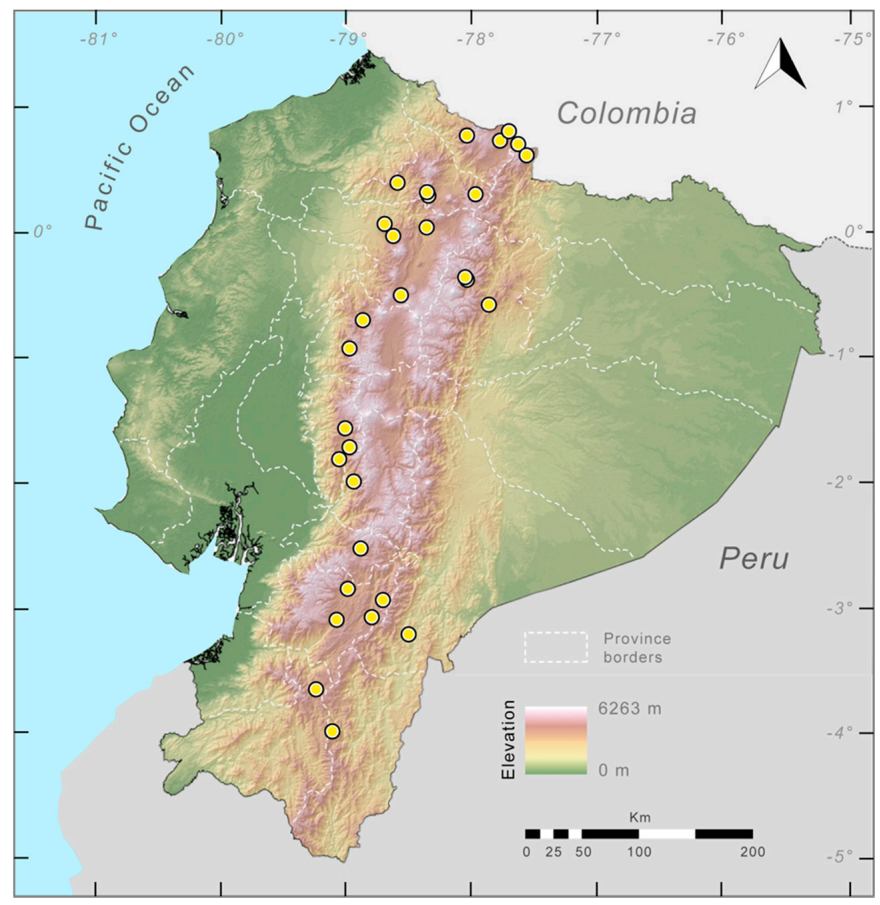

Figure 29. Distribution of the species complex currently recognized as Centrolene buckleyi in Ecuador (yellow dots).

Conservation status: Centrolene buckleyi is listed as Vulnerable at a global level by the IUCN [103]. In Ecuador, Centrolene buckleyi was abundant along the high Andes, but recent fieldwork demonstrates population crashes at historical localities (e.g., Pilaló, Cuicocha, Cashca Totoras, Quito, San Pablo de Atenas, Papallacta) ([91], JMG pers. obs.). The last records of the species in Ecuador are from Bosque Protector Cashca-Totoras in 2002 [91], Morán on February 2017 (Diego Batallas, pers. com., Mario Yánez-Muñoz, pers. com.); Yanayacu Biological Station in 2001-2003 [20], Sigchos ( $0^{\circ} 42^{\prime}$ S, $78^{\circ} 53^{\prime}$ W; $2080 \mathrm{~m}$ ) on March 2008, Zamorahuaico, near Loja ( $3^{\circ} 59^{\prime}$ S, 79 $12^{\prime}$ W; $2100 \mathrm{~m}$ ) on August 2008, and nearby Oyacachi (3012 m) on May 2012. The habitat (Páramo, Andean shrub, and montane forest) occupied by the species is heavily impacted by human activities, mainly agriculture and pasture lands. Considering that that populations declines are widespread in the species complex, we suggest the category of Critically Endangered in Ecuador (IUCN criteria A2c,e).

Evolutionary relationships (Figure 24): As defined herein, Centrolene buckleyi is sister to Centrolene ballux. See Taxonomic Remarks.

Taxonomic Remarks: Centrolene buckleyi is a species complex that requires formal subdivision [20,98]. Moreover, morphologically, Centrolene buckleyi is almost identical to four Andean species, namely C. altitudinalis, C. venezuelensis (Venezuela), Centrolene hesperia, and C. lemniscata (Peru). Myers and Donnelly [104] elevated the Venezuelan populations of Centrolene buckleyi (Centrolenella buckleyi venezuelensis Rivero, 1968 [105]) to the species status, without morphological justification; Señaris and Ayarzagüena [106] provided morphological and acoustic data supporting the recognition of Centrolene venezuelensis. The original descriptions of $C$. hesperia and C. lemniscata 
did not include a comparison between these species and C. buckleyi; therefore, a reevaluation of their species status is necessary. Genetic [20,98] and morphological $[105,106]$ differences support the validity of Centrolene altitudinalis; for example, the lower two-thirds of the tympanic annulus is visible in C. altitudinalis, whereas the tympanum is completely or mostly concealed in C. buckleyi, C. lemniscata, and C. hesperia. Also, we call attention to the conspicuous geographical barriers that have the potential of limiting gene flow among these species. The Peruvian C. hesperia and C. lemniscata are isolated from other species by the Huacambamba Depression, and isolated from each other by interandean valleys. Likewise, the Venezuelan C. venezuelensis and C. altitudinalis are isolated from other species by the Táchira Depression. The distribution of C. buckleyi is restricted, mostly, to the Andes of Ecuador and Colombia, but these populations, based on genetic and call data, represent several independent evolutionary lineages (Figure 24). Thus, clearly, further work is necessary within this species complex.

Measurements of neotype (in mm): The morphometric data for the neotype (female, KU 202770) are as follows: $\mathrm{SVL}=32.6$; tibia length $=16.8$; foot length $=15.1$; head length $=9.3$; head width $=10.3$; interorbital distance $=3.3$; upper eyelid width $=2.6$; internarial distance $=2.8$; eye-nostril distance $=2.2$; snout-eye distance $=4.3$; eye diameter $=4.6$; tympanum diameter $=-$; eye-tympanum distance $=-$; radio-ulna length $=6.72$; hand length $=10.4$; Finger I length $=6.3$; Finger II length $=6.7$; disc of Finger III = 2.3; and Finger III width = 1.2.

Specimens examined: Centrolene buckleyi: Ecuador: Provincia del Azuay: $10 \mathrm{~km}$ N Girón (3.0833 S, 79.0833 W; 2750 m), KU 202777; 11.5 km SE Gualaceo (2.9333 S, 78.71667; 2940 m); Sigsig (3.05 S, 78.8 W; 2450), QCAZ 1245. Provincia de Bolivar: Bosque Protector Cashca-Totoras (1.71 S, 78.98 W; 2800-3159 m), QCAZ 740, 21231; Guanujo (1.5667 S, 79.01667 W. 2600 m), KU 182214; San Pablo de Atenas (1.8 S, 79.0667 W), QCAZ 372, 2415-16; Santiago (1.7167 S, 78.9833 W), QCAZ 1531. Provincia de Carchi: near Tulcán (0.8 N, 77.7167 W; 2770 m), KU 118005-08; 14 km SW Tulcán (0.72889 N, 77.7958, 3340 m), KU 164516; 5.7 km NW El Carmelo (0.6908 N, 77.63389 W, 2910 m), KU 178053-67; Santa Bárbara (0.61667 N, 77.5833; 2650 m), KU 190017-19; El Goatal, Morán, 0.5 km from Escuela de Morán via La Cortadera, QCAZ 43110; Morán (0.7686 N, 78.056 W, 2785 m), DBR 187, 193. Provincia de Cañar: 4 km W Ingapirca (2.51667 S, 78.9 W; 3000 m), KU 178077. Provincia de Cotopaxi: near Pilaló (0.933 S, 78.9833 W; 2410 m), KU 178034-50, 202780-83. Provincia de Imbabura: La Delicia (0.0667 N, 78.7 W; 2710 m), KU 178079-81, 180311; Lago Cuicocha (0.3 N, 78.3667 W; 3010 m), KU 138822, 178030-33; S shore of Lago Cuicocha (0.29194 N, 78.35389; 3070 m), KU 202703-74; Isla Wolf in Lago Cuicocha (0.3019 N, 78.366 W; 3070 m), KU 202770-72; Mariano Acosta (0.3 N, 77.9833 W; 3000 m), QCAZ 12172. Provincia de Loja: 13 km E Loja, Abra de Zamora (3.9744 S, 79.1114 W; 2800 m), KU 164511-15, 166321; 2 km SSW Saraguro (3.6397 S, 79.24 W; 2560 m), KU 178068-76; 3.7 km S Saraguro (3.6469 S, 79.245 W; 2800 m), KU 202778-79. Provincia de Morona Santiago: 25.5 km WSW Plan de Milagro (3.21667 S, 78.5 W; 2600 m), KU 202775. Provincia de Napo: 9.2 km ESE Papallacta (0.3761 S, 78.0683 W; 2750 m), KU 178052; 11 km ESE Papallacta (0.3869 S, 78.0569; 2660 m), KU 164507-09; 11.2 km ESE Papallacta (0.388 S, 78.055; 2660 m), KU 178051; 12 km ESE Papallacta (0.39194 S, 78.04944 W; 2630 m), KU 155481-92, 164505-06; 31 km N Jondachi (0.5711 S, 77.869 W; 2190 m), QCAZ 2740; Oyacachi-El Chaco road (0.219 S, 78.044 N; 3012 m), MZUTI 763. Provincia de Pichincha: 9.5 km NW Nono (0.026389 S, 78.6403 W; 2530 m), KU 164510; Hacienda El Beaterio, KU 178078; near Machachi (0.5 S, 78.5667 W; 2950 m), KU 148429-30. Provincia de Zamora Chinchipe: 13.5 km E Loja (3.973 S, 79.107 W; 2800 m), KU 142648; Guarumales (3.9405 S, 78.987 W; 2070 m), CJ-11364.

Localities from the literature: Centrolene buckleyi: Ecuador: Provincia del Azuay: Sinicay, $2560 \mathrm{~m}$, AMNH 17464. Provincia de Chimborazo: Pallatanga (1.9833 S, 78.95 W; 1520 m), BMNH 80.12.5.201. Provincia de Imbabura: Intac (0.4 N, 78.6 W), BMNH 78.1.25.16. Provincia de Zamora Chinchipe: Sabanilla (4.033 S, 79.0 W), AMNH 13530 [22,93]. 
Centrolene charapita Twomey, Delia, and Castroviejo-Fisher 2014 [19] (Figures 30 and 31).

Centrolene charapita Twomey, Delia, and Castroviejo-Fisher, 2014 [19]. Holotype: MHNCP 13933. Type locality: "near the village of La Oliva, past the village of Muyo (a larger village roughly

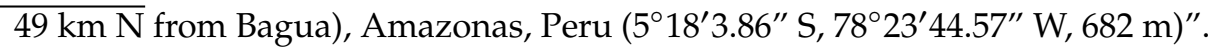

Common names: English: Charapita Glassfrog. Spanish: Rana de Cristal Charapita.

Etymology: The specific name charapita derives from a type of yellow chili pepper (ají charapita), which resembles the dorsal ocelli of the species [19].

Identification: Centrolene charapita is the only glassfrog with yellow dorsal ocelli, scalloped and enameled ulnar and tarsal folds (Figure 30), and relatively large size (adult male SVL $=34.7-37.0$ ).

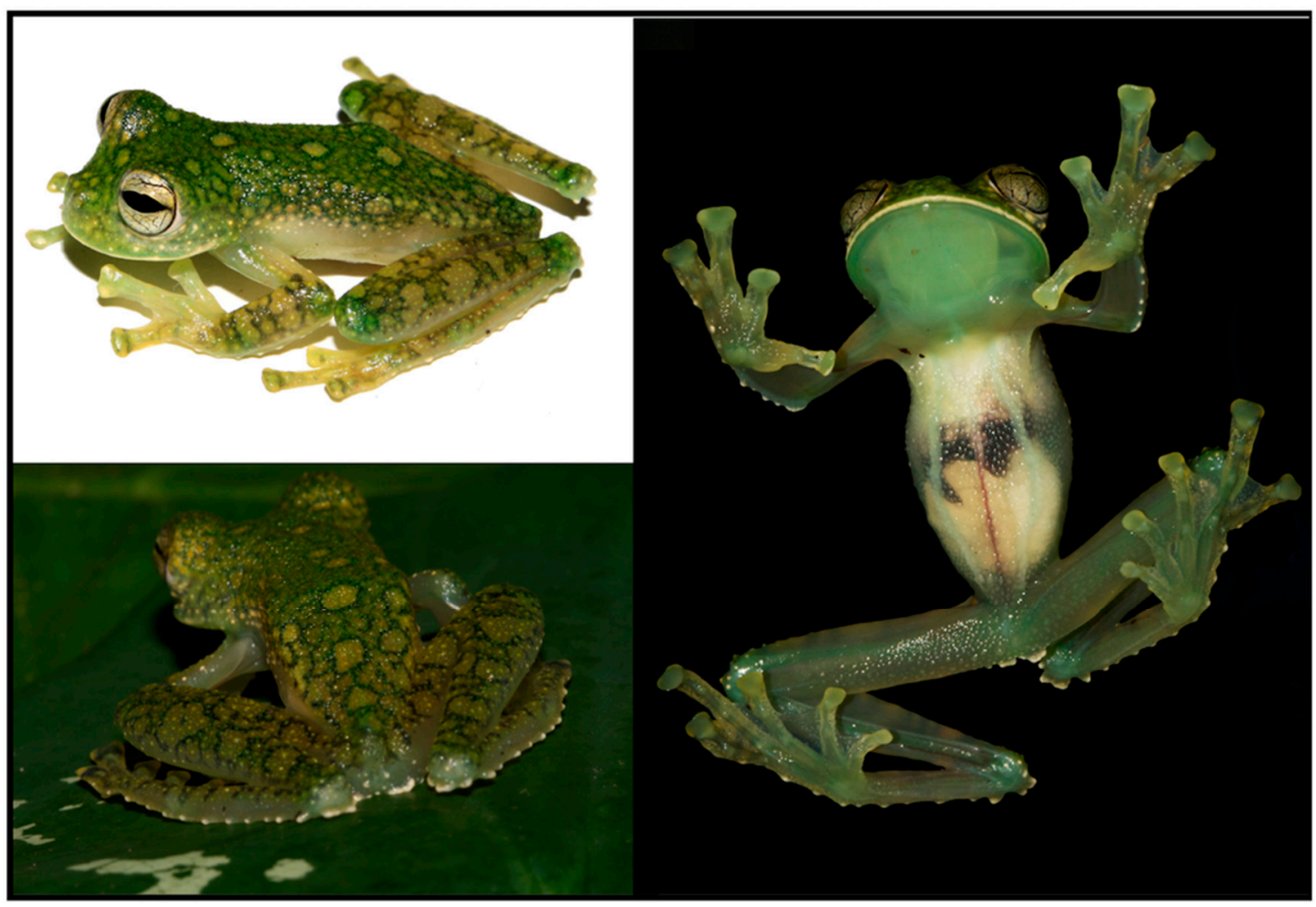

Figure 30. Centrolene charapita in life. Type series from near La Olivia, $682 \mathrm{~m}$, Departamento Amazonas, Peru. Photos by Santiago Castroviejo-Fisher and Evan Twomey.

Diagnosis: Centrolene charapita is recognized by (modified from Twomey et al. [19]): (1) Vomers with 4-10 vomerine teeth; (2) in Peruvian population, snout truncated in dorsal view and truncated to slightly rounded in profile; in Ecuadorian population, snout round in dorsal view and sloping in profile; (3) tympanum small, partially hidden under skin; supratympanic fold present; (4) dorsal skin smooth with microspicules and low enameled warts on ocelli; venter and thighs coarsely areolate, other ventral surfaces smooth; (5) cloacal ornamentation conspicuous, formed by enameled folded skin (flaps) surrounded by lower warts; pair of enlarged subcloacal warts; (6) anterior third-to-half of parietal peritoneum white, posterior portion transparent (state P2); pericardium, hepatic, renal, and gonadal peritonea transparent, visceral peritoneum white; (7) liver trilobed, lacking iridophores (state H0); (8) humeral spines absent; (9) no webbing between Fingers I and II; webbing formula for outer fingers: II $2^{-}-3^{1 / 3}$ III $2-\left(1^{+}-1^{1 / 3}\right)$ IV; (10) webbing formula on foot: I $\left(1^{1 / 3}-1^{1 / 2}\right)-\left(2^{-}-2\right)$ II $1-\left(2^{-}-2^{1 / 3}\right)$ III $\left(1-1^{+}\right)-\left(2-2^{+}\right)$IV $\left(2-2^{1 / 3}\right)-1$ V; (11) scalloped enameled ulnar and tarsal folds, extending from fringe on postaxial edge of Finger IV to elbow, and from fringe on postaxial edge of Toe V to ankle, respectively; (12) concealed prepollex; in males, nuptial pad Type I, not pigmented; 
(13) when appressed, Finger I about equal length or slightly longer than Finger II; (14) eye diameter about 2.5 times the width of disc on Finger III; (15) in life, dorsal and dorsolateral surfaces covered with yellow or pale green spots of different size (ocelli); upper lip and tip of finger and toes I, II, and III white (enameled); ventral surfaces not pigmented; bones green; (16) in preservative, dorsal surfaces and dorsolateral surfaces with cream spots of different size (ocelli), bearing enameled warts and microspicules set in a lavender-greyish reticulum; upper lip and tip of finger and toes I, II, and III white (enameled); ventral surfaces not pigmented; (17) iris in life off-white to light grey with yellow tones and black dots and reticulation, with black ring delimiting iris; in preservative, iris silvery white with black dots and reticulation, with black ring delimiting iris; (18) in life and preservative, tip of fingers and toes white (enameled), Finger IV and Toes IV and V pigmented, Finger II and Toe III not pigmented, but for a small group of melanophores towards the tip, Fingers and Toes I and II not pigmented; (19) males call from upper side of leaves; call not described; (20) fighting behavior unknown; (21) eggs deposition site unknown; parental care unknown; (22) tadpoles undescribed; (23) large size in adult males; SVL 34.7-37.0 mm $(n=5)$ in males; females unknown.

Color in life (Figure 30): Modified from Twomey et al. [19]. Dorsal and dorsolateral surfaces green, with yellow or pale green spots of different size (ocelli). Upper lip and discs of fingers and toes I, II, and III white (enameled). Ventral surfaces, flanks, upper arms, Fingers I and II, and Toes I and II not pigmented. Iris delimited by a black ring, background coloration off white to light grey with yellow shades and black dots and reticulation. Anterior third-to-half of parietal peritoneum white, posterior portion transparent. Visceral peritoneum white. Hepatic peritoneum transparent.

Color in ethanol: Obtained from Twomey et al. [19]. Dorsal and dorsolateral surfaces with relatively large cream spots bearing enameled warts and microspicules set in a lavender-greyish reticulum, which is formed by minute melanophores that are darker around the ocelli. Upper lip and tips of fingers and toes I, II, and III white (enameled). Ventral surfaces, flanks, upper arms, Fingers I and II, and Toes I and II not pigmented.

Biology and ecology: Very little is known about Centrolene charapita. Twomey et al. [19] report that, at the type locality, individuals were found perched on riverine vegetation during the night, and that sympatric amphibians included Ameerega trivittata, Bolitoglossa altamazonica, Cochranella erminea, Hyloscirtus sp., Rulyrana mcdiarmidi, Pristimantis aff. acuminatus, Pristimantis sp., and Rhaebo glaberrimus. Parental care is unknown.

Call: Unknown.

Tadpole: Not described.

Distribution (Figure 31): Centrolene charapita is known from the type locality, a stream $\left(5^{\circ} 18^{\prime} 3.86^{\prime \prime} \mathrm{S}\right.$, $78^{\circ} 23^{\prime} 44.57^{\prime \prime}$ W, $\left.682 \mathrm{~m}\right)$ near La Oliva, Peru [19], and Reserva Natural Maycu (4.2 ${ }^{\circ} \mathrm{S}, 78.6^{\circ}$ W, 940-1219 m) in southeast Ecuador. 


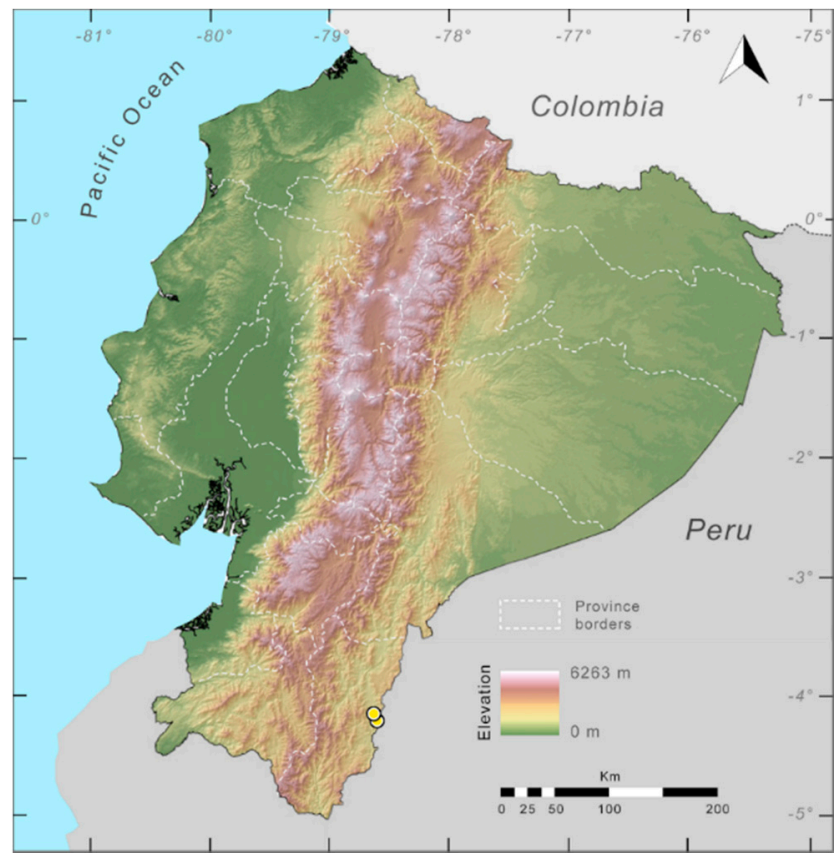

Figure 31. Distribution of Centrolene charapita in Ecuador (yellow dots).

Conservation status: The conservation status of Centrolene charapita has not been evaluated by the IUCN. In Ecuador, populations are within a private reserve (Reserva Natural Maycu). The whole distribution range of the species is within a mining concession. Based on IUCN criteriaB2, Ba, Bb(iii), we suggest that $C$. charapita should be considered as Critically Endangered in Ecuador.

Evolutionary relationships (Figure 24): Our phylogeny places Centrolene charapita as the sister species to a clade formed by several Centrolene species. A previous analysis had inferred C. charapita as sister to C. geckoidea [19].

Specimens examined: Centrolene charapita: Ecuador: Provincia de Zamora Chinchipe: Reserva Natural Maycu $\left(4.207^{\circ} \mathrm{S}, 78.630^{\circ} \mathrm{W}\right.$, QCAZ 66783; $4.222^{\circ} \mathrm{S}, 78.645^{\circ} \mathrm{W}$, QCAZ 66786-87; 4.229 ${ }^{\circ} \mathrm{S}$, $78.616^{\circ} \mathrm{W}$, QCAZ 66785; $4.226^{\circ} \mathrm{S}, 78.620^{\circ} \mathrm{W}$, QCAZ 66784).

Centrolene condor Cisneros-Heredia and Morales-Mite 2008 [107] (Figures 32 and 33).

Centrolene condor Cisneros-Heredia and Morales-Mite, 2008 [107]. Holotype: QCAZ 37279.

Type locality: "Destacamento Militar Cóndor Mirador, western slope of the Cordillera del

Cóndor $\left(03^{\circ} 18^{\prime} 25^{\prime \prime} \mathrm{S}, 78^{\circ} 23^{\prime} 36^{\prime \prime} \mathrm{W}\right.$, between $1750-1850 \mathrm{~m}$ elevation), Provincia de Zamora Chinchipe, República del Ecuador".

Common names: English: Condor Glassfrog. Spanish: Rana de Cristal del Cóndor.

Etymology: The name of this species is in reference to its type locality, Cordillera del Cóndor, a mountain chain shared by Ecuador and Peru [107].

Identification: Centrolene condor can be distinguished from all other glassfrogs by having a green dorsum with many small yellowish-white flecks and dark bluish-black/brown flecks and punctuations (Figure 32), sloping snout in lateral view, light labial stripe, vomerine teeth, small humeral spine in males, enameled ulnar fold, and enameled metatarsal fold followed by a row of distinct enameled tubercles along the outer edge of the tarsus. Among Ecuadorian centrolenids, only C. pipilata shares a similar dorsal pattern, but $C$. condor has vomerine teeth (absent in C. pipilata) and a small, curved humeral spine (larger and straight in C. pipilata). 


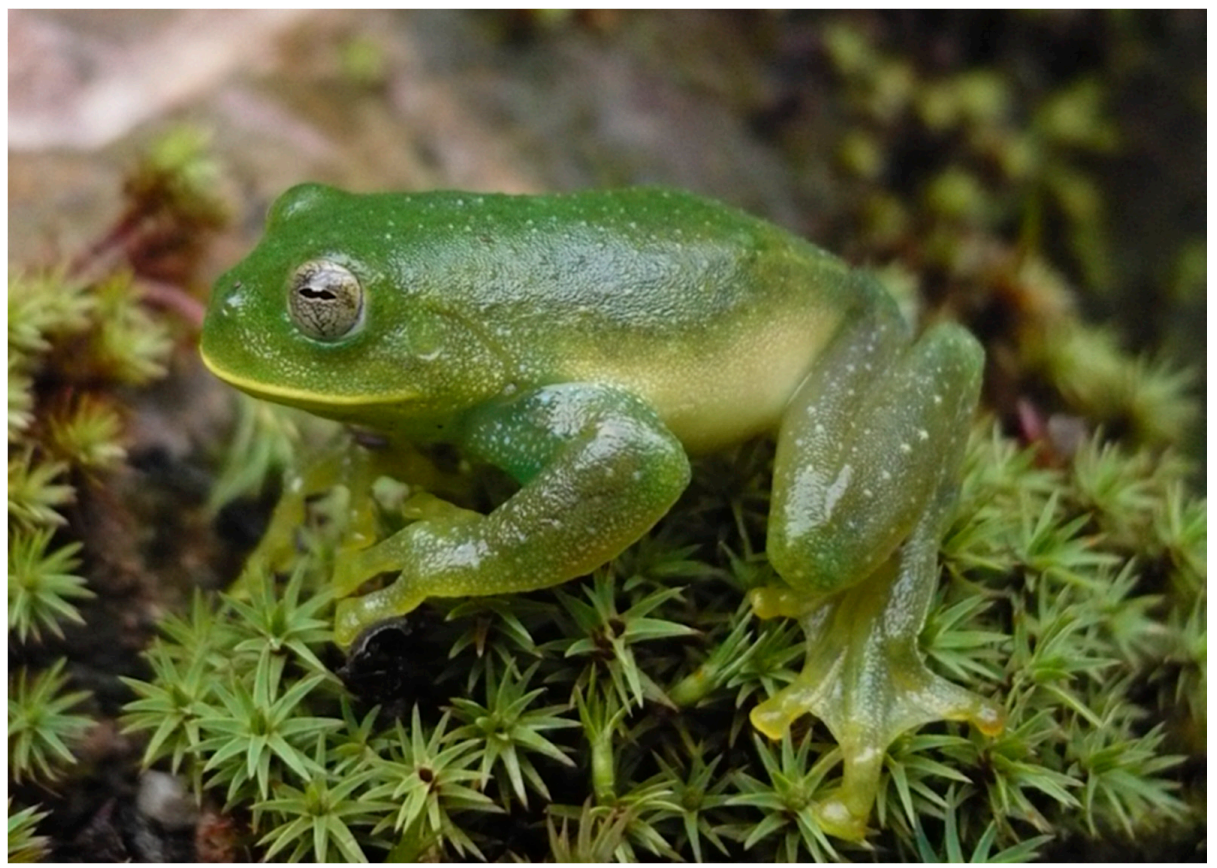

Figure 32. Centrolene condor in life. Ecuador, Zamora Chinchipe province, Paquisha, EPN 11343. Photo by Ana Almendáriz.

Diagnosis: Centrolene condor is diagnosed by the following traits (modified from Cisneros-Heredia and Morales-Mite [107]): (1) Vomerine teeth present; (2) snout subacuminate in dorsal view and sloping in profile; nostrils slightly elevated, producing depression in the internarial area; (3) tympanic annulus visible, vertical, with slight dorsolateral orientation; tympanic membrane not differentiated from surrounding skin; (4) dorsal skin shagreen, but with low warts and abundant spicules; (5) ventral skin granular; subcloacal area also granular with several enameled warts; (6) upper two-thirds of parietal peritoneum covered by iridophores (condition P3), pericardium white, all other peritonea not covered by iridophores (condition V1); (7) liver lobed, lacking iridophores (condition H0); (8) small humeral spines present in adult males; (9) webbing absent between Fingers I and II, basal between II and III, moderate between outer fingers: III $2-2^{-}$IV; $(10)$ webbing between toes moderate: I $1^{1 / 2}-2^{+}$ II 1-2+ III 1-2 IV 2-1 V; (11) enameled ulnar fold; enameled fringe on edge of toe $V$ that continues into thin enameled metatarsal fold and then into row of enameled tubercles along outer edge of tarsus; (12) nuptial excrescences present, Type I; concealed prepollex; (13) first finger shorter than second; (14) eye diameter larger than width of disc on Finger III; (15) in life, green dorsum with abundant yellowish-white flecks and abundant dark flecks; green bones; (16) in preservative, dorsal surfaces greyish with slight lavender hue and abundant light and dark flecks; (17) in life, iris cream-yellow with fine dark reticulation; in preservative, iris light grey with fine dark reticulation; (18) melanophores absent from fingers and toes, except for few on dorsal surfaces of outer fingers and outer toes; (19) males call from upper side of leaves; call composed by two pulsed notes, with dominant frequency at $2.62-2.97 \mathrm{KHz} ;(20,21,22)$ parental care, fighting behavior, egg clutches, and tadpoles unknown; and (23) medium body size, SVL in adult males $23.2-27.6 \mathrm{~mm}(\bar{X}=25.4 \pm 1.826 ; n=5)$; females unknown.

Color in life (Figure 32): Green dorsum with abundant yellowish-white flecks and dark punctuations. Enameled spots and yellowish-white flecks on arms and legs. Whitish-yellow labial line present. Enameled arm and leg folds. Green bones [107].

Color in ethanol: Dorsal surfaces greyish with slight lavender tint, with abundant light and dark flecks. Anterior two-thirds of ventral parietal peritoneum white, pericardium white, all other peritonea lack white lining (modified from Cisneros-Heredia and Morales-Mite [107]).

Biology and ecology: Centrolene condor is a recently described species and little information is available on its natural history. It is nocturnal and males call from amidst the leaves of riverine 
vegetation a few centimeters over water in mature elfin forest. The species seems to be fairly common at Loma Tigres Bajo, where about 30 males were heard calling [108]. Tadpoles have a bright red coloration and are benthic [108].

Call: The advertisement call has a duration of $650-700 \mathrm{~ms}(n=3)$; it is similar to a trill, composed of two pulsed notes; the first note has a duration of $435-510 \mathrm{~ms}$ and is conspicuously longer than the second (101-102 ms); the time between notes is $66-118 \mathrm{~ms}$, and the dominant frequency is $2.62-2.97 \mathrm{KHz}$ [108].

Tadpole: Not described.

Distribution (Figure 33): Centrolene condor is endemic to Ecuador, from localities in the Cordillera del Cóndor, Ecuador, at an elevation of 1737-2920 m [107,108]. The species is distributed within the Eastern Montane Forest ecoregion. Additional searches in the Cordillera del Cóndor have not yielded additional localities for the species [108].

Conservation status: Centrolene condor is currently listed as Data Deficient by the IUCN [109]. Given that the species is known from few localities in an isolated mountain range (Cordillera del Cóndor) with extensive mining activities and associated deforestation and contamination, we suggest considering the species as Endangered-EN B1ab(iii), at the global and local levels, in agreement with Almendáriz and Batallas [108].

Evolutionary relationships (Figure 24): Terminals identified as Centrolene condor are placed in different positions in the tree. Thus, it is likely that more than one species is found in what is currently recognized as C. condor.

Specimens examined: Centrolene condor: Ecuador: Provincia Zamora Chinchipe: Destacamento Militar Cóndor Mirador, western slope of the Cordillera del Cóndor $\left(03^{\circ} 18^{\prime} 25^{\prime \prime}\right.$ S, $78^{\circ} 23^{\prime} 36^{\prime \prime}$ W, 1750-1850 m), QCAZ 37279.

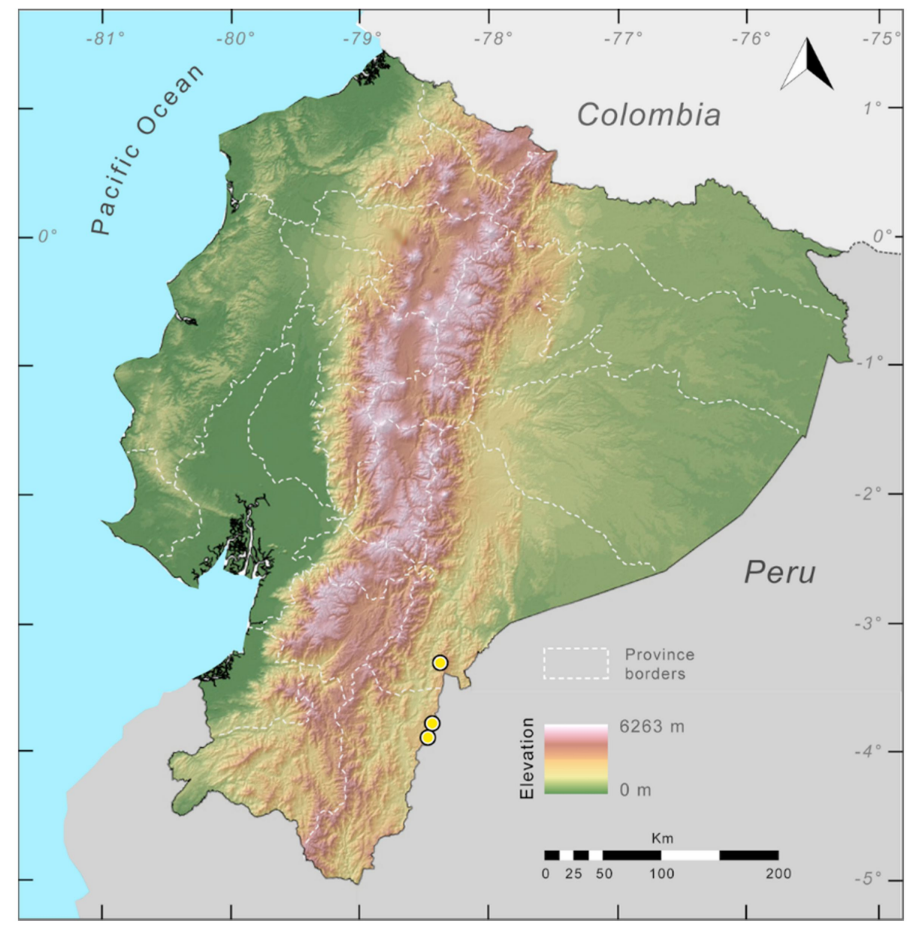

Figure 33. Distribution of Centrolene condor in Ecuador (yellow dots). 
Centrolene geckoidea Jiménez de la Espada 1872 [83] (Figures 34-36).

Centrolene geckoideum Jiménez de la Espada, 1872 [83]. Holotype: MNCN 1596.

Type locality: "las riberas del río Napo en el Ecuador". See comment in Distribution.

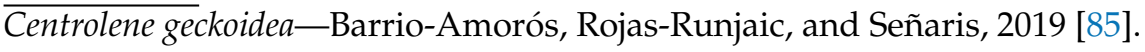

Common names: English: Gecko Glassfrog. Spanish: Rana de Cristal Geco.

Etymology: The specific epithet geckoidea refers to the enormous size of the discs on fingers and toes of this species, which resemble those of gecko lizards (Gekkonidae). For almost 150 years, this species was known as C. geckoideum, but its specific ephited was recently modified to geckoidea [85].

Identification: Centrolene geckoidea is unique among centrolenids in having a giant body size (adult males, SVL 70.2-80.7 mm; females, SVL 61.8-72.9 mm) and webbing between the two innermost fingers (Figure 35). Males also have a conspicuous humeral spine (Figure 34), which in some individuals, perforates the skin of the arm. Only C. paezorum, endemic of the high Andes of Colombia, could be confused with C. geckoidea; $C$. paezorum is known only from a single female and is reported to be smaller (SVL $44.5 \mathrm{~mm}$; see Remarks) and with less hand webbing than C. geckoidea [110].

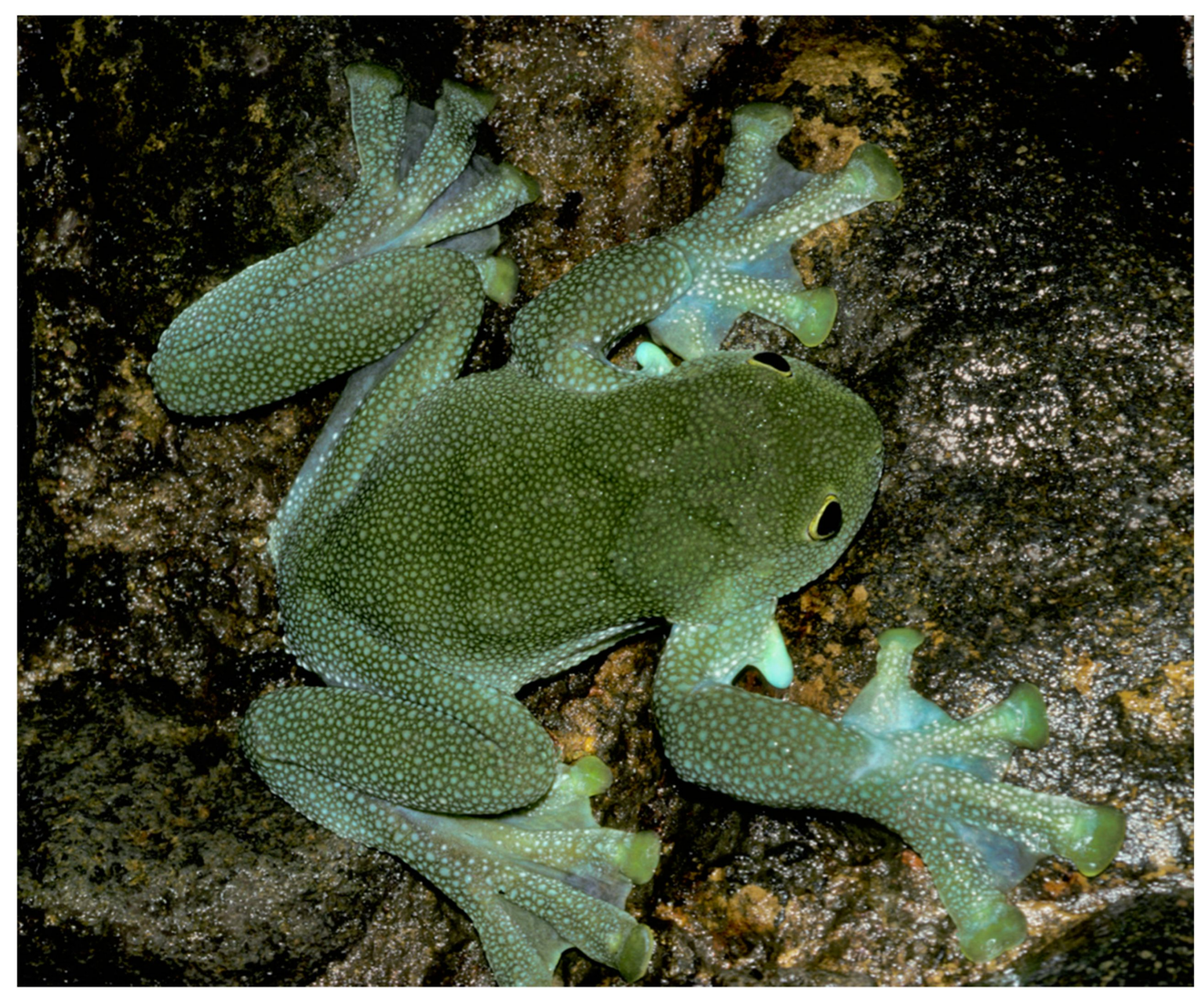

Figure 34. Centrolene geckoidea in life. Ecuador, Carchi province, Río La Plata $\left(00^{\circ} 48^{\prime} \mathrm{N}, 78^{\circ} 02^{\prime} \mathrm{W}\right.$; 2525 m), on the Maldonado-Tulcán road, DHMECN 0900. Photo by Doug Wechsler (25 July 1988).

Diagnosis: (1) Each vomer with four or five teeth; (2) snout truncated in dorsal and lateral profiles (Figure 35); (3) tympanum visible and small, oriented almost vertically, its diameter $40.3 \%-50.0 \%$ of eye diameter; supratympanic fold moderate; tympanic membrane completely pigmented, differentiated from surrounding skin; (4) dorsal surfaces of males and females covered with warts, spicules evident only in males; (5) ventral surfaces of thighs below vent lacking pair of enlarged warts; (6) anterior two-thirds or the entire ventral parietal peritoneum white (conditions P3-P4); silvery white pericardium; no iridophores in peritonea covering intestines, stomach, testes, kidneys, gall bladder, and urinary 
bladder (condition V1); (7) liver tetralobed, lacking iridophores (condition H0); (8) in males, humeral spines present; (9) webbing present, but reduced between Fingers I, II, and III; extensive webbing between Fingers III and IV; hand webbing formula I $2-\left(2-2^{+}\right)$II $\left(1-1^{+}\right)-\left(2^{3 / 4}-3^{+}\right)$III $\left(1^{1 / 3}-1^{2 / 3}\right)-1$ IV (Figure 35); (10) webbing formula on foot I $0^{+}-\left(0^{+}-1\right)$ II $0^{+}-\left(0^{+}-1\right)$ III $0^{+}-\left(1-1^{1 / 2}\right)$ IV $\left(1-1^{1 / 2}\right)-0^{+}$V; (11) ulnar fold with small, white tubercles; inner tarsal fold low, short; outer tarsal fold low, with small, white tubercles; (12) concealed prepollex; in males, nuptial pad Type I; (13) Finger I about same length as Finger II (Finger I 91.7\%-100.0\% of Finger II); (14) disc of Finger III wide, about $115 \%-130 \%$ of eye diameter; (15) in life, dorsum dull green to dark grey; upper lip yellow; bones green; (16) in preservative, dorsal surfaces grey to dark grey; (17) iris greenish gold with fine black reticulation; (18) melanophores covering dorsal surfaces of hands and feet; (19) males call from rocks behind waterfalls or within or near spray zones of fast-flowing streams; call loud, high-pitched, trilled whistle that lacks any consistent pattern of amplitude modulation; weakly to moderately pulsed, duration 155-373 ms; emitted infrequently at intervals of $1.48-5.05 \mathrm{~min}$; dominant frequency modulated, $3468-4187 \mathrm{~Hz}$; (20) fighting behavior unknown; (21) black eggs deposited on rocks in spray zones of streams; males provide prolonged parental care; (22) tadpoles dark, labial tooth row formula (LTRF) 2/3, but see below; (23) giant body size, males SVL 70.2-80.7 mm ( $\bar{X}=75.2, n=12)$; females, SVL 61.8-72.9 $\mathrm{mm}(\bar{X}=68.1$, $n=9)$.

A

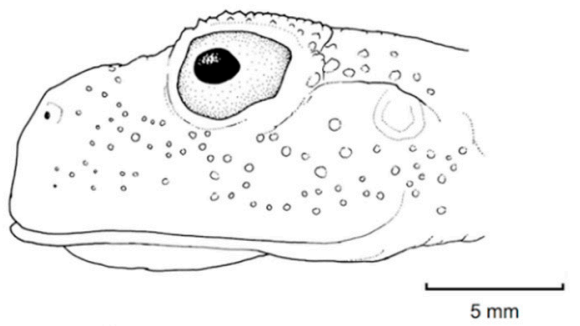

C

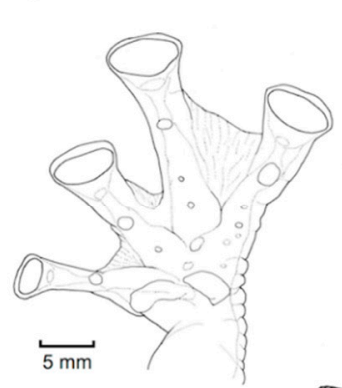

D

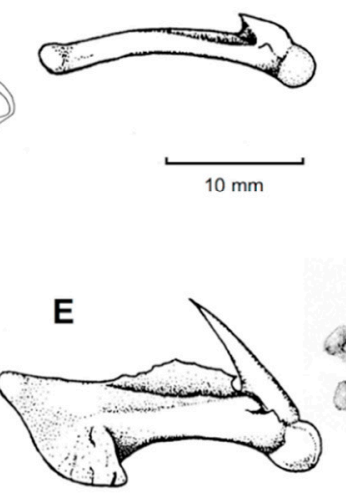

B

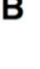

B
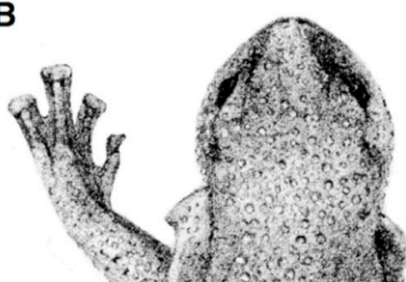
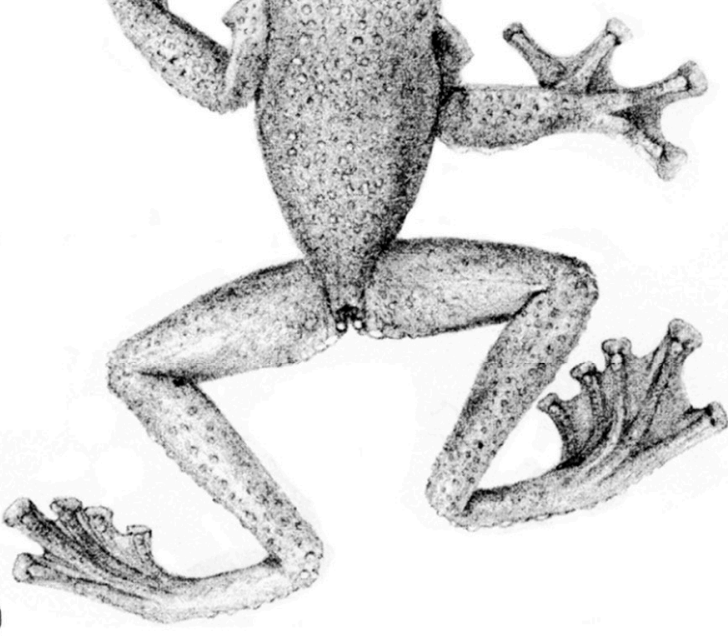

Figure 35. Centrolene geckoidea. (A) Head in lateral view, male, KU 116447. (B) Drawing of holotype, not to scale [83]. (C) Hand in ventral view, male, KU 116447; drawing by Juan M. Guayasamin. (D) Humeral spine of adult female; modified from Rueda-Almonacid [111]. (E) Humeral spine of adult male; modified from Rueda-Almonacid [111].

Color in life (Figure 34): Dorsum dull green, with enameled greenish or bluish warts; throat greenish yellow; margin of upper lip yellow; venter cream or yellow cream; ulnar, tarsal, and cloacal tubercles creamy white; white flecks on flanks; iris pale greenish gold with fine black reticulation; palpebrum clear (W. E. Duellman field notes, 9 April 1975; this work); bones green [111]. Males and females are dark grey to brownish green during the night [112]. 
Color in ethanol: Dorsal surfaces of head, body, and limbs cream grey to dark grey with tips of spicules being white; cloacal, ulnar, and tarsal tubercles white; ventral surfaces cream. Anterior two-thirds of the ventral parietal peritoneum white, posterior third transparent; pericardium white; no iridophores in peritonea covering liver, kidneys, and digestive tract.

Biology and ecology: Males and females of Centrolene geckoidea have been found clinging to vertical or overhanging rock surfaces in the spray zone behind waterfalls [112-114]. Males have remarkable call-site fidelity. Egg clutches are deposited on rocks within the spray zone and contain 89-112 black eggs, which are glued to the rocks by a brittle jelly unknown in other centrolenids [112,113]; an "empty space" is evident in the center of the attached clutch [113]. Although oviposition has not been observed, Grant et al. [112] suggested that the ova may be deposited as the female rotates through a circle with the head at the center, a scenario that would explain the origin of the "empty space" near the center of the egg mass. During the night, males have been observed sitting on or near up to four clutches of eggs while calling. During the day, males also have been observed sitting near or on clutches on the rockface behind a waterfall or hidden in spaces between rocks [112]. Thus, all observations by Grant et al. [112] suggest that males provide prolonged parental care to clutches.

Call: Grant et al. [112] described the call of Centrolene geckoidea from El Queremal (3.483 N, 76.7 W), Valle del Cauca, Colombia. The information shown below is based on their study. Males call from behind waterfalls or within or near spray zones of fast-flowing streams. Males have call-site fidelity and have been observed vocalizing at the same site for up to a month. The call is a loud, high-pitched, trilled whistle that lacks any consistent pattern of amplitude modulation. The call is weakly to moderately pulsed and has a duration of 155-373 ms. Calls were emitted infrequently at intervals or 1.48-5.05 min; however, males typically call less frequently (i.e., as little as less than once per hour). The dominant frequency is at $3468-4187 \mathrm{~Hz}$, and it is modulated, beginning at low frequencies (3593-3781 Hz) and rising to a maximum of $3718-4187 \mathrm{~Hz}$, after which it falls, ending at $3468-3718 \mathrm{~Hz}$.

Tadpole: Lynch et al. [113] and Rueda-Almonacid [111] provide descriptions and illustrations of the tadpole of Centrolene geckoidea. Lynch et al. [113] briefly described a tadpole (total length of $22.3 \mathrm{~mm}$ ) as having a typical centrolenid body form; mouth lacking upper tooth rows, but with two evident lower rows ( $\mathrm{P}_{1}$ with a wide medial gap); upper jaw sheath thick with minute serrations; lower jaw sheath thin and poorly keratinized; one row of large subconical marginal papillae borders the oral disc ventrolaterally and posteriorly. Rueda-Almonacid [111] mentioned that tadpoles in Gosner stage 22 , one month after hatching, had two incomplete tooth rows on the anterior labium and three tooth rows on the posterior labium. However, three months after hatching, all the tooth rows were lost, and only dermal ridges were evident [111]. The dorsal surfaces of the body and the tail musculature were black, and the venter lacked pigmentation [111].

Distribution (Figure 36): Centrolene geckoidea occurs across the three Andean Cordilleras of Colombia (Cordillera Occidental, Central, and Oriental; in the departments of Antioquia, Valle del Cauca, Caldas, Quindio, Risaralda, Tolima, Boyacá, and Caquetá), south to the Pacific Andean slope of Ecuador (Carchi and Pichincha provinces) at elevations of 1750-2525 m [111-116] (Figure 35). In Ecuador, the potential distribution of the species covers an area of $10,579 \mathrm{~km}^{2}$ within the Western Montane Forest region.

Jiménez de la Espada [83] mentioned that the species was found at "las riberas del Río Napo en el Ecuador". During his trip in South America, Jiménez de la Espada visited several eastern Andean localities (e.g., Basin of Río Quijos, San José de Moti, Cordillera de Guacamayos, Cosanga) before reaching the lowlands near the Río Napo. It has been suggested that the type locality is in error [110], but the holotype of $C$. geckoidea could have been collected in the headwaters of the Napo river, or at one of the eastern Andean localities [17]. 


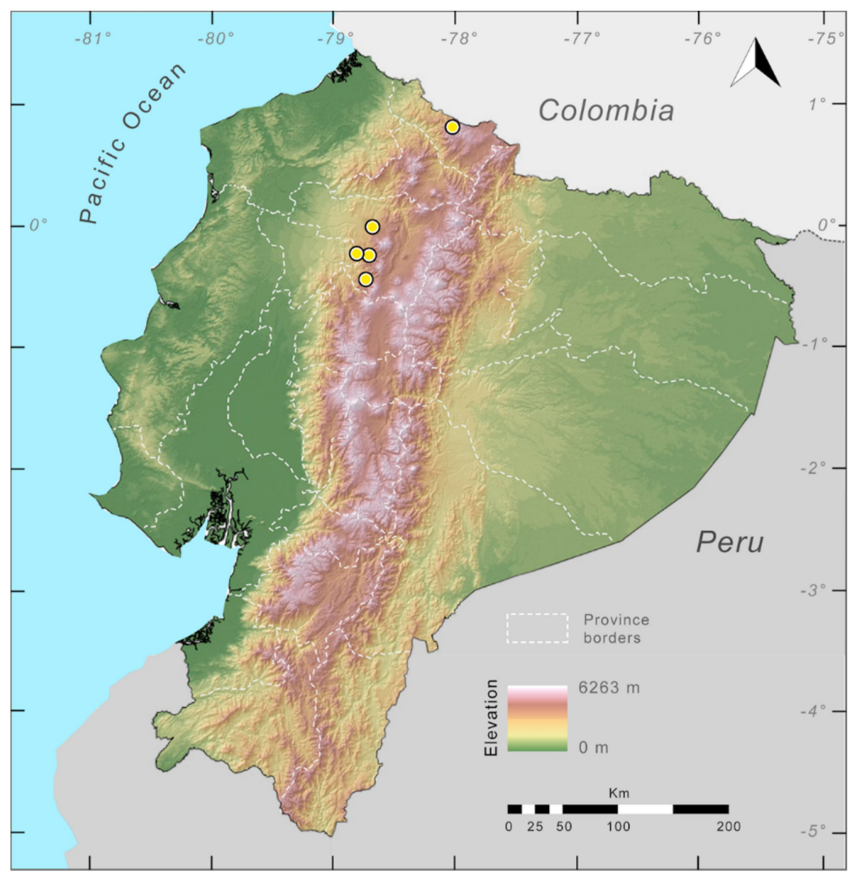

Figure 36. Distribution of Centrolene geckoidea in Ecuador (yellow dots).

Conservation status: Globally, Centrolene geckoidea is listed by the IUCN as a Critically Endangered species [117]. In Ecuador, the species has a severely fragmented distribution, and evidence of population declines. Intensive fieldwork in historical localities such as Quebrada Zapadores has failed in finding the species [91] (JMG, pers. obs.; DFCH, pers. obs.). The last reports of C. geckoidea in Ecuador are from Río La Plata $\left(00^{\circ} 48^{\prime}\right.$ N, $78^{\circ} 02^{\prime}$ W; 2525 m), on the Maldonado-Tulcán road, on 25 July 1988, and from Bosque Protector Río Guajalito in January to May between 1998 and 1999 [17]. A similar situation exists for populations of $C$. geckoidea found at Valle del Cauca in the Cordillera Occidental (Colombia), as they have not been seen for more than 10 years (W. Bolivar and J.J Sarria-Ospina, pers. com.).

Evolutionary relationships (Figure 24): The molecular tree reported by Twomey et al. [19] places Centrolene geckoidea as the sister species of $C$. charapita. However, our inferred tree recovers $C$. geckoidea as sister to all other Centrolene species. Since C. geckoidea is the type species for the genus Centrolene, its phylogenetic placement has fundamental taxonomic implications.

Remarks: The external morphology, osteology, and myology of Centrolene geckoidea was studied in detail by Rueda-Almonacid [111]. Given the remarkable morphological similarly between C. geckoidea and C. paezorum, we consider the possibility that C. paezorum represents a junior synonym of C. geckoidea. Differences between these species include the absence of vomerine teeth in C. paezorum, smaller size, and reduced webbing [110]. Also, the two species occupy different elevations; C. geckoidea is found at elevations between $1750-2525 \mathrm{~m}$, whereas C. paezorum occurs at $3030 \mathrm{~m}$. Additional specimens from the type locality of C. paezorum (Colombia: Departamento del Cauca: km 55-56 on the Popayán-Inza road, $3030 \mathrm{~m}$ ) are necessary to clarify its status. Until recently, the holotype of Centrolene geckoidea was thought to be lost [118], but in a recent publication, González-Fernández [119] provided dorsal and ventral photographs of the holotype (MNCN 1596).

Specimens examined: Centrolene geckoidea: Ecuador: Provincia de Pichincha: $1 \mathrm{~km}$ SW of San Ignacio (0.4486 S, 78.7478 W, 1920 m), KU 178015-17; Quebrada Zapadores, 5 km ESE of Chiriboga on Chiriboga-Quito road (0.245278 S, $78.7261 \mathrm{~W} ; 2010 \mathrm{~m})$, KU 164492; $9 \mathrm{~km}$ SE of Tandayapa (0.0167 S, 78.683 W; 2150 m), KU 164490-91. Provincia del Carchi: Río La Plata, on the Maldonado-Tulcán road (0.8 N, $78.033 \mathrm{~W} ; 2525 \mathrm{~m})$, DHMECN 0900. 
Centrolene heloderma (Duellman, 1981 [120]; Figures 37-40).

Centrolenella heloderma Duellman, 1981 [120]. Holotype: KU 164715.

Type locality: "Quebrada Zapadores, 5 km east-southeast of Chiriboga, $2010 \mathrm{~m}$, Provincia de Pichincha, Ecuador $\left(00^{\circ} 17^{\prime} \mathrm{S}, 78^{\circ} 47^{\prime} \mathrm{W}\right)^{\prime \prime}$.

Centrolene helodermum —-Ruiz-Carranza and Lynch, 1991 [6].

Centrolene heloderma-Guayasamin, Castroviejo-Fisher, Trueb, Ayarzagüena, Rada, and Vilà, 2009 [1].

Common names: English: Warty Glassfrog. Spanish: Rana de Cristal Verrugosa.

Etymology: The specific epithet heloderma combines the Greek words "helos" (wart) and "derma" (skin) and is used in allusion to the dorsal texture of the species.

Identification: Centrolene heloderma differs from all glassfrogs by having a green pustular dorsum and males with humeral spines (Figure 34). Centrolene heloderma mostly resembles Centrolene buckleyi; both species have humeral spines in males, snout inclined in lateral profile, and a narrow white labial stripe. The most conspicuous difference between these species is that Centrolene buckleyi lacks a pustular dorsal skin. Further, C. buckleyi differs by having a concealed tympanum (completely visible in C. heloderma; Figure 37).
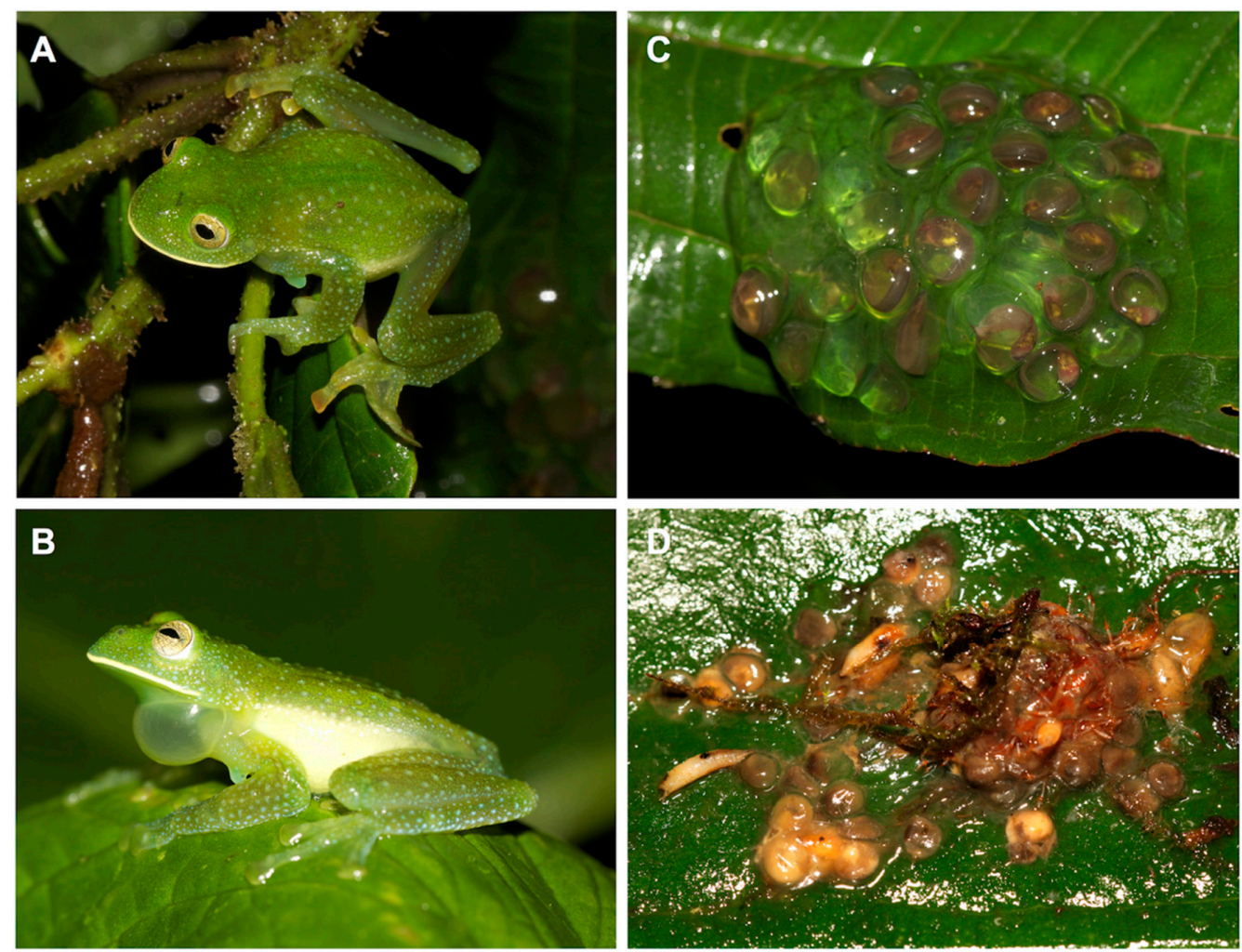

Figure 37. Centrolene heloderma from Reserva Las Gralarias, Ecuador. (A,B) Adult male. (C) Egg clutch. (D) Egg clutch parasitized by larvae of Drosophilidae fly. Photos by Jaime Culebras.

Diagnosis: (1) Vomers lacking teeth; (2) snout subacuminate in dorsal profile, inclined anteriorly from nostrils to margin of lip in lateral profile (Figures 37 and 38); (3) tympanum completely visible, oriented almost vertically, relatively large, its diameter $38.5 \%-44.5 \%$ of eye diameter; supratympanic fold moderate; tympanic membrane pigmented, clearly differentiated from surrounding skin; (4) dorsal surfaces of males and females pustular; in males, minute spicules evident only on flanks and tympanic region; (5) pair of enlarged subclocacal warts; (6) anterior three-fourths of ventral parietal peritoneum 
with white iridophores (condition P3); white pericardium; no iridophores in peritonea covering intestines, stomach, kidneys, testes, gall bladder, and urinary bladder (condition V1); (7) liver tetralobed, lacking iridophores (condition H0); (8) in males, humeral spines present; (9) webbing absent between Fingers I, II, and III; moderate webbing between Fingers III and IV; webbing formula III $\left(2-2^{1 / 2}\right)-\left(1^{2 / 3}-2^{+}\right)$IV (Figure 37); (10) webbing formula on foot: I $\left(1^{1 / 4}-1^{1 / 2}\right)-2$ II $\left(1-1^{+}\right)-\left(2^{+}-2^{1 / 4}\right)$ III $\left(1-1^{+}\right)-\left(2-2^{+}\right)$IV $\left(2^{+}-2^{1 / 2}\right)-\left(1-1^{1 / 4}\right)$ V; (11) external ulnar fold evident, white; inner tarsal fold low, short; outer tarsal fold long, with low white tubercles; (12) concealed prepollex; in males, nuptial pad Type I; (13) Finger II slightly longer than Finger I (Finger I 91.0\%-95.5\% of Finger II); (14) disc of Finger III of moderate width, about $59.3 \%-74.2 \%$ of eye diameter; (15) in life, dorsum green with green to bluish white warts; upper lip white; bones green; (16) in preservative, dorsal surfaces dull lavender, sometimes with minute white or cream spots; (17) in life, iris yellow to pale golden yellow with fine black reticulations; (18) melanophores mostly absent from fingers and toes, except for some on Finger IV, and Toes IV and V; (19) males call from upper sides of leaves near streams; call short (133-188 ms, mean $=161 \mathrm{~ms}, \mathrm{SD}=15.4 \mathrm{~ms})$, with two notes per call; notes strongly pulsed; dominant frequency at 4393-4823 (mean = 4682, SD = 104) Hz; (20) fighting behavior unknown; (21) egg placed on the upper surfaces of leaves; parental care unknown; (22) tadpoles unknown; (23) medium body size, male SVL 26.8-31.5 $\mathrm{mm}(\overline{\mathrm{X}}=29.0, n=17)$; in one female, SVL $32.3 \mathrm{~mm}$.

A
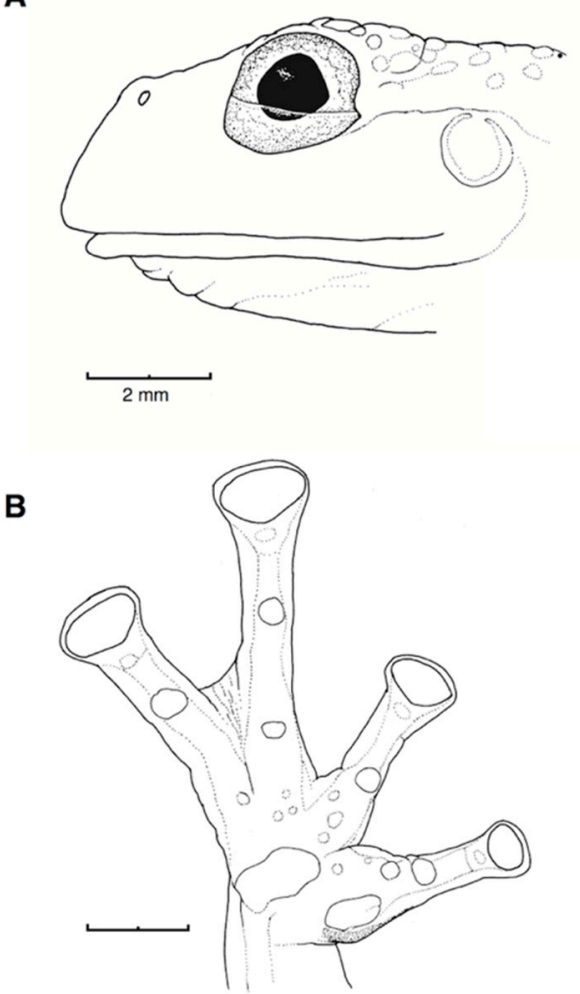

Figure 38. Centrolene heloderma, male, KU 164718. (A) Head in ventral view. (B) Hand in ventral view. Illustrations by Juan M. Guayasamin.

Color in life (Figure 37): Dorsum yellow green to dark green with green to bluish white pustules; margin of lip whitish yellow; ventral parietal peritoneum whitish yellow; throat pale greenish yellow; cloacal, heel, and ulnar tubercles white; heart not visible; bones green; iris yellow to pale golden yellow with fine black reticulations [120].

Color in ethanol: Dorsal surfaces of head, body, forearms, thighs, and shanks dull lavender; other surfaces dull cream; flanks white; margin of upper lip and cloacal tubercles white (Duellman, 1981). 
White parietal peritoneum covering the anterior three-fourths of the venter; pericardium white; no iridophores in peritonea covering liver, intestines, stomach, kidneys, and urinary bladder.

Biology and ecology: During the rainy season (December-April), at night, Centrolene heloderma has been found active on vegetation near streams in primary and disturbed forest. Occasionally, males have been observed away from streams, probably looking for new territories [87]. Males call from the upper surfaces of leaves near streams. Egg clutches, with 25-29 brownish eggs, are placed on the upper side of leaves near streams [87]. At Reserva Las Gralarias, C. heloderma is abundant at Five-frog Creek, but has also been observed at Ballux Creek, Heloderma Creek, and Hercules Creek [88,92]. Parental care is unknown.

Call (Figure 39): The following description is based on the analysis of 58 notes contained within 29 calls from 3 individuals (LBE-C-001, 012, 015); individuals are from Río Alambí (2390 m), and Reserva Las Gralarias (1822-1864 m), in Pichincha province, Ecuador. The typical advertisement call is relatively short $($ range $=133-188 \mathrm{~ms}$, mean $=161 \mathrm{~ms}, \mathrm{SD}=15.4 \mathrm{~ms})$, and has two notes per call. Notes are strongly pulsed. The first note is longer than the second note (first note duration: Range $=38-76 \mathrm{~ms}$, mean $=60.2 \mathrm{~ms}, \mathrm{SD}=9.89 \mathrm{~ms}$; second note duration: Range $=17-44 \mathrm{~ms}$, mean $=27.8 \mathrm{~ms}, \mathrm{SD}=6.283 \mathrm{~ms}$ ). The two notes are also separated by an internote duration of 50-99 (mean $=72.9, \mathrm{SD}=9.5) \mathrm{ms}$. Notes are pulsed and similarly variable in number, with $2-7$ (mean $=3.741, \mathrm{SD}=1.906)$ amplitude peaks throughout the note. The first note tends to have more pulses than the second note. Pulses within a note have a rate of $45.5-117.6($ mean $=83, \mathrm{SD}=15)$ pulses per second. Notes generally have their peak amplitude in the first $50 \%$ of the note (relative peak time: Range $=0.032-0.8697$, mean $=0.273, \mathrm{SD}=0.242$ ), but infrequently the first note can have its peak amplitude in the last $50 \%$ of the note. Frequencies between both notes are also highly similar. The dominant frequency of a note measured at peak amplitude is $4393-4823$ (mean $=4682, \mathrm{SD}=104$ ) $\mathrm{Hz}$ and is contained within the fundamental frequency. The fundamental frequency has a lower limit of 4221-4651 (mean $=4513$, SD $=138) \mathrm{Hz}$ and a higher limit of 4651-5082 (mean = 4875, SD = 104) Hz.

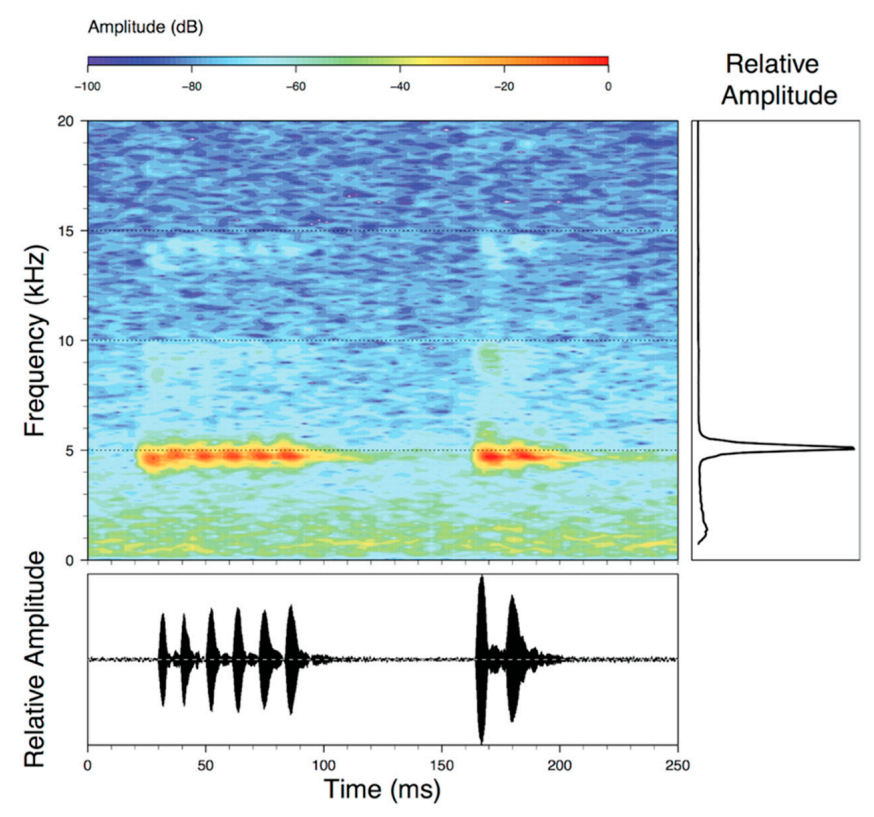

Figure 39. Call of Centrolene heloderma (LBE-C-012) recorded from Reserva Las Gralarias, Pichincha province, Ecuador. Note that each call has two distinctive pulsed notes.

Tadpole: Not described.

Distribution (Figure 40): Centrolene heloderma occurs on the Pacific slopes of the Cordillera Occidental in Colombia (departments of Antioquia, Cauca, Valle del Cauca, and Risaralda) south to the Tandayapa and Saloya Valleys, in Ecuador (provinces of Imbabura, Pichincha, and Santo Domingo de los Tsáchilas) at elevations of 1850-2575 m ([87,120,121], this work). In Ecuador, Centrolene heloderma 
has been recorded from seven localities at elevations between 1960 and $2575 \mathrm{~m}([87,120,121])$ in this work and has a potential distribution of $1067 \mathrm{~km}^{2}$, within the Western Montane Forest ecoregion.

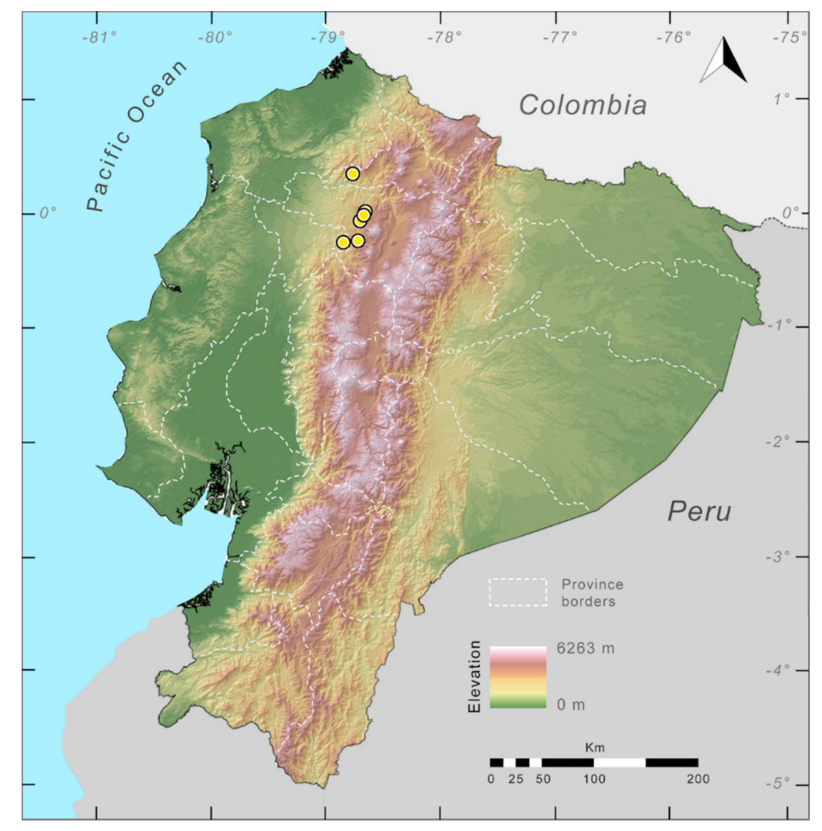

Figure 40. Distribution of Centrolene heloderma in Ecuador (yellow dots).

Conservation status: Globally, Centrolene heloderma is currently listed as Vulnerable by the IUCN [122]. In Ecuador, major threats include habitat loss, introduction of exotic predatory fish (Trout), climate change, and emerging diseases [87,123]. The type locality (Quebrada Zapadores), as well as nearby localities, have been visited numerous times in the last years (2000-2015; wet and dry seasons) with no new records of the species [91] (JMG, pers. obs.; DFCH, pers. obs.); in this area, the last record of the species dates from March 1979, when three individuals where collected at Quebrada Zapadores. In 2006, an individual apparently assignable to C. heloderma was photographed in the western versant of the Pichincha volcano (M. H. Yánez-Muñoz, pers. com.). On March 2009, C. heloderma was discovered at Reserva Las Gralarias (0.00806 S, 78.72433 W, 1852 m), Pichincha Province, where it maintains three nearby, reproductive populations. During September 2015, a population of C. heloderma was found at Cordillera de Toisán. Krynak et al. [121] report on a relatively large population (20+ individuals) at Río Alambi observed on 24 April 2017. The potential distribution of the species in Ecuador is $1067 \mathrm{~km}^{2}, 34 \%$ of which is affected by human activities. The amphibian chytrid fungus Batrachochytrium dendrobatidis has been found infecting C. heloderma at Reserva Las Gralarias, but no recent declines have been observed [92]. Given the current information of the species, we suggest that it should be considered as Endangered in Ecuador, following IUCN criteria B2, Ba, Bb(iii).

Evolutionary relationships (Figure 24): Centrolene heloderma is sister to a clade formed by several Centrolene species.

Specimens examined: Centrolene heloderma: Ecuador: Provincia de Imbabura: Cordillera de Toisán $\left(0.50276^{\circ} \mathrm{N}, 78.5515^{\circ} \mathrm{W} ; 2575 \mathrm{~m}\right), \mathrm{MZUTI}$ 4234. Provincia de Pichincha: Quebrada Zapadores, $5 \mathrm{~km}$ ESE of Chiriboga on Chiriboga-Quito road $\left(0.2453^{\circ} \mathrm{S}, 78.726^{\circ} \mathrm{W}, 2010 \mathrm{~m}\right), \mathrm{KU} 164714-15 ; 9 \mathrm{~km} \mathrm{SE}$ Tandayapa $\left(0.01667^{\circ} \mathrm{S}, 78.683^{\circ} \mathrm{W}, 2160 \mathrm{~m}\right) ; 8.6 \mathrm{~km}$ SE Tandayapa $\left(0.0333^{\circ} \mathrm{S}, 78.7^{\circ} \mathrm{W}, 2000 \mathrm{~m}\right), \mathrm{USNM}^{\circ}$ 211218; $13.1 \mathrm{~km}$ SW Nono (0.0025 S, 78.659 $\mathrm{W}, 2140 \mathrm{~m})$, MCZ 97834, USNM 211216-17; Reserva Las Gralarias (0.00806 ${ }^{\circ}$ S, 78.72433 $\left.{ }^{\circ} \mathrm{W}, 1852 \mathrm{~m}\right)$, QCAZ 40200. Provincia de Santo Domingo de los Tsáchilas: $14 \mathrm{~km}$ west of Chiriboga on Chiriboga-Santo Domingo road $\left(0.2653^{\circ} \mathrm{S}, 78.848^{\circ} \mathrm{W}, 1960 \mathrm{~m}\right)$, KU 164716-21. 
Centrolene huilensis (Ruiz-Carranza and Lynch, 1995 [26]) (Figure 41).

Centrolene huilense Ruiz-Carranza and Lynch, 1995 [26]. Holotype: ICN 7462.

Type locality: "Colombia, Departamento de Huila, Municipio San José de Isnos, 1 km NW Isnos, vertiente oriental de la Cordillera Central, $1^{\circ} 57^{\prime}$ Latitud N, $76^{\circ} 15^{\prime}$ W Greenwich, 2190 m”.

Centrolene huilensis-Barrio-Amorós, Rojas-Runjaic, and Señaris, 2019 [85].

Common names: English: Huila Glassfrog. Spanish: Rana de Cristal de Huila.

Etymology: The specific epithet huilensis refers to the type locality of the species, within the Huila Department, Colombia [26].

Identification: Centrolene huilensis (Figure 41) can be differentiated from other glassfrogs by having a green dorsum with a combination of dark green to dark lavender and white spots, white tubercles on the ventrolateral edges of the Finger V, forearm, elbow, Toe V, tarsus, and heel, a humeral spine in adult males, and a relatively large body size (SVL $=23.6-26.7 \mathrm{~mm}$ in males; $\mathrm{SVL}=28.7 \mathrm{~mm}$ in 1 female). Species with a similar dorsal color pattern include Centrolene peristicta, C. daidalea, C. condor, C. lynchi, C. muelleri, C. pipilata, C. savagei, C. solitaria, and Nymphargus truebae. Body size of C. huilensis is larger than C. peristicta, C. pipilata, C. savagei, and C. solitaria (in C. peristicta, male SVL $=17.9-22.0 \mathrm{~mm}$, female SVL $=20.8-20.9 \mathrm{~mm}$; in C. pipilata, male SVL $19.7-22.6 \mathrm{~mm}$, female SVL 22.6-23.6 mm; in C. savagei, male SVL $=23.3-23.9 \mathrm{~mm}$, female SVL $=19.8-22.6 \mathrm{~mm}$; in C. solitaria, holotype male SVL $=19.3$ ). Males of $C$. huilensis have humeral spines, which are absent in males of $C$. daidalea, $C$. savegei, C. solitaria, and N. truebae. Additionally, some of the species are located in different biogeographic regions; C. peristicta and C. lynchi are found on the Pacific slopes of the Andes of Ecuador and Colombia (C. peristicta is also found on the western slopes of the Cordillera Central, Colombia), and C. muelleri and N. truebae are only known from the Andes of Peru.

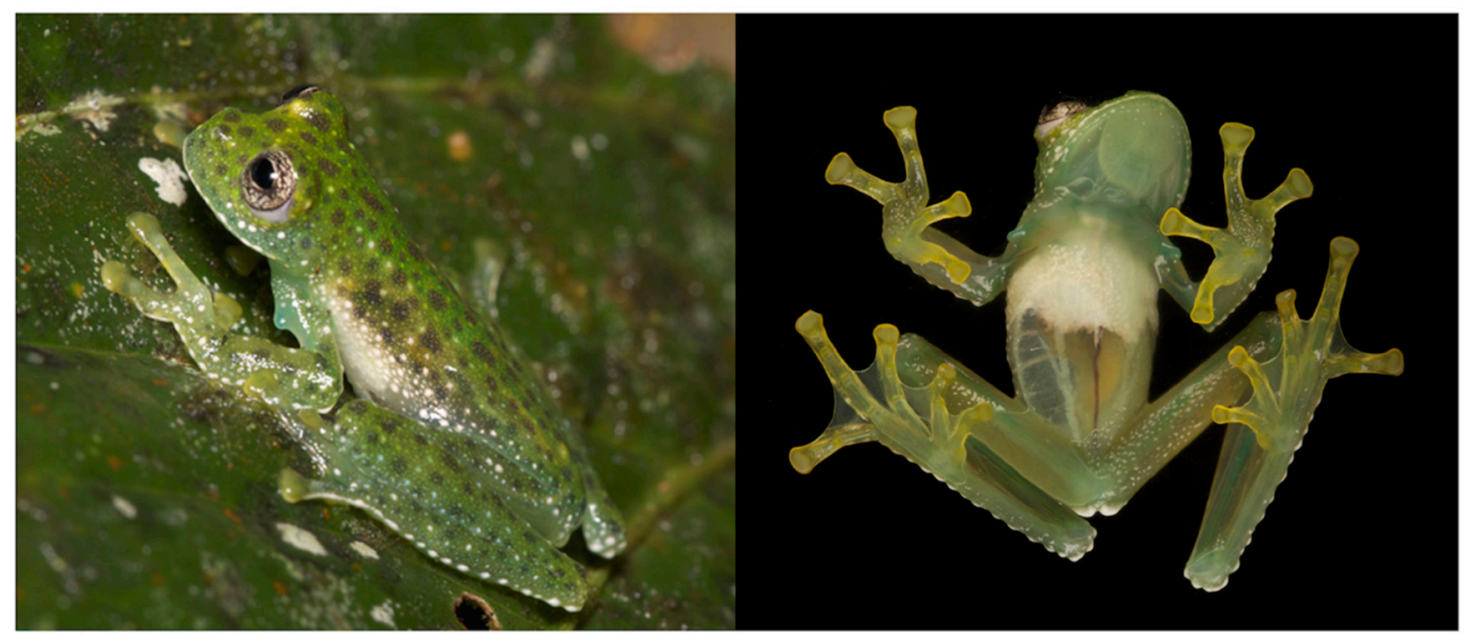

Figure 41. Centrolene huilensis in life. Ecuador, Napo province, Yanayacu Biological Station, QCAZ 45905. Photos by Santiago R. Ron (BioWebEcuador). 
Diagnosis: (1) Vomers lacking teeth; (2) snout short, round in dorsal aspect, slightly sloping in lateral view; (3) tympanum moderate, oriented almost vertically, with slight lateral and posterior inclinations, its diameter $31 \%-40 \%$ of eye diameter; tympanic annulus completely visible, except for upper border; supratympanic fold evident; tympanic membrane translucent and pigmented as surrounding skin; (4) dorsal skin shagreen, males with low warts and spicules uniformly distributed; (5) pair of enlarged subcloacal warts (Figure 15); (6) anterior $40 \%-60 \%$ of the ventral parietal peritoneum white, posterior portion translucent (condition P3); white pericardium; no iridophores in peritonea covering intestines, stomach, kidneys, gall bladder, and urinary bladder (condition V1); (7) lobed liver, lacking iridophores (condition H0); (8) males with conspicuous humeral spines; (9) webbing absent between Fingers I, II, and III; moderate between outer fingers; webbing formula: III $\left(2^{+}-2^{1 / 2}\right)-\left(2-2^{+}\right) \mathrm{IV} ;(10)$ webbing between toes extensive; foot three/fourths webbed: I $\left(1-1^{2 / 3}\right)-\left(1^{3 / 4}-2^{+}\right)$II $\left(1-1^{+}\right)-\left(2^{-}-2^{1 / 2}\right)$ III $\left(1-1^{1 / 2}\right)-\left(2^{+}-2^{2 / 3}\right)$ IV $\left(2-3^{-}\right)-\left(1^{-}-1^{1 / 2}\right) \mathrm{V} ;(11)$ ulnar and tarsal folds with white tubercles; (12) concealed prepollex; nuptial pad Type I; (13) Finger I slightly shorter than Finger II (Finger I length 94\%-97\% of Finger II); (14) disc of Finger III width 51\%-63\% of eye diameter; (15) in life, dorsum green with small diffuse dark green to dark lavender spots and smaller white spots; bones green; (16) in preservative, dorsum cream to light lavender with dark lavender spots and smaller white spots; (17) in life, iris cream with a slight yellow hue and thin black reticulations, yellowish-cream circumpupilar ring; (18) melanophores absent from dorsal surfaces of fingers and toes, except for Finger IV, and Toes IV and V; (19) males call from upper side of leaves; call undescribed; (20) fighting behavior unknown; (21) eggs deposition site unknown; parental care unknown; (22) tadpoles unknown; (23) small to medium body size; in Colombian populations, adult males, SVL 23.6-26.7 mm (X $=25.1 \pm 1.703, n=7$ [26]); in Ecuador, SVL 23.8 in one adult male and $28.7 \mathrm{~mm}$ in one adult female.

Color in life (Figure 41): Dorsum green with dark lavender and dark green spots of different sizes, and smaller white spots; upper lip white; region below eye with small white warts; bones green. Upper flanks with same color pattern as dorsum; lower flanks with numerous small white warts. Ulnar and tarsal folds with white tubercles; small white cloacal tubercles. Iris cream with a slight yellow hue and thin black reticulations, yellowish-cream circumpupilar ring.

Color in ethanol: Dorsal surfaces of head, body, and limbs cream to light lavender with dark lavender spots and smaller white spots; margin of upper lip white; region below eye with small white warts; white tubercles just posterior to cloaca. White parietal peritoneum covers anterior $40 \%-60 \%$ of venter; white pericardium; iridophores absent from peritonea covering digestive tract, liver, kidneys, and gall and urinary bladders.

Biology and ecology: In Ecuador, individuals were found active during the night on upper surfaces of leaves along slow-flowing streams. Parental care is unknown.

Call: Not described.

Distribution (Figure 42): Centrolene huilensis is known from two localities, one in the Amazonian slope of the Andes of Ecuador (Yanayacu Biological Station, 2000 m, Napo Province), and the type locality in the Cordillera Central of Colombia (near Isnos, Huila Department) at elevations between 2000-2190 m ([26], this work). 


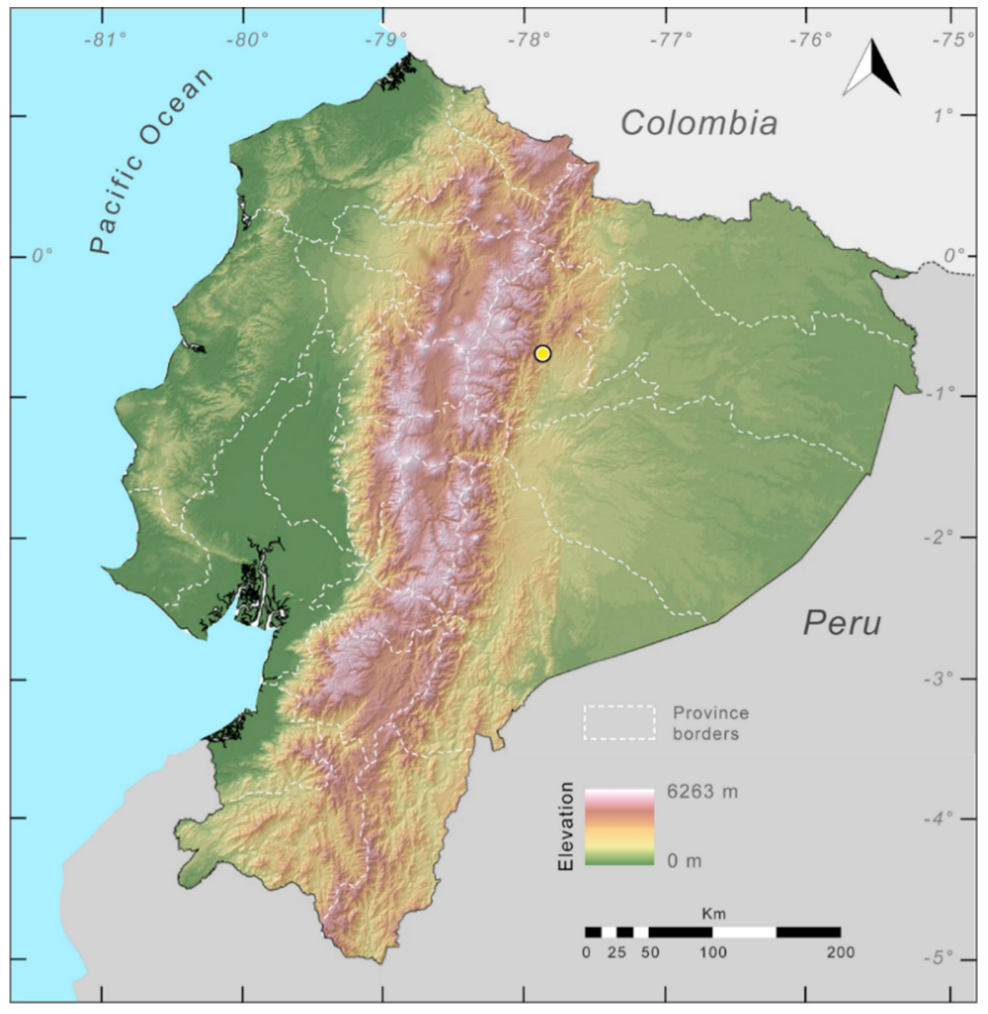

Figure 42. Distribution of Centrolene huilensis in Ecuador (yellow dot).

Conservation status: Globally, Centrolene huilensis is currently listed as Endangered by the IUCN [124]. In Ecuador, assessing the conservation status of this species remains challenging because only a single additional locality (Yanayacu Biological Reserve) has been registered since its description in 1995. Yanayacu Biological Reserve is a relatively well-studied site [20,125] and we have been unable to find it during recent surveys (August 2014, June 2016; January 2017); thus, it is possible that $C$. huilensis spends most of its time in the canopy and/or is extremely rare. We suggest the that C. huilensis should be placed in the Data Deficient category for Ecuador.

Evolutionary relationships (Figure 24): With the current gene and taxon sampling, Centrolene huilensis is inferred as sister to C. muelleri.

Specimens examined: Centrolene huilensis: Ecuador: Provincia de Napo: Yanayacu Biological Station $\left(0^{\circ} 41^{\prime} \mathrm{S}, 77^{\circ} 53^{\prime} \mathrm{W} ; 2100 \mathrm{~m}\right)$, QCAZ 37230, 45905. 


\section{Centrolene lynchi (Duellman, 1980 [126]; Figures 43-46)}

Centrolenella lynchi Duellman, 1980 [126]. Holotype: KU 164691.

Type locality: "a stream $4 \mathrm{~km}$ northeast (by road) of Dos Ríos, Provincia Pichincha, Ecuador, $1140 \mathrm{~m}\left(0^{\circ} 21^{\prime} \mathrm{S}, 78^{\circ} 54^{\prime} \mathrm{W}\right)$ " (now in Provincia de Santo Domingo de los Tsáchilas).

Centrolene lynch-Ruiz-Carranza and Lynch, 1991 [6].

Centrolenella grandisonae - Lynch and Duellman, 1973 [22].

Centrolenella gemmata Flores, 1985 [46]. Holotype: MCZ 104073. Type locality: “San Francisco de las Pampas, $1500 \mathrm{~m}$ in elevation, Provincia Cotopaxi, Ecuador $\left(00^{\circ} 25^{\prime} \mathrm{S}, 78^{\circ} 57^{\prime} \mathrm{W}\right.$, just NW of junction of Río Las Juritas and Río Toachi)". New synonymy.

Centrolene gemmatum-Ruiz-Carranza and Lynch, 1991 [6]. Guayasamin, Castroviejo-Fisher, Trueb, Ayarzagüena, Rada, and Vilà, 2009 [1].

Centrolenella scirtetes In part, Duellman and Burrowes, 1989 [86]. Holotype: KU 202720. Type locality: "1.4 km (by road) southwest of Tandayapa $\left(00^{\circ} 07 \mathrm{~S}, 78^{\circ} 40 \mathrm{~W}\right), 1820 \mathrm{~m}$, Provincia de Pichincha, Ecuador". New synonymy.

Centrolene scirtetes-Ruiz-Carranza and Lynch, 1991 [6]. Guayasamin, Castroviejo-Fisher, Trueb, Ayarzagüena, Rada, and Vilà, 2009 [1].

Common names: English: Lynch's Glassfrog. Spanish: Rana de Cristal de Lynch.

Etymology: The specific epithet lynchi honors Dr. John D. Lynch, who has made multiple and meaningful contributions to the field of amphibian systematics.

Identification: Centrolene lynchi is distinguished from most glassfrogs by having, in life, a green dorsum with minute yellowish-white flecks and diffuse small black spots (Figure 43). Among centrolenids found on the Pacific slopes of the Andes, only C. peristicta has a similar dorsal color pattern; however, body size is clearly different between the two species (in males, SVL 23.3-26.5 mm in C. lynchi; 17.9-21.2 $\mathrm{mm}$ in C. peristicta). The Colombian C. antioquiensis lacks black spots on the dorsum and has a white gastrointestinal peritoneum. Centrolene lynchi is also similar to the Colombian C. quindianum, which invariably has iridophores on the digestive tract (iridophores absent in C. lynchi). Other species, such as Nymphargus truebae (from the Amazonian slopes of the Peruvian Andes) and N. garciae (from the Cordillera Central of the Colombian Andes and the Amazonian slope of the Ecuadorian Andes), have a dorsal coloration similar to that found in C. lynchi, but lack humeral spines in males and webbing between Fingers III and IV.

Diagnosis: (1) Vomerine teeth absent; (2) snout round or truncated in dorsal aspect and truncated to slightly inclined in lateral profile; (3) tympanic annulus visible, oriented almost vertically, with slight lateral and posterior inclinations, its diameter about $31.3 \%-39.4 \%$ of eye diameter; supratympanic fold evident; tympanic membrane translucent, partially pigmented, differentiated from surrounding skin; (4) dorsal skin shagreen in males and females, males have low, white warts, and spicules and spiculated warts on sides of head; (5) pair of enlarged subcloacal warts (Figure 15); (6) anterior half to two-thirds of ventral parietal peritoneum white, remaining posterior portion transparent (condition P2-P3); white pericardium; no iridophores in peritonea covering intestines, stomach, and kidneys; transparent peritoneum around gall bladder and urinary bladder (condition V1); (7) liver with four clearly defined lobes, lacking iridophores (condition H0); (8) males with conspicuous humeral spines; (9) webbing absent between Fingers I and II, absent or greatly reduced between Fingers II and III, and moderate between outer fingers; hand webbing formula III $\left(2-2^{1 / 4}\right)-\left(2^{-}-2^{+}\right)$IV; (10) webbing between toes extensive; foot webbing formula: I $\left(1-1^{+}\right)-\left(2-2^{+}\right)$II $\left(1-1^{+}\right)-\left(2-2^{+}\right)$III $\left(1-1^{+}\right)-\left(2-2^{+}\right)$IV $2^{+}-\left(1-1^{+}\right) \mathrm{V}$; (11) ulnar fold present, white; external tarsal fold absent, internal tarsal fold short, low; (12) concealed prepollex, except in a few individuals; nuptial pad Type II; (13) Finger I slightly shorter than Finger II or about equal its length (Finger I 94.5\%-100.0\% of Finger II); (14) disc of Finger III width about $48.4 \%-57.0 \%$ of eye diameter; (15) in life, dorsum dull green with minute yellowish-white warts and small diffuse black spots (Figure 43); green bones; (16) in preservative, dorsum lavender with 
numerous minute white spots and larger dark lavender spots (Figure 44); (17) in life, iris greyish-white, with a yellow hue around the pupil; (18) melanophores mostly absent from fingers and toes, except for a few on base of Fingers III and IV, and along Toes IV and V; (19) males call from upper sides of leaves; call is relatively short and consists of a tonal note followed by one to three peaked notes; notes separated by 9.0-138.0 ms; mean tonal note dominant frequency $5296 \mathrm{~Hz}(\mathrm{SD}=58$, range $=4995-5599 \mathrm{~Hz})$; mean peaked note dominant frequency $5264 \mathrm{~Hz}(\mathrm{SD}=72$, range $=4995-5513)$; notes lack frequency modulation; (20) males fight while hanging upside down, grasping one another venter to venter; (21) eggs placed on upper surfaces of leaves; females provide short-term parental care; prolonged parental care absent; (22) tadpoles unknown; (23) small body size; male SVL 23.3-26.5 mm (X $=24.7$, $n=22)$; in two females SVL 24.6-25.0 $\mathrm{mm}$.

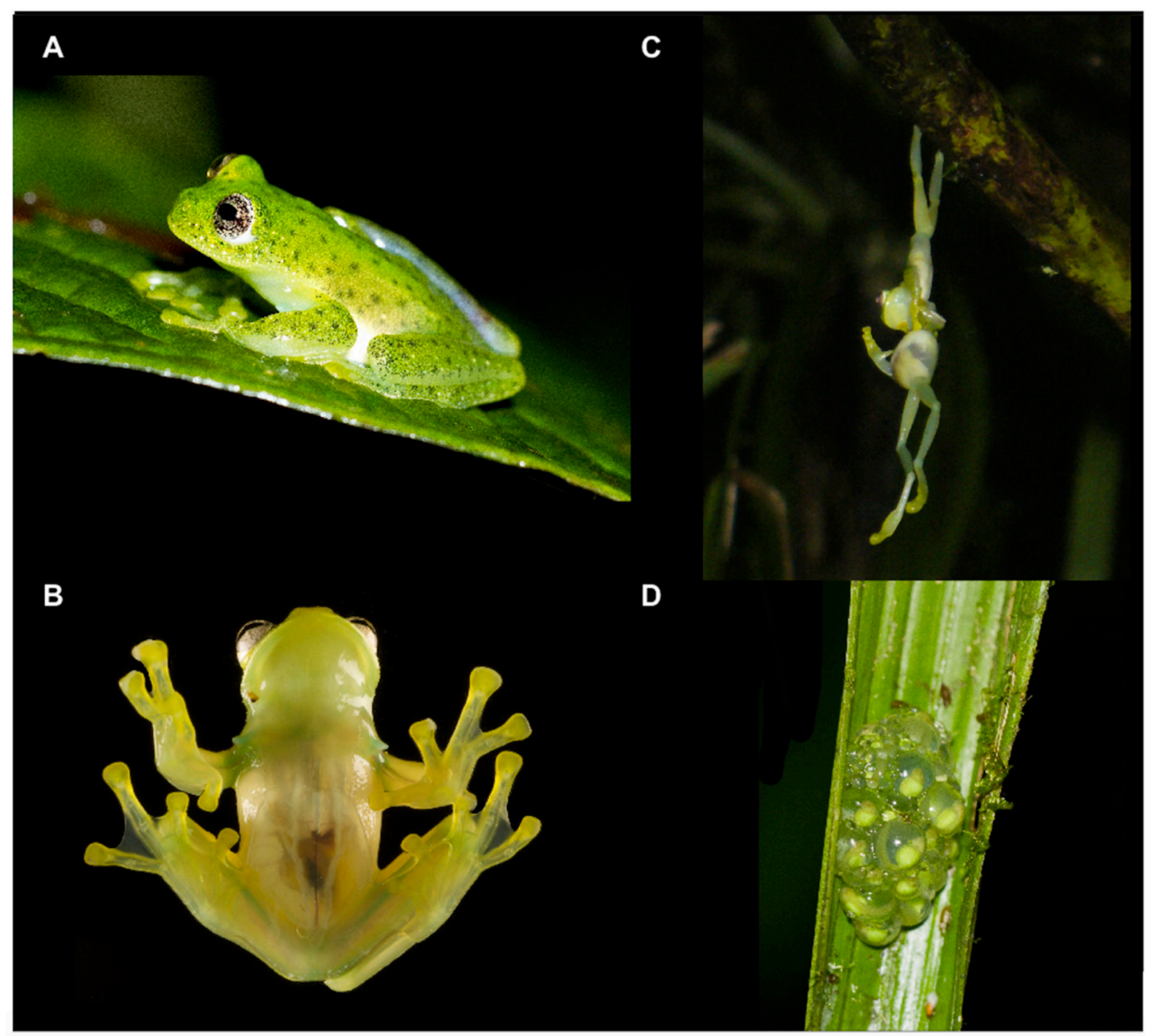

Figure 43. Centrolene lynchi in life from Reserva Las Gralarias, Pichincha province, Ecuador. (A) Adult male, not collected. (B) Adult male in ventral view, QCAZ 40192; photo by Luis A. Coloma. (C) Fight between males; photo by Henry Imba and Rebecca Abuza. (D) Egg clutch.

Color in life (Figure 43): Dorsum yellow green with minute yellowish-white warts (spiculated in males) and small and diffuse black spots; bones green; throat and venter cream white; fingers and toes dull yellow; upper lip white; ulnar and outer tarsal folds with thin white line or low white tubercles; flanks and venter cream white; small white tubercles just posterior to cloaca. White parietal peritoneum covers anterior half to two-thirds of venter; white pericardium; visceral and hepatic peritonea lacking iridophores. Iris greyish white with black reticulation, and a yellow hue surrounding the pupil. 
Color in ethanol (Figure 44): Dorsal surfaces of head, body, and limbs lavender with minute white warts and small black spots; margin of upper lip white; region below eye with small white warts; small white tubercles just posterior to cloaca. White parietal peritoneum covering the anterior half to two-thirds of the venter; pericardium white; no iridophores in peritonea covering liver, intestines, stomach, kidneys, gall bladder, and urinary bladder.

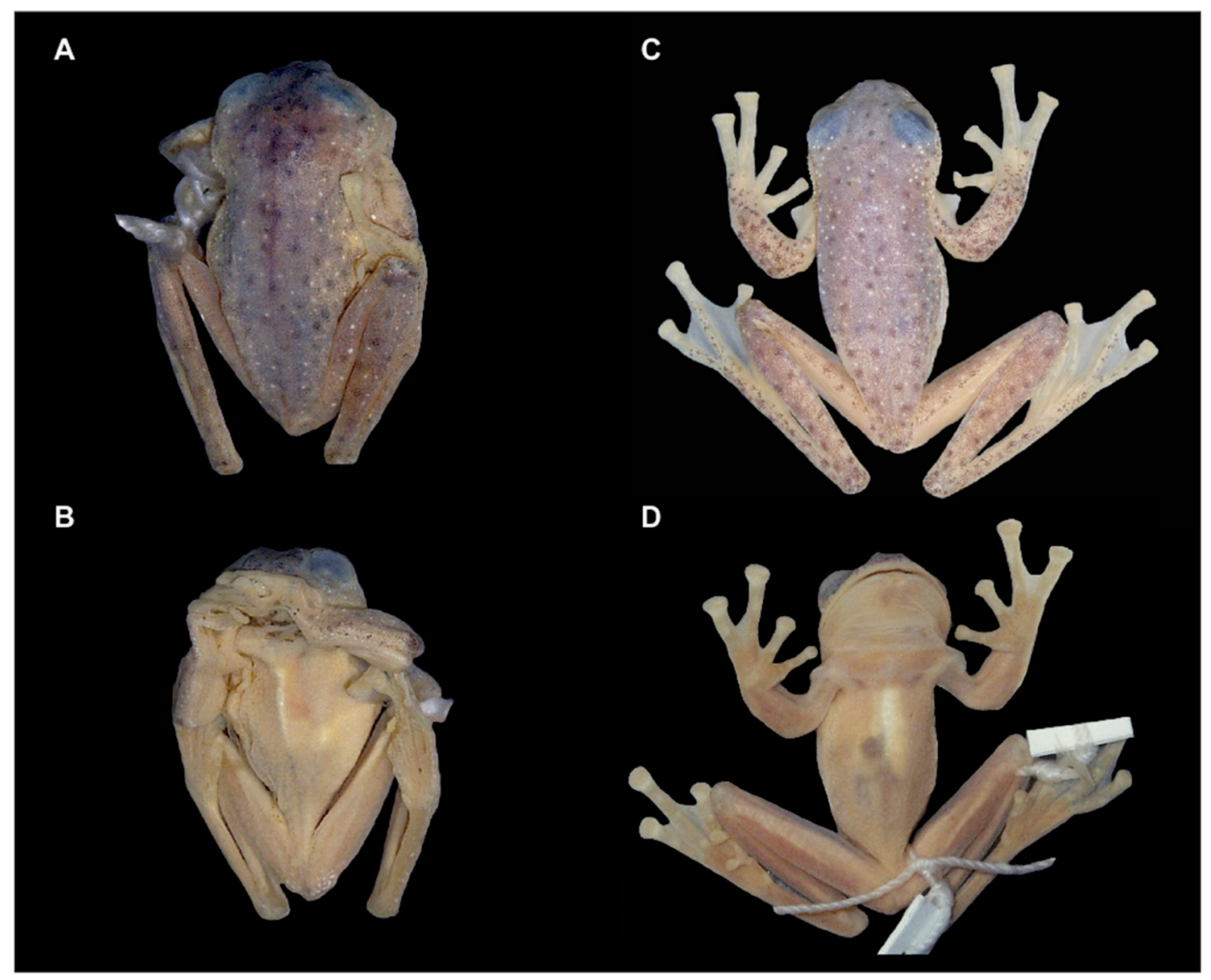

Figure 44. Type material of Centrolene lynchi and C. gemmata in preservative. (A,B) C. gemmata, MCZ 104077, paratype. (C) C. lynchi, KU 164698, paratype, dorsal view. (D) C. lynchi, KU 164691, holotype, ventral view.

Variation: The dorsum of most examined specimens except one (KU 164695) have spicules and spiculated warts; it is possible that this variation is a result of the reproductive condition of this particular male individual. Females of Centrolene lynchi lack spicules, normal sexual dimorphism in Centrolenidae.

Biology and ecology: The following description is from Dautel et al. [50]. At Reserva Las Gralarias (Lucy's Creek), females place clutches of 21-24 neon green eggs on vegetation in males' territories $(n=4$, mean $=22.25$, SD $=1.08)$; most egg clutches are placed on top of large leaves or ferns above a fast-flowing stream at a height of 165-600 cm $(n=14$, mean height $=313.3 \mathrm{~cm}, \mathrm{SD}=78.7)$. Dautel et al. [50] suggested that males provide long-term parental care; however, a more detailed study by Delia et al. [25] showed that only females provide parental care (short term) and that prolonged parental care is absent in the species. 
Calls (Figure 45): The following description is from Dautel et al. [50]. The typical advertisement call is relatively short and consists of a tonal note followed by one to three peaked notes. The first note is tonal and generally longer than the following notes, which are pulsed and show clear frequency peaks. Notes are separated by $9.0-138.0 \mathrm{~ms}$. The dominant frequencies of tonal and peaked notes are similar (mean tonal note dominant frequency $=5296 \mathrm{~Hz}, \mathrm{SD}=58$, range $=4996-5599 \mathrm{~Hz}$; mean peaked note dominant frequency $=5264 \mathrm{~Hz}, \mathrm{SD}=73$, range $=4996-5513$ ) and show no frequency modulation. The aggressive call in this species is markedly different in structure from the advertisement call. It consists of a single short note containing two pulses $(n=5$, mean length duration $=150.4 \mathrm{~ms}$, $\mathrm{SD}=6.7$, range $140.0-156.0 \mathrm{~ms}$ ), at a dominant frequency significantly lower than the advertisement call (mean frequency $=4892 \mathrm{~Hz}, \mathrm{SD}=39$, range $=4823-4910 \mathrm{~Hz}$ ); like the advertisement call, the note of the aggressive call is not frequency modulated.

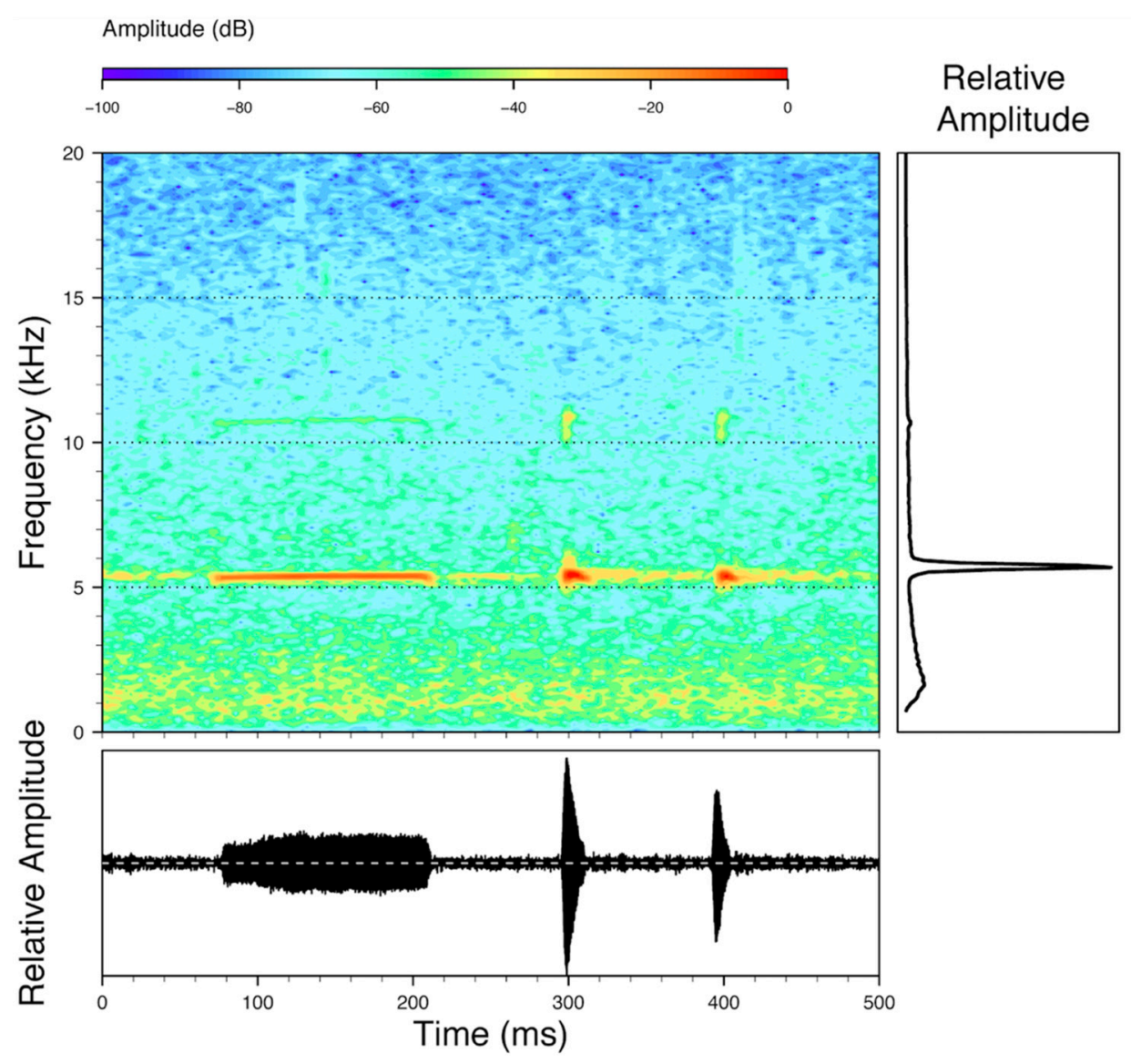

Figure 45. Call of Centrolene lynchi (LBE-C-013) recorded at Reserva Las Gralarias, 1822 m, Pichincha province, Ecuador.

Tadpole: Not described.

Distribution (Figure 46): Centrolene lynchi is known from the Pacific slope of the Cordillera Occidental of the Andes in Ecuador and southern Colombia. In Colombia, the species has been reported in only one locality (Reserva La Planada, $7 \mathrm{~km}$ route of Chucunés, $1780 \mathrm{~m}$; as C. scirtetes [86], but see Taxonomic Remarks); specimens cited as C. lynchi by Coloma et al. [126] from Risaralda Department, Colombia, actually corresponds to C. quindianum (Marco Rada, pers. obs.). In Ecuador, Centrolene lynchi is known from seven localities from the Pacific slope of the Cordillera Occidental of the Andes at elevations of 1140-1852 m (see Specimens Examined), with a potential distribution of $1442 \mathrm{~km}^{2}$. The habitat of the species in Ecuador is within the Western Foothill Forest and the Western Montane Forest regions. 
Conservation status: Globally, Centrolene lynchi is currently listed as Endangered by the IUCN [126]. Arteaga et al. [87] also suggested the Endangered category for Ecuadorian populations. Although the distribution of the species is larger than previously thought (see Distribution and Remarks), the species has not been found in some of its historic localities in the last 20 years, suggesting that the species has suffered population declines (i.e., San Francisco de Las Pampas). In recent years, reproductive populations of $C$. lynchi have been found at Reserva Las Gralarias (2009-2019) and at Bosque Protector Río Guajalito (2006) ([87], JMG pers. obs., DFCH pers. obs., Mario Yánez-Muñoz pers. comm.). The amphibian chytrid fungus Batrachochytrium dendrobatidis has been found infecting C. lynchi at Reserva Las Gralarias, but no recent declines have been observed [92].

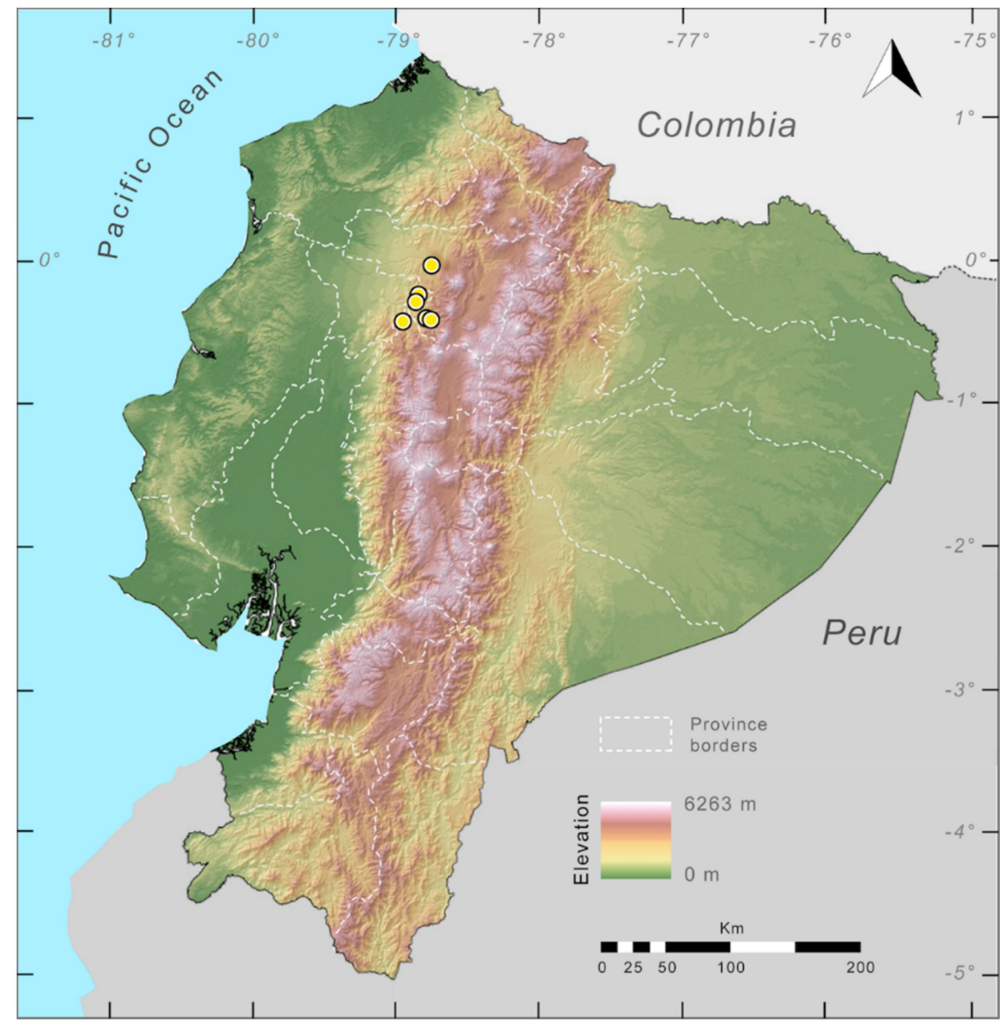

Figure 46. Distribution of Centrolene lynchi in Ecuador (yellow dots).

Evolutionary relationships (Figure 24): Centrolene lynchi is sister to a clade formed by C. sabini and an unidentified species of Centrolene.

Taxonomic remarks: Centrolene lynchi was described by Duellman [127] from a locality $4 \mathrm{~km} \mathrm{NE}$ (by road) of Dos Ríos, Provincia de Pichincha. After a few years, Flores [46] described Centrolene gemmata from San Francisco de Las Pampas, Provincia de Cotopaxi. Flores [46] mentioned that Centrolene lynchi differs from Centrolene gemmata mainly by: (i) Having a snout truncated in dorsal view and round in profile (snout round in dorsal view and slightly anteroventrally sloping in C. gemmata); (ii) having slightly more webbing on the hands (webbing formula of IV $2-2 \mathrm{~V}$ in Centrolene lynchi; webbing formula of IV $\left(2-2^{1 / 3}\right)-\left(2^{-}-2^{+}\right) \mathrm{V}$ in C. gemmata); and (iii) in overall head shape, with a squatter, more semicircular head shape when viewed from above, with little or no post-cephalic constriction, and nostrils only very slightly protuberant, in contrast to the more elongated, circular head shape of gemmata when viewed from above, with a marked post-cephalic constriction and very protuberant nostrils. We have examined the complete type series of Centrolene lynchi and three paratypes of $C$. gemmata (MCZ A-104397, A-104074, A-104077) and, as noted by Cisneros-Heredia and McDiarmid [17], find that the differences mentioned above are not consistent. Several of the characteristics present in C. gemmata fall into the variation observed in Centrolene lynchi, and others are the product of preservation artifacts. It is 
clear that the type material of $C$.gemmata was poorly preserved, causing dehydration of the specimens, which usually produces changes in head shape (i.e., post-cephalic constriction and protuberant nostrils present in the type series of $C$. gemmata). The examined type series of $C$. gemmata has a snout that is truncated to slightly sloping in profile; the exact same variation is present in the type material of Centrolene lynchi. Also, the hand webbing formula in the two species are nearly identical [III $\left(2-2^{1 / 4}\right)-\left(2^{-}-2^{+}\right)$IV in Centrolene lynchi, and III $\left(2-2^{1 / 3}\right)-\left(2^{-}-2^{+}\right)$IV in C. gemmata]. Therefore, none of the characters listed by Flores (1985) to differentiate C. gemmata from Centrolene lynchi are valid. Based on the evidence mentioned above, we consider these to represent the same species and place Centrolene gemmata in the synonymy of Centrolene lynchi.

Duellman and Burrowes [86] described Centrolenella scirtetes from a locality $1.4 \mathrm{~km}$ SW Tandayapa (Ecuador, male holotype KU 202720) and from Reserva La Planada (Colombia, two female paratypes IND-AN 1405 and 1533). For unknown reasons, C. scirtetes was never compared with specimens of Centrolene lynchi. As pointed out by Cisneros-Heredia and McDiarmid [17], the holotype of C. scirtetes is undistinguishable from the holotype of C. lynchi (KU 164691). Consequently, herein we formally place C. scirtetes, as defined by its holotype, in the synonymy of Centrolene lynchi. We have not examined the paratypes of $C$. scirtetes, but material from Colombia identified as C. scirtetes (ICN 12172-74) and resembling the description and photograph of the paratypes provided by Duellman and Burrowes (1989) are indistinguishable from individuals of Nymphargus griffithsi, in which the dorsum has black flecks and the humeral crista ventralis presents a distal prolongation. Accordingly, we conclude that the Colombian material assigned to C. scirtetes is in fact representative of N. griffithsi.

Specimens examined: Centrolene lynchi: Ecuador: Provincia de Cotopaxi: San Francisco de Las Pampas, just NW of junction of río Las Juritas and río Toachi (0.433 S, $78.9667 \mathrm{~W}$; ca. $1500 \mathrm{~m}$ ), MCZ A-104397, A-104074, A-104077; Provincia de Pichincha: 1.4 km SW of Tandayapa (0.033 S, 78.7667 W; 1820 m), KU 202720; Tandapi (0.4164 S, 78.7989 W; 1460 m), KU 118036, 118047-50, 178095-104; 2.1 km E Tandapi (0.4258 S, 78.7853 W; 1500 m), MCZ A-93313-14, 95742; Reserva Las Gralarias (0.01675 S, 78.73165; $1852 \mathrm{~m})$, QCAZ 40191-2, 40194. Provincia de Santo Domingo de los Tsáchilas: stream $4 \mathrm{~km}$ northeast (by road) of Dos Ríos (0.3028 S, 78.8678 W; 1140 m), KU 164691 (holotype), KU 164692-99 (paratypes); $14.4 \mathrm{~km}$ ENE La Palma on the road La Palma-Chiriboga (0.25 S, $78.846 \mathrm{~W} ; 1380 \mathrm{~m}$ ), MCZ A-91455. 
Centrolenella medemi Cochran and Goin, 1970 [96]. Holotype: USNM 152277.

Type locality: "Puerto Asís, upper Río Putumayo, [Comisaría] Putumayo, Colombia" (apparently in error; see Distribution).

Centrolene medemi-Ruiz-Carranza and Lynch, 1991 [6].

"Centrolene" medemi-Guayasamin, Castroviejo-Fisher, Trueb, Ayarzagüena, Rada, and Vilà, 2009 [1].

Common names: English: Medem's Glassfrog. Spanish: Rana de Cristal de Medem.

Etymology: The epithet medemi honors Dr. Fred Medem, who discovered the species [96].

Identification: "Centrolene" medemi is unique among Ecuadorian glassfrogs by having a dark olive-green dorsum with large greenish-cream spots (Figure 47 ), wide disc on Finger III ( $>80 \%$ of eye diameter), small tympanum ( $<20 \%$ of eye diameter), and fully webbed foot. Adults are robust and relatively large (SVL $25.5-44.3 \mathrm{~mm}$ ).

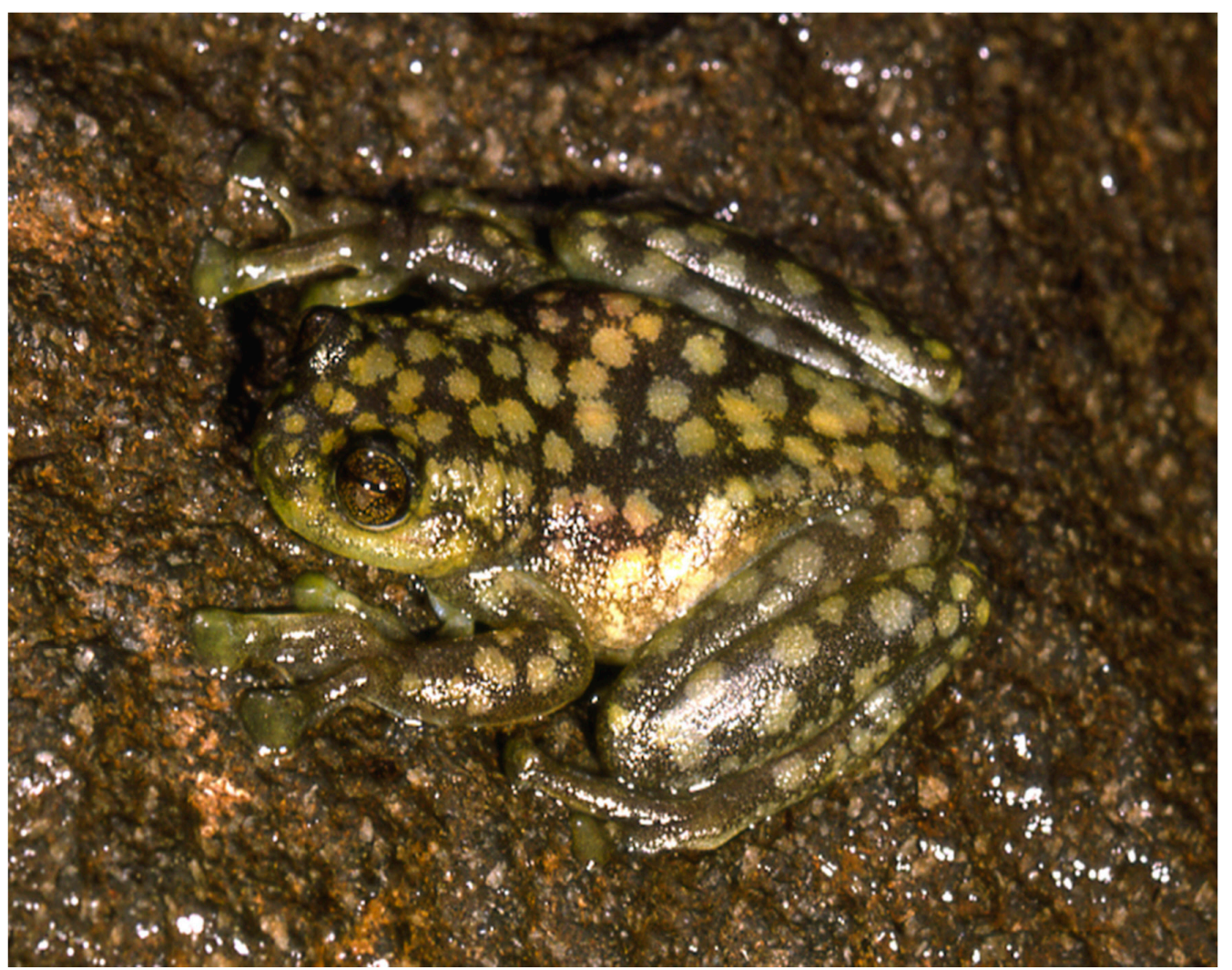

Figure 47. "Centrolene" medemi in life. Adult female (KU 164493) from $2 \mathrm{~km} \mathrm{SSW} \mathrm{of} \mathrm{junction} \mathrm{between}$ Río Reventador and Baeza-Lumbaqui road, Ecuador. Photo by William E. Duellman.

Diagnosis: (1) Teeth on dentigerous process of the vomer present or absent, each process bearing zero to four teeth; (2) snout round in dorsal profile, truncated to slightly protruding in lateral profile (Figure 48 ); (3) tympanum small, tympanum diameter $17.1 \%-18.5 \%$ of eye diameter, dorsal third of tympanum covered by supratympanic fold, tympanic membrane pigmented and not clearly differentiated from surrounding skin; (4) dorsal surfaces of males and females smooth to shagreen; males with small spicules on dorsum and flanks; (5) pair of slightly enlarged subcloacal warts; (6) anterior half of the ventral parietal peritoneum white (condition P2); silvery white pericardium; no iridophores in peritonea covering the intestines, stomach, testes, kidneys, gall bladder, and urinary bladder (condition V1); (7) liver tetralobed, two large ventral lobes covering two smaller lobes; hepatic peritoneum lacking iridophores (condition H0); (8) in males, small humeral spines present; (9) hand 
webbing: Webbing between Fingers I, II, and III absent or basal, extensive webbing between Fingers III and IV; webbing formula as follows: II $\left(1^{+}-2\right)-3^{+}$III $\left(1^{1 / 4}-2\right)-\left(0-1^{1 / 4}\right) \mathrm{IV} ;(10)$ fully webbed foot: I $\left(0-0^{+}\right)-\left(0^{+}-1\right)$ II $\left(0-0^{+}\right)-(0-1)$ III $\left(0-0^{+}\right)-\left(0^{+}-1\right)$ IV $\left(1^{-}-1\right)-0^{+} \mathrm{V} ;(11)$ ulnar and tarsal folds low; (12) concealed prepollex; in males, nuptial pad Type I; (13) Finger I slightly shorter than Finger II (Finger I about 91\%-98\% length of Finger II); (14) disc of Finger III large, 80\%-91\% of eye diameter; (15) in life, dorsal surfaces of head, body, and limbs olive green to greyish brown with large (up to $2.8 \mathrm{~mm}$ ) cream spots (Figure 47); bones bluish green or green; (16) in ethanol, dorsal surfaces of head, body, and limbs pale brown with large cream spots; (17) iris greenish brown with black reticulation; (18) melanophores covering dorsal surfaces of fingers and toes; (19) calling behavior unknown; (20) fighting behavior unknown; (21) eggs deposited on rocks along streams; parental care unknown; (22) tadpoles unknown; (23) medium body size; in adult males, SVL $25.5-30.8 \mathrm{~mm}$; in adult females, SVL 34.7-44.3 mm.

\section{A}

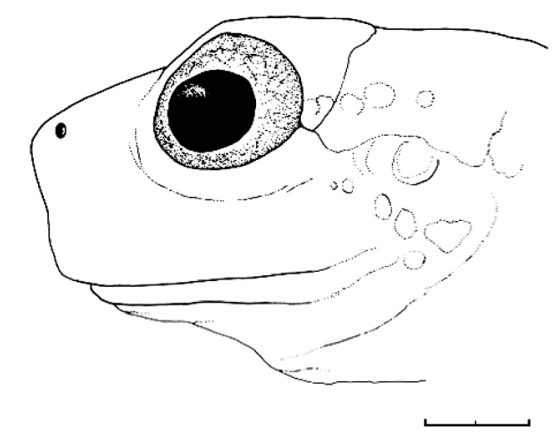

B

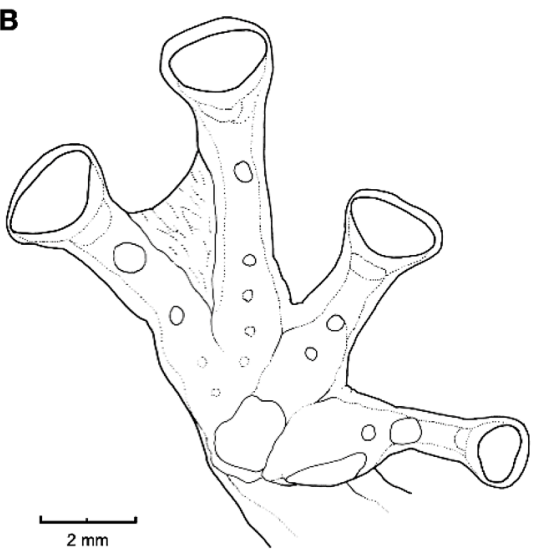

Figure 48. "Centrolene" medemi. (A) Head in lateral view, KU 164493. (B) Hand in ventral view, KU 164494. Illustrations by Juan M. Guayasamin.

Variation: The size of the nuptial pad varies in males and can be restricted to the dorsolateral area of the base of Finger I or extend until reaching the typical Type I morphology.

Color in life (Figure 47): At night, dorsum black with bluish green spots; venter dull blue. By day, dorsum dark olive-brown with pale green spots; flanks cream. Lining of mouth and tongue pale blue. Bones green. Iris dull greyish-bronze with minute black flecks. Webbing pale yellowish tan (W. E. Duellman field notes, 19 March 1975).

Color in ethanol: Dorsal surfaces of head, body, and limbs pale brown with large cream spots. White lining on the anterior half of the ventral parietal peritoneum; silvery white pericardium; no iridophores in peritonea covering the liver, intestines, stomach, testes, kidneys, gall bladder, and urinary bladder. 
Biology and ecology: During the night, adults have been found on rocks, in rock crevices, and on rock cliffs along streams; juveniles were found on palm leaves or in rock crevices [128]. The oviductal eggs of one female (KU 164493) are dark brown. It is likely that females of "Centrolene" medemi deposit their eggs on rocks, as reported in species with similar microhabitats (e.g., Centrolene geckoidea, "Centrolene" petrophilum [113,129]). Parental care is unknown.

Call: Not described.

Tadpole: Not described.

Distribution (Figure 49): "Centrolene" medemi is known from localities on the eastern and western slopes of the Cordillera Oriental of the Colombian Andes and the Amazonian slopes of the Cordillera Oriental of Ecuador at elevation between 790 and 1800 m [101,128,130]. In Ecuador, "Centrolene" medemi has been registered from a single stream nearby Volcán Reventador at $1490 \mathrm{~m}$ (Specimens Examined), within the Eastern Montane Forest ecoregion. Although this species was described from a locality in lowlands of Amazonian Colombia (Puerto Asís, upper Río Putumayo at about 280 m [96]), all subsequent records are from Andean localities. Based on this evidence, Ruiz-Carranza et al. [101] rejected the record from Amazonian Colombia.

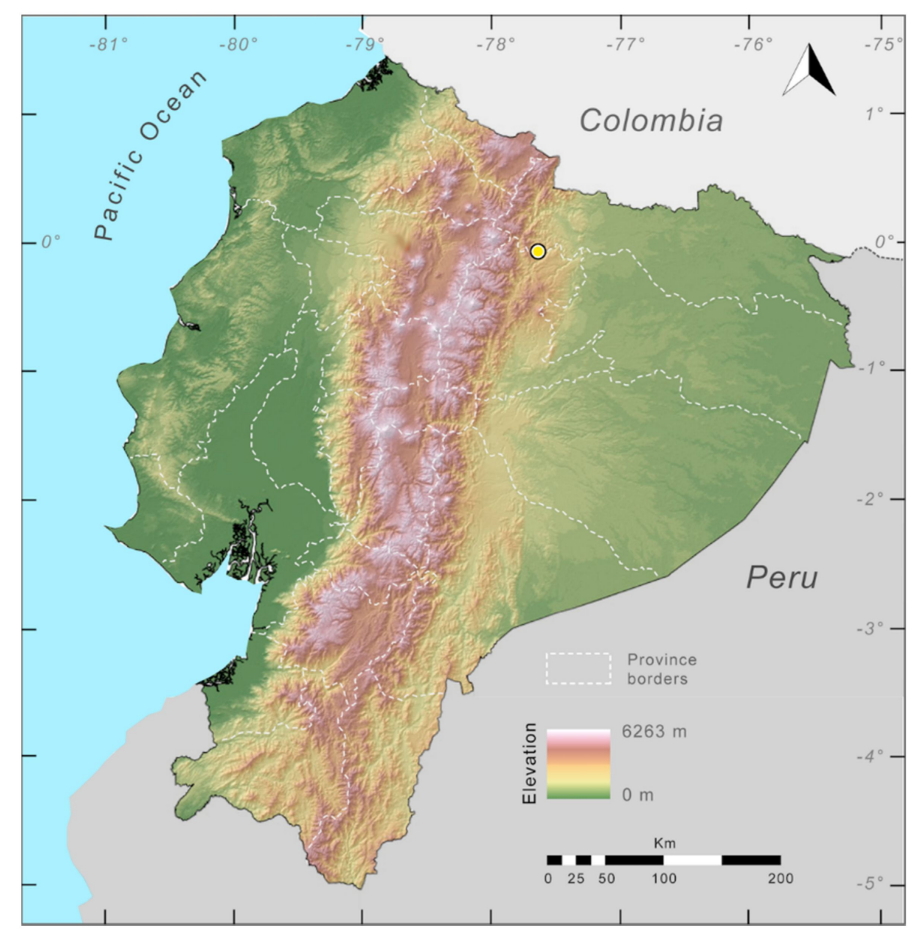

Figure 49. Distribution of "Centrolene" medemi in Ecuador (yellow dot).

Conservation status: Globally, "Centrolene" medemi is currently listed as Endangered by the IUCN [131]. In Ecuador, the only record is from a stream nearby Volcán Reventador on 19 March 1975 [130], and area that has been visited several times during the last 10 years. We suggest that the species should be locally listed as Critically Endangered.

Evolutionary relationships (Figure 24): Based on morphological traits, "Centrolene" medemi was placed in the Centrolene geckoidea species group by Ruiz-Carranza and Lynch [6]. Guayasamin et al. [1] considered the generic placement of "Centrolene" medemi as incertae sedis within the subfamily Centroleninae. No genetic data are available for this species.

Specimens examined: "Centrolene" medemi: Ecuador: Provincia de Napo: Stream $2 \mathrm{~km} \mathrm{SSW}$ of junction between Río Reventador and Baeza-Lumbaqui road (0.1 S; 77.6 W, 1490 m), KU 164493-94. 
Centrolene peristicta (Lynch and Duellman, 1973 [22]; Figures 50-53).

Centrolenella peristicta Lynch and Duellman, 1973 [22]. Holotype: KU 118051.

Type locality: "Tandapi, 1460 m, Provincia Pichincha, Ecuador".

Centrolene peristictum-Ruiz-Carranza and Lynch, 1991 [6]. Guayasamin, Castroviejo-Fisher,

Trueb, Ayarzagüena, Rada, and Vilà, 2009 [1].

Centrolene peristicta-Barrio-Amorós, Rojas-Runjaic, and Señaris, 2019 [85].

Common names: English: Dappled Glassfrog. Spanish: Rana de Cristal Punteada.

Etymology: The specific epithet is derived from the Greek peristiktos, meaning dappled, and refers to the spotted color pattern of the species [22].

Identification: Centrolene peristicta is distinguished from most glassfrogs by its minute body size (SVL $<21.3 \mathrm{~mm}$ ) and having, in life, a yellowish-green dorsum with minute white flecks and small diffuse black spots (Figure 50). Additionally, adult males of $C$. peristicta have a small, curved humeral spine that is morphologically different from the spines present in most glassfrogs (i.e., not curved). Similar species include C. antioquiensis, C. lynchi, C. pipilata, and Nymphargus truebae. Centrolene antioquiensis, an endemic species from Colombia, is remarkably similar to C. peristicta (see Taxonomic Remarks), but $C$. antioquiensis has less hand webbing: hand webbing formulae in $C$. antioquiensis, III $\left(2^{+}-2^{-}\right)-\left(2-2^{-}\right)$IV; in C. peristicta, III $\left(2^{+}-2^{-}\right)-\left(1^{1 / 2}-1^{+}\right)$IV. Centrolene lynchi is larger than C. peristicta (in males, SVL 23.3-26.5 mm in Centrolene lynchi) and has a very different call. Centrolene pipilata occurs on the Amazonian slopes of the Andes, whereas C. peristicta is restricted to the Pacific slopes of the Andes. Nymphargus truebae, a species only known from the Andes of southern Peru, has the same color pattern as C. peristicta, but N. truebae lacks humeral spines and webbing between Fingers III and IV (present in C. peristicta).

Diagnosis: (1) Vomers lacking teeth; (2) snout round in dorsal aspect, round or truncated in lateral profile (Figure 51); (3) tympanum large, oriented almost vertically, with slight lateral and posterior inclinations, its diameter $44.0 \%-51.9 \%$ of eye diameter; tympanic annulus visible, supratympanic fold evident; tympanic membrane translucent, partially pigmented, differentiated from surrounding skin; (4) dorsal skin shagreen with small warts corresponding to yellowish-white spots, males and females lack spicules; (5) pair of enlarged subcloacal warts (Figure 15); (6) anterior half of the ventral parietal peritoneum white, posterior half transparent (condition P2); white pericardium; iridophores partially or completely covering stomach and colon; no iridophores in peritonea covering kidneys, gall bladder, and urinary bladder (condition V2); (7) liver with four clearly defined lobes, lacking iridophores (condition H0); (8) males with conspicuous humeral spines; (9) webbing absent between Fingers I and II, reduced between Fingers II and III, and moderate to extensive between outer fingers (Figure 51); webbing formula: II $\left(1^{3 / 4}-2^{-}\right)-\left(3^{+}-3^{1 / 4}\right)$ III $\left(2^{+}-2^{-}\right)-\left(1^{1 / 2}-1^{+}\right) \mathrm{IV}$; (10) webbing between toes extensive; webbing formula on foot I $1-\left(1^{1 / 2}-2\right)$ II $1-\left(2^{-}-2^{+}\right)$III $\left(1^{-}-1^{+}\right)-\left(2^{-}-2^{+}\right)$IV $\left(2^{-}-2^{+}\right)-\left(1-1^{1 / 3}\right)$ V; (11) ulnar fold present, with low white tubercles; outer tarsal fold present, with low white tubercles; internal tarsal fold low and short; (12) prepollex usually exposed; nuptial pad Type I or Type III; (13) Finger I slightly shorter or as long as Finger II (Finger I length $90.9 \%-102.7 \%$ Finger II); (14) disc of Finger III width about $45.6 \%-67.3 \%$ of eye diameter; (15) in life, dorsum green with minute yellowish-white spots and larger black spots (Figure 50); green bones; (16) in preservative, dorsum lavender with numerous minute white spots and larger diffuse dark lavender spots; (17) in life, iris white grey with a yellow hue and thin black reticulation; thin yellow line surrounds the pupil; (18) melanophores mostly absent from fingers and toes, except for a few on dorsal surfaces of Finger IV and proximal portion of Finger III; (19) males call from mostly from the lower sides of leaves; each call has one pulsed note with a duration of $0.036-0.087 \mathrm{~s}$ and a dominant frequency of $6471-7278 \mathrm{~Hz}$; (20) fighting behavior unknown; (21) egg clutches usually deposited on the underside of leaves; short-term maternal care absent; prolonged parental care provided by males; (22) tadpoles undescribed; (23) minute body size; in adult males, SVL $17.9-21.2 \mathrm{~mm}(\bar{X}=19.9, n=14)$; in two adult females SVL $20.8-20.9 \mathrm{~mm}$. 

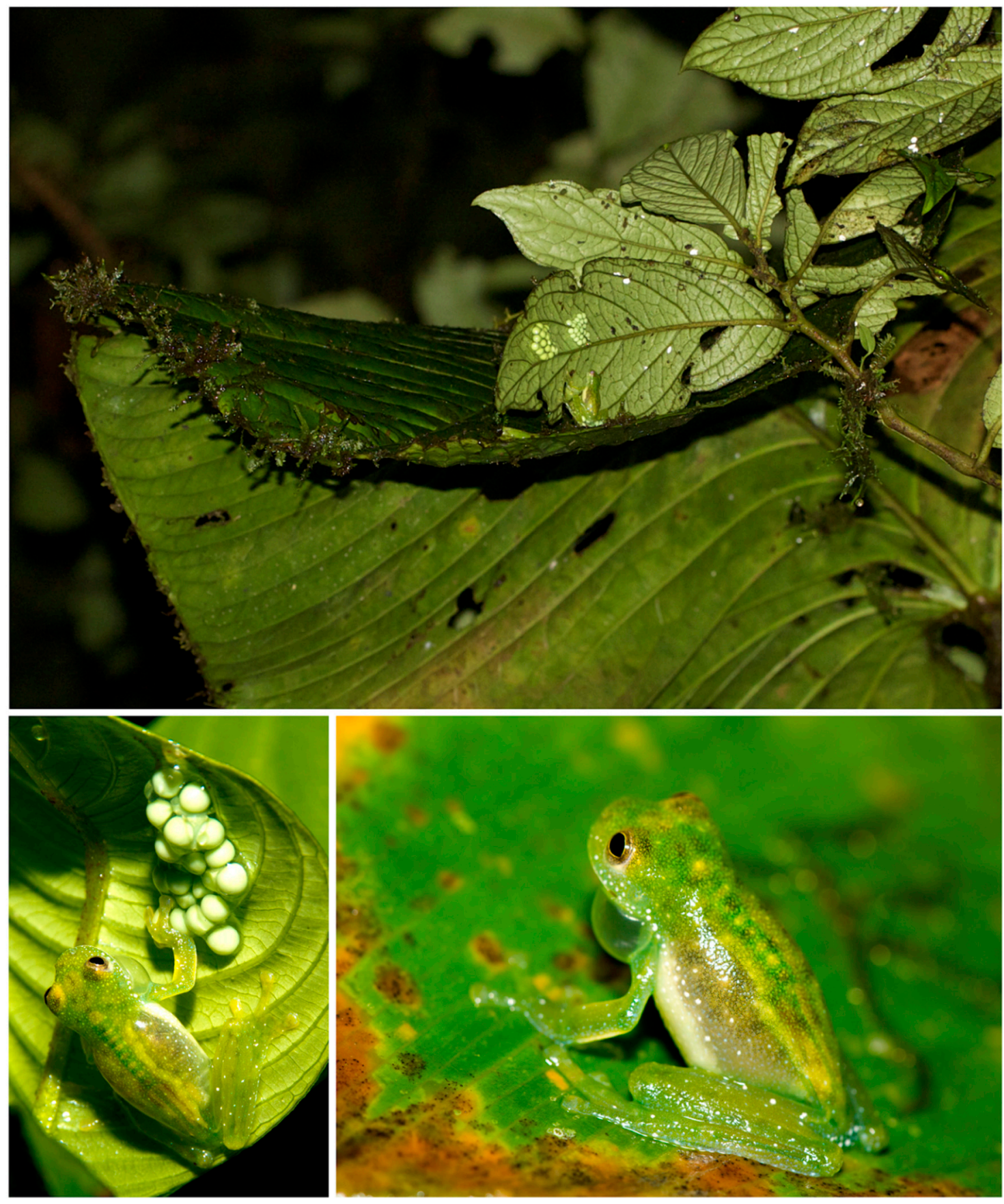

Figure 50. Centrolene peristicta in life. (Top row): Male guarding two egg clutches; Reserva Las Gralarias. (Bottom left): Adult male guarding eggs, from Mindo Biological Reserve, QCAZ 22313; photo by Martín Bustamante. (Bottom right): Individual from Reserva Las Gralarias; photo by Marco Rada.

Diagnosis: (1) Vomers lacking teeth; (2) snout round in dorsal aspect, round or truncated in lateral profile (Figure 51); (3) tympanum large, oriented almost vertically, with slight lateral and posterior inclinations, its diameter $44.0 \%-51.9 \%$ of eye diameter; tympanic annulus visible, supratympanic fold evident; tympanic membrane translucent, partially pigmented, differentiated from surrounding skin; (4) dorsal skin shagreen with small warts corresponding to yellowish-white spots, males and females lack spicules; (5) pair of enlarged subcloacal warts (Figure 15); (6) anterior half of the ventral parietal peritoneum white, posterior half transparent (condition P2); white pericardium; iridophores partially or completely covering stomach and colon; no iridophores in peritonea covering kidneys, gall bladder, and urinary bladder (condition V2); (7) liver with four clearly defined lobes, lacking 
iridophores (condition H0); (8) males with conspicuous humeral spines; (9) webbing absent between Fingers I and II, reduced between Fingers II and III, and moderate to extensive between outer fingers (Figure 51); webbing formula: II $\left(1^{3 / 4}-2^{-}\right)-\left(3^{+}-3^{1 / 4}\right) \mathrm{III}\left(2^{+}-2^{-}\right)-\left(1^{1 / 2}-1^{+}\right) \mathrm{IV} ;(10)$ webbing between toes extensive; webbing formula on foot I $1-\left(1^{1 / 2}-2\right)$ II $1-\left(2^{-}-2^{+}\right)$III $\left(1^{-}-1^{+}\right)-\left(2^{-}-2^{+}\right)$IV $\left(2^{-}-2^{+}\right)-\left(1-1^{1 / 3}\right)$ $\mathrm{V}$; (11) ulnar fold present, with low white tubercles; outer tarsal fold present, with low white tubercles; internal tarsal fold low and short; (12) prepollex usually exposed; nuptial pad Type I or Type III; (13) Finger I slightly shorter or as long as Finger II (Finger I length 90.\%-102.7\% Finger II); (14) disc of Finger III width about $45.6 \%-67.3 \%$ of eye diameter; (15) in life, dorsum green with minute yellowish-white spots and larger black spots (Figure 50); green bones; (16) in preservative, dorsum lavender with numerous minute white spots and larger diffuse dark lavender spots; (17) in life, iris white grey with a yellow hue and thin black reticulation; thin yellow line surrounds the pupil; (18) melanophores mostly absent from fingers and toes, except for a few on dorsal surfaces of Finger IV and proximal portion of Finger III; (19) males call from mostly from the lower sides of leaves; each call has one pulsed note with a duration of $0.036-0.087 \mathrm{~s}$ and a dominant frequency of $6471-7278 \mathrm{~Hz}$; (20) fighting behavior unknown; (21) egg clutches usually deposited on the underside of leaves; short-term maternal care absent; prolonged parental care provided by males; (22) tadpoles undescribed; (23) minute body size; in adult males, SVL 17.9-21.2 mm ( $\bar{X}=19.9, n=14)$; in two adult females SVL 20.8-20.9 mm.

A

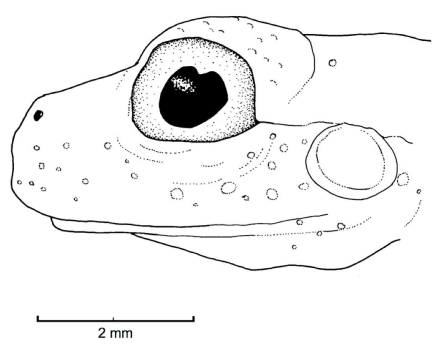

C

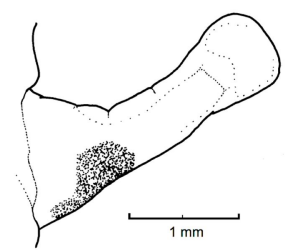

B

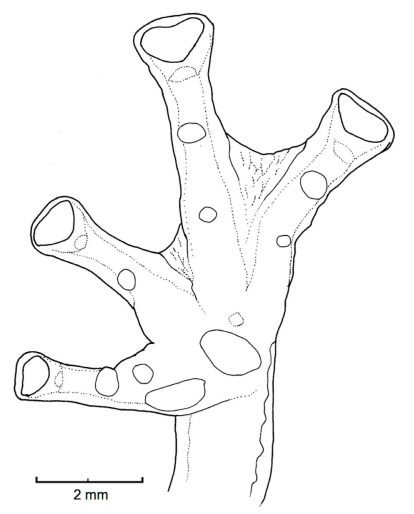

Figure 51. Centrolene peristicta, KU 178148. (A) Head in lateral view. (B) Hand in ventral view. (C) Dorsal view of Finger I, showing nuptial pad. Illustrations by Juan M. Guayasamin.

Color in life (Figure 50): Dorsum green with minute yellowish-white flecks and small dark grey spots; upper lip white; region below eye with small white warts; bones green; vocal sac green; upper flanks green with minute white spots; lower flanks cream with minute white spots; venter yellowish cream; fingers and toes dull yellow green; ulnar fold with thin white line or with low white ulnar tubercles; outer tarsal fold with low white tubercles; small white tubercles just posterior to cloaca.

Color in ethanol: Dorsal surfaces of head, body, and limbs lavender with minute white spots and small black spots; margin of upper lip white; region below eye with small white warts; white tubercles just posterior to cloaca. White parietal peritoneum covers anterior half of venter; white pericardium; clear peritoneum on liver and kidneys; digestive tract partially or completely covered with white lining. 
Variation: One individual (QCAZ 16313) has considerably less webbing on the hands (III $2^{1 / 2}-2^{+}$IV). Individuals from streams nearby the town of Mindo lack iridophores on the gastrointestinal peritonea.

Biology and ecology: The information shown below is from Salgado and Guayasamin [132]. At Reserva Las Gralarias, during the night, Centrolene peristicta is active on vegetation $40-600 \mathrm{~cm}$ above permanent streams in primary evergreen lower-montane forests and cloudforests. Its breeding season is in the rainy (December-April), but peaks in February-April. Males vocalize to advertise themselves and defend territories in which females place clutches containing 6-41 eggs. Most of the time, egg clutches are placed on the underside of leaves and ferns 70-500 cm directly above streams, or under dead leaves nearby streams. Males are polygynous and exhibit high site fidelity; some males were observed simultaneously guarding egg clutches at different stages of development. Parental care by males was demonstrated experimentally; unattended clutches have a significantly lower eclosion rate than attended clutches, and prolonged hatching time. Clutch mortality was mainly because of desiccation, predation, and parasitism. Embryos develop for 17-27 days, then hatching as free-swimming larvae. At Reserva Las Gralarias, the species is abundant at Lucy's Creek, but it is also found at Kathy's Creek and Santa Rosa River [88].

Call (Figure 52): The information shown below is from Salgado and Guayasamin [132]. Advertisement call of males of Centrolene peristicta consists of one short and pulsed note that resembles the sound of a cricket chirp. The note has a duration of $0.036-0.087 \mathrm{~s}(X+S E=0.062+1.07, N=35)$ and each call has one note. The dominant frequency is at $6471-7278 \mathrm{~Hz}(X+S E=6878+177 \mathrm{~Hz} ., N=35)$. The fundamental frequency is the same as the dominant frequency; there is one (range $=3235-6198 \mathrm{~Hz}$ ) or two harmonics (range $=6471-7278 \mathrm{~Hz}$ ). There is no conspicuous frequency modulation during the call. The repetition rate of the advertisement call varies from two to 20 calls per minute.

Tadpole: Not described.

Distribution (Figure 53): Centrolene peristicta is known from the Pacific slope of the Cordillera Occidental of the Andes in Ecuador and Colombia at elevations between 1380 and $1900 \mathrm{~m}([22,87,133,134]$, this work). In Ecuador, C. peristicta is known from localities in the provinces of Carchi, Pichincha, and Santo Domingo de los Tsáchilas, at elevations of $1400-1852 \mathrm{~m}$, with a potential distribution of $12,603 \mathrm{~km}^{2}$. All localities are within the Western Montane Forest ecoregion.

Conservation status: Globally, Centrolene peristicta is currently listed as Least Concern by the IUCN [135]. In Ecuador, Arteaga et al. [87] suggested the category of Near Threatened. Several recent observations show that the species has a wider distribution than previously thought. Reproductive populations have been observed at Reserva Las Gralarias (December 2009-May 2018; JMG, pers. obs.), Mindo Biology Station (February 2002; December 2014; M. R. Bustamante and L. Bustamante, pers. com.), and at Río Pachijal on August 2001 (I. Tapia, pers. com.). The potential distribution of the species covers an area of $12,603 \mathrm{~km}^{2}, 44.6 \%$ of which is affected by human activities. At Reserva Las Gralarias, the species is infected by the amphibian chytrid fungus Batrachochytrium dendrobatidis [92], but populations look healthy and there is no evidence of declines. The conservation category of Least Concern seems too optimistic, given the fragmented distribution of the species. We suggest that the species should be considered as Near Threatened, in agreement with Arteaga et al. (2013). 


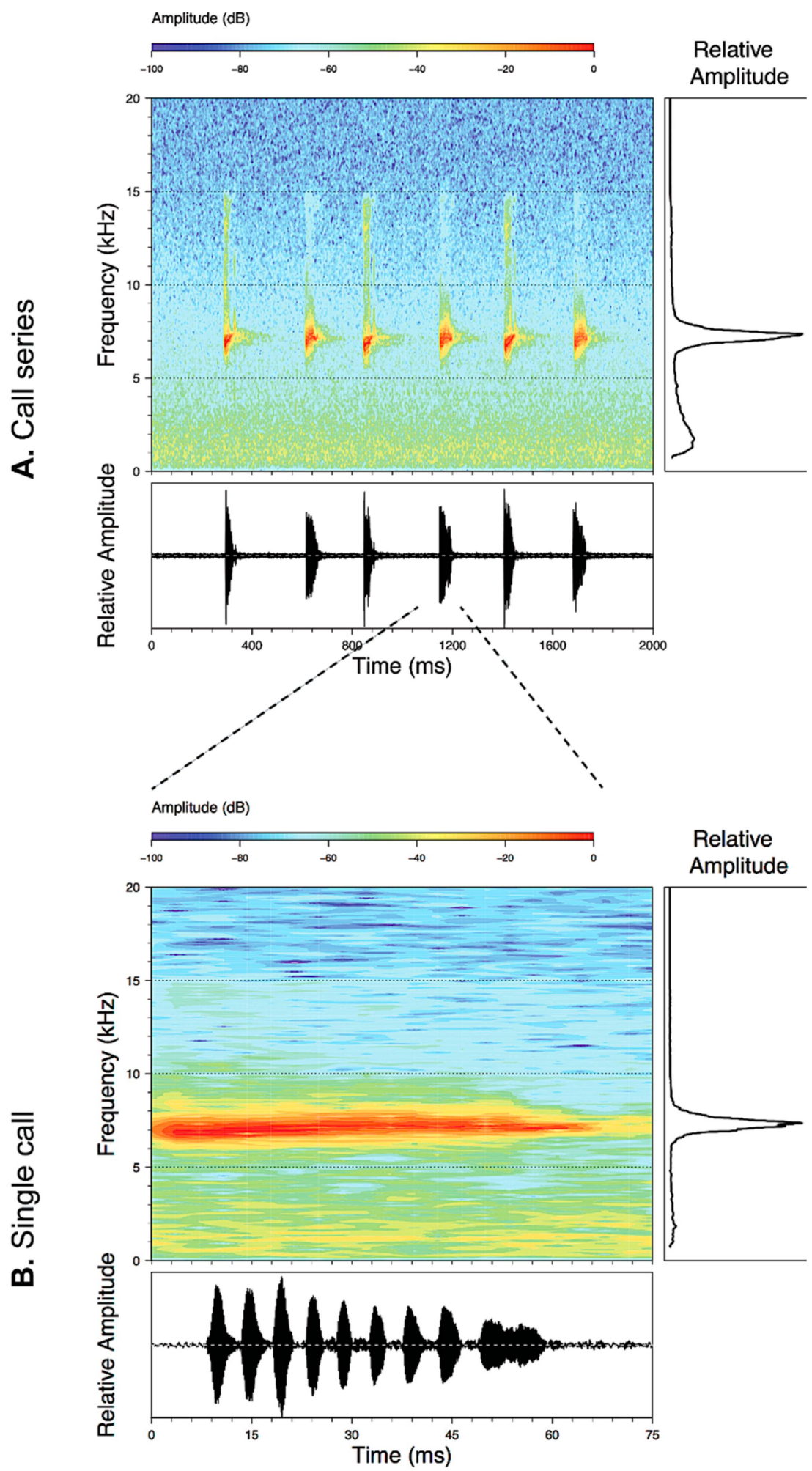

Figure 52. Call of Centrolene peristicta (LBE-C-047), recorded at Reserva Las Gralarias, $1800 \mathrm{~m}$, Pichincha province, Ecuador. (A) Series of calls. (B) Single, pulsed call. 


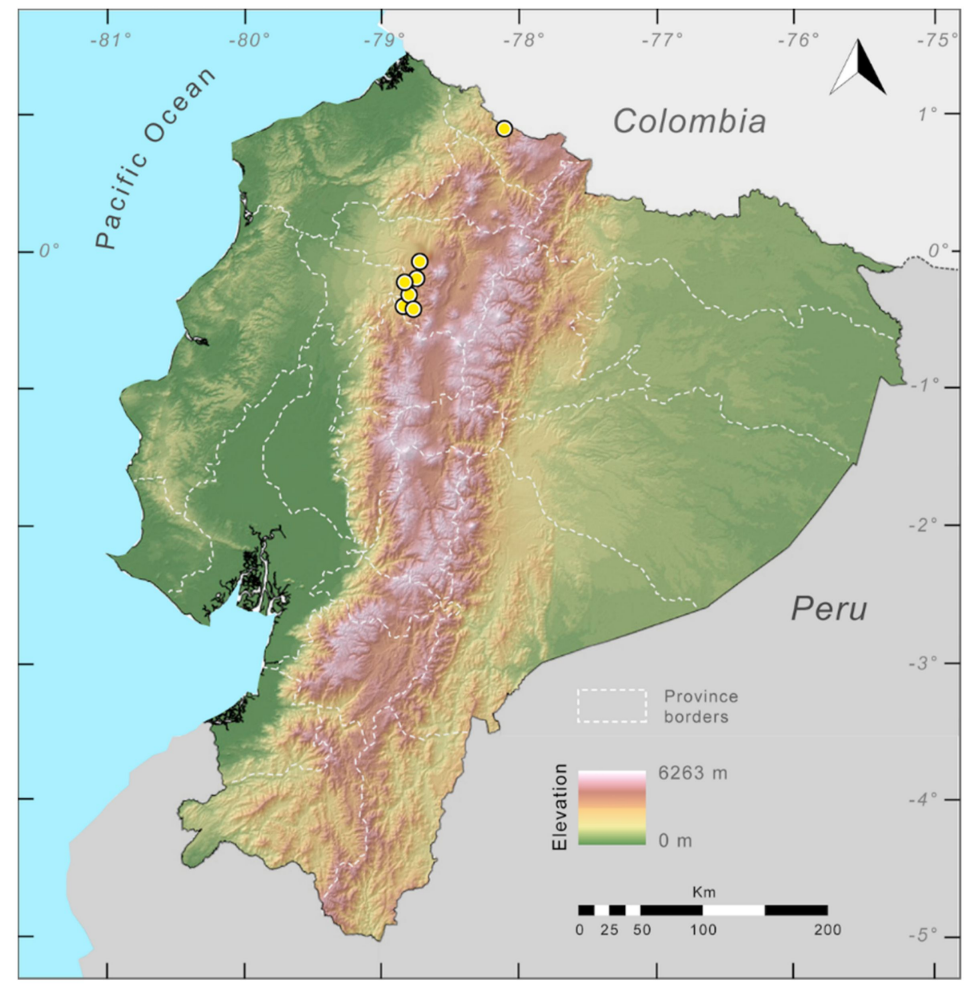

Figure 53. Distribution of Centrolene peristicta in Ecuador (yellow dots).

Evolutionary relationships (Figure 24): Molecular evidence places Centrolene peristicta and C. antioquiensis as sister species.

Taxonomic Remarks: Centrolene antioquiensis and C. peristicta are almost identical in morphology and could represent a single species. The subtle differences found between these two species might be a consequence of incomplete sampling or intraspecific geographic variation. The analysis of calls from C. antioquiensis is critical to assess the validity of the species status of $C$. peristicta.

Specimens examined: Centrolene peristicta: Ecuador: Provincia de Carchi: Maldonado (0.9 N, 78.1 W, 1410 m), KU 178137-44, 178145-51, 180325; Provincia de Pichincha: Bosque Protector Río Guajalito (0.233 S, 78.817 W; 1900 m), QCAZ 6446; stream near Mindo Biology Station (0.07805 S, 78.7319 W; 1600 m), QCAZ 22757-59, 22312-14; Tandapi (0.416389 S, 78.7989 W, 1520 m), KU 118051-52, 121053; $1.6 \mathrm{~km} \mathrm{~W}$ of Tandapi (0.40472 S, $78.8058 \mathrm{~W} ; 1400 \mathrm{~m}), \mathrm{KU} 178152 ; 5 \mathrm{~km} \mathrm{~W}$ of Tandapi on the Tandapi-Atenas road (0.3954 S, 78.8326 W; 1670 m), QCAZ 15901, 15922; Río Pachijal (0.2 S, 78.75 W; 1740 m), QCAZ 16316; Reserva Las Gralarias (0.00806 S, 78.72443 W; 1852 m), QCAZ 47298. Provincia de Santo Domingo de los Tsáchilas: Río Faisanes, ca. $15 \mathrm{~km}$ NE of La Palma, on the Quito-Chiriboga-Santo Domingo road (0.3167 S, 78.817 W; 1380 m), USNM 286714. Colombia: Departamento de Nariño, Reserva La Planada, ICN 12114 (PR 7871). 
Centrolene pipilata (Lynch and Duellman 1973 [22]; Figures 54-56).

Centrolenella pipilata Lynch and Duellman, 1973 [22]. Holotype: KU 143278.

Type locality: "16.5 km NNE of Santa Rosa, 1700 m, on Quito-Lago Agrio road, Provincia de

Napo, Ecuador".

Centrolene pipilatum - Ruiz-Carranza and Lynch, 1991 [6].

Centrolene pipilata-Barrio-Amorós, Rojas-Runjaic, and Señaris, 2019 [85].

Common names: English: Peeping Glassfrog. Spanish: Rana de Cristal Piadora.

Etymology: The specific epithet pipilata is an adjectival derivative of the Latin verb pipila, meaning to peep, and refers to the call of this centrolenid frog [22].

Identification: Centrolene pipilata is distinguished from most glassfrogs by having, in life, a green dorsum with yellowish-white flecks and diffuse dark green marks, and a distinct prepollex (Figures 54 and 55). On the Amazonian slopes of Ecuador, the only species that have a similar dorsal color pattern are $C$. sanchezi and C. huilensis. Centrolene sanchezi has a short, thin humeral spine (large, wide, and usually with the tip projected anteriorly in C. pipilata) and lacks a distinct prepollex. Centrolene huilensis is conspicuously larger than C. pipilata (in C. huilensis, male SVL $=23.6-26.7 \mathrm{~mm} ; \mathrm{SVL}=28.7 \mathrm{~mm}$ in 1 female; in C. pipilata, male SVL 19.7-22.6 mm, female SVL 22.6-23.6 mm). Nymphargus truebae, a species only known from the Andes of southern Peru, has the same color pattern as C. pipilata, however, males in N. truebae lack humeral spines (present in males of C. pipilata). The Colombian Centrolene hybrida has a white gastrointestinal peritoneum (iridophores absent in C. pipilata), and lacks a distinct prepollex.

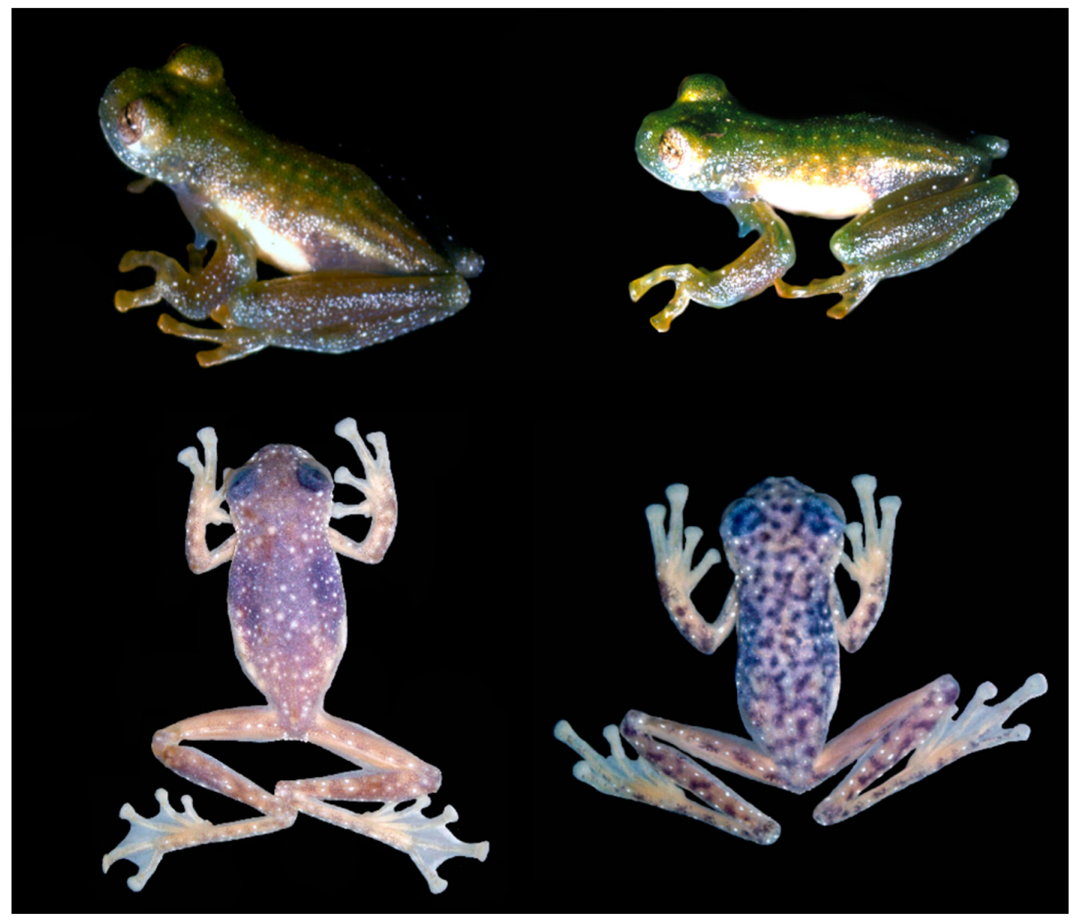

Figure 54. Centrolene pipilata. (Top row): Coloration in life, adult male, holotype, KU 143278; photos by William E. Duellman. (Bottom row): Coloration in preservative of KU 178155 (left) and KU 143287 (right); photos by Juan M. Guayasamin.

Diagnosis: (1) Vomers lacking teeth; (2) snout round in dorsal aspect, round or truncated in lateral profile (Figure 55); (3) tympanum moderate, oriented almost vertically, with slight lateral and posterior inclinations, its diameter $31.0 \%-39.4 \%$ of eye diameter; tympanic annulus completely visible; supratympanic fold evident; tympanic membrane translucent, partially pigmented, clearly 
differentiated from surrounding skin; (4) dorsal skin shagreen, males with spicules coinciding with white spots; (5) pair of enlarged subcloacal warts (Figure 15); (6) anterior 50\%-60\% of the ventral parietal peritoneum white, posterior portion transparent (condition P2-P3); white pericardium; no iridophores in peritonea covering intestines, stomach, kidneys, gall bladder, and urinary bladder (condition V1); (7) liver with four clearly defined lobes, lacking iridophores (condition H0); (8) males with conspicuous humeral spines; (9) webbing absent between Fingers I, II, and III; moderate between outer fingers (Figure 55); webbing formula: III $\left(2^{+}-2^{1 / 2}\right)-\left(2-2^{+}\right)$IV; (10) webbing between toes extensive; webbing formula on foot: I $\left(1^{+}-2^{-}\right)-\left(2-2^{+}\right)$II $\left(1-1^{1 / 3}\right)-\left(2-2^{1 / 3}\right)$ III $\left(1-1^{1 / 2}\right)-2^{+}$IV $\left(2-2^{1 / 2}\right)-\left(1-1^{1 / 2}\right) \mathrm{V}$; (11) white ulnar fold present; outer tarsal margin with low white tubercles: Internal tarsal fold low; (12) exposed prepollex; nuptial pad Type II; (13) Finger I as long as Finger II or slightly shorter (Finger I $90.0 \%-100 \%$ of Finger II); (14) disc of Finger III width $44.8 \%-56.5 \%$ of eye diameter; (15) in life, dorsum green with small diffuse black spots and yellowish-white flecks (Figure 54); green bones; (16) in preservative, dorsum lavender with numerous minute white spots and larger dark lavender spots (Figure 54); (17) in life, iris greyish-white with thin black reticulations and a yellow hue around pupil; (18) melanophores mostly absent from fingers and toes, except for a few on proximal half of Finger IV, and along Toes IV and V; (19) males call from upper side of leaves; call undescribed; (20) fighting behavior unknown; (21) eggs placed on upper surface of leaves; parental care unknown; (22) tadpoles unknown; (23) minute body size; in adult males, SVL 19.7-22.6 $\mathrm{mm}(\bar{X}=21.5, n=9)$; in two adult females SVL 22.6-23.6 mm.

Color in life (Figure 54): Dorsum green with minute yellowish-white flecks and larger, diffuse black spots; upper lip white; region below eye with small white warts that are spiculated in males; bones green; upper flanks green with minute white spots; lower flanks whitish cream; ulnar fold with thin white line; outer tarsal fold with low white tubercles; small white tubercles just posterior to cloaca; iris greyish-white with thin black reticulations and a yellow hue around pupil.

Color in ethanol: Dorsal surfaces of head, body, and limbs lavender with small white spots and larger dark lavender spots (Figure 54); margin of upper lip white; region below eye with small, spiculated white warts; white tubercles just posterior to cloaca. White parietal peritoneum covers anterior $50 \%-60 \%$ of venter; white pericardium; no iridophores in peritonea covering digestive tract, liver, kidneys, gall bladder, and urinary bladder.

Variation: In preservative, some individuals lack dorsal dark spots.
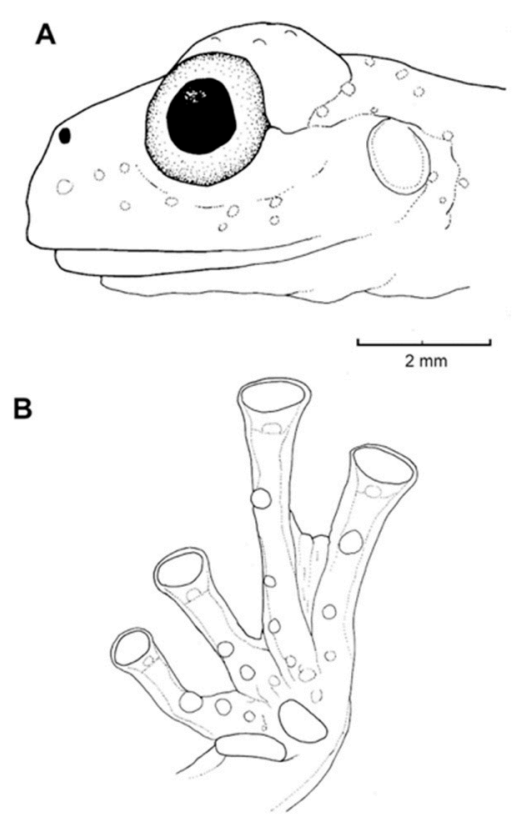

Figure 55. Centrolene pipilata, KU 143278, holotype. (A) Head in lateral view. (B) Hand in ventral view. Illustrations by Juan M. Guayasamin. 
Biology and ecology: All individuals have been found at night on vegetation along cascading mountain streams. In captivity, a female deposited a clutch of 18 eggs. Males call from the upper side of leaves. At Río Azuela, Centrolene pipilata was found in sympatry with Nymphargus anomalus, N. megacheirus, N. siren, and Hyalinobatrachium pellucidum. At 16.5 NNE of Santa Rosa, the species was found with Espadarana audax, N. megacheirus, and N. siren [22]. Eggs have clear jelly and pale green yolks [22]. Parental care is unknown.

Call: Not described.

Tadpole: Not described.

Distribution (Figure 56): Centrolene pipilata is endemic to the cloud forest on the Amazonian slope of the Ecuadorian Andes at elevations between 1300-1910 m ([17,22], this work). The species has been recorded from four localities in the provinces of Napo and Sucumbíos. The habitat of the species is within the Eastern Montane Forest region.

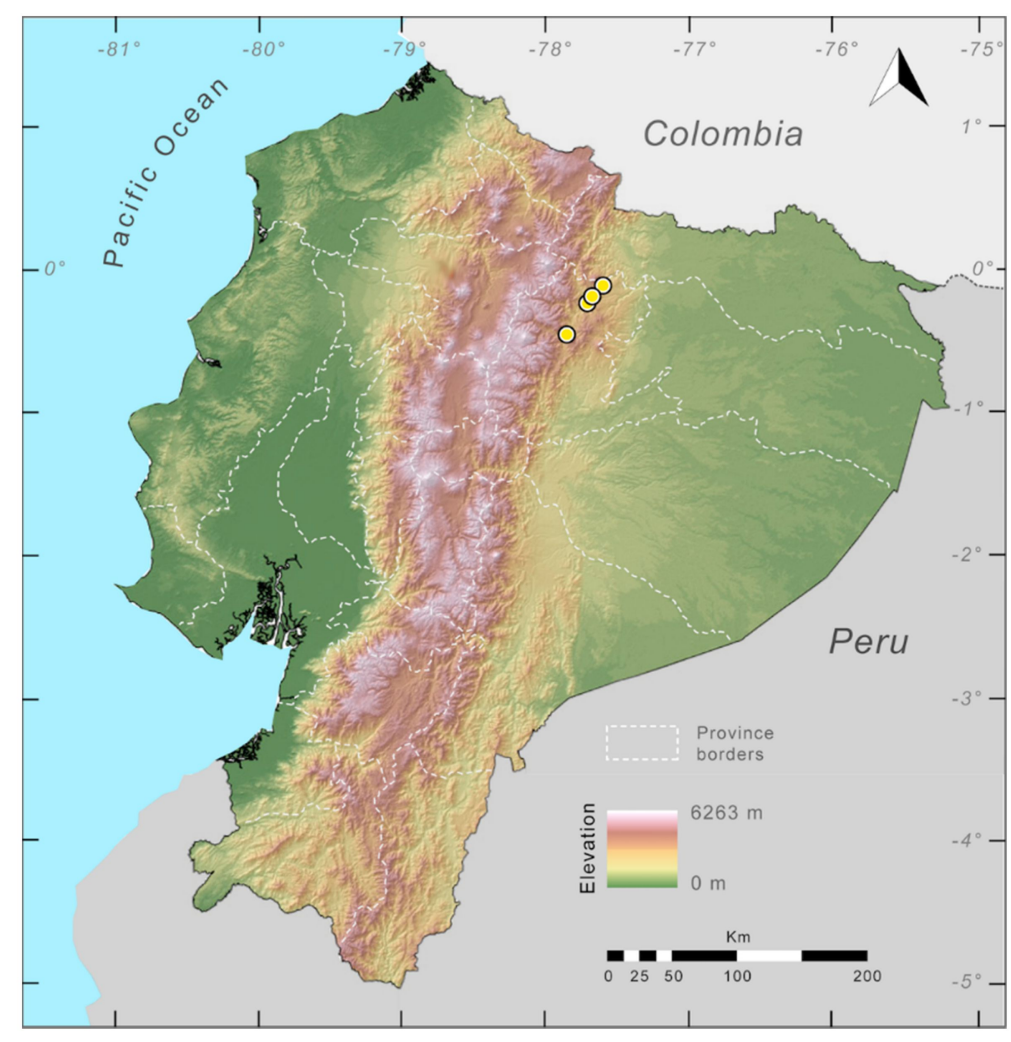

Figure 56. Distribution of Centrolene pipilata in Ecuador (yellow dots).

Conservation status: Globally, Centrolene pipilata is listed by the IUCN as Endangered [136] because of its limited distribution and the continuing decline in the extent and quality of suitable habitat. The last confirmed report of C. pipilata was at $14.7 \mathrm{~km}$ NE of Río Salado on February 1979 [17]. Recent surveys at Río Azuela [91] and the type locality (JMG, pers. obs.) have failed to find the species. In Ecuador, based on the IUCN criteria A2c,e, we suggest that the species should be considered as Critically Endangered.

Evolutionary relationships (Figure 24): Given the current taxon and gene sampling, Centrolene pipilata and C. hybrida are sister species.

Specimens examined: Centrolene pipilata: Ecuador: Provincia de Napo: $16.5 \mathrm{~km}$ NNE Santa Rosa (0.2186 S, 77.732 W, 1700 m), KU 143278-83, 143554; 3.2 km NNE Oritoyacu (0.4597 S, 77.8672 W; 1910 m), KU 178153; Río Azuela (0.11667 S, 77.61667 W; 1740 m), KU 143284-87, 155498, 166331; Río Salado, 1 km upstream from Río Coca (0.19167 S, 77.6997 W; 1420 m), KU 178154-55. 
Centrolene sanchezi Ruiz-Carranza and Lynch, 1991 [129] (Figures 57-61).

Centrolene sanchezi Ruiz-Carranza and Lynch, 1991 [129]. Holotype: ICN 24293.

Type locality: "Departamento de Caquetá, municipio de Florencia, vereda Gabinete, $3.1 \mathrm{Km}$ por carretera abajo del Alto Gabinete, vertiente oriental, Cordillera Oriental, $1^{\circ} 4^{\prime}$ latitud N, $75^{\circ}$ 4 ' W de Greenwich, 2190 m", Colombia.

Centrolene bacatum Wild, 1994 [137]. Holotype: KU 202803. Type locality: "11.2 km WSW Plan de Milagro $\left(03^{\circ} 02^{\prime} \mathrm{S}, 78^{\circ} 35^{\prime} \mathrm{W}, 2350 \mathrm{~m}\right)$, Provincia Morona Santiago, Ecuador". New synonymy.

Centrolene guanacarum Ruiz-Carranza and Lynch, 1995 [26]. Holotype: ICN 11686. Type locality: “Departamento del Cauca, municipio de Inzá, Km. 84 carretera Popayán a Inzá, Río Guanacas, quebrada afluente, Internado Indígena Río Guanacas, vertiente oriental Cordillera Central, $2^{\circ} 34^{\prime}$ Latitud N, 7605' W de Greenwich, 1800-1900 m”, Colombia. New synonymy.

"Centrolene" guanacarum-Guayasamin, Castroviejo-Fisher, Trueb, Ayarzagüena, Rada, and Vilà, 2009 [1]. New synonymy.

Centrolene bacata—Barrio-Amorós, Rojas-Runjaic, and Señaris, 2019 [85].

Common names: English: Sánchez's Glassfrog. Spanish: Rana de cristal de Sánchez.

Etymology: The specific epithet sanchezi honors Ricardo Sánchez, who, with John D. Lynch, discovered the species.

Identification: Centrolene sanchezi is easily distinguished from other glassfrogs by its minute body size (SVL 18.9-22.3 mm), green dorsum with small white spots, and the presence of white warts in an area that extends from below the eye to the insertion of the arm (Figures 57 and 58A). Additionally, adult males have conspicuous humeral spines. The only other centrolenid from eastern Ecuador that can be confused with Centrolene sanchezi is Centrolene pipilata, which has a green dorsum with small, diffuse black spots and yellowish-white flecks (Figure 54), and a distinct prepollex. Also, the two species occupy different elevations on the Amazonian slope of the Andes; $C$. sanchezi is found at elevations of 1950-2350 m, whereas C. pipilata occurs at 1420-1910 m.

Diagnosis: (1) Vomerine teeth absent; (2) snout rounded in dorsal aspect, bluntly rounded or truncated in lateral profile (Figure 58); (3) tympanum oriented almost vertically, its diameter $31.4 \%-37.8 \%$ of eye diameter; tympanic annulus visible except for dorsal border covered by supratympanic fold; tympanic membrane partially pigmented, but differentiated from surrounding skin; (4) dorsal surfaces shagreen, with small spicules evident in most males; (5) pair of enlarged subcloacal warts (Figure 15); (6) anterior half of ventral parietal peritoneum white, posterior half translucent (condition P2); white pericardium, translucent visceral peritoneum (condition V1); (7) liver tetralobed, lacking iridophores (condition H0); (8) humeral spines present in adult males; (9) no webbing between Fingers I and II; webbing formula on hand: II $2-3^{1 / 3} \mathrm{III} 2^{1 / 2}-2^{1 / 4}$ IV (Figure 58); (10) webbing formula on foot: I $1^{1 / 2}-2^{+}$ II $\left(1-1^{1 / 2}\right)-\left(2-2^{1 / 3}\right)$ III $1^{+}-\left(2^{+}-2^{1 / 4}\right)$ IV $2^{1 / 2}-\left(1-1^{+}\right) \mathrm{V}$ (Figure 58); (11) ulnar and inner tarsal folds low or absent; outer tarsal fold absent; (12) nuptial pad Type I, concealed prepollex; (13) Fingers I and II about equal in length (FII/FI $=91.3 \%-104.5 \%)$; (14) disc of Finger III of moderate size, about $40.3 \%-50.6 \%$ of eye diameter; (15) in life, dorsum dark green with small white spots (Figure 57); conspicuous white warts below the eye and tympanum; upper lip white; bones green; (16) in preservative, dorsum lavender with small white spots; (17) iris pale bronze with black reticulation; (18) melanophores mostly absent from fingers and toes, except for a few on Toes IV and V and on base of outer fingers; (19) males call from the upper side of leaves; calls are produced in series; each call has one or two notes, with a duration of 6-21 ms (mean $=11, \mathrm{SD}=2.8$ ); dominant frequency at peak amplitude is $5719-6188 \mathrm{~Hz}$ (mean = 5996, SD = 131); (20) fighting behavior unknown; (21) eggs deposited on upper side of leaves; short-term maternal care unknown; parental care by males absent; (22) tadpoles unknown; (23) minute body size, SVL $18.9-22.3 \mathrm{~mm}$ in males $(n=15) ; 20.9 \mathrm{~mm}$ in one female. 


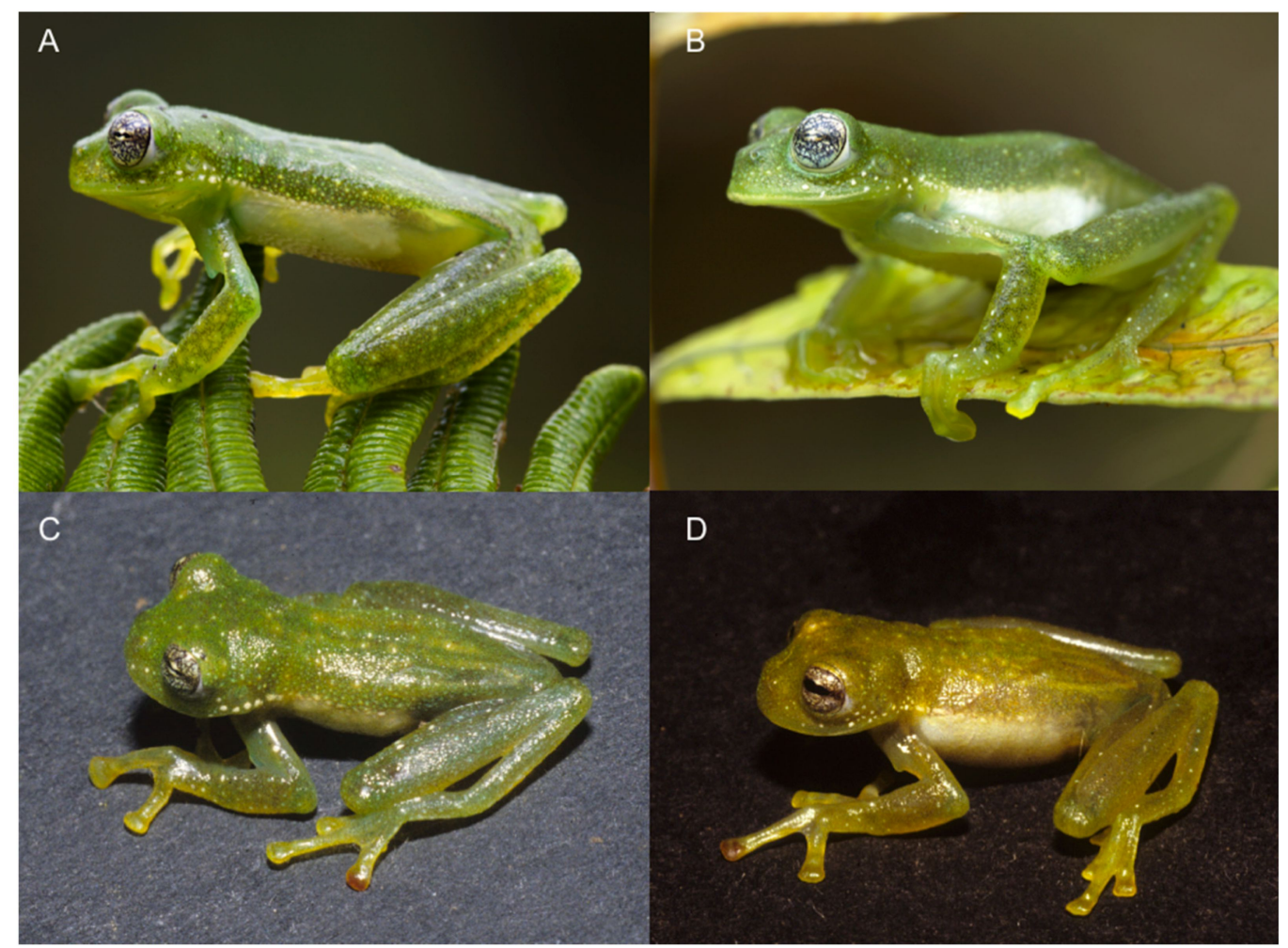

Figure 57. Centrolene sanchezi in life. (A,B) Male and female from Yanayacu Biological Station, Ecuador. (C) Holotype of C. sanchezi, ICN 24293. (D) Paratype of C. guanacarum, ICN 11685. Photos by A. Arteaga $(\mathbf{A}, \mathbf{B})$ and P. Ruiz-Carranza (C,D).

A
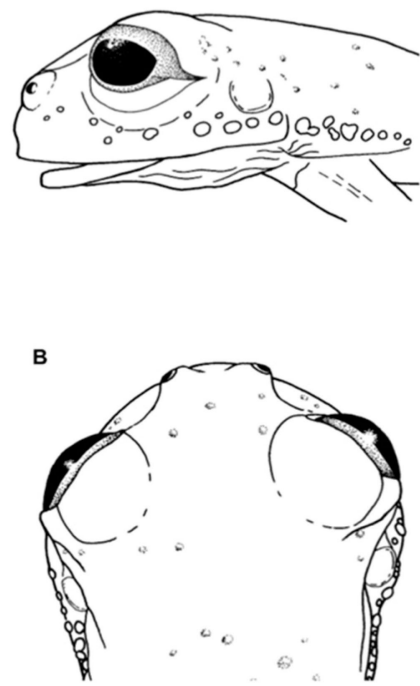

C

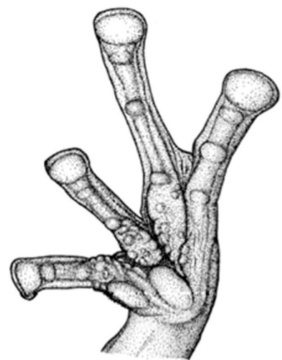

D

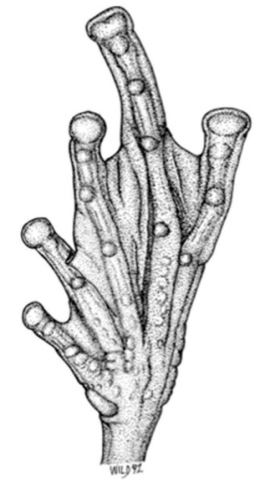

Figure 58. Centrolene sanchezi, KU 202803 (holotype of Centrolene bacata). (A) Head in lateral view. (B) Head in dorsal view. (C) Hand in ventral view. (D) Foot in ventral view. Drawings not to scale. Modified from Wild [137].

Color in life (Figure 57): Based on field notes by W. E. Duellman (4 March 1984), reported in Wild [137], and observation by authors. Dorsum dark green; series of white-cream tubercles under eye; 
throat and ventral surfaces of limbs green; digits pale green; cloacal region with white warts; ventral parietal peritoneum white anteriorly and translucent posteriorly; visceral peritoneum translucent; bones green; iris pale bronze with thin black reticulation.

Color in ethanol (Figure 59): Dorsal surfaces lavender with small, unpigmented spots and white warts; limbs cream lavender with numerous small, unpigmented spots and few white warts; white warts on lateral surface of head; upper lip white; tympanum pigmented with purple specks; cloacal region with white or cream warts; iris silvery white with dark purple reticulation. Fingers I and II and Toes I-III dorsally unpigmented; some pigmentation visible on Fingers III and IV, and Toes IV and V. White parietal peritoneum covering anterior half of venter, posterior half translucent; silvery-white pericardium; translucent peritonea covering liver, gastrointestinal track, and renal capsules (dissected male: QCAZ 22386).

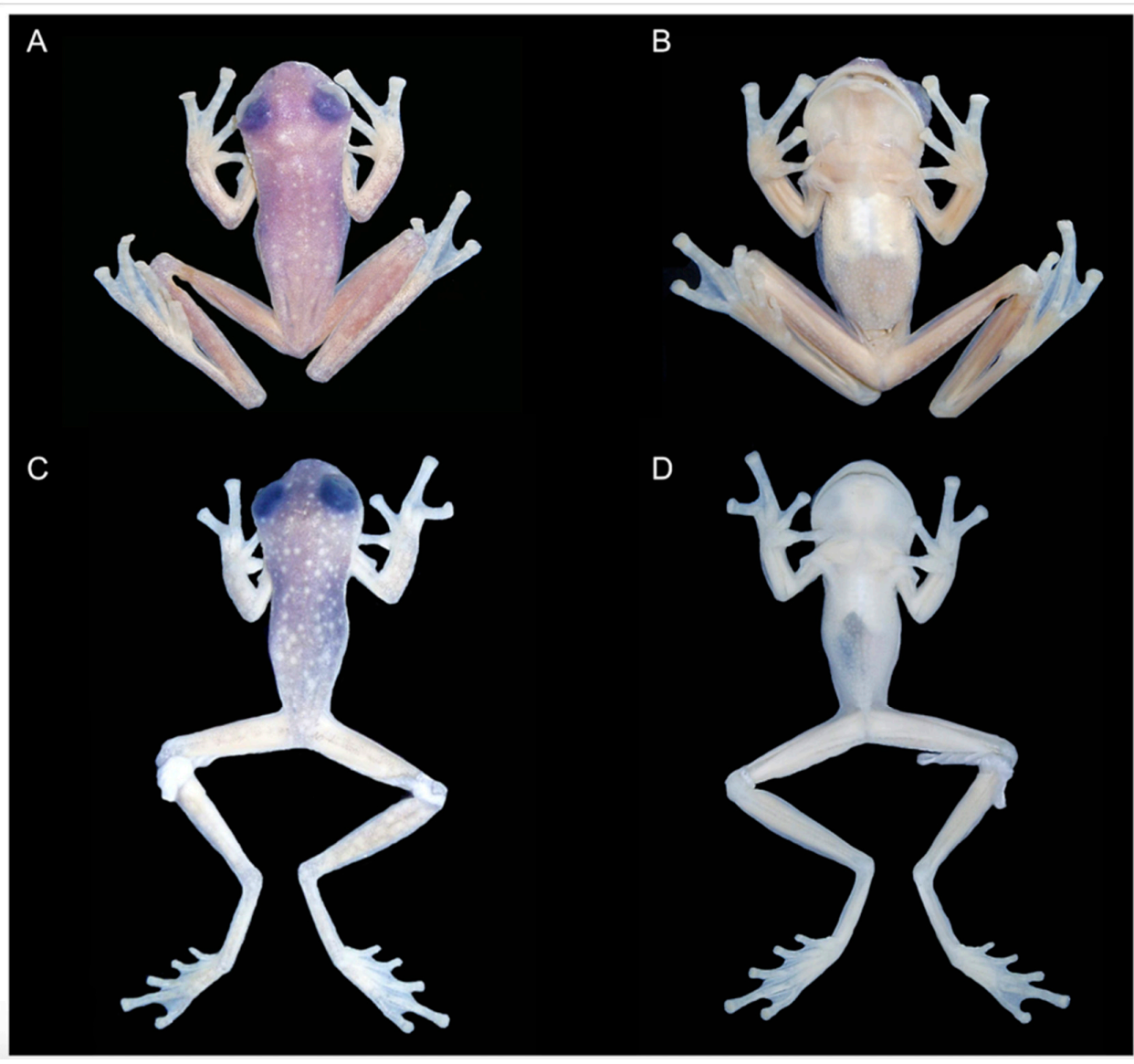

Figure 59. Types of Centrolene sanchezi and C. bacata in preservative. (A,B) Centrolene bacata, holotype KU 202803. (C,D) C. sanchezi, paratype ICN 24294. Photos by Juan M. Guayasamin.

Biology and ecology: During the night, Centrolene sanchezi has been found on leaves approximately 130-300 cm above streams in primary and secondary forest. Males call from the upper sides of leaves. A male (QCAZ 22728) was found nearby two egg clutches, one on the underside and the other on the upper side of a single leaf; egg clutches have 14-18 pale yellowish-green eggs. During February 2013, males have been heard calling at Yanayacu Biological Station. At this locality, Centrolene sanchezi (reported as C. bacata) is the most abundant centrolenid; other sympatric species at Yanayacu include Centrolene aff. buckleyi, C. huilensis, Nymphargus posadae, N. siren, and N. wileyi [20,125]. Short-term maternal care unknown; parental care by males absent ([25], as C. bacata).

Call (Figure 60): We analyzed 63 notes contained within 11 calls from 1 individual (LBE-C-023). Calls are produced in series, which can be relatively long (range $=618-3085 \mathrm{~ms}$, mean $=1462.6 \mathrm{~ms}$, 
$\mathrm{SD}=639.5 \mathrm{~ms}$ ); each can have one or two notes; note repetition rate is $3-9$ (mean $=5.7, \mathrm{SD}=1.6$ ) notes per call. Notes sometimes occur in pairs (i.e., much shorter note interval than compared to the rest of the call). Each call is very short, with a duration of 6-21 (mean $=11, \mathrm{SD}=2.8) \mathrm{ms}$. Notes are strongly pulsed and have one or two (mean $=1.4, \mathrm{SD}=0.5$ ) amplitude peaks throughout the note, where the second amplitude peak is generally weaker than the first. Pulses within a note have a rate of 83-200 $($ mean $=122, \mathrm{SD}=29)$ pulses per second. Notes have their peak amplitude in the first $50 \%$ of the note (relative peak time: Range $=0.0987-0.5497$, mean $=0.216, \mathrm{SD}=0.076$ ). The dominant frequency measured at peak amplitude is 5719-6188 (mean $=5996, \mathrm{SD}=131) \mathrm{Hz}$ and is contained within the fundamental frequency. The fundamental frequency has a lower limit of 4688-6000 (mean $=5714$, $\mathrm{SD}=222) \mathrm{Hz}$ and a higher limit of 5906-6656 (mean = 6268, SD = 144) Hz.

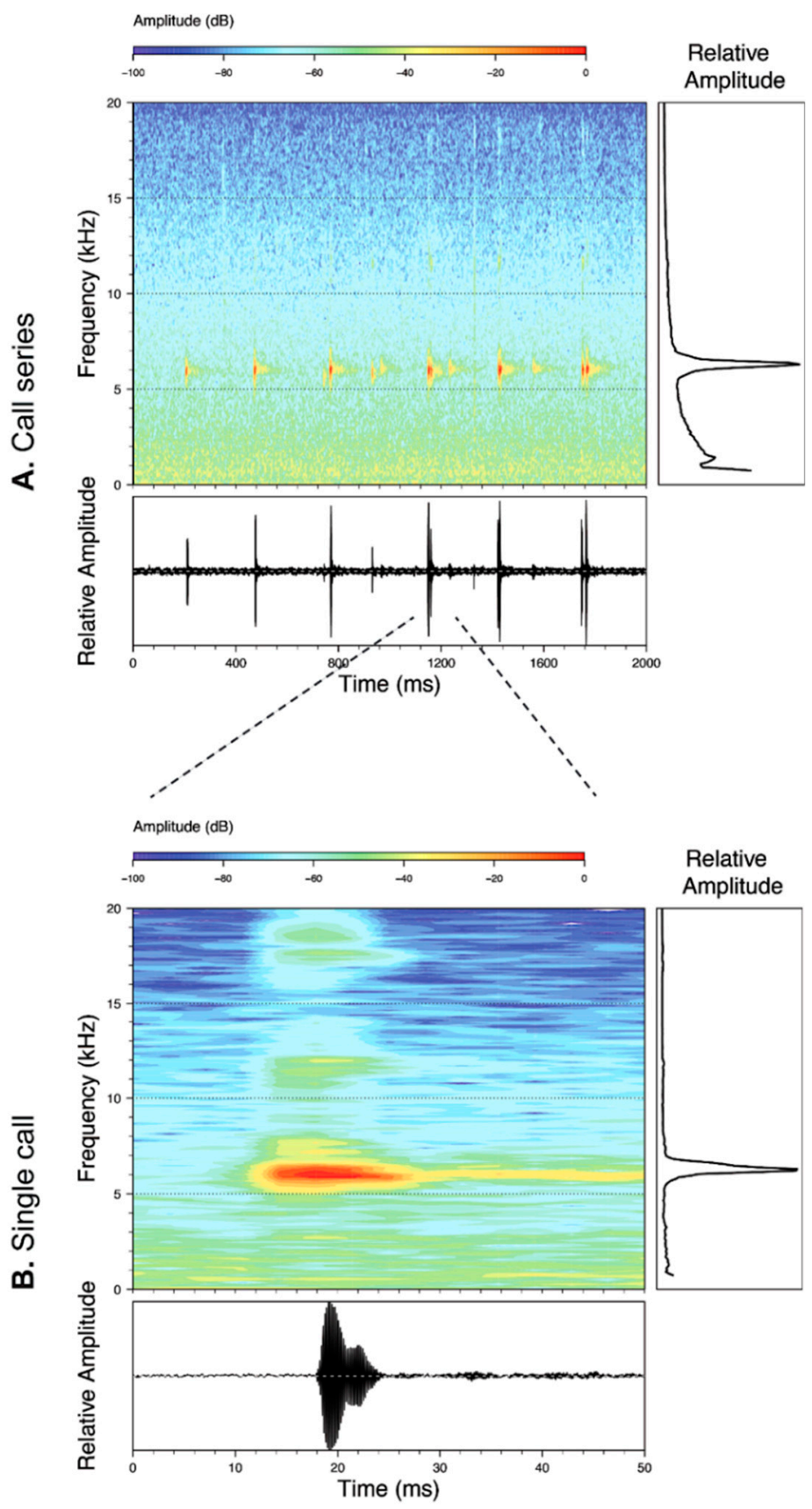

Figure 60. Call of Centrolene sanchezi (LBE-C-023), recorded at Reserva Yanayacu, 2150 m, Napo province, Ecuador. (A) Series of calls. (B) Single, pulsed call. 
Tadpole: Not described.

Distribution (Figure 61): Centrolene sanchezi is known from a few localities on the Amazonian slopes of the Andes of Ecuador and Colombia and from one locality on the eastern slope of the Colombian Cordillera Central (see Specimens Examined), at elevations between 1800 and 2350 m [20,101,129,137]. In Ecuador, the habitat of the species is within the Eastern Montane Forest region.

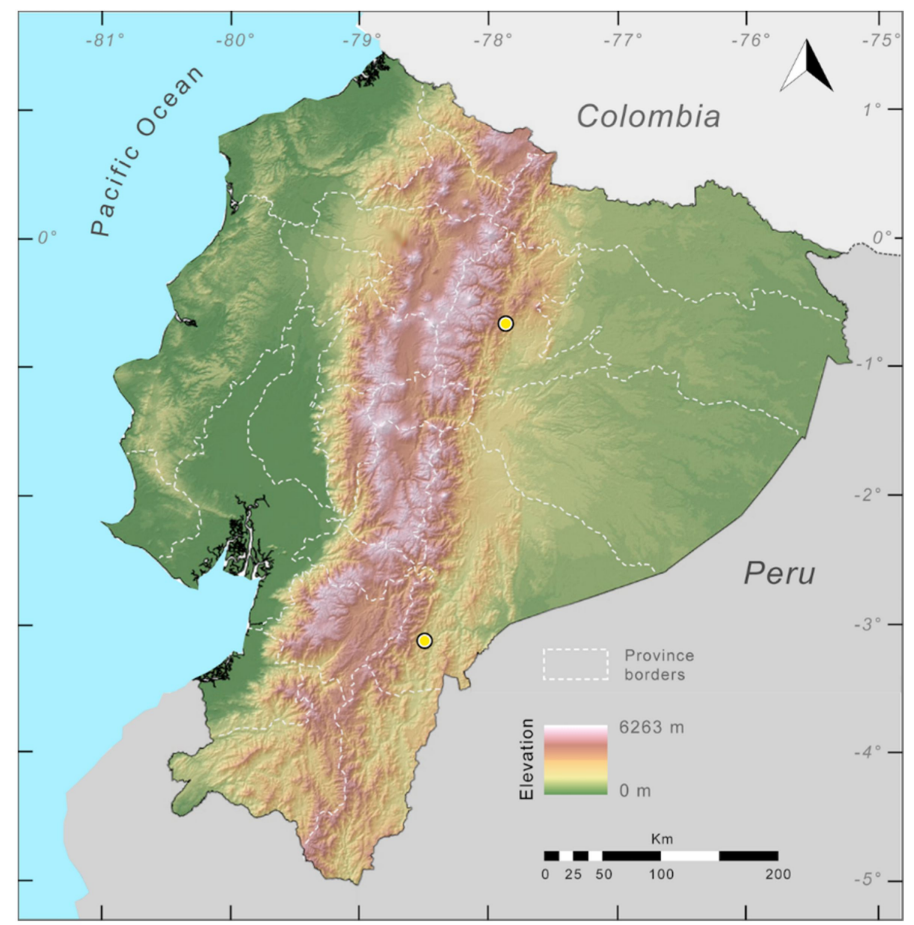

Figure 61. Distribution of Centrolene sanchezi in Ecuador (yellow dots).

Conservation status: Globally, Centrolene sanchezi is listed as Data Deficient by the IUCN [138], but the evaluation does not account for the synonym presented herein. The habitat of the species is fragmented by agriculture and pastureland and threatened by mining (mainly in southern Ecuador). We suggest that the species should be considered as Endangered, following IUCN criteria B2, Ba, Bb(iii).

Evolutionary relationships (Figure 24): Centrolene sanchezi is the sister species to a clade formed by C. pipilata plus C. hybrida. These three species are found on the Amazonian slopes of the Andes.

Taxonomic Remarks: Examination of the type material of Centrolene sanchezi, C. bacata, and C. guanacarum reveals no morphological differences among them. Moreover, all specimens share two distinctive traits; a small, laminar humeral spine in males and the presence of a lateral row of enameled warts that extends from below the eye to just posterior to the insertion of the arm (Figure 51). Therefore, we place Centrolene bacatum Wild 1994 [137] and Centrolene guanacarum Ruiz-Carranza and Lynch 1995 [26] under the synonymy of Centrolene sanchezi Ruiz-Carranza and Lynch, 1991 [129].

Specimens examined: Centrolene sanchezi: Ecuador: Provincia de Morona Santiago: $11.2 \mathrm{~km}$ WSW Plan de Milagro $\left(03^{\circ} 07^{\prime}\right.$ S, $78^{\circ} 30^{\prime}$ W; 2350 m), KU 202803 (holotype of Centrolene bacata), 202804, 202807-12 (paratypes of C. bacata); Provincia de Napo: Yanayacu Biological Station $\left(0^{\circ} 41^{\prime} \mathrm{S}, 77^{\circ} 53^{\prime} \mathrm{W}\right.$; 2100 m), QCAZ 16212, 17807, 22386-87, 22728, 26025-27, 26056, 27438. Colombia: Departamento de Caquetá: Municipio de Florencia, Vereda Gabinete, $3.1 \mathrm{Km}$ por carretera abajo del Alto Gabinete, vertiente oriental, Cordillera Oriental, $1^{\circ} 4^{\prime}$ latitud N, 75 $4^{\prime}$ W de Greenwich, 2190 m, ICN 24293 (holotype of C. sanchezi); Departamento del Cauca: Municipio de Inzá, Km. 84 carretera Popayán a Inzá, Río Guanacas, quebrada afluente, Internado Indígena Río Guanacas, vertiente oriental Cordillera Central, $2^{\circ} 34^{\prime}$ Latitud N, $76^{\circ} 05^{\prime} \mathrm{W}$ de Greenwich, 1800-1900 m, ICN 11685 (paratype of $C$. guanacarum). 
Genus Chimerella Guayasamin, Castroviejo-Fisher, Trueb, Ayarzagüena, Rada, \& Vilà, 2009 [1].

Etymology: The name Chimerella comes from the Greek Khimaira and the suffix-ella diminutive. In Greek mythology, the Chimera is a creature composed of parts of multiple animals; the name refers to the peculiar combination of morphological characteristics of Chimerella mariaelenae [1].

Chimerella mariaelenae (Cisneros-Heredia and McDiarmid, 2006 [139]; Figures 62-65).

Centrolene mariaelenae Cisneros-Heredia and McDiarmid, 2006 [139]. Holotype: DFCH-USFQ D125.

Type locality: "small stream, tributary of the Jambue River, ca. $16 \mathrm{~km} \mathrm{~S}$ from Zamora, Podocarpus National Park (ca. $04^{\circ} 15^{\prime} \mathrm{S}, 78^{\circ} 56^{\prime} \mathrm{W}, 1820 \mathrm{~m}$ ), on the western slope of Contrafuerte de Tzunantza, Cordillera Oriental, eastern slopes of the Andes, Provincia de Zamora Chinchipe, Republic of Ecuador".

Cochranella parabambae (in part)—Goin, 1961 [97].

Chimerella mariaelenae-Guayasamin, Castroviejo-Fisher, Trueb, Ayarzagüena, Rada, and Vilà, 2009 [1].

Common names: English: María Elena's Glassfrog. Spanish: Rana de Cristal de María Elena.

Etymology: The specific epithet mariaelenae is a noun in the genitive case and a patronym for María Elena Heredia, Diego F. Cisneros-Heredia's mother [139].

Identification: Chimerella mariaelenae (Figures 62 and 63), Chimerella corleone, and Vitreorana gorzulae are the only known glassfrog that have the following combination of traits: Humeral spine in adult males, transparent ventral parietal peritoneum, and white pericardial, hepatic, and visceral peritonea. Vitreorana gorzulae, an endemic to the Guiana Shield, is distinguished by lacking dark spots on the dorsum (present in C. mariaelenae). Chimerella mariaelenae is easily differentiated from the Peruvian C. corleone by having an orange to reddish iris (silvery white in C. corleone) and a dorsum with small black dots (dorsum with yellow dots in C. corleone [19]). On the Amazonian slopes of Ecuador, only species in the genus Hyalinobatrachium and Teratohyla amelie could be confused with C. mariaelenae. However, these species lack the small dark spots that characterize the dorsum of C. mariaelenae. Additionally, adult males of $C$. mariaelenae have small humeral spines, which are absent in all Hyalinobatrachium species and Teratohyla amelie.

Diagnosis: (1) Vomers lacking teeth; (2) snout truncated in dorsal aspect, truncated to slightly protruding in lateral profile (Figure 63); (3) tympanum oriented posterolaterally with slight dorsal inclination, its diameter $23.0 \%-27.4 \%$ of eye diameter; tympanic membrane translucent, clearly differentiated from surrounding skin; (4) dorsal skin shagreen; males with minute dorsal spicules (only visible under magnification $\times 250$ ); (5) pair of enlarged subcloacal warts; (6) ventral parietal peritoneum transparent (condition $\mathrm{P} 0$ ); iridophores in pericardium and peritonea covering digestive tract and testes; kidneys and urinary bladder lacking iridophores (condition V5); (7) liver bulbous and covered by iridophores (condition H2); (8) males with small humeral spines; (9) webbing absent or basal between inner fingers, moderate between outer fingers (Figure 63); webbing formula IV $\left(2^{+}-2^{1 / 2}\right)-\left(2^{+}-2^{1 / 2}\right)$ $\mathrm{V}$; (10) webbing between toes extensive; webbing formula on foot I $\left(1^{1 / 2}-2^{-}\right)-\left(2-2^{1 / 2}\right)$ II $1-2^{+}$III $\left(1^{+}-1^{1 / 2}\right)-\left(3^{-}-3^{+}\right)$IV $\left(2^{1 / 2}-3^{1 / 4}\right) —\left(1^{+}-1^{1 / 4}\right) \mathrm{V}$; (11) ulnar and tarsal folds absent; (12) concealed prepollex; nuptial pad Type I; (13) Finger I slightly longer than Finger II (Finger II length 95.6\%-97.3\% of Finger I); (14) disc of Finger III relatively narrow, its width about $22.3 \%-25.7 \%$ of eye diameter; (15) in life, dorsum yellowish green with small grey to black spots (Figure 62); bones light green; (16) in preservative, dorsum pale lavender with small, dark, lavender spots; (17) in life, iris white with abundant dark flecks, pupil surrounded by a rufous to orange ring, outlined by a dark grey to blue ring (Figure 62); (18) dorsal surfaces of fingers and toes lacking melanophores, except for some on base of Toe V; (19) males 
call from the upper surface of leaves; typical call with two notes; each note extremely short at 4-7 (mean $=6, \mathrm{SD}=0.9) \mathrm{ms}$; dominant frequency measured at peak amplitude is 6718-8010 (mean = 7510, $\mathrm{SD}=408) \mathrm{Hz}$; (20) fighting behavior unknown; (21) eggs laid on the upper surfaces of leaves; short-term maternal care present; parental care by males absent; (22) tadpoles with elongated body, head with dorsoventral compression; labial tooth row formula $2(1)(2) / 3$; 23 ) minute body size; adult males, SVL 17.9-19.7 mm ( $n=3)$; one adult female SVL $20.8 \mathrm{~mm}$.

Color in life (Figure 62): Dorsal surfaces yellowish green, with several grey to black spots. No white coloration is evident on upper lip or ulnar and tarsal regions. Iris bicolored, with dark brown circumpupilar area separated from pupil by orange to red-brown ring; whitish external background with abundant dark flecks on uppermost and lowermost portions of iris. Venter completely transparent (clear ventral parietal peritoneum), showing white heart (covered by white pericardium); white digestive tract, liver, testes, and gall bladder. Transparent peritoneum covering urinary bladder. Bones white to light green.

Color in ethanol: Dorsal surfaces of head, body, and limbs pale lavender, with small dark lavender spots. Ventral parietal peritoneum and kidneys lack iridophores. White pericardial, hepatic, and visceral peritonea.

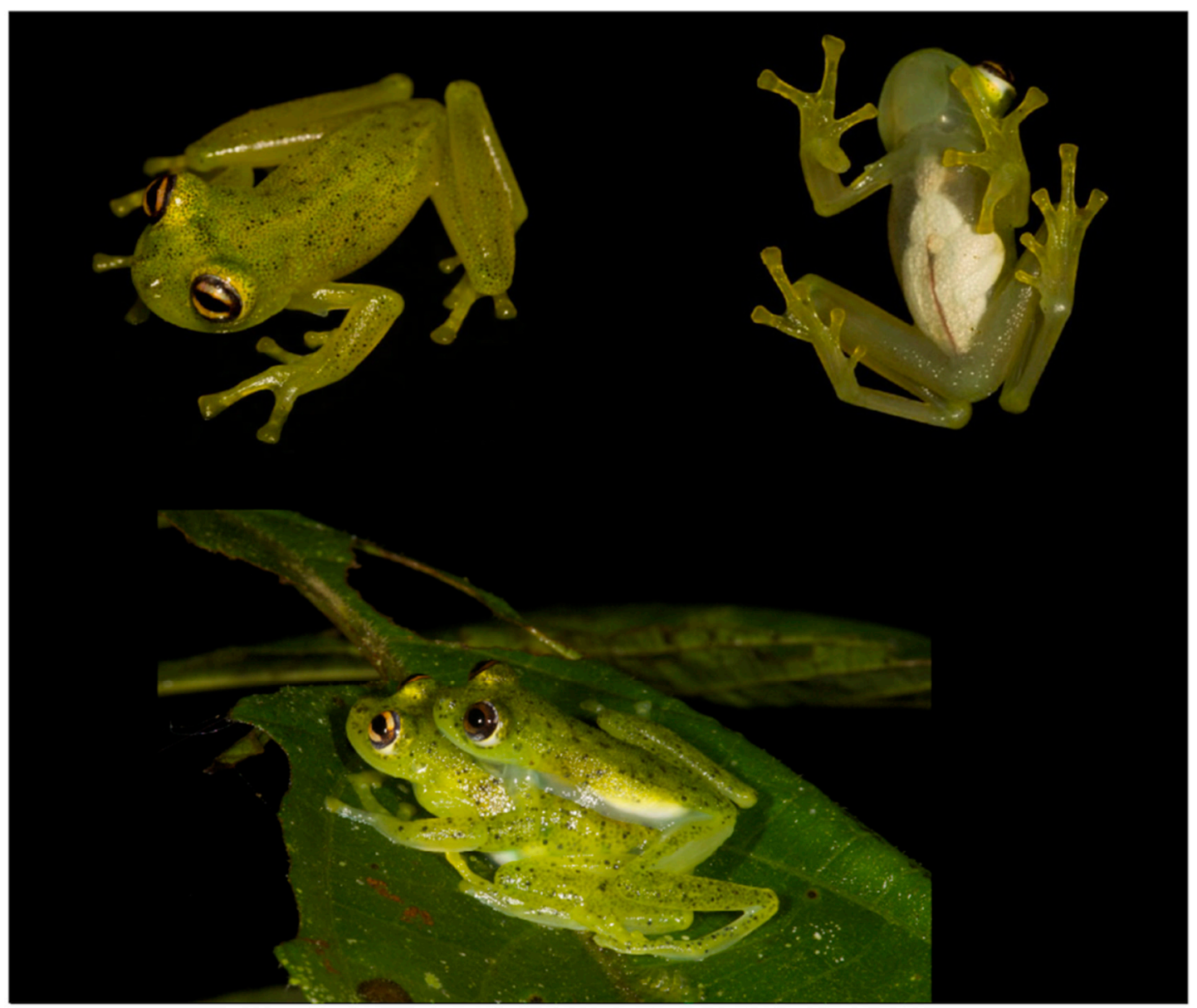

Figure 62. Chimerella mariaelenae in life. (Top row): Adult male from Bigal River Biological Station, 931 m, Ecuador; photos by Ross Maynard. (Bottom row): Amplectant pair, Quebrada Pangayaku, 930 m, Napo province, Ecuador, MZUTI 1680-81; photo by Eduardo Toral. 
A
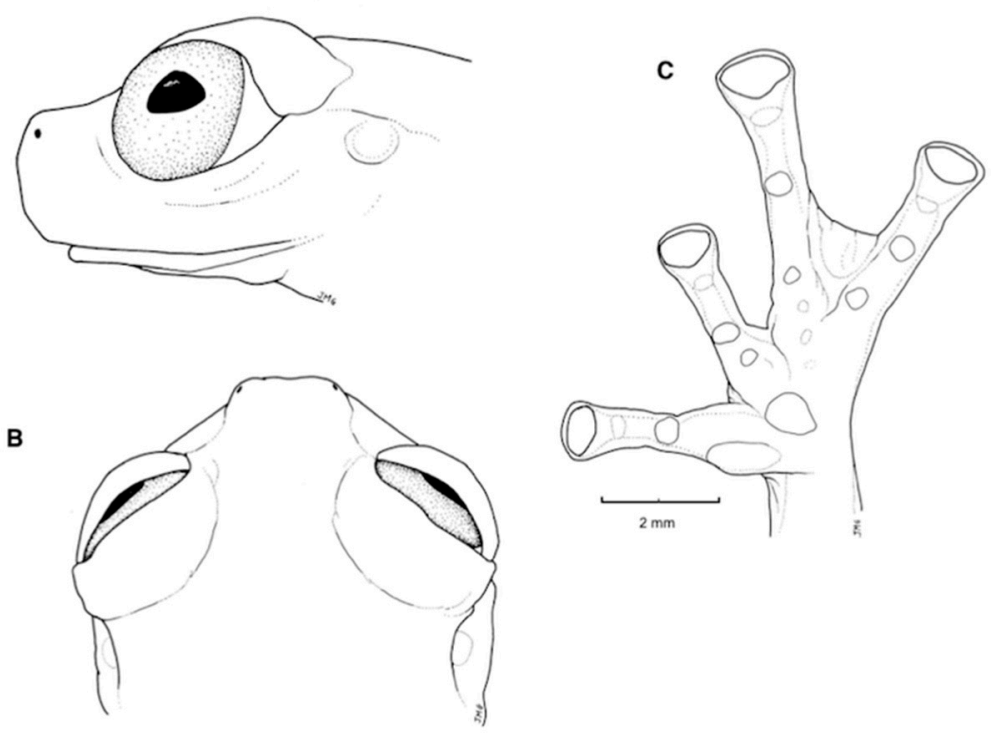

Figure 63. Chimerella mariaelenae. (A) Head in lateral view, QCAZ 31729. (B) Head in dorsal view, QCAZ 21252. (C) Hand in ventral view, QCAZ 22363. Illustrations by Juan M. Guayasamin.

Biology and ecology: The biology of Chimerella mariaelenae is poorly known. All individuals have been found on the upper surfaces of leaves along small streams and ditches in cloud forest. At the type locality, C. mariaelenae is sympatric with Nymphargus cochranae and Hyloscirtus phyllognathus [139]. Reproductively active individuals have been observed nearby Cascada San Rafael in Quebrada Pangayacu in August 2012. Short-term maternal care present; parental care by males absent [25].

Tadpole: The following information is summarized from Terán-Valdez and Guayasamin [140] and is based on a specimen at Gosner Stage 39 raised in laboratory conditions. Body elongated and oval-depressed, wider (body width $=5.1 \mathrm{~mm}$ ) than higher (body height $=3.8 \mathrm{~mm}$ ). Chondrictial elements not visible. Snout rounded in dorsal and lateral views. Lateral line system visible, formed by several stitches parallel or perpendicular to longitudinal axis of body. Short, single, sinistral spiracle located at posterolateral region of body; spiracular aperture with dorsoposterior orientation, with inner wall present as a low ridge. Vent tube short and abdominal, free posteriorly, opening directed posteriorly. Tail long, with subacute tip. Myotomes visible throughout length of tail; straight medial line visible, separating dorsal and ventral myotomes. Dorsal fin originating at about mid-length of tail; height relatively uniform until distal end, where it decreases abruptly. Proximally, ventral fin originating at base of tail muscle, reaching its maximum height after mid-length of tail. Oral disc non-emarginated and surrounded by 49 marginal uniserial papillae. Only ventral and lateral papillae present, lacking dorsal papillae. Upper and lower jaw sheaths nearly straight and fully keratinized, with serrated edge. Labial tooth row formula 2(1)(2)/3; gap in tooth row A-1 could be artificial (because of teeth loss). In life, dorsally, tadpoles at Stage 39 brownish with two areas without pigmentation at anterolateral border of eye. Reddish coloration visible on anterior half of dorsum because of its transparency. Anterior-most part of head is grey. Iridophore aggregations present on dorsum, along vertebral column. Iris bronze. Ontogenetic variation is provided in Terán-Valdez and Guayasamin [140].

Call (Figure 64): We analyzed 26 notes contained within six calls from one individual (LBE-C-021). The typical advertisement call is variable from being short to a moderate length call (range $=231-1761 \mathrm{~ms}$, mean $=679 \mathrm{~ms}, \mathrm{SD}=623.3 \mathrm{~ms}$ ). The typical call has two notes, but some call can have up to 10 $($ mean $=4.3, \mathrm{SD}=3.4)$ notes. Each note is extremely short at $4-7($ mean $=6, \mathrm{SD}=0.9) \mathrm{ms}$. Notes have a single amplitude peak. The dominant frequency measured at peak amplitude is 6718-8010 (mean $=7510$, $\mathrm{SD}=408) \mathrm{Hz}$ and is contained within the fundamental frequency. The fundamental frequency has a lower limit of 6460-7752 (mean $=7222, \mathrm{SD}=387) \mathrm{Hz}$ and a higher limit of 7063-8441 $($ mean $=7828$, $\mathrm{SD}=398) \mathrm{Hz}$. 

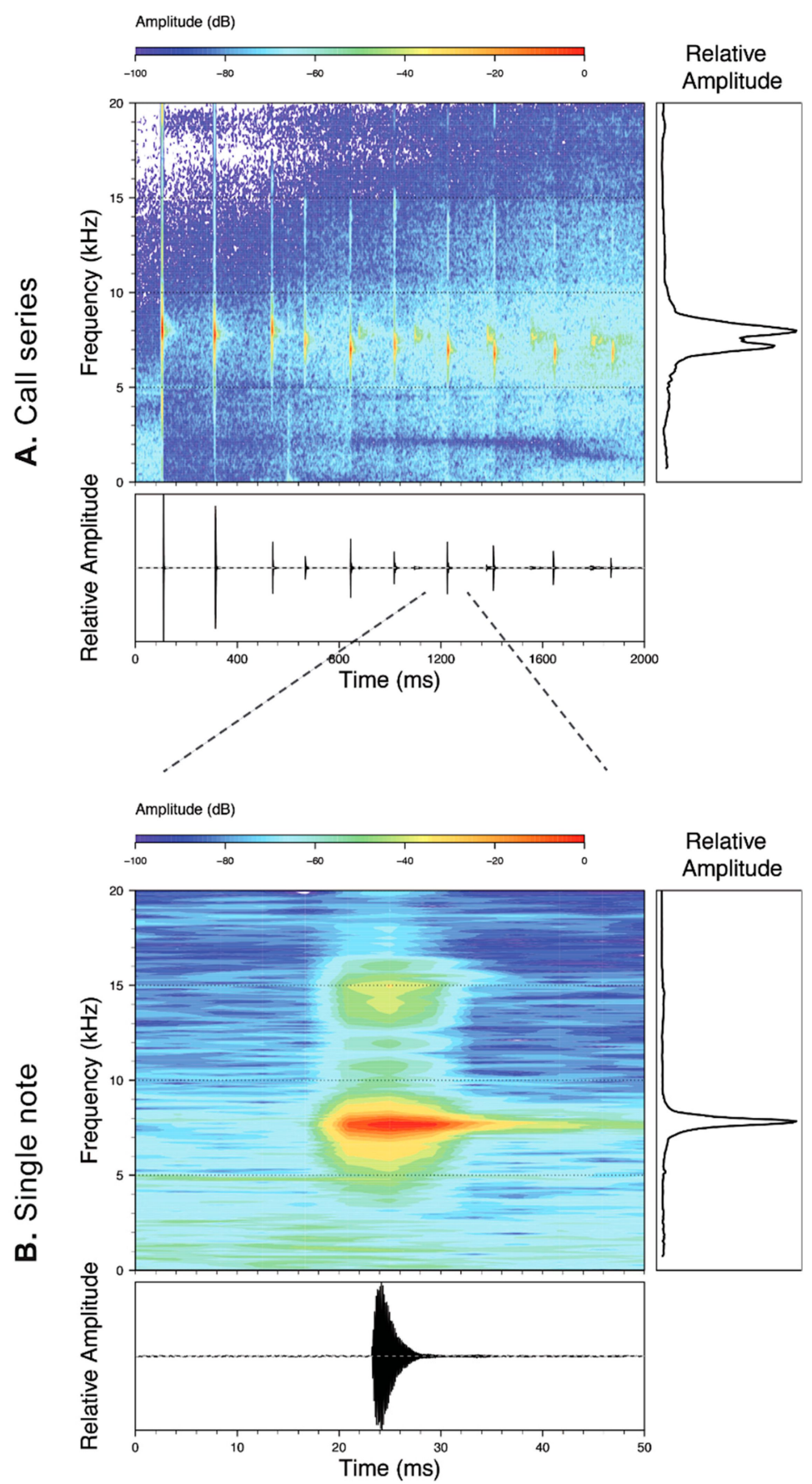

Figure 64. Call of Chimerella mariaelenae (LBE-C-021), recorded at Pangayaku creek, 929 m, Napo province, Ecuador. (A) Series of calls. (B) Single, pulsed note.

Distribution (Figure 65): Chimerella mariaelenae occurs on the Amazonian slopes of the Ecuadorian Andes at elevations between 813 and $1820 \mathrm{~m}$ ([139,141,142], this work), and was recently reported from Peru [143]. The species is known from a few localities in the provinces of Napo, Morona Santiago, Orellana, Tungurahua, and Zamora Chinchipe (Specimens Examined). The potential distribution of the species is $25,472 \mathrm{~km}^{2}$ within the Eastern Foothill and Montane Forest regions. 


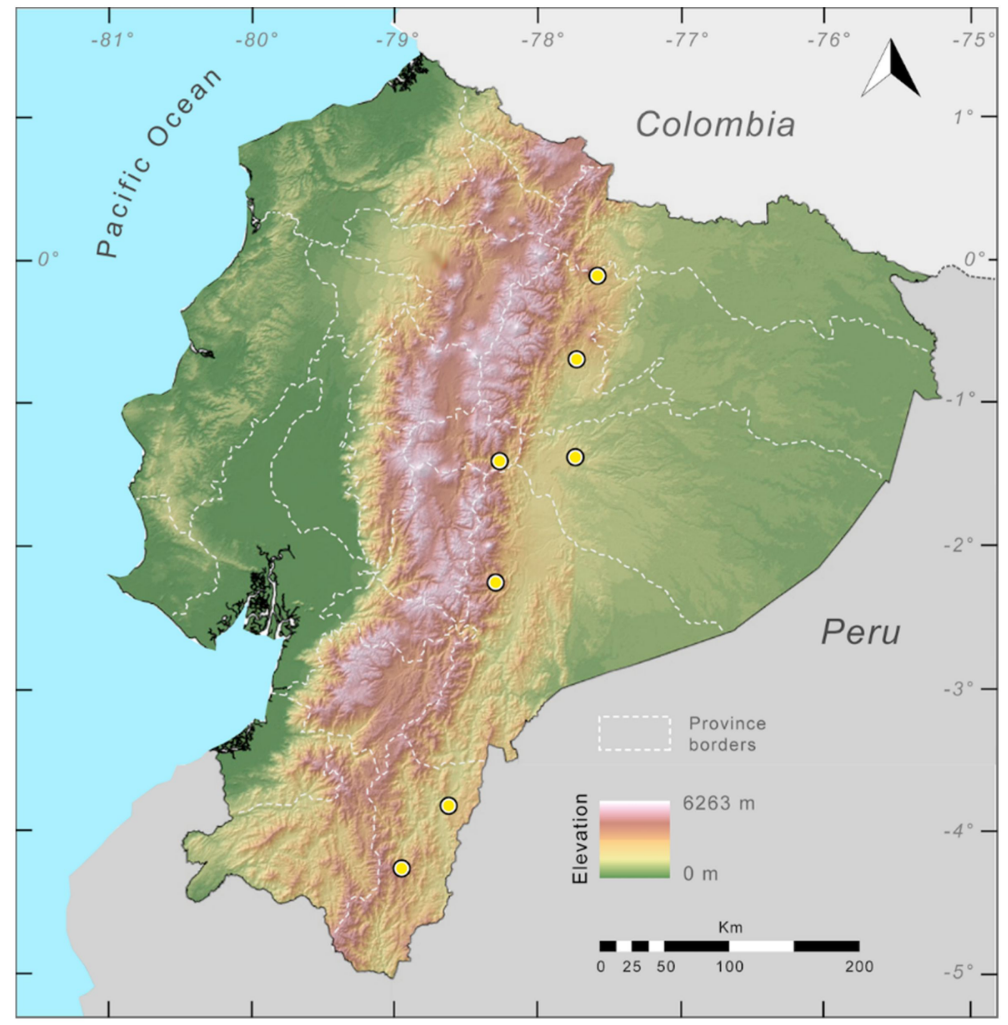

Figure 65. Distribution of Chimerella mariaelenae in Ecuador (yellow dots).

Conservation status: Globally, Chimerella mariaelenae is currently listed as Least Concern by the IUCN [144]. The species is threatened by human activities, although it tolerates some habitat disturbance and has a relatively large distribution, including populations within protected areas (i.e., Bigal River Biological Station, Parque Nacional Podocarpus, Parque Nacional Sangay, Reserva Ecológica Cayambe-Coca, Reserva Narupa). In Ecuador, major threats for the species include deforestation and mining; thus, we suggest that the species should be considered as Near Threatened at the local level.

Evolutionary relationships (Figures 19 and 66): In the original description and based on morphological data, Chimerella mariaelenae was assigned to the Centrolene gorzulai group, which, otherwise, consisted of species from the Guiana Shield. Under this hypothesis, the distribution of C. mariaelenae was thought to support a biogeographical connection between the Andes and the Guiana Shield [139]. Subsequently, Cisneros-Heredia and McDiarmid [17], based on differences in the chromatophore organization, considered that the relationships of $C$. mariaelenae were uncertain. Phylogenetic trees based on molecular data show that Chimerella mariaelenae and C. corleone are sister species [19] (Figure 66); both species are restricted to the Amazonian versant of the Andes, with no close relationship with species from the Guiana Shield. The genus Chimerella is herein inferred as sister to Espadarana (Figure 19), but with low nodal support. 


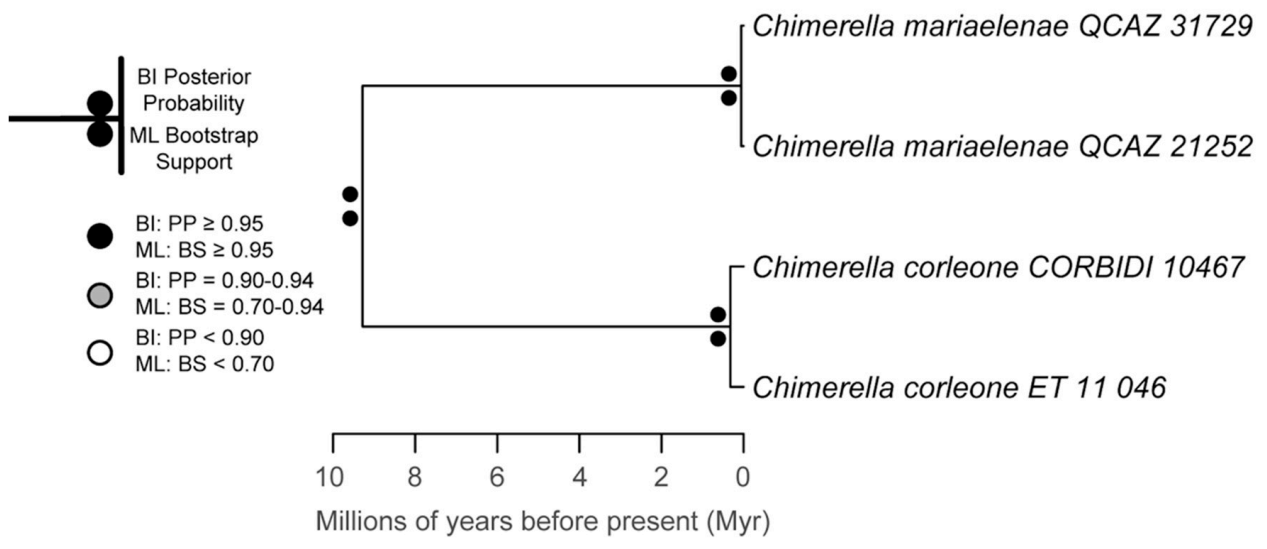

Figure 66. Evolutionary relationships between species in the genus Chimerella, inferred using maximum likelihood and Bayesian criteria.

Remarks: One of the specimens reported by Goin [97] as Centrolenella parabambae from the Topo River is an adult female Chimerella mariaelenae.

Specimens examined: Chimerella mariaelenae: Ecuador: Provincia de Napo: Río Hollín (ca. $00^{\circ} 58^{\prime} \mathrm{S}$, $77^{\circ} 45^{\prime} \mathrm{W}$, ca. $\left.1400 \mathrm{~m}\right)$, QCAZ 18618-19, 22363. Quebrada Pangayaku (0.78255 S, $\left.77.791 \mathrm{~W}, 929 \mathrm{~m}\right)$, MZUTI 1680-81; Reserva Narupa (0.684 S, 77.741 W, 1179-1208 m), ZSFQ 0437-38; Reserva Narupa (0.671 S, 77.774 W, $1502 \mathrm{~m}$ ), ZSFQ 0439-41. Provincia de Morona Santiago: $6.7 \mathrm{~km} \mathrm{~W}$ of 9 de Octubre $\left(02^{\circ} 13^{\prime} 30.5^{\prime \prime} \mathrm{S}, 78^{\circ} 17^{\prime} 25.6^{\prime \prime} \mathrm{W}, 1715 \mathrm{~m}\right)$, QCAZ 32643. Provincia de Tungurahua: near Río Negro $\left(01^{\circ} 24^{\prime} \mathrm{S}\right.$, $78^{\circ} 15^{\prime}$ W, $1423 \mathrm{~m}$ ), on the Río Negro-Río Verde road, QCAZ 21252, 31729; Río Topo, BM 1912.11.1.69. Provincia de Zamora Chinchipe: stream tributary of the Río Jambue (ca. $4^{\circ} 15^{\prime} \mathrm{S}, 78^{\circ} 56^{\prime} \mathrm{W}$, ca. $1820 \mathrm{~m}$ ), ca. $16 \mathrm{~km} S$ from Zamora, Parque Nacional Podocarpus, DFCH-USFQ D125; gravel road E to Sarsa (3.80783976 S, 78.60593076 W; 1500 m), QCAZ 47053.

Photographic records: Provincia de Orellana: Reserva Río Bigal (0.532913오 S, 77.423228 W; $981 \mathrm{~m})$. Photo by Morley Read.

Genus Cochranella Taylor, 1951 [15].

Etymology: Named in honor of Doris M. Cochran, herpetologist and curator of the Smithsonian Institution, Washington, D.C.

Cochranella granulosa (Taylor, 1949 [145]; Figures 67 and 68).

Centrolenella granulosa Taylor, 1949 [145]. Holotype: FMNH 178269.

Type locality: “Los Diamantes, one mile south of Guápiles, (Cantón de Pococí, Provincia Limón), Costa Rica".

Cochranella granulosa-Taylor, 1951 [15].

Common names: English: Granular Glassfrog. Spanish: Rana de Cristal Granulosa.

Etymology: The specific epithet granulosa comes from the Latin word granum (grain), in allusion to the granular dorsal skin texture of the species.

Identification: Cochranella granulosa can be distinguished from most glassfrogs by having a dark green to bluish-green dorsum with whitish granules and faint to well-defined dark spots (Figure 67), yellowish-green hands and feet, a reduced white ventral parietal peritoneum (which covers less than 
$40 \%$ of the venter), white digestive tract, and by lacking humeral spines. Another distinctive trait is the granular texture of its dorsal skin. Species that might have a sympatric distribution with C. granulosa and that present a similar dorsal coloration include Cochranella litoralis and some populations of Espadarana prosoblepon. However, C. granulosa has a granular skin (shagreen in E. prosoblepon and C. litoralis) and lacks humeral spines (present in males of E. prosoblepon and C. litoralis). Also, C. litoralis has an orange to red iris (yellow to golden in C. granulosa) and E. prosoblepon has a digestive tract that lacks white iridophores (present in C. granulosa).

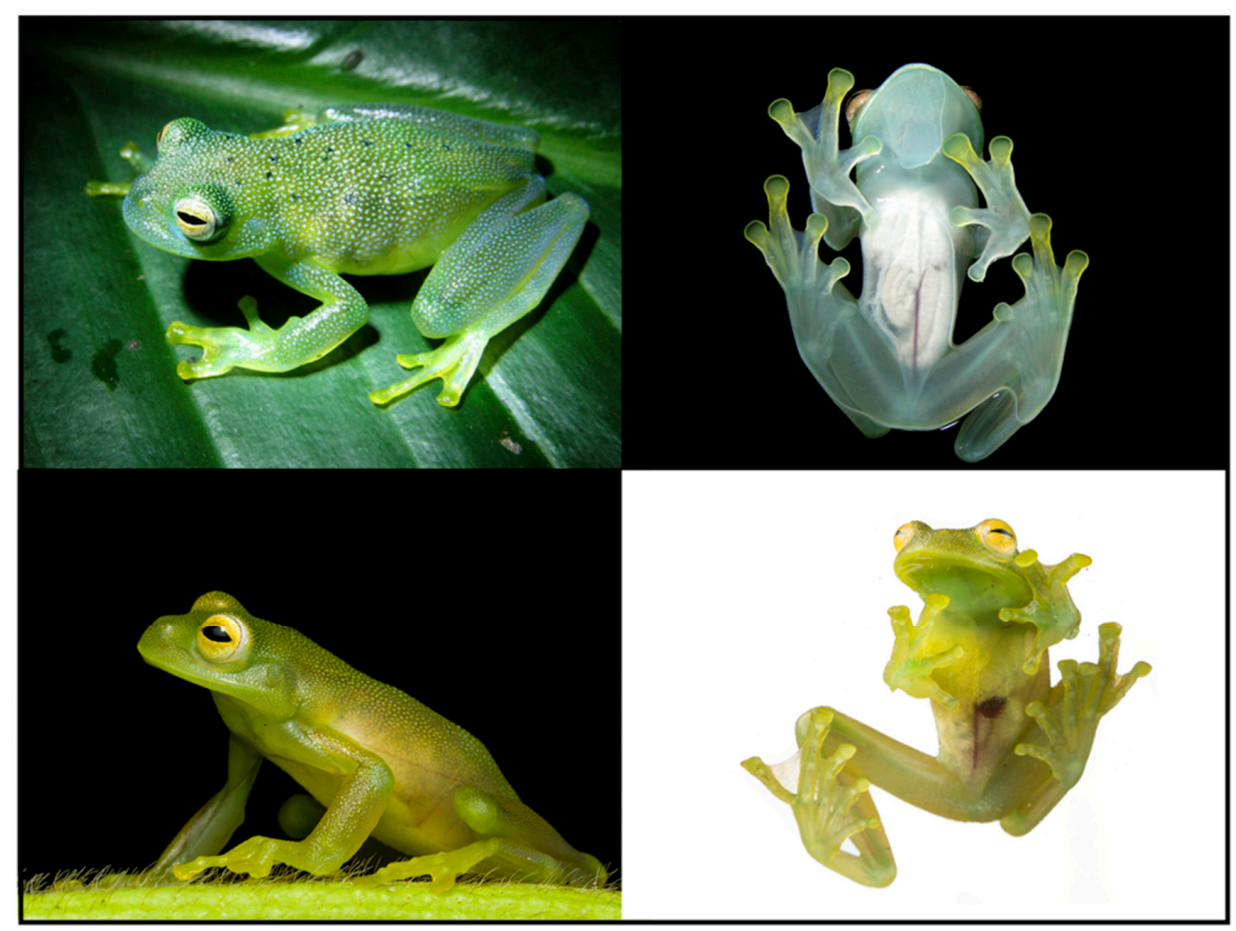

Figure 67. Cochranella granulosa in life. (Top row): Reserva Guayacán, Costa Rica; photos by Brian Kubicki. (Bottom row): Reserva El Jardín de los Sueños, 461 m, Cotopaxi province, Ecuador, MZUTI 4811; photos by Jaime Culebras (dorsolateral) and Javier Aznar (ventral).

Diagnosis: (1) Vomerine teeth present, each vomer with one to three teeth; (2) snout truncated in dorsal aspect, slightly sloping in lateral profile; (3) tympanum oriented dorsolaterally, with slight posterior inclination, its diameter about $35 \%$ of eye diameter; tympanic annulus visible, low supratympanic fold evident, tympanic membrane partially pigmented and clearly differentiated from surrounding skin; (4) dorsum granular, lacking spicules; (5) venter areolate, lacking pair of enlarged subcloacal warts; (6) white lining on the anterior $20 \%-40 \%$ of the ventral parietal peritoneum (condition P1); peritoneum with white iridophores covering digestive tract (condition V2); (7) liver tetralobed; hepatic peritoneum lacking iridophores (condition H0); (8) humeral spines absent; (9) webbing absent between Fingers I-II, vestigial to moderate between Fingers II-III, extensive between III-IV; webbing formula on hand: II $\left(1^{+}-2\right)-\left(3-3^{+}\right)$III $\left(1^{1 / 3}-2^{1 / 2}\right)-\left(1-2^{+}\right)$IV; $(10)$ webbing on foot extensive, formula: I $0^{+}-1^{1 / 2}$ II $0^{+}-1^{2 / 3}$ III $\left(1-1^{+}\right)-2^{-}$IV $2-1^{-} \mathrm{V}$; (11) ulnar fold low; inner and outer tarsal folds low and thin; (12) concealed prepollex; nuptial pad Type I; (13) Finger I about same length as Finger II; (14) disc of Finger III narrow, about 40\% of eye diameter; (15) in life, dorsum dark green to bluish green with fine, yellowish-white granules and faint to clearly marked dark spots (Figure 67); bones green; (16) in preservative, dorsum cream to light lavender with faint to clearly defined dark spots; (17) iris yellow to golden with few, faint brownish streaks; (18) melanophores absent from dorsal surfaces of hands and toes; (19) males call from the upper side of leaves; each call consists of three to five notes, the first note being slightly longer that the others; average duration for a three-note call is $0.8-0.9 \mathrm{~s}$; dominant frequency at $3700 \mathrm{~Hz}$; (20) males fight venter to venter, hanging from the vegetation by the tips of their 
toes; (21) dark egg are placed on the upper sides of leaves; short-term maternal care present; parental care by males absent; (22) tadpoles with a flattened body and slender tail; tadpole in early stages have a brown pigmentations that is lost in older, red larvae; jaw sheaths are strongly serrated, the upper jaw forms a smooth M-shape; the lower sheath is V-shaped; labial tooth row formula 2/3; (23) medium body size; in males, SVL $22.5-29.0 \mathrm{~mm}$; in females, SVL $29-32 \mathrm{~mm}$.

Color in life (Figure 67): Dorsal surfaces green to bluish green, with yellowish or bluish granules and faint to clearly marked blue to black spots. Anterior $20 \%-40 \%$ of venter white, posterior portion translucent. Iris yellow to golden. Pale or whitish lip in populations from Central America (Savage, 2002; Kubicki, 2007). One individual from Ecuador (MZUTI 4811) lacks dark dorsal spots.

Color in ethanol: Dorsum cream to light lavender to dark lavender with faint to clearly marked dark spots (the Ecuadorian specimen lacks dark spots, MZUTI 4811); iridophores on the anterior $20 \%-40 \%$ of the ventral parietal peritoneum; pericardium and gastrointestinal peritonea with white iridophores; hepatic peritoneum lacking iridophores.

Biology and ecology: The information below is from Kubicki [24] and RWM (pers. obs.) Cochranella granulosa is active at night in riparian habitats of streams through pristine tropical forest, but also sometimes along streams in disturbed areas. Males fight venter to venter, hanging from the vegetation by the tips of their toes. Reproduction usually occurs in riparian habitats, but Kubicki [24] also reported reproductive activity in a small forest pond about $10 \mathrm{~m}$ away from the nearest stream. Egg clutches consist of 40 to 104 eggs $[24,146,147]$ that are attached on masses on the upper distal half of a leaf overhanging the stream. Following hydration, the eggs form a pendent mass (i.e., drip tip) that hangs off the leaf and thereby ensures a constant flow of water over the developing larvae $[4,146]$. There is no long-term parental care in this species [148]. Delia et al. [25] experimentally demonstrated that females provide short-term parental care (brooding) to their egg clutches just after oviposition; this behavior, although brief (i.e., few hours), reduces embryo mortality from dehydration.

Call: Males often call in a chorus, with one male initiating calling and then being answered by several males. The call consists of a rapid high-pitched pulsed trill, usually composed by three notes (range three to five notes; [24]). Usually, the first note is longer (average duration $=0.3 \mathrm{~s}$ ) than the subsequent notes (average duration $=0.15 \mathrm{~s}$ ). The mean duration for a three-note call is $0.8-0.9 \mathrm{~s}$ [24]. The dominant frequency is $3700-4500 \mathrm{~Hz}[24,149,150]$. In Ecuador (Los Laureles, Cotopaxi province) males were actively calling in February 2016 (Jaime Culebras, pers. obs.).

Tadpoles: The tadpole of Cochranella granulosa was first described by Starrett [146]. Hoffmann [147] recently provided an additional and detailed description; below, we present a summary based on Hoffmann's description. Tadpoles of C. granulosa and C. euknemos share a particular slim shape. Recently hatched tadpoles (one to five days old) are markedly slender and dark brown. In the laboratory, older tadpoles are slender with a very long tail; they lack much body pigment and their bright red coloration is from the highly vascularized internal anatomy anterior to the body cavity and visible through the body wall. The oral disc is not emarginate and is bordered laterally and along the posterior margin with $28-41$ marginal papillae (mean $=33 \pm 4$ papillae). Jaw sheaths are strongly serrate; the upper jaw forms a smooth M-shape, and the lower sheath is V-shaped. Generally, all five tooth rows are well developed; LTRF is 2(2)/3; the A2 row has a large central gap with the two halves extending as short wings on each side of the lateral descendent ends of the upper jaw sheath.

Distribution (Figure 68): The distribution of Cochranella granulosa includes the humid lowland and premontane slopes from the Atlantic drainage of eastern Honduras to central Panama and on the Pacific versant in humid upland or gallery forests from northern Costa Rica to northern Ecuador, 40-1500 m elevation ([148,151], this work). Records of Cochranella granulosa in Ecuador are from El Jardín de los Sueños reserve, Cotopaxi province [151], and Durango, 238 m, Esmeraldas province.

Conservation status: Globally, Cochranella granulosa is listed as Least Concern by the IUCN [152]. We suggest Data Deficient in Ecuador, since it is known from two recent records (Figure 68).

Evolutionary relationships (Figure 69): Cochranella granulosa is sister to C. resplendens, being an example of allopatric speciation mediated by the uplift of the Andes. 


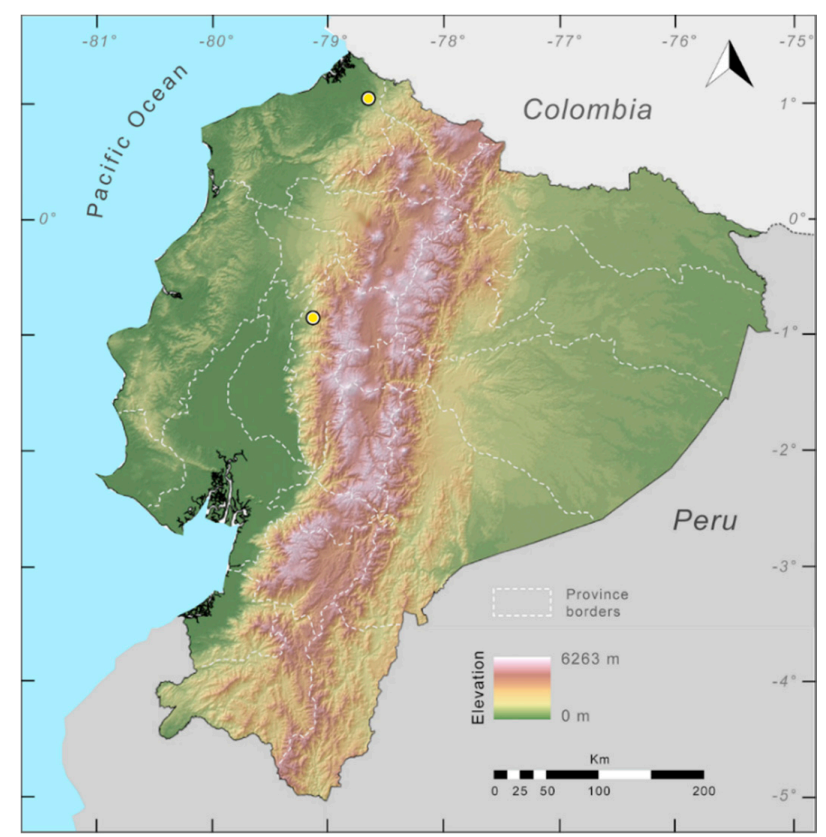

Figure 68. Distribution of Cochranella granulosa in Ecuador (yellow dot).
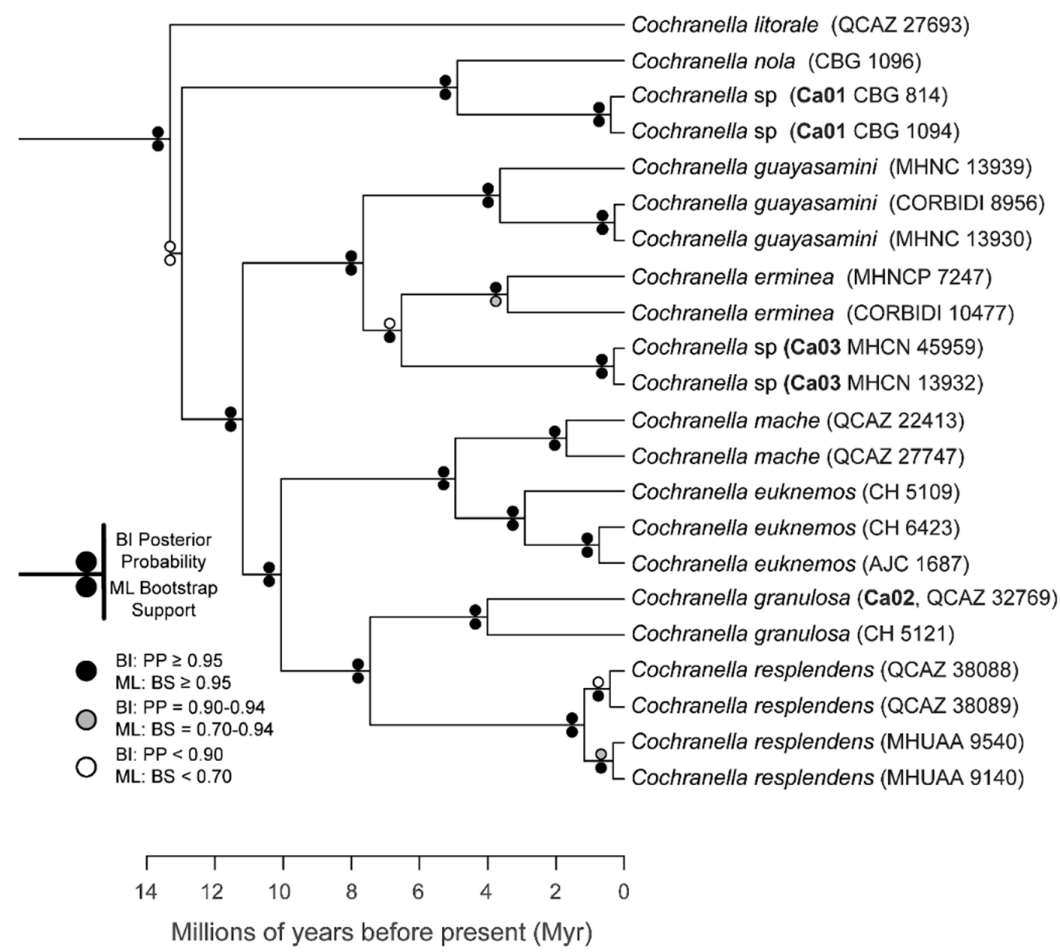

Figure 69. Evolutionary relationships among species in the genus Cochranella, inferred using maximum likelihood and Bayesian criteria.

Remarks: Karyotype of Cochranella granulosa is 2N = 20 [153].

Specimens examined: Cochranella granulosa: Ecuador: Provincia de Esmeraldas: $4 \mathrm{~km}$ W Durango $\left(1.042^{\circ} \mathrm{N}, 78.1081^{\circ} \mathrm{W}, 253 \mathrm{~m}\right)$, QCAZ 32769. Provincia de Cotopaxi: Reserva El Jardín de los Sueños $\left(0.8416^{\circ} \mathrm{S}, 79.2006^{\circ} \mathrm{W}, 461 \mathrm{~m}\right), \mathrm{MZUTI} 4811$. 
Cochranella litoralis (Ruiz-Carranza and Lynch, 1996 [154]; Figures 70-73).

Centrolene litoralis Ruiz-Carranza and Lynch, 1996 [154]. Holotype: ICN 13821.

Type locality: "Departamento de Nariño, municipio de Tumaco, La Guayacana, Litoral Pacífico, $1^{\circ} 49.8^{\prime}$ Latitud N, 78 46.2' W de Greenwich, 100 m, (Colombia)".

Centrolene litorale-Frost, 2004 [155].

Cochranella litoralis-Guayasamin, Castroviejo-Fisher, Trueb, Ayarzagüena, Rada, and Vilà, 2009 [1].

Common names: English: Litoral Glassfrog. Spanish: Rana de Cristal del Litoral.

Etymology: The specific epithet litoralis makes reference to the proximity of the type locality to the ocean [154].

Identification: Cochranella litoralis is the only species in Centrolenidae that has a bright orange to red iris (Figures 70 and 71) and adult males with humeral spines and a nuptial pad that partially covers the two innermost fingers (Figure 72). Additionally, its dorsum is pale yellow green with small grey to black dots and faint yellow-cream dorsolateral stripes. Males are small (SVL $<20 \mathrm{~mm}$ ) and have humeral and distinct prepollex. In the Chocoan lowlands, only some populations of Espadarana prosoblepon and Nymphargus griffithsi have a green dorsum with dark dots and humeral spines. Both E. prosoblepon and N. griffithsi are considerably larger, have a cream to white iris, and lack prepollical spines. The Peruvian Cochranella guayasamini also has a red iris and humeral spines, but lacks dark dorsal spots [19].

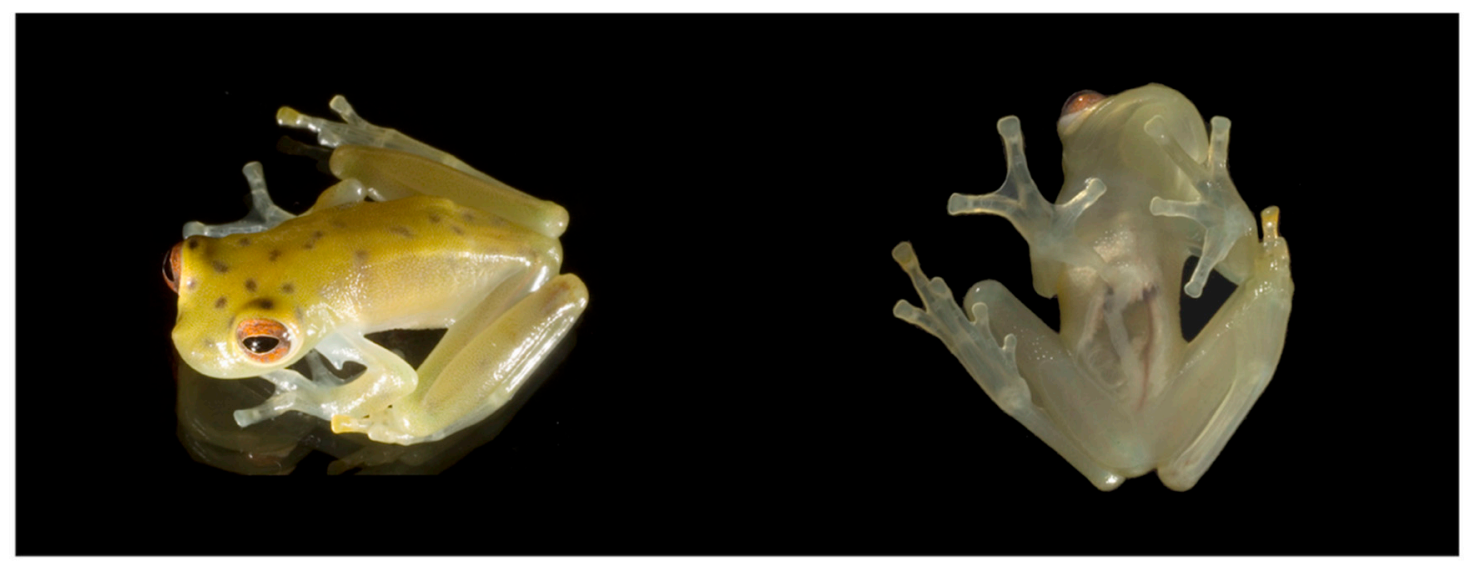

Figure 70. Cochranella litoralis in life. Adult male, QCAZ 27693, from near Durango, 220 m, Esmeraldas province, Ecuador. Photos by Luis A. Coloma.

Diagnosis: (1) Vomers lacking teeth; (2) snout truncated in dorsal and lateral profiles (Figure 72); (3) tympanum of moderate size, oriented almost vertically, with slight lateral and posterior inclinations, its diameter about $30 \%$ of eye diameter; tympanic annulus mostly visible, with supratympanic fold covering its posterodorsal margin; tympanic membrane translucent, partially pigmented, clearly differentiated from surrounding skin; (4) dorsal skin smooth anteriorly and shagreen in sacral region, lacking spicules; (5) lacking pair of enlarged subcloacal warts; (6) anterior half of ventral parietal peritoneum with iridophores, posterior half translucent (condition P2); iridophores in pericardium and gastrointestinal peritoneum; no iridophores on testes, gall bladder, urinary bladder, and kidneys (condition V2); (7) liver with clearly defined lobes covered by transparent peritoneum (condition H0); (8) males with small and pointy humeral spines; (9) webbing absent between Fingers I and II, absent or vestigial between Fingers II and III, moderate between outer fingers; webbing formula IV $2-2^{-}$V; (10) webbing between toes moderate; webbing formula on foot I $1-2$ II $1-2^{+}$III $1-2^{1 / 2}$ IV $2^{1 / 2}-1$ $\mathrm{V}$; (11) ulnar and tarsal folds absent or low and inconspicuous, lacking white coloration; (12) distinct prepollex; nuptial pad Type V; (13) Finger I as long as Finger II; (14) disc of Finger III width about 
$33 \%$ of eye diameter; (15) in life, dorsum green usually with small dark spots and faint yellow-cream dorsolateral stripes (Figures 70 and 71); pale green bones; (16) in preservative, dorsum lavender with dark spots; (17) in life, iris orange to red; (18) dorsal surfaces of fingers and toes lacking melanophores, except for some on base of Toe V; (19) calling behavior unknown; call undescribed; (20) fighting behavior unknown; (21) egg deposition site unknown; parental care unknown; (22) tadpoles unknown; (23) minute body size; in two adult males, SVL 19.4-20.0 mm; females unknown.

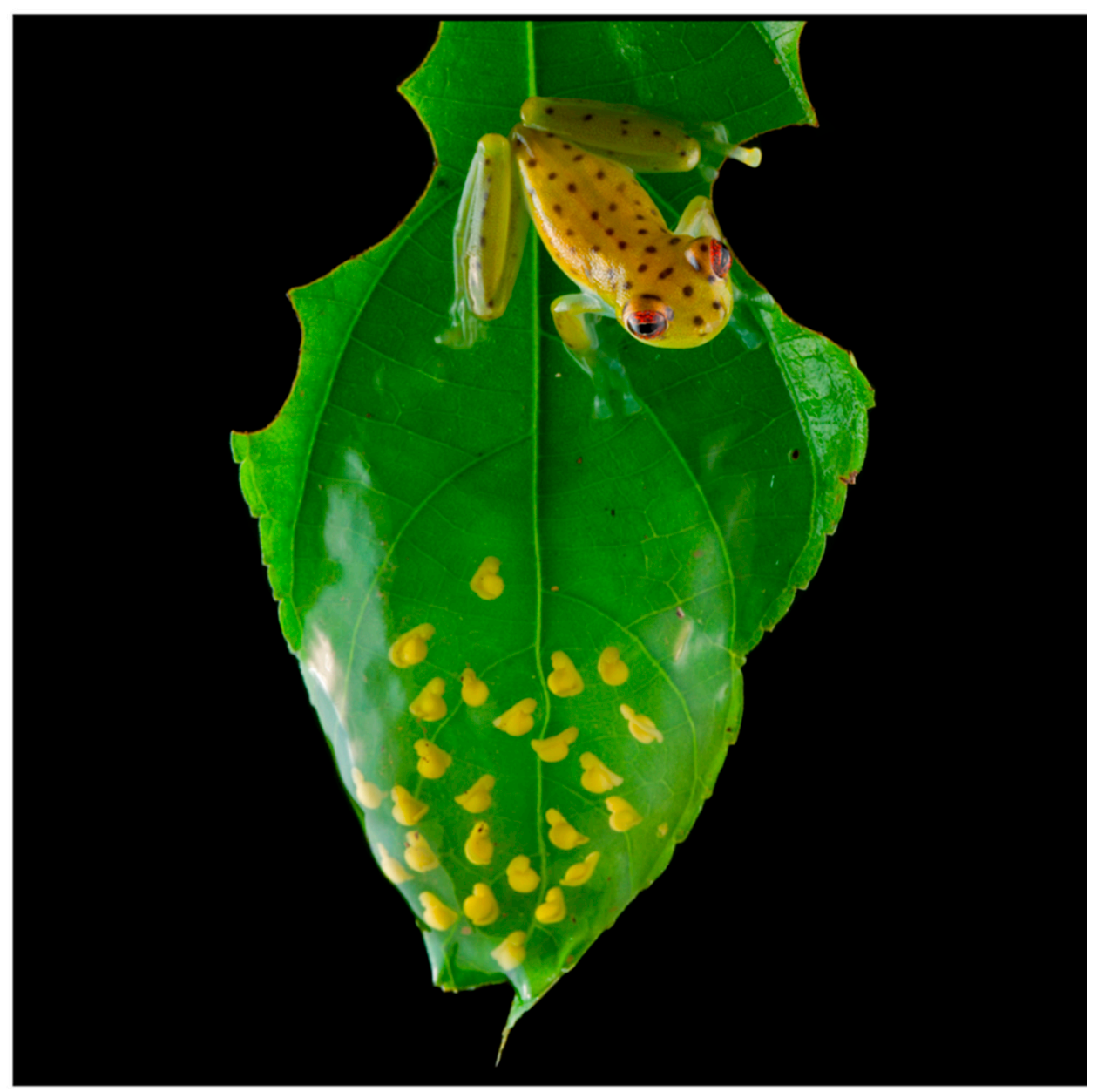

Figure 71. Cochranella litoralis in life. Male from Tundaloma Lodge (1.182 N, 78.749 W; 74 m), Esmeraldas province, Ecuador (3 January, 2014; not collected). Photo by Lucas Bustamante/Tropical Herping.

Color in life (Figures 70 and 71): Cochranella litoralis has a pale yellowish-green dorsum with dark spots that vary in size and conspicuousness; the anterior half of the venter is white, turning transparent posteriorly; the iris is bright orange to red.

Color in ethanol: Dorsal surfaces cream lavender with small dark spots, and two faint white dorsolateral lines. White parietal peritoneum covering anterior half of venter. White pericardium; white peritonea covering stomach and lower colon. Liver, testes, kidneys, and urinary and gall bladders covered by translucent peritonea. Iris silvery white, with black punctuations.

Biology and ecology: A male of Cochranella litoralis and an egg clutch presumed to be from the same species were found on riverine vegetation (L. Bustamante, pers. comm.). The egg clutch was placed on the upper side of a leaf and contained 25 embryos (Figure 71). Parental care unknown.

Call: Not described.

Tadpole: Not described. 
A

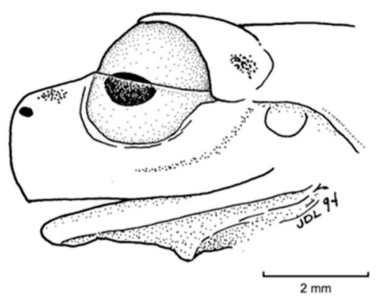

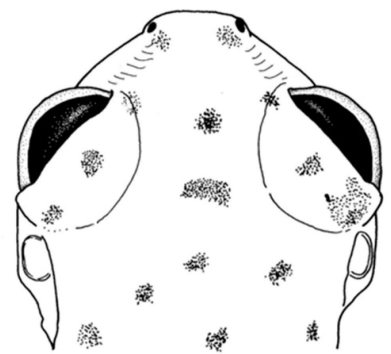

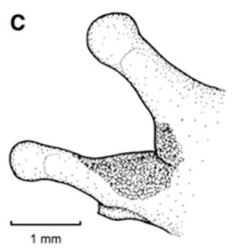

Figure 72. Cochranella litoralis, holotype, adult male, ICN 13821. (A) Head in lateral view. (B) Head in dorsal view. (C) Fingers I and II in dorsal view; note that nuptial pad extends on the two fingers; illustrated by Juan M. Guayasamin. (A,B) Modified from Ruiz-Carranza and Lynch [154].

Distribution (Figure 73): Cochranella litoralis has been reported from the type locality in Colombia and four localities in Ecuador at elevations below $260 \mathrm{~m}$ ([130,154], this work). In Ecuador, this species has a potential distribution of $5784 \mathrm{~km}^{2}$ within the Chocoan Tropical Forest region.

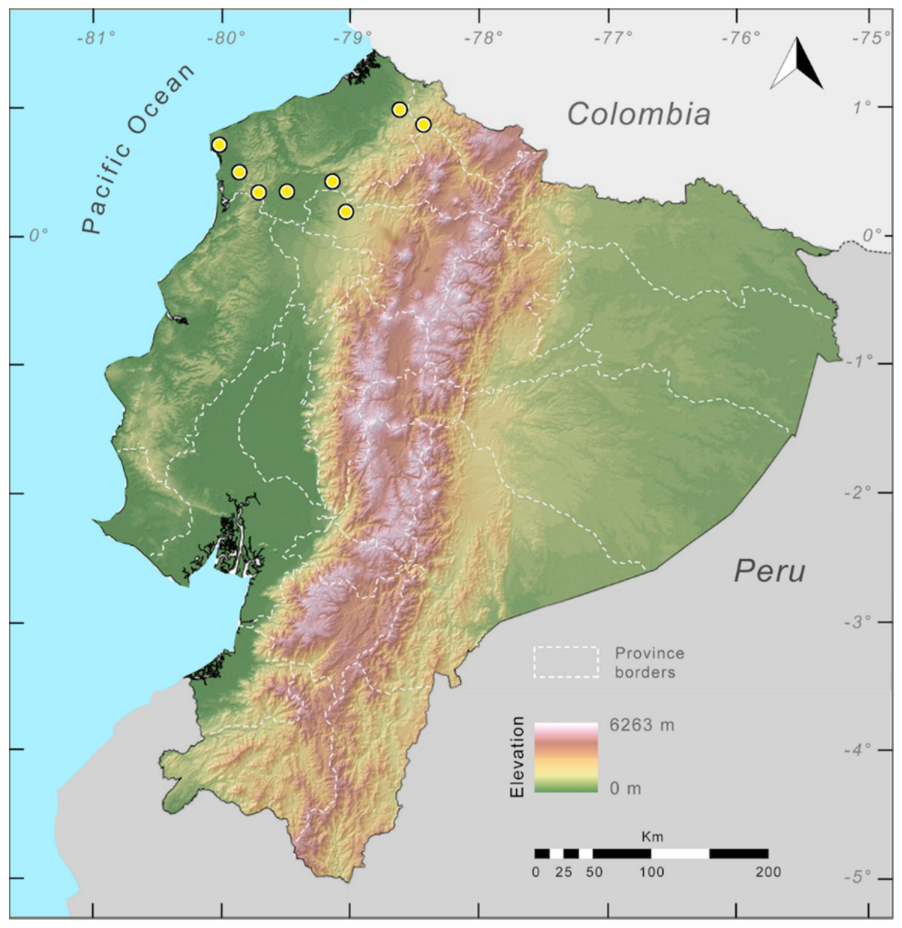

Figure 73. Distribution of Cochranella litoralis in Ecuador (yellow dots).

Conservation status: Globally, Cochranella litoralis is currently listed as Vulnerable by the IUCN [156]. In Ecuador, it has a distribution restricted to the provinces of Esmeraldas and Cotopaxi (Chocó ecoregion), where logging is causing continuous habitat reduction and fragmentation. The most recent reports of this species are from Río Cachabí (September 2005), Tundaloma (January 2014), and Jardín de los Sueños (2018). In Ecuador, because of habitat loss and mining, we suggest that the species should be considered as Endangered, following IUCN criteria B2a, B2(iii). 
Evolutionary relationships (Figure 69): Cochranella litoralis is sister to all other member of the genus Cochranella, but with low nodal support. Twomey et al. [19] recovered a sister relationship between C. litoralis and C. nola.

Specimens examined: Cochranella litoralis: Colombia: Departamento de Nariño: Municipio de Tumaco, La Guayacana (1.83 N, 78.77 W; 100 m), ICN 13821. Ecuador: Provincia de Esmeraldas: stream near Durango (1.047 N, 78.618 W; 220 m), QCAZ 27693; Pichiyacu, Comunidad Chachi, Río Cayapas (0.9397 N, 79.005 W; 260 m), QCAZ 31705; Río Cachabí (1.03 N, 78.77 W, 200 m), 2 km NE Urbina on the San Lorenzo-Lita

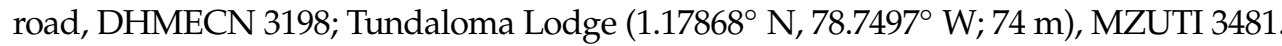

Localities from the literature: Cochranella litoralis: Ecuador: Provincia de Esmeraldas: Tsejpu, Río Zapallo $(0.7 \mathrm{~N}, 78.9 \mathrm{~W}, 150 \mathrm{~m})$ [156].

Cochranella mache Guayasamin and Bonaccorso, 2004 [157] (Figures 74-76).

Cochranella mache Guayasamin and Bonaccorso, 2004 [157]. Holotype: QCAZ 22412.

Type locality: "Riachuelo La Ducha $\left(0^{\circ} 20^{\prime} 41^{\prime \prime} \mathrm{N}, 79^{\circ} 42^{\prime} 36^{\prime \prime} \mathrm{W} ; 510 \mathrm{~m}\right)$, tributary of Río Aguacatal, Reserva Biológica Bilsa, $27.4 \mathrm{~km} \mathrm{~W}$ (airline distance) of the town of Quinindé, Montañas del Mache, Provincia Esmeraldas, Ecuador".

Common names: English: Mache Glassfrog. Spanish: Rana de Cristal de Mache.

Etymology: The specific name mache is a noun in apposition and refers to the Montañas de Mache, the type locality of the species [157].

Identification: Cochranella mache is differentiated from most glassfrogs by having a snout gradually inclined in profile and dermal folds with white tubercles on the ventrolateral edges of Finger $\mathrm{V}$, forearm, elbow, Toe V, tarsus, and heel (Figures 74 and 75). Species sharing similar characteristics are: Centrolene daidalea, C. savagei, C. solitaria, Cochranella resplendens, and C. euknemos. Three of these species (C. daidalea, C. savagei, and C. solitaria) are restricted to the Andes, and Cochranella resplendens is found only in the Amazon Basin. The closely related C. euknemos lacks the tubercles that are characteristic in C. mache [157].

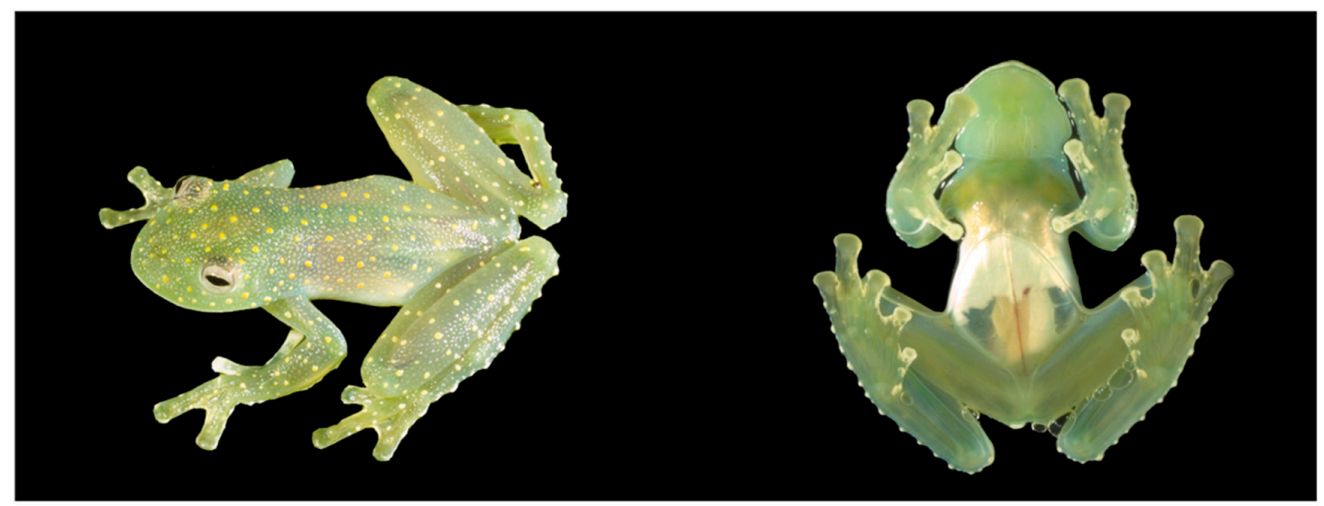

Figure 74. Cochranella mache in life. Adult male, QCAZ 27764, from Río La Carolina, 500 m, Esmeraldas province, Ecuador. Photos by Luis A. Coloma.

Diagnosis: (1) Each vomer with three or four teeth on dentigerous process; (2) snout subacuminate in dorsal aspect and gradually inclined in lateral profile (Figure 75); (3) tympanum oriented almost vertically, with slight lateral and posterior inclinations, its diameter about $33 \%-37 \%$ of eye diameter; tympanic annulus visible, low supratympanic fold evident, tympanic membrane translucent and pigmented as surrounding skin; (4) dorsal skin shagreen with warts that usually correspond to light spots; males with numerous minute spicules; (5) ventral skin granular; several round, enameled warts around cloaca; 
cloacal fold present; pair of enlarged subcloacal warts; (6) anterior one-third of parietal peritoneum covered by iridophores (condition P1); iridophores over pericardium and visceral peritonea (digestive tract, gonads); renal capsules covered by iridophores in some individuals (condition V2); (7) liver trior tetralobed, hepatic peritoneum clear or with small, isolated patches of iridophores (condition $\mathrm{H} 0$ ); (8) humeral spines absent; (9) webbing absent between Fingers I and II, reduced between Fingers II and III, and extensive between outer fingers (Figure 75); webbing formula II $\left(1^{-}-1^{+}\right)-\left(3^{-}-3^{+}\right)$III $\left(2^{-}-2\right)-\left(1-1^{+}\right)$ IV; (10) webbing between toes extensive (Figure 75); webbing formula on foot I $\left(1^{-}-1\right)-\left(2-2^{-}\right)$II $1-2$ III $\left(1-1^{-}\right)-2^{-}$IV $\left(2^{-}-2\right)-\left(1-1^{-}\right) \mathrm{V}$; (11) ventrolateral edges of Finger IV, forearm, elbow, Toe V, tarsus, and heel with dermal enameled folds and tubercles; (12) concealed prepollex; nuptial pad large; (13) Finger I about same length as Finger II (Finger I about 94\%-98\% of Finger II); (14) disc of Finger III width about $44 \%-54 \%$ of eye diameter; (15) color in life, dark olive-green to lavender-blue or pale blue dorsum with numerous small yellow to orange spots, large dull to bright yellow patch on top of head (Figure 74); (16) color in preservative, dorsal surfaces pale lavender with small white or cream spots; tubercles on dermal folds of limbs, fingers, and toes cream-white; inner fingers and toes white or unpigmented; (17) in life, iris whitish cream to beige with thin brown reticulation; white to golden circumpupilary ring; (18) melanophores covering dorsal surfaces of Fingers III and IV and Toes IV and V; (19) males call from the upper sides of leaves; each call formed by two notes; dominant frequency at 5383-5426 $\mathrm{Hz}$; (20) fighting behavior unknown; (21) brown eggs placed on upper sides of leaves; parental care unknown; (22) tadpoles unknown; (23) small body size; in adult males, SVL 22.0-27.0 mm ( $n=43$ ); in adult females, SVL 28.0-33.4 $\mathrm{mm}(n=4)$.

A

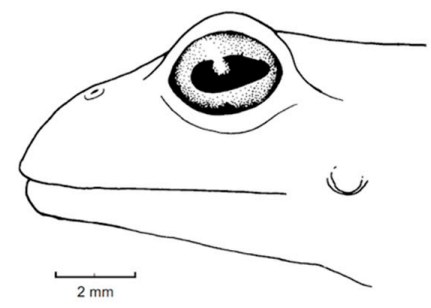

C

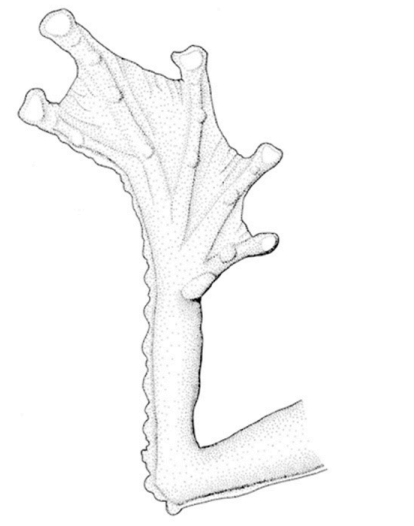

B

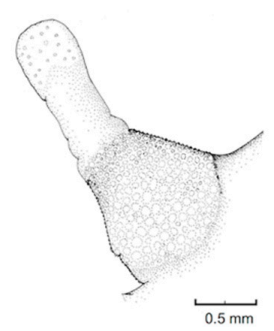

D

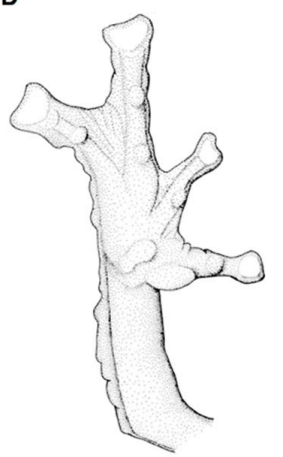

Figure 75. Cochranella mache. (A) Head in lateral view, paratype, adult male, KU 291176. (B) Nuptial excrescences on dorsal surface of Finger I, paratype, adult male, QCAZ 22413. (C) Foot in ventral view, KU 291176. (D) Hand in ventral view, KU 291176. Hand and foot not drawn to scale. Modified from Guayasamin and Bonaccorso [157].

Color in life (Figure 74): Dorsal surfaces vary from green to lavender blue or pale blue, with small yellow to orange spots. Upper lip with a thin, white margin. White tubercles visible on dermal folds of hind- and forelimbs. Innermost fingers and toes (Fingers I and II, Toes I and II) white in males and partially white in females. Throat and ventral surfaces of limbs blue green. White parietal peritoneum covering anterior half of venter, posterior portion translucent; white pericardial and visceral peritonea. Transparent hepatic peritoneum, but in some individuals, 
a small patch of white iridophores covers part of liver. White warts surround cloaca. Iris whitish cream to beige with thin brown reticulation; white to golden ring surrounding pupil. Bones green ([157,158], this work).

Color in ethanol: Dorsum of head, body, and limbs lavender with small white or cream spots. Anterior one-third of parietal peritoneum covered by iridophores; iridophores also cover pericardium and visceral peritonea (digestive tract and gonads); hepatic peritoneum lacking iridophores or with small, isolated patches of iridophores; renal capsules covered by iridophores in some specimens ([157,158], this work).

Biology and ecology: The information shown below was obtained mainly from Ortega-Andrade et al. [159] and, to a lesser extent, from Guayasamin and Bonaccorso [157]. Cochranella mache seems to be restricted to small streams and rivulets in primary and secondary forests in lowlands and piedmont forest. Abundance of the species is correlated with rainfall, being higher during rainy season. Males call from the upper surface of leaves or branches on trees and bushes; reproduction seems to be restricted to the rainy season. Although individuals have been observed on different strata of the forest up to $6 \mathrm{~m}$ high, $C$. mache prefers the midstory vegetation. Amplexus is axillary and a gravid female was observed to have about 30 eggs. The diversity of amphibians and reptiles at the type locality (Reserva Biológica Bilsa) of C. mache is described by Ortega-Andrade et al. [160]. Parental care unknown.

Call: The advertisement call of Cochranella mache was described by Ortega-Andrade et al. [159]. The recorded male was calling from the upper side of a dead Heliconia leaf, about $2.5 \mathrm{~m}$ above ground, horizontally separated from the stream by about $3 \mathrm{~m}$. A call consists of two notes, separated by an interval of $0.107-0.130 \mathrm{~s}$. Each note has a duration of $0.038 \pm 0.008(0.029-0.049) \mathrm{s}$. The dominant frequency is at $5410.2 \pm 17.9(5383-5426) \mathrm{Hz}$. The harmonics are not visible. The call rate is 1.46 calls per minute.

Tadpole: Not described.

Distribution (Figure 76): Cochranella mache has been reported from few localities in northwestern Ecuador, provinces of Esmeraldas, Imbabura, and Manabí, at elevations between 38 and $800 \mathrm{~m}$ ([157-159], this work), and from the Pacific lowlands of Colombia, Departments of Antioquia and Valle del Cauca, at elevations of 750-1030 m [161]. Three localities lie within protected areas (Reserva Biológica Bilsa, Reserva Biológica Canandé, Reserva Jama-Coaque). In Ecuador, the potential distribution of C. mache is $27,433 \mathrm{~km}^{2}$ (see also Ortega-Andrade et al. [159]) within the Chocoan Tropical Forest and the Western Foothill Forest regions. When deforestation is taken into account, $\sim 70 \%$ of the predicted distribution is reduced [159]. 


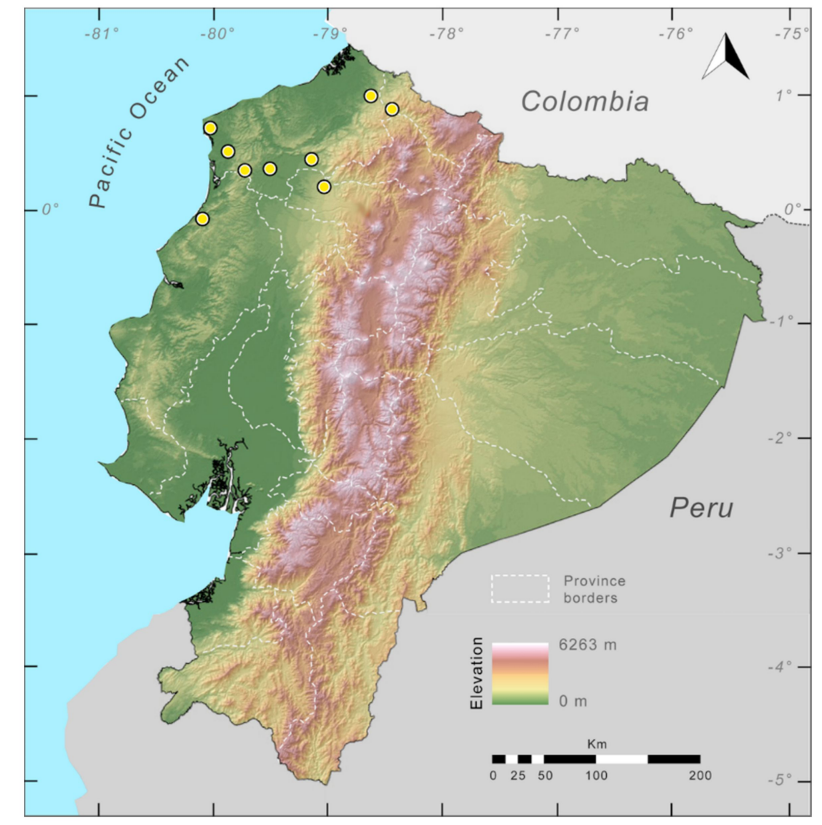

Figure 76. Distribution of Cochranella mache in Ecuador (yellow dots).

Conservation status: Listed as Endangered by the IUCN at a global level [162]. Other studies suggest that the species should be classified into the category of Critically Endangered [159,163]. The distribution of the species is likely to correspond to the remaining lowland forest in northwestern Ecuador and southwestern Colombia, an area under the constant pressure by wood companies. Although the range of $C$. mache is partially within the Mache-Chindul Ecological Reserve and three private reserves (Reserva Biológica Bilsa, Reserva Biológica Canandé, Reserva Jama-Coaque), most conservation measures are ineffective because of institutional and funding restrictions and a lack of law enforcement. Some of the larger fragments are preserved by private organizations but many remain unprotected. Habitat degradation is mainly caused by unsustainable timber extraction, uncontrolled expansion of the agricultural frontier, and replacement by non-native plantations $[159,163]$. Records from Colombia, however, expand considerably the distribution of $C$. mache. More than half of this distribution area of the species is affected by human activities [159]. Under scenarios of climate changes, the potential distribution of $C$. mache suffers a reduction of $13 \%-21 \%$ of its predicted range [159].

Evolutionary relationships (Figure 69): Cochranella mache is the sister species of C. euknemos.

Specimens examined: Cochranella mache: Ecuador: Provincia de Esmeraldas: Montañas de Mache, Reserva Biológica Bilsa, Riachuelo La Ducha $\left(0^{\circ} 20^{\prime} 41^{\prime \prime} \mathrm{N}, 79^{\circ} 42^{\prime} 36^{\prime \prime} \mathrm{W} ; 510 \mathrm{~m}\right)$, tributary of Río Aguacatal, $27.4 \mathrm{~km} \mathrm{~W}$ (airline distance) of the town of Quinindé, QCAZ 22412 (holotype), QCAZ 22413, KU 291176; Río Balthazar (0.9745 N, 78.61675 W; 645 m), QCAZ 27747, 31327; Monte Saíno, Punta Galeras region $(0.700 \mathrm{~N}, 80.017 \mathrm{~W} ; 100 \mathrm{~m})$, DHMECN 2611; $3 \mathrm{~km} \mathrm{NW}$ of Quinindé $(0.350 \mathrm{~N}, 79.483 \mathrm{~W}$; 150 m), DFCH-USFQ LQ23; Reserva Biológica Canandé (0.433 N, 79.133 W; 270 m), DHMECN 3560. Provincia de Imbabura: Río La Carolina (0.70449 N, 78.20115 W; 500 m), on the Ibarra-San Lorenzo Road, nearby Jijón y Caamaño, QCAZ 27764. Colombia: Departamento de Antioquia: Municipio Dabeiba, Río Amparradó, Quebrada Iotó, 805 m, ICN 10689-90, 8665; Municipio Frontino, Vereda Venados, PNN Las Oriquideas, Quebrada La Miguera, 1030 m, ICN 19638-9.

Records from the literature: Ortega-Andrade et al. [159]: Ecuador: Comunidad San Salvador (0.496710 N, 79.85298 W; 38 m); Hacienda Shangrilá (0.18630 N, 79.03019 W; 499 m).

Photographic record: Ryan Lynch: Ecuador: Provincia de Manabi: Reserva Jama-Coaque (0.0978 S, 80.147 W). 
Cochranella resplendens Lynch and Duellman, 1973 [22] (Figures 77-82).

Cochranella resplendens Lynch and Duellman, 1973 [22]. Holotype: KU 118053.

Type locality: "Santa Cecilia, 340 m, Provincia de Napo (Sucumbíos), Ecuador".

Cochranella resplendens-Ruiz-Carranza and Lynch, 1991a. Guayasamin, Castroviejo-Fisher,

Trueb, Ayarzagüena, Rada, and Vilà, 2009 [1].

Cochranella phryxa Aguayo and Harvey, 2006 [164]. Holotype: CBG 778. Type locality:

"approximately $20 \mathrm{~km}$ west of Población de la Cascada (Territorio Comunitario de Origen

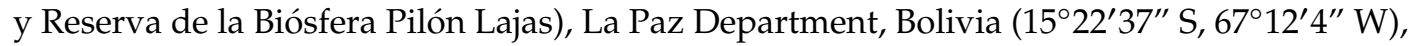

$1000 \mathrm{~m}^{\prime \prime}$. New synonymy.

Common names: English: Resplendent Glassfrog. Spanish: Rana de Cristal Resplandeciente.

Etymology: The specific name resplendens is derived from the Latin verb resplendo, meaning to glitter, and is used in allusion to the jewel-like appearance of this frog [22].

Identification: Cochranella resplendens is distinguished from most glassfrogs by having a snout gradually inclined in profile and ventrolateral edges of Finger IV, forearm, elbow, Toe V, tarsus, and heel with dermal folds and enameled tubercles (Figure 77, Figure 78, Figure 81). Additionally, the species lacks humeral spines and has a white venter except for the posterior one-fourth, which is transparent. The following species could be confused with Cochranella resplendens: Centrolene daidalea, Cochranella mache, Centrolene savagei, and Centrolene solitaria. However, none of these species is found in the Amazon basin, where Cochranella resplendens occurs; C. mache is distributed in the Pacific lowlands of Ecuador, whereas C. daidalea, C. savagei, and C. solitaria are endemic to the Colombian Andes.

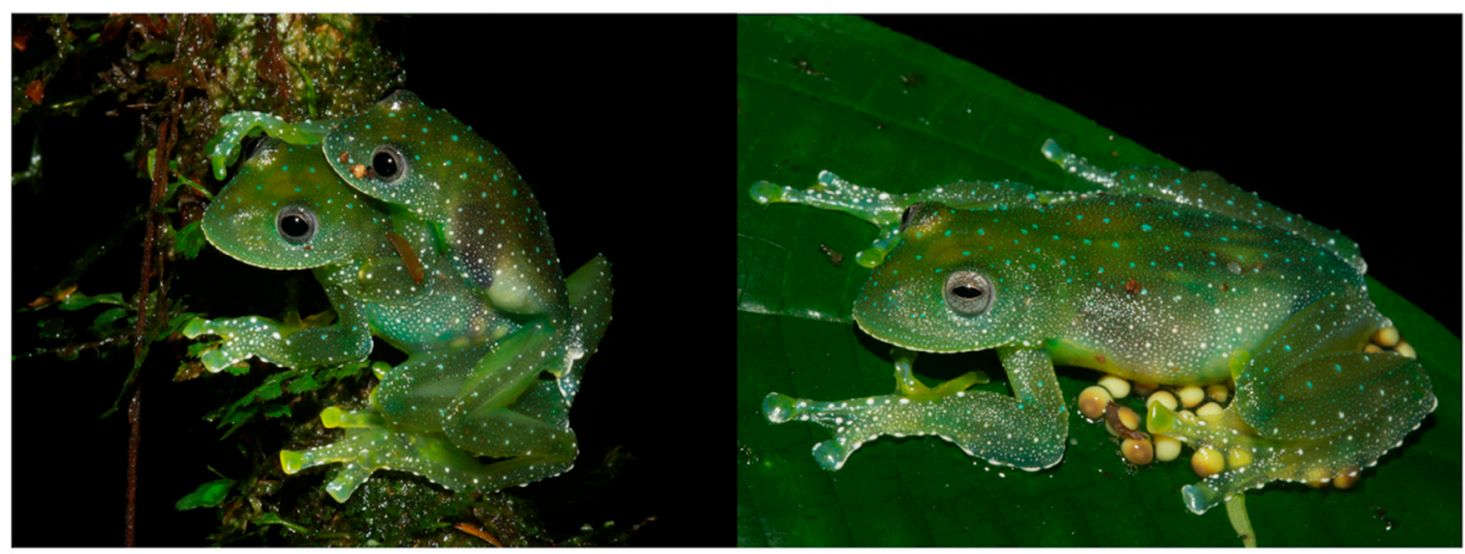

Figure 77. Cochranella resplendens in life. (Left): Amplectant pair. (Right): Female brooding clutch. Locality: $2 \mathrm{~km} \mathrm{~N}$ from HW 20 on a dirt road out of Guagua Sumaco, Napo province, Ecuador. Photos by Jesse Delia.

Diagnosis: (1) Each vomer with three or four teeth on dentigerous process; (2) snout round in dorsal aspect and gradually inclined in lateral profile (Figure 78); (3) tympanum oriented almost vertically, with slight lateral and posterior inclinations, its diameter about $38 \%$ of eye diameter; tympanic annulus partially visible, low supratympanic fold evident, tympanic membrane barely translucent, pigmented as surrounding skin; (4) dorsal skin shagreen with elevated and spiculated warts corresponding to white spots; (5) venter granular; pair of slightly enlarged subcloacal warts; enlarged cloacal fold present; (6) white lining (iridophores) on the anterior three-fourths of the ventral parietal peritoneum, posterior one-fourth transparent (condition P3); iridophores in pericardium and peritonea covering intestines and stomach; renal capsules and gall bladder and urinary bladder lacking iridophores (condition V2); (7) liver lobate, covered by transparent peritoneum (condition H0); (8) humeral spines absent; (9) webbing absent between inner fingers, and extensive between outer fingers (Figure 78$)$; webbing formula III $\left(1^{1 / 2}-2^{-}\right)-\left(1-1^{1 / 2}\right)$ IV; $(10)$ webbing between toes 
extensive (Figure 81); webbing formula on foot I $\left(1-1^{+}\right)-\left(1^{2 / 3}-2\right)$ II $\left(0-0^{+}\right)-\left(2-2^{+}\right)$III $\left(1-1^{1 / 2}\right)-\left(2-2^{+}\right)$ IV $\left(2^{-}-2^{+}\right)-\left(1^{-}-1^{+}\right) \mathrm{V}$; (11) ventrolateral edges of Finger IV, forearm, elbow, Toe V, tarsus, and heel with dermal folds and enameled tubercles (Figures 77, 79 and 81); (12) concealed prepollex; nuptial pad not evident; (13) Finger I about same length as Finger II; (14) disc of Finger III width about 55\% of eye diameter; (15) in life, dorsum dark green with numerous small white spots (Figures 77 and 79); bones green; (16) in preservative, dorsum lavender with small white spots (Figure 81); (17) iris whitish cream to beige, with a fine grey to brown reticulation; pale yellow circumpapilar ring; (18) dorsal surfaces of fingers and toes with few small, enameled spots; melanophores only on surfaces of Finger IV and Toe V; (19) calling behavior unknown; call undescribed; (20) fighting behavior unknown; (21) egg clutches placed on upper sides of leaves; short-term maternal care present; parental care provided by males absent; (22) tadpoles with non-emarginate oral apparatus; tooth row formula 2(2)/3; upper jaw slightly curved; (23) medium body size; in two adult males, SVL 26.5-26.6 mm; females unknown.

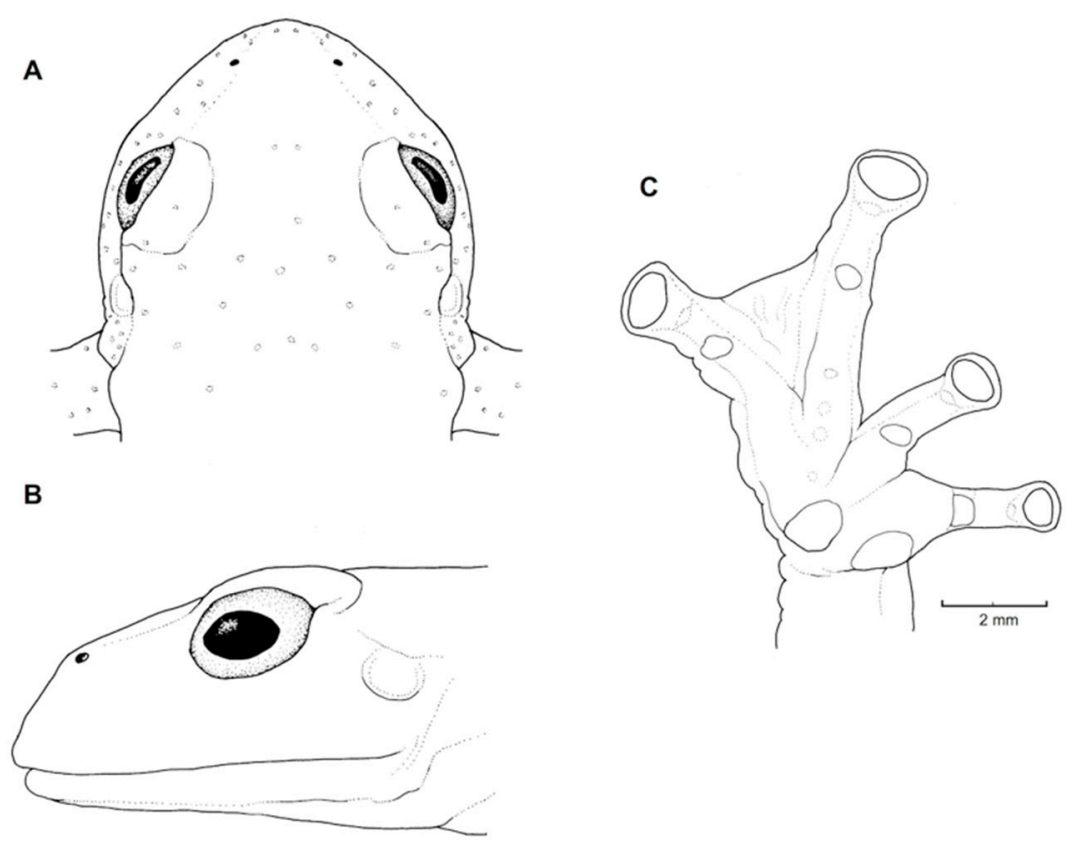

Figure 78. Cochranella resplendens, holotype KU 118053. (A) Head in dorsal view. (B) Head in lateral view. (C) Hand in ventral view. Drawings of head not to scale. Illustrations by Juan M. Guayasamin.

Color in life (Figures 77 and 79): Dorsum green with numerous, small white to bluish-white spots. Ventral surfaces mostly white, except posterior portion, which is translucent. Upper lip, tubercles on forearm and foot, and cloacal warts white. Bones green. Iris whitish cream to beige, with fine grey to brown reticulation; pale yellow circumpapilar ring ([22,164], this work).

Color in ethanol (Figure 81): Dorsal surfaces of head, body, and limbs slate grey to lavender with small white spots, often corresponding to small, flat tubercles. Upper lip white; tympanum pigmented as surrounding skin. White tubercles present on Fingers III and IV and Toes II-V. White on dermal folds of forearm and tarsus and on tips of Finger IV and Toe V. White cloacal tubercles. Pericardium and anterior three-fourths of the ventral parietal peritoneum white. White peritonea covering intestine, stomach, and colon. Transparent peritonea covering kidney, gall bladder, and urinary bladder. Hepatic peritoneum clear in holotype and most known specimens, but with a patch of iridophores in two Ecuadorian specimens and in Bolivian specimen ([22,164], this work).

Biology and ecology: Cochranella resplendens is a rare species. Since its description in 1973, only eight additional individuals have been reported (Specimens Examined). The scarcity of Cochranella resplendens is not related to low sampling effort. At the type locality (Santa Cecilia), fieldwork from 1967 through 1972 resulted in the collection of 7765 specimens of amphibians and 
reptiles, but no additional specimens of Cochranella resplendens [165]. However, canopy surveys may reveal that its rarity is an artifact of microhabitat sampling [166]. Sixty-six species of amphibians, including Teratohyla midas and Hyalinobatrachium munozorum, are known to occur at Santa Cecilia [165]. At the Bolivian locality (20 km W of Población La Cascada), Cochranella resplendens was found sympatric with Rulyrana spiculata and Cochranella sp. [164]. At the Tiputini Biodiversity Station, Cochranella resplendens was found sympatric with Teratohyla midas, Hyalinobatrachium munozorum, and Vitreorana ritae ([134], this work). Females provide short-term parental care; male parental care is absent [25].
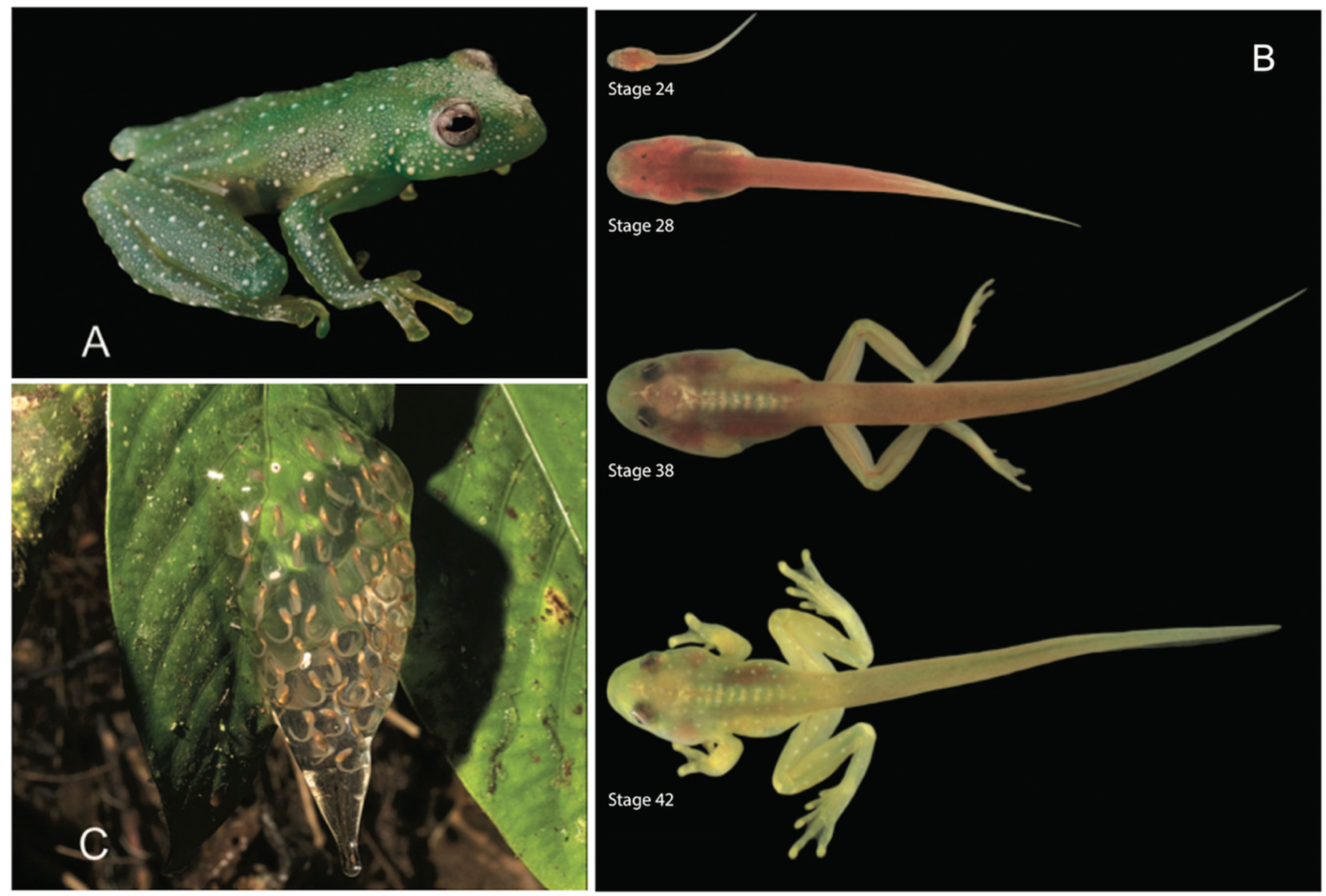

Figure 79. Life cycle in Cochranella resplendens. (A) Juvenile, QCAZ 38088. (B) Ontogenetic variation of tadpoles. (C) Egg clutch. Photos by Luis A. Coloma. Figure modified from Terán-Valdez et al. [167].

Tadpole (Figures 79 and 80): At Río Napinaza, a clutch with 74 embryos was found on the upper side of a leaf [167]. According to Terán-Valdez et al. [167], the tadpole of Cochranella resplendens has the following traits (based on tadpole in Gosner Stage 36): Body elongated, oval-depressed (sensu [168]), wider than high; snout rounded in dorsal and lateral views. Eyes located on dorsal surface of head; in early stages, eyes C-shaped; after Stage 35, eyes become round. Short, single, sinistral spiracle, at the posterolateral region of the body; vent tube short and abdominal, free posteriorly, opening directed posteriorly; myotomes visible throughout length of tail; dorsal fin originating at about mid-length of tail; ventral fin originating almost at base of tail muscle and reaching its maximum height posterior to mid-length of tail. Oral disc non-emarginate; marginal papillae uniserial, distributed around oral disc, but larger on the lower labium; upper labium with papillae only on lateral extremes. Upper jaw sheath completely keratinized with serrated edge; slightly curved. Lower jaw sheath keratinized, U-shaped, and with serrated edge. Labial tooth row formula 2(2)/3; A-2 with medial gap. For ontogenetic variation, see Terán-Valdez et al. [167]. Dorsally, the tadpole is mostly red, with some aggregations of iridophores that form an interorbital line and a middorsal band from behind the eyes to nearly the end of the body (based on a tadpole in Gosner Stage 36). Dorsally, the anterior-most part of the body is pale yellow. Laterally, the tadpole is translucent. The iris is mostly black with a yellow ring around the pupil [167]. 


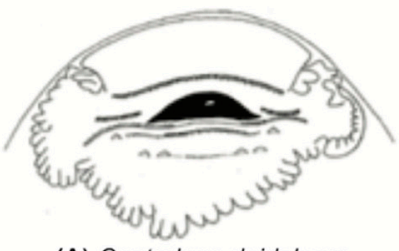

(A) Centrolene daidaleum

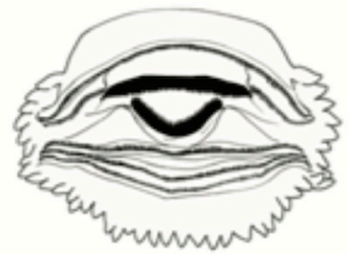

(C) Cochranella resplendens

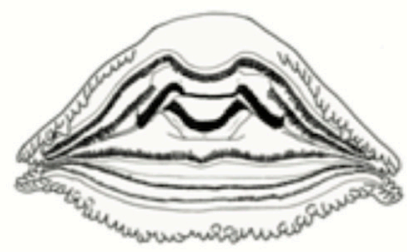

(E) Hyalinobatrachium aureoguttatum

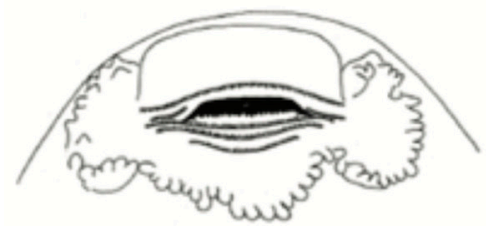

(G) Hyalinobatrachium ibama

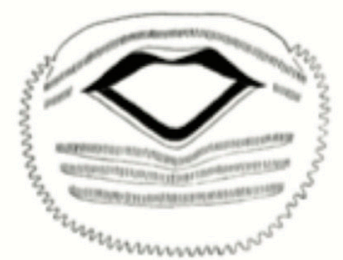

(I) Hyalinobatrachium valerioi
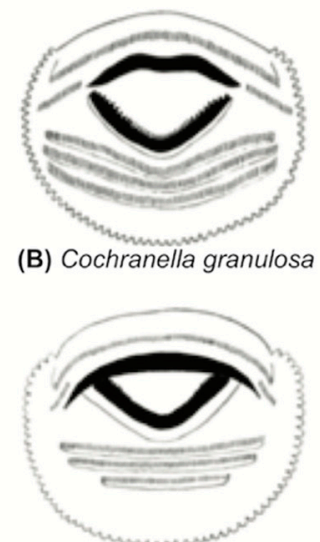

(D) Espadarana prosoblepon

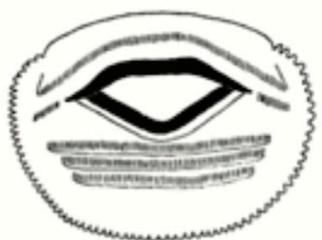

(F) Hyalinobatrachium fleischmanni

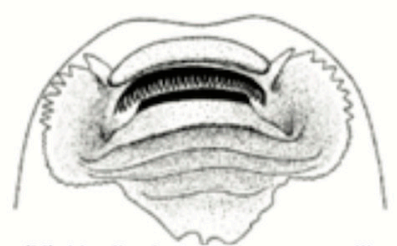

(H) Hyalinobatrachium cappelli

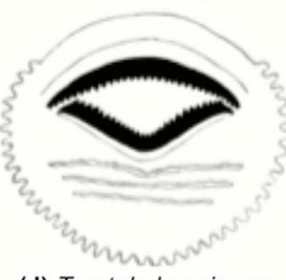

(J) Teratohyla spinosa

Figure 80. Oral apparatus of different species of Centrolenidae (from Terán-Valdez et al. [167]). Cochranella granulosa and Hyalinobatrachium ibama are in Gosner Stage 24, Cochranella resplendens in Stage 36, H. cappellei in Stage 25, H. aureoguttatum in Stage 35. Gosner stages of the remaining species are not provided in the original descriptions. Figures modified from: (A,G) Rada et al. [169]; (B,D,F,I,J) Starrett [146]; (C,E) Terán-Valdez et al. [167], (H) Noonan and Bonett [170].

Taxonomic Remarks: Aguayo and Harvey [164] described Cochranella phryxa from the Amazonian slopes of the Bolivian Andes. These authors mentioned that C. phryxa can be distinguished from Cochranella resplendens (characteristics in parenthesis) by having a hidden tympanum (tympanum visible), a first finger longer than the second (second finger longer than the first), and a straight cloacal fold (U-shaped cloacal fold). After examining the holotype and six additional specimens (QCAZ 38099, MHNSM 19507, DFCH-USFQ D103-4; FHGO 1305, 1324) of Cochranella resplendens, we find that the tympanic membrane in Cochranella resplendens is only slightly differentiated from the skin surrounding the tympanum. Therefore, one could interpret the tympanum in Cochranella resplendens as hidden, which is the character state that Aguayo and Harvey [164] described for C. phryxa. The relative length of the two innermost fingers has been used for many authors when comparing centrolenid species. Although we agree that the character is useful when the differences are obvious (e.g., comparing species of Hyalinobatrachium), it is problematic when differences are minor, as in C. resplendens. We have tried 
to minimize the error in the assessment of this character by measuring the fingers with a digital caliper. Consistently, we found that these fingers have almost the same length in Cochranella resplendens (Finger I length 96\%-102\% of Finger II). The last character used by Aguayo and Harvey [164] is the shape of the cloacal fold, which they described as straight in C. phryxa and U-shaped in Cochranella resplendens. Differences in shape of the cloacal ornaments may be either artificial, associated with how the specimens are preserved (i.e., posterior extremities fixed with an anterior, posterior, or parallel orientation in relation to the sagittal axis of body), or due to intraspecific variation. The cloacal ornamentation (i.e., white warts and folds) is the same in the two species (compare Lynch and Duellman [22]: Figure 2c; Aguayo and Harvey [164]: Figure 4). Cochranella mache, a species with U-shaped cloacal folds, shows the same intraspecific variation observed between C. resplendens and C. phryxa. The only difference that we find between the holotype of Cochranella resplendens and the Bolivian specimen is the presence of a small patch of iridophores on the hepatic peritoneum of the latter. However, it is possible that this patch is either an artifact of preservation (i.e., iridophores from the ventral parietal peritoneum can be attached to the liver) or intraspecific variation (i.e., the presence/absence of patches of iridophores in the peritoneum has been observed in other centrolenids (e.g., Cochranella mache [17,158]). For the reasons discussed above, we formally place Cochranella phryxa Aguayo and Harvey, 2006 [164], in the synonymy of Centrolenella resplendens Lynch and Duellman, 1973 [22].

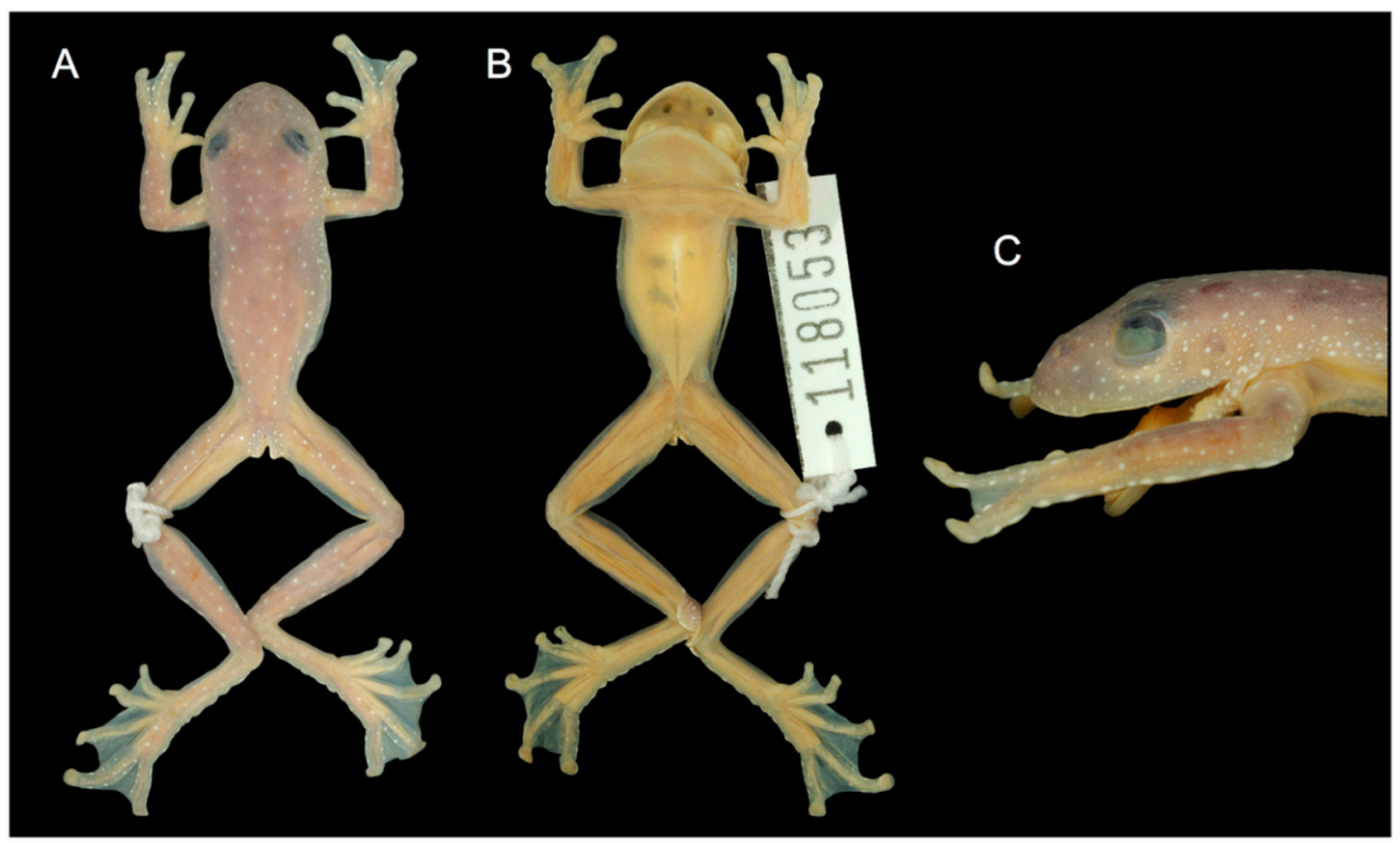

Figure 81. Cochranella resplendens in preservative. Holotype (KU 118053) from Santa Cecilia, Sucumbíos province, Ecuador. (A) Dorsal view. (B) Ventral view. (C) Lateral view. Photos by Martín Bustamante.

Distribution (Figure 82): Cochranella resplendens in known from the Amazon basin of Colombia, Ecuador, Peru, and Bolivia, at elevations between 190 and $1100 \mathrm{~m}$ ([22,134,164,167,171], this work).

A disjunct population of the species was recently found on the eastern slope of the central Andes in the Departamento Antioquia, Colombia, at much higher elevations (1309-1699 m) [172]. In Ecuador, this species is known from localities in the provinces of Morona Santiago, Napo, Orellana, Pastaza, and Sucumbíos at elevations between 250-1100 m. In Ecuador, the potential distribution of C. resplendens is $77,793 \mathrm{~km}^{2}$ within the Amazonian Tropical Rainforest and Eastern Foothill Forest ecoregions. 


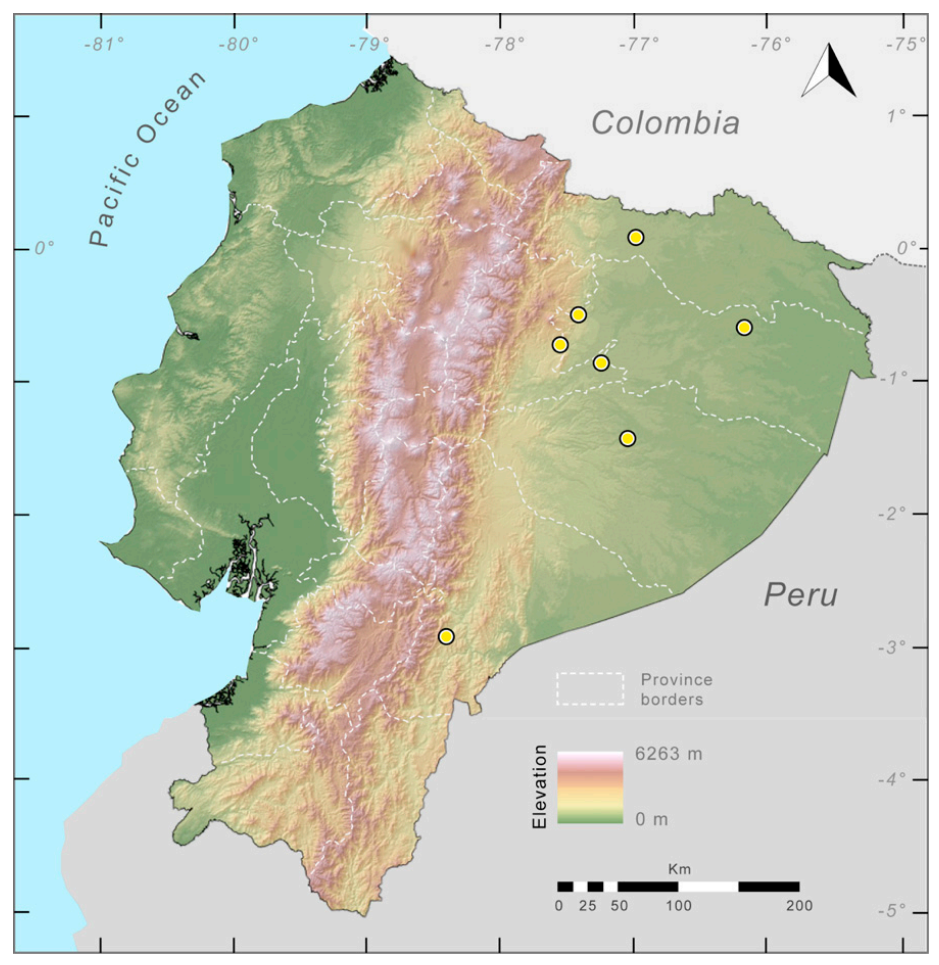

Figure 82. Distribution of Cochranella resplendens in Ecuador (yellow dots).

Conservation status: Globally, Cochranella resplendens is currently listed as Least Concern by the IUCN [173]. Although it is evident that $C$. resplendens is rare in collections (see above), we presume that this is a consequence of inadequate sampling [166]. The potential distribution of this species in Ecuador is $77,793 \mathrm{~km}^{2}, 14 \%$ of which is affected by human activities. Given the broad distribution of C. resplendens and the lack of immediate threats, the category of Least Concern is justified.

Evolutionary relationships (Figure 69): With the current genetic and taxon sampling, the sister species of $C$. resplendens is $C$. granulosa. These two species are an example of vicariant speciation, mediated by the uplift of the Andes.

Specimens examined: Cochranella resplendens: Colombia: Departamento de Putumayo: Santa María de Sucumbíos (ca. $00^{\circ} 16^{\prime} \mathrm{N}, 76^{\circ} 55^{\prime} \mathrm{W}$ ), AMNH 88083 (Lynch and Duellman, 1973). Ecuador: Provincia de Sucumbios: Santa Cecilia $\left(00^{\circ} 03^{\prime}\right.$ N, 76 58' W; 340 m), KU 118053 (holotype). Provincia de Morona Santiago: Río Napinaza $\left(2.927^{\circ} \mathrm{N}, 78.407^{\circ} \mathrm{W} ; 1100 \mathrm{~m}\right)$, QCAZ 38088. Provincia de Napo: Reserva Yachana $\left(00^{\circ} 52^{\prime} 21.71^{\prime \prime}\right.$ S, $77^{\circ} 14^{\prime} 13.43^{\prime \prime}$ W; 300-350 m), QCAZ 38099; Provincia de Orellana: San José Viejo de Sumaco (0.5333 S, 77.4167 W; ca. $810 \mathrm{~m})$, USNM 288460; Tiputini Biodiversity Station $\left(00^{\circ} 37^{\prime} \mathrm{S}\right.$, $76^{\circ} 10^{\prime} \mathrm{W}$; 190-270 m), DFCH-USFQ D103-04; Provincia de Pastaza: Pozo Garza, Oryx (012 $26^{\prime} \mathrm{S}, 77^{\circ} 03^{\prime} \mathrm{W}$; 300 m), FHGO 1305, 1324. Peru: Departamento de San Martín: Cainarachi Valley $\left(6^{\circ} 43^{\prime} 10\right.$ S, $76^{\circ} 29^{\prime} 13$ W; $550 \mathrm{~m}), \mathrm{Km} 33$, Carretera Tarapoto-Yurimaguas, MHNSM 19507. Bolivia: Departamento de La Paz:

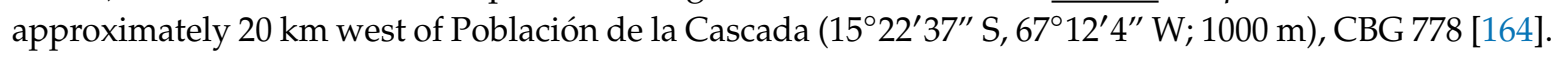

Photographic records: Ecuador: Provincia de Napo: ca. $2 \mathrm{~km}$ north from HW 20 on a dirt road out of Guagua Sumaco ( $0.688^{\circ}$ S, $77.6^{\circ} \mathrm{W}$; ca. $\left.900 \mathrm{~m}\right)$; photographs by Jesse Delia (Figure 77 ). 
Genus Espadarana Guayasamin, Castroviejo-Fisher, Trueb, Ayarzagüena, Rada, \& Vilà 2009 [1].

Etymology: The name Espadarana honors Marcos Jiménez de la Espada, a Spanish zoologist who was part of the Comisión Científica del Pacífico that explored America between 1862 and 1865. Jiménez de la Espada described the first centrolenid frog, Centrolene geckoideum in 1872. In Spanish, the word Espada means sword, in allusion to the humeral spines present in males of species in this genus. Espadarana is a combination of the words Espada and rana (frog) and is feminine in gender [1].

Espadarana audax (Lynch and Duellman, 1973 [22]; Figures 83-87).

Centrolenella audax Lynch and Duellman, 1973 [22]. Holotype: KU 146624.

Type locality: "Salto de Agua, 2.5 km NNE of Río Reventador on Quito-Lago Agrio road, $1660 \mathrm{~m}$, Provincia de Napo, Ecuador".

Centrolene audax - Ruiz-Carranza and Lynch, 1991 [6].

"Centrolene" audax-Guayasamin, Castroviejo-Fisher, Trueb, Ayarzagüena, Rada, Vilà, 2009 [1].

Centrolene fernandoi-Duellman and Schulte, 1993 [174]. Synonymy by Cisneros-Heredia and Guayasamin, 2014 [175].

Espadarana audax-Twomey, Delia, and Castroviejo-Fisher, 2014 [19].

Common names: English: Daring Glassfrog. Spanish: Rana de Cristal Audaz.

Etymology: The specific name audax is Latin, meaning daring, and is used in allusion to the precipitous regions inhabited by this species [22].

Identification: Espadarana audax is unique among Ecuadorian glassfrogs by having small yellow spots on the dorsum, short and distally curved humeral spines in males, and extensive webbing only between Fingers III and IV (Figures 83-85). In Ecuador, species with a similar dorsal coloration include Nymphargus buenaventura, N. siren, N. humboldti sp. nov., Rulyrana flavopunctata, and Teratohyla midas; however, males of these species lack humeral spines. In addition, Teratohyla midas has visceral peritonea covered by iridophores; $N$. buenaventura, $N$. siren, and $N$. humboldti sp. nov. have considerably less hand webbing; and R. flavopunctata has more webbing between Fingers III and IV. The Colombian Centrolene notosticta has a similar dorsal color pattern but lacks vomerine teeth (present in E. audax) and has less webbing between the outer fingers. Espadarana audax is most similar to E. durrellorum (see Taxonomic Remarks), but the latter differs by lacking yellow dorsal spots. Also, the two species are found at slightly different, although overlapping, elevations; E. audax inhabits the Amazonian slopes of the Andes (800-1900 m), whereas E. durrellorum is found mostly in the Amazonian lowlands and foothills (220-1150 m).
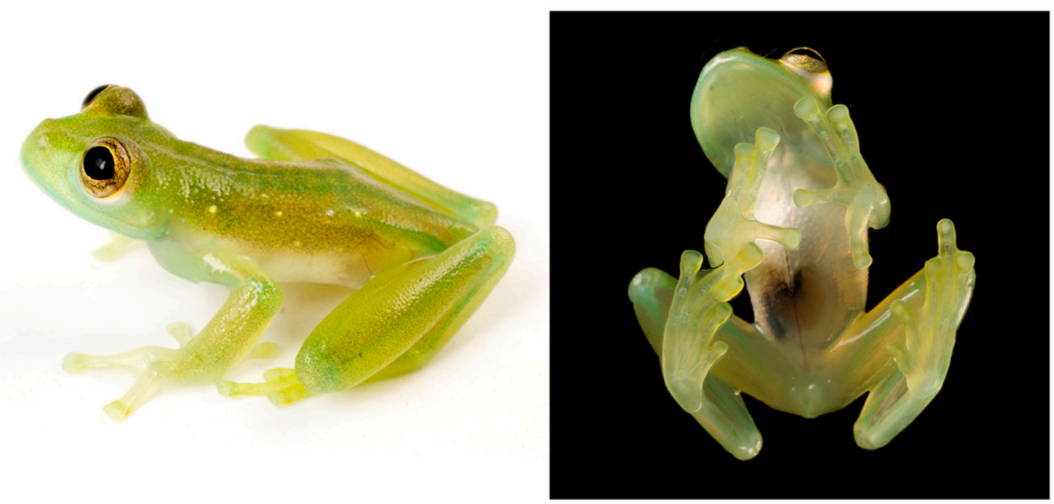

Figure 83. Espadarana audax in life. Adult male, QCAZ 37871, from Gral. Leonidas Plaza Gutiérrez (Limón), Quebrada del Río Napinaza, Morona Santiago, Ecuador. Photos by Luis A. Coloma. 
Diagnosis: (1) Dentigerous process of the vomer bearing two to four teeth; (2) snout rounded in dorsal profile, rounded to truncated in lateral profile; (3) tympanum of moderate size, tympanum diameter $23 \%-29 \%$ of eye diameter, low supratympanic fold evident, tympanic membrane partially pigmented, clearly differentiated from surrounding skin; (4) dorsal surfaces of males and females shagreen, with minute spicules in males; (5) pair of enlarged subcloacal warts, other cloacal ornamentation absent; (6) anterior two-thirds of the ventral parietal peritoneum covered with white iridophores, posterior third transparent (condition P2); white pericardium; no iridophores in peritonea covering intestines, stomach, testes, kidneys, gall bladder, and urinary bladder (condition V1); (7) liver tetralobed, hepatic peritoneum lacking iridophores (condition H0); (8) in adult males, humeral spines present; (9) webbing absent between Fingers I, II, and III; webbing formula for outer fingers III $\left(2^{-}-2^{1 / 3}\right)-\left(2^{-}-2^{+}\right)$IV; (10) extensively webbed foot: I $\left(1-1^{+}\right)-\left(2-2^{+}\right)$II $\left(1^{-}-1^{+}\right)-\left(2-2^{1 / 4}\right)$ III $\left(1-1^{1 / 4}\right)-\left(2^{+}-2^{1 / 3}\right)$ IV $\left(2^{+}-2^{1 / 3}\right)-\left(1-1^{+}\right) \mathrm{V}$; (11) ulnar fold present, inner tarsal fold present, outer tarsal fold absent; (12) concealed prepollex; in males, nuptial pad Type I; (13) Finger I about same length as Finger II (Finger II 95.6\%-102\% length of Finger I); (14) disc of Finger III moderate, its width $43 \%-56 \%$ of eye diameter; (15) in life, dorsal surfaces of head, body, and limbs green with small yellow spots; bones green; (16) in ethanol, dorsal surfaces of head, body, and limbs lavender with small white spots; (17) in life, iris white with yellowish hue and thin black reticulations; (18) melanophores on outer fingers and outer toes; (19) males call from upper sides of leaves; calls are produced in series, with each series having four or five calls; each call is composed by a single, pulsed note; dominant frequency is at 5426-6718 (mean = 6146, SD = 368) Hz; (20) fighting behavior unknown; (21) eggs deposited in moss on branches; short-term maternal care present; parental care by males absent; (22) tadpoles unknown; (23) small body size; in adult males, SVL 21.6-25.5 $\mathrm{mm}(\overline{\mathrm{X}}=23.5 \pm 0.722, n=41)$; in adult females, SVL $24.5-28.8(\bar{X}=27.0 \pm 1.468, n=7)$.
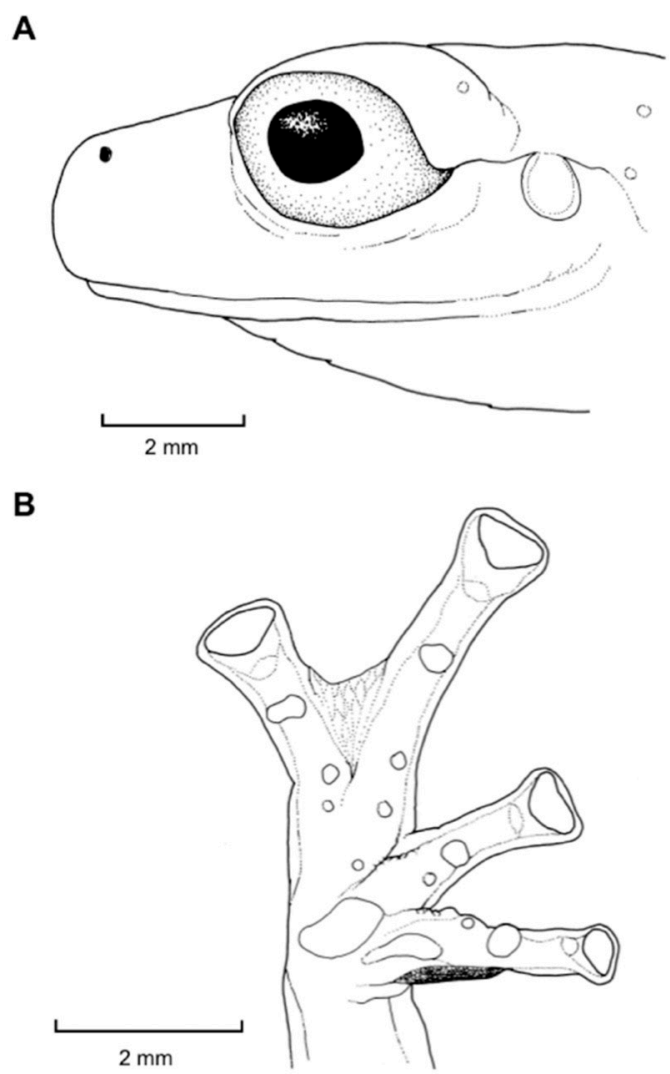

Figure 84. Espadarana audax, adult males. (A) Head in lateral view, KU 164503. (B) Hand in ventral view, KU 178018. Illustrations by Juan M. Guayasamin. 
A

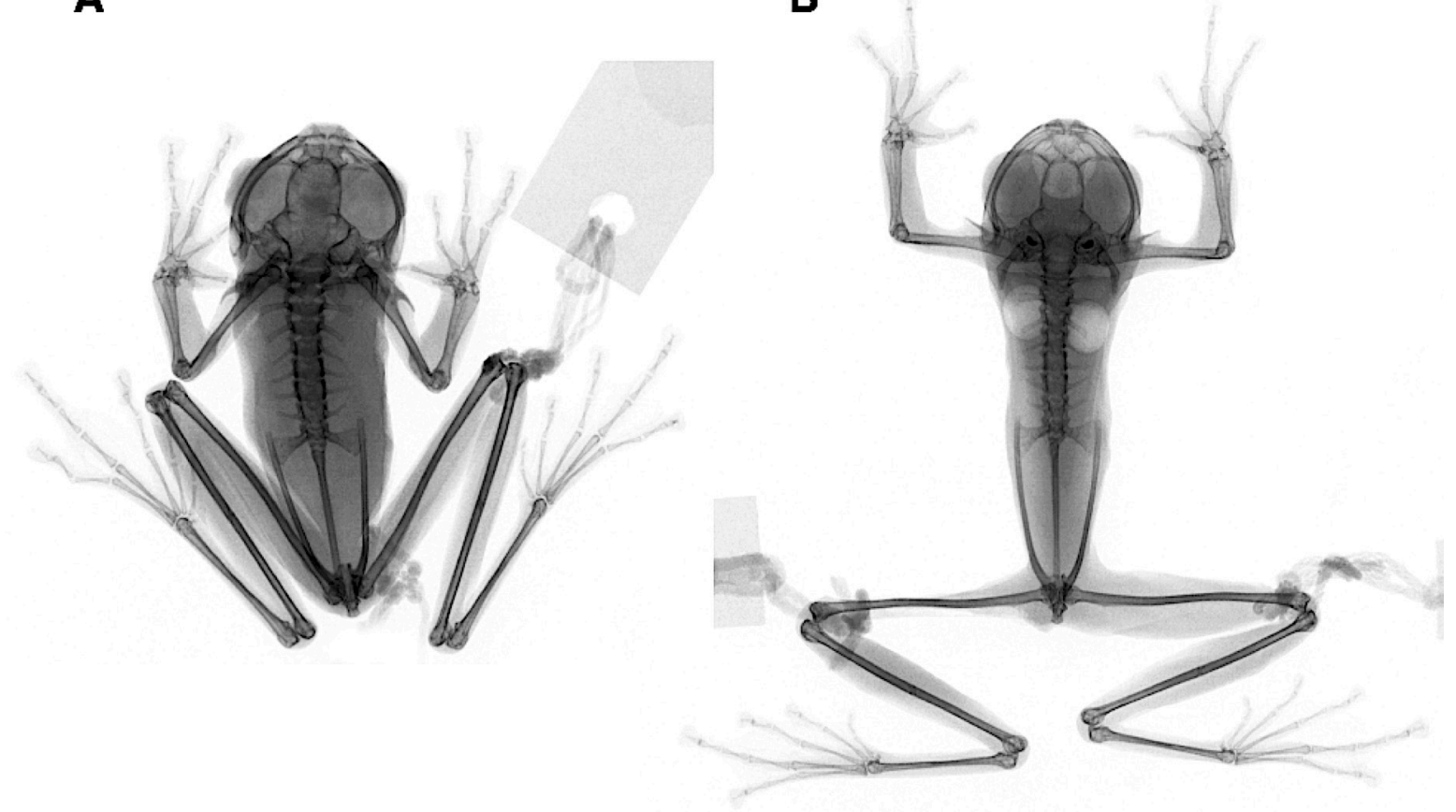

Figure 85. Humeral spines of Espadarana audax and E. durrellorum. (A) Espadarana audax, KU 164500.

(B) Espadarana durrellorum, QCAZ 47909. Photos by Juan M. Guayasamin.

Variation: In several males, the dorsal spicules are minute and only visible under magnification. A population from Leonidas Plaza Gutiérrez (Limón) has a dorsum with very few and small dorsal yellow spots.

Color in life (Figure 83): Dorsum green, with small yellow spots; fingers and toes pale yellow; parietal peritoneum white; heart not visible; visceral peritoneum lacking iridophores. Ventral surfaces of limbs unpigmented; bones green; iris pale bronze to mustard with thin black reticulation ([22], this work).

Color in ethanol: Dorsal surfaces of head, body, and limbs lavender with small white dots; Fingers I-III and Toes I-III cream (without melanophores); upper lip white. White lining on the anterior two-thirds of ventral parietal peritoneum; white pericardium; no iridophores in peritonea covering liver, intestines, stomach, testes, kidneys, gall bladder, and urinary bladder. Some preserved individuals (KU 164497-98) have lost their dorsal white spots; however, close examination revealed the presence of collapsed chromatophores (apparently iridophores).

Biology and ecology: By day, one individual (KU 146624) was found in a bromeliad. During the night, adults are found on the upper sides of leaves along streams, a site from which males call (W. E. Duellman field notes, 19 March 1975; this work). On 18 July 1981, 12 individuals were found in Río Salado; the males were calling and one female (KU 178023) had dark brown oviductal eggs visible through the body wall. Females provide short-term parental care; male parental care is absent [25].

Call (Figure 86): We analyzed 14 notes contained within four calls from two individuals (MZUTI 1492-93). Calls are emitted in series; a typical call series has four or five calls (mean $=4.3, \mathrm{SD}=0.6$ ) and is relatively long (range $=2398-3285 \mathrm{~ms}$, mean $=2711 \mathrm{~ms}, \mathrm{SD}=497.8 \mathrm{~ms}$ ). Each call has a single note with a duration of 26-53 (mean $=38, \mathrm{SD}=8.2) \mathrm{ms}$. Notes have clearly defined pulses with 5-11 (mean $=7.4, \mathrm{SD}=1.7$ ) amplitude peaks throughout the note. Pulses within a note have a rate of 171-208 (mean $=189, \mathrm{SD}=10)$ pulses per second. Notes have their peak amplitude in the first $50 \%$ of the note (relative peak time: Range $=0.0144-0.0722$, mean $=0.043, \mathrm{SD}=0.02$ ), whereby the first note usually has the highest amplitude. The dominant frequency of a note measured at peak amplitude is 5426-6718 (mean $=6146, \mathrm{SD}=368) \mathrm{Hz}$ and is contained within the fundamental frequency. The fundamental 
frequency has a lower limit of 5254-6288 (mean =5925, SD = 374) Hz and a higher limit of 6115-7063 $($ mean $=6608, \mathrm{SD}=297) \mathrm{Hz}$.
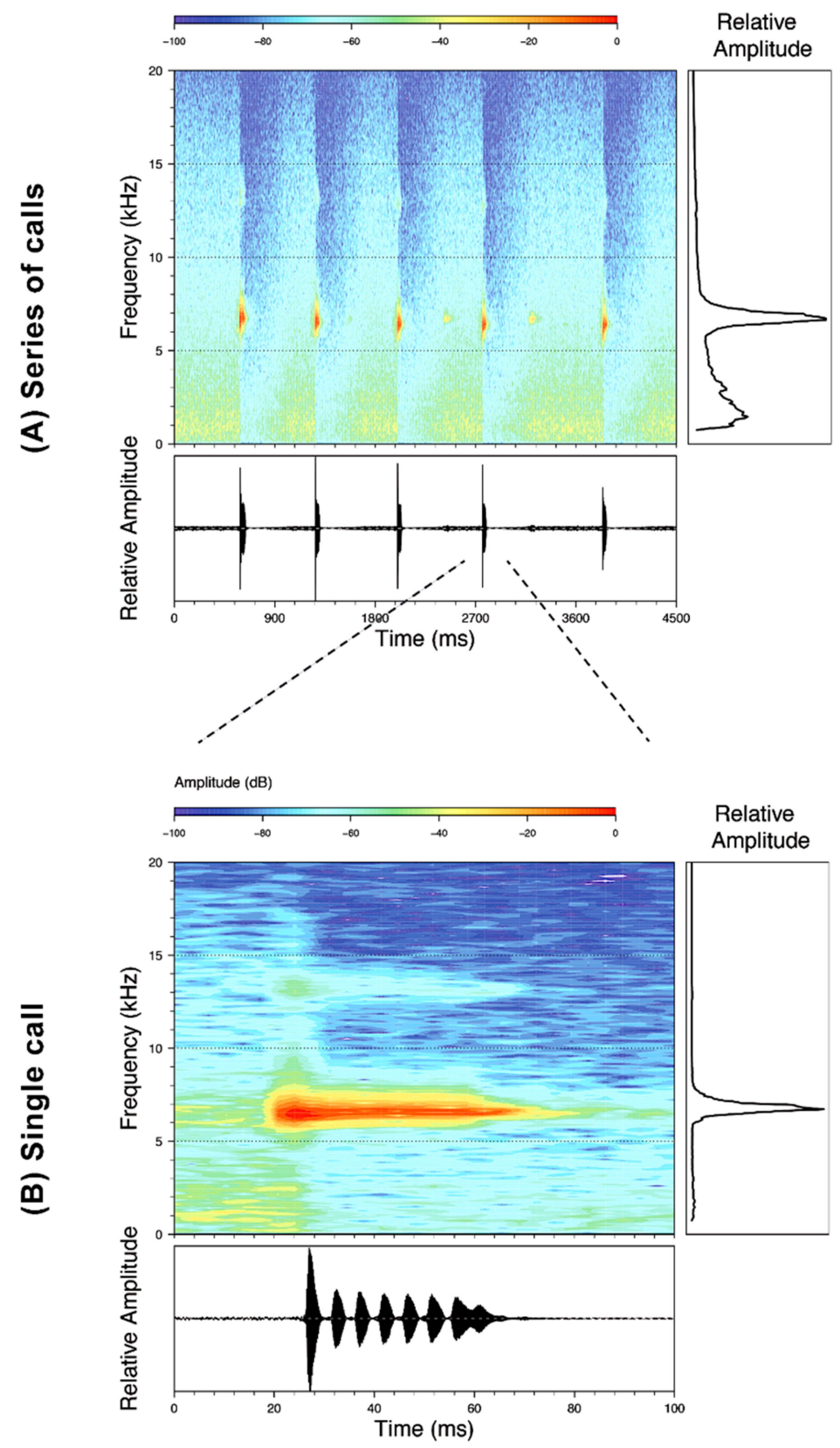

Figure 86. Calls of Espadarana audax, MZUTI 1492, recorded at Río Hollín, 1038 m, Napo province, Ecuador. (A) Call series. (B) Single call.

Tadpole: Not described.

Distribution (Figure 87): Espadarana audax occurs through the Eastern Montane region of southeastern Colombia, Ecuador, and northern Peru at elevations between 800 and $1900 \mathrm{~m}$. This species has been recorded from the provinces of Napo, Morona Santiago, Sucumbíos, and Zamora Chinchipe in Ecuador, the departments of Huila (eastern slope of Cordillera Central), Putumayo, Cauca, Caquetá, and Boyacá (eastern slope of Cordillera Oriental) in Colombia, and the Department of San Martín in Peru ([19,22,174-176], this work). In Ecuador, the species is found within the Eastern Foothill Forest and Eastern Montane Forest ecoregions. The potential distribution of E. audax is $6738 \mathrm{~km}^{2}, 9 \%$ of which is affected by human activities. 


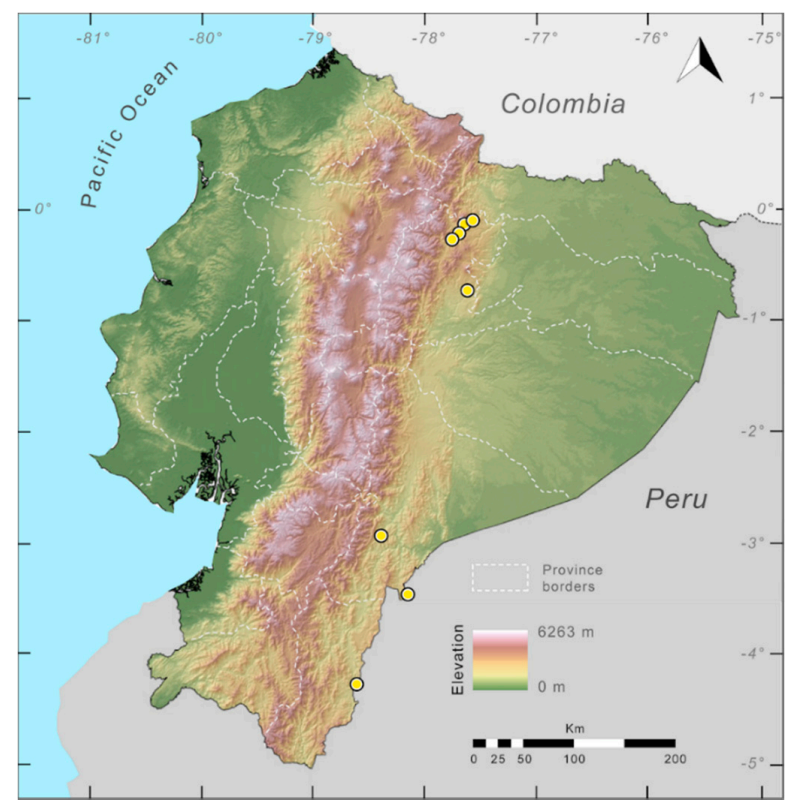

Figure 87. Distribution of Espadarana audax in Ecuador (yellow dots).

Conservation status: Globally, Espadarana audax is currently listed as Least Concern by the IUCN [177]. In Ecuador, E. audax has not been found in some of its historical localities (e.g., Río Azuela, Río Salado ([91], JMG, pers. obs.)), but has been discovered recently at several new localities (Miazi Alto, General Leonidas Plaza Gutiérrez, Zamora); see Specimens Examined. The distribution of the species is fragmented because of agriculture, pasture lands, and mining. We suggest that, in Ecuador, the species should be considered as Near Threatened.

Evolutionary relationships (Figure 88): Given the current gene and taxon sampling, Espadarana audax and E. durrellorum are sister species.

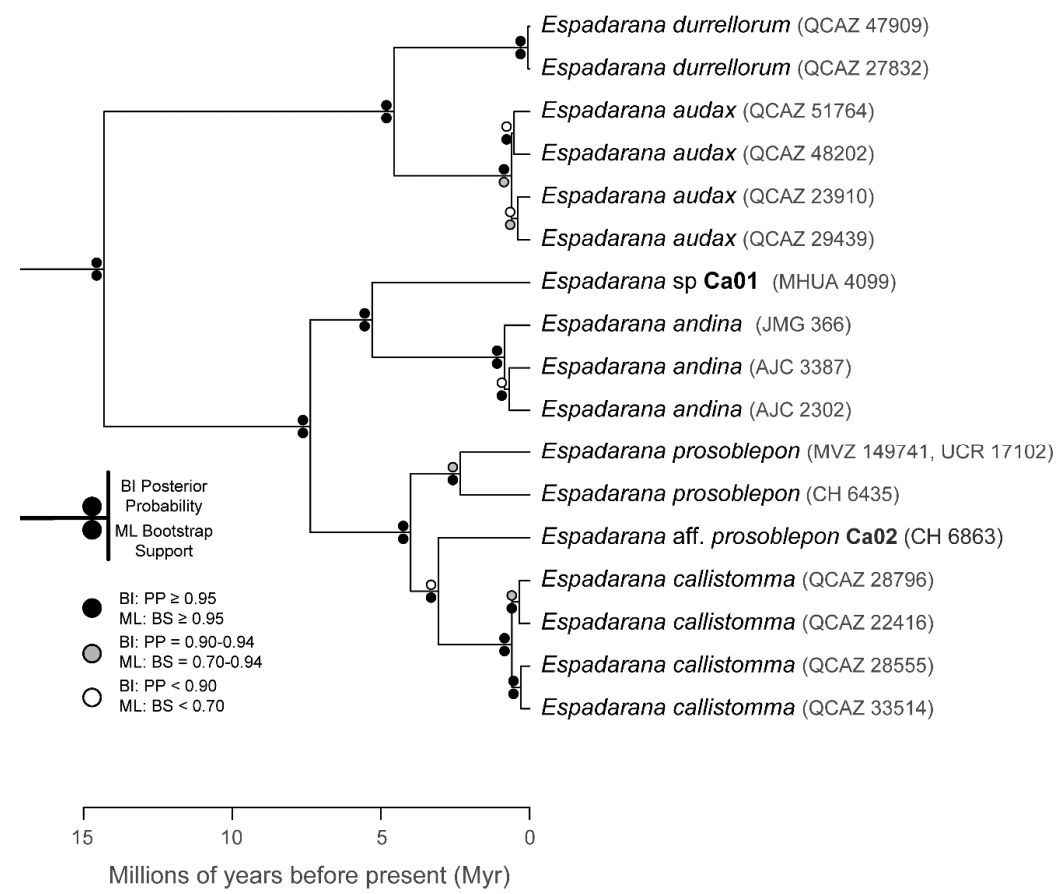

Figure 88. Evolutionary relationships among species in the genus Cochranella, inferred using maximum likelihood and Bayesian criteria. 
Taxonomic Remarks: The morphological differences that separate Espadarana durrellorum and E. audax are subtle, but given the available genetic and morphological data, we consider them as valid species. "Centrolene" fernandoi was recently placed in the synonymy of E. audax [175].

Specimens examined: Espadarana audax: Ecuador: Provincia Napo: $2.5 \mathrm{~km}$ NNE of Río Reventador on Quito-Lago Agrio road (0.133 S, 77.633 W, 1600 m), KU 146624 (holotype); 16.5 km NNE Santa Rosa (0.2186 S; 77.7319 W, 1700 m), KU 143290, 143292; 2 km SSW of junction between Río Reventador and Baeza-Lumbaqui road (0.1 S, 77.6 W, 1700 m), KU 164497-504; 7 km SW Río Azuela on Quito-Lago Agrio road (0.1667 S, 77.667 W), KU 155502-03; Río Salado (0.19167 S, 77.6997 W, 1420 m), KU 178018-27; 43 km NE Santa Rosa (0.1186 S, 77.6003 W, 1490 m), KU 190015; 8.9 km NE Santa Rosa on Quito-Lago Agrio road (0.1667 S, 77.667 W), KU 190016; Río Hollín (0.72 S, 77.639 W; 1100 m), QCAZ 6898; Reserva Narupa (0.6848 S, 77.742 W, 1164 m), ZSFQ 382-86. Provincia Sucumbios: Río Azuela (0.11667 S, 77.6167 W, 1740 m), KU 164496. Provincia Morona Santiago: Quebrada del Río Napinaza, $6.6 \mathrm{~km} \mathrm{~N}$ in the road Limón-Macas (2.92665 S, 78.40701 W; 1100 m), QCAZ 37871, 29439; La Y (3.43236 S, 78.60449 W, 835 m), QCAZ 23910. Provincia Zamora Chinchipe: Alto Miazi (4.25026 S, 78.61746 W; 1250 m), QCAZ 41653; Cordillera del Cóndor, Centro Shuar El Tink, ca. 1050 m, QCAZ 48202. Colombia: Departamento Huila: Parque Arqueológico San Agustín, 3 km SW of San Agustín, 1750 m. Peru: Departamento San Martín: W slope of Abra Tangarana, 7 km (by road) NE of San Juan de Pacaysapa (6.2 S, 76.733 W; 1080 m), KU 211770-75.

Espadarana callistomma (Guayasamin and Trueb 2007 [9]; Figures 89-92).

Centrolene callistommum—Guayasamin and Trueb, 2007 [9]. Holotype: QCAZ 25832.

Type locality: "stream affluent of Río Bogotá ( $1^{\circ} 05^{\prime} 13.8^{\prime \prime}$ N, $78^{\circ} 41^{\prime} 25.8^{\prime \prime}$ W, 83 m), nearby San

Francisco de Bogotá, Provincia de Esmeraldas, Ecuador."

Espadarana callistomma-Guayasamin, Castroviejo-Fisher, Trueb, Ayarzagüena, Rada, and Vilà, 2009 [1].

Common names: English: Beautiful eyes Glassfrog. Spanish: Rana de cristal de ojos bellos.

Etymology: The specific name callistomma is derived from the Greek kallistos-, meaning "most beautiful" and omma, meaning "eye", as a reference to the fantastic iris pattern in this species [9].

Identification: Espadarana callistomma is easily distinguished from most glassfrogs by its large size (in males, SVL 26.7-29.6 mm; in females, SVL 29.5-31.8 mm), uniform green dorsal coloration, and silvery white iris with black reticulations (Figure 89). Espadarana callistomma closely resembles Sachatamia ilex; however, males of E. callistomma have a conspicuous humeral spine, whereas males of S. ilex have a small humeral spine that is embedded in the arm musculature (Figure 201). Some populations of Espadarana prosoblepon have the same color pattern as E. callistomma, but they have a significantly smaller body size (in males, SVL 23.2-27.5 mm; in females, SVL 25.3-27.8 mm) and a two-note call (three to four notes in E. callistomma). See Taxonomic Remarks. 


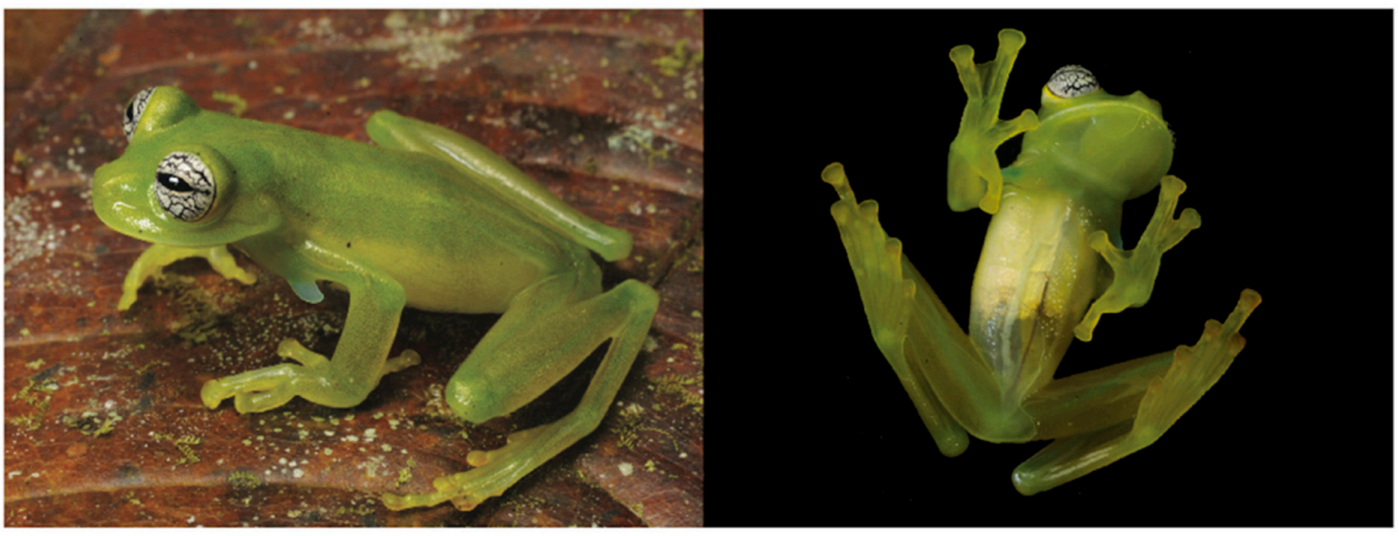

Figure 89. Espadarana callistomma in life from Durango, Esmeraldas province, Ecuador. Adult male, QCAZ 32055. Photo by Martín Bustamante.

Diagnosis: (1) Vomerine teeth present, each vomer with two to seven teeth; (2) snout truncated in dorsal and lateral views (Figure 90); (3) tympanum small (tympanum diameter 20\%-31\% eye diameter), oriented vertically, with lateral inclination; tympanic annulus visible except for upper border, which is covered by supratympanic fold; tympanic membrane partially pigmented, differentiated from surrounding skin; (4) dorsal surfaces of males and females shagreen, with minute spicules evident in males (visible under magnification); (5) pair of enlarged subcloacal warts (Figure 90); (6) anterior two-thirds of ventral parietal peritoneum covered with white iridophores, posterior third transparent (condition P3); white pericardium; translucent peritoneum covering intestines, stomach, gall bladder, testes, and urinary bladder; kidneys covered with translucent peritoneum (condition V1); (7) liver tetralobed, covered by transparent peritoneum (condition H0); (8) humeral spines present in adult males; (9) no webbing between Fingers I and II, webbing between Fingers II and III reduced, webbing between Fingers III and IV extensive (Figure 90), webbing formula: II $\left(1^{2 / 3}-2\right)-\left(3^{+}-3^{1 / 4}\right)$ III $\left(1^{1 / 2}-1^{2 / 3}\right)-\left(1-1^{1 / 2}\right) \mathrm{IV} ;(10)$ webbing on foot extensive (Figure 90$)$, webbing formula: $\mathrm{I}\left(0^{+}-1\right)-\left(2^{-}-2^{+}\right)$ II $\left(0^{+}-1\right)-\left(2^{-}-2^{+}\right)$III $\left(0^{+}-1\right)-2^{-}$IV $\left(2^{-}-2^{1 / 3}\right)-\left(1^{-}-1^{+}\right) \mathrm{V}$; (11) ulnar and inner tarsal folds low; outer tarsal fold absent; (12) concealed prepollex; in males, nuptial pad Type I; (13) Finger II slightly longer than Finger III (Finger III 93.3\%-100\% length of Finger II); (14) disc of Finger III of moderate size, about 29\%-34\% eye diameter; (15) in life, dorsum olive green (Figure 89); bones green; (16) in preservative, dorsum dark lavender; (17) iris silvery white with thin black reticulations; (18) melanophores covering dorsal surfaces of Fingers III and IV and Toes IV and V; (19) males call from upper side of leaves; each call consists of three to four pulsed notes, dominant frequency at $5343-5812 \mathrm{~Hz}$; (20) fighting behavior unknown; (21) eggs deposited on upper side of leaves; parental care unknown; (22) tadpoles unknown; (23) in males, SVL 26.7-29.6 mm ( $\bar{X}=27.8 \pm 0.762 ; n=19)$; in females, SVL $29.5-31.8 \mathrm{~mm}$ $(\overline{\mathrm{X}}=30.5 \pm 0.796 ; n=13)$. 
A

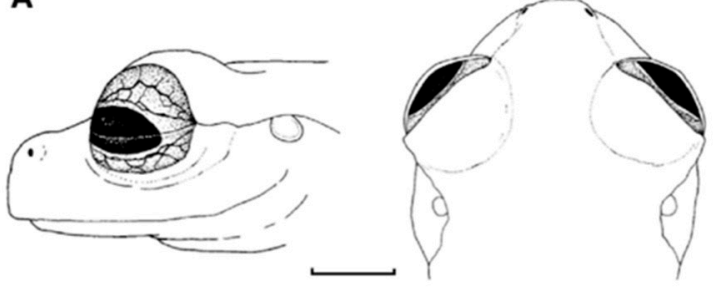

C
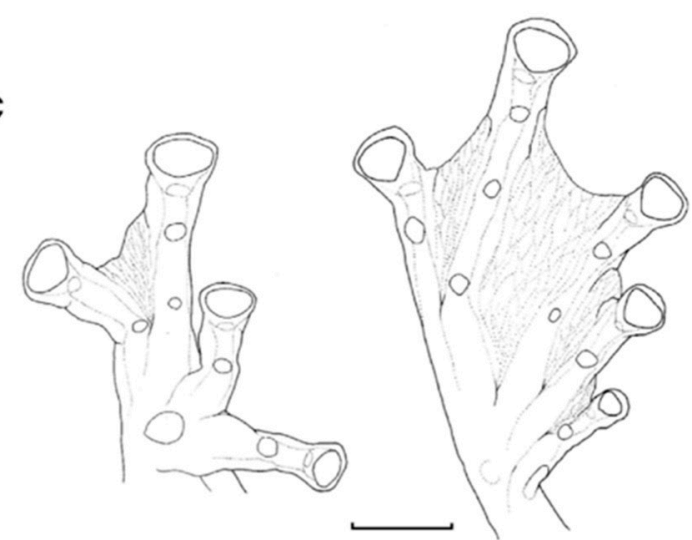

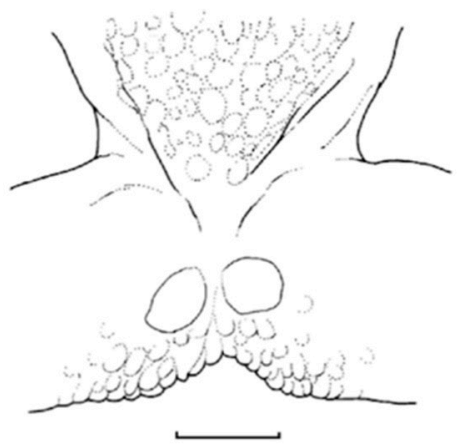

D

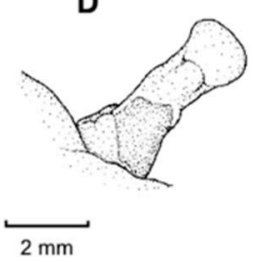

Figure 90. Espadarana callistomma. (A) Head in lateral and dorsal views, paratype, adult male, QCAZ 28803. (B) Ventral surfaces of thighs showing enlarged subcloacal tubercles, holotype, adult male, QCAZ 25832. (C) Hand and foot in ventral view, paratype, adult male, QCAZ 28803. (D) Nuptial pad and thumb in dorsal view, holotype, adult male, QCAZ 25832. Modified from Guayasamin and Trueb [9].

Osteology: A detailed osteological description of Espadarana callistomma was provided by Guayasamin and Trueb [9]; they mentioned that the frontoparietals were exceedingly slender along the orbital margin of the braincase. After reexamining the cleared-and-stained material, it seems that the frontoparietals extend medially and their medial margins partially delimit the frontal fontanelle (area shown as cartilage in [9]: Figure 8A).

Color in life (Figure 89): Dorsum uniform olive green, without spots; upper lip with whitish-cream coloration; iris silvery white with marked black reticulations; flanks white; parietal peritoneum white, covering anterior two-thirds of abdomen (heart not visible); bones green [9].

Color in preservative: Dorsal surfaces of head, body, and limbs uniform lavender; upper lip cream; iris white with marked dark lavender reticulations; nuptial pad on Finger II cream; dorsally, Fingers II and III and Toes I-III unpigmented; venter cream [9].

Biology and ecology: The natural history of Espadarana callistomma is poorly known. The species is active during the night and has been found on leaves along streams. Males call from the upper side of leaves, and females deposit pigmented eggs on the upper side of leaves. It is unknown if males or females provide parental care [9].

Call (Figure 91): Description based on a call (LBE-C-022) of a male E. callistomma recorded by JMG on 17 May 2010 at Reserva Otokiki, Ecuador. Each call consists of three to four pulsed notes $(\bar{X}=3.7 \pm 0.483, n=10)$ and lasts $0.28-0.44 \mathrm{~s}(\bar{X}=0.38 \pm 0.066, n=10)$. Notes are produced at a rate of 9.1-11.0 notes/s $(\bar{X}=9.76 \pm 0.596, n=10)$; each note has a duration of $0.014-0.04 \mathrm{~s}(\bar{X}=0.03 \pm 0.007$, $n=10)$. The call is not frequency modulated; dominant frequency at $5343-5812 \mathrm{~Hz}(n=10)$. 
(A)

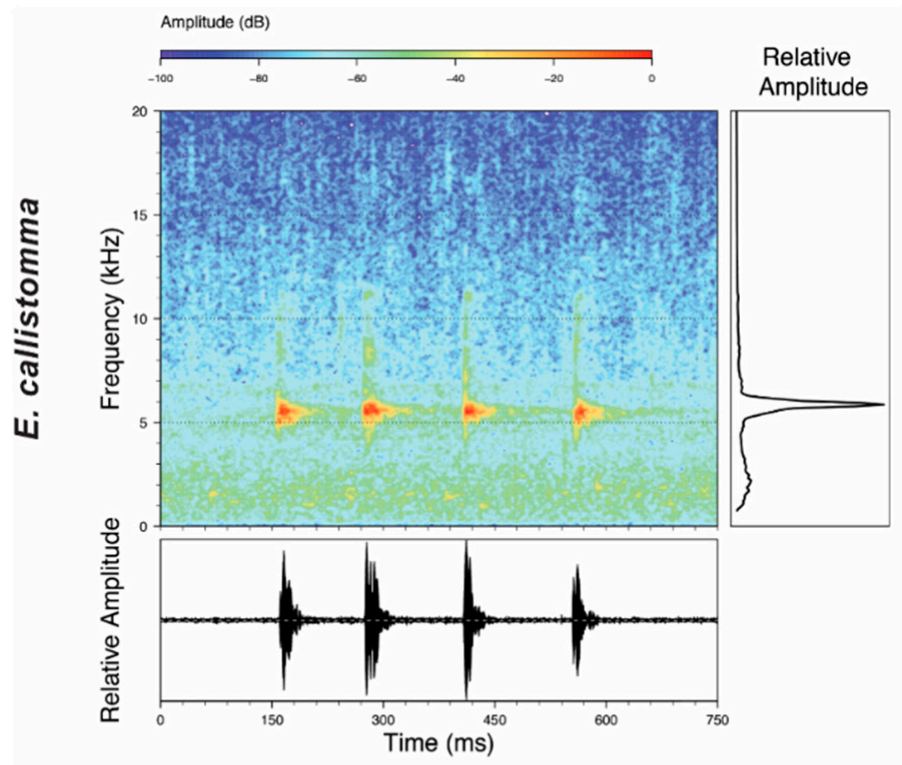

(B)

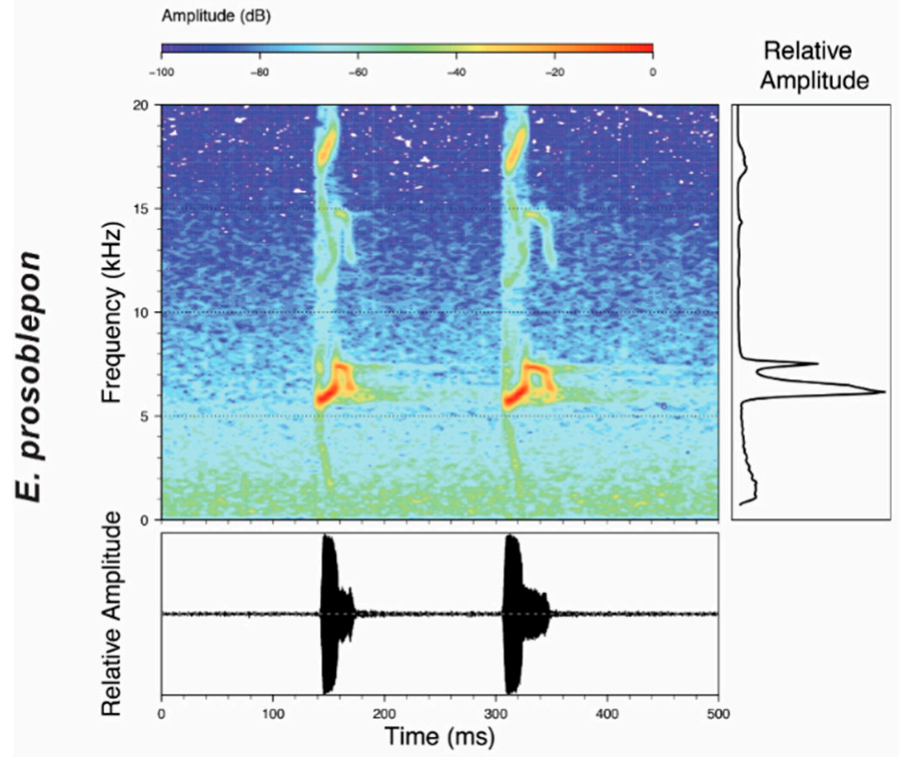

Figure 91. Calls of Espadarana. (A) Call of Espadarana callistomma from Reserva Otokiki, 706 m, Esmeraldas province, Ecuador, LBE-C-022. (B) Call of E. prosoblepon from Cordillera de Chontilla, 908 m, Pichincha province, Ecuador, MZUTI 601.

Tadpole: Not described.

Distribution (Figure 92): Espadarana callistomma is known from four localities in the lowland rainforest of northwestern Ecuador (provinces of Esmeraldas and Carchi) at elevations below $500 \mathrm{~m}$ ([9], this work) and the Pacific lowlands of Colombia [178]. The habitat of the species is within the Chocoan Tropical Forest and the Western Foothill Forest regions (see Biogeographic Regions). 


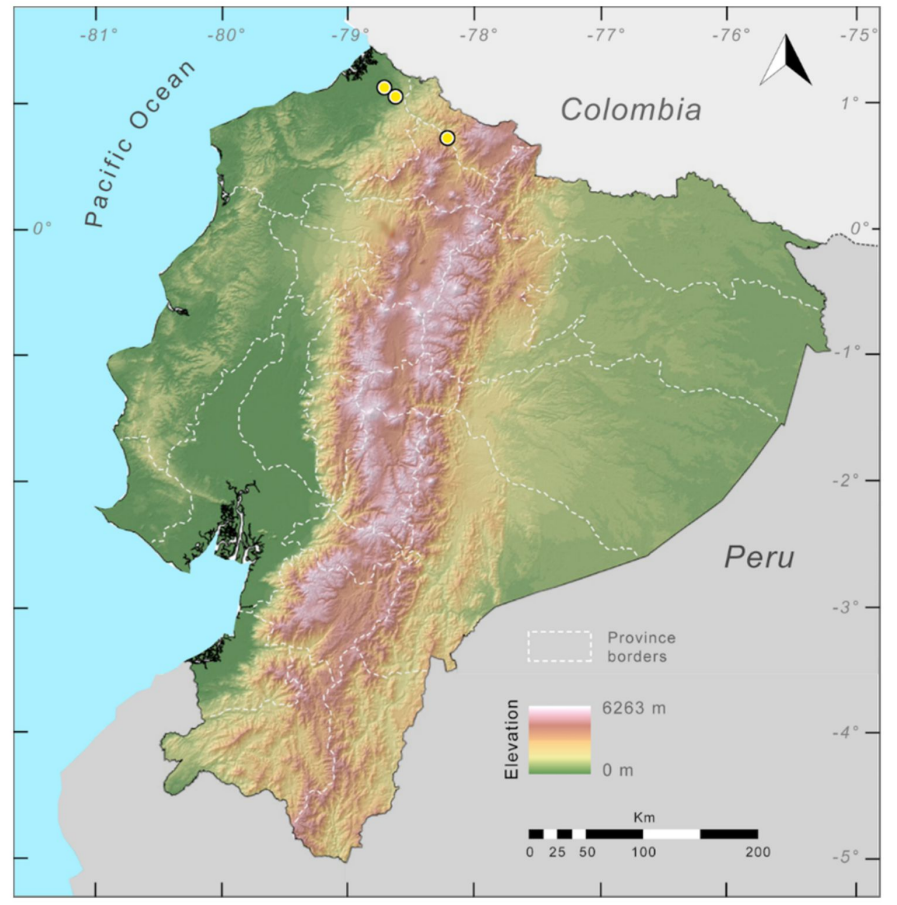

Figure 92. Distribution of Espadarana callistomma in Ecuador (yellow dots).

Conservation status: Globally, Espadarana callistomma is currently listed as Least Concern by the IUCN [179]. At present, E. callistomma is known from a few localities in the Pacific lowlands of Ecuador and Colombia $[9,178]$. The most likely scenario, however, is that E. callistomma is restricted to portions of the Chocó ecoregion, an area with high rates of deforestation and mining; we suggest that the species is considered as Endangered in Ecuador, following IUCN criteria B1, B2a, B2b(iii).

Evolutionary relationships (Figure 88): Espadarana prosoblepon is paraphyletic with respect to E. callistomma, although E. callistomma is monophyletic. The most likely explanations to the observed pattern are: (i) Divergence between the two species is recent and reciprocal monophyly was not yet achieved, (ii) E. callistomma is a synonym of E. prosoblepon, or (iii) E. prosoblepon is a species complex that requires further subdivision. Given the morphological and acoustic data at hand, we favor the first and third hypotheses.

Taxonomic Remarks: The specific status of Espadarana callistomma is uncertain because of the conflict among different sets of data. Genetically, Espadarana callistomma and E. prosoblepon are not reciprocally monophyletic (Figure 88). On the other hand, body size of males and females of E. callistomma is significantly larger than those of E. prosoblepon ( $t$-test,$P<0.001)$, and the dorsal and iris color patterns of E. callistomma are different from most E. prosoblepon (Figure 89 and Figure 95). In terms of vocalization, E. callistomma has a call with more notes (three to four notes per call) than E. prosoblepon (two notes per call; Figure 91). Given that we find biologically meaningful differences among the species (i.e., body size, vocalizations), we recognize both species as valid. The lack of molecular divergence could be the product of a recent divergence, but this is a hypothesis that remains untested. Another pending taxonomic problem is that the type of Hylella parabambae matches the spotless coloration of E. callistomma and some populations of E. prosoblepon.

Specimens examined: Espadarana callistomma: Ecuador: Provincia de Esmeraldas: stream affluent of Río Bogotá $\left(1^{\circ} 05^{\prime} 13.8^{\prime \prime}\right.$ N, 78 $41^{\prime} 25.8^{\prime \prime}$ W, 83 m), nearby San Francisco de Bogotá, QCAZ 25832 (holotype), 27776-8, 28555-56, 28557 (C\&S), 28558; stream affluent of Río Bogotá $\left(1^{\circ} 05^{\prime} 9.06^{\prime \prime} \mathrm{N}\right.$, $\left.78^{\circ} 41^{\prime} 8.7^{\prime \prime} \mathrm{W}, 77 \mathrm{~m}\right), 2 \mathrm{~km}$ E of San Francisco de Bogotá on the San Francisco-Durango road, QCAZ 28803; $2.1 \mathrm{~km}$ E of Durango (1.02477 N, 78.61746 W; $284 \mathrm{~m})$, QCAZ 32169. Provincia de Carchi: Río La Carolina $\left(0^{\circ} 42^{\prime} 16.16^{\prime \prime} \mathrm{N}, 78^{\circ} 12^{\prime} 4.14^{\prime \prime} \mathrm{W}, 500 \mathrm{~m}\right)$, on the Ibarra-Lita road, nearby Jijón y Caamaño, QCAZ 27744-45, 27768. 
Espadarana durrellorum (Cisneros-Heredia, 2007 [180]; Figures 85, 93 and 94).

Centrolene durrellorum Cisneros-Heredia, 2007 [180]. Holotype: DFCH-USFQ D131.

Type locality: "small rivulet tributary of the Jambue River, ca. $6 \mathrm{~km} \mathrm{~S}$ from Zamora (ca. $04^{\circ} 03^{\prime} \mathrm{S}$, $78^{\circ} 56^{\prime} \mathrm{W}, 1150 \mathrm{~m}$ ), on the western slope of Contrafuerte de Tzunantza, Cordillera Oriental, eastern slopes of the Andes, Provincia de Zamora Chinchipe, República del Ecuador".

"Centrolene" durrellorum - Guayasamin, Castroviejo-Fisher, Trueb, Ayarzagüena, Rada, and Vilà, 2009 [1].

Espadarana durrellorum —-Twomey, Delia, and Castroviejo-Fisher, 2014 [19].

Common names: English: Durrell's Glassfrog. Spanish: Rana de Cristal de Durrell.

Etymology: The specific name durrellorum honours Gerald Durrell and Lee Durrell (Durrell Wildlife Conservation Trust) for their contributions to the conservation of biodiversity [180].

Identification: Espadarana durrellorum can be distinguished from all other glassfrogs by having a green dorsal coloration (Figure 93), humeral spines short and straight in adult males (Figure 85), moderate body size (25.7-26.1 mm adult males), and lacking iridophores on the visceral peritonea. Among Ecuadorian centrolenids, E. durrellorum is most similar to E. audax. The main trait to differentiate between the two species is the absence of yellow dorsal spots in E. durrellorum (present in E. audax). E. audax inhabits higher elevations (800 to $1900 \mathrm{~m}$ ) than E. durrellorum (220-1150 m).

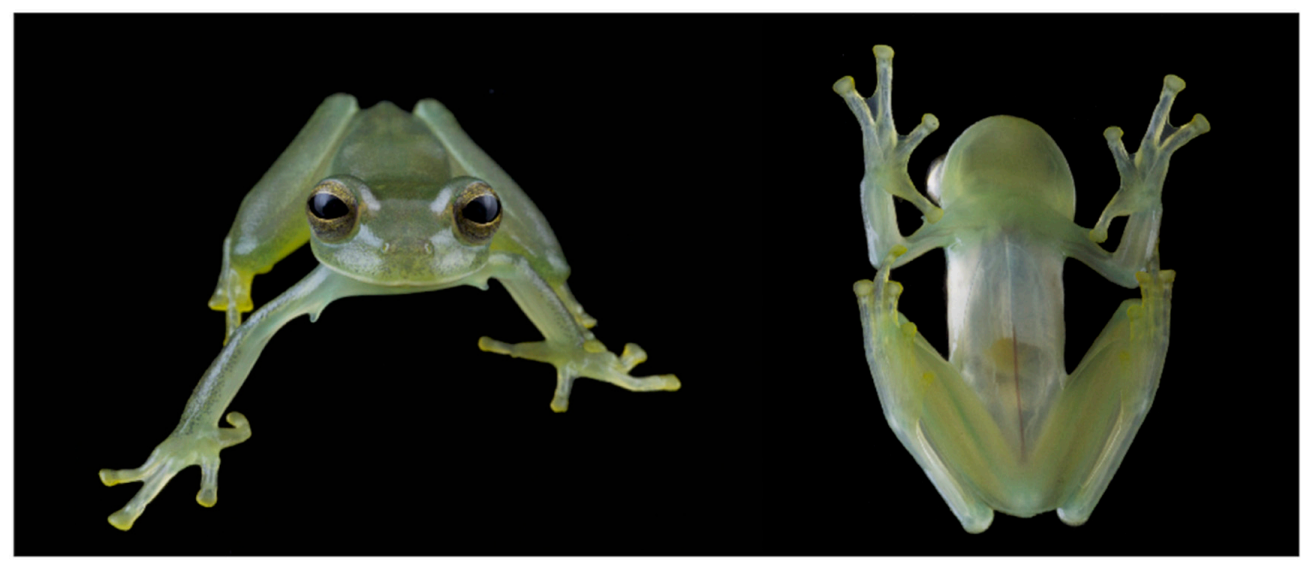

Figure 93. Espadarana durrellorum in life. Ecuador, Napo province, Comunidad Nukanchi Allpa, 403 m, QCAZ 47909. Photos by Luis A. Coloma.

Diagnosis: (1) Vomerine teeth present; (2) snout rounded in dorsal view, bluntly truncated in lateral view; (3) tympanic annulus evident, oriented dorsolaterally; very weak supratympanic fold above tympanum; (4) dorsal skin shagreen, with minute spicules uniformly distributed; (5) ventral skin granular; cloacal area granular, with two large, rounded, flat subcloacal tubercles, and two folds on the sides of the cloacal opening; distinct cloacal sheath; (6) upper two-thirds of the parietal peritoneum covered by iridophores (condition P3), pericardium white, all other peritonea lacking iridophores (condition V1); (7) liver lobed, lacking iridophores (condition H0); (8) in adult males, humeral spine short and straight, with sharp point; (9) webbing absent between Fingers I and II, basal or absent between II and III, moderate between outer fingers: In males, III $2-2^{-}$IV; in one female III $1^{2 / 3}-\left(1^{1 / 2}-2^{-}\right) \mathrm{IV} ;(10)$ webbing formula on feet: In males, I $2-2^{-}$II $1-2$ III $1^{+}-2^{-}$IV $2^{1 / 3}-1^{+} \mathrm{V}$; in one female, I $1-1^{3 / 4}$ II $1-2^{-}$III $1^{+}-2$ IV $2-1 \mathrm{~V}$; (11) no dermal folds on hands, forearms, feet, or tarsus; (12) nuptial excrescences present, Type I; concealed prepollex; (13) first finger slightly longer than second; (14) eye diameter larger than width of disc on finger III; (15) in life, dorsal surfaces uniform green; (16) in preservative, dorsal surfaces uniform pale lavender; (17) in life, iris golden with thin dark reticulations; in preservative, lavender with darker reticulation; (18) melanophores widespread on outer fingers and outer toes; (19) males call from upper surfaces of leaves; call undescribed; $(20,21$, 
22) fighting behavior, egg clutches, tadpoles, and parental care unknown; (23) small body size; SVL 24.8-26.1 $\mathrm{mm}$ in adult males $(n=3) ; 27.0$ in one female.

Color in life (Figure 93): Uniform green dorsum without flecks or spots. Iris golden with dark reticulations. Green bones.

Color in ethanol: All dorsal surfaces pale lavender (no light or dark spots). Ventral surfaces cream. Parietal peritoneum covered by iridophores to the level of the lower stomach; pericardium white, all other peritonea lacking iridophores.

Biology and ecology: Espadarana durrellorum is a recently described species and little information is available on its natural history. It is nocturnal, and males call from the tops of leaves of riverine vegetation in mature Foothill and Lowland Evergreen forests. Parental care unknown.

Call: Not described.

Tadpole: Not described.

Distribution (Figure 94): Espadarana durrellorum is known from few localities on the foothills of Cordillera Oriental and the Amazonian lowlands of Ecuador, at elevations of 300-1267 m [176,180].

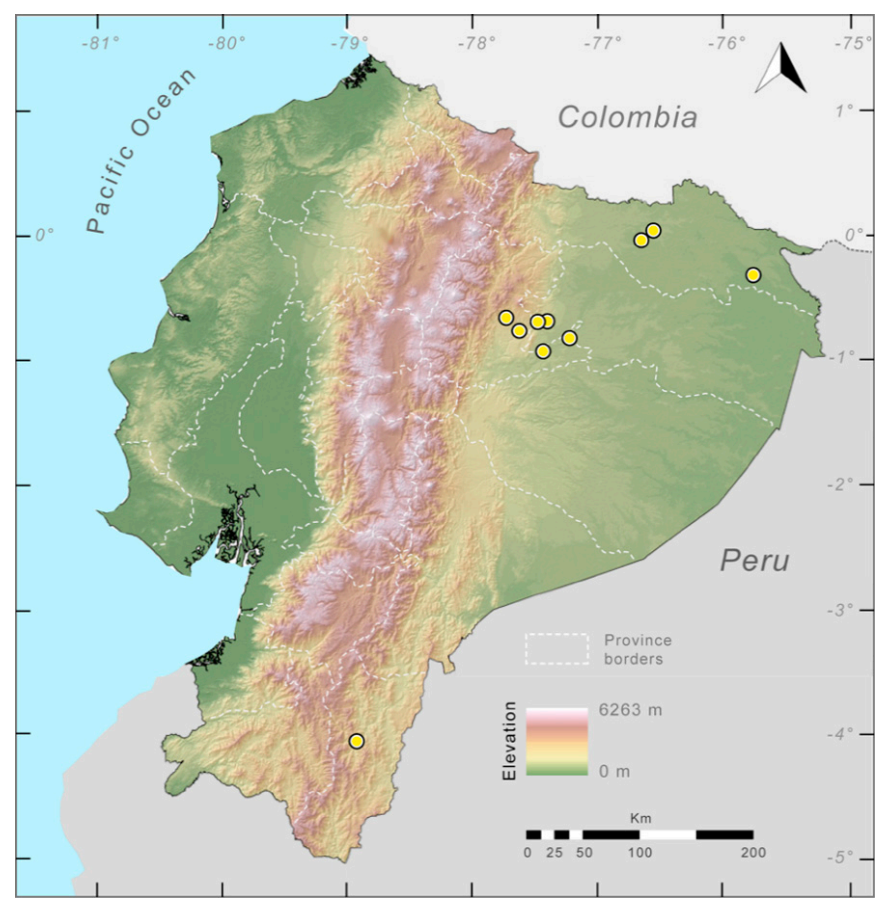

Figure 94. Distribution of Espadarana durrellorum in Ecuador (yellow dots).

Conservation status: Globally, E. durrellorum is Least Concern by the IUCN [181]; the species is known from few confirmed records, and a re-evaluation of its conservation status may be required.

Evolutionary relationships (Figure 88): Espadarana durrellorum and E. audax are sister species.

Taxonomic Remarks: See Taxonomic Remarks under Espadarana audax.

Specimens examined: Espadarana durrellorum: Ecuador: Provincia de Napo: ca. $45 \mathrm{~km} \mathrm{E}$ of Narupa, on the Hollín-Loreto road (ca. 800 m), DFCH-USFQ D291; Parroquia Chontapunta, comunidad Nukanchi Allpa, cabecera del río Canoayacu (0.99965 S, 77.39619 W W $403 \mathrm{~m})$, QCAZ 47909; Reserva Yachana $\left(00^{\circ} 52^{\prime} 21.7^{\prime \prime} \mathrm{S}, 77^{\circ} 14^{\prime} 13.4^{\prime \prime} \mathrm{W}\right.$; 300-350 m), DHMECN 03492, 06790-91; Pungarayacu $\left(00^{\circ} 42^{\prime} 27.8^{\prime \prime} \mathrm{N}, 77^{\circ} 44^{\prime} 26.2^{\prime \prime} \mathrm{W} ; 1267 \mathrm{~m}\right)$, DHMECN 03476. Provincia de Sucumbios: Zábalo $\left(0.3181333^{\circ} \mathrm{S}\right.$,

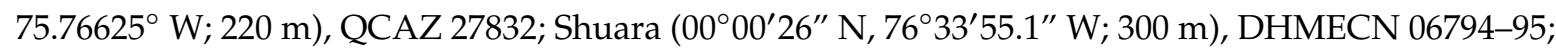
Plataforma Shushufindi $\left(00^{\circ} 05^{\prime} 14.8^{\prime \prime} \mathrm{S}, 76^{\circ} 40^{\prime} 03.8^{\prime \prime} \mathrm{W} ; 330 \mathrm{~m}\right)$, DHMECN 06793. Provincia de Zamora Chinchipe: tributary of the Jambue River, ca. $6 \mathrm{~km} \mathrm{~S}$ from Zamora (ca. 04 $03^{\prime} \mathrm{S}, 78^{\circ} 56^{\prime} \mathrm{W} ; 1150 \mathrm{~m}$ ), on the western slope of Contrafuerte de Tzunantza, Cordillera Oriental, eastern slopes of the Andes, DFCH-USFQ D131. 
Espadarana prosoblepon (Boettger, 1892 [182]; Figures 91 and 95-97).

Hyla prosoblepon Boettger, 1892 [182]. Syntypes: SMF 3756 (formerly 1400.1a, according to Boettger, 1892 [182]), and ZMB 28019, according to Duellman, 1977 [118]; SMF 3756 designated lectotype by Mertens, 1967.

Type locality: "Plantage Cairo (La Junta) bei Limon, (Cantón de Siquirres, Provincia de Limón) atlantische Seite von Costa Rica". Savage, 1974 [183], commented on the type locality.

Hylella puncticrus Boulenger, 1896 [184]. Syntypes: BM 96.10.8.70-71. Type locality: "La Palma"

San José Province, Costa Rica. Placed in synonymy by Günther, 1901 [185].

Hyla parabambae Boulenger, 1898. Holotype: BM 98.4.28.163. Type locality: “Paramba” Imbabura Province, Ecuador. Noted elsewhere in the original publication as "Paramba, a farm on the W. bank of the River Mira, at 3500 feet altitude; it is still in the forest region, but the open country commences two or three miles higher up the Mira". Placed in synonymy by Lynch and Duellman, 1973 [22].

Centrolene prosoblepon-Noble, 1924 [186].

Cochranella parabambae-Taylor, 1951 [15].

Centrolenella parabambae-Goin, 1964 [187].

Centrolenella prosoblepon-Goin, 1964 [187].

Hyla ocellifera Boulenger, 1899. Holotype: BM 98.5.19.3. Type locality: "Paramba, (Provincia Imbabura,) N. W. Ecuador". Placed in synonymy by Cisneros-Heredia and McDiarmid, 2007 [17].

Espadarana prosoblepon-Guayasamin, Castroviejo-Fisher, Trueb, Ayarzagüena, Rada, and Vilà, 2009 [1].

Common names: English: Variable Glassfrog. Spanish: Rana de Cristal Variable.

Etymology: The specific name prosoblepon is apparently derived from the Greek words proso (forward, onward, in front) and blepo (look or see), probably referring to the forward orientation of the eyes in centrolenid frogs [84].

Identification: Espadarana prosoblepon is distinguished from most glassfrogs from the Pacific versant of the Andes by having a large, flat, and projected humeral spine, and green dorsum with small black spots (Figure 95); however, E. prosoblepon has a highly variable dorsal coloration, including individuals that have both black and yellows spots, only yellow spots, only black spots, or absence of spots all together. In Ecuador, the only species that have a green dorsum with dark spots are Cochranella litoralis, Vitreorana ritae, Nymphargus cochranae, and N. megacheirus. In three of these species (V. ritae, N. cochranae, N. megacheirus), males lack humeral spines; additionally, they occur on the Amazonian lowlands or Amazonian slope of the Andes and are never in sympatry with E. prosoblepon. Cochranella litoralis has a bright orange iris and is smaller than E. prosoblepon (in males, SVL $<22.1 \mathrm{~mm}$ in C. litoralis; $23.2-27.5 \mathrm{~mm}$ in E. prosoblepon). Unspotted E. prosoblepon can be confused with E. callistomma and C. buckleyi; E. callistomma is distinguished by having a larger body size (in males, SVL 26.7-29.6 $\mathrm{mm}$; in females, SVL $29.5-31.8 \mathrm{~mm}$ ), contrasting black-and-white iris, and a call with three to four notes (call with two notes in E. prosoblepon; see Taxonomic remarks). Centrolene buckleyi has an inclined snout in lateral view (Figure 26) and is only found at elevations above $2000 \mathrm{~m}$. Individual of E. prosoblepon with uniform dorsum and white iris with black reticulations resemble Sachatamia ilex; however, males of E. prosoblepon have a conspicuous humeral spine, whereas males of $S$. ilex have a small humeral spine that is embedded in the arm musculature (Figure 201). The closely related E. andina is similar to E. prosoblepon by having dark spots on the dorsum but has a pointy humeral spine that is almost parallel to the humerus, whereas in E. prosoblepon, the spine is broad, laminar, and projected at an angle of about $45^{\circ}$ from the humerus. 

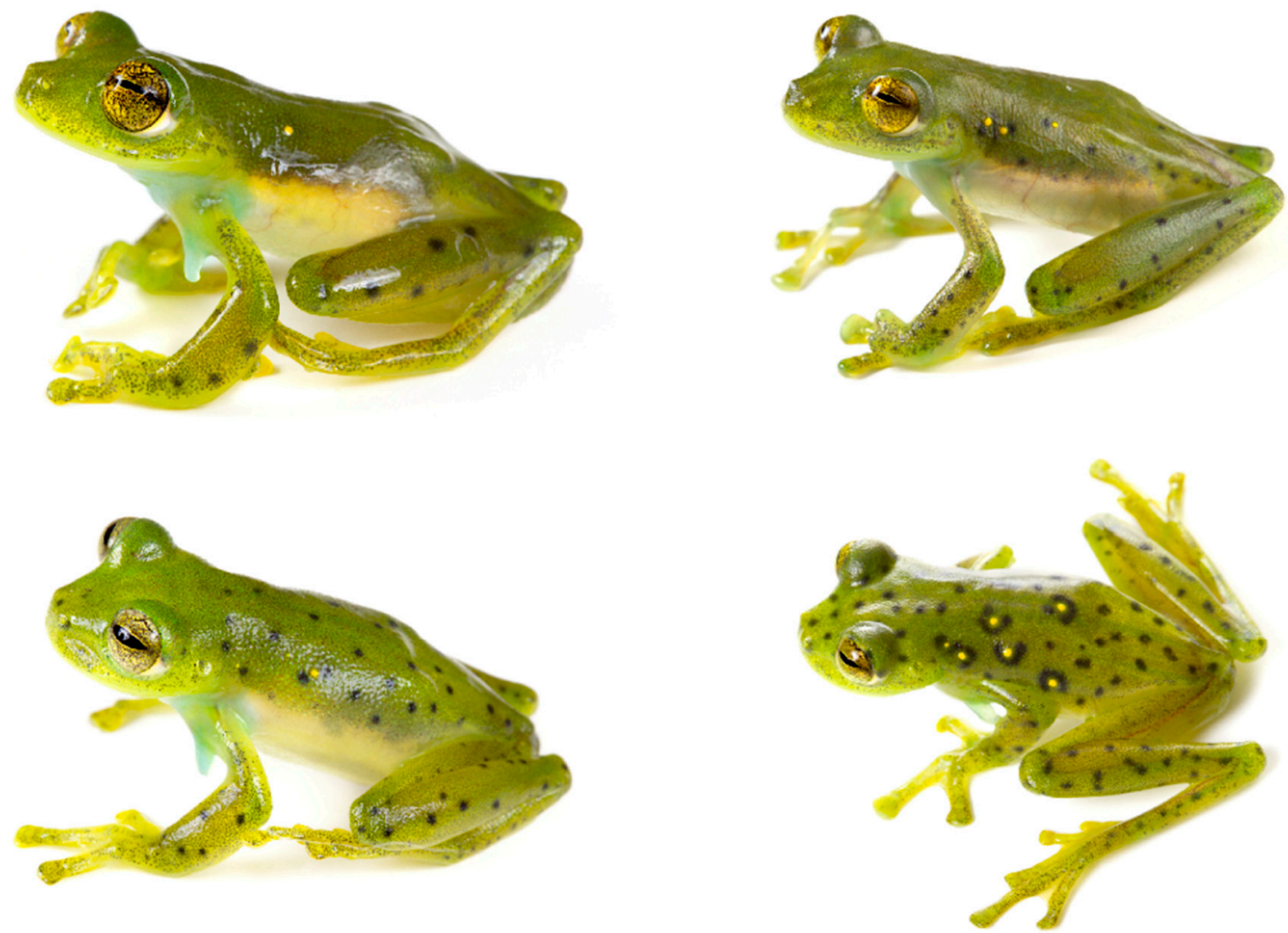

Figure 95. Espadarana prosoblepon in life. Note variation of dorsal patterns. Frogs from Mindo and surroundings, Pichincha province, Ecuador; not collected. Photos by Alejandro Arteaga/Tropical Herping.

Diagnosis: (1) Each vomer with two to seven teeth on dentigerous process; (2) snout usually truncated in dorsal and lateral profiles (Figure 96); (3) tympanum small, oriented almost vertically, with slight lateral and posterior inclinations, its diameter $20.5 \%-30.8 \%$ of eye diameter; tympanic annulus mostly visible, with supratympanic fold covering its posterodorsal margin; tympanic membrane translucent, partially pigmented, clearly differentiated from surrounding skin; (4) dorsal skin shagreen; males and females may possess minute spicules on flanks and tympanic region; (5) pair of enlarged subcloacal warts; (6) white iridophores on the anterior $50 \%-70 \%$ of the ventral parietal peritoneum, posterior portion transparent (condition P2-P3); white pericardium; translucent peritonea covering intestines, stomach, kidneys, gall bladder, and urinary bladder (condition V1); (7) liver with four clearly defined lobes covered by transparent peritoneum (condition H0); (8) males with conspicuous humeral spines; (9) webbing absent between Fingers I and II, absent or basal between Fingers II and III; moderate between outer fingers (Figure 96); webbing formula III $\left(1^{2 / 3}-2\right)-(1-2)$ IV; (10) webbing between toes moderate; webbing formula on foot $\mathrm{I}\left(0^{+}-1\right)-\left(2^{-}-2^{+}\right) \mathrm{II}\left(0^{+}-1\right)-\left(2^{-}-2^{+}\right) \mathrm{III}\left(0^{+}-1\right)-\left(2^{-}-2^{+}\right)$ IV $\left(2^{-}-2^{1 / 3}\right)-\left(1-1^{+}\right) \mathrm{V} ;(11)$ ulnar and tarsal folds absent or low and inconspicuous, lacking white coloration; (12) concealed prepollex; nuptial pad Type I; (13) Finger I as long as Finger II or slightly longer (Finger II length $93.8 \%-101 \%$ Finger I); (14) disc of Finger III moderate, width $28.6 \%-49.0 \%$ of eye diameter; (15) in life, dorsum green usually with small dark spots (Figure 95; but see Color in life section); bones green; (16) in preservative, dorsum lavender with or without cream and/or dark spots; (17) in life, iris varies from grey with fine dark reticulations to white with thick black reticulations; (18) melanophores covering dorsal surfaces of Fingers III and IV and Toes IV and V; (19) males call from upper side of leaves or small branches; (20) males fight upside down, grasping one another venter to venter; (21) black eggs are deposited on the upper surface of leaves, moss-covered rocks, or branches; short-term maternal care present; males do not provide parental care; (22) tadpoles with non-emarginated oral apparatus; tooth row formula 2/3; upper jaw curved; (23) small to medium body 
size; in adult males, SVL $23.2-27.5 \mathrm{~mm}(\overline{\mathrm{X}}=24.8 \pm 0.982, n=53)$; in adult females, SVL $25.3-27.8 \mathrm{~mm}$ $(\bar{X}=26.6 \pm 0.859, n=15)$.
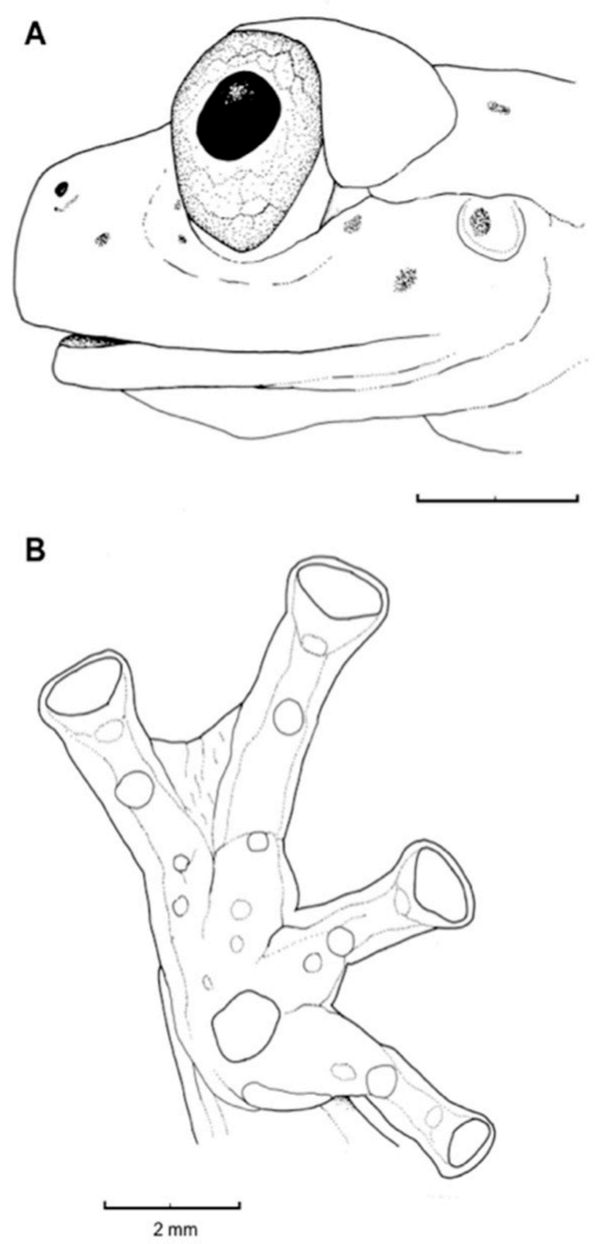

Figure 96. Espadarana prosoblepon, KU 132462. (A) Head in lateral view. (B) Hand in ventral view. Illustrations by Juan M. Guayasamin

Color in life (Figure 95): In Costa Rica, dorsal surfaces green dorsum with dark spots [148]. About one-half of Honduran specimens lack small dark dorsal spots [84]. In Ecuador, several color patterns have been reported: (1) Uniform green dorsum; (2) dorsum green with dark spots; (2) dorsum green with yellow spots; (3) dorsum green with dark and yellow spots, separated from each other; and (4) dorsum green with dark spots surrounding yellow spots, forming false ocelli. Iris varies from greyish white to pale bronze with fine dark reticulation, to silvery white with thick black reticulations. Green bones; whitish cream upper lip; white venter that is transparent posteriorly; ventrolateral margins of forearm and tarsus lacking white coloration.

Color in ethanol: As described above, but green turns into lavender and yellow spots turn white. Some individuals (e.g., KU 132463-64) present black and smaller white spots on dorsum. White parietal peritoneum covering about anterior $60 \%$ of venter. Translucent peritonea cover digestive tract, liver, kidneys, and urinary and gall bladders; white pericardium.

Biology and ecology: The following information is based on studies by Jacobson [188], Hayes [189], Savage [148], Hoffmann [147], and Arteaga et al. [87]. At night, during the breeding season, Espadarana prosoblepon is found on vegetation along margins of streams in primary to slightly degraded evergreen forests and, sporadically, even in pastures. Reproduction peaks in the rainy season, when males become more vocal and often engage in aggressive territorial combats. Males initiate amplexus by jumping on the back of approaching gravid females. Females lay $20-52$ black eggs on a variety 
of substrates and directly above the water. Females provide short-term parental care; male parental care is absent [25]. After hatching, tadpoles usually hide under leaf litter or sand at the bottom of streams. Males are territorial, and the advertisement call is used to space them along the stream. If an intruder moves into an occupied territory, the resident male produces a rapid series of calls; if the intruder approaches too closely, a fight ensues with both males dangling upside down while holding onto vegetation with their legs and grappling with their arms and humeral spines. The combat concludes when the loser drops from the fight site or signals submission by flattening his body against the leaf surface. Espadarana prosoblepon feeds on a variety of small arthropods including beetles, moths, spiders, and mites. As a defense mechanism, this glassfrog produces pungent odors when grabbed. Espadarana prosoblepon is the only glassfrog species for which survival information is available; McCaffery and Lips [190] report that mean annual survival probability is $0.46(0.41-0.52,95 \%$ CI). These authors also provide abundance data on several populations from Panama.

Call (Figure 91): The following description is based on a call of a male Espadarana prosoblepon (MZUTI 601) recorded by Italo Tapia during the night of 4 July 2012 at Río Sune Chico (908 m, Cordillera Chontilla, Pachijal-Mashpi) Pichincha province, Ecuador. Air temperature at the moment of the recording was $18.8^{\circ} \mathrm{C}$. Calls are produced every $4-7 \mathrm{~min}$. Each call consists of two pulsed notes and lasts $0.207-0.223 \mathrm{~s}(\overline{\mathrm{X}}=0.212 \pm 0.007, n=4)$. Each note has a duration of $0.032-0.054$ notes $/ \mathrm{s}$ $(\bar{X}=0.040 \pm 0.008, n=8)$; time between the two notes of each call is $0.130-0.137 \mathrm{~s}(\overline{\mathrm{X}}=0.134 \pm 0.004$, $n=4)$. Calls are frequency modulated; the dominant frequency at the beginning of each note is $5712-5825 \mathrm{~Hz}(\bar{X}=5759 \pm 56.1, n=4)$, whereas at the end of the note is at $6196-6394 \mathrm{~Hz}(\bar{X}=6252 \pm 95.7$, $n=4)$. Harmonics are also frequency modulated, showing complex spectral patterns.

The call of E. prosoblepon from Costa Rica shows some differences from the Ecuadorian call described above. The following information is from Jacobson [188] and describes a call from Monteverde, Costa Rica. Males of Espadarana prosoblepon call at irregular intervals (17 calls/h) from the upper surfaces of leaves during the night. The advertisement call consists of two to five short "beeps". When encountering another frog within $15 \mathrm{~cm}$, the resident males often give a series of rapid short beeps. Males of Espadarana prosoblepon call vigorously while in amplexus and also immediately after egg deposition. Kubicki [24] described the call of E. prosoblepon as a rapid three-note series, but sometimes males emit four to five notes; each note has an average duration of $0.03 \mathrm{~s}$; the dominant frequency is $5.5-5.8 \mathrm{kHz}$. Typical call series have a total duration lasting $0.5 \mathrm{~s}$ (average three-note series) or $0.75 \mathrm{~s}$ (average four-note series). Because males call from exposed sites on the upper surfaces of leaves and twigs, these periodic calling bouts, often synchronized among a few, nearby males, may make it more difficult for predatory bats (i.e., Trachops cirrhosus) to locate and eat calling male E. prosoblepon (RWM, pers. obs.).

Tadpole: Females lay egg clutches on the upper side of leaves, moss-covered rocks, or branches; clutch size varies from 20 to 52 eggs that have a dark brown to black coloration; females remain with the eggs for some time (up to $131 \mathrm{~min}$ ), but once they leave neither parent returns to the clutch $[87,147,148,188,189]$. Embryos are black but quickly turn yellow. By the time the tadpoles hatch and fall into the stream, they are red colored [148]. At Stage 25 [191], larvae have a sinistral spiracle, a relatively simple oral disc with medium-sized jaw sheaths, 2/3 tooth rows, and a single row of marginal papillae with a wide dorsal gap. The second anterior (upper) tooth row (A-2) also has a wide gap [148]. Drawings of the mouth and body can be found in Starrett [146], Savage [148]), and McCranie and Wilson [84]. 
Distribution (Figure 97): Espadarana prosoblepon is found from eastern Honduras, Nicaragua, Costa Rica, and Panama, south along the Pacific slopes of the Andes of Colombia and Ecuador from sea level to about $1600 \mathrm{~m}$ elevation. In Colombia, it occurs on the northern and eastern flanks of the Eastern Cordillera south to Caldas, and in the Magdalena Valley [192]. In Ecuador, Espadarana prosoblepon has been reported from several localities below $1620 \mathrm{~m}$ [87] (Specimens examined). The habitat of the species in Ecuador is mainly within the Chocoan Tropical Forest and the Western Foothill Forest regions, but it is also found in Deciduous Forest and the lower limit of the Western Montane Forest region. In Ecuador, it has a potential distribution of $41,612 \mathrm{~km}^{2}$.

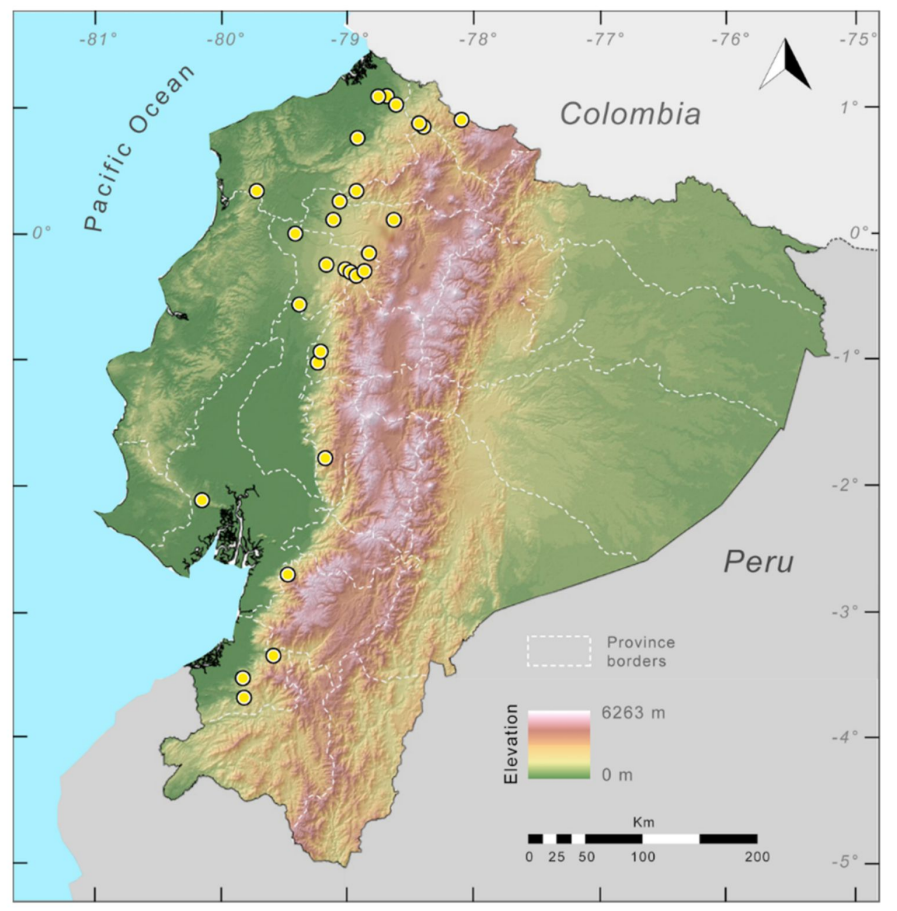

Figure 97. Distribution of Espadarana prosoblepon in Ecuador (yellow dots).

Conservation status: Globally, Espadarana prosoblepon is listed as Least Concern [192] in view of its large distribution and presumed large populations. In Ecuador, this species is common and is found even in habitats with moderate alterations; the category of Least Concern is justified.

Evolutionary relationships (Figure 88): Espadarana prosoblepon is paraphyletic, containing populations currently assigned to E. callistomma, a pattern that can be explained, mainly, by recent species divergence or the two species actually representing a single evolutionary lineage. See Taxonomic Remarks below.

Internal morphology: A detailed osteological and myological description of Espadarana prosoblepon was provided by Eaton [193]. The hyoid apparatus illustrated by Eaton lacks the anterolateral processes that are evident in cleared-and-stained material from Ecuador (KU 178163) and Costa Rica (KU 65178). We assume that the normal condition is the presence of these processes.

Taxonomic remarks: While the general morphology of Espadarana prosoblepon is mostly conservative, its color pattern is extremely variable, and because of an insufficient understanding of the species' variation, different names have been assigned to distinctive morphs. For example, populations whose individuals have dorsal coloration consisting of black spots surrounding yellow spots and forming ocelli were called ocellifera, while others with dorsum lacking spots have been variously named parambae and callistomma. Several authors, including Lynch and Duellman [22], Savage [42], and Cisneros-Heredia and McDiarmid [17], have described some of the interspecific variation characteristic of E. prosoblepon, but much remains to be done. For example, most descriptions and color photographs of E. prosoblepon depict the iris of this species as grey with fine dark reticulations, 
but Kubicki [24] reported individuals with a white iris with black reticulations. Unfortunately, most centrolenid descriptions have paid little attention to iris patterns; in fact, with the exception of the descriptions of Sachatamia ilex, Hyalinobatrachium ignioculus, and H. eccentricum (the last two taxa now under the synonymy of $H$. cappellei), iris coloration, if reported at all, usually is based on examination of photographs; thus, the inter and intraspecific variation in iris color is poorly known. Genetic data suggest that E. prosoblepon and E. callistomma might represent one evolving lineage (Figure 88). Morphological differences between E. callistomma and E. prosoblepon are in body size (callistomma being larger), dorsal coloration (without spots in callistomma; usually with spots in prosoblepon), and iris coloration (white with contrasting black reticulation in E. callistomma; less contrasting in E. prosoblepon). In terms of vocalization, E. callistomma has a call with more notes (three to four notes per call) than E. prosoblepon (two notes per call; Figure 91). At the moment, we consider that the morphological and acoustic differences justify recognition of E. callistomma as a valid species.

Specimens examined: Espadarana prosoblepon: Ecuador: Provincia de Azuay: $12.9 \mathrm{~km} \mathrm{~W}$ Luz María (2.6889 S, 79.474 W, 740 m), KU 217502, QCAZ 12603-04; Provincia de Bolivar: Balzapamba (1.7667 S, 79.1833 W, 800 m), KU 132555-56, 132462-65; Provincia de Carchi: near Maldonado (0.9 N, 78.1 W, 1410 m), KU 178156-57; Provincia de Cotopaxi: near La Mana (0.933 S, 79.2167 W, 300 m), QCAZ 8641; near Sigchos (0.7 S, 78.883 W), USNM 288441; km 8 of the Pucayacu-Sigchos road (1.0097 S, 79.23769 W), QCAZ 40674. Provincia de Esmeraldas: Reserva Biológica Bilsa (0.3447 S, 79.71 W, 500 m), KU 291165-75, QCAZ 22414-17; Viruela, QCAZ 10267; Reserva Biológica Bilsa (0.3447 S, 79.71 W, 500 m), KU 291165-75; Reserva Ecológica Cotacachi-Cayapas, Charco Vicente (0.792 N, 79.1978 W; $60 \mathrm{~m}$ ), QCAZ 11364-65; $5 \mathrm{~km} \mathrm{~W}$ of Durango (1.0858 N, $78.74 \mathrm{~W})$, QCAZ 13206, 13212, 13242. Provincia de El Oro: near Valle Hermoso (3.50194 S, 79.81722 W; 379 m), QCAZ 37249; Río Chillayacu (3.32834 S, $79.58102 \mathrm{~W} ; 395 \mathrm{~m}$ ), $16.8 \mathrm{~km} \mathrm{~W}$ of Piñas (3.667 S, 79.667 W, $600 \mathrm{~m}$ ), USNM 286738-39. Provincia del Guayas: Chongon-Colonche hills near Guayaquil, (ca. -2.1 S, -80.15 W), USNM 288438; Provincia de Imbabura: near Lita (0.833 N, 78.4667 W, 520 m), KU 133482-83; 6 km E of Lita (0.79472 N, 78.4286 W), QCAZ 4318-19; Zona de amortiguamiento de Reserva Cotacachi Cayapas, near Rio Aguas Verdes $\left(0.331010^{\circ} \mathrm{N}, 78.93152^{\circ} \mathrm{W} ; 670 \mathrm{~m}\right)$, QCAZ 46009; $\mathrm{km} 5$ in the Lita-Ibarra road $(0.84773$ N, 78.42175 W), QCAZ 39919. Provincia de Los Rios: Estación Biológica Río Palenque, $56 \mathrm{~km} \mathrm{~N}$ of Quevedo (0.55 S, 79.3667 W, 220 m), KU 164616-22. Provincia de Santo Domingo de los Tsáchilas: Río Orito, on the Toachi-Chiriboga road (0.30561 S, 78.882 W, 1315 m), QCAZ 15356; Río Faisanes, on the Toachi-Chiriboga road (0.2608 S, 78.845 W; $1400 \mathrm{~m})$, QCAZ 15357, 15360, 15362; La Florida (0.28361 S, 79.0189 W), QCAZ 20726-28, 20730-32; Otongachi, near La Unión del Toachi (0.3167 S, 78.95 W; $900 \mathrm{~m})$, QCAZ 25094; $5 \mathrm{~km}$ NE of La Florida (0.25694 S, $79.0539 \mathrm{~W})$, QCAZ 7184-893; $4 \mathrm{~km}$ NE of the Dos Ríos-Chiriboga road (0.305139 S, 78.884333 W; 1270 m), QCAZ 31982; Santo Domingo de los Colorados (0.25 S, 79.15 W, 660 m), KU 121054-55; 4 km NE of Dos Ríos (0.30278 S, 78.8678 W, 1140 m), KU 164623-34; 2 km E and 1 km S of Santo Domingo de los Colorados (0.24512 S, 79.15509 W, $600 \mathrm{~m})$, KU 178158-66; La Palma (0.3167 S, 78.9167 W, 920 m), KU 178167. Provincia de Pichincha: Reserva Maquipucuna $(0.12429$ N, 78.62936 W; $1343 \mathrm{~m})$, QCAZ 42179; 6 km NW (by air) of Pedro Vicente Maldonado (0.10421 N, 79.10279 W; 544 m), QCAZ 35430; La Concordia, Bosque Protector La Perla (0.01 N, 79.4 W, 190 m), QCAZ 12602, Reserva Mashpi, 18 km N of San Miguel de Los Bancos (0.15 S, $78.883 \mathrm{~W}, 1100 \mathrm{~m})$, DFCH-USFQ 293-95. 
Genus Hyalinobatrachium Ruiz-Carranza and Lynch, 1991 [6].

Etymology: The generic name Hyalinobatrachium comes from the Greek words hyalos (glass) and batrachion (frog), alluding to the translucent and delicate appearance of the species in this genus [6].

Hyalinobatrachium adespinosai Guayasamin, Vieira, Glor, Hutter 2019 [194] (Figures 98-101).

Hyalinobatrachium adespinosai Guayasamin, Vieira, Glor, Hutter, 2019 [194]. Holotype: ZSFQ 1648.

Type locality: “San Jacinto River (1.3447 S, 78.1814 W; 1795 m asl), Tungurahua province, Ecuador".

Common names: English: Adela's Glassfrog. Spanish: Rana de Cristal de Adela.

Etymology: The specific epithet adespinosai honors Adela Espinosa, an Ecuadorian conservationist and board member of the Jocotoco Foundation (http://www.jocotoco.org/wb\#/EN/LaFundacion). Adela has concentrated her work to the conservation of species and ecosystems. Hyalinobatrachium adespinosai is found only within the limits of a natural reserve owned by Adela and her husband, Antonio Páez [194].

Identification: Among glassfrogs, H. adespinosai (Figure 98) is diagnosable mainly by having a transparent pericardium. However, it is morphologically cryptic with four closely related taxa (H. anachoretus, H. pellucidum, H. esmeralda); these species display a similar size and color pattern (pale green dorsum with yellow dots and a transparent venter and pericardium; red heart visible ventrally). However, calls have diverged noticeably (Figure 99); the major difference is the structure of the call, with two species (H. adespinosai and $H$. anachoretus) having pulsed calls and the others having tonal vocalizations. The call of $H$. adespinosai sp. nov. is further differentiated from that of $H$. anachoretus by being longer, having more pulses per note, and being produced at a higher rate [194]. Genetic distances for the $16 \mathrm{~S}$ marker between $H$. adespinosai and closely related species (H. pellucidum, H. esmeralda, $H$. yaku) are $>2.5 \%$. However, H. adespinosai and $H$. anachoretus only have a $1 \%$ genetic distance, although they are separated by a major biogeographic barrier (i.e., Marañon river valley) [194].

Diagnosis: The following characters are found in Hyalinobatrachium adespinosai: (1) Dentigerous process of the vomer lacking teeth; (2) snout truncated in dorsal and lateral profiles; (3) tympanum barely visible, hidden under skin, with coloration similar to that of surrounding skin; (4) dorsal skin shagreen, lacking tubercles; (5) ventral skin areolate; cloacal ornamentation absent, paired round subcloacal warts absent; (6) parietal peritoneum transparent; pericardium with thin layer of iridophores (in life, a red heart is mostly visible ventrally); liver, viscera, and testes covered by iridophores; (7) liver white, bulbous; (8) humeral spines absent; (9) hand webbing formula: I (2-3)-(2-2+) II $\left(1-1^{+}\right)-3^{1 / 3}$ III $\left(2-2^{+}\right)-\left(2^{-}-2\right)$ IV; (10) foot webbing moderate; webbing formula: I $1-\left(1^{2 / 3}-2^{-}\right)$II $\left(1-1^{-}\right)-\left(2^{-}-2^{1 / 3}\right)$ III $\left(1-1^{+}\right)-\left(2^{+}-2^{1 / 3}\right)$ IV $2^{+}-\left(1^{+}-1^{1 / 3}\right) \mathrm{V}$; (11) fingers and toes with thin lateral fringes; ulnar and tarsal folds present, but difficult to distinguish, with thin layer of iridophores that extends to ventrolateral edge of Finger IV and Toe V; (12) nuptial excrescence present as a small pad on Finger I (Type V), concealed prepollex; (13) when appressed, Finger I longer than II; (14) diameter of eye about two times wider than disc on Finger III; (15) coloration in life: Dorsal surfaces pale yellowish green with small pale yellow spots and minute grey to black melanophores; bones white; (16) coloration in preservative: Dorsal surfaces pale cream with minute melanophores; (17) iris coloration in life: White with pale yellow hue and minute lavender spots; (18) melanophores absent from most fingers and toes, but present on Finger IV and Toes IV and V; (19) males call from underside of leaves; advertisement call consisting of single note, distinctly pulsed (9-13 pulses per call), with duration of $0.382-0.430 \mathrm{~s}$, and dominant frequency at 4645-5001 Hz; (20) fighting behavior unknown; (21) males attend egg clutches located on 
the underside of leaves overhanging streams; clutch size of 22 embryos $(n=1)$; (22) tadpoles unknown; (23) SVL in adult males 20.5-22.2 $\mathrm{mm}(n=3)$, females unknown.

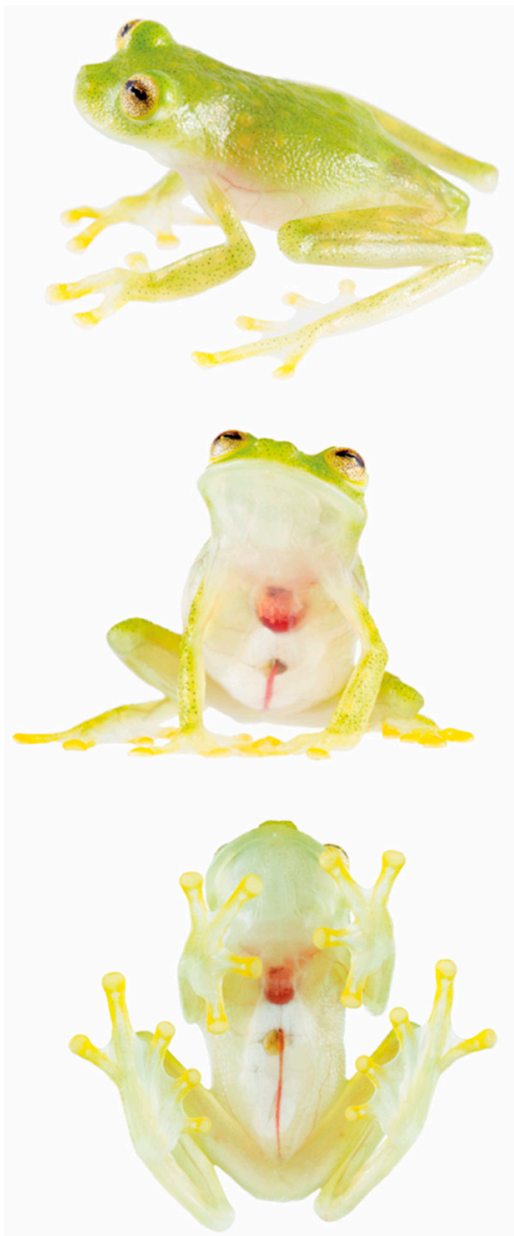

Figure 98. Hyalinobatrachium adespinosai in life, holotype, ZSFQ 1648. Photos by Jose Vieira/Tropical Herping.

Color in life (Figure 98): Dorsal surfaces apple green to yellowish green with diffuse yellow spots and minute grey to black melanophores. Melanophores absent from fingers and toes, except Finger IV and Toes IV and V. Ventrally, parietal peritoneum and pericardium transparent, with a red heart always visible, even when a very thin layer of iridophores is present on the pericardium of some individuals. Visceral peritoneum of gall bladder and urinary bladder transparent; hepatic and visceral peritonea white; ventral vein red. Iris pale yellowish white, with numerous minute lavender spots. Bones white [194].

Color in ethanol: Dorsal surfaces cream dotted with minute dark lavender melanophores; venter uniform cream; visceral peritoneum lacking iridophores; pericardium with a very thin layer of iridophores. Iris silvery white with minute lavender melanophores [194].

Biology and Ecology: All individuals were found on the underside of leaves of riverine vegetation along the San Jacinto River. The section of river was fast-flowing and had visible rapids. Although the population is locally abundant, individuals are difficult to observe because they are usually found at the canopy level (4-16 $\mathrm{m}$ above ground level). Males were calling in the months of July and August. One male (ZSFQ 1648) was apparently guarding an egg clutch containing 22 embryos; both the adult male and the egg clutch were on the same leaf most of the time, but the male also moved to nearby leaves [194]. 
Call (Figure 99): The description is based on recording from nine individuals. The call of Hyalinobatrachium adespinosai has a striking resemblance to the chirp of a cricket. Each call is composed by a single and high-pitched pulsed note and has a duration of $0.38-0.44 \mathrm{~s}(\overline{\mathrm{X}}=0.38 \pm 0.017)$. Time between calls varied from $2.0-11.0 \mathrm{~s}(\overline{\mathrm{X}}=4.58 \pm 2.3)$. The fundamental frequency, the same as the dominant frequency, is at $4645-5203 \mathrm{~Hz}(\bar{X}=4855 \pm 152)$. There is no frequency modulation. The first harmonic is at $9336-9754 \mathrm{~Hz}$ and the second harmonic is at $14,159-14,444 \mathrm{~Hz}$ [194].

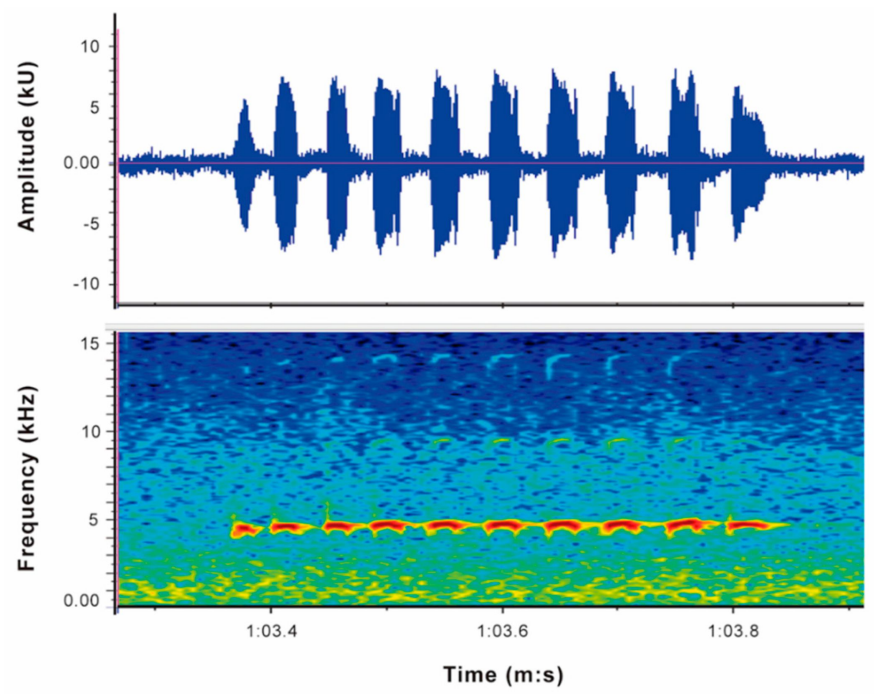

Figure 99. Call of Hyalinobatrachium adespinosai, holotype, ZSFQ 1648, recorded in field conditions at the type locality (San Jacinto River, $1795 \mathrm{~m}$ asl), Tungurahua province, Ecuador). Air temperature $=18^{\circ} \mathrm{C}$. Obtained from Guayasamin et al. [194].

Tadpole: Not described.

Distribution. Hyalinobatrachium adespinosai is only known from the type locality: San Jacinto River (1.3447 S, 78.1814 W; 1795 m asl), Tungurahua Province, Ecuador (Figure 100) [194].

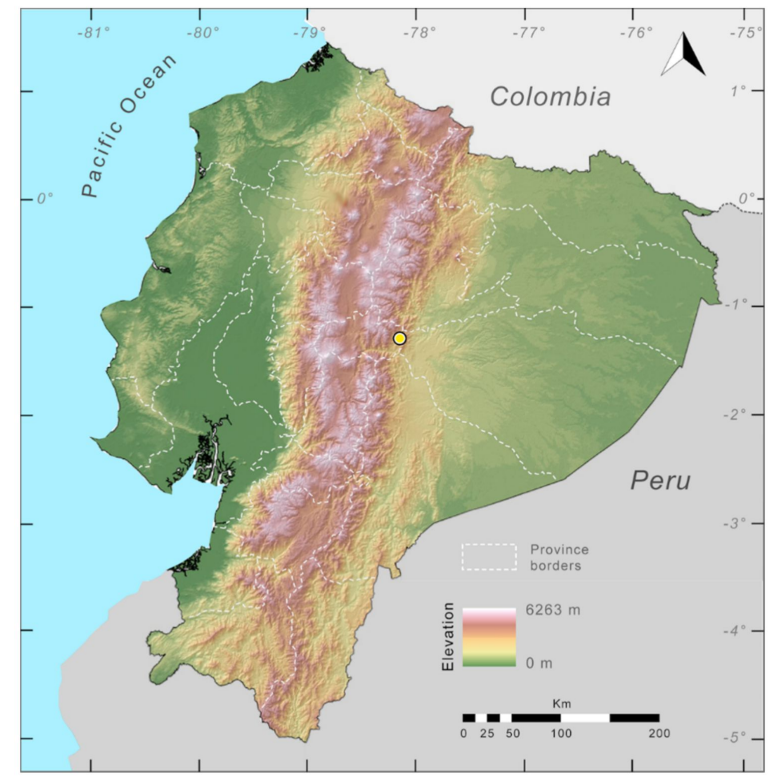

Figure 100. Distribution of Hyalinobatrachium adespinosai in Ecuador (yellow spot).

Evolutionary relationships. Hyalinobatrachium adespinosai is sister to the Peruvian H. anachoretus [194]. Since the species was recently described, it is not included in the Hyalinobatrachium 
tree shown in Figure 101. The most closely related species to H. adespinosai share several morphological traits, including a red heart exposed ventrally $(H$. adespinosai $+H$. anachoretus $+H$. pellucidum + H. yaku) [194].

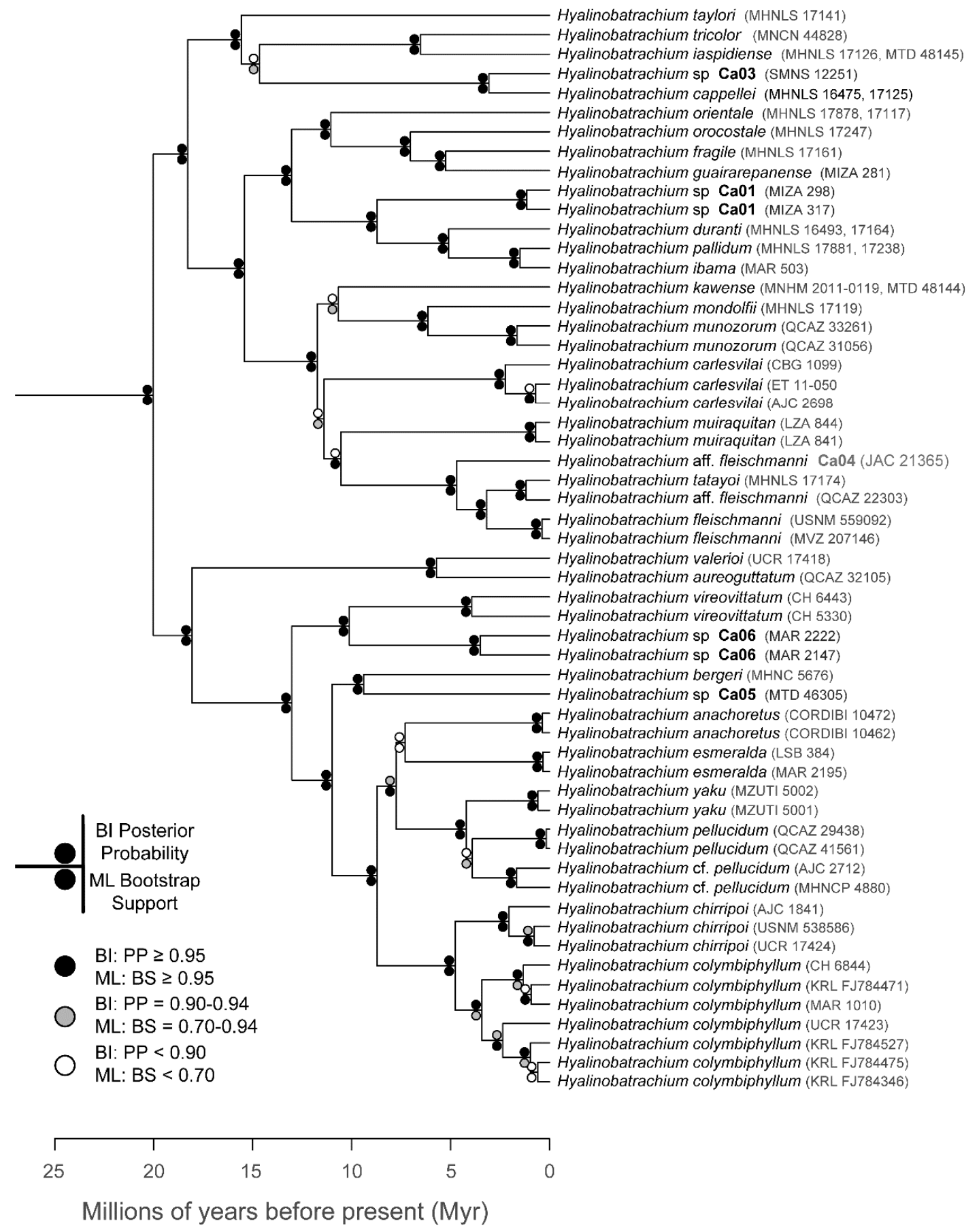

Figure 101. Evolutionary relationships among species in the genus Hyalinobatrachium, inferred using maximum likelihood and Bayesian criteria.

Conservation status: Hyalinobatrachium adespinosai has not been evaluated by the IUCN. However, Guayasamin et al. [194] suggested that it should be considered as Data Deficient.

Specimens examined. Hyalinobatrachium adespinosai: Ecuador: Provincia de Tungurahua: San Jacinto River (1.3447 S, 78.1814 W; 1795 m asl), ZSFQ 1647-48, 1650-52 (type series). 
Hyalinobatrachium aureoguttatum (Barrera-Rodríguez and Ruiz-Carranza, 1989 [195];

Figures 101-105).

Centrolenella aureoguttata Barrera-Rodriguez and Ruiz-Carranza, 1989 [195]. Holotype: ICN 17506.

Type locality: “Colombia, Departamento del Chocó, vertiente occidental de la cordillera

Occidental, Municipio El Carmen de Atrato, Km 23 carretera El Carmen-Quibdó, 54 $7^{\prime}$

latitud $\mathrm{N}$ y $76^{\circ} 20^{\prime}$ W, 1030 m.s.n.m.".

Hyalinobatrachium aureoguttatum-Ruiz-Carranza and Lynch, 1991 [6].

Common names: English: Sun Glassfrog. Spanish: Rana de Cristal del Sol.

Etymology: The specific name aureoguttatum is derived from the Latin words aureus (gold) and guttatus (dappled, speckled, spotted), referring to the dorsal pattern of the species [195].

Identification: Hyalinobatrachium aureoguttatum is easily distinguished from most glassfrogs by having a completely transparent ventral parietal peritoneum, a white bulbous liver, white visceral peritoneum, and by the absence of humeral spines. It differs from all other Hyalinobatrachium by having, in life, large yellow spots on the dorsum (Figure 102). The most similar and related species is H. valerioi, from which is differentiated mainly by having large dorsal yellow spots produced by xanthophores and iridophores (absent in H. valerioi; see Figure 121).
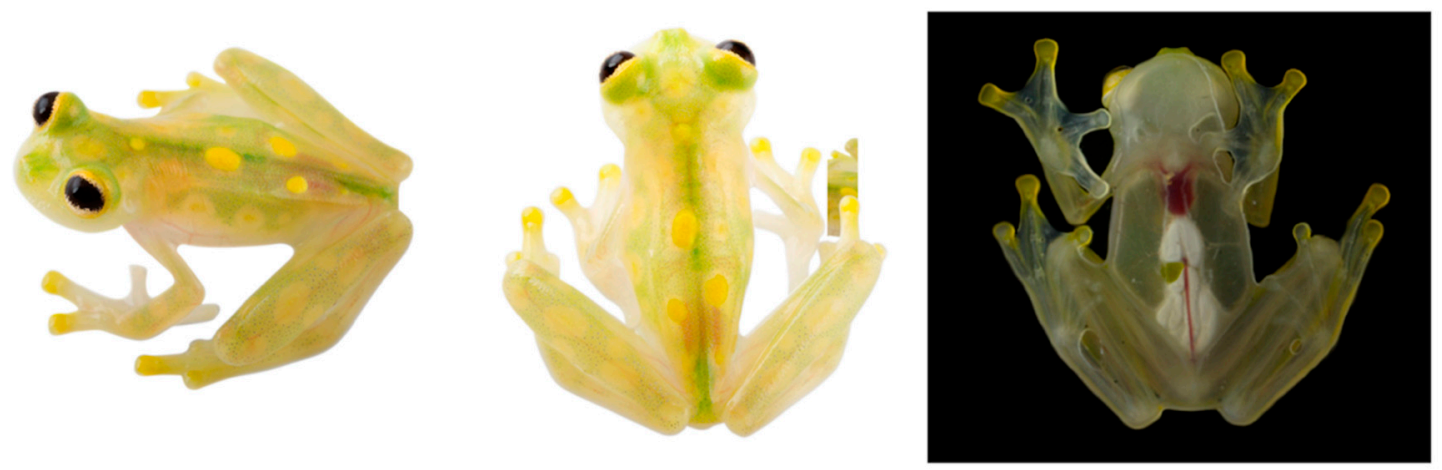

Figure 102. Hyalinobatrachium aureoguttatum in life. (Left and center) Adult male, QCAZ 45365; photos by L. A. Coloma. (Right) Adult male, QCAZ 32068; photo by Martín Bustamante.

Diagnosis: (1) Vomers lacking teeth; (2) snout truncated in dorsal and lateral profiles (Figure 103); (3) tympanum of moderate size (tympanum diameter $30 \%-34 \%$ of eye diameter), with dorsolateral orientation and posterior inclination, supratympanic fold low, tympanic membrane clearly differentiated from surrounding skin; (4) dorsal surfaces smooth to shagreen, lacking spicules; (5) venter smooth; lacking pair of enlarged subcloacal warts; (6) ventral parietal peritoneum transparent (condition P0); pericardium polymorphic, with or lacking iridophores; white peritonea covering intestines, stomach, and testes; transparent peritoneum covering kidneys, and urinary and gall bladders (Figure 102, Condition V5-V6); (7) liver bulbous, covered by white peritoneum (condition H2); (8) humeral spines absent; (9) basal webbing between Fingers I and II, extensive webbing between outer finger: $\mathrm{I}\left(2-2^{1 / 4}\right)-\left(2-2^{1 / 4}\right) \mathrm{II}\left(1^{-}-1^{+}\right)-\left(2-3^{+}\right) \mathrm{III}\left(1-2^{+}\right)-\left(1-1^{+}\right) \mathrm{IV} ;(10)$ foot webbing extensive: I $\left(0^{+}-1\right)-\left(1-1^{2 / 3}\right)$ II $\left(0^{+}-1\right)-\left(1-1^{1 / 2}\right)$ III $\left(0^{-}-1\right)-\left(1^{1 / 2}-2\right)$ IV $\left(1^{1 / 2}-2^{+}\right)-\left(1^{-}-1\right) \mathrm{V}$; (11) ulnar and tarsal folds absent; (12) concealed prepollex; in males, nuptial pad Type III; (13) Finger I longer than Finger II (Finger II about $87 \%-95 \%$ length of Finger I); (14) disc of Finger III of moderate size, $35 \%-56 \%$ of eye diameter; (15) in life, dorsum greenish yellow with two to seven large yellow spots, and with or without brown flecks; ventral parietal peritoneum transparent, pericardium polymorphic (white or transparent), gastrointestinal peritoneum white; bones white; (16) in ethanol, dorsum cream with large white spots, and with or without brown flecks; (17) in life, iris white to yellow, with minute dark lavender flecks around the pupil or forming an horizontal stripe; (18) fingers and toes lacking melanophores, except for 
few melanophores on proximal portions of Toes IV and V; (19) males usually call from the underside of leaves; call undescribed; (20) fighting behavior unknown; (21) eggs deposited on the underside of leaves; prolonged parental care provided by males; maternal care absent; (22) oral apparatus of tadpoles with an emarginate disc; M-shaped upper jaw sheath; tooth row formula 2(2)/3; (23) minute body size; in males, SVL $20.4-24.0 \mathrm{~mm}(\overline{\mathrm{X}}=21.8 \pm 0.631, n=36)$; in females, SVL 22.9-23.9 $\mathrm{mm}(\overline{\mathrm{X}}=23.3$, $n=3)$.
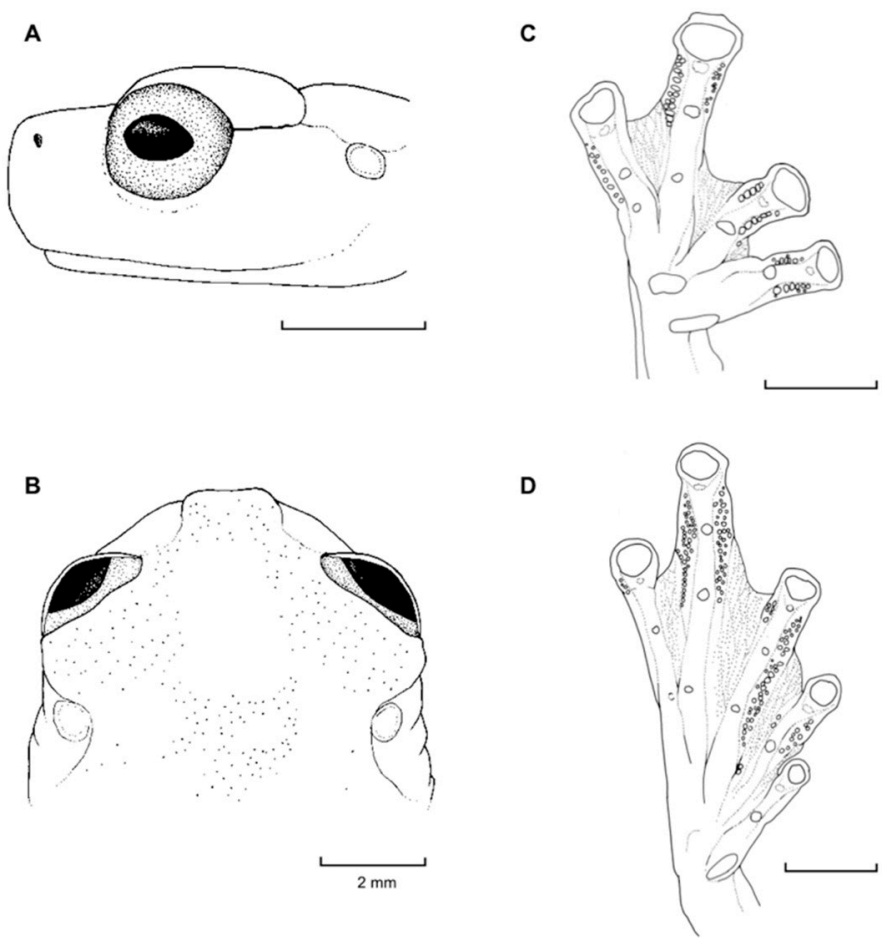

Figure 103. Hyalinobatrachium aureoguttatum, adult male, QCAZ 27429. (A) Head in lateral view. (B) Head in dorsal view. (C) Hand in ventral view. (D) Foot in ventral view. Illustrations by Juan M. Guayasamin

Color in life (Figure 102): Dorsum greenish yellow with two to seven large yellow spots (diameter 0.5-2.1 mm), and with or without black flecks; upper lip unpigmented; ventral parietal peritoneum transparent; pericardium polymorphic, transparent (red heart visible ventrally) or white (heart not visible ventrally); transparent peritonea covering the kidneys, and urinary and gall bladders; white peritonea covering the liver, intestines, stomach, and testes; bones white; iris white to yellow, with minute dark lavender flecks around the pupil or forming a horizontal stripe.

Color in ethanol: Dorsum cream with large white spots and with or without dark flecks; iris white with dark lavender pigment; white peritonea covering the liver, intestines, stomach, and testes; pericardium polymorphic (white, partially white, or transparent).

Biology and Ecology: According to Barrera-Rodríguez and Ruiz-Carranza [195], most individuals of Hyalinobatrachium aureoguttatum were found on the underside of leaves (Heliconia spp.) $100-700 \mathrm{~cm}$ above small streams during the night. Amplectant pairs and egg clutches were found during July and August 1987. Amplexus is axillary, and eggs are deposited on the underside of leaves. In Durango (Provincia de Esmeraldas, Ecuador), individuals were reproductively active (amplectant pairs and egg clutches) 24-26 May 2006. At Estero Piedras, the species was reproducing in August 2007; a clutch with 36 eggs was found on the underside of a leaf on a bush along a stream [167]. Valencia-Aguilar et al. [196] studied populations from the Pacific lowlands of Colombia. They found that males exhibit high fidelity to their territory; each male repeatedly uses the same leaf (Heliconia sp., Anthurium sp., Philodendron sp., Cyclanthus sp., Calathea sp., Musa sp.) for perching, calling, mating, and clutch attendance. Territoriality 
seems to be low, since several males where found in close proximity and fights or aggressive behaviors were not observed in intrusion events by co-specific males.

Female place green eggs on the underside of leaves; clutches 25-49 eggs [167,195-197]. Males provide parental care during the day and night until hatching (mean $=17.1$ days \pm 1.8 ). Males are polygynous and simultaneously attend up to five clutches [196].

Call: Most males call from the undersides of leaves, but some have been observed calling from leaf tops. The specific spectral and temporal characteristics of the call are unknown.

Tadpole: A description of the tadpole can be found in Ibáñez et al. [197] and Terán-Valdez et al. [167] (Figures 80 and 104).

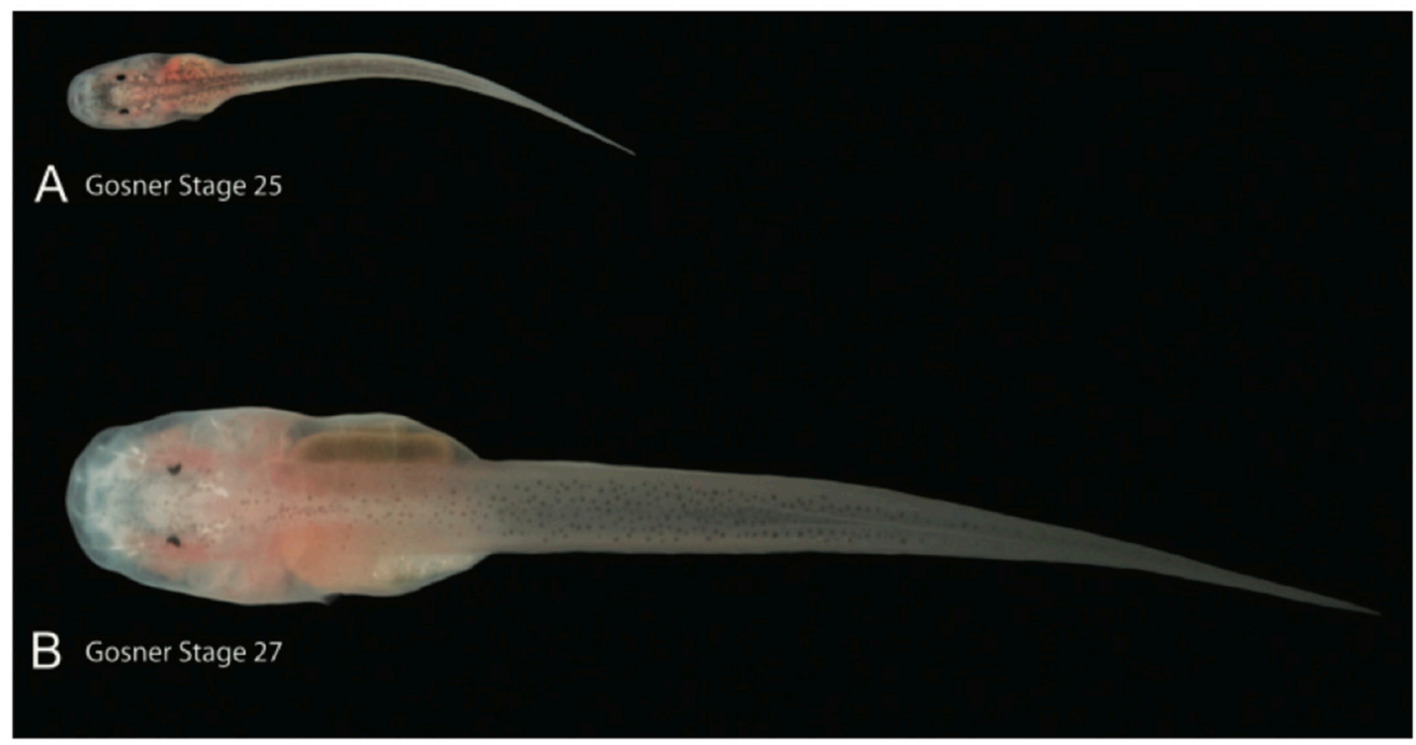

Figure 104. Hyalinobatrachium aureoguttatum, ontogenetic variation of tadpoles. (A) Gosner Stage 25, QCAZ 37752. (B) Gosner Stage 27, QCAZ 32072. Photos by L. A. Coloma. Figure modified from Terán-Valdez et al. [167].

Distribution (Figure 105): Hyalinobatrachium aureoguttatum is known from extreme southwestern Panama and the Pacific lowlands and western slopes of the Cordillera Occidental of Colombia and Ecuador at elevations below 1340 m [101,167,195,197-199]. In Ecuador, this species has been reported from the provinces of Esmeraldas and Imbabura at elevations below $600 \mathrm{~m}$ (Specimens Examined). In Ecuador, the species has a potential distribution of $4,481 \mathrm{~km}^{2}$ within the Chocoan Tropical Forest and Western Foothill Forest ecoregions.

Conservation status: Listed globally as Near Threatened by the IUCN [200]. Given that Ecuadorian populations of the species are fragmented because of agriculture, pasture lands, and mining, we suggest placing the species in the Endangered category based on IUCN criteria B1, B2a, B2b(iii). The species is partially protected within the Mache-Chindul reserve.

Evolutionary relationships (Figure 101): Hyalinobatrachium aureoguttatum and H. valerioi are sister species.

Remarks: Some populations from Colombia usually have small (but visible) brown flecks on the dorsal surfaces of the head and body; Ecuadorian populations lack these flecks (Figure 102). Also, all Colombian specimens examined by us have a white pericardium, a character that is polymorphic in the Ecuadorian populations (white, partially white, or transparent pericardium). It is possible that these differences correspond to independent evolutionary lineages; however, we prefer to maintain these populations as one species until more data (e.g., acoustic, molecular) are available. 


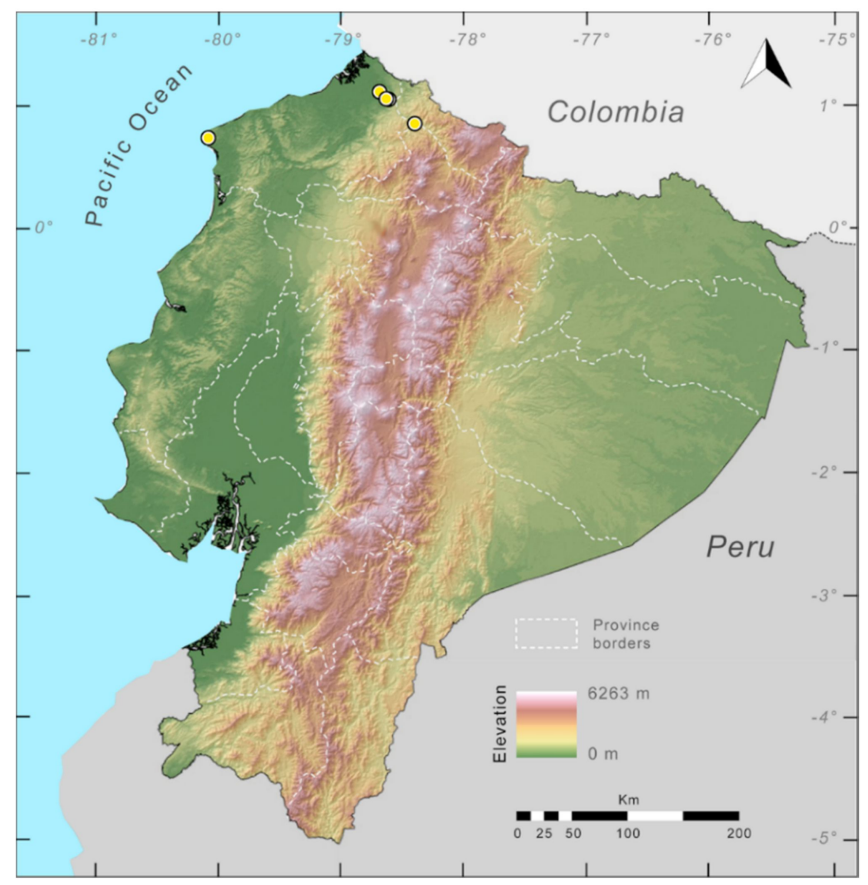

Figure 105. Distribution of Hyalinobatrachium aureoguttatum in Ecuador (yellow dots).

Specimens examined: Hyalinobatrachium aureoguttatum: Ecuador: Provincia de Esmeraldas: stream affluent of the Río Durango (1.05 N, 78.6167 W; 100-150 m), QCAZ 27429, 6302, 6303, 6441-42, 28802; $2 \mathrm{~km}$ E of San Francisco (1.0872 N, 78.6905 W; 60-80 m), on the San Francisco-Durango road, QCAZ 32101-02, 32105, 32129, 32132-33; Río Quingue, nearby Caimito (0.72096 S, 80.09117 W, 47 m), QCAZ 37306. Provincia de Imbabura: $6 \mathrm{~km} \mathrm{SE}$ of Lita $(0.79 \mathrm{~N}, 78.43 \mathrm{~W} ; 600 \mathrm{~m})$, QCAZ 4323. Colombia: Departamento del Chocó: Municipio El Carmen de Atrato, $\mathrm{km} 23$ on road El Carmen-Quibdó $\left(5^{\circ} 47^{\prime} \mathrm{N}\right.$; $76^{\circ} 20^{\prime} \mathrm{W}, 1030 \mathrm{~m}$ ), ICN 17507, 17509-10, 17512; km 44 on road El Carmen-Quibdó, $630 \mathrm{~m}$, ICN 17252-54, 17515-16; km 53 on road El Carmen-Quibdó, 420 m, ICN 17248, 17257, 17260, 17262, 17266-67, 17520-21, 17525, 17527-28, 17531-34, 17536-37.

Hyalinobatrachium chirripoi (Taylor, 1958 [201]; Figures 106-108).

Cochranella chirripoi Taylor, 1958 [201]. Holotype: KU 36865.

Type locality: “Cocales Creek, Suretka, (Cantón de Talamanca,) Limón Province”, Costa Rica.

Savage [183] commented on the type locality.

Centrolenella chirripoi-Savage, 1967 [202].

Hyalinobatrachium chirripoi-Ruiz-Carranza and Lynch 1991 [6].

Hyalinobatrachium cardiacalyptum McCranie and Wilson, 1997 [203]. Holotype: USNM 342161.

Type locality: “Caño El Cajón ( $14^{\circ} 21^{\prime} \mathrm{N}, 85^{\circ} 29^{\prime}$ W), at its junction with the Río Patuca, Departamento de Olancho, Honduras, elevation 200-225 m". Placed in synonymy by Cisneros-Heredia and McDiarmid, 2007 [17].

Common names: English: Chirripó Glassfrog. Spanish: Rana de Cristal Chirripó.

Etymology: The specific name chirripoi is named for the Chirripó Indians, local inhabitants of the area where the species was first found [201].

Identification: Hyalinobatrachium chirripoi is easily distinguished from most glassfrogs by having, in life, a lime green dorsum with small yellow spots, a completely transparent ventral parietal 
peritoneum (red heart visible ventrally; Figure 106), and by lacking humeral spines. Additionally, it differs from most Hyalinobatrachium by having more webbing between Fingers II and III.
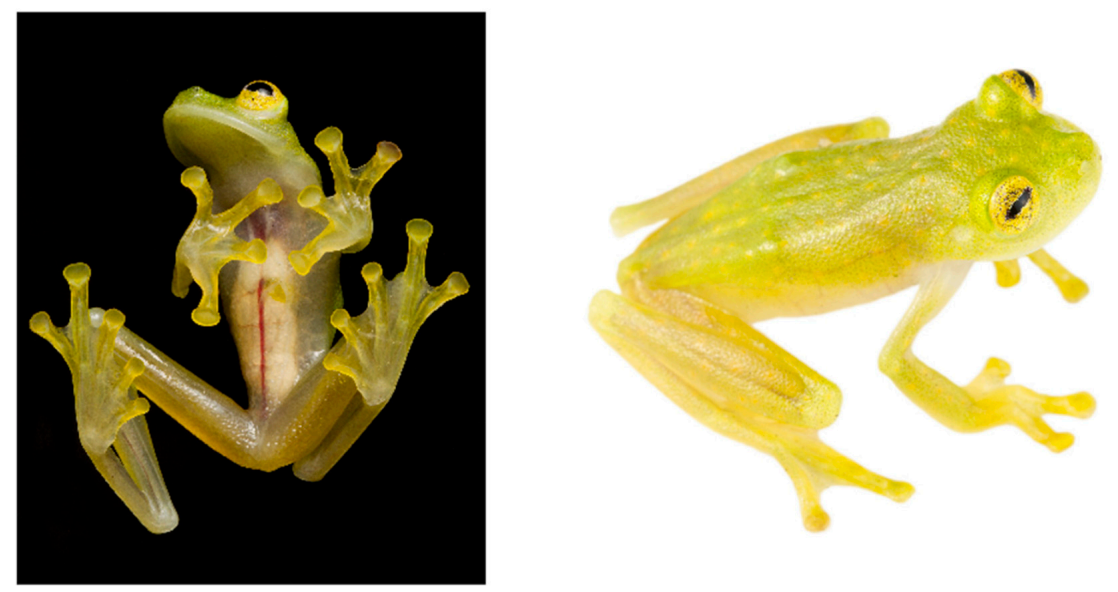

Figure 106. Hyalinobatrachium chirripoi in life. Reserva Canandé, 372 m, Esmeraldas province, Ecuador. Photos by Jaime Culebras.

Diagnosis: (1) Vomers lacking teeth; (2) snout truncated in dorsal view, truncated to slightly protruding in lateral profile; (3) tympanum almost completely concealed, small when visible (tympanum diameter $2.3 \%-2.8 \%$ of SVL); tympanic membrane not differentiated from surrounding skin; (4) dorsal surfaces shagreen, lacking spicules; (5) venter areolate; lacking pair of enlarged subcloacal warts; (6) ventral parietal peritoneum transparent (condition P0); pericardium transparent; white peritonea covering the intestines and stomach; transparent peritoneum covering urinary and gall bladders; kidneys covered by a mostly translucent peritoneum, except for some iridophores on their ventral portions (condition V6); (7) liver bulbous, covered by white peritoneum (condition H2); (8) humeral spines absent; (9) basal to moderate webbing between Fingers I and II, extensive webbing between outer finger: I $\left(2^{+}-2^{1 / 3}\right)-\left(2-2^{-}\right)$II $1-\left(2^{2 / 3}-3^{-}\right)$III $\left(2^{-}-2\right)-\left(1^{1 / 3}-1^{1 / 2}\right) I V ;(10)$ foot webbing extensive: I $\left(0^{+}-1\right)-\left(1^{1 / 2}-1^{2 / 3}\right)$ II $1-\left(1^{1 / 2}-1^{2 / 3}\right)$ III $\left(0^{+}-1\right)-2^{-}$IV $\left(2^{-}-2\right)-\left(1-1^{+}\right)$V; $(11)$ ulnar and tarsal folds present, with minute iridophores; (12) concealed prepollex; in males, nuptial pad Type V; (13) Finger I longer than Finger II (Finger II about 85\%-90\% length of Finger I); (14) disc of Finger III of moderate size, $38 \%-47 \%$ of eye diameter; (15) in life, dorsum line green with small yellow spots, venter transparent (red heart visible; Figure 106); bones white; (16) in ethanol, dorsum cream with minute lavender spots and iridophores; (17) in life, iris yellowish white, with minute dark lavender flecks; (18) fingers and toes lacking melanophores, except for few on Toes IV and V; (19) males call from the upper and undersides of leaves; call undescribed; (20) fighting behavior unknown; (21) eggs deposited on the underside of leaves; maternal care absent; prolonged parental care provided by males; (22) elongate tadpole, with emarginate oral disc; tooth row formula 2/3; (23) small body size; in Ecuadorian males, SVL 25.0-25.5 mm $(n=2)$; Savage [148] reported that adult males have a SVL $=24-26 \mathrm{~mm}$ and that females are probably larger.

Color in life (Figure 106): Dorsum lime green with several small yellow spots; ventral parietal peritoneum transparent; pericardium transparent (red heart visible ventrally); transparent peritonea covering urinary bladder; white peritonea covering liver, intestines, and stomach; transparent peritoneum covering most of kidneys; bones white; iris yellowish white, with minute dark lavender flecks.

Color in ethanol: Dorsum cream with minute lavender spots and iridophores; ventral parietal pericardium translucent; white peritonea covering liver, intestines, and stomach; pericardium transparent; iris silvery white with dark lavender flecks.

Biology and Ecology: According to Kubicki [24,204], in southeastern Costa Rica, Hyalinobatrachium chirripoi deposits 65-80 greenish-white eggs in a single layer on the underside of 
leaves overhanging streams. Males were most often seen calling from below palm fronds or other smooth leaves between 1-4 $\mathrm{m}$ above the water. Males were also seen calling from the upper sides of vegetation, but much less frequently. One male was seen guarding eggs during the night, and another male was observed guarding eggs during daylight hours [24]. At Reserva Itapoa, Ecuador, in June 2014, a male was observed calling and guarding an egg clutch on the underside of a leaf. Maternal care is absent; prolonged parental care is provided by males [25].

Call (Figure 107): Most males call from the undersides of leaves, but some have been observed calling from the upper sides [24,204]. The call is a high-pitched insect-like buzz, very similar to that of H. colymbiphyllum [204]. We analyzed two notes from one individual (LBE-019). The typical advertisement call is composed by a single note. Note duration is $230-270$ (mean $=250, S D=28.3$ ) ms. Notes are strongly pulsed and have 14-16 (mean $=15, \mathrm{SD}=1.4$ ) amplitude peaks throughout the note, with pulses becoming difficult to distinguish near the end of the note. Pulses within a note have a rate of 59-61 (mean $=60, \mathrm{SD}=1$ ) pulses per second. Notes have their peak amplitude in the first $50 \%$ of the note (relative peak time: Range $=0.0623-0.0638$, mean $=0.063$, SD $=0.001$ ), where the peak amplitude occurs in the first several pulses. The dominant frequency of a note measured at peak amplitude is 4565 (mean $=4565, \mathrm{SD}=0) \mathrm{Hz}$ and is contained within the fundamental frequency. The fundamental frequency has a lower limit of 1895-3273 (mean = 2584, SD =974) Hz and a higher limit of 4651-5082 $($ mean $=4866, \mathrm{SD}=305) \mathrm{Hz}$.

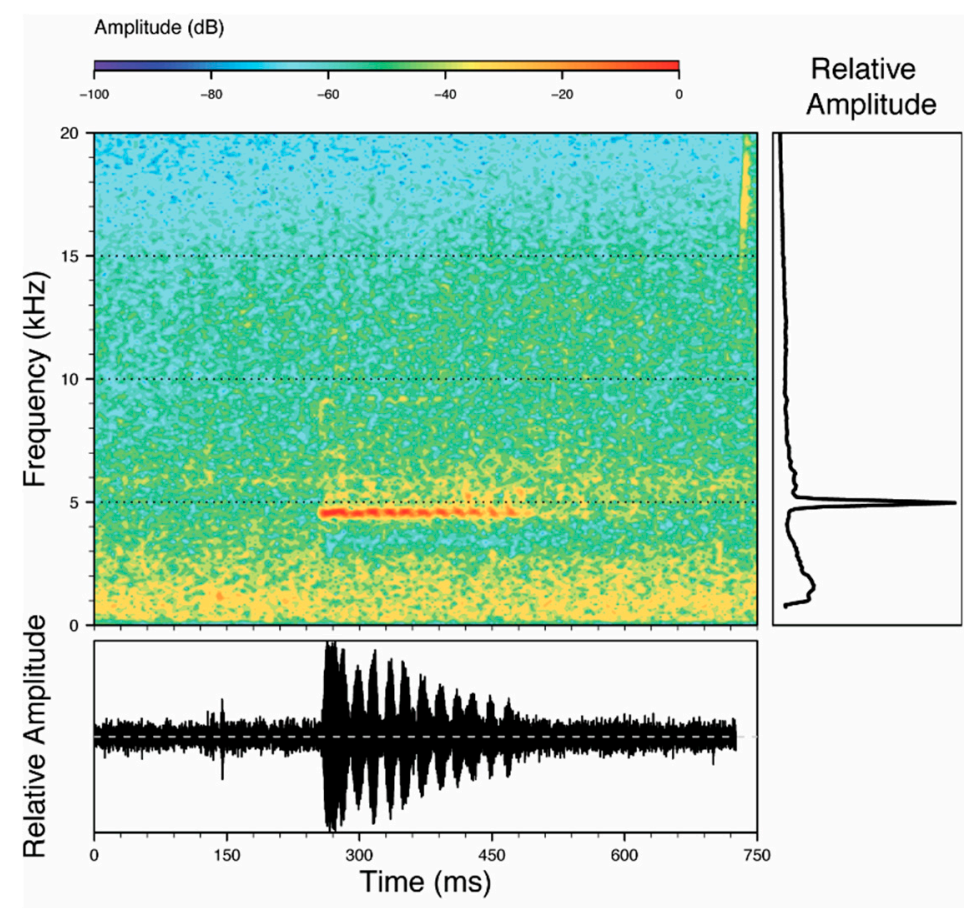

Figure 107. Call of Hyalinobatrachium chirripoi recorded at Reserva Itapoa, $321 \mathrm{~m}$, Esmeraldas province, Ecuador, LBE-C-019.

Egg masses and tadpoles: Greenish-white eggs (53-80) are deposited in a single layer on the underside of leaves; as development continues the embryos become pale tannish red [24,147,204]. Below, we present a summary of the tadpole description by Hoffmann [147]. Hatchlings (Gosner stages 25 and 26) have an unusual pattern on their dorsum: Two rows of brown-pigmented, spider-like dots of melanophores stretch longitudinally over the entire body and join in a semicircle at the tip of snout; another line of pigmented spots extends dorsally over the tail musculature. Because of the general lack of pigment and high transparency, the body coloration is partially determined by the red color of the gills and heart. As development continues (Gosner stages 25-41), the tadpoles become very elongated and are among the most elongated centrolenid larvae known (ratio of body length to body 
width of $2.41 \pm 0.22$ ); they have a completely transparent skin and the dorsolateral lines are mostly lost; the body has a pale rose shine and the tail is cream or, sometimes, yellowish. The oral disc is emarginate and, except for a moderate dorsal gap, is bordered by a single row of about 45 marginal papillae; the ventral ones being flatter than the lateral ones. The LTRF is 2(2)/3; the tooth rows are about of equal width (P-3 is slightly narrower) and extend across most of the oral disc. The A-2 gap is about as wide as the upper jaw, which is broadly arched; the lower jaw is V-shaped; the edges of both jaw sheaths are edged by many narrow serrations [147].

Distribution (Figure 108): Hyalinobatrachium chirripoi is known from lowland forest localities in Central America in southeastern Costa Rica and eastern Panama, and south into South America in western Colombia and Ecuador at elevations below $600 \mathrm{~m}$ ([24,148,204], this work). In Ecuador, this species has been observed in few localities within the Esmeraldas province (Río Quingue, Río Bogotá, Reserva Itapoa, Tesoro Escondido, Reserva Canandé), in the Chocó ecoregion, at elevations below $320 \mathrm{~m}$.

Conservation status: Listed globally as Least Concern by the IUCN [205]. In Ecuador, the species has been recently found in five localities in the Chocó Ecoregion, an area under constant deforestation pressure. Although the Least Concern category seems accurate at the global level, in Ecuador, the species is threatened by habitat destruction because of agriculture, pasture lands, and mining. Thus, we suggest placing the species in the Endangered category at the local level, based on IUCN criteria B1, B2a, B2b(iii).

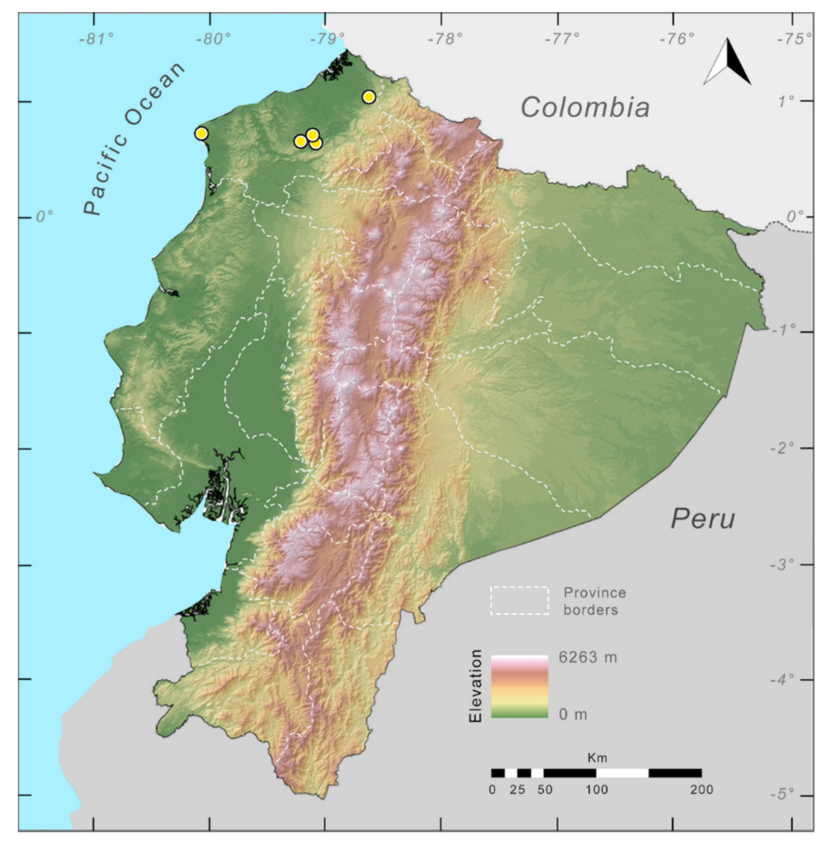

Figure 108. Distribution of Hyalinobatrachium chirripoi in Ecuador (yellow dots).

Evolutionary relationships (Figure 101): Molecular data support a sister relationship between Hyalinobatrachium chirripoi and $H$. colymbiphyllum.

Specimens examined: Hyalinobatrachium chirripoi: Ecuador: Provincia de Esmeraldas: Río Quingue $\left(0.722^{\circ} \mathrm{N}, 80.08^{\circ} \mathrm{W} ; 47 \mathrm{~m}\right)$, QCAZ 37309, 48271; Río Bogotá, DFCH-USFQ C1903; Reserva Itapoa $\left(0.513^{\circ} \mathrm{N}, 79.134^{\circ} \mathrm{W} ; 320 \mathrm{~m}\right)$, MZUTI 3609-10; Tesoro Escondido $\left(0.542^{\circ} \mathrm{N}, 79.145^{\circ} \mathrm{W} ; 225 \mathrm{~m}\right)$, MZUTI 3625; Reserva Canandé (0.526 N, 79.209 W; 310 m), MZUTI 4745. Costa Rica: Limón Province: Suretka, along Cocales Creek, KU 36862-64, 36866-70. 
Hyalinobatrachium fleischmanni (Boettger, 1893 [206]; Figures 109-111).

Hylella fleischmanni Boettger, 1893 [206]. Lectotype: SMF 3760, designated by Mertens (1967) [207].

Type locality: "San José, Costa Rica".

Hylella chrysops Cope, 1894 [208]. Neotype: SMF 3760 (= holotype of Hylella fleischmanni), designated by Starrett and Savage (1973) [209]. Placed in synonymy by Boulenger (1895) [210].

Centrolenella fleischmanni-Noble (1924) [186].

Centrolenella viridissima Taylor, 1942 [211]. Holotype: EHT-HMS 27725 (now FMNH 100093). Type locality: "Agua de Obispo, Guerrero", Mexico. Placed in synonymy by Starrett and Savage (1973) [209].

Cochranella fleischmanni-Taylor (1951) [15].

Cochranella decorata Taylor, 1958. Holotype: KU 36896. Type locality: “Hda. La Florencia, about 3 miles west of Turrialba, Cartago Province, Costa Rica". Placed in synonymy by Starrett and Savage (1973) [209].

Cochranella millepunctata Taylor, 1958 [201]. Holotype: KU 36887. Type locality: “La Palma, San José Province, Costa Rica". Placed in synonymy by Starrett and Savage (1973) [209].

Centrolenella fleischmanni-Goin (1964) [187].

Hyalinobatrachium fleischmanni-Ruiz-Carranza and Lynch (1991) [6].

Common names: English: Fleischmann's Glassfrog (Liner, 1994). Spanish: Rana de Cristal de Fleischmann.

Etymology: The specific name fleischmanni is a patronym for Carl Fleischmann, a German collector-naturalist who donated the specimens used by Boettger to describe the species [84].

Identification: Hyalinobatrachium fleischmanni is easily recognizable by having, in life, a lime green dorsum with small yellowish spots, a completely transparent ventral parietal peritoneum, white heart and digestive tract (pericardium and gastrointestinal peritoneum covered by iridophores), lacking humeral spines, and having reduced webbing between inner fingers (Figure 110). In the Ecuadorian Pacific lowlands, similar species include H. aureoguttatum, which has large yellow spots on the dorsum; $H$. valerioi, distinguished by having a green dorsal reticulum; and $H$. chirripoi, which, in life, has a transparent pericardium (red heart visible through ventral skin). We note that $H$. fleischmanni represents a species complex that requires taxonomic revision [212]. 


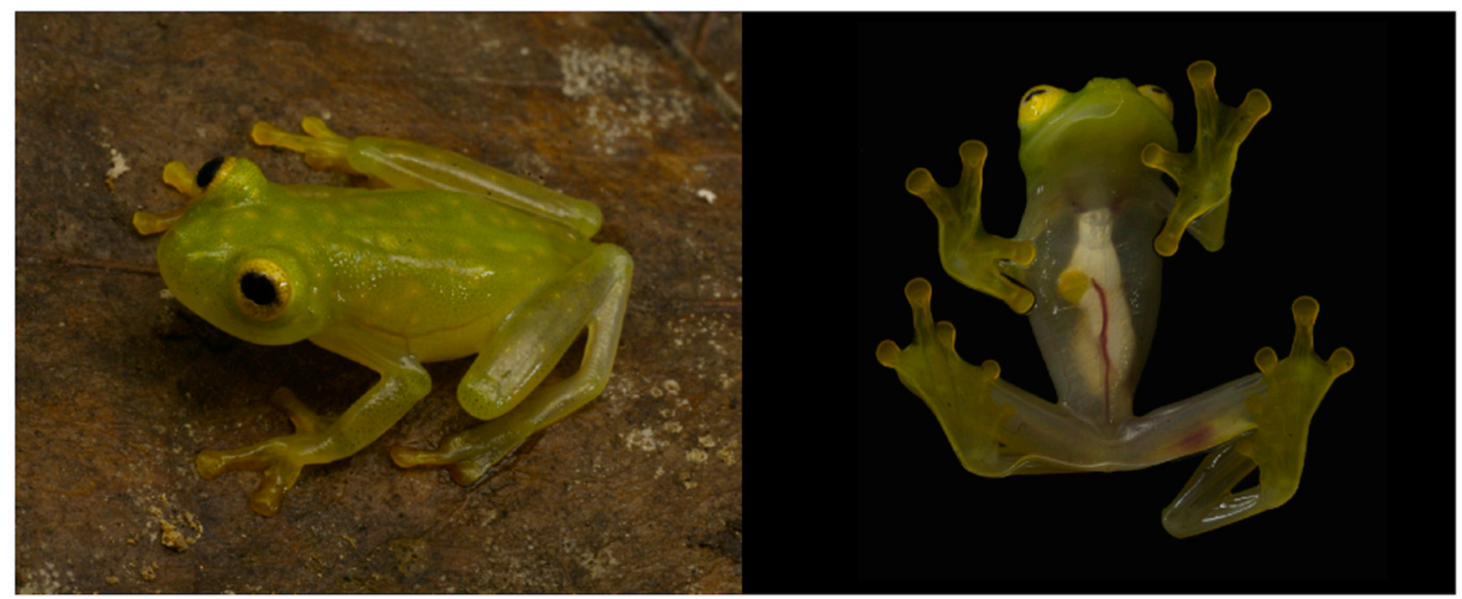

Figure 109. Hyalinobatrachium fleischmanni in life. Ecuador, near Durango, $77 \mathrm{~m}, \mathrm{QCAZ} 32107$. Photos by Martín Bustamante.

Diagnosis: (1) Vomerine teeth absent; (2) snout subacuminate in dorsal aspect and rounded in profile; (3) tympanum not visible; supratympanic fold absent; (4) dorsal skin shagreen; (5) venter smooth; lacking pair of enlarged subcloacal warts; (6) ventral parietal peritoneum transparent (condition P0); white peritoneum covering heart, intestines and stomach; transparent peritoneum on urinary bladder (condition V5); (7) liver bulbous, hepatic peritoneum white (condition H2); (8) humeral spines absent; (9) webbing reduced between Fingers I, II and III, moderate between outer fingers (Figure 110); webbing formula I $\left(2-2^{+}\right)$-2 II $\left(1-1^{+}\right)$-(3) III (2)-(1+-2) IV (1-2) IV; (10) webbing between toes moderate; webbing formula on feet I $\left(1-1^{1 / 2}\right)-(2)$ II $(1)-\left(2-2^{+}\right)$III $(1)-\left(2^{+}-2^{-}\right)$IV $\left(2-2^{+}\right)-\left(1-1^{+}\right) \mathrm{V}$; (11) ulnar and tarsal fold absent; (12) concealed prepollex; nuptial pad Type IV; (13) Finger II shorter than Finger I; (14) eye diameter larger than width of disc on Finger III (disc of Finger III width 33\%-37\% of eye diameter); (15) in life, lime green dorsum with yellow spots (Figure 109); venter transparent, pericardium usually white (but see Color in life); bones white; (16) in preservative, dorsum cream; (17) in life, iris yellowish to greyish white with some dark punctuations; (18) fingers and toes lacking melanophores; (19) males call from the underside of leaves; the call consists of a single "wheet" note, with duration of $150-300 \mathrm{~ms}$, and a dominant frequency of $3800-4500 \mathrm{~Hz}$ at the beginning and 4800-5300 HZ at the end; (20) fighting behavior varies from vent to vent to amplexus-like; (21) egg clutches usually laid on the underside of leaves; maternal care absent; males provide prolonged parental care; (22) oral apparatus complete; oral disc with single row of marginal papillae laterally and ventrally, wide dorsal gap; jaw sheaths normal; 2(2)/3 labial tooth rows, A-2 with wide gap, tooth rows situated nearly lateral to mouth and upper jaw sheath; (23) minute body size; snout-vent length in adult males $19.3-26.8 \mathrm{~mm}(n=13)$, and in adult females $22.4-31.1 \mathrm{~mm}(n=7)$.

Color in life (Figure 109): Dorsum lime green with pale yellow or greenish spots. Venter transparent, pericardium usually white, visceral and hepatic peritonea white. Twomey et al. [19] report that within a single population of H. fleischmanni near San Gabriel Mixtepex (Oaxaca, Mexico), adults exhibited variation in the condition of the pericardium (from white to transparent). 
A

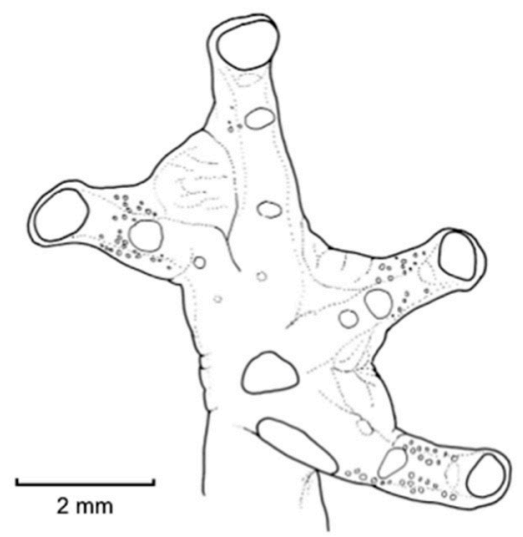

B

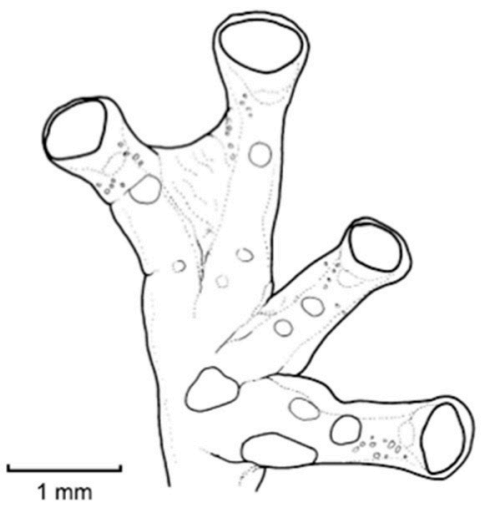

Figure 110. Hyalinobatrachium fleischmanni, variation in hand webbing, ventral view. (A) KU 116447.

(B) QCAZ 22301. Illustrations by Juan M. Guayasamin.

Color in ethanol: Cream dorsum with dark melanophores in the places where green coloration was in life. Venter translucent. Parietal peritoneum completely transparent, heart and all viscera covered by white lining.

Biology and ecology: The natural history of Hyalinobatrachium fleischmanni has been reviewed by several studies, including Greer and Wells [213], Villa [214], Jacobson [188], Hayes [189], Savage [148], Kubicki [24], and Delia et al. [215]. We summarize the essential information here but refer readers to those papers for more data. Individuals of Hyalinobatrachium fleischmanni have been found on vegetation up to $10 \mathrm{~m}$ above streams at night. Males are territorial and call from the lower (mainly) and upper surfaces of leaves. Females usually deposit eggs clutches on the lower surfaces of leaves, although some variation has been reported [215]; maternal care is absent [25]. Physical combat occurs when a male intrudes into an occupied territory. Initially the owner of the territory will call vigorously, but if that strategy fails, male-male combat starts usually with both males adopting an amplexus-like position. Both males may give quick calls. Although venter to venter combat was thought to be absent in Hyalinobatrachium, $H$. fleischmanni has been observed to adopt this combat position, with both males dangling upside down while holding vegetation with their hind limbs [215]. Males attend egg clutches at night, and may continue to advertise, sometimes ending with multiple clutches from different females. During the day, the male parent retreats to nearby vegetation. Only males are involved in parental care of the eggs. Delia et al. [25] observed that males of this species are attentive to individual embryo needs. Eggs are pale greenish white, and clutches are deposited on the underside of leaves. Each egg clutch has one layer of 10-50 eggs [189,216].

Call: The call consists of a single "wheet" note that rises at the end, with duration of 150-300 ms. The dominant frequency is $3800-4500 \mathrm{~Hz}$ at the beginning and $4800-5300 \mathrm{HZ}$ at the end. Calls are emitted 4-19 per minute $[148,188,209,213]$.

Tadpole: A description of the tadpole can be found in Starrett [146], Savage [148], and Hoffmann [147].

Distribution (Figure 111): Hyalinobatrachium fleischmanni is known from southern Mexico, across Mesoamerica, south to central Ecuador at elevations below $800 \mathrm{~m}[24,148,212,217,218]$. In Ecuador, the species is known from localities in the Pacific lowlands (mostly below $300 \mathrm{~m}$ ) in the provinces of Esmeraldas, Pichincha, Santo Domingo de los Tsáchilas, Los Ríos, and Guayas. In Ecuador, the potential distribution of the species is $39,738 \mathrm{~km}^{2}$. The distribution of $H$. fleischmanni is an overestimation because, as currently recognized, it is a species complex [212]. 


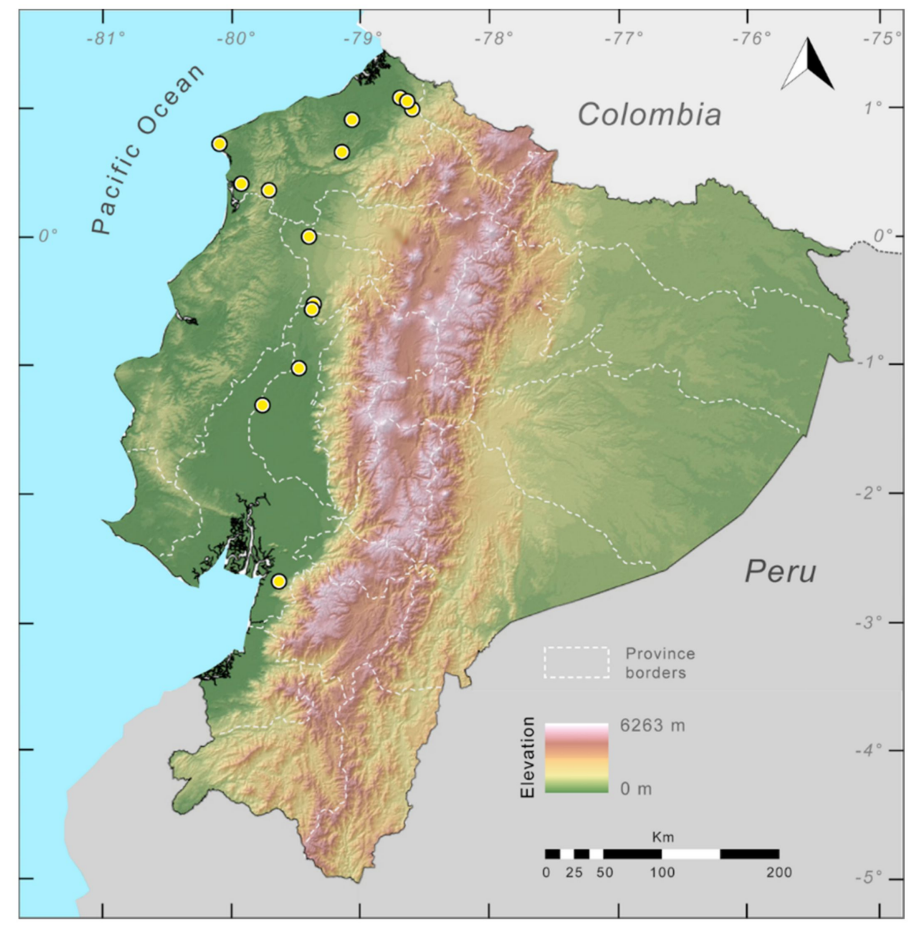

Figure 111. Distribution of Hyalinobatrachium fleischmanni in Ecuador (yellow dots).

Conservation status: Globally, Hyalinobatrachium fleischmanni is considered as Least Concern by the IUCN because of its wide distribution and tolerance of habitat modifications [219]. However, recent studies suggest that this taxon represents a species complex that requires subdivision [212]. In Ecuador, about $55 \%$ of the potential distribution of the species is affected by human activities. Even though habitat destruction is considerable, H. fleischmanni is known to tolerate a degree of disturbance [24]. In Ecuador, we suggest maintaining the category of Least Concern until new taxonomic studies are available.

Evolutionary relationships (Figure 101): Our tree shows Hyalinobatrachium fleischmanni as the sister species of H. muiraquitan, which is endemic to the Brazilian Amazon basin. Although the Venezuelan $H$. tatayoi falls within the genetic variation of $H$. fleischmanni, recent studies suggest that H. fleischmanni represents a species complex that requires taxonomic revision [212].

Specimens examined: Hyalinobatrachium fleischmanni: Costa Rica: Alajuela, USNM 219249-61. San José, USNM 219263-80. Guanacaste, USNM 219282-303. Ecuador: Provincia de Los Ríos: Quevedo, USNM 60520; Río Palenque, USNM 286639-40; Patricia Pilar, USNM 286645; Hacienda Cerro Chico, USNM 286646. Provincia de Esmeraldas: $4 \mathrm{~km} \mathrm{~W}$ Durango, QCAZ $23549 \mathrm{~km}^{2}$ in the San Francisco-Durango road, QCAZ 32073; Río Quingue, nearby Caimito (0.72096 S, 80.09117 W, 47 m), QCAZ 37308; Río Onzole, QCAZ 10433; Tesoro Escondido (0.542 N, 79.145 S, 225 m), MZUTI 3621-3625. Provincia de Santo Domingo de los Tsáchilas: Bosque Protector La Perla, QCAZ 12606. Honduras: Olancho: USNM 342162-342213. Nicaragua: Matagalpa: USNM 220013-18. Nueva Segovia: USNM 220019-36. México: Chiapas: USNM 115499.

Localities from the literatura: Ecuador: Provincia de Guayas: Cerro de Hayas $\left(2.7299^{\circ} \mathrm{S}\right.$, 79.6297 W, 127 m), MZUA.AN.1693-1694; Provincia de Los Ríos: Macul (1.2279 S, $79.7531^{\circ} \mathrm{W}$, 84 m), MZUA.AN.660-661 [218]. 
Hyalinobatrachium iaspidiense (Ayarzagüena, 1992 [220]; Figures 112 and 113).

Centrolenella iaspidiensis Ayarzagüena, 1992 [220]. Holotype: EBD 28803.

Type locality: "Quebrada Jaspe. San Ignacio de Yuruaní. Edo. Bolivar. Venezuela."

Centrolene iaspidiensis_Duellman, 1993 [221]. Unintended combination.

Hyalinobatrachium iaspidiense-Myers and Donnelly, 1997 [104].

Hyalinobatrachium nouraguensis-Lescure and Marty, 2001 [222]. Holotype: MNHNP 1999.8604.

Type locality: "Saut Arataye (environs du camp de base), Réserve des Nouragues (bassin

de l'Approuague), Guyane française". Placed in synonymy by Yánez-Muñoz, Pérez-Peña, and Cisneros-Heredia, 2009 [223].

Common names: English: Jaspe Glassfrog. Spanish: Rana de Cristal de Jaspe.

Etymology: The specific name iaspidiense is derived from the Greek word iaspis, meaning jasper, in reference to the type locality of the species, Quebrada de Jaspe.

Identification: Hyalinobatrachium iaspidiense is one of the most easily recognizable centrolenid. In life, it has a dorsum with large, lime green, irregular blotches and small, black spots (Figure 112). The only species with a similar dorsal coloration is H. mesai, a species known only from the southern slope of Sarisariñama-tepui, Venezuela [224]. It has been suggested, however, that $H$. mesai and H. iaspidiense represent the same species [223].
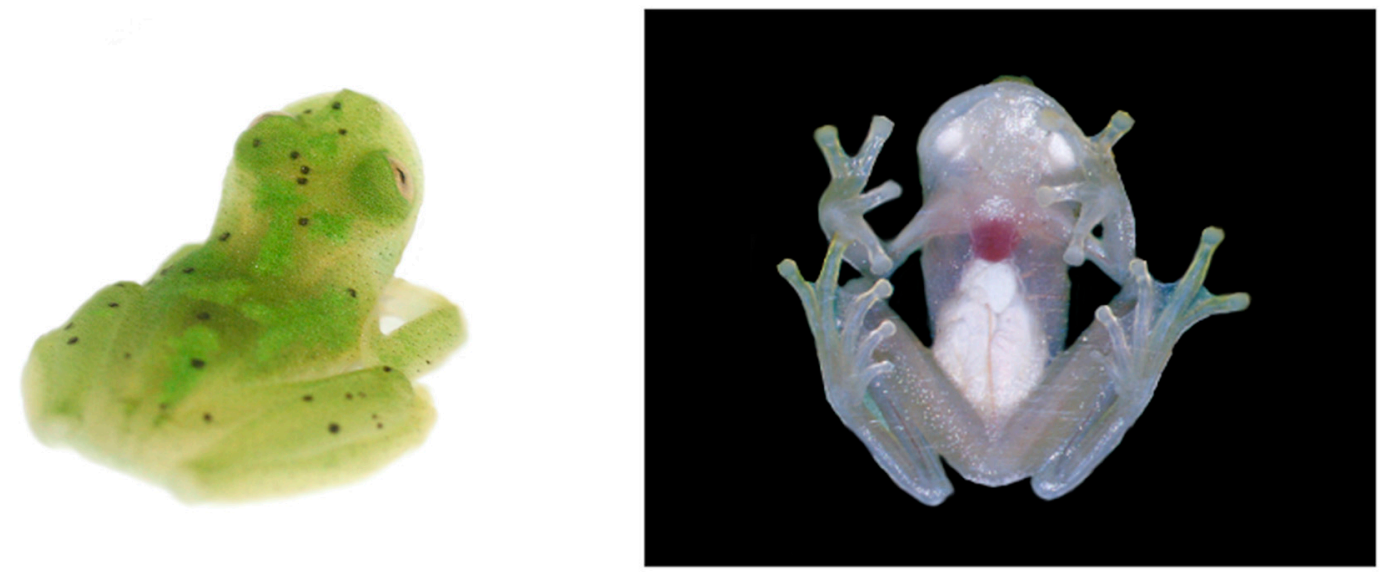

Figure 112. Hyalinobatrachium iaspidiense in life. (Left): Adult female (QCAZ 38438) from Ecuador, Yachana Reserve, 300-350 m; photo by Susan North. (Right): Adult male (SMNS 12247) from Guyana, Mabura Hill Forest Reserve, 60 m; photo by Raffael Ernst.

Diagnosis: (1) Vomerine teeth absent; (2) snout truncated in dorsal aspect and slightly protruding in profile; (3) tympanum not visible; supratympanic fold absent; (4) dorsal skin shagreen; (5) venter smooth; pair of enlarged subcloacal warts, but low and difficult to see; (6) ventral parietal peritoneum transparent (condition P0); pericardium transparent; white peritoneum covering intestines and stomach; transparent peritoneum on urinary bladder (condition V6); (7) liver bulbous, hepatic peritoneum white (condition H2); (8) humeral spines absent; (9) webbing absent between Fingers I, II, and III, moderate between outer fingers; webbing formula III $\left(2-2^{+}\right)-\left(1^{+}-2^{-}\right) \mathrm{IV} ;(10)$ webbing between toes moderate; webbing formula on foot I $\left(1-1^{+}\right)-\left(2^{+}-2^{1 / 3}\right)$ II $\left(1^{+}-1^{1 / 3}\right)-\left(2^{+}-2^{1 / 4}\right)$ III $\left(1-1^{+}\right)-\left(2-2^{3 / 4}\right)$ IV $\left(2^{+}-2^{1 / 4}\right)-\left(1^{+}-1^{1 / 4}\right) \mathrm{V} ;(11)$ ulnar fold present, enameled; external tarsal fold present, enameled; internal tarsal fold short and low; (12) concealed prepollex; nuptial pad Type IV; (13) Finger II shorter than Finger I (Finger II about $93 \%$ of Finger I); (14) disc of Finger III width $39 \%-57 \%$ of eye diameter; (15) in life, dorsum translucent with a yellowish-green background coloration, large lime green blotches, and small black spots (Figure 112); bones white; (16) in preservative, dorsum cream with large, irregular white blotches and small, black spots; (17) in life, iris yellowish to greyish white; (18) fingers and toes 
lacking melanophores, except few present on Finger IV and Toes IV and V; (19) males call from the underside of leaves; the call consists of a single pulsed note, with a dominant frequency at $4440-4710 \mathrm{~Hz}$; (20) fighting behavior unknown; (21) egg deposition site unknown; parental care unknown; (22) tadpole unknown; (23) minute body size; in Venezuelan specimens: SVL in females $22.7 \mathrm{~mm}(n=1)$, in males 19.8-21.8 $\mathrm{mm}(n=8)$ [106]; in Ecuador, male SVL $=19.9 \mathrm{~mm}(n=1)$, and female SVL $=21.9 \mathrm{~mm}(n=1)$.

Color in life (Figure 112): Dorsum translucent, with a yellowish-green background coloration, large lime-green blotches, and small black spots. Venter transparent, pericardium transparent (red heart visible), visceral and hepatic peritonea white $[223,225]$.

Color in ethanol: Dorsum cream lavender, with large irregular white marks and small black spots. Ulnar and tarsal folds enameled; some of the warts below cloaca enameled. Venter transparent, pericardium transparent, visceral and hepatic peritonea white; peritonea around urinary bladder transparent; gall bladder white (description based on two adults, MECN 4033, QCAZ 38438).

Variation: Ulnar and tarsal folds less evident and with few iridophores (QCAZ 38438).

Biology and ecology: Found on vegetation 4-7 m above streams [106]. In Ecuador (Yachana Reserve), an adult female was found on a long blade of tall grassy shrub overhanging water, located in the middle of a stream ( $4 \mathrm{~m}$ wide). Stream habitat is variable, but the female was found in a shallow area ( $20 \mathrm{~cm}$ deep) where the stream becomes a riffle and is more fast-flowing. Stream bottom here is composed of about $80 \%$ pebbles and small rocks and $20 \%$ sand near edges. The forest adjacent to the stream is near pristine and about $25-30 \mathrm{~m}$ high [225]. Parental care unknown.

Call: The call consists of a single note, with 16 pulses and a duration of 62.7-75.1 ms. Dominant frequency at $4440-4710 \mathrm{~Hz}$. The total frequency range for the call is between 3710 and $5850 \mathrm{~Hz}$, with a secondary frequency at $8600-9200 \mathrm{~Hz}$. The call was emitted frequently (7-10 calls per minute) [106].

Tadpole: Not described.

Distribution (Figure 113): Hyalinobatrachium iaspidiense is known from the Guiana region of Venezuela, central Guyana, Surinam (Sipaliwini District), and French Guiana, as well as from the Amazon Basin of Ecuador, Peru, and Brazil at elevations below 1000 m [106,222,225-229]. In Ecuador, the species is known from few localities in the Amazonian raiforest.

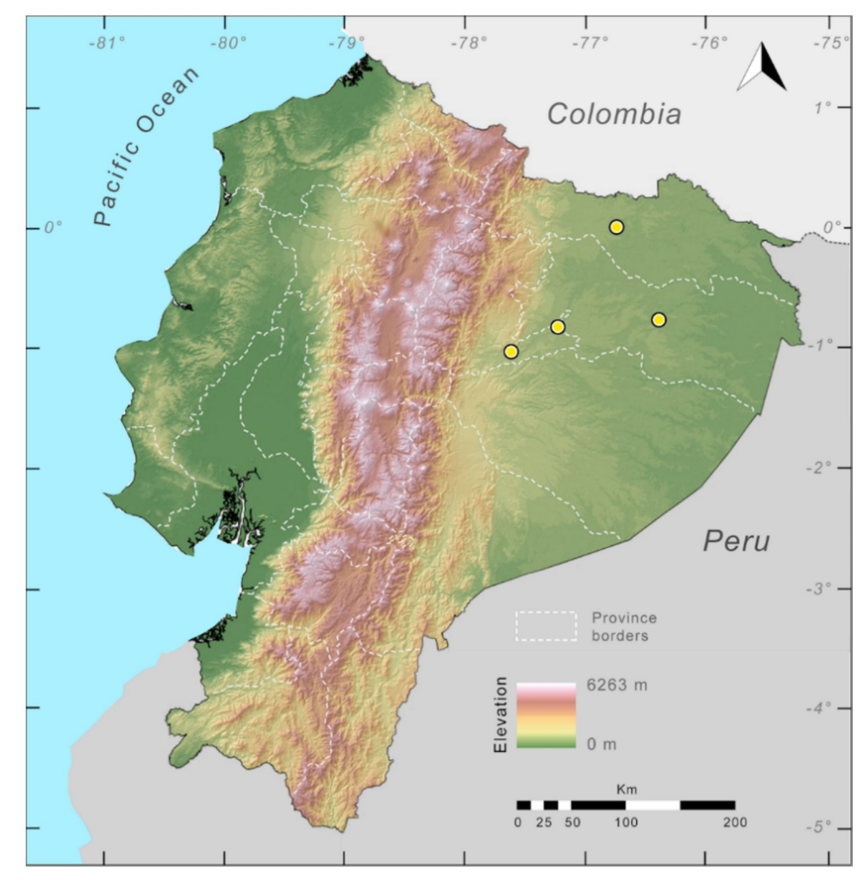

Figure 113. Distribution of Hyalinobatrachium iaspidiense in Ecuador (yellow dots). 
Conservation status: Hyalinobatrachium iaspidiense is considered as Data Deficient by the IUCN [230]. However, given the large distribution of the species and the absence of immediate threats, we suggest that it should be considered as Least Concern, both globally and in Ecuador.

Evolutionary relationships (Figure 101): H. iaspidiense is the sister species of $H$. tricolor.

Specimens examined: H. iaspidiense: Ecuador: Provincia Napo: Yachana Reserve (052'21.71" S, 77¹4'13.43" W; 300-350 m), QCAZ 38438; Estación Biológica Jatun Sacha (1.066 S, 77.617 W, 405 m), QCAZ 53023. Provincia Orellana: Km 66 on the Pompella Sur-Iro road (0.8022 S, 76.398 W, 280 m), QCAZ 54947. Provincia Sucumbíos: Totoa Nai'qui $\left(0.03442^{\circ} \mathrm{S}, 76.75278^{\circ} \mathrm{W}\right.$, ca. $\left.280 \mathrm{~m}\right), \mathrm{MECN} 4033$.

Hyalinobatrachium munozorum (Lynch and Duellman, 1973 [22]; Figures 114-116).

Centrolenella munozorum Lynch and Duellman, 1973 [22]. Holotype: KU 118054.

Type locality: "Santa Cecilia, 340 m, Provincia Napo (Sucumbíos), Ecuador".

Hyalinobatrachium munozorum-Ruiz-Carranza and Lynch, 1991 [6].

Hyalinobatrachium ruedai Ruiz-Carranza and Lynch, 1998 [27]. Holotype: ICN 40409. Type

locality: "(Colombia,) Departamento de Caquetá, municipio de Miraflores, Parque Nacional Natural de Chiribiquete, campamento base, 530 m". New synonymy.

Common names: English: Muñoz's Glassfrog. Spanish: Rana de Cristal de Muñoz.

Etymology: The specific name munozorum is a patronym for Ildefonso Muñoz B. and Blanca Muñoz, hosts of the extensive herpetological work carried out in Santa Cecilia by W. E. Duellman and his students [22].

Identification: Hyalinobatrachium munozorum can be distinguished from most glassfrogs by having a green dorsum with pale yellow spots, a completely transparent ventral parietal peritoneum, white liver and digestive tract, and by lacking humeral spines (Figure 114). Similar species with a completely transparent venter that inhabit the Amazon basin include H. bergeri, H. carlesvilai, H. iaspidiense, H. mondolffi, Chimerella mariaelenae, and Teratohyla amelie. Hyalinobatrachium munozorum differs from C. mariaelenae by having, in life, a green dorsum with pale yellow spots (dorsum green with dark grey spots in C. mariaelenae) and by lacking humeral spines (small humeral spines present in adult males of C. mariaelenae). Teratohyla amelie has a uniform green dorsum, lacking the pale-yellow spots visible in H. munozorum. Hyalinobatrachium iaspidiense, in life, has a dorsum with large, green, irregular marks and small, black spots. Morphological differentiation among H. munozorum, H. mondolfii, and $H$. carlesvilai is minimal, although molecular divergence is considerable [22,231,232]; the pupil of $H$. bergeri and H. carlesvilai is surrounded by a dark grey ring (absent in H. munozorum).

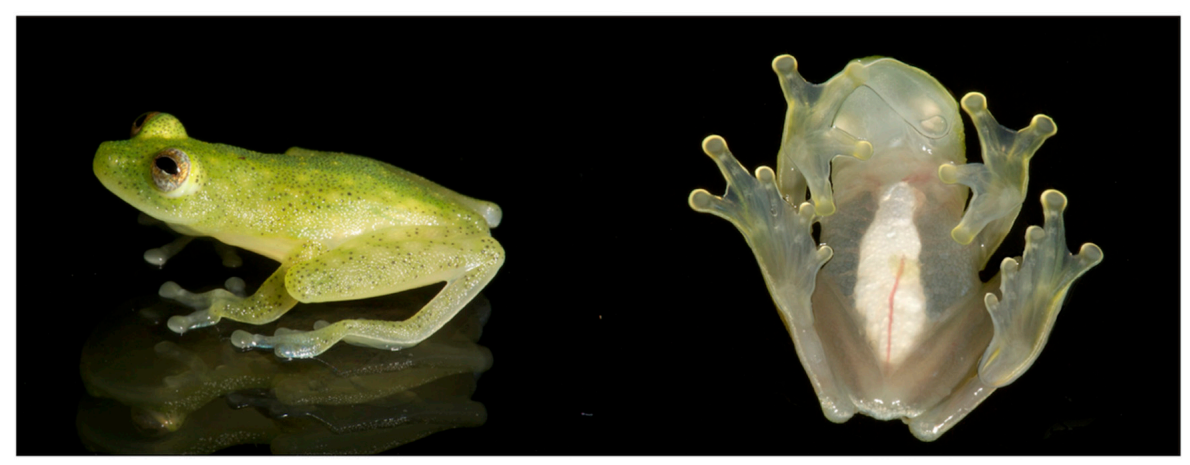

Figure 114. Hyalinobatrachium munozorum in life. Adult male from stream near Tena, $708 \mathrm{~m}$, MZUTI 1616. Photos by Eduardo Toral. 
Diagnosis: (1) Vomers lacking teeth; (2) snout varies from truncated to rounded in dorsal aspect and round to truncated in lateral view; (3) tympanum usually obscured by skin, small when evident, its diameter about $25 \%$ of eye diameter; supratympanic fold low; (4) dorsal skin shagreen; males lacking spicules; (5) ventral skin texture areolate; lacking pair of enlarged subcloacal warts; (6) ventral parietal peritoneum transparent, white pericardium, white peritonea covering intestines and stomach, transparent urinary bladder; (7) liver bulbous, covered by white peritoneum; (8) humeral spines absent; (9) webbing between inner fingers absent; webbing formula for outer fingers: III $\left(1^{1 / 2}-2^{-}\right)-\left(1-2^{-}\right)$IV; $(10)$ feet about three-fourths webbed; webbing formula: I $\left(0^{+}-1^{-}\right)-\left(1^{1 / 3}-2^{-}\right)$II $\left(0^{+}-1\right)-\left(1^{1 / 2}-2\right)$ III $\left(0^{+}-1^{1 / 3}\right)-\left(2^{-}-2^{1 / 3}\right)$ IV $\left(2^{-}-2^{1 / 3}\right)-\left(0^{+}-1\right) \mathrm{V}$; (11) ulnar and tarsal folds variable, from inconspicuous to pronounced; (12) concealed prepollex; in males, nuptial pad not evident; (13) Finger I slightly longer than Finger II (Finger II length 93.7\% $-97.6 \%$ of Finger I); (14) disc of Finger III of moderate size, its width $37.9 \%-56.2 \%$ of eye diameter; (15) in life, dorsum green with diffuse yellow spots, venter transparent; bones white; (16) in preservative, dorsum cream lavender with small unpigmented spots; (17) in life, iris pale to bright gold with dark punctuations; (18) dorsal surfaces of fingers and toes lacking melanophores; (19) call composed by a single note with a duration of $145-178$ (mean $=170, \mathrm{SD}=9.9) \mathrm{ms}$; each call is mostly tonal, with a dominant frequency at 5719-5906 (mean $=5812, \mathrm{SD}=64) \mathrm{Hz}$; (20) fighting behavior unknown; (21) egg clutches laid on the underside of leaves; parental care unknown; (22) tadpoles unknown; (23) minute body size; in males, SVL 19.9-21.9 mm ( $\bar{X}=20.6 \pm 0.691 ; n=8)$; in females, SVL 20.9-23.6 mm $(n=3)$.

Color in life (Figure 114): Dorsal surfaces of head and body green with small, pale yellow spots and minute dark brown flecks. Parietal peritoneum transparent. White peritonea covering heart, liver, digestive tract, and testes; transparent urinary bladder. Iris pale gold with minute dark flecks. See Taxonomic Remarks.

Color in ethanol: Dorsal surfaces of head, body, and limbs cream with numerous minute lavender flecks. White visceral and hepatic peritonea. Layer of iridophores covering heart.

Variation: Specimens in the type series have a round snout in lateral view, and low ulnar and tarsal folds that are inconspicuous and unpigmented. Additional specimens from the type locality (Santa Cecilia) show the following variation: Snout truncated in lateral view, ulnar and tarsal folds conspicuous and white (KU 155493-96); conspicuous tarsal fold and low ulnar fold (KU 152488, 152489, 175215). Specimens identified as Hyalinobatrachium ruedai (a synonym of H. munozorum; see below) by Ruiz-Carranza and Lynch [27] and Cisneros-Heredia and McDiarmid [233] show the following variation: Snout truncated to rounded in dorsal and lateral views, ulnar and tarsal folds vary from inconspicuous to low and white. A female (KU 154749) has a truncated snout and conspicuous white ulnar and tarsal folds. The pericardium of all specimens from Ecuador and Colombia (including the type series) is white. In some individuals (KU 123225, 152488-89, 155494, 155496, 175504), the layer of iridophores is thinner. Cisneros-Heredia and McDiarmid [17] reported that one specimen showed a bicolored iris in life, with a light grey circumpupilary zone. These authors also reported variation in the iris coloration in preservative, from lavender-cream background with dense dark punctuations and lavender mid-line to uniform white.

Biology and ecology: The type series was found on leaves of bushes and trees at night: One over a pond, one away from water in primary forest, one on a palm frond $2 \mathrm{~m}$ above a stream, and one on an herbaceous leaf more than $2 \mathrm{~m}$ above a stream. The specimen from Lago Agrio was obtained from the foliage of a large tree that was felled during the clearing of primary forest [22]. A specimen from Tena was collected at night on the leaf of a bush at a rivulet in secondary forest [17]. Males called from riverine vegetation at a locality nearby Tena on August 2012. Parental care is unknown.

Call (Figure 115): We analyzed 18 notes from 1 individual (LBE-C-020) recorded at Río Bigal, Orellana province, Ecuador. The call is composed by a single note. Note duration is $145-178$ (mean $=170$, $\mathrm{SD}=9.9$ ) ms. Notes are mostly tonal, but they exhibit one to seven (mean $=4.5, \mathrm{SD}=1.6$ ) low-amplitude peaks. Notes usually have their peak amplitude in the first $50 \%$ of the note (relative peak time: Range $=0.1699-0.661$, mean $=0.448, \mathrm{SD}=0.123$ ). The dominant frequency of a note measured at peak amplitude is $5719-5906$ (mean $=5812, \mathrm{SD}=64) \mathrm{Hz}$ and is contained within the fundamental frequency. 
The fundamental frequency has a lower limit of 5625-5812 (mean $=5708, \mathrm{SD}=63$ ) Hz and a higher limit of 5812-6000 (mean = 5906, SD = 64) Hz.

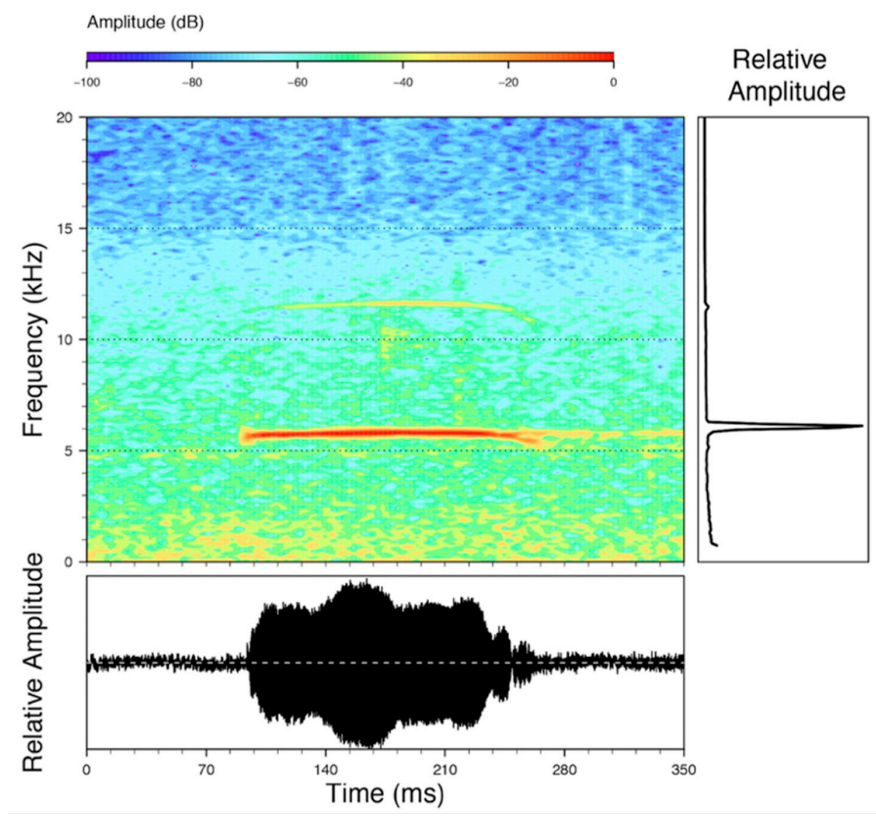

Figure 115. Vocalization of Hyalinobatrachium munozorum recorded at Río Bigal, $930 \mathrm{~m}$, Orellana province, Ecuador, by Morley Read (LBE-C-020).

Tadpole: Not described.

Distribution (Figure 116): Hyalinobatrachium munozorum is known from localities in the Amazonian lowlands and Andean foothills of Colombia, Ecuador, Peru, and Bolivia at elevations below $980 \mathrm{~m}$ ([17,22,27,134,232], this work). In Ecuador, this species has been recorded from localities below $300 \mathrm{~m}$; although, there is one juvenile (identification unconfirmed), found at $920 \mathrm{~m}$ (Specimens examined). In Ecuador, the potential distribution of the species is $101,986 \mathrm{~km}^{2}$.

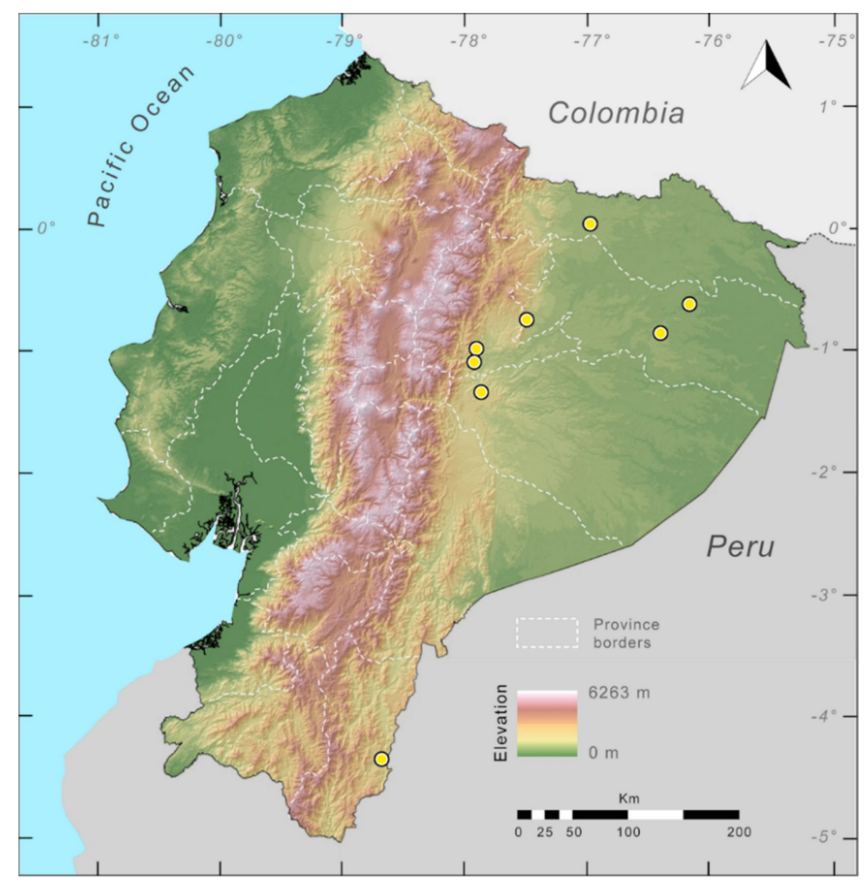

Figure 116. Distribution of Hyalinobatrachium munozorum in Ecuador (yellow dots). 
Conservation status: Globally, Hyalinobatrachium munozorum is listed as Least Concern by the IUCN [234]. Although H. munozorum is rare in collections, we presume that this is a consequence of inadequate sampling at the canopy level [166]. The distribution of the species is large and lacks immediate threats; thus, the Least Concern conservation status is justified.

Evolutionary relationships (Figure 101): H. mondolfii is the closest relative of H. munozorum.

Taxonomic Remarks: Lynch and Duellman [22] used the terms "heart visible" and "heart not visible" to illustrate the condition of the ventral parietal peritoneum; species that have a transparent (=clear) peritoneum were considered as having a "heart visible", whereas species with a white parietal peritoneum had a "heart not visible". Ruiz-Carranza and Lynch [27] discussed the character states of the pericardium; they applied the term "heart visible" for species that have a transparent parietal peritoneum as well as a transparent pericardium (red heart visible in life). In the same work, Ruiz-Carranza and Lynch [27] described H. ruedai, which was diagnosed by having a white pericardium; H. ruedai was compared with congenerics with a white heart, a list that did not include H. munozorum. We assume that Ruiz-Carranza and Lynch [27] interpreted the condition of "heart visible" for H. munozorum as equivalent to a visible red heart. As mentioned above, the type series of $H$. munozorum and H. ruedai have a white heart. The only other characteristic that could separate $H$. ruedai from $H$. munozorum is the hand webbing; however, the range observed in H. ruedai falls within the variation of H. munozorum. Therefore, herein we place Hyalinobatrachium ruedai Ruiz-Carranza and Lynch, 1998 [27], in the synonymy of Centrolenella munozorum Lynch and Duellman, 1973 [22].

Specimens examined: H. munozorum: Ecuador: Provincia Sucumbios: Santa Cecilia $\left(00^{\circ} 03^{\prime} \mathrm{N}\right.$, $76^{\circ} 58^{\prime} \mathrm{W} ; 340 \mathrm{~m}$ ), KU 118054 (holotype), 105251, 123225, 150620 (paratypes), 152488-89, 155493-96, 175504. Provincia Orellana: Río Yasuní $\left(00^{\circ} 51^{\prime} \mathrm{S}, 76^{\circ} 23^{\prime} \mathrm{W}\right.$; ca. $\left.250 \mathrm{~m}\right), \mathrm{KU}$ 175215; Tiputini Biodiversity Station $\left(00^{\circ} 37^{\prime} \mathrm{S}, 76^{\circ} 10^{\prime} \mathrm{W}\right.$; 190-270 m), DFCH-D105. Provincia Zamora Chinchipe: Shaime $\left(4^{\circ} 20^{\prime} \mathrm{S}\right.$, $78^{\circ} 40^{\prime}$ W; ca. 920 m), QCAZ 31056 (identification not certain). Provincia Napo: Tena (00 $59^{\prime} \mathrm{S}, 77^{\circ} 49^{\prime} \mathrm{W}$; 500 m), DFCH-USFQ 0735. Provincia Pastaza: Río Manderoyacu, EPN 6427; km 6 vía San Ramón-El Triunfo (1.355S, 77.86456), QCAZ 33261. Colombia: Departamento Caquetá: Municipio de Miraflores, Parque Nacional Natural Chiribiquete, 530 m, ICN 40409-11 (type series of H. ruedai), IND-AN 5448-52. Peru: Departamento de Huanuco: Finca Panguana, Río Llullapichis, 4-5 km upstream from Río Pachitea (9 $36^{\prime}$ S, 7455' W; 200 m), KU 154749, 172167-69; Departamento de Cuzco: 40 km E Quince Mil on road

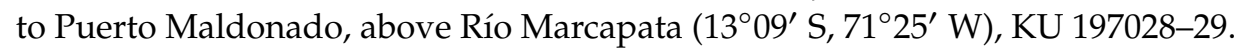

Hyalinobatrachium pellucidum (Lynch and Duellman, 1973 [22]; Figures 117-120).

Centrolenella pellucida Lynch and Duellman, 1973 [22]. Holotype: KU 143298.

Type locality: "Río Azuela, 1740 m, Quito-Lago Agrio road, Provincia Napo (Sucumbíos), Ecuador."

Hyalinobatrachium pellucidum -Ruiz-Carranza and Lynch, 1991 [6].

Hyalinobatrachium lemur Duellman and Schulte, 1993. Holotype: KU 211768. Type locality: “west slope of Abra Tangarana, $7 \mathrm{~km}$ (by road) northeast of San Juan de Pacaysapa $\left(06^{\circ} 12^{\prime} \mathrm{S}\right.$, $76^{\circ} 44^{\prime}$ W, 1080 m), Provincia Lamas, Departamento San Martín, Perú". Synonymy by Castroviejo-Fisher, Padial, Chaparro, Aguayo, and De la Riva, 2009 [231].

Common names: English: Andean Glassfrog. Spanish: Rana de Cristal Andina.

Etymology: The specific name pellucidum is derived from the Latin word pellucidus (clear, transparent) and refers to the transparent parietal peritoneum of this centrolenid frog [22]. 
Identification: Hyalinobatrachium pellucidum is distinguishable from most glassfrogs by having a completely transparent ventral parietal peritoneum, a white liver, and transparent pericardium (in life, red heart visible ventrally; Figure 117). On the Amazonian slopes of the Andes and Amazon basin, the only other species with a visible red heart in life is H. iaspidiense, which differs from H. pellucidum by having large lime green blotches and small black spots on the dorsum (both absent in H. pellucidum).

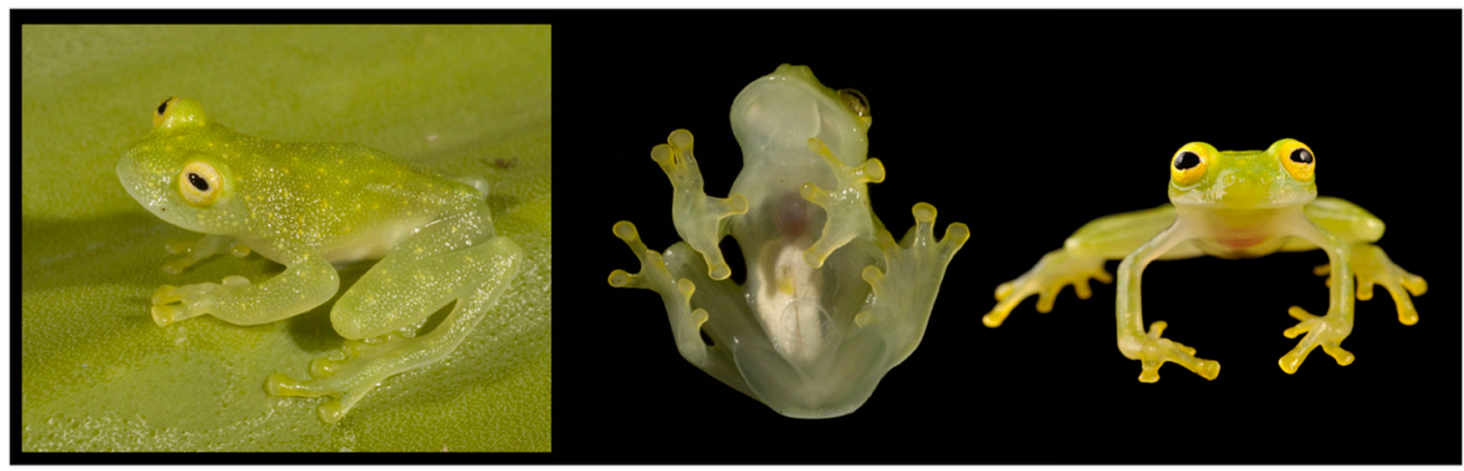

Figure 117. Hyalinobatrachium pellucidum in life. (Left and center): Male from Río Napinaza, Morona Santiago province, Ecuador, QCAZ 42000. (Right): Male from Miazi Alto, Zamora Chinchipe province, 1250 m, QCAZ 41648. Photos by Luis A. Coloma.

Diagnosis: (1) Vomerine teeth absent; (2) snout truncated in dorsal aspect and profile (Figure 118); (3) tympanum partially hidden under skin, its diameter about $30 \%$ of eye diameter; supratympanic fold low; (4) dorsal skin shagreen; (5) ventral skin texture areolate; lacking pair of enlarged subcloacal warts; (6) ventral parietal peritoneum transparent (condition P0); pericardium transparent; white peritoneum covering intestines and stomach; transparent peritoneum on urinary bladder (condition V6); (7) liver bulbous, hepatic peritoneum white (condition H2); (8) humeral spines absent; (9) webbing absent between Fingers I and II, extensive between outer fingers (Figure 118); webbing formula II $1^{1 / 2}-3^{+}$III $2^{+}-\left(2^{-}-2\right)$ IV; (10) webbing between toes extensive; webbing formula on foot I $1-1^{1 / 2}$ II $1^{+}-2^{-}$III $1^{+}-2^{+}$IV 2-1 V; (11) ulnar and tarsal folds present, usually white (but see Variation); (12) concealed prepollex; nuptial pad type unknown; (13) Finger I slightly longer than Finger II (Finger II about 95\% of Finger I); (14) disc of Finger III width about 50\% of eye diameter; (15) in life, dorsum pale green with diffuse yellow spots; venter transparent, exposing the red heart (Figure 117); color of bones white; (16) in preservative, dorsum creamy white with minute purple flecks visible under magnification; (17) iris pale silvery bronze in life; (18) dorsal surfaces of fingers and toes lacking melanophores; (19) each has a single, tonal note with a duration of 98-140 (mean = 128, SD = 8.7) ms; dominant frequency is at 5599-5857 (mean = 5690, SD = 58) Hz; (20) fighting behavior unknown; (21) egg clutches placed on the underside of leaves; maternal care absent; prolonged parental care provided by males; (22) tadpoles undescribed; (23) minute body size; in males, SVL 20.4-21.4 mm; in one female SVL $21.6 \mathrm{~mm}$. 
A

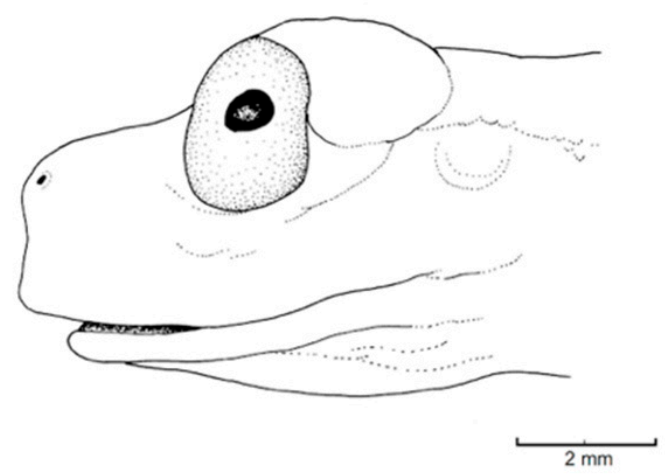

B

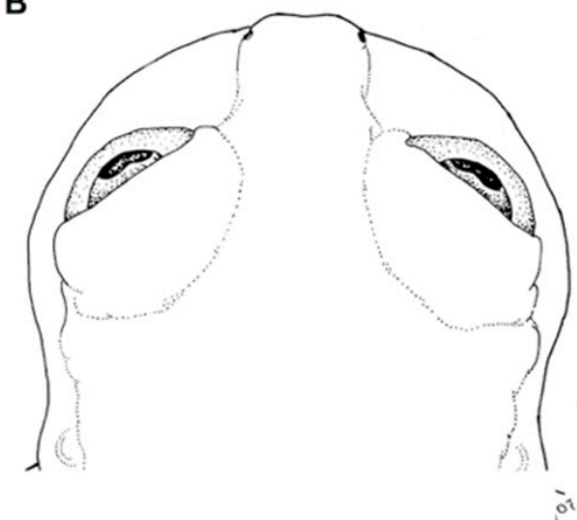

C

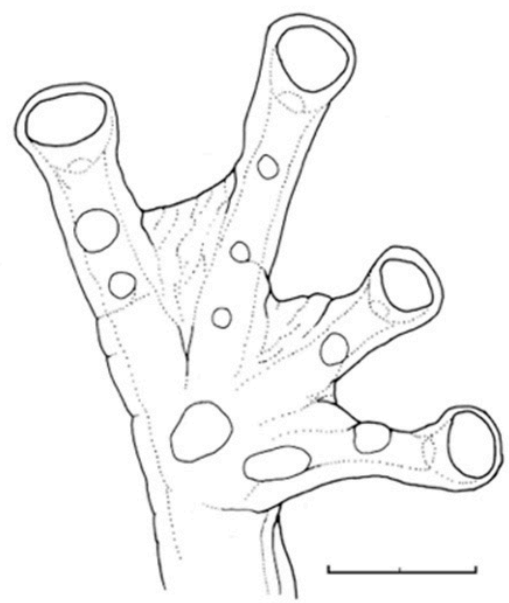

Figure 118. Hyalinobatrachium pellucidum, holotype, KU 143298. (A) Head in lateral view. (B) Head in dorsal view. (C) Hand in ventral view. Illustrations by Juan M. Guayasamin.

Color in life (Figure 117): Dorsum pale green with diffuse yellow spots; venter and hidden surfaces of limbs lacking pigment; fingers and toes yellow; parietal peritoneum clear; red heart visible; bones white; iris pale silvery bronze [22].

Color in ethanol: Dorsum creamy white with minute purple flecks and small white granules visible under magnification; digestive tract and liver covered by white peritonea; pericardium lacking iridophores; ulnar and tarsal folds white.

Variation: Castroviejo-Fisher et al. [231] reported the following variation: The holotype of H. pellucidum has marked and enameled ulnar, tarsal, and cloacal folds, while specimens previously identified as $H$. lemur (a synonym of H. pellucidum) only show weak and non-enameled folds. The variation is interpreted as being the product of preservation artifacts and intraspecific variation. Two additional specimens from the same locality and near the type locality of $H$. lemur ( $45 \mathrm{Km}$ straight line) show intermediate states regarding ulnar, tarsal, and cloacal folds. The specimen KU 217297 has an enameled but weak ulnar fold, a weak but non-enameled tarsal fold, and an enameled and weak cloacal fold; KU 217295 has an enameled and marked ulnar fold, an enameled but weak tarsal fold, and an enameled and marked cloacal fold. A specimen (MHNCP 4880) collected in Cusco, Peru, and assigned to H. pellucidum, has very weak and barely enameled ulnar, tarsal, and cloacal folds.

Biology and ecology: The holotype of Hyalinobatrachium pellucidum was found on the leaf of an herb over a small stream at night. The following species were in the same stream and in other small streams nearby: Nymphargus megacheirus, N. anomalus, N. siren, Centrolene pipilata, Hyloscirtus phyllognathus [22]. Short-term maternal care is absent; males provide prolonged parental care [25]. 
Call (Figure 119). We analyzed 36 notes from one individual (USNM 286708), recorded at the type locality of the species, Río Azuela, 1740 m, Napo province, Ecuador, by Roy McDiarmid. The advertisement call is relatively short which has a single note per call (i.e., call $=$ note). Notes are moderate in duration and the note duration is $98-140$ (mean $=128, \mathrm{SD}=8.7) \mathrm{ms}$. Notes are tonal and do not show any clear amplitude peaks. The dominant frequency is 5599-5857 (mean $=5690, \mathrm{SD}=58$ ) $\mathrm{Hz}$ and is contained within the fundamental frequency. The fundamental frequency has a lower limit of 5163-5685 $($ mean $=5381, \mathrm{SD}=678) \mathrm{Hz}$ and a higher limit of 5685-5943 (mean $=5778, \mathrm{SD}=56) \mathrm{Hz}$.

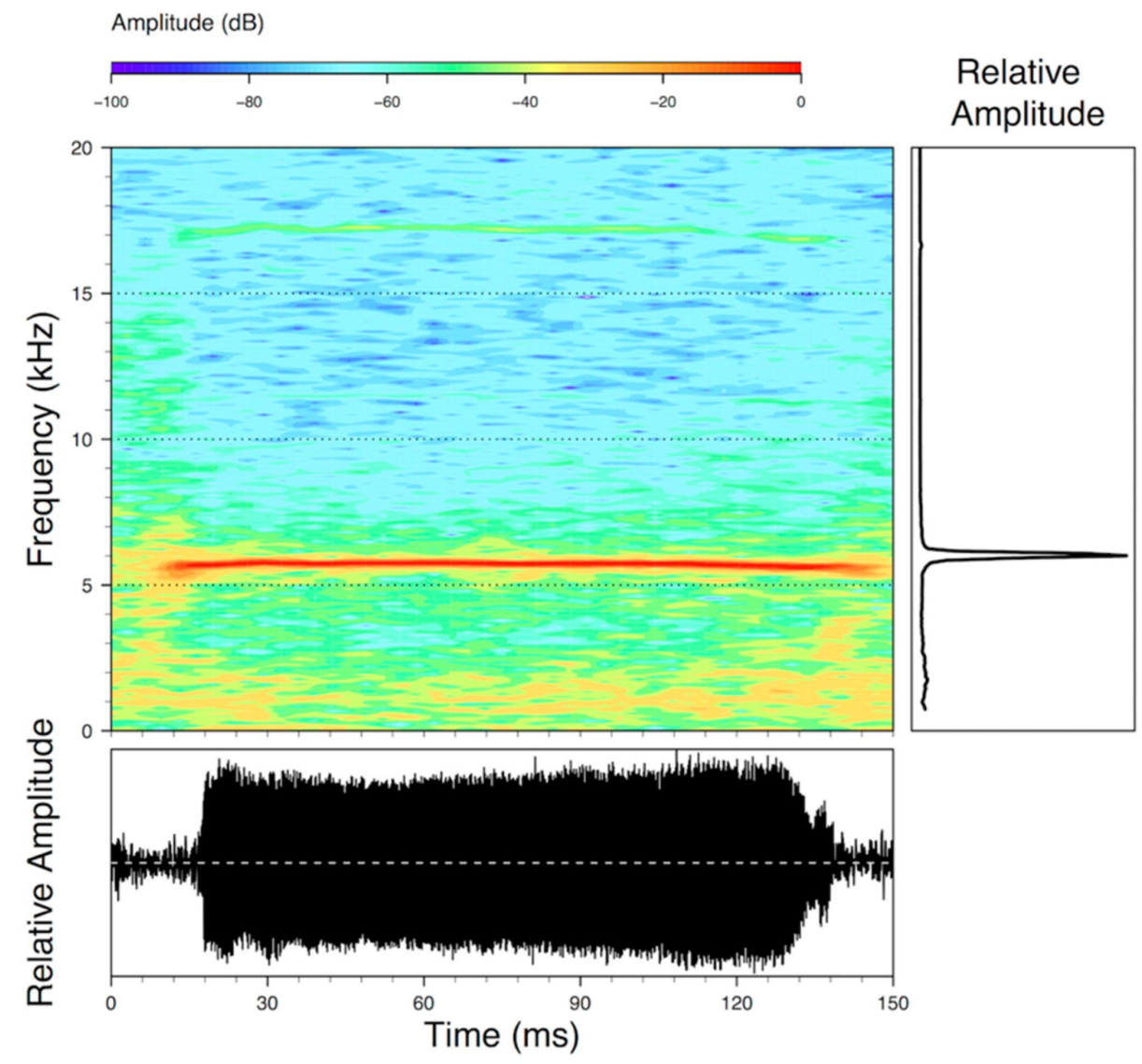

Figure 119. Call of Hyalinobatrachium pellucidum recorded at Río Azuela, 1740 m, Napo province, Ecuador, recorded by Roy McDiarmid (USNM 286708).

Tadpole: Not described.

Distribution (Figure 120): Hyalinobatrachium pellucidum is known from a few records in the lower montane rainforest on the Amazonian Andean slopes of Ecuador and Peru, at elevations between $1000-1740$ m ([22,231], this work). In Ecuador, Hyalinobatrachium pellucidum inhabits the Eastern Foothill Forest and Eastern Montane Forest ecoregions, and it is known from localities between 1013 and 1740 m; these localities are Río Azuela, Río Reventador, km 6.6 on the Limón-Macas road, and Cordillera del Cóndor (Specimens Examined). 


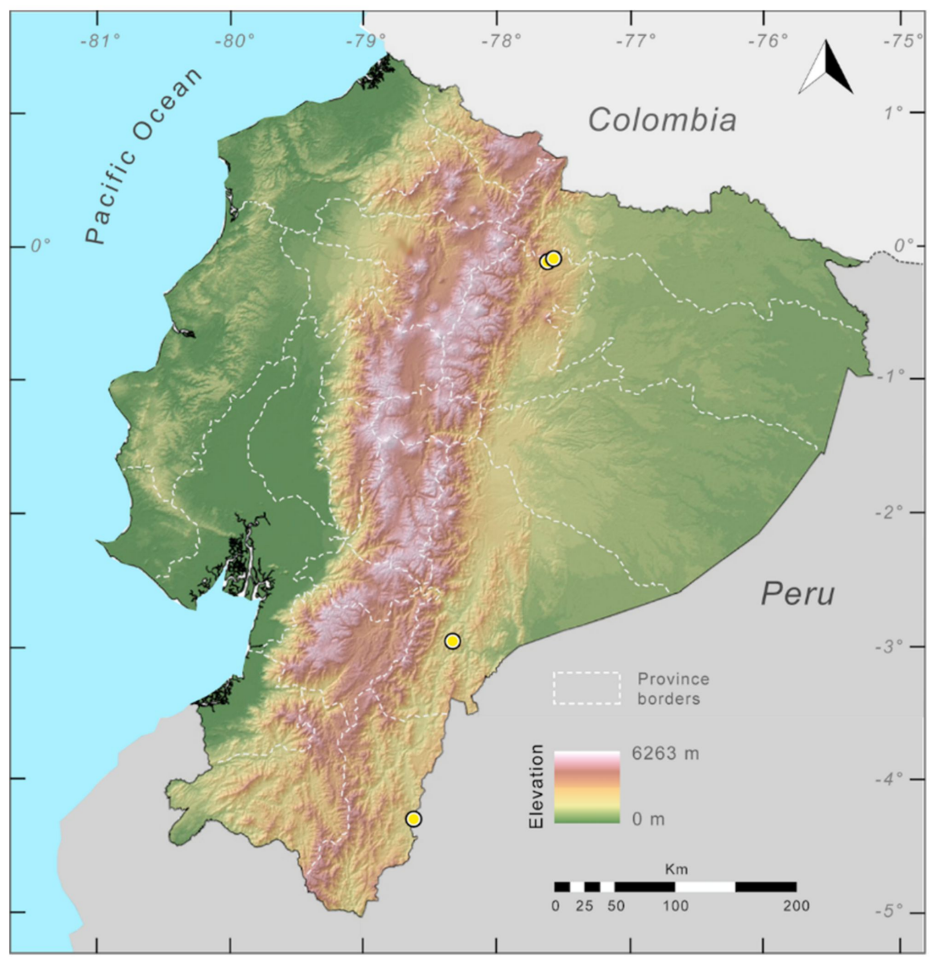

Figure 120. Distribution of Hyalinobatrachium pellucidum in Ecuador (yellow dots).

Conservation status: Globally, Hyalinobatrachium pellucidum is listed as Near Threatened by the IUCN [235]. In Ecuador, the species is severely fragmented because of agriculture, pasture lands, and mining. Thus, we suggest that, locally, it should be placed in the Vulnerable category, following IUCN criteria b1, B2a, B2biii.

Evolutionary relationships (Figure 101): Hyalinobatrachium pellucidum is sister to H. yaku.

Specimens examined: Hyalinobatrachium pellucidum: Ecuador: Provincia de Sucumbíos: Río Azuela (0.1167 S, 77.6167 W; 1740 m), Quito-Lago Agrio road; KU 164691 (holotype), USNM 286708-10; Río Reventador, USNM 286711-12. Provincia de Morona Santiago: km 6.6 on the Limón-Macas road (ca. 2.92816 S, 78.344 W; 1013 m), QCAZ 29438. Provincia de Zamora Chinchipe: Cordillera del Cóndor, Miazi Alto (4.25044 S, 78.61356 W; 1282 m), QCAZ 41560-61.

Hyalinobatrachium esmeralda: Colombia: Departamento de Boyacá, Municipio de Pajarito, Inspección Policía Corinto, finca 'El Descanso', quebrada 'La Limonita', 1600-1650 m, ICN 9592-94, 9596, 9602-03 (type series of H. esmeralda). 
Hyalinobatrachium valerioi (Dunn, 1931 [236]; Figures 121-123).

Centrolene valerioi Dunn, 1931 [236]. Holotype: MCZ 16003.

Type locality: "La Palma, Costa Rica, 4500 feet".

Cochranella valerioi-Taylor, 1951.

Cochranella reticulata-Taylor, 1958 [201]. Holotype: KU 32922. Type locality: "near bridge across

Río Reventazón at the Inter-American Institute of Agriculture, Turrialba, Cartago Province,

Costa Rica". Placed in synonymy by Starrett and Savage, 1973 [209].

Centrolenella valerioi-Starrett and Savage, 1973 [209].

Hyalinobatrachium valerioi-Ruiz-Carranza and Lynch, 1991 [6].

Common names: English: Reticulated glassfrog [237], Valerio's glassfrog. Spanish: Rana de Cristal Reticulada, Rana de Cristal de Valerio.

Etymology: The specific name valerioi is a patronym for Manuel Valerio, who, with Emmett R. Dunn, discovered the species in the field.

Identification: Ecuadorian population tentatively assigned to Hyalinobatrachium valerioi can be distinguished from all other glassfrogs by its green dorsum with numerous large yellowish-green spots (Figure 121), transparent ventral parietal peritoneum, and most visceral peritonea covered by iridophores. The pericardium varies from white to mostly transparent (red in life). Among Ecuadorian centrolenid, only H. aureoguttatum is similar, but differs by having large yellow to golden dorsal spots (Figure 102), which are produced by the interaction of xanthophores (yellow) and iridophores (white); the spots in $\mathrm{H}$. valerioi are structurally different since they lack iridophores.

Diagnosis: (1) Vomerine teeth absent; (2) snout truncated in dorsal view, truncated to protruding in lateral view; (3) tympanum with a dorsolateral orientation, of moderate size (tympanum diameter $30 \%-43 \%$ of eye diameter); tympanic membrane evident; only lower border of tympanic annulus visible; (4) dorsal skin finely shagreen; (5) ventral skin granular; no cloacal ornamentation; (6) parietal peritoneum transparent (condition P0), iridophores covering all visceral peritonea; pericardium variable, from white to mostly translucent (condition V5-V6); (7) liver bulbous, covered by white peritoneum (condition H2); (8) humeral spine absent; (9) webbing between Fingers I and II reduced, moderate between Fingers II and III, expanded between outer fingers, webbing formula: I $\left(2^{+}-2^{1 / 3}\right)-2$ II $\left(1-1^{+}\right)-\left(3^{-}-3^{1 / 3}\right)$ III $\left(1^{1 / 2}-2^{2 / 3}\right)-\left(1^{+}-2^{-}\right) \mathrm{IV} ;(10)$ webbing on feet: I $\left(1-1^{1 / 2}\right)-\left(2-2^{+}\right)$II $\left(1-1^{2 / 3}\right)-\left(2-2^{1 / 4}\right)$ III $\left(1^{-}-1^{1 / 3}\right)-\left(2^{+}-2^{1 / 3}\right)$ IV $\left(2-2^{1 / 2}\right)-\left(1-1^{+}\right)$V; (11) ulnar and tarsal fold absent; (12) nuptial excrescences Type $\mathrm{V}$ in adult males; concealed prepollex; (13) first finger slightly longer than second; (14) eye diameter larger than width of disc on Finger III (disc of Finger III 32\%-36\% of eye diameter); (15) in life, dorsal surfaces yellowish green with green reticulum (or green with numerous yellowish-green spots); ventral parietal peritoneum transparent; bones white; (16) in preservative, dorsal surfaces cream with dark melanophores; (17) in life, iris golden with dark pigmentation scattered throughout, especially around the pupil; (18) melanophores absent from fingers and toes, except for few on Toes IV and V; (19) males usually call from underside of leaves, but sometimes they call from the upper leaf surface; call is a short seet, with a duration of 200-250 milliseconds, and a modulated frequency; (20) amplexus-like fighting behavior; (21) egg clutches laid on underside of leaves; nocturnal and diurnal parental care by males; maternal care absent; (22) tadpole with ventral mouth, spiracle posterior and mid-lateral; oral disc complete, moderate, with single row of marginal papillae laterally and ventrally, large dorsal gap; tooth row formula 2(2)/3, A-2 with large gap above mouth; (23) minute body size; SVL in adult males $18.1-24.4 \mathrm{~mm}(n=23)$, in adult females $20.2-25.1 \mathrm{~mm}(n=7)$. 

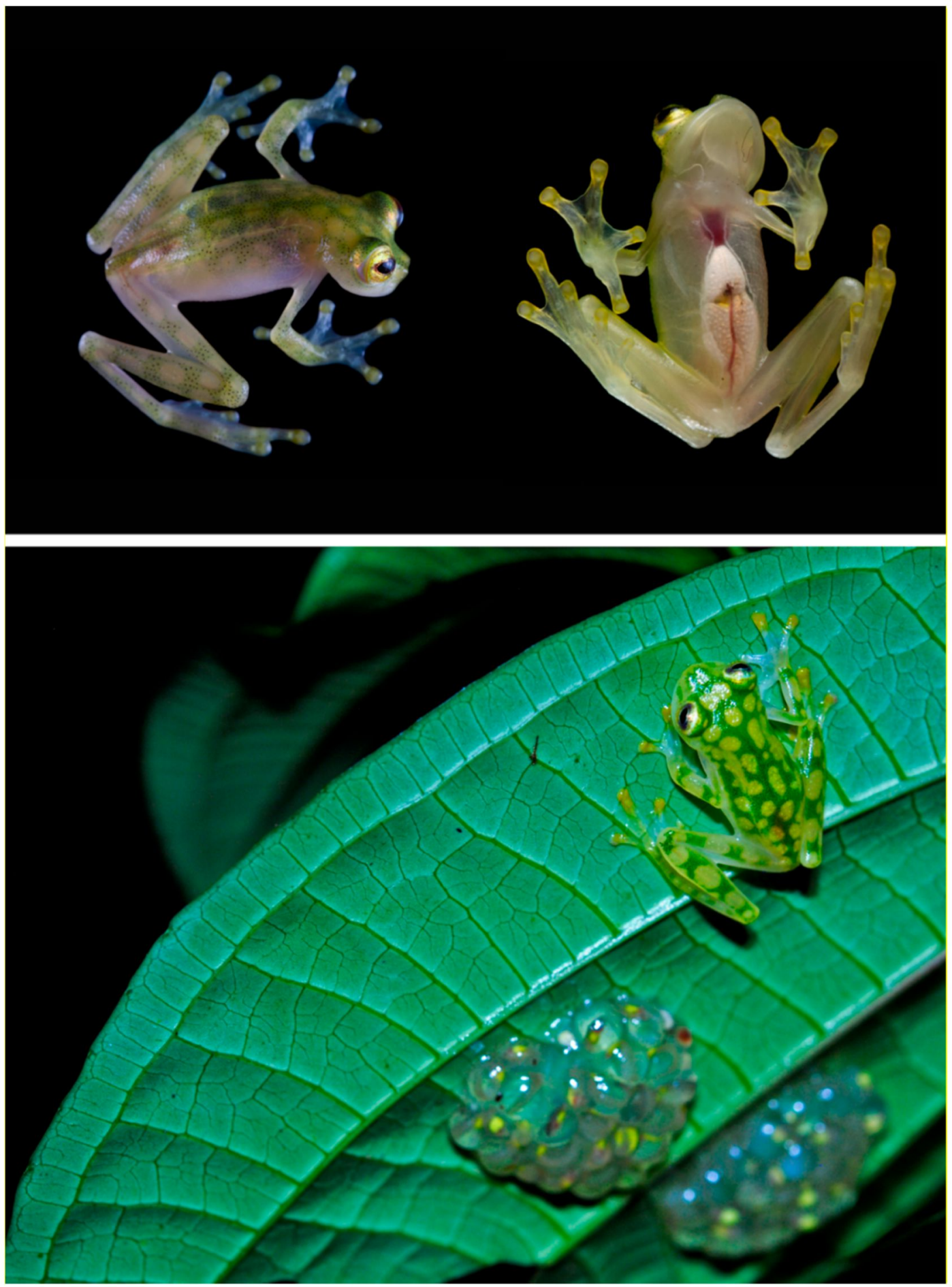

Figure 121. Hyalinobatrachium valerioi in life. (Top row): Male from Reserva de Biodiversidad Mashpi, 1080 m, Ecuador; photos by Lucas Bustamante/Tropical Herping. (Bottom row): Male guarding eggs, Selva Verde Lodge, Costa Rica; photo by Carlos Martínez. Note differences in coloration.

Color in life (Figure 121): According to Kubicki [24], dorsum yellowish green with green reticulation. Transparent venter; pericardium varies from white to almost transparent; white liver and digestive tract. Iris golden with dark pigmentation scattered throughout, especially surrounding pupil; several individuals with dark pigmentation restricted to lateral regions of pupil. Bones white. 
Color in ethanol: Cream dorsum with dark melanophores in the places that where green in life. Venter translucent cream. Parietal peritoneum completely transparent, all visceral peritonea covered by white lining. Pericardium polymorphic and white or translucent.

Biology and ecology: The following information was obtained from Savage [42], McDiarmid and Adler [238], McDiarmid [216], and Hayes [189]. A nocturnal frog that inhabits forested streams. Males are territorial and vigorously call from under leaves where females deposit their egg clutches. Physical combat occurs between males if another male intrudes into a male's territory despite the calls of the owner; both males may squeak during the fight; once one of the males is pinned venter down, he is held for a while, then leaves. Pale greenish-white eggs (25-40 in number) are deposited in a single-layer on the underside of a leaf. Males continue to advertise and may end up with as many as seven clutches from different females. The males attend the eggs both during the day and at night. At night, the male continues to call and, occasionally exhibits hydric brooding behavior, in which he apparently empties his bladder over the eggs. Only males are involved in parental care of the eggs. McDiarmid [4] attributed the higher survivorship to hatching in this species than in the syntopic Hyalinobatrachium colymbiphyllum to the diurnal parental care. Vockenhuber et al. [239] experimentally verified the positive effect that parental care has on embryonic survivorship; also, they identified arthropod predation as the main cause for embryonic mortality.

Call (Figure 122): Males usually call from the underside of leaves, but sometimes they vocalize from the upper leaf surface. In Costa Rica, the call is a high-pitched seet lasting 200 to 250 milliseconds, with a dominant frequency initially of $7.0 \mathrm{kHz}$ rising to $7.5 \mathrm{kHz}$ and then dropping again to $7.2 \mathrm{kHz}$, repeated every 7 to $10 \mathrm{~s}$ [209]. Kubicki [24] reported call variation among Costa Rican populations. Below, we describe a call of an individual tentatively assigned to Hyalinobatrachium valerioi (USNM 201475) recorded near Santo Domingo de los Colorados by RWM; we analyzed 19 notes from one individual (Figure 122). Each note is composed by a single note. The note duration is $46-78$ (mean $=72$, $\mathrm{SD}=7.7) \mathrm{ms}$. Notes are generally tonal and do not show any clear amplitude peaks throughout the note. The dominant frequency at peak amplitude is 5771-6632 (mean $=6197, \mathrm{SD}=253$ ) Hz and is contained within the fundamental frequency. The fundamental frequency has a lower limit of $5599-5943($ mean $=5771, \mathrm{SD}=91) \mathrm{Hz}$ and a higher limit of 6374-6718 (mean = 6632, SD = 76) Hz.

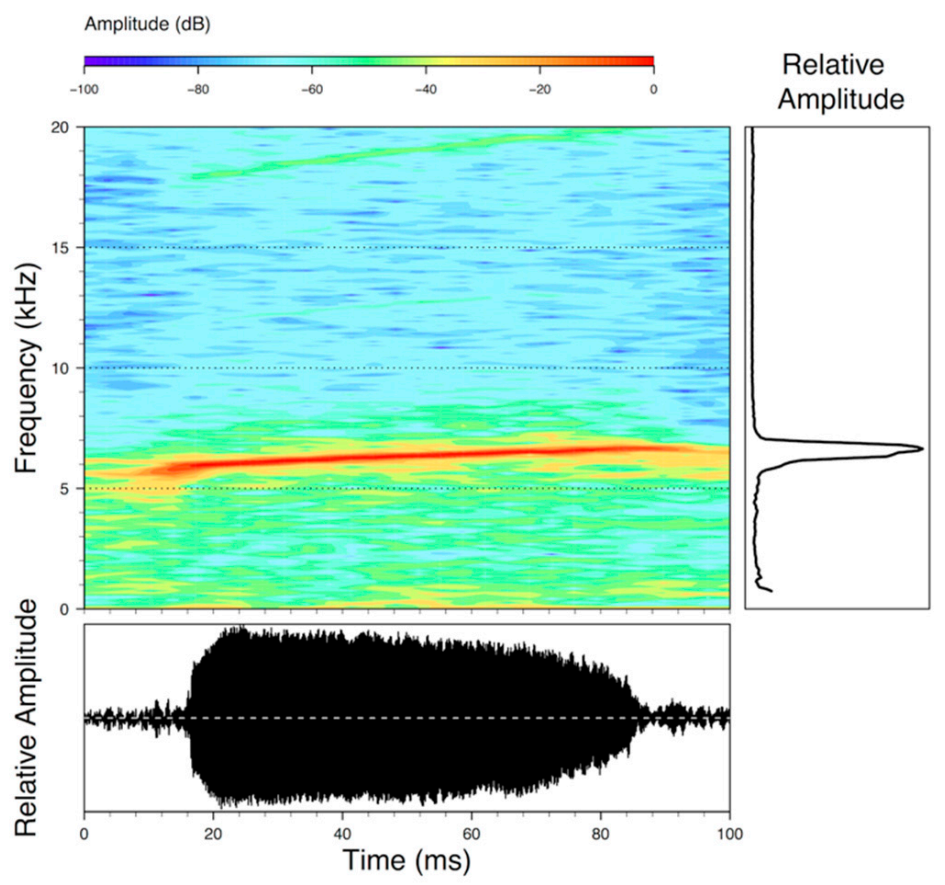

Figure 122. Call of a male (USNM 201475) tentatively assigned to Hyalinobatrachium valerioi, recorded near Santo Domingo de los Colorados, Ecuador, recorded by RWM. 
Egg masses and tadpoles: The following information was obtained from Savage (2002) and incorporates data from McDiarmid and Adler [238], McDiarmid [216], and Hayes [189]. Green egg masses are deposited in a single-layer jelly mass on the underside of leaves; average clutch size is 35, with 40 eggs being the upper limit. Egg masses are attacked by diurnal wasps, which remove eggs one at a time and carry them away, presumably to a nest, until the egg mass is depleted [4]. Starrett [146] described the tadpole of $H$. valerioi as follows (as Cochranella reticulata): Tadpole similar to that of H. fleischmanni, but tail longer at hatching and color paler; tail of older tadpole two- and three-fifths times as long as body; dorsal part of body with brown blotches; tail musculature with brown blotches dorsally and laterally; pigment is in depressions between myotomes posteriorly; tail fins clear. Mouth ventral, nearly terminal; papillae surrounding all but anterior portion of the disc. LTRF 2(2)/3; A-1 complete, A-2 rows very short, occurring only lateral to the jaw sheaths; outermost posterior row not well developed at this stage (probably, in larger tadpoles, nearly as long as inner two); anterior jaw sheath is more heavily pigmented than the posterior one that is doubly arched and weakly pigmented medially, often appearing broken; posterior jaw sheath armed with small, equal length serrations. Hoffmann [147] recently provided a very detailed description of the tadpole of the species. He mentioned that tadpoles of $H$. valerioi are distinguished by their accented slenderness and by the noticeably longer tail, about three times longer than the body; additionally, the oral disc of H. valerioi is more ventrally positioned than in other glassfrog species [147].

Distribution (Figure 123): As currently recognized, Hyalinobatrachium valerioi occurs from Costa Rica to southwestern Ecuador [156]. In Ecuador, it occurs in the northern and southern Pacific lowlands, foothills, and slopes below $1500 \mathrm{~m}$ in the provinces of Azuay, Carchi, Esmeraldas, Los Ríos, Pichincha, and Santo Domingo de los Tsáchilas (Specimens examined), within the Western Foothill Forest and Western Montane Forest ecoregions. In Ecuador, it has a potential distribution of $49,705 \mathrm{~km}^{2}$.

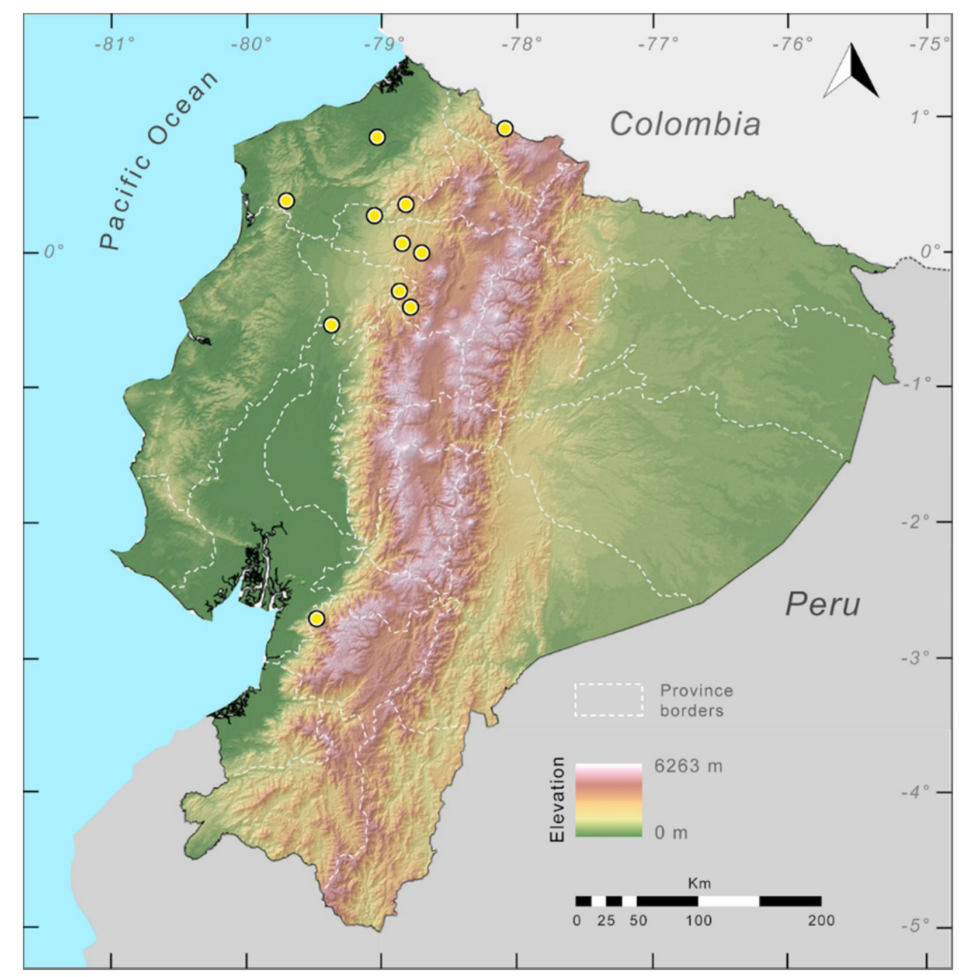

Figure 123. Distribution of populations tentatively assigned to Hyalinobatrachium valerioi in Ecuador (yellow dots).

Conservation status: Globally, Hyalinobatrachium valerioi is categorized as Least Concern by the IUCN [240]. The Ecuadorian populations currently assigned to H. valerioi (see Figure 123) might represent an undescribed species. The habitat of the species is severely fragmented, and the species 
has exhibited populations declines in several historical localities (e.g., La Florida, Río Palenque, Manta Real; Luis A. Coloma, pers. comm.; JMG, pers. obs.). During the last year (2015-2019), we have found reproducing populations at Reserva Los Cedros and Reserva Mashpi. Based on the current available information, we suggest that $H$. valerioi should be considered as Endangered in Ecuador (IUCN criteria A2c, A2e).

Evolutionary relationships (Figure 101): Hyalinobatrachium valerioi is the sister species to H. aureoguttatum.

Taxonomic remarks: The coloration of Hyalinobatrachium valerioi is variable across its distribution. Population may differ in having the pericardium completely transparent or covered with iridophores [24]. Also, at least in Costa Rica, there is notorious call variation [24]. At the moment, we are still uncertain about the taxonomic position of the populations from Ecuador; further studies are needed to assess if $H$. valerioi, as currently defined, is composed by several morphologically similar species.

Specimens examined: Hyalinobatrachium valerioi: Ecuador: Provincia de Azuay: $12.9 \mathrm{~km} \mathrm{~W}$ of Luz María, KU 217503-04. Provincia de Carchi: Maldonado, KU 178082-91. Provincia de Cañar: Manta Real $\left(03^{\circ} 10^{\prime} \mathrm{S} 80^{\circ} 26^{\prime} \mathrm{W}\right)$, DHMECN 0134. Provincia de Imbabura: Reserva Los Cedros $\left(0.3026^{\circ} \mathrm{N}, 78.781^{\circ} \mathrm{W}\right.$; 1360 m), MZUTI 3268. Provincia de Los Ríos: Río Palenque (0.55 ${ }^{\circ}$ S, $\left.79.36667^{\circ} \mathrm{W}\right)$, USNM $286746-49$, KU 147580, 164650. Provincia de Santo Domingo de los Tsáchilas: $5 \mathrm{~km} \mathrm{~W}$ of La Florida $\left(0.25694^{\circ} \mathrm{S}, 79.0538^{\circ} \mathrm{W}\right.$;

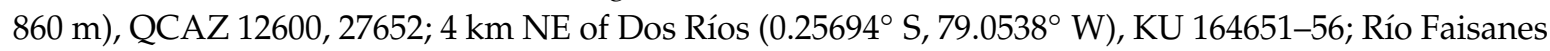
(0.26083 ${ }^{\circ}$ S, $\left.78.845^{\circ} \mathrm{W}\right)$. Provincia de Pichincha: Tandapi $\left(0.41638^{\circ} \mathrm{S}, 78.7988^{\circ} \mathrm{W}\right), \mathrm{KU} 178092 ; 1 \mathrm{~km} \mathrm{E}$ of Pedro Vicente Maldonado ( $\left.0.833^{\circ} \mathrm{S}, 79.0347^{\circ} \mathrm{W} ; 670 \mathrm{~m}\right)$, QCAZ 12605; Reserva de Biodiversidad Mashpi (0.164 $\left.{ }^{\circ} \mathrm{N}, 78.867^{\circ} \mathrm{W} ; 1080 \mathrm{~m}\right)$, MUTI 3921.

Localities from the literature: Hyalinobatrachium valerioi: Ecuador: Provincia de Esmeraldas: Bilsa Biological Station [160].

Hyalinobatrachium yaku Guayasamin, Cisneros-Heredia, Maynard, Lynch, Culebras, Hamilton 2017 [241] (Figures 124-126).

Hyalinobatrachium yaku Guayasamin, Cisneros-Heredia, Maynard, Lynch, Culebras, Hamilton, 2017 [241]. Holotype: MZUTI 5001.

Type locality: "Stream affluent of the Kallana river $\left(1.4696^{\circ}\right.$ S, $\left.77.2784^{\circ} \mathrm{W}, 325 \mathrm{~m}\right)$, nearby the Kichwa community of Kallana, province of Pastaza, Ecuador".

Common names: English: Yaku Glassfrog. Spanish: Rana de Cristal Yaku.

Etymology: The epithet yaku is the Kichwa word for water [241].

Identification: In life, Hyalinobatrachium yaku is distinguishable from all other glassfrogs by having middorsal dark green spots on the anterior half of the body and, ventrally, a completely transparent peritoneum and pericaridum (Figure 124).

Diagnosis: (1) Dentigerous process of the vomer lacking teeth; (2) snout truncated in dorsal and lateral views; (3) lower half of tympanic annulus visible; tympanic membrane clearly differentiated and with coloration similar to that of surrounding skin; (4) dorsal skin shagreen; (5) ventral skin areolate; cloacal area glandular, with tubercular and slightly enameled patch on each side of cloaca, lacking paired round subcloacal warts; (6) parietal peritoneum, pericardium, kidneys, and urinary bladder transparent (lacking iridophores); hepatic, gastrointestinal, and testicular peritonea covered by iridophores; (7) liver white, bulbous; (8) humeral spines absent; (9) basal webbing between Fingers I and II, moderate webbing between external fingers; hand webbing formula: I $2-2 \mathrm{II} 0^{+}-3^{+}$III $2^{-}-\left(1-2^{-}\right) \mathrm{IV}$; (10) foot webbing moderate; webbing formula: I $\left(1-1^{+}\right)-\left(2-2^{-}\right)$II $\left(0^{+}-1\right)-\left(2^{+}-2^{1 / 3}\right)$ III $1-2^{1 / 3} \operatorname{IV~} 2^{1 / 3}-\left(1-1^{1 / 3}\right) \mathrm{V}$; (11) fingers and toes with thin lateral fringes; ulnar and tarsal folds present, 
but difficult to distinguish, with thin layer of iridophores that extends to ventrolateral edge of Finger IV and Toe V; (12) nuptial excrescence present as a small pad on Finger I (Type V), concealed prepollex; (13) when appressed, Finger I longer than Finger II; (14) diameter of eye about 2.1 times wider than disc on Finger III; (15) coloration in life: Dorsal surfaces apple green to yellowish green with small yellow spots and minute grey to black melanophores; posterior head and anterior half of the body with few small, well-defined dark green spots placed mid-dorsally; bones white; (16) coloration in preservative: Dorsal surfaces pale cream with minute lavender to black melanophores; (17) iris coloration in life: Silver to yellow, with minute dark spots concentrated around pupil; (18) melanophores present on Finger IV and Toes IV-V, absent on other fingers and toes; in life, hands and feet are cream with a light green hue, with tips of fingers and toes being yellowish green; (19) males call from the undersides of leaves; advertisement call consisting of a single tonal note; call duration note $0.3-0.4 \mathrm{~s}$, dominant frequency $5219-5330 \mathrm{~Hz}$, with no frequency modulation; $(20,21)$ clutch size unknown; maternal care unknown; prolonged parental care provided by males; (22) tadpoles unknown; (23) adults small; SVL in adult males $20.8-22.3 \mathrm{~mm}(n=3)$, in adult female $21.1 \mathrm{~mm}(n=1)$.

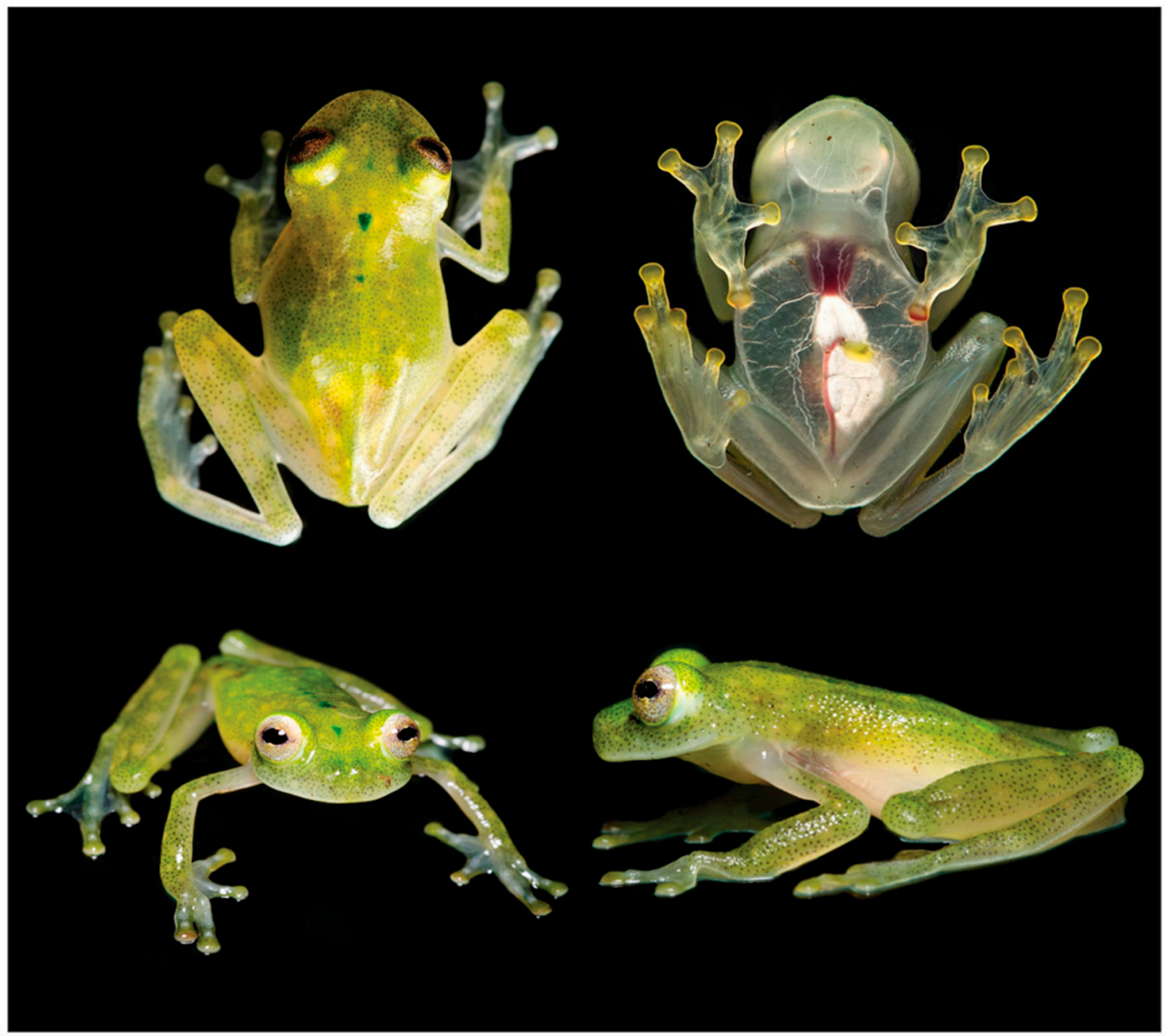

Figure 124. Hyalinobatrachium yaku in life. (Top row): adult male, MZUTI 5001, holotype, in dorsal and ventral view. (Bottom row): adult male, paratype, QCAZ 55628. Obtained from Guayasamin et al. [241].

Color in life (Figure 124): In adults, dorsum apple green to yellowish green with small yellow spots and minute dark melanophores; posterior head and anterior half of the body with few small, well-defined dark green spots placed mid-dorsally, the anterior-most spot generally being the largest. Hands and feet cream with a light green hue, with tips of fingers and toes being yellowish green; 
melanophores absent from fingers and toes, except Finger IV and Toes IV and V. Ventrally, parietal peritoneum and pericardium transparent (red heart fully visible); visceral peritoneum of gall bladder and urinary bladder transparent; hepatic and visceral peritonea white. Ventral vein red. Iris silver to yellow, with minute dark spots that encircle the pupil, giving the impression of diffuse rings. Bones white [241].

Color in ethanol: Dorsal surfaces cream dotted with minute dark lavender to black melanophores; venter uniform white; peritonea as in life. Iris white with lavender melanophores that become more numerous near the pupil. There are no traces of the characteristic middorsal dark-green spots in preserved specimens [241].

Variation: Juveniles have the same color pattern as adults; the number and extent of the middorsal green dots varies, but they are usually smaller and less pronounced posteriorly [241].

Biology and ecology: Only basic biological information of H. yaku is known. The data presented below are from Guayasamin et al. [241]. Males call from the underside of leaves of riverine vegetation. One male (holotype) was on the same leaf as two egg clutches, approximately $3 \mathrm{~m}$ above the stream. Observations suggest that prolonged parental care is provided by males. Syntopic species at the type locality are: Nymphargus mariae, Teratohyla midas, Agalychnis hulli, Callimedusa tomopterna, Boana calcarata, B. geographica, Osteocephalus fuscifacies, Pristimantis enigmaticus, and P. peruvianus. At the locality of Ahuano, the species was found along a small stream, tributary of the Arajuno River; the stream was slow flowing, very narrow (approximately $1 \mathrm{~m}$ wide), shallow (approximately $40 \mathrm{~cm}$ deep), and covered by secondary forest. At Ahuano, syntopic species were Teratohyla midas and H. ruedai. Individuals from San José de Payamino were found perched on leaves of small shrubs, ferns, and grasses (30-150 $\mathrm{cm}$ above ground) in disturbed secondary forest. Additionally, all individuals recorded at San José de Payamino were found $>30 \mathrm{~m}$ from any stream. Syntopic species at San José de Payamino are reported by Maynard et al. [242].

Call (Figure 125): The information provided below is taken from Guayasamin et al. [241]. The advertisement call of Hyalinobatrachium yaku is a single and high-pitched tonal note, with no frequency nor amplitude modulation. The call lasts $0.27-0.4 \mathrm{~s}(0.3 \pm 0.03)$ and has an average call rate of 9.0 calls $/$ minute. Time between calls varied from $5.3-8.9 \mathrm{~s}(7.1 \pm 1.1)$. The dominant frequency ranges from $5219-5330 \mathrm{~Hz}(5284 \pm 35.0)$.

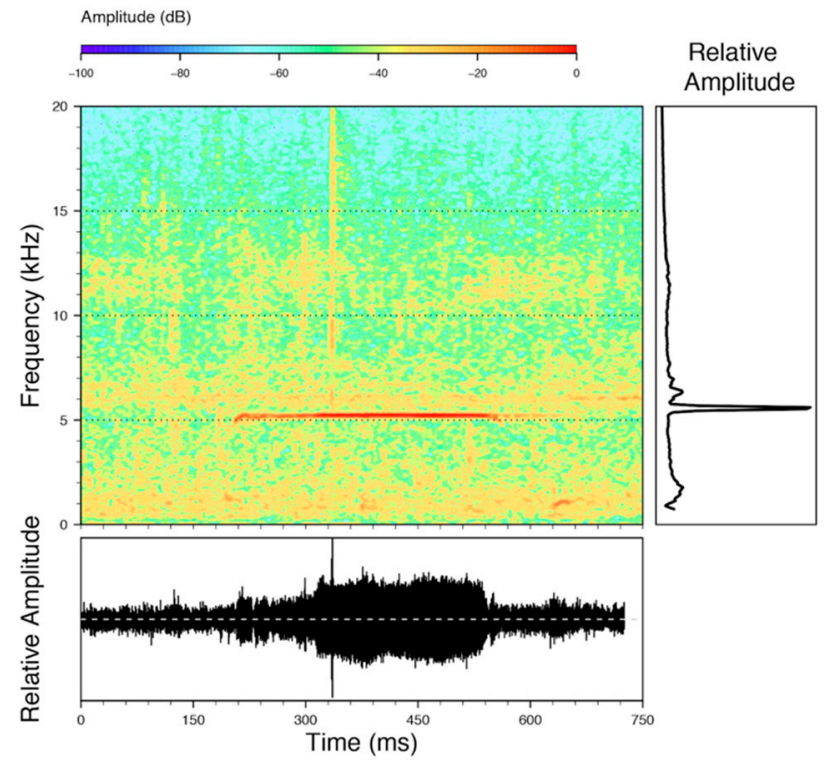

Figure 125. Call of Hyalinobatrachium yaku from Kallana, 325 m, Pastaza province, Ecuador; holotype, MZUTI 5001. 
Tadpole: Not described.

Distribution (Figure 126): Hyalinobatrachium yaku is known from three localities on the Amazonian lowlands of Ecuador at elevations between $300-360 \mathrm{~m}$. It is likely that $H$. yaku has a broader distribution, including areas in Amazonian Colombia and Peru [241].

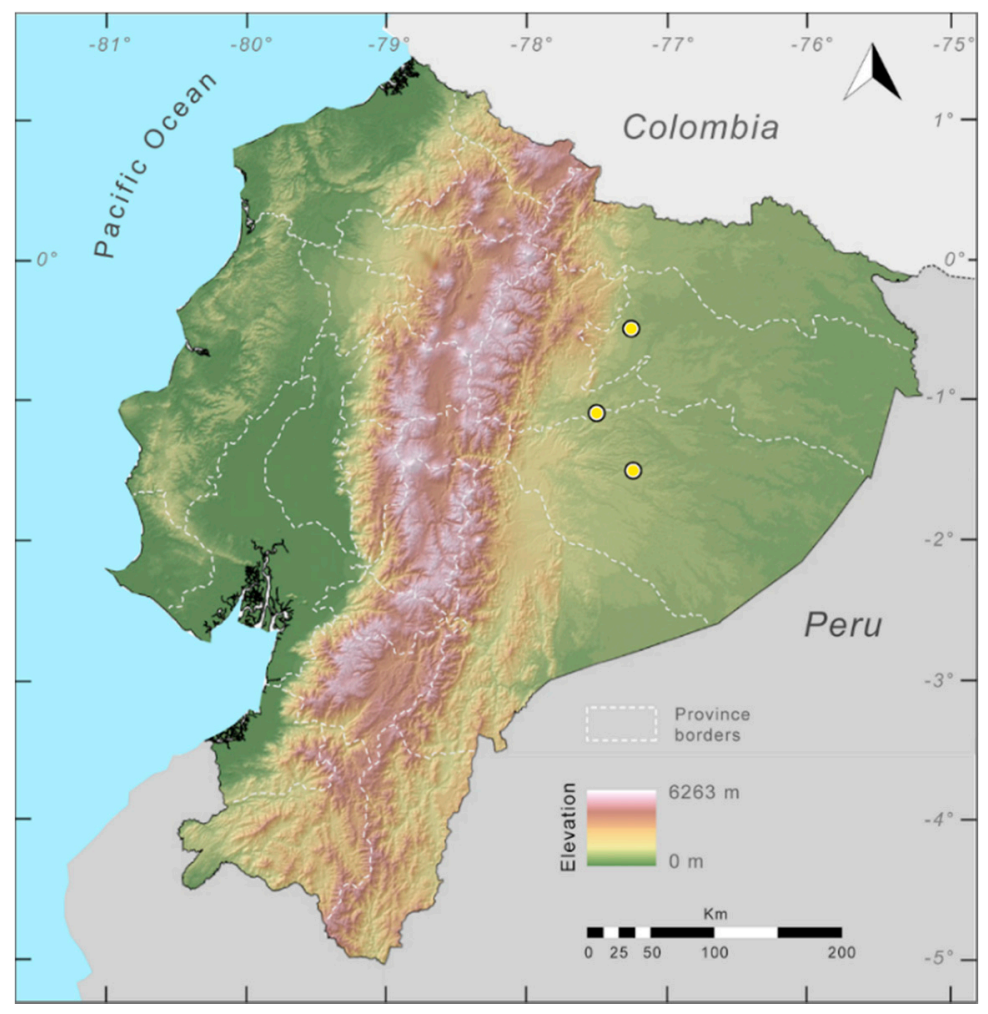

Figure 126. Distribution of Hyalinobatrachium yaku in Ecuador (yellow dots).

Conservation status: According to Guayasamin et al. [241], available information is insufficient to suggest a conservation category, thus $H$. yaku is a Data Deficient species.

Evolutionary relationships (Figure 101): H. yaku and H. pellucidum are sister species.

Specimens examined: Hyalinobatrachium yaku: Ecuador: Provincia Pastaza: stream affluent of Kallana river (1.4696 ${ }^{\circ}$ S, 77.2784 $\mathrm{W}, 325 \mathrm{~m}$ ), MZUTI 5001 (holotype), 5002 (paratypes). Provincia Orellana: Timburi-Cocha Research Station $\left(0.4800^{\circ} \mathrm{S}, 77.2829^{\circ} \mathrm{W}, 300 \mathrm{~m}\right)$ near San José de Payamino, QCAZ 55628, 53352 (paratypes). Provincia Napo: Ahuano (1.0632 ${ }^{\circ}$ S, 77.5265 W, 360 m), ZSFQ 2322.

Genus Nymphargus Cisneros-Heredia and McDiarmid 2007 [17].

Etymology: The name Nymphargus is formed from the Greek nymphae in allusion to the nymphs, beautiful goddesses in Greek mythology that personify the creative and fostering activities of nature, living in mountains, valley, springs, and rivers; and, argus in allusion to the mythological Greek Argus, nephew of the nymph Io, a giant with a hundred eyes, whose eyes became the ocelli in the peacock's tail. The name is masculine and alludes to the ocelli found on the dorsum of some of the species of the genus [17]. 
Nymphargus anomalus (Lynch and Duellman, 1973 [22]; Figures 127-130).

Centrolenella anomala Lynch and Duellman, 1973 [22]. Holotype: KU 143299.

Type locality: "Río Azuela, 1740 m, Quito-Lago Agrio road, Provincia Napo, Ecuador".

Cochranella anomala-Ruiz-Carranza and Lynch, 1991 [6], 57:21.

Nymphargus anomalus_Cisneros-Heredia and McDiarmid, 2007 [17].

Common names: English: Anomalous Glassfrog. Spanish: Rana de Cristal Anómala.

Etymology: The specific name anomalous refers to the unusual dorsal coloration of this species [22].

Identification: Nymphargus anomalus is unique by having, in life, a tan dorsum with black ocelli with orangish-tan centers (Figures 127 and 128), instead of the usual green that characterizes most glassfrogs. Among centrolenids, only one species, N. ignotus, has a similar dorsal color pattern; however, N. ignotus is found on the Pacific slopes of the Andes, whereas N. anomalus is restricted to the Amazonian slopes of the Andes. Nymphargus anomalus further differs from other species having ocellated patterns (N. cochranae, N. ignotus, N. laurae) by having scattered black and lavender flecks between ocelli (Figure 127).

Diagnosis: (1) Vomers lacking teeth; (2) snout truncated in dorsal and lateral profiles (Figure 129); (3) tympanum relatively small, oriented almost vertically, with evident lateral and posterior inclinations, its diameter about $20 \%$ of eye diameter; tympanic annulus mostly visible, with supratympanic fold covering its dorsal margin; tympanic membrane differentiated and translucent, partially pigmented; (4) in males, dorsal skin shagreen with or without minute spiculae; in females, dorsal skin shagreen without spiculae; (5) venter areolate; pair of enlarged subcloacal warts (Figure 15); (6) anterior half of ventral parietal peritoneum white, posterior half transparent (condition P2); white pericardium; translucent peritoneum covering intestines (condition V1); (7) liver with four clearly defined lobes covered by transparent peritoneum (condition H0); (8) humeral spines absent; (9) webbing absent between Fingers I-III, basal or moderate between Fingers III and IV; webbing formula: III $\left(2^{1 / 3}-3^{+}\right)-\left(2^{+}-2^{2 / 3}\right)$ IV (Figure 129); (10) webbing between toes moderate; webbing formula on foot I $2^{-}-\left(2-2^{1 / 4}\right)$ II $\left(1-1^{1 / 4}\right)-\left(2^{+}-2^{1 / 3}\right)$ III $\left(1-1^{+}\right)-\left(2^{+}-2^{1 / 4}\right)$ IV $\left(2^{+}-2^{2 / 3}\right)-\left(1^{+}-1^{1 / 2}\right)$ V; (11) ulnar fold low; inner and outer tarsal folds present, but low and difficult to distinguish; (12) concealed prepollex; nuptial pad Type I; (13) Finger I slightly shorter than Finger II (Finger I length $91.5 \%-99.2 \%$ of Finger II); (14) disc width of Finger III about 50\% of eye diameter; (15) in life, dorsum pale brown or tan with dark brown flecks and black ocelli with brownish-orange centers (Figure 127); color of bones white; (16) in preservative, dorsum cream to tan with black dots and lavender flecks and black and lavender ocelli enclosing whitish centers; (17) iris pale yellow with thin black reticulation; bright yellow circumpupilar ring; (18) dorsal surfaces of all fingers and toes usually with few melanophores, except Finger I that usually lacks melanophores; (19) males call from the upper surfaces of leaves; calls undescribed; (20) fighting behavior unknown; (21) eggs deposited on mossy branches over streams; parental care unknown; (22) tadpoles unknown; (23) small body size; SVL in males 21.2-24.8 mm ( $\overline{\mathrm{X}}=$ $23.1 \mathrm{~mm} ; n=16$ ); SVL in three adult females: $25.7,27.0$, and $27.0 \mathrm{~mm}$. 

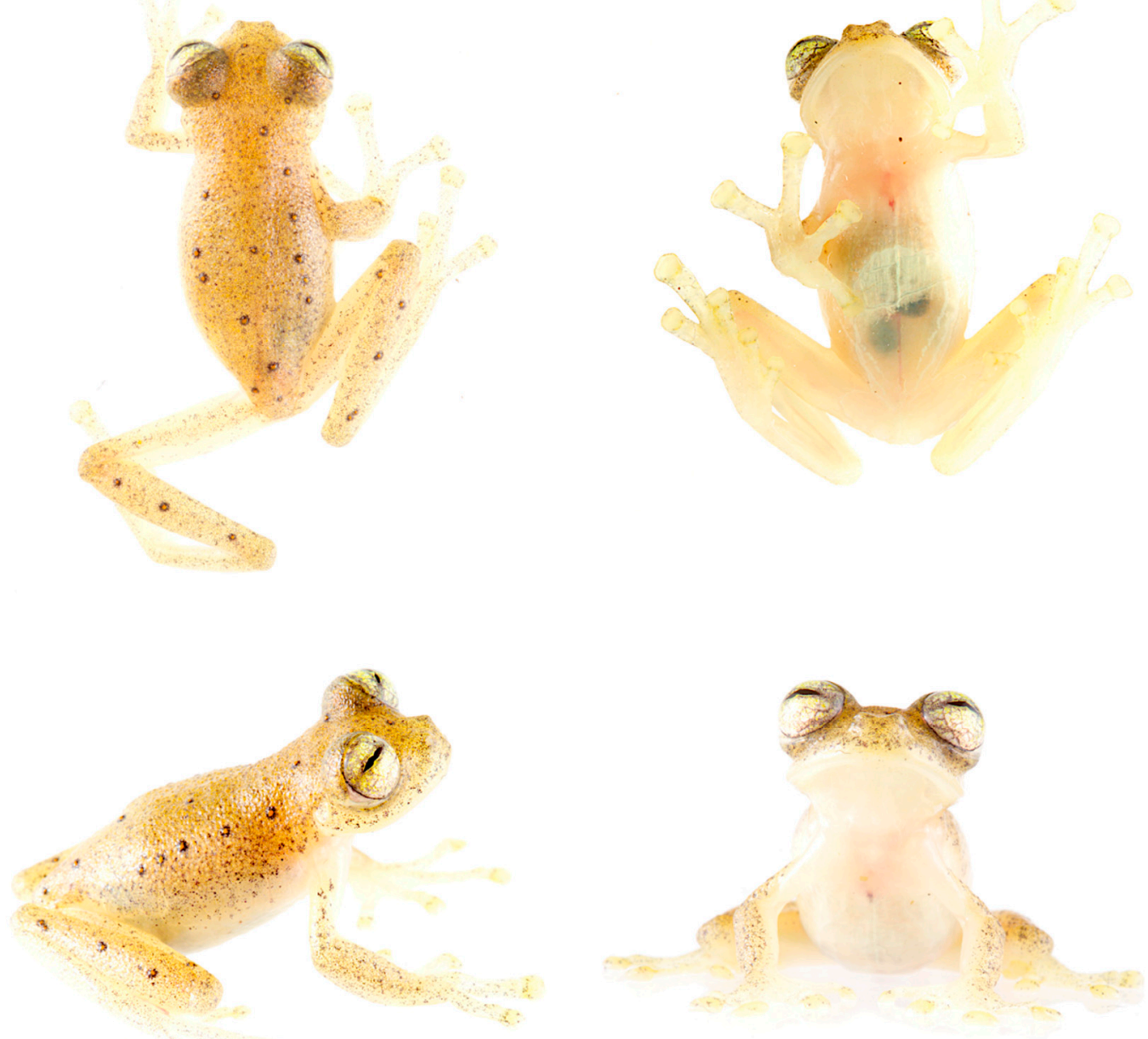

Figure 127. Nymphargus anomalus in life, ZSFQ 2123, from a tributary of Río San Jacinto, $1672 \mathrm{~m}$, Tungurahua province. Photos by Jose Vieira/Tropical Herping.

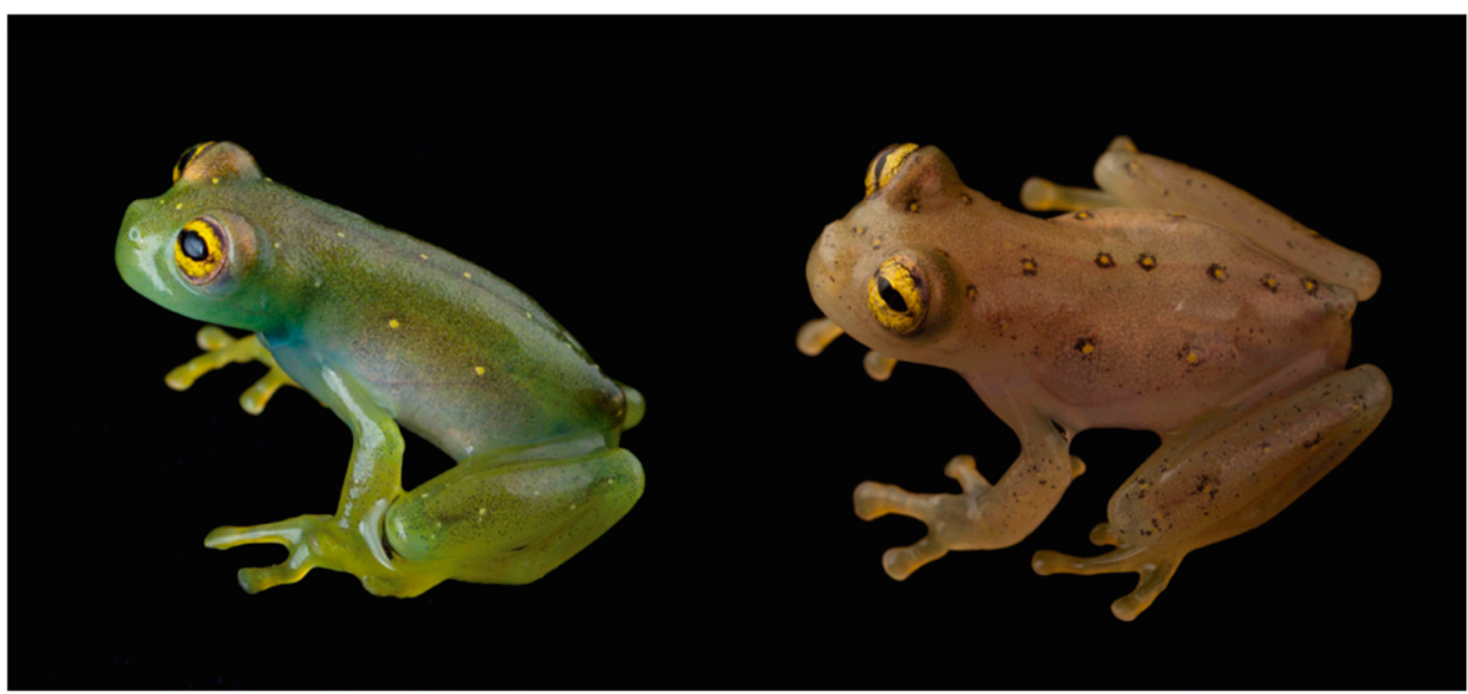

Figure 128. Ontogenetic color change in Nymphargus anomalus, QCAZ 48107. Photos by Luis A. Coloma. 

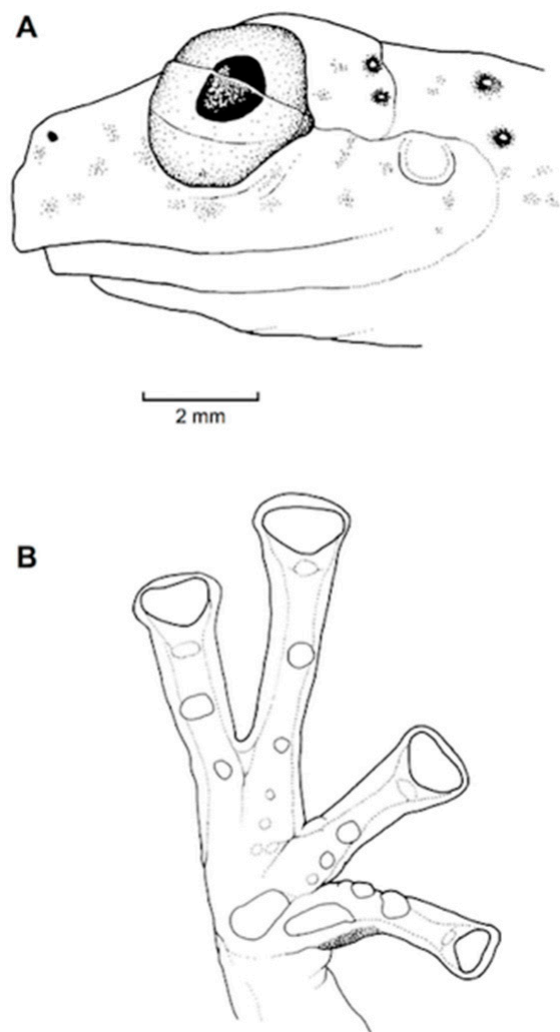

Figure 129. Nymphargus anomalus, adult male, KU 143299. (A) Head in lateral view. (B) Hand in ventral view. Illustrations by Juan M. Guayasamin.

Color in life (Figures 127 and 128): Dorsum pale brown or tan with slight yellow to pink hue; dorsal surfaces of head, body, and limbs with small flecks and black ocelli that enclose orange spots. Anterior part of venter white, posterior half of venter translucent. Iris pale yellow with black reticulations; color of iris becomes whitish towards margins. Nymphargus anomalus exhibits ontogenetic variation in its dorsal coloration, being green in postmetamorphs and then gradually acquiring the tan to pale brown coloration that is characteristic of adults. The spotted pattern also changes ontogenetically; postmetamorphs have yellow spots that progressively change towards ocelli composed of black rings with orange centers.

Color in ethanol: Dorsum cream to tan with lavender flecks and black and lavender ocelli enclosing whitish centers. Eyelids bear some iridophore aggregations visible through the skin. White pericardium; hepatic and visceral peritonea are translucent. Peritonea covering urinary and gall bladders, kidneys, and testes without iridophores.

Biology and ecology: The holotype of Nymphargus anomalus was found on a mossy limb of a bush about $1.5 \mathrm{~m}$ above a cascading rivulet at night. The following species were found in the same stream and in other small streams nearby: Hyloscirtus phyllognathus, Centrolene pipilata, Nymphargus megacheirus, N. siren, and Hyalinobatrachium pellucidum [22]. At Río Yana Challuwa Yaku, males where found calling on leaves and branches during the night. Two egg clutches were on a mossy branch above the stream. Parental care is unknown.

Call: Not described.

Tadpole: Not described. 
Distribution (Figure 130): Nymphargus anomalus is known only from four localities (Volcán Sumaco, Río Azuela, Río Yana Challuwa Yaku, nearby Río Jacinto) on the Amazonian slopes of the Ecuadorian Andes, at elevations between 1668-1795 m. The habitat of the species is within the Eastern Montane Forest region ([22], this work).

Conservation status: Nymphargus anomalus is listed as Critically Endangered by the IUCN [243]. Until recently, the species was known from a single individual collected on 23 October 1971 (Río Azuela). Surveys at the type locality have failed in find this species ([91], RWM and JMG, pers. obs.), but other populations have been discovered (Figure 130; Specimens examined). In Ecuador, because of its restricted distribution and habitat fragmentation, we suggest that it should be considered as Endangered (IUCN criteria B1, B2a, B2biii).

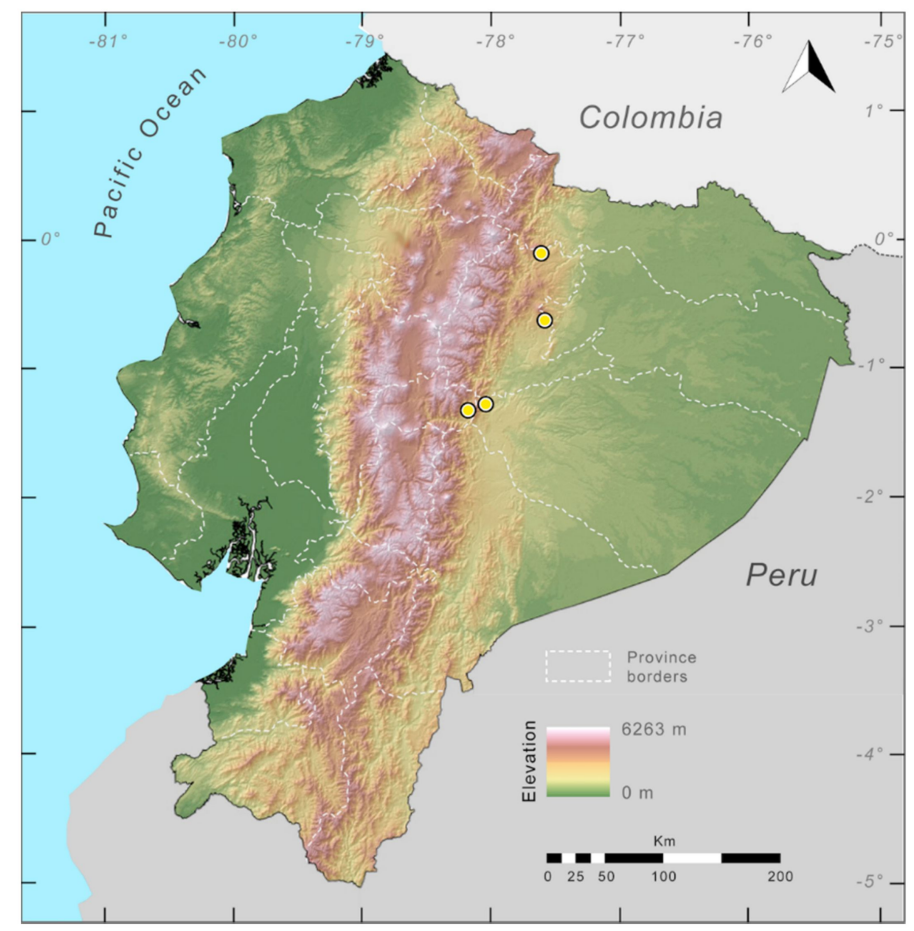

Figure 130. Distribution of Nymphargus anomalus in Ecuador (yellow dots).

Evolutionary relationships (Figure 101): Lynch [244] suggested that N. anomalus is the sister species of N. ignotus. The hypothesis by Lynch is based on the presence of two putative synapomorphies: Pale brown coloration and small ocelli on elevated warts, with the corresponding plesiomorphic conditions being green coloration and no ocelli. Based on mitochondrial genes and a taxon sampling that does not include N. ignotus, we found that the sister species of N. anomalus is N. megacheirus, which has a coloration that matches the plesiomorphic states.

Specimens examined: Nymphargus anomalus: Ecuador: Provincia de Napo: Río Azuela (0.11667 S, 77.6167 W, 1740 m), KU 143299. Parque Nacional Sumaco, Volcán Sumaco, near the Pavayacu refuge (0.61497 S; 77.59065 W; 1771 m), QCAZ 41312-13. Provincia de Pastaza: Reserva Comunitaria Ankaku, zona de amortiguamiento del Parque Nacional Llanganates, cabecera del Río Yana Challuwa Yaku (01.26764 S; 78.04797 W; 1668 m), males: QCAZ 45696-97, 45699, 45701, 45703-11, 45728-29; females: QCAZ 45698, 45700, 45702. Provincia de Tungurahua: stream tributary of the San Jacinto River (1.3447 S, $78.1814 \mathrm{~W} ; 1795 \mathrm{~m}$ asl), ZSFQ 899. 
Nymphargus balionotus (Duellman, 1981 [120]; Figures 131-133).

Centrolenella balionota Duellman, 1981 [120]. Holotype: KU 164702.

Type locality: " $3.5 \mathrm{~km}$ (by road) northeast of Mindo, $1540 \mathrm{~m}$, Provincia de Pichincha, Ecuador $\left(00^{\circ} 01^{\prime} \mathrm{S}, 78^{\circ} 44^{\prime} \mathrm{W}\right)^{\prime \prime}$.

Cochranella balionota-Ruiz-Carranza and Lynch, 1991 [6].

Centrolene balionotum - Cisneros-Heredia and McDiarmid, 2006 [17].

"Cochranella" balionota-Guayasamin, Castroviejo-Fisher, Trueb, Ayarzagüena, Rada, Vilà, 2009

[1].

Nymphargus balionotus - Guayasamin, Cisneros-Heredia, Vieira, Kohn, Gavilanes, Lynch, Hamilton, Maynard, 2019 [21].

Common names: English: Mindo Glassfrog. Spanish: Rana de Cristal de Mindo.

Etymology: The specific epithet balionotus combines the Greek words balios (spotted, dappled) and notos (back), and is used in allusion to the dorsal color pattern of the species [120].

Identification: Nymphargus balionotus is unique by having, in life, a pale green dorsum with reddish-brown dorsolateral stripes, small reddish-brown spots, and larger yellow spots (Figure 131). Additionally, males are small (SVL $<23 \mathrm{~mm}$ ) and possess a blade-like ventral crest on the humerus that can be confused with a humeral spine. See Remarks.

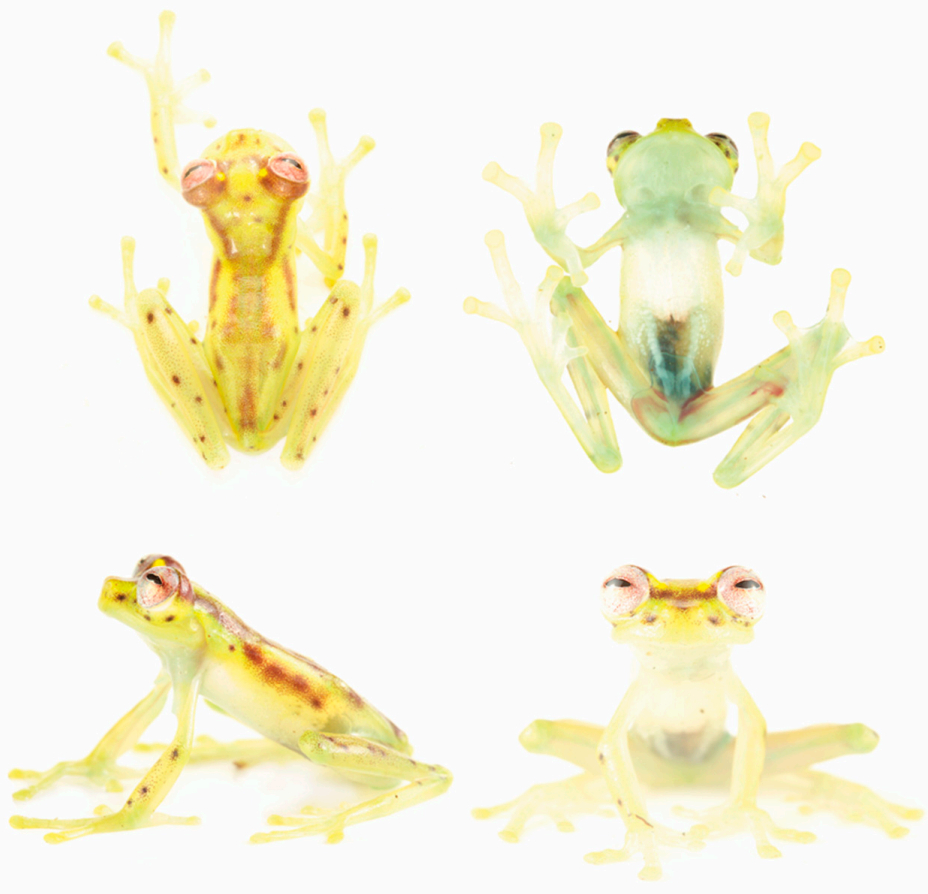

Figure 131. Nymphargus balionotus in life, ZSFQ 533. Ecuador, Reserva Río Manduriacu, $1254 \mathrm{~m}$, Tungurahua province. Photos by Jose Vieira/Tropical Herping.

Diagnosis: (1) Vomers lacking teeth; (2) snout truncated in dorsal view, protruding lateral profile (Figure 132); (3) tympanum relatively small, oriented almost vertically, with evident lateral and posterior inclinations, its diameter $23 \%-30 \%$ of eye diameter; tympanic annulus mostly visible, with supratympanic fold covering its dorsal margin; tympanic membrane differentiated and translucent, not pigmented; (4) in males, dorsal skin smooth to shagreen, lacking spicules; females unknown; (5) venter slightly granular; pair of enlarged subcloacal warts; (6) anterior half of ventral parietal peritoneum with iridophores, posterior half transparent (condition P2); pericardium covered by iridophores; peritoneum covering digestive tract lacking iridophores (condition V1); (7) liver with four or five lobes, lacking 
iridophores (condition H0); (8) males with a bladelike ventral crest on the humerus that resembles a small humeral spine; (9) webbing absent between inner fingers; webbing formulae for outer fingers IV $\left(2-2^{1 / 2}\right)-\left(2^{-}-2\right) \mathrm{V}$ (Figure 132); (10) webbing between toes moderate; webbing formula on foot: I $\left(1^{1 / 3}-1^{1 / 2}\right)-\left(2-2^{+}\right)$II $\left(1^{+}-1^{1 / 2}\right)-\left(1-1^{1 / 2}\right)$ III $\left(1^{1 / 3}-2\right)-\left(2^{-}-3\right)$ IV $\left(2^{-}-3\right)-1^{1 / 2} \mathrm{~V}$; (11) ulnar fold low; inner and outer tarsal folds present, but low and difficult to distinguish; (12) concealed prepollex; nuptial pad in males variable, ranging from Type I to Type III; (13) Finger I slightly longer than Finger II (Finger II length $91.8 \%-97.4 \%$ Finger I); (14) disc of Finger III width about $36 \%-44 \%$ of eye diameter; (15) in life, dorsum pale green with reddish-brown dorsolateral stripes, small reddish-brown spots, and larger yellow spots (Figure 131); color of bones pale green; (16) in preservative, dorsum cream with lavender and white dorsolateral stripes, small dark lavender spots, and larger white spots; (17) iris greyish white with numerous minute brown spots; (18) dorsal surfaces of fingers and toes lacking melanophores; (19) males call from the upper sides of leaves overhanging streams; call undescribed; (20) fighting behavior unknown; (21) egg deposition site unknown; parental care unknown; (22) tadpoles unknown; (23) minute body size; in adult males, SVL 20.1-21.8 $\mathrm{mm}(\bar{X}=20.8 \pm 0.534, n=11)$; females unknown.

A

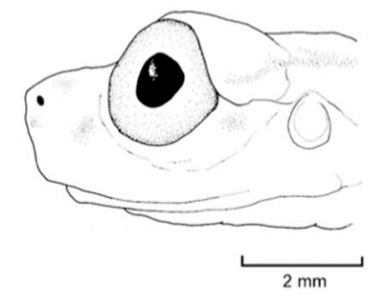

B

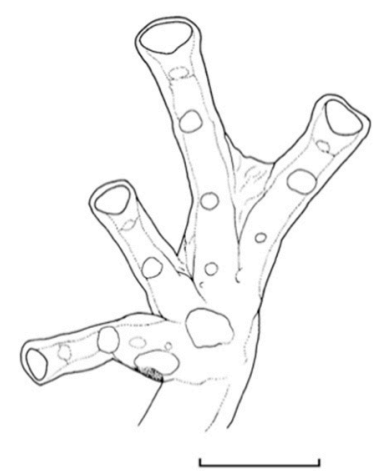

Figure 132. Nymphargus balionotus, adult male, KU 164708. (A) Head in lateral view. (B) Hand in ventral view. Illustrations Juan M. Guayasamin.

Color in life (Figure 131): Pale green dorsum with reddish-brown dorsolateral stripes, small reddish-brown spots, and elevated larger yellow spots. Head with reddish-brown interorbital bar and postorbital stripe that is continuous with dorsolateral stripe. Large, elevated yellow spot on anteromedial edge of each eyelid. Pale green bones ([120], this work).

Color in ethanol: Dorsal surfaces cream with lavender and white dorsolateral stripes, small dark lavender spots, and larger white spots. White lining covers about anterior half of ventral parietal peritoneum. White pericardium; digestive tract, liver and kidneys covered by translucent peritonea.

Biology and ecology: During the night, all individuals at the type locality were calling less than $1 \mathrm{~m}$ above the water from the upper surfaces of leaves of herbs and ferns overhanging a trickling stream. Other stream-breeding frogs at the type locality included Nymphargus grandisonae, N. griffithsi, and Hyloscirtus alytolylax [120]. Nymphargus balionotus is nocturnal, arboreal, epiphyllous, and usually found on vegetation along clear-water streams in pristine or in moderately disturbed foothill and cloud forests [87]. Parental care unknown.

Call: Not described. 
Tadpole: Not described.

Distribution (Figure 133): Nymphargus balionotus occurs between 400 and $1540 \mathrm{~m}$ along the western slope of the Cordillera Occidental of Colombia, from El Tambito in the Departamento de Cauca, south to Ecuador $[21,87,115,116,120,245]$. In Ecuador, it is known from localities in the provinces of Carchi, Imbabura, Pichincha, and Cotopaxi at elevations between 1400 and $1540 \mathrm{~m}$ (Specimens Examined). It is found within the Western Foothill and Montane Forest ecoregions.

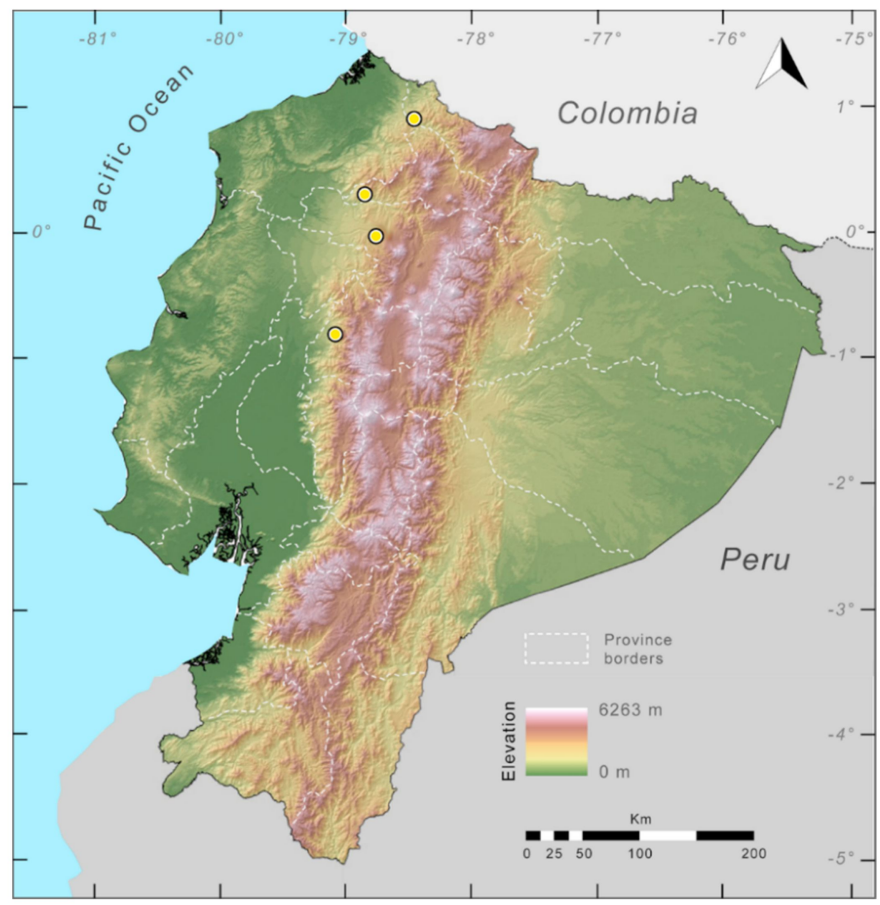

Figure 133. Distribution of Nymphargus balionotus in Ecuador (yellow dots).

Conservation status: Nymphargus balionotus is listed by the IUCN as Vulnerable at a global level [245]. The species was abundant at the type locality ( $3.5 \mathrm{~km}$ NE of Mindo), where 13 individuals were observed in two nights (7-8 April 1975) [120]. A single reproductive population is known in Ecuador, Reserva Río Manduriacu, which is threatened by mining activities [21]. Thus, in Ecuador, we suggest the category of Critically Endangered, following IUCN criteria B2a + B2b(iii).

Evolutionary relationships: Lynch and Ruiz-Carranza [246] suggested that Nymphargus balionotus is the nearest relative of Nymphargus armatus and N. griffithsi, based on the following characters: (i) Snout short and truncate, (ii) slender habitus, (iii) similar webbing and dentition, and (iv) a large bladelike ventral crest present on the humerus. Based on mitochondrial data, a recent study found that $N$. balionotus is sister to N. manduriacu [21].

Remarks: Ecuadorian individuals of Nymphargus balionotus have a small, pointed humeral spine. The Colombian populations have a variable crista ventralis that, in some cases, takes the form of a pointed humeral spine. The polymorphism in this characteristic has created confusion in the generic placement of the species $[6,21,139]$. It also has been suggested that at least two species are currently confused under the name Nymphargus balionotus (M. Rada, pers. com.)

Specimens examined: Nymphargus balionotus: Ecuador: Provincia de Carchi: Cabeceras del Río Baboso (00 53" N, 78 27" W; $1400 \mathrm{~m}$ ), DH-MECN 0865. Provincia de Pichincha: $3.5 \mathrm{~km}$ NE Mindo (0.0322 S, 78.761 W, 1540 m), KU 164702 (holotype), 164701, 164703-11. Provincia de Imbabura: Reserva Río Manduriacu, 1240-1254 m, ZSFQ 0531-33.

Photographic record: Ecuador: Provincia de Cotopaxi: Río Lomapi, NE of La Maná, Reserva Ecológica Illinizas (0.8270275 S, 79.0843359 W, ca. 1300 m); photo by Martín Bustamante. 
Nymphargus buenaventura Cisneros-Heredia and Yánez-Muñoz, 2007 [115] (Figures 134 and 135).

Cochranella buenaventura Cisneros-Heredia and Yánez-Muñoz, 2007 [115]. Holotype: DHMECN 3563.

Type locality: “Reserva Buenaventura $\left(03^{\circ} 38^{\prime}\right.$ S, $79^{\circ} 45^{\prime}$ W, $1200 \mathrm{~m}$ elevation), canton Piñas,

Provincia de El Oro, República del Ecuador".

Nymphargus buenaventura-Cisneros-Heredia and McDiarmid, 2007 [17].

Common names: English: Buenaventura Glassfrog. Spanish: Rana de Cristal de Buenaventura. Etymology: The specific epithet refers to the type locality, Reserva Buenaventura [115].

Identification: Nymphargus buenaventura can be distinguished from most centrolenids by its green dorsum with small pale yellow to cream spots, reduced webbing between fingers, absence of humeral spine, and absence of iridophores on the digestive visceral peritonea, but with iridophores covering the renal capsules. The last character is shared with at least three other species, N. cariticommatus, N. griffithsi, and N. wileyi. Nymphargus cariticommatus occurs only on the Amazonian Andean slopes of Ecuador, whereas N. buenaventura is restricted to the Pacific Andean slopes. Nymphargus griffithsi differs by having dark dorsal spots. Nymphargus wileyi differs by having a uniform green dorsum and inhabiting the Amazonian slopes of the Ecuadorian Andes. Another species that could be confused with $N$. buenaventura is N. lasgralarias, which lacks the yellow spots characteristic of the former.

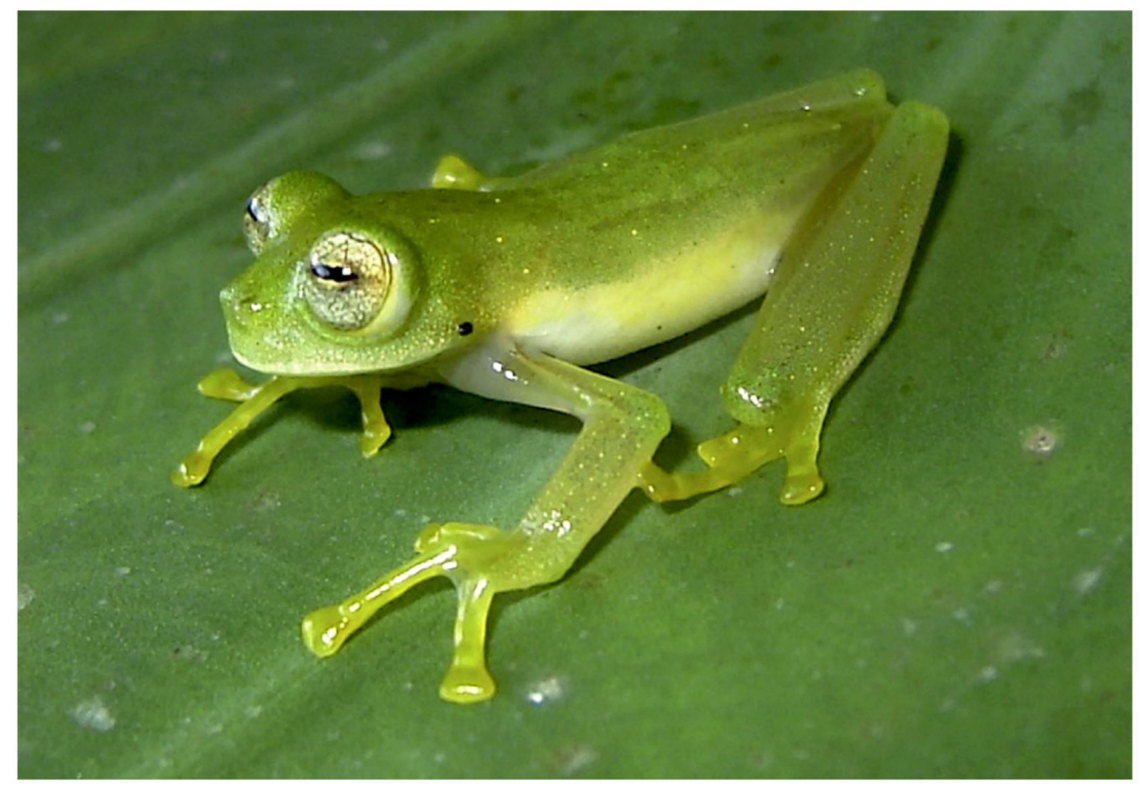

Figure 134. Nymphargus buenaventura in life from Reserva Buenaventura, $1200 \mathrm{~m}$, El Oro province, Ecuador. Photo by Mario Yánez-Muñoz.

Diagnosis: Nymphargus buenaventura has the following traits: (1) Vomerine teeth absent; (2) snout truncated in dorsal view and profile; nostrils elevated, slightly concave internarial area; (3) lower half of tympanic annulus evident, oriented dorsolaterally with dorsoventral inclination; supratympanic fold absent or very weak; (4) dorsal skin slightly shagreen with scattered flat tubercles corresponding to light spots; (5) ventral skin areolate; pair of large, flat subcloacal warts; subcloacal skin granular and enameled; (6) upper half of parietal peritoneum covered by iridophores (condition P2), all other peritonea transparent, except for renal capsules and pericardium covered by iridophores (condition V1); (7) liver tetralobed, uncovered by iridophores (condition H0); (8) humeral spine absent; (9) webbing absent between Fingers I, II, and III; basal between Fingers III and IV; webbing formulae: III $2^{2 / 3}-2^{1 / 2}$ IV; (10) webbing on feet moderate; webbing formulae: I $2-2^{+}$II $1^{+}-2^{1 / 2}$ III $1-2^{1 / 2}$ IV $2^{1 / 2}-1^{2 / 3} \mathrm{~V}$; (11) outer ventral edges of forearms and tarsi with low folds; (12) unpigmented nuptial pad Type I, 
concealed prepollex; (13) first finger shorter than second, (14) eye diameter larger than width of disc on Finger III; (15) color in life: Dorsum green with scattered pale yellow spots; bones green; (16) color in preservative: Dorsal surfaces pale lavender with scattered cream spots; (17) in life, iris yellowish silver with thin dark maroon reticulations; (18) yellow-green hands with bright yellow discs, melanophores present on outer fingers and outer toes; (19) males call from upper sides of leaves along streams; call undescribed; (20) fighting behavior unknown; (21) egg clutches placed on upper sides of leaves along streams; parental care unknown; (22) tadpoles unknown; (23) small body size; SVL of adult males 20.9-22.4 mm $(n=4)$; SVL in one adult females $23.5 \mathrm{~mm}$.

Color in life (Figure 134): Pale green dorsum with pale yellow to cream spots on all dorsal surfaces, including arms and legs. Hands and feet yellowish green with pale yellow discs. Venter cream. Iris yellowish silver with fine maroon reticulations.

Color in ethanol: Lavender dorsum with cream spots. Anterior two-thirds of parietal peritoneum white, posterior section translucent; pericardium white; most visceral peritonea clear except for white peritoneum covering the renal capsules.

Biology and ecology: Very little information is known on the natural history of Nympharugus buenaventura. It has been found on leaves of shrubs and low trees, 1-3 $\mathrm{m}$ above streams. A male was found near an egg clutch with 38 embryos [115]. Parental care is unknown.

Call: Not described.

Tadpole: Not described.

Distribution (Figure 135): Nymphargus buenaventura is known from three localities in El Oro province (Reserva Buenaventura, Marcabelí, Cascadas de Manuel) and one in Azuay province (Luz María), southwestern Ecuador, within the Deciduous Forest ecoregion. The localities are: Reserva Buenaventura $\left(03^{\circ} 38^{\prime} 43^{\prime \prime} \mathrm{S}, 79^{\circ} 45^{\prime} 48^{\prime \prime} \mathrm{W}, 1200 \mathrm{~m}\right)$, Luz María $\left(02^{\circ} 41^{\prime} 02^{\prime \prime} \mathrm{S}, 79^{\circ} 25^{\prime} 01^{\prime \prime} \mathrm{W}, 770 \mathrm{~m}\right)$, Marcabelí $\left(03^{\circ} 44^{\prime} 48^{\prime \prime}\right.$ S, $\left.79^{\circ} 53^{\prime} 36^{\prime \prime} \mathrm{W}, 667 \mathrm{~m}\right)$, and Cascadas de Manuel $\left(03^{\circ} 12^{\prime} 22^{\prime \prime} \mathrm{S}, 79^{\circ} 43^{\prime} 34^{\prime \prime} \mathrm{W}\right.$, $800 \mathrm{~m})[115,247]$.

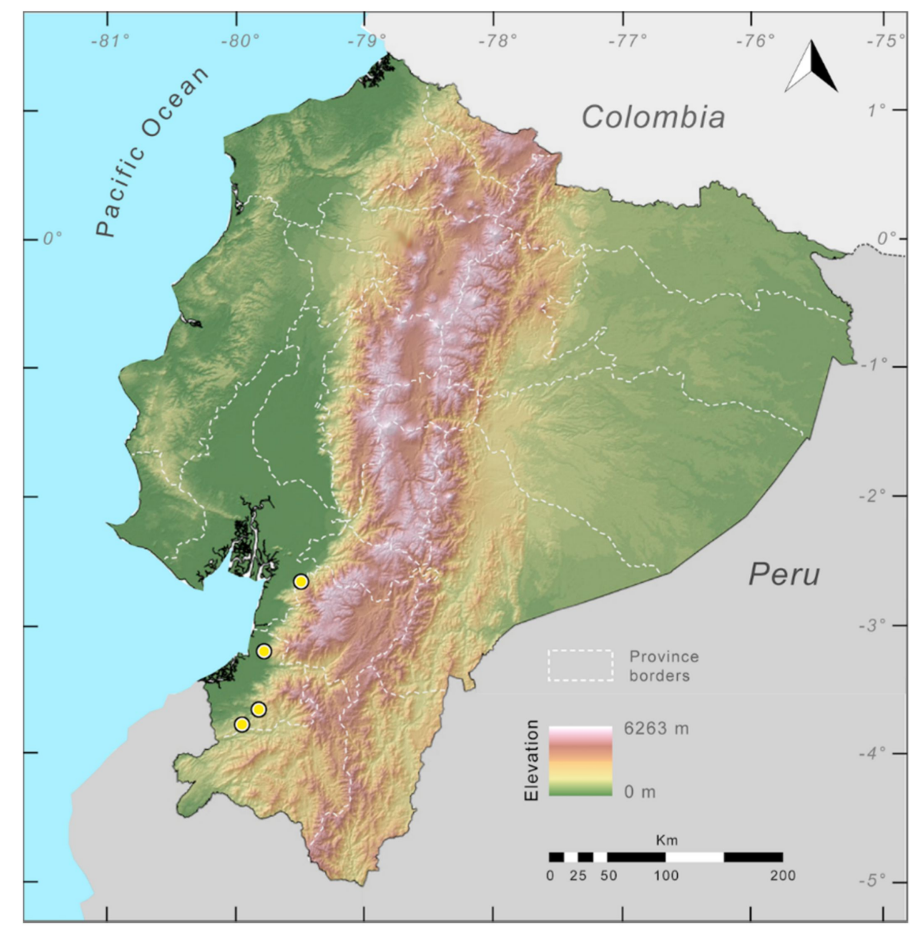

Figure 135. Distribution of Nymphargus buenaventura in Ecuador (yellow dots).

Conservation status: Nymphargus buenaventura is classified as Data Deficient by the IUCN [248]. The species seems to be endemic to southwestern Ecuador, an area with severe deforestation. Thus, we suggest placing the species in the Endangered conservation category, following IUCN criteria B1, B2a, 
B2biii. The species is partially protected by a private reserve (Reserva Buenaventura, managed by Fundación Jocotoco).

Evolutionary relationships (Figure 136): Nymphargus buenaventura has not yet been included in any molecular phylogeny. However, because of its close morphological resemblance to N. griffithsi, N. wileyi, and N. cariticommatus, it is considered as part of the Nymphargus clade (sensu Guayasamin et al. [1]).

Specimens examined: Nymphargus buenaventura: Ecuador: Provincia de El Oro: Reserva Buenaventura ( $03^{\circ} 38^{\prime} \mathrm{S}, 79^{\circ} 45^{\prime} \mathrm{W}, 1200 \mathrm{~m}$ ), DHMECN 3563 (holotype), 2524, 3561, 3562 (paratypes).

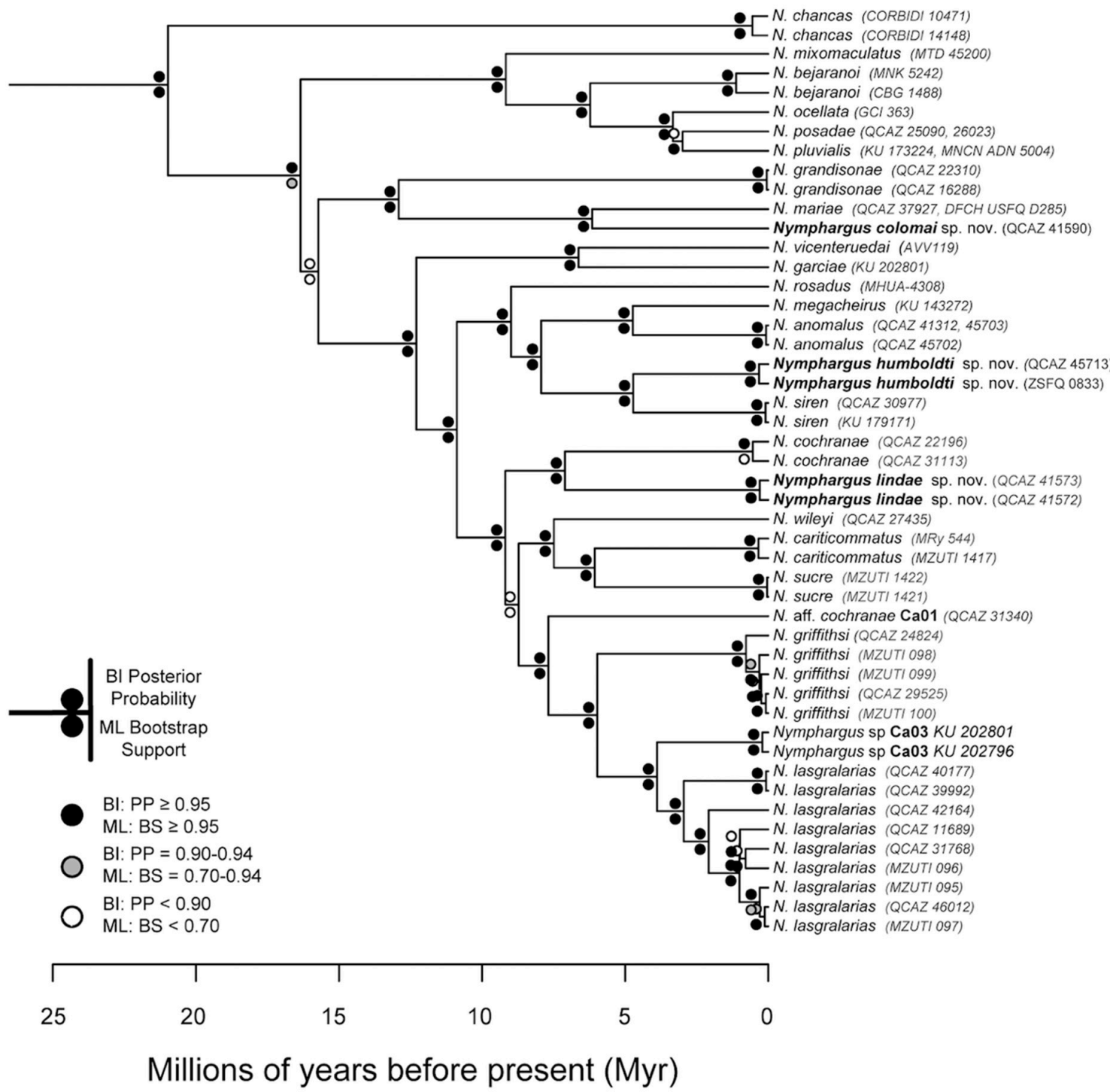

Figure 136. Evolutionary relationships of glassfrogs in the genus Nymphargus, inferred using maximum likelihood and Bayesian criteria. 
Nymphargus cariticommatus (Wild, 1994 [137]; Figures 137-139).

Cochranella cariticommata Wild, 1994 [137]. Holotype: KU 202806.

Type locality: “11.2 km WSW Plan de Milagro ( $03^{\circ} 02^{\prime}$ S, 78 $35^{\circ}$ W, $\left.2350 \mathrm{~m}\right)$, Provincia Morona-

Santiago, Ecuador".

Nymphargus cariticommatus_Cisneros-Heredia and McDiarmid, 2007 [17].

Common names: English: Unadorned Glassfrog. Spanish: Rana de Cristal Escueta.

Etymology: The specific epithet, cariticommatus, is an adjective formed from the Latin word caritus, meaning without, joined with Kommos, a Greek work meaning decoration or embellishment. The name refers to the species' plain appearance and lack of distinctive features [137].

Identification: Nymphargus cariticommatus is likely to be confused with Nymphargus wileyi, $N$. griffithsi, and N. buenaventura. However, in life, N. cariticommatus has a green dorsum with small yellow dots (Figure 137; uniform green dorsum in N. wileyi), an esophageal peritonea covered by iridophores (translucent in N. griffithsi and N. buenaventura, and with a thin layer of iridophores in $N$. wileyi; but see Remarks), and slightly less hand webbing on the outer fingers than N. buenaventura. Additionally, N. cariticommatus is found on the Amazonian versant of the Andes, whereas N. griffithsi and N. buenaventura inhabit the Pacific versant.
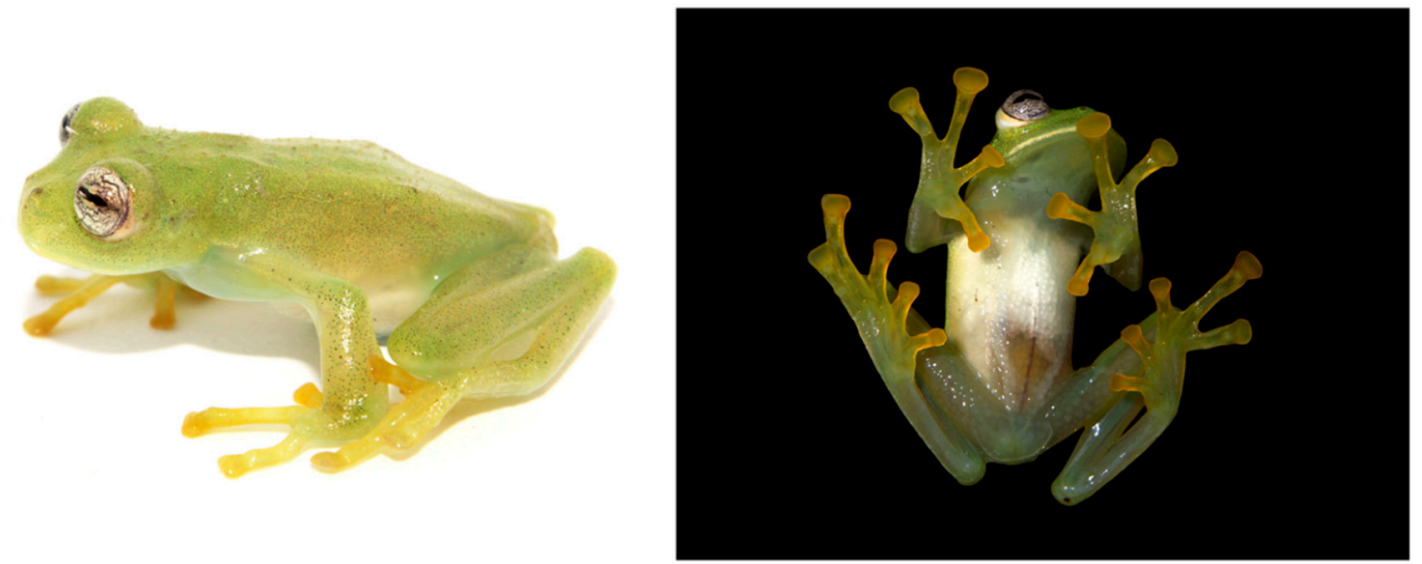

Figure 137. Nymphargus cariticommatus in life from Ecuador, Zamora Chinchipe province, Reserva Tapichalaca, $2200 \mathrm{~m}$. Photos by Mario Yánez (left) and Marco Reyes (right).

Diagnosis: (1) Vomers lacking teeth; (2) snout round in dorsal profile, and truncated in lateral profile (Figure 138); (3) tympanum evident and of moderate size (tympanum diameter $26.7 \%-27.1 \%$ of eye diameter), dorsal border of tympanic annulus covered by supratympanic fold, tympanic membrane differentiated from surrounding skin; (4) dorsal surfaces shagreen, with minute spicules in males; (5) pair of enlarged subcloacal warts; (6) anterior two-thirds of ventral parietal peritoneum white, posterior third transparent (condition P2); silvery white pericardium; translucent peritonea covering the intestines, stomach, testes, gall bladder, and urinary bladder; esophagus white; kidneys white with unpigmented spots (condition V1); (7) liver tetralobed, three ventral lobes partially covering one smaller lobe; hepatic peritoneum transparent (condition H0); (8) humeral spines absent; (9) no webbing between inner fingers; webbing formula as follows: IV $2^{3 / 4}-2^{2 / 3} \mathrm{~V}$ in one male, IV $3^{+}-2^{3 / 4} \mathrm{~V}$ in one female; (10) foot webbing moderate: I $2-2^{1 / 4} \mathrm{II}\left(1-1^{1 / 2}\right)-\left(2^{1 / 3}-2^{2 / 3}\right) \mathrm{III}\left(1^{1 / 3}-1^{1 / 2}\right)-\left(2^{1 / 2}-2^{2 / 3}\right)$ IV $\left(2^{2 / 3}-2^{3 / 4}\right)-2$ V (Figure 138); (11) low ulnar fold in males, not visible in females; low inner tarsal fold present in both sexes; (12) concealed prepollex; nuptial pad Type I in males; (13) Finger II slightly longer than Finger I (Finger I about 90\%-94\% length of Finger II); (14) disc of Finger III of moderate size, $50 \%-56 \%$ of eye diameter; (15) in life, dorsum green with small yellow spots (Figure 137); (16) in ethanol, dorsum lavender with small white spots; (17) iris silvery white with thin black reticulation, 
yellow ring around pupil; (18) dorsal surfaces of fingers and toes lacking melanophores; (19) males call from the upper side of leaves; call described as soft 'zeet, zeet, zeet', but specific characteristics unknown; (20) fighting behavior unknown; (21) eggs deposited on the upper side of leaves; parental care unknown; (22) tadpoles unknown; (23) small body size; one adult male, SVL $23.3 \mathrm{~mm}$; one adult female, SVL $25.5 \mathrm{~mm}$.
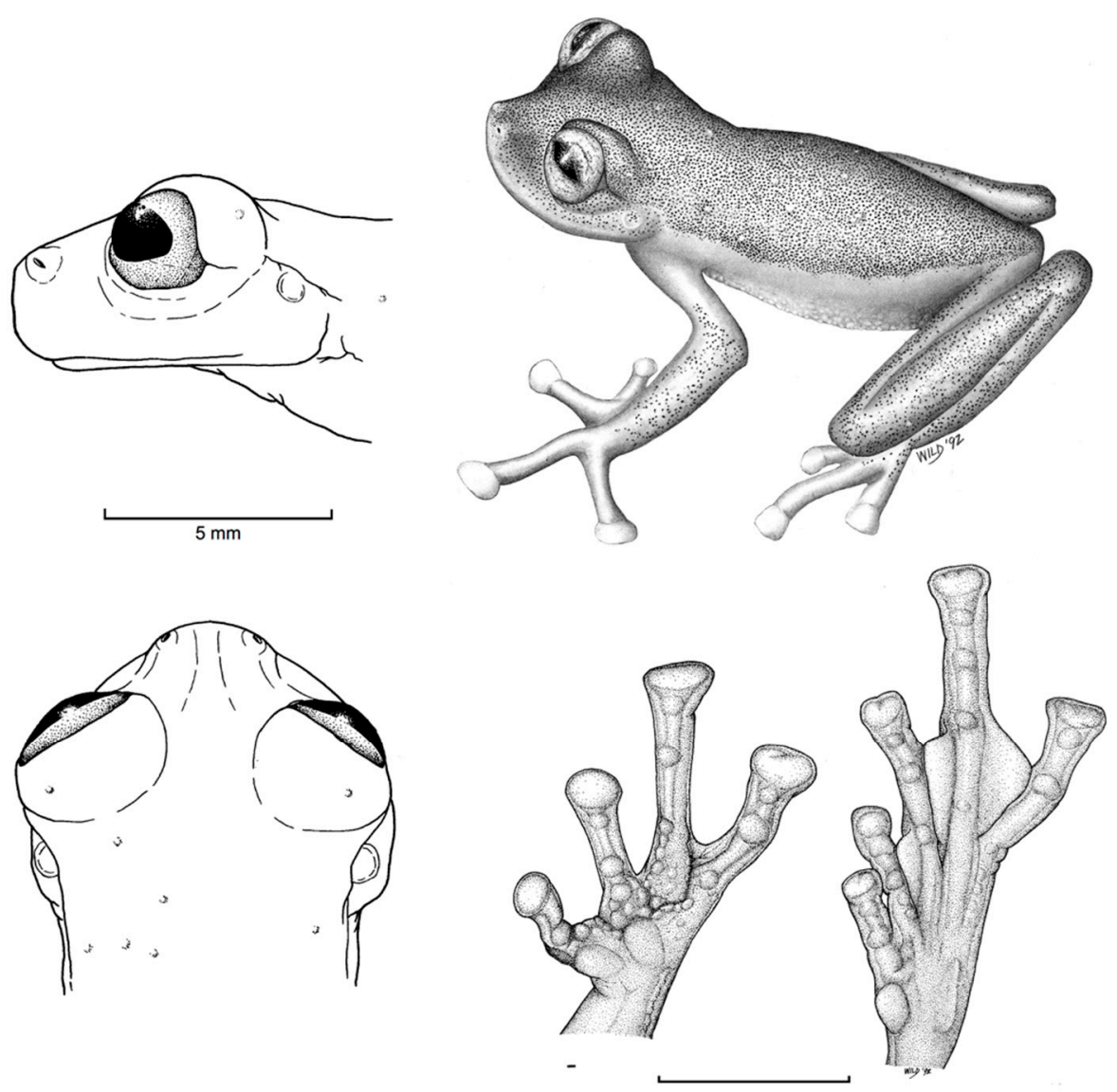

Figure 138. Nymphargus cariticommatus. Drawings of the holotype, adult male, KU 202806. Modified from Wild [137].

Color in life (Figure 137): Dorsal surfaces of head, body, and limbs green with small yellow spots. Dorsal surfaces of fingers and toes yellow. Iris silvery white with black reticulations.

Color in ethanol: Dorsum of body and limbs lavender with few, small, scattered white spots (fewer in females). Cheek with pale white flecks; margin of lip unpigmented; tympanum with few lavender flecks in males, lacking in females. Hands and feet lacking pigment [137]. Liver covered by transparent peritoneum; white parietal peritoneum covering anterior two-thirds of venter; silvery white pericardium; transparent peritonea covering the intestines, stomach, testes, gall bladder, and urinary bladder; peritoneum around kidneys with a thin silvery white lining; iris silvery white, with purple reticulations. In the original description, Wild [137] stressed the white esophagus in N. cariticommatus, similar to that seen in Teratohyla midas. In the preserved type series, only a thin layer of iridophores is evident.

Biology and ecology: Nymphargus cariticommatus was found on the upper sides of leaves and ferns within $2 \mathrm{~m}$ of cascading streams [137]. Parental care is unknown.

Call: Not described.

Tadpole: Not described.

Distribution (Figure 139): Nymphargus cariticommatus is endemic to the Amazonian slopes of the southern Andes of Ecuador at elevations between 2200 and $2700 \mathrm{~m}$ ([115,116,137,139], this work). 
The species has been recorded from localities in the provinces of Zamora Chinchipe and Morona Santiago. The habitat of the species is within the Eastern Montane Forest ecoregion.

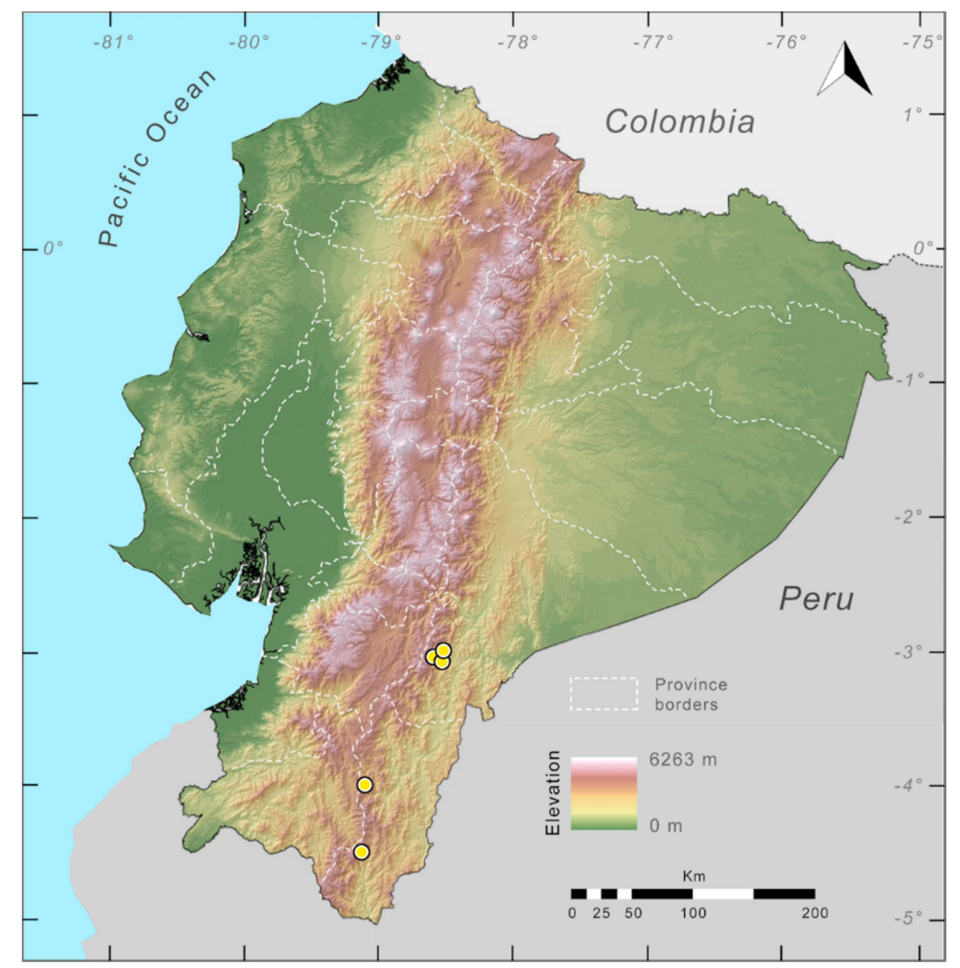

Figure 139. Distribution of Nymphargus cariticommatus in Ecuador (yellow dots).

Conservation status: Globally, Nymphargus cariticommatus is listed as Data Deficient by the IUCN [249]. The last reports of the species come from surveys at the Reserva Biológica Tapichalaca on 2004-2005 ([115], Yánez-Muñoz and Meza-Ramos, pers. com.). In Ecuador, the species is threatened by habitat destruction and fragmentation because of agriculture, pasture lands, and mining. We suggest considering the species as Endangered (IUCN criteria B1, B2a, B2biii).

Evolutionary relationships (Figure 136): Based on mitochondrial data, Nymphargus cariticommatus is sister to N. sucre.

Taxonomic Remarks: As mentioned in the diagnosis, subtle morphological differences separate Nymphargus cariticommatus from $N$. wileyi. We have examined all the available material of the two species (see Specimens Examined), including the type series, and observed that none of the specimens of $N$. wileyi have dorsal spots, whereas all individuals of N. cariticommatus have them. Also, in the preserved material, the esophageal peritoneum of $N$. cariticommatus is more pronounced and extended than in N. wileyi, in which the iridophores are restricted to the anterior portion of the esophageal peritoneum. Considering the data at hand, we maintain the species status of N. wileyi.

Specimens examined: Nymphargus cariticommatus: Ecuador: Provincia de Morona Santiago: $11.2 \mathrm{~km}$

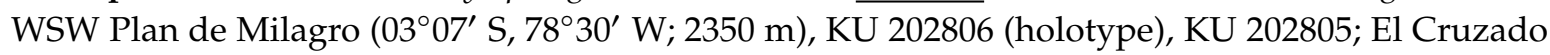
(3.050 S, 78.517 W; 2194 m), USNM 288435-36. Provincia de Zamora Chinchipe: Reserva Biológica Tapichalaca (4.49208 S, 79.128389 W; 2200 m), DH-MECN 1974, 2429; $18.1 \mathrm{~km}$ E of Loja on the old road to Zamora, 2700 m, QCAZ 33977; Shucos, on the old road from Loja to Zamora, MRy 544. 
Nymphargus cochranae (Goin 1961 [97]; Figures 140-144).

Cochranella cochranae Goin, 1961 [97]. Holotype: BM 1912.11.1.68.

Type locality: "El Topo, Río Pastaza, Eastern Ecuador, 4200 feet."

Centrolenella cochranae-Goin, 1964 [187].

Cochranella cochranae-Ruiz-Carranza and Lynch, 1991 [6].

Nymphargus cochranae-Cisneros-Heredia and McDiarmid, 2007 [17].

Common names: English: Cochran's Glassfrog. Spanish: Rana de Cristal de Cochran.

Etymology: The specific epithet honors Doris M. Cochran (1898-1968), herpetologist and curator of the Smithsonian Institution [97].

Identification: Nymphargus cochranae can be distinguished from all other glassfrogs by its green dorsum with small dark blue to black ocelli enclosing orange dots (Figure 140), relatively large size (adult males, SVL 24.0-26.2 mm; adult females, SVL 27.8-30.3 mm), absence of webbing between fingers (Figure 141), and lacking humeral spines. Nymphargus cochranae further differs from other species with dorsal ocellated patterns (N. anomalus, N. lindae sp. nov., N. ignotus, N. laurae, N. ocellatus) by having relatively smaller ocelli (Figure 142). Additionally, N. ignotus is found on the Pacific slopes of the Andes, whereas N. cochranae is restricted to the Amazonian slopes of the Andes. N. anomalus further differs by having scattered black and lavender flecks between ocelli (absent in N. cochranae); N. ocellatus has a green dorsal coloration with large dark rings that, in life, have greenish white centers; N. laurae, known from a single adult male is smaller $(\mathrm{SVL}=19.7 \mathrm{~mm})$, has pointed papillae on Toes I-IV (absent in N. cochranae), and larger ocelli. Nymphargus cochranae is most similar to its sister species, $N$. lindae sp. nov., in female body size (N. cochranae, SVL = 27.8-30.3 mm; N. lindae sp. nov., SVL 27.2-27.8 mm) and the relative size of ocelli (minute in N. cochranae and clearly larger in N. lindae sp. nov.), which is the most conspicuous difference between the two species. The only other species similar to N. cochranae is N. megacheirus, the dorsal dots of which coincide with spicules and could be confused with ocelli. However, N. megacheirus is larger (SVL of males $=26.8-31.5 \mathrm{~mm}$; SVL of females $=31.2-32.9 \mathrm{~mm}$ ) and the males have conspicuous spicules and spiculated warts on the dorsum (minute spicules in males of N. cochranae).

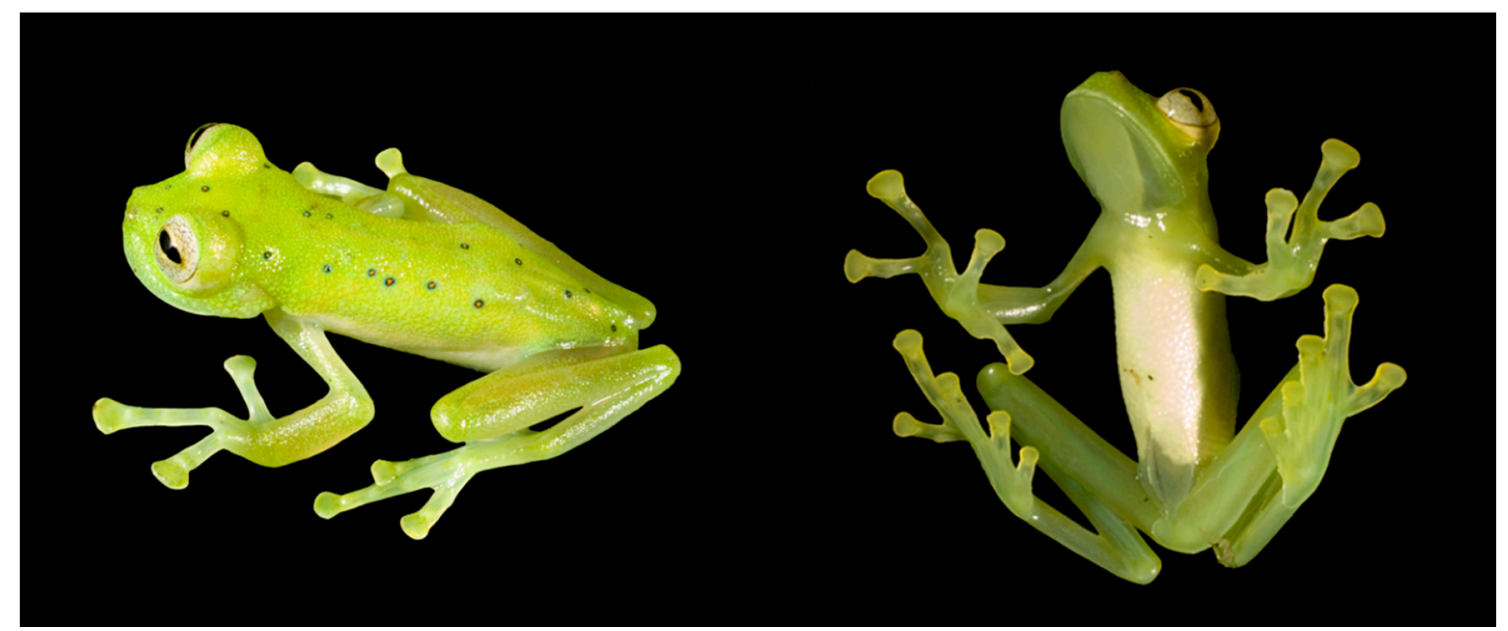

Figure 140. Nymphargus cochranae in life. Ecuador, Volcán Sumaco, 1500 m, QCAZ 31113. Photos by Luis A. Coloma.

Diagnosis: (1) Vomers usually with teeth, but see Variation; (2) snout truncated in dorsal profile, and truncated to slightly protruding in lateral profile (Figure 141); (3) tympanum relatively small, its diameter $19.5 \%-27.8 \%$ eye diameter, dorsal border of tympanic annulus covered by supratympanic fold, tympanic membrane pigmented as surrounding skin; (4) dorsal skin of males and females shagreen, 
minute spicules usually present in males; (5) pair of enlarged subcloacal warts; (6) anterior two-thirds of ventral parietal peritoneum white, posterior third transparent (condition P2); white pericardium; translucent peritonea covering intestines, stomach, testes, kidneys, gall bladder, and urinary bladder (condition V1); (7) liver tetralobed, two large ventral lobes partially covering two smaller lobes; hepatic peritoneum transparent (condition H0); (8) humeral spines absent; (9) hand webbing absent; (10) foot about two-thirds webbed: I $\left(2-2^{+}\right)-\left(2^{1 / 3}-2^{1 / 2}\right)$ II $\left(1^{1 / 2}-2^{-}\right)-\left(3^{-}-3\right)$ III $\left(1^{3 / 4}-2\right)-\left(3^{-}-3^{+}\right)$IV $\left(3^{-}-3^{+}\right)-\left(2-2^{+}\right) \mathrm{V}$; (11) ulnar and tarsal folds low; (12) concealed prepollex; nuptial pad Type I in males; (13) Finger I about same length as Finger II (Finger II 96.3\%-101.8\% of length of Finger I); (14) disc of Finger III small, $19.4 \%-28.3 \%$ of eye diameter; (15) in life, dorsum green with small dark blue to black ocelli enclosing orange dots (Figure 140); bones green; (16) in ethanol, dorsal surfaces lavender with small black ocelli enclosing white dots; (17) iris creamy white with thin dark grey reticulation, pupil surrounded by pale brownish-yellow coloration; (18) dorsal surfaces of hands and feet lacking melanophores, except for proximal portion of Finger IV and Toe V; (19) males call from the upper side of leaves or branches overhanging streams; single, high-pitched note; spectral and temporal characteristics of call unknown; (20) fighting behavior unknown; (21) eggs deposition site unknown; parental care unknown; (22) tadpoles unknown; (23) small to medium body size; SVL of adult males 24.0-26.2 mm ( $\overline{\mathrm{X}}=25.0 \pm 0.812, n=6)$; SVL of adult females $27.8-30.3 \mathrm{~mm}(\overline{\mathrm{X}}=28.9 \pm 1.014, n=7)$.

Color in life (Figure 140): Green dorsum with small dark blue to black ocelli enclosing bright orange spots. Ventral surfaces mostly white, except for posterior third, which is translucent. Bones green. Iris greyish white with a thin black reticulation; area immediately around pupil pale brownish yellow.

Color in ethanol (Figure 143): Dorsal surfaces lavender with small black ocelli enclosing white spots. Pericardium and anterior two-thirds of ventral parietal peritoneum white (presence of iridophores). Liver, intestines, stomach, testes, kidneys, gall bladder, and urinary bladder without white lining.

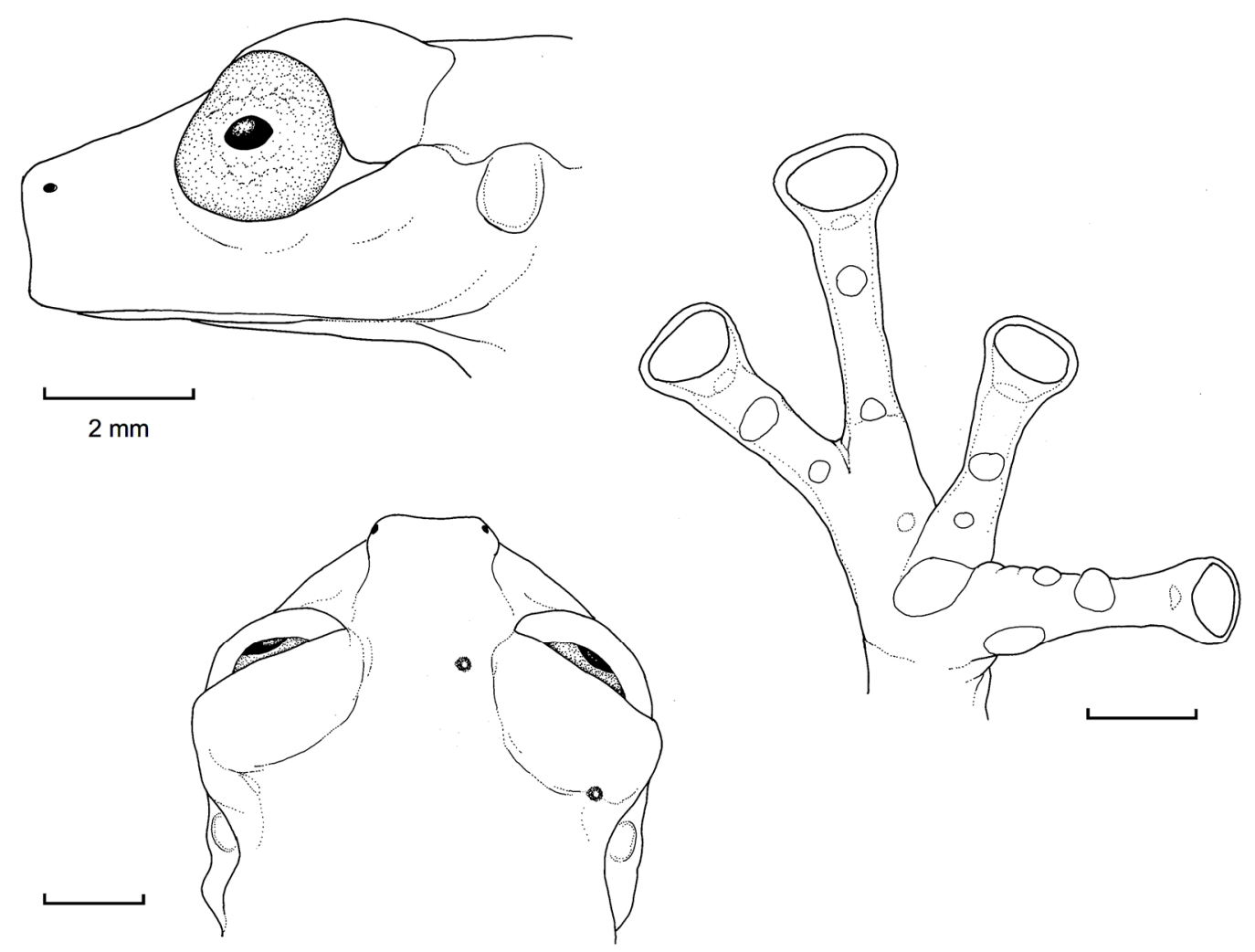

Figure 141. Nymphargus cochranae. Head in lateral and ventral views, adult female, QCAZ 22197. Hand in ventral view, adult male, QCAZ 31113. Illustrations by Juan M. Guayasamin. 
A

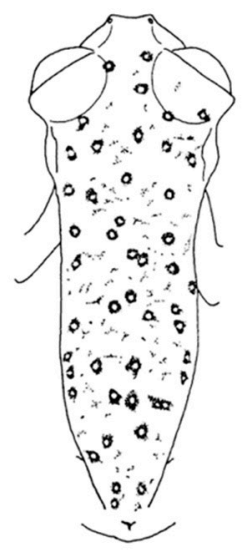

B

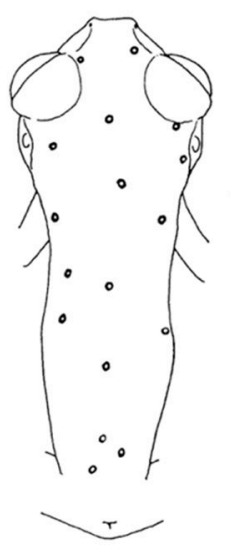

C

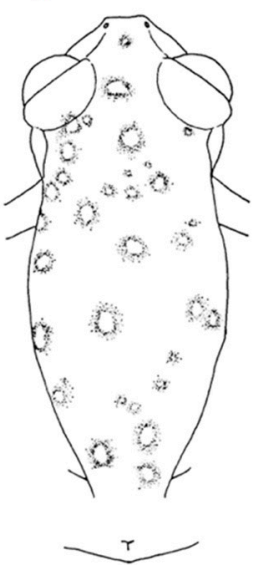

D

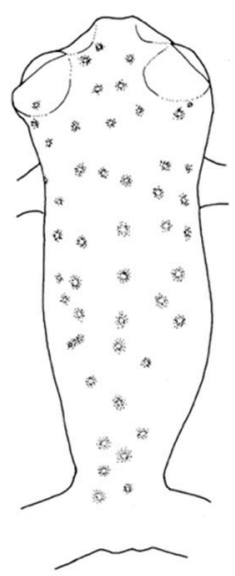

Figure 142. Dorsal patterns of ocellated glassfrogs, excluding Nymphargus laurae and N. lindae sp. nov. (A) N. anomalus, KU 143299. (B) N. cochranae, KU 121035. (C) N. ocellatus, LSU 25990. (D) N. ignotus, ICN 14750. Figure modified from Lynch and Duellman [22].

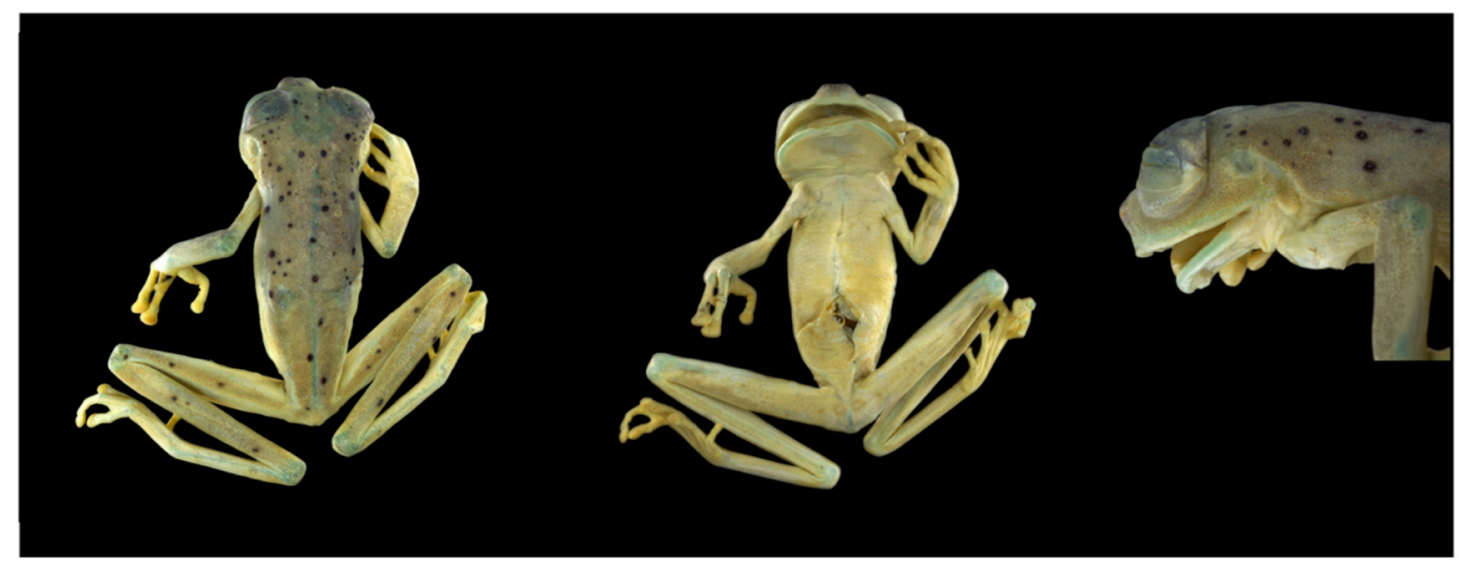

Figure 143. Nymphargus cochranae, holotype in preservative, BMNH 1912.11.1.68. Ecuador, El Topo, Río Pastaza. Photos by Martín Bustamante.

Variation: Goin [97] described Nymphargus cochranae as lacking teeth on the dentigerous process of the vomer, but also noted the presence of teeth in six other specimens [187]. Most specimens $(n=13)$ examined by us present teeth (USNM 286634 lacks teeth) and we assume that this is the usual character state in the species.

Biology and ecology: Nymphargus cochranae is active during the night. In the reproductive season, males call at night from the upper surfaces of leaves or branches near streams. Parental care is unknown.

Call: Described by Lynch and Duellman [22] as a single, high-pitched note. The specific spectral and temporal characteristics of the call are unknown.

Tadpole: Not described.

Distribution (Figure 144): Nymphargus cochranae occurs in Ecuador and Colombia on the Amazonian slopes of the Andes at elevations between $1170 \mathrm{~m}$ and $1960 \mathrm{~m}$. The species has been reported from localities in the provinces of Napo, Orellana, Pastaza, Tungurahua, Sucumbíos, and Zamora Chinchipe (Specimens Examined). There is an unconfirmed record from the Ecuadorian Amazonia (Garza 1, at $300 \mathrm{~m}$; QCAZ 1216). The potential distribution of the species is 21,723 $\mathrm{km}^{2}$, within the Eastern Foothill Forest and Eastern Montane Forest regions. The only record of the species in Colombia comes from the Serranía de Churumbelos [250]. 


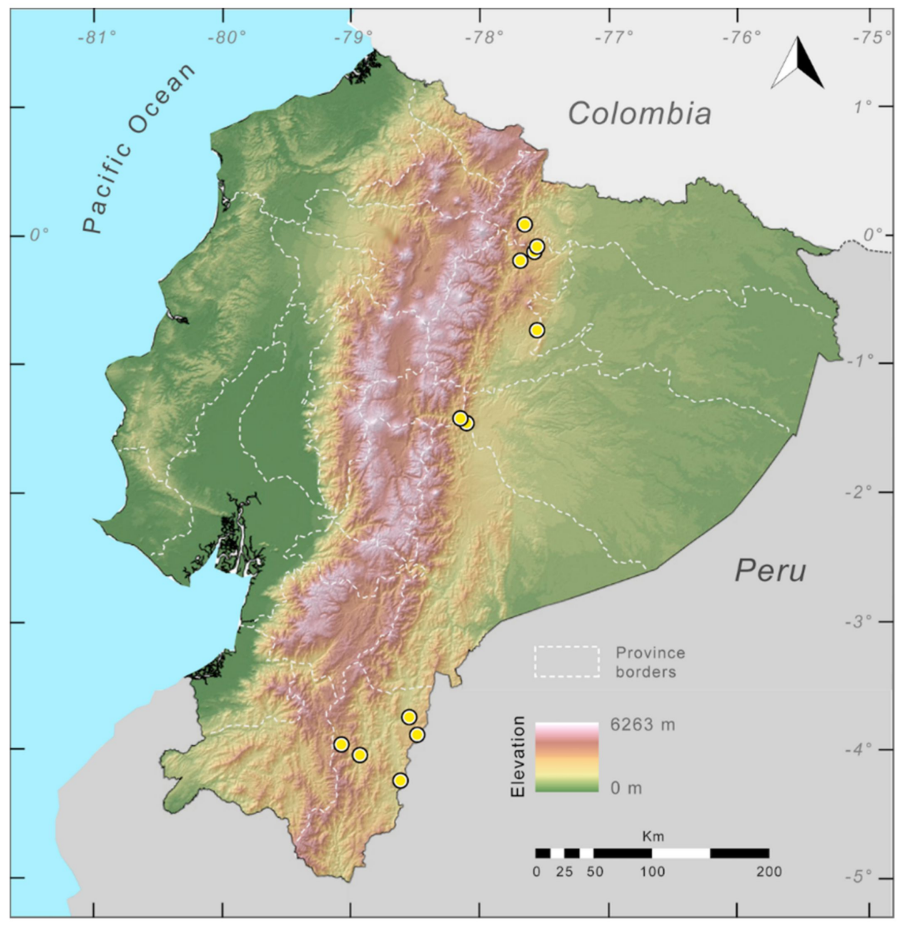

Figure 144. Distribution of Nymphargus cochranae in Ecuador (yellow dots).

Conservation status: Globally, Nymphargus cochranae is considered as Vulnerable by the IUCN [251]. In Ecuador, the species remains abundant at several localities, including the Sumaco and Cayambe Coca National Parks. However, part of the species' range is fragmented; thus, we suggest considering N. cochranae as Near Threatened.

Evolutionary relationships (Figure 136): Nymphargus cochranae is sister to N. lindae sp. nov. However, one sequenced individual (QCAZ 31340) is inferred as sister to a clade formed by N. griffithsi $+N$. lasgralarias.

Taxonomic Remarks: Nymphargus cochranae might be a species complex (see Evolutionary relationships). Also, see taxonomic remarks of $N$. laurae and N. lindae sp. nov.

Specimens examined: Nymphargus cochranae: Ecuador: Provincia de Orellana: $\mathrm{km} 13$ on Loreto-Coca road (0.5836 S, 77.234 W), QCAZ 22196-97; Provincia Napo: Cascada San Rafael (0.1127 S, 77.596 W, 1280-1372 m), QCAZ 002, USNM 286632-37, 284304-10; 14.7 km (by road) NE of Río Salado (0.1289 S, $77.608 \mathrm{~W}, 1310 \mathrm{~m}$ ), USNM 286638; $14 \mathrm{~km}$ by road SW of Reventador (ca. $0.11278 \mathrm{~S}$, 77.596 W; 1400-1500 m), USNM 284304-06; Pacto Sumaco (0.726 S, 77.566 W; 1400 m), QCAZ 31113; Río Salado, 1 km upstream from Rio Coca (0.1916 S, 77.6997 W, 1420 m), KU 164517-18. Provincia de Pastaza: Abitagua, 8 km NW Mera (1.41667 S, 78.1667 W, 1300 m), KU 121033-35; Provincia de Tungurahua: Río El Topo (1.4166 S, 78.1667 W, 1220 m), BMNH 1912.11.1.68; 11 km E Río Negro (1.433 S, 78.13 W, 1170 m), KU 146605; Provincia de Sucumbios: S slope Cordillera del Due above Río Coca (0.0833 N, 77.66 W, 1150 m), KU 123216-18. Provincia de Zamora Chinchipe: Estación Científica San Francisco (3.967 S, 79.066 W, 1960 m), QCAZ 31340-41.

Localities from the literature: Nymphargus cochranae: Ecuador: Provincia de Zamora Chinchipe: Alto Nangaritza (4.25026 S, 78.61746 W; 1256-1430 m) [252]; Contrafuerte de Tzunantza (4.046 S, 78.922 W) [253]; Alto Machinaza 1 (3.8976 S, 78.482 W) [254], Alto Machinaza 2 (3.7708 S, 78.554 W) [254]. 
Nymphargus colomai new species Guayasamin and Hutter (Figure 145).

http://zoobank.org/urn:lsid:zoobank.org:act:46978D55-22DF-409E-870C-F3C2203A5E6E

Common names: English: Coloma's Glassfrog. Spanish: Rana de Cristal de Coloma.

Etymology: The specific name is a patronym for Luis A. Coloma in recognition of his pioneer and continual efforts in studying and protecting amphibians, as well as mentoring numerous students, including JMG. Luis Coloma is the Director of the Jambatu Center for Research and Conservation of Amphibians (Centro Jambatu de Investigación y Conservación de Anfibios; see http://www. anfibiosecuador.ec/). The Jambatu Center houses dozens of critically endangered amphibians, in an outstanding effort to conserve frogs and toads. Luis received the Sabin Award for Amphibian Conservation in 2007 (http://www.amphibians.org/grants/sabin-award/).

Holotype: QCAZ 41590, adult male, collected from Miazi Alto $\left(4.25044^{\circ} \mathrm{S}, 78.61356^{\circ} \mathrm{W} ; 1260 \mathrm{~m}\right)$, Cordillera del Cóndor, Provincia de Zamora Chinchipe, Ecuador, by Juan M. Guayasamin and Elicio Tapia on 8 April 2009.

Paratypes: QCAZ 41591-92, adult males, and QCAZ 41641, juvenile, collected by Juan M. Guayasamin, Elicio Tapia, Silvia Aldás, and Holger Braun on 8-12 April 2009, at the same locality as holotype.

Generic placement: The new species is placed in the clade Nymphargus (sensu Guayasamin et al. [1]) based on morphological and molecular data. All species in Nymphargus share an absence of webbing between Fingers I-III and an absence or reduced webbing between Fingers III and IV; additionally, males lack humeral spines (except N. grandisonae). Nymphargus colomai sp. nov. has the aforementioned traits. Molecular analyses of mitochondrial genes unambiguously place the new species in the clade Nymphargus (Figure 16).

Identification: Nymphargus colomai sp. nov. is unique by having a white iris with a contrasting black horizontal stripe and a dorsum that varies from dull yellowish green to tangerine yellow, brown, or grey olive, always with numerous small yellow to orange spots (Figure 145). Additionally, N. colomai sp. nov. lacks humeral spines and hand webbing. Among glassfrogs that inhabit the Amazonian slopes of the Andes, only N. cariticommatus, N. chancas, N. humboldti sp. nov., N. siren, and N. sucre could be confused with N. colomai sp. nov. However, N. cariticommatus, N. chancas, N. siren, and N. humboldti sp. nov. have a green dorsum with few and well-defined dorsal spots, whereas $N$. colomai sp. nov. has a non-green dorsum (see above) with numerous and diffuse yellow dorsal spots. Moreover, N. siren is smaller than $N$. colomai sp. nov. ( $N$. siren, SVL $<23.3 \mathrm{~mm}$; N. colomai sp. nov. SVL $=24.7-25.7 \mathrm{~mm}$ ); and N. cariticommatus has white esophagus and renal capsules (cream in N. colomai sp. nov.) Both N. colomai sp. nov. and the Peruvian N. chancas share the clearly defined black horizontal stripe on a silver background, but the two species are easily differentiated by their dorsal color patterns (in N. colomai sp. nov.: Dull yellowish green to tangerine yellow, brown, or grey olive, with numerous small yellow to orange spots; in N. chancas: Yellowish-green dorsum with small yellow dots; compare Figures 145 and 146) and genetics (Figure 136). 


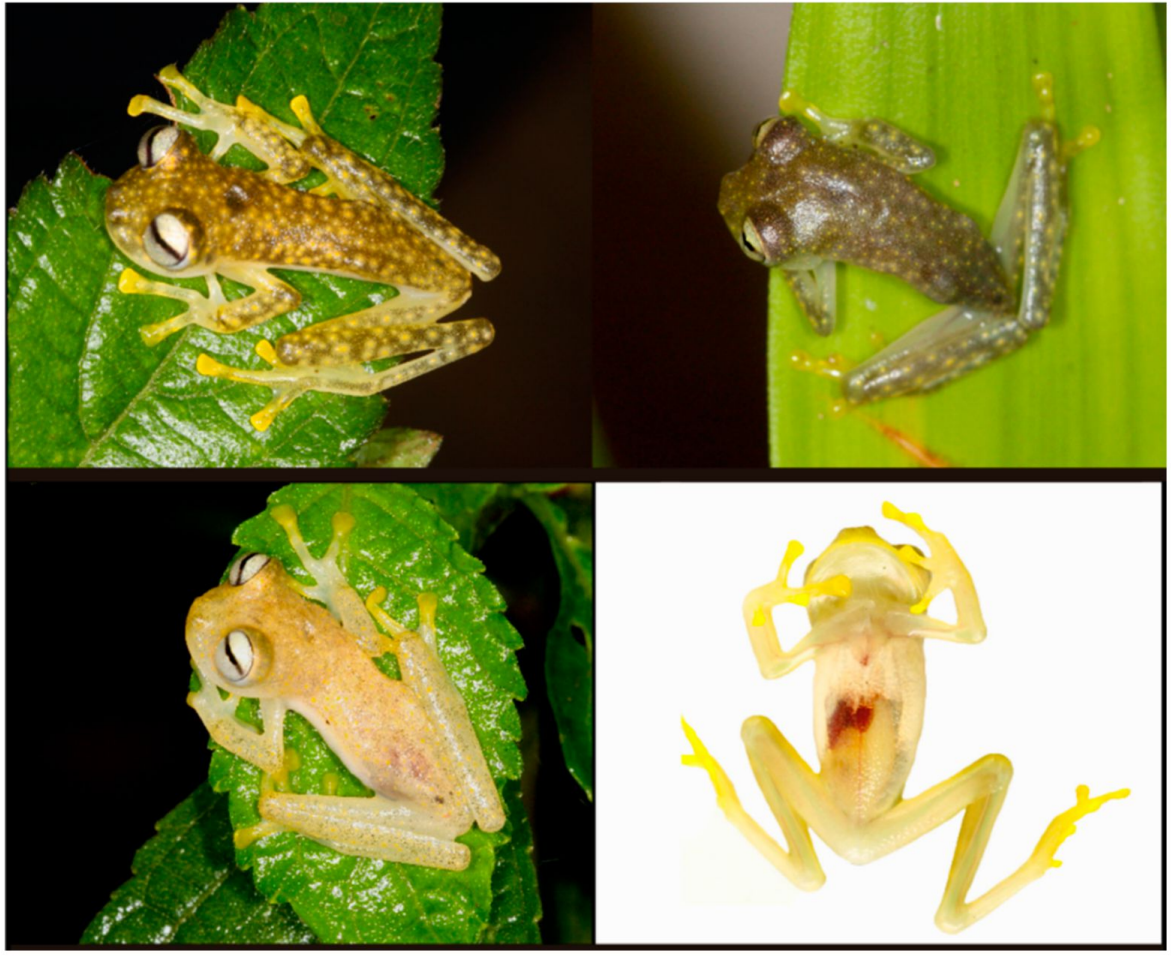

Figure 145. Nymphargus colomai sp. nov. in life from stream nearby Miazi Alto, Zamora Chinchipe province, Ecuador. (Top left): QCAZ 41590, holotype; other frogs are part of the type series. Photos by Holger Braun and Juan M. Guayasamin.
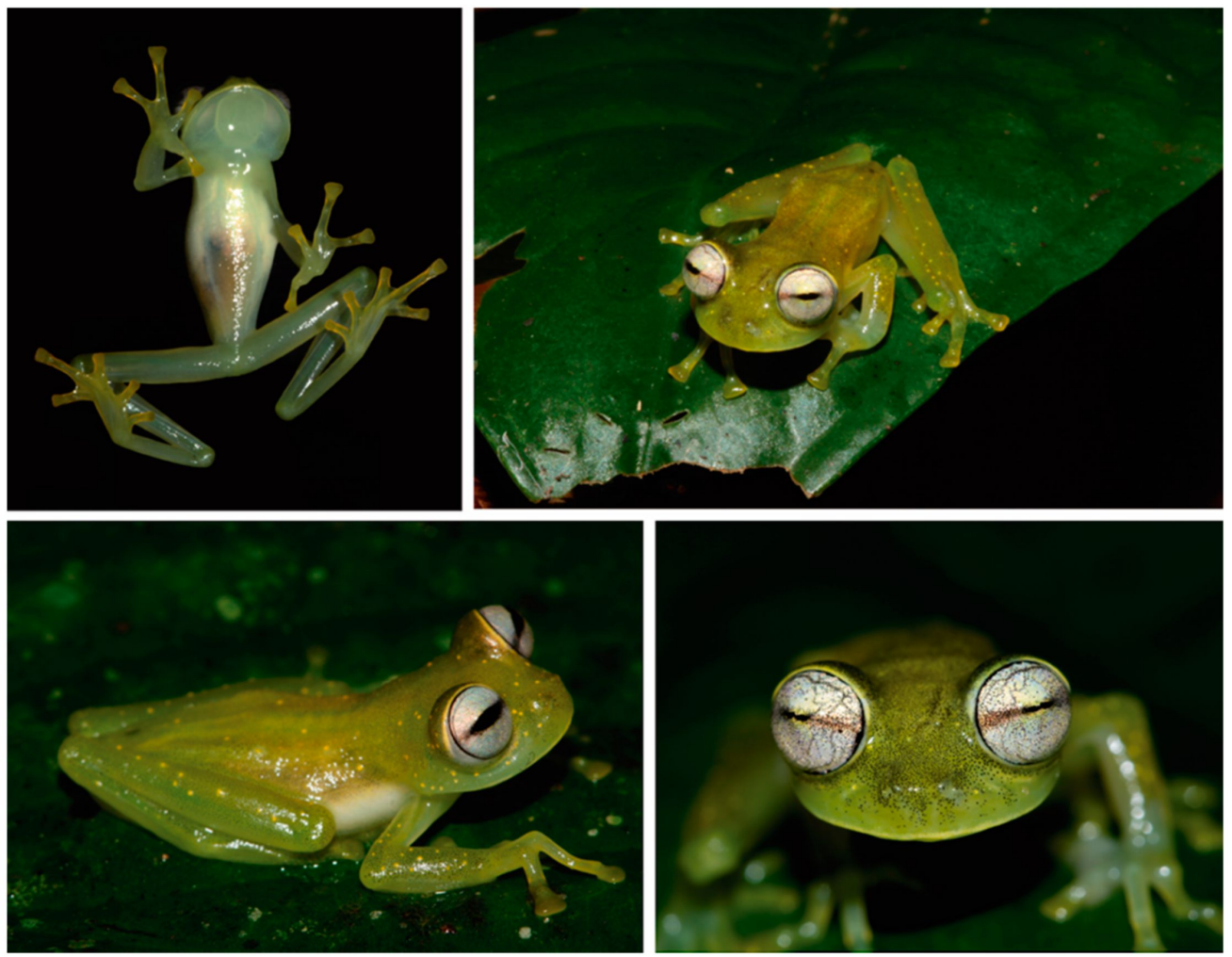

Figure 146. Nymphargus chancas in life from $5.9 \mathrm{~km}$ SE from the type locality of Abra Tangarana, San Martín, $6^{\circ} 19^{\prime} 15.65^{\prime \prime} \mathrm{S} 76^{\circ} 41^{\prime} 44.16^{\prime \prime}$ W, 973 m, CORBIDI 10471. Photos by Jesse Delia (upper row) and Evan Twomey (lower row). 
Diagnosis: (1) Dentigerous process of the vomer lacking teeth or with few teeth (up to 3); (2) snout truncated to slightly protruding in lateral profile; truncated in dorsal view; (3) tympanum oriented almost vertically, with slight lateral and posterior inclinations, its diameter about $23 \%-27 \%$ of eye diameter; upper half of tympanic annulus obscured by supratympanic fold and warts; tympanic membrane pigmented as surrounding skin; (4) dorsal skin shagreen, with numerous spiculated warts and spicules in males; females unknown; (5) venter areolate; pair of enlarged subcloacal warts; (6) white parietal peritoneum covering about anterior half of venter (condition P2); white pericardium; translucent peritonea on kidneys, intestines, stomach, gall and urinary bladders (condition V1); (7) liver lobate, covered by translucent peritoneum (condition H0); (8) humeral spines absent; (9) webbing absent between Fingers I, II, and III, absent or basal between Fingers III and IV; webbing formula III $\left(2^{3 / 4}-3\right)-\left(2^{1 / 2}-2^{2 / 3}\right) \mathrm{IV}$; (10) feet about two-thirds webbed; webbing formula: I $2^{-}-2^{1 / 3} \mathrm{II}\left(1^{+}-1^{1 / 3}\right)-2^{1 / 2}$ III $1^{1 / 2}-\left(2^{2 / 3}-2^{3 / 4}\right)$ IV $3^{-}-\left(1^{1 / 2}-2^{-}\right) \mathrm{V}$; (11) ulnar and tarsal folds present, low; (12) concealed prepollex; in males, nuptial pad Type I; (13) Finger II slightly longer than Finger I; (14) disc of Finger III width about $46 \%-50 \%$ of eye diameter; (15) in life, dorsum varies from dull yellowish green to tangerine yellow, brown, or grey olive with numerous small yellow to orange spots; bones green; (16) in preservative, dorsum grey to greyish lavender with numerous unpigmented spots; (17) in life, iris silvery white with slight yellow hue and a clearly marked horizontal black stripe; (18) melanophores on dorsal surfaces of Fingers III and IV and Toes IV and V; (19) males call from the upper surfaces of leaves; call unknown; (20) fighting behavior unknown; (21) egg deposition site unknown; parental care unknown; (22) tadpole unknown; (23) small body size; in males, SVL 25.0-25.7 $\mathrm{mm}(n=3)$; females unknown.

Description of holotype: Adult male, SVL $25.0 \mathrm{~mm}$. Head slightly wider than long (head length $98 \%$ of head width); snout truncated in dorsal and lateral profiles; canthus rostralis indistinct, slightly concave; loreal region slightly concave; lips slightly flared; nostril protuberant, closer to tip of snout than to eye, directed frontolaterally; internarial area barely depressed. Eyes large, directed anterolaterally at an angle $\sim 50^{\circ}$; transverse diameter of disc of Finger III $48 \%$ eye diameter. Supratympanic fold low, obscuring upper portion of tympanic annulus; tympanum oriented mostly vertically, but with slight posterolateral inclination; tympanic membrane translucent, pigmented as surrounding skin. Dentigerous process of vomer low, situated transversely between choanae, with one or two teeth; choanae large, longitudinally rectangular; tongue ovoid, with ventral posterior fifth not attached to floor of mouth and posterior margin slightly notched; vocal slits extending posterolaterally from about the lateral margin of tongue (at about half the length of tongue) to angle of jaws. Humeral spine absent. Low ulnar folds evident on external and internal ventrolateral margins of arm; relative lengths of fingers: III > IV > II > I; webbing absent between Fingers I-III, basal between Fingers III and IV, webbing formula III 3-2/3 IV; discs expanded, nearly elliptical; disc pads nearly triangular shaped; subarticular tubercles small, round, simple; low supernumerary tubercles present; palmar tubercle elliptical, simple; nuptial pad large (Type I), ovoid, granular, extending from ventrolateral base to dorsal surface of Finger I, covering proximal half of Finger I. Length of tibia 57\% SVL; low inner tarsal fold evident; outer tarsal fold absent; foot two-thirds webbed; webbing formula of foot: I $2^{-}-2^{1 / 3}$ II $1^{1 / 4}-2^{1 / 2}$ III $1^{1 / 2}-2^{3 / 4}$ IV $3^{-}-2^{-}$V; discs on toes round to elliptical, lacking papillae; disc on Toe IV slightly narrower that disc on Finger III; disc pads triangular; inner metatarsal tubercle large, ovoid; outer metatarsal tubercle small and inconspicuous; subarticular tubercles small, round; supernumerary tubercles low. Skin on dorsal surfaces of head, body, and lateral surface of head and flanks shagreen with numerous spiculated warts and minute spicules; lower flanks show glandular cells; throat smooth; belly and lower flanks areolate; cloacal opening directed posteriorly at upper level of thighs; cloacal warts present, unpigmented. Ventral surface of thighs with pair of enlarged tubercles.

Coloration of holotype in life (Figure 145): The holotype has a grey olive dorsal coloration, with numerous yellow to orange spots. The venter is white anteriorly and translucent posteriorly. The iris is silvery white, with a clearly marked black horizontal stripe. Dorsally, at the posterior end of the head, there is a circular, concave area with dark grey collocation. 
Color variation in life (Figure 145): Dorsum can be dull yellowish green, tangerine yellow, brown, or grey olive, always with numerous small and diffuse yellow to orange spots. Anterior half of venter white, posterior portion transparent. Iris might have a slight yellow hue.

Coloration of holotype in ethanol: Dorsal surfaces of head, body, and limbs greyish brown, with small, unpigmented spots. Middorsal dark lavender spot at scapular level. Anterior half of ventral parietal peritoneum white, posterior half cream. White pericardium; translucent peritonea covering digestive tract, liver, kidneys, and gall and urinary bladders.

Color variation in ethanol: Dorsal surfaces of head, body, and limbs vary from greyish brown to lavender with small, unpigmented spots.

Measurements of holotype (mm): Nymphargus colomai sp. nov., adult male, QCAZ 41590: $\mathrm{SVL}=25.0$, head length $=8.1$, head width $=8.3$, snout length $=3.3$, IOD $=2.6$, upper eyelid width $=2.5$, eye diameter $=3.3$, tympanum diameter $=0.9$, tympanum-eye distance $=1.7$, femur $=13.1$, tibia $=$ 14.2, foot length $=11.5$, hand length $=5.7$, disc of Finger III width $=1.6$, disc of Toe IV width $=1.5$.

Biology and ecology: Nymphargus colomai sp. nov. is active during the night. All individuals were found on vegetation 100-170 cm above fast-flowing streams. Males call from the upper surfaces of leaves. Parental care is unknown.

Call: Not described.

Tadpole: Not described.

Distribution (Figure 147): Nymphargus colomai sp. nov. is known only from its type locality at the Cordillera del Cóndor, Zamora Chinchipe province, Ecuador.

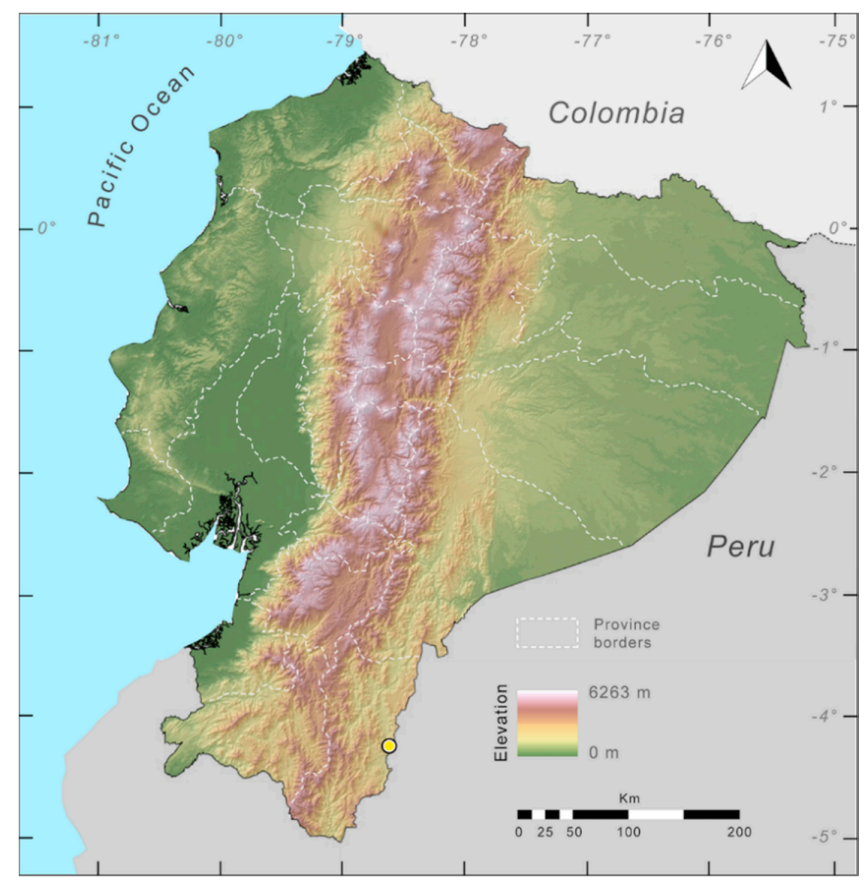

Figure 147. Distribution of Nymphargus colomai sp. nov. in Ecuador (yellow dot).

Conservation status: Following UICN criteria, we consider Nymphargus colomai sp. nov. as Endangered, following IUCN criteria B2a, B2(iii). The main threats for this species are habitat destruction (i.e., cattle, agriculture) and contamination associated with mining.

Evolutionary relationships (Figure 136): N. colomai sp. nov. is inferred as sister to N. mariae.

Taxonomic comments: Nymphargus colomai sp. nov. was previously confused with N. chancas [252], which we restrict to Peru. Preserved specimens are morphologically similar, but in life, several differences are evident (Figures 145 and 146). The two species are not closely related (Figure 136). 
Nymphargus garciae (Ruiz-Carranza and Lynch, 1995 [255]; Figures 148 and 149).

Cochranella garciae Ruiz-Carranza and Lynch, 1995 [255]. Holotype: ICN 11752.

Type locality: "Departamento de Cauca, municipio de Inzá, Km 64-73 carretera Popayán a Inzá, vertiente oriental Cordillera Central, $2^{\circ} 34^{\prime}$ latitud N, $76^{\circ} 4^{\prime}$ W de Greenwich, 2590-2660 m [Colombia]".

Nymphargus garciae-Cisneros-Heredia and McDiarmid, 2007 [17].

Common names: English: García's Glassfrog. Spanish: Rana de Cristal de García.

Etymology: The specific epithet is a patronym for Dr. Evaristo García, author of the pioneer book Los ofidios venenosos del Cauca, published in 1896 [255].

Identification: Nymphargus garciae can be differentiated from other glassfrogs by its moderate body length (SVL 25.9-28.4 mm in adult females, SVL 25.1-29.9 $\mathrm{mm}$ in adult males) ([255], this work), green dorsum usually with dark green to blue spots, and absence of humeral spines. In Ecuador, N. garciae could be confused with Centrolene buckleyi and N. megacheirus. However, C. buckleyi has basal webbing between Fingers III and IV (absent in N. garciae), lacks dark spots on the dorsum (usually present in N. garciae), and males with prominent humeral spines (spines absent in N. garciae). Nymphargus megacheirus has a similar dorsal coloration and hand-webbing pattern as N. garciae, but the two species have allopatric distributions, N. garciae inhabiting higher elevations (1900-2700 m) than N. megacheirus (1300-1740 m). Additionally, N. megacheirus is slightly larger than N. garciae (in N. megacheirus, SVL $26.8-31.5 \mathrm{~mm}$ in adult males, 31.2-32.9 $\mathrm{mm}$ in adult females). Two species endemic to Colombia, N. nephelophilus and N. oreonympha, are extremely similar to N. garciae. Nymphargus oreonympha is reported to have basal webbing between Fingers III and IV (webbing absent in N. garciae), whereas N. nephelophilus has a smooth skin (shagreen in N. garciae) and lacks ulnar and tarsal folds (present in N. garciae). See Remarks.

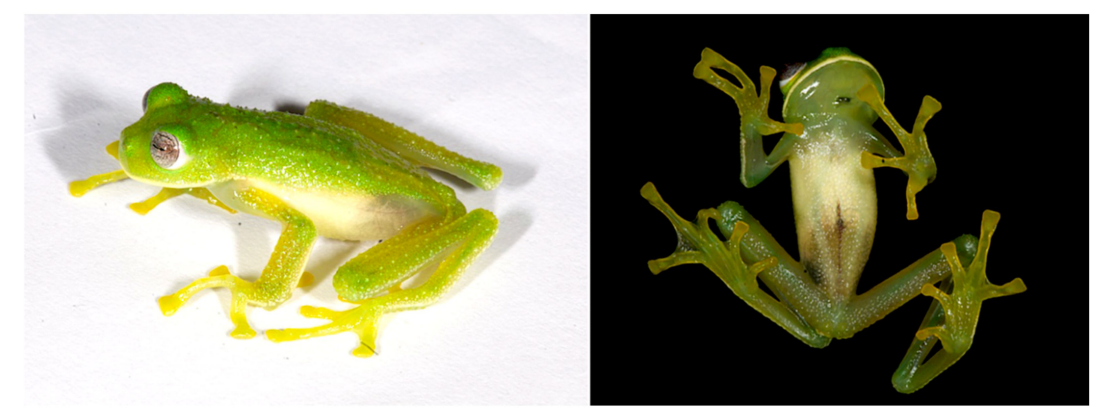

Figure 148. Nymphargus garciae in life from Ecuador, Napo province, trail from Oyacachi to El Chaco, 3012 m, MZUTI 764. Photos by Eduardo Toral.

Diagnosis: (1) Vomerine teeth absent; (2) snout rounded in dorsal aspect, truncated to slightly sloping in lateral profile; (3) tympanum oriented almost vertically, with slight posterior inclination, small in size (tympanum diameter $22.9 \%-30.6 \%$ of eye diameter); tympanic annulus visible except for dorsal border covered by supratympanic fold; tympanic membrane partially pigmented but differentiated from surrounding skin; (4) dorsal surfaces shagreen, with spicules evident in males; (5) pair of enlarged subcloacal warts (Figure 15); (6) anterior half of parietal peritoneum white (condition P02; white pericardium and renal capsules, translucent visceral peritoneum (condition V1); (7) tetralobed liver covered by transparent peritoneum (condition H0); (8) humeral spines absent; (9) no webbing between fingers, although junction of lateral fringes resemble basal webbing; (10) webbing formula on foot: I $\left(2^{-}-2^{+}\right)-\left(2^{+}-2^{2 / 3}\right)$ II $\left(1-1^{3 / 4}\right)-\left(2^{1 / 2}-3^{-}\right)$III $\left(1^{1 / 4}-1^{3 / 4}\right)-\left(2^{1 / 3}-3^{-}\right)$IV $\left(2^{1 / 3}-3^{+}\right)-\left(1^{1 / 4}-2^{+}\right) \mathrm{V} ;$ (11) ulnar and tarsal folds present, enameled; (12) nuptial pad Type I, concealed prepollex; (13) Finger II slightly longer than Finger I (FI/FII = 0.87-0.95); (14) disc of Finger III relatively large (3DW/ED = 0.56-0.77); (15) in life, dorsum green with or without green to blue spots; white upper lip and ulnar and tarsal 
folds; bones green; (16) in preservative, dorsum lavender with or without dark lavender spots; (17) iris greyish white with thin black reticulation; (18) fingers lacking melanophores dorsally; melanophores restricted to proximal dorsal areas of Toes IV and V; (19) males call from upper side of leaves; call unknown; (20) fighting behavior unknown; (21) eggs deposition site unknown; parental care unknown; (22) tadpoles unknown; (23) medium body size; in Ecuador, males SVL 24.9-29.9 $\mathrm{mm}(\bar{X}=26.7 \pm 1.723$; $n=7)$; in Colombia, males SVL 25.1-27.7 mm ( $\bar{X}=26.3 \pm 0.745 ; n=15)$, females SVL 25.9-28.4 mm $(n=3)$.

Color in life (Figure 148): Dorsum dark green with cream tubercles and dark green to blue spots; hands and feet yellowish green. Glandular pericloacal region white. Pericardium and anterior half of ventral parietal peritoneum white; translucent visceral peritonea. Based on observations on preserved specimens, we assume that part of the type series of Nymphargus garciae (ICN 11743,11759) was uniform green in life, corresponding to the uniform lavender coloration in ethanol. Some of the photographs of Ecuadorian individuals of $N$. garciae show a uniform green dorsal coloration.

Color in ethanol: Dorsal surfaces lavender with or without small dark spots; spicules resemble minute white spots in males. White upper lip; tympanic membrane pigmented with purple specks. Cloacal region with white warts. Dorsally, fingers and toes mostly unpigmented, but some pigmentation visible on proximal half of Toes IV and V. White parietal peritoneum covering anterior half of venter; silvery-white pericardium; transparent peritoneum covering liver and urinary bladder; gastrointestinal peritoneum translucent; renal capsules white with minute unpigmented spots, as those in N. wileyi ([20]: Figure 12). Internal traits based on a dissected male (ICN 11759).

Biology and ecology: Adults of Nymphargus garciae were found on vegetation and rocks along streams; one gravid female (ICN 7495) had numerous eggs, which had a dark brown animal and a cream vegetal pole [255]. Parental care is unknown.

Call: Not described.

Tadpole: Not described.

Distribution (Figure 149): Nymphargus garciae is known from localities on the eastern slope of the Cordillera Central at elevations of $1900-2700 \mathrm{~m}$ in Colombia $[101,255]$, and from the Cordillera Oriental of the Ecuadorian Andes at 2550-3012 m. In Ecuador, this species is found in the Eastern Montane Forest ecoregion.

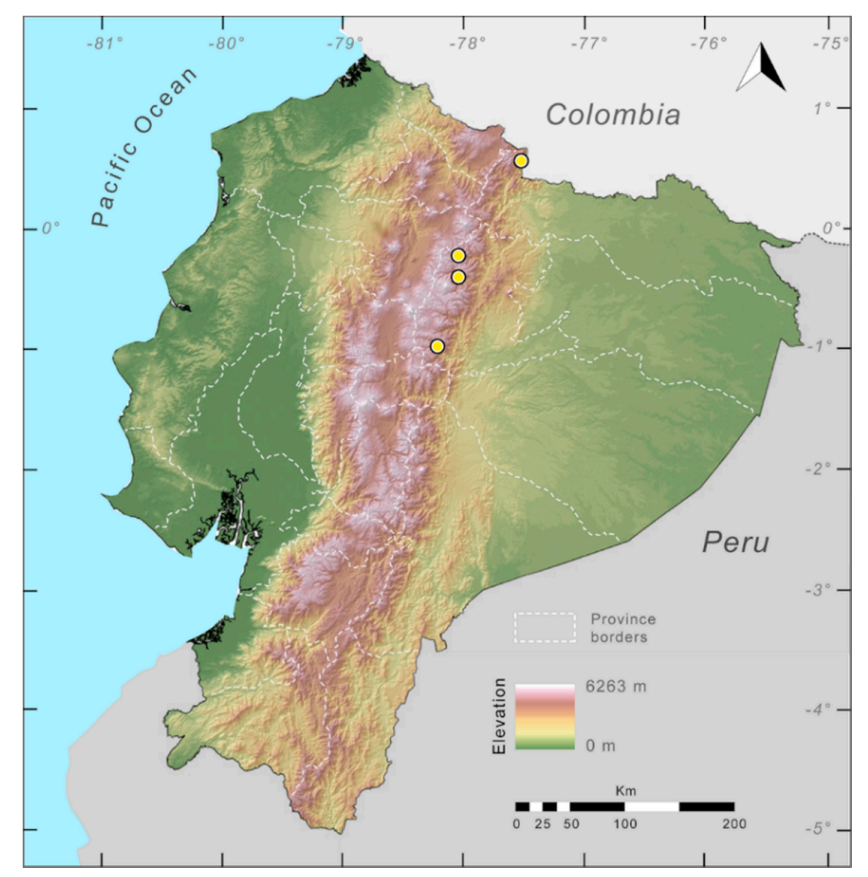

Figure 149. Distribution of Nymphargus garciae in Ecuador (yellow dots). 
Conservation status: Nymphargus garciae is classified as Vulnerable by the IUCN [256]. We consider the current conservation status justified.

Evolutionary relationships (Figure 136): N. garciae is the sister species to N. vicenteruedai.

Remarks: Given the morphological similarities between Nymphargus garciae, N. nephelophilus, and $N$. oreonympha, it is possible that they are actually one species with geographic variation.

Specimens examined: Nymphargus garciae: Ecuador: Provincia de Napo: $11 \mathrm{~km}$ ESE Papallacta $\left(0.38694^{\circ} \mathrm{S}, 78.05694^{\circ} \mathrm{W} ; 2660 \mathrm{~m}\right), \mathrm{KU}$ 164658-62; $60 \mathrm{~km}$ E San Miguel de Salcedo $\left(0.96667^{\circ} \mathrm{S}, 7^{\circ} .21667^{\circ}\right.$; $2550 \mathrm{~m})$, KU 202793; trail from Oyacachi to El Chaco $\left(0.21891^{\circ} \mathrm{S}, 78.04442^{\circ}\right.$; $\left.3012 \mathrm{~m}\right)$, MZUTI 764. Provincia de Sucumbios: 18 km E Santa Bárbara $\left(0.575^{\circ} \mathrm{N}, 77.51138^{\circ} \mathrm{W}\right), \mathrm{KU} 202796$.

Nymphargus grandisonae (Cochran and Goin, 1970 [96]; Figures 150-153).

Centrolenella grandisonae Cochran and Goin, 1970 [96]. Holotype: BM 1910.7.11.68. Type locality: "Pueblo Rico, (Departamento) Caldas, southwestern Colombia, 5000 feet." Centrolene grandisonae-Ruiz-Carranza and Lynch, 1991 [6].

Nymphargus grandisonae-Guayasamin, Castroviejo-Fisher, Trueb, Ayarzagüena, Rada, and Vilà, 2009 [1].

Common names: English: Red-spotted Glassfrog, Measles' Glassfrog, Grandison's Glassfrog. Spanish: Rana de Cristal Sarampiona, Rana de Cristal de Grandison.

Etymology: The specific epithet is a patronym for Alice G. C. Grandison, former curator of the British Museum [96].

Identification: Nymphargus grandisonae is unique by having a green dorsum with small bright red spots (Figure 150). Another diagnostic trait is the presence of a white urinary bladder, a characteristic otherwise known only in glassfrogs from the Atlantic forest of Brazil and Argentina.

A

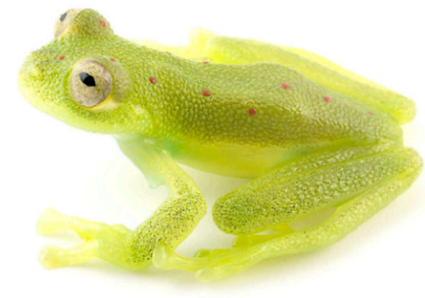

C

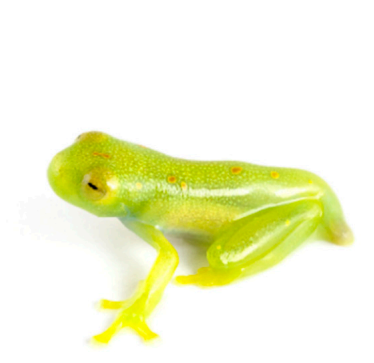

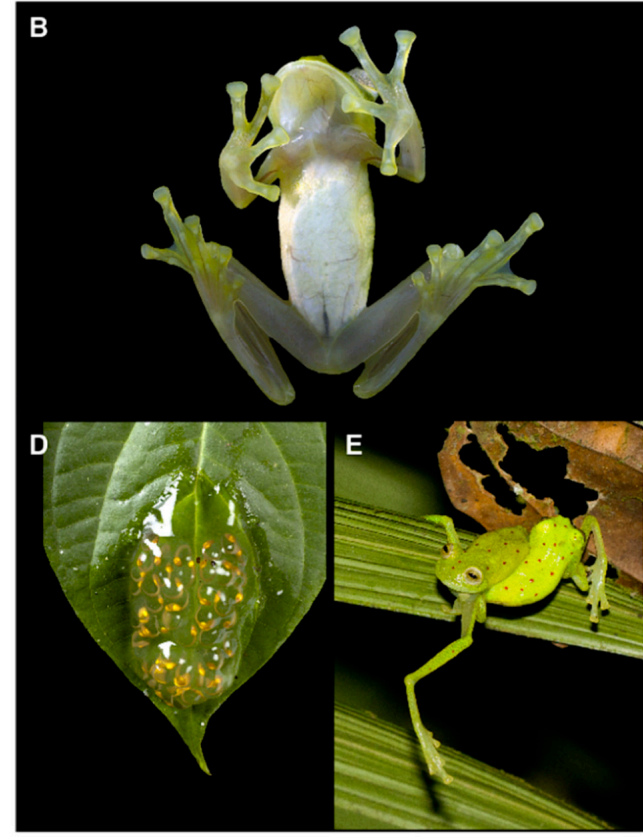

Figure 150. Nymphargus grandisonae in life. (A) Adult male, QCAZ 40001. (B) Adult female, ventral view, QCAZ 32282. (C) Metamorph. (D) Egg clutch, QCAZ 40004. (E) Fight between males. Photos by: (A,C,D) Luis A. Coloma, (B) Martín Bustamante, (E) Carl R. Hutter. 
Diagnosis: (1) Dentigerous process of vomer usually bearing teeth, each process with zero to seven teeth; (2) snout round in dorsal view, truncated in lateral profile (Figure 151); (3) tympanum partially hidden under skin, oriented almost vertically, its diameter $27.0 \%-34.5 \%$ of eye diameter; supratympanic fold moderate; tympanic membrane pigmented, barely differentiated from surrounding skin; (4) dorsal surfaces of males and females finely pustular, minute spicules evident only in males; (5) pair of enlarged subcloacal warts; (6) white iridophores covering all or most of ventral parietal peritoneum (condition P4); white pericardium; translucent peritoneum covering intestines, stomach, testes, and gall bladder; kidneys dorsally and laterally covered with white lining; urinary bladder completely covered with white iridophores (condition V4); (7) liver tetralobed, covered by transparent peritoneum (condition H0); (8) in males, humeral spines present, small; (9) webbing absent between Fingers I, II, and III; moderate webbing between Fingers III and IV; webbing formula III $\left(2^{1 / 3}-2^{1 / 2}\right)-\left(2-2^{1 / 4}\right)$ IV (Figure 151); (10) webbing formula on foot, I $\left(1-1^{3 / 4}\right)-\left(2-2^{1 / 4}\right)$ II $\left(1-1^{1 / 2}\right)-\left(2-2^{1 / 2}\right)$ III $\left(1-1^{1 / 2}\right)-\left(2-2^{1 / 4}\right)$ IV $\left(2-2^{1 / 3}\right)-\left(1-1^{1 / 2}\right) \mathrm{V}$; (11) ulnar fold low, white; inner tarsal fold low, short; outer tarsal fold absent or low and inconspicuous; (12) concealed prepollex; in males, nuptial pad Type I; (13) Finger I about same length as Finger II (Finger I 92.0\%-102.2\% of Finger II); (14) disc of Finger III of moderate width, about $55.2 \%-64.0 \%$ of eye diameter; (15) in life, dorsum green with small red spots; upper lip white; bones green; (16) in preservative, dorsal surfaces lavender with cream white spots; (19) males call from upper sides of leaves near streams; advertisement call formed by a single note, note duration 0.056-0.158 s, 18-22 pulses per note, dominant frequency at 3100-4048 Hz; (20) fighting behavior variable (see Biology and ecology section); (21) females deposit eggs on upper side of leaves near streams; short-term maternal care present; parental care by males absent; (22) tadpoles with M-shaped upper jaw sheath, small gap in row A-2, and non-emarginate oral disc; (23) medium body size; males, SVL 25.1-29.3 mm ( $\bar{X}=27.2, n=44)$; females, SVL 28.9-30.7 mm $(\bar{X}=29.8, n=4)$.

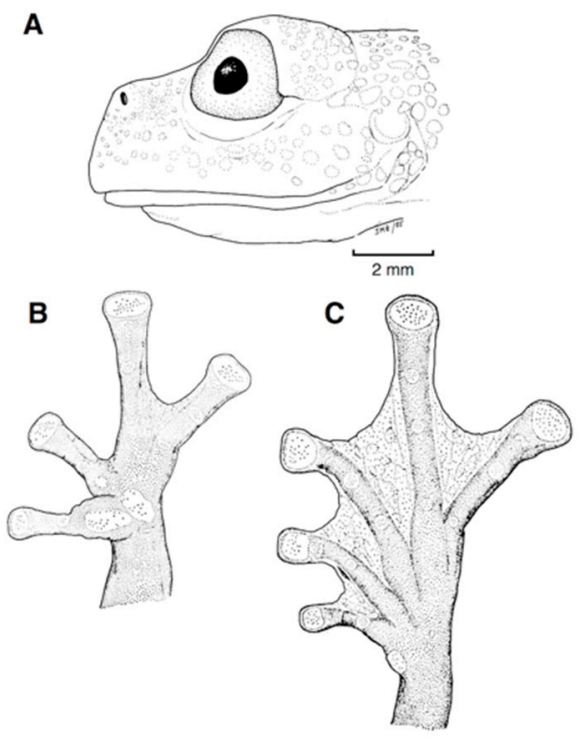

Figure 151. Nymphargus grandisonae. (A) Head in lateral view, KU 164688, drawing by Juan M. Guayasamin. (B) Hand in ventral view, KU 164688. (C) Foot in ventral view, KU 118047. (B,C) Modified from Lynch and Duellman [22], not to scale.

Color in life (Figure 150): Dorsum green with small red spots; throat pale green; margin of upper lip white; flanks and venter white; iris yellowish grey; bones green; peritonea on liver and digestive tract lacking iridophores.

Color in ethanol: Dorsal surfaces of head and body lavender with creamy-white spots; flanks white. White parietal peritoneum covering all or most of venter; pericardium white; translucent peritoneum covering liver, intestines, and stomach; kidneys dorsally and laterally covered with white iridophores; white urinary bladder. 
Biology and ecology: Nymphargus grandisonae is a nocturnal and epiphyllous glassfrog that prefers riparian vegetation in evergreen and cloud forests. The species is active on vegetation near streams in primary and secondary forest, and on shrubs along the borders of pastures [51,87]. Nymphargus grandisonae is a highly territorial species, with males having site fidelity for prolonged periods of time [51]. Also, males have frequent fights and complex combat behaviors (Figure 6), including the following types: (1) Dangling amplexus-like; (2) dangling venter to venter; (3) amplexus-like; (4) a head to vent wrestle; and (5) reverse dangling amplexus-like. As a consequence of fighting, males usually present injuries produced, likely, by humeral spines (see Hutter et al. [51]; Figure 6). Interspecific combat has also been observed between $N$. aff. grandisonae and Espadarana prosoblepon [257]. Nymphargus grandisonae reproduces in the rainy season (December-April); at this time of the year, males call from the upper sides of leaves. Amplexus occurs within male's territories and egg clutches, containing 30-71 eggs, are deposited on vegetation above streams [51]. At Reserva Las Gralarias, the species has been found at Ballux Creek, Five-frog Creek, Heloderma Creek, Hercules Creek, Chalguayacu River, Kathy's Creek, Lucy's Creek, Waterfall Trail, and Santa Rosa River Trail ([88], this work). Short-term parental care is provided by females; no parental care is provided by males [25].

Call: Hutter et al. [51] presented a detailed description of the advertisement, courtship, territorial, encounter, distress, and release calls of Nymphargus grandisonae. The information of these calls is summarized in Tables 5-7 and Figure 152.

A Interindividual variation

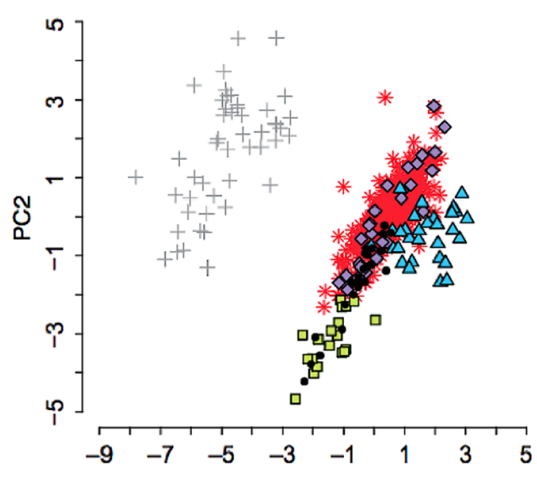

\section{B Intraindividual variation}
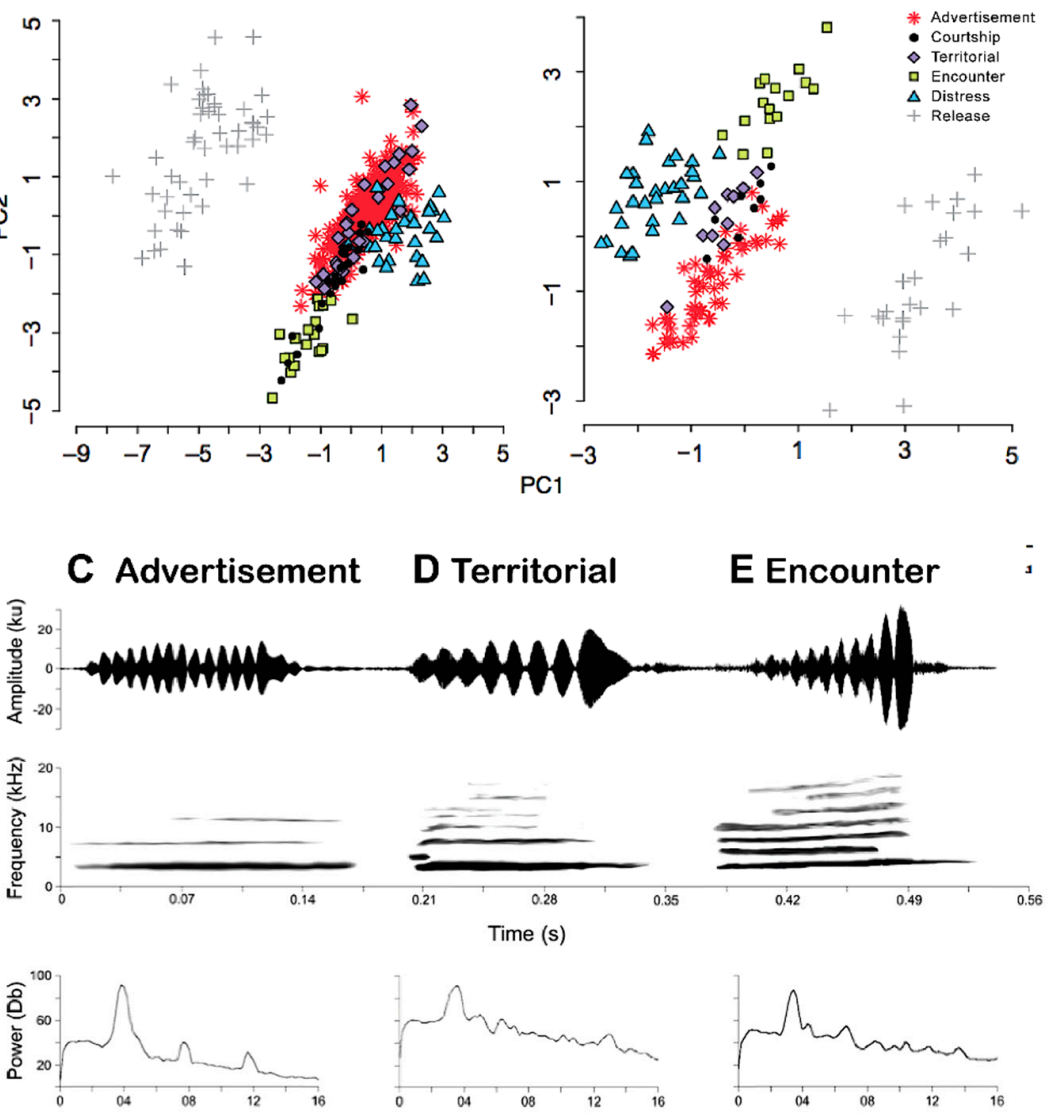
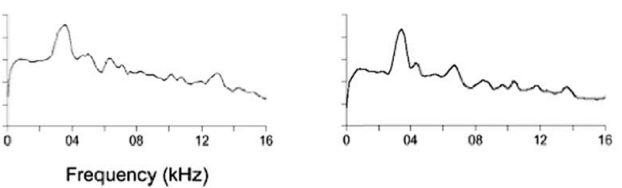

Figure 152. Call types in Nymphargus grandisonae. (A) Principal component analyses (PCA) of call variables for different types of calls of all individuals. (B) PCA plot showing call variation within an individual. (C-E) Oscillogram, spectrogram, and power spectrum of different types of calls. Modified from Hutter et al. [51]. 
Table 5. Call types and associated behaviors described for Nymphargus grandisonae [51]. Definitions follow Bogert [258], Duellman and Trueb [259], and McDiarmid and Adler [238].

\begin{tabular}{cc}
\hline Call Type & Description \\
\hline Advertisement & Call intended to advertise a male's location to other nearby males in addition to attracting females \\
\hline Courtship & Communicative call emitted close-range $(0.5 \mathrm{~m}-1 \mathrm{~m})$ in the presence of a female \\
\hline Territorial & $\begin{array}{c}\text { Modification of the advertisement call; emitted by a male territory holder in response to the presence } \\
\text { of another invading male; invading male may or may not offer a response call; emitted long range }\end{array}$ \\
\hline Encounter & $\begin{array}{c}\text { Further modification of the advertisement call; Produced during close-range antagonist interactions } \\
\text { between males; prior to, or during combat; emitted short range }\end{array}$ \\
\hline Release & Call given during combat, in which a male is clasping another male; accompanied by vibrations \\
\hline Distress & $\begin{array}{c}\text { Call usually emitted in antagonistic inter-specific interactions; in situations of duress. Here, they are } \\
\text { random, loud variable peeps emitted during combat or during the observed "throating grasping } \\
\text { while dangling" behavior. }\end{array}$ \\
\hline
\end{tabular}

Table 6. Description of combat types observed for Nymphargus grandisonae [51].

\begin{tabular}{|c|c|}
\hline Combat Type & Description \\
\hline Venter-to-venter & $\begin{array}{l}\text { Two males dangle from the substrate by their hind limbs, positioned venter-to-venter; may } \\
\text { include males grasping the other around the head }\end{array}$ \\
\hline Head-to-vent wrestle & $\begin{array}{l}\text { One male's head is positioned near the vent of the other; one or both males grasp its } \\
\text { opponent around the waist with its forelimb }\end{array}$ \\
\hline Amplexus-like & One male is position upon the dorsum of another; accompanied by struggling and jumping \\
\hline Dangling amplexus-like & $\begin{array}{l}\text { Two males are dangling facing vent to dorsum, often grasping the head of the other male; } \\
\text { results from tumbling off the substrate in an amplexus-like position }\end{array}$ \\
\hline $\begin{array}{l}\text { Dangling reverse } \\
\text { amplexus-like }\end{array}$ & $\begin{array}{l}\text { Two males are dangling from the substrate with the head of one male positioned near the } \\
\text { vent of another; results from tumbling off the substrate where one male climbs the other }\end{array}$ \\
\hline Limb grasping & $\begin{array}{l}\text { One male immobilizes the other by grasping its limbs; occurred while one male remains } \\
\text { dangling from the substrate while the other attempts to exit onto the substrate surface }\end{array}$ \\
\hline
\end{tabular}

Table 7. Comparisons of call types recorded for Nymphargus grandisonae. Data are the mean \pm standard deviation, followed by the range (modified from Hutter et al. [51]).

\begin{tabular}{|c|c|c|c|c|}
\hline \multirow[t]{2}{*}{ Call Variables } & \multicolumn{4}{|c|}{ Call Type } \\
\hline & Advertisement & Courtship & Territorial & Encounter \\
\hline $\begin{array}{l}n \text {-calls } \\
\text { (individuals) }\end{array}$ & 417 (22) & $27(3)$ & $30(3)$ & $19(2)$ \\
\hline \multirow{2}{*}{ Call duration (s) } & $0.115 \pm 0.018$ & $0.120 \pm 0.023$ & $0.110 \pm 0.015$ & $0.115 \pm 0.016$ \\
\hline & $0.056-0.158$ & $0.082-0.170$ & $0.076-0.141$ & $0.091-0.148$ \\
\hline \multirow{2}{*}{ Call rise time (s) } & $0.061 \pm 0.037$ & $0.069 \pm 0.023$ & $0.065 \pm 0.030$ & $0.066 \pm 0.033$ \\
\hline & $0.003-0.482$ & $0.022-0.113$ & $0.010-0.109$ & $0.004-0.109$ \\
\hline \multirow{2}{*}{ Pulse rate (/s) } & $143.2 \pm 18.8$ & $140.2 \pm 12.1$ & $137.3 \pm 17.1$ & $131.4 \pm 12.3$ \\
\hline & 107.9-320.8 & 111.8-168.8 & 105.3-190.9 & 115.7-169.8 \\
\hline \multirow{2}{*}{$\begin{array}{c}\text { Dominant } \\
\text { frequency }(\mathrm{Hz})\end{array}$} & $3588 \pm 189.6$ & $3541 \pm 206.0$ & $3353 \pm 101.0$ & $3441 \pm 142.0$ \\
\hline & $3101-4048.2$ & $3187-3876$ & $3101-3445.3$ & $3187-3618$ \\
\hline \multirow{2}{*}{$\begin{array}{c}\text { Frequency } \\
\text { modulation }(\mathrm{Hz})\end{array}$} & $142 \pm 110.4$ & $469 \pm 198.9$ & $213 \pm 116.9$ & $639 \pm 135.6$ \\
\hline & $0-517$ & $258-861$ & $0-430$ & $345-861$ \\
\hline \multirow{2}{*}{$\begin{array}{l}\text { Lower dominant } \\
\text { frequency }(\mathrm{Hz})\end{array}$} & $3159 \pm 185$ & $3076 \pm 218.7$ & $2959 \pm 118.1$ & $2950 \pm 117.2$ \\
\hline & $2694-3645$ & $2615-3407$ & $2700-3109$ & 2700-3109 \\
\hline \multirow{2}{*}{$\begin{array}{l}\text { Higher dominant } \\
\text { frequency }(\mathrm{Hz})\end{array}$} & $4039 \pm 210.3$ & $4003 \pm 197.3$ & $3736 \pm 136.4$ & $3832 \pm 165.7$ \\
\hline & $3442-4651$ & $3721-4372$ & $3527-4000$ & $3527-4070$ \\
\hline \multirow{2}{*}{ First harmonic $(\mathrm{Hz})$} & $7180 \pm 409.1$ & $7057 \pm 377.5$ & $6524 \pm 296.0$ & $6700 \pm 234.3$ \\
\hline & $5857-8613$ & $6503-7752$ & $6029-7149$ & $6202-7020$ \\
\hline
\end{tabular}


Tadpole: The tadpole of Nymphargus grandisonae was described by Ospina-Sarria et al. [260]. Characteristic traits include M-shaped upper jaw sheath, small gap in row A-2, and a non-emarginated oral disc. In life, tadpoles (Gosner stage 36) exhibit a cream coloration; hyobranchial apparatus and heart are pinkish. Caudal musculature is reddish cream; caudal and ventral fins are translucent, with small darks spots at the distal end of the tail.

Distribution (Figure 153): Nymphargus grandisonae occurs on the western slopes of the Cordillera Occidental and Cordillera Central in Colombia, from Departamento de Antioquia, south to the Pacific versant of the Andes of north and central Ecuador [51,87,96,127,261,262]. In Ecuador, N. grandisonae has been found in the provinces of Carchi, Cotopaxi, Pichincha, El Oro, and Santo Domingo de los Tsáchilas, at elevations between 1140-2150 m (Specimens Examined). In Ecuador, the potential distribution of the species is $8087 \mathrm{~km}^{2}$, mostly within the Western Montane Forest ecoregion, but also including the Deciduous and Western Foothill ecoregions.

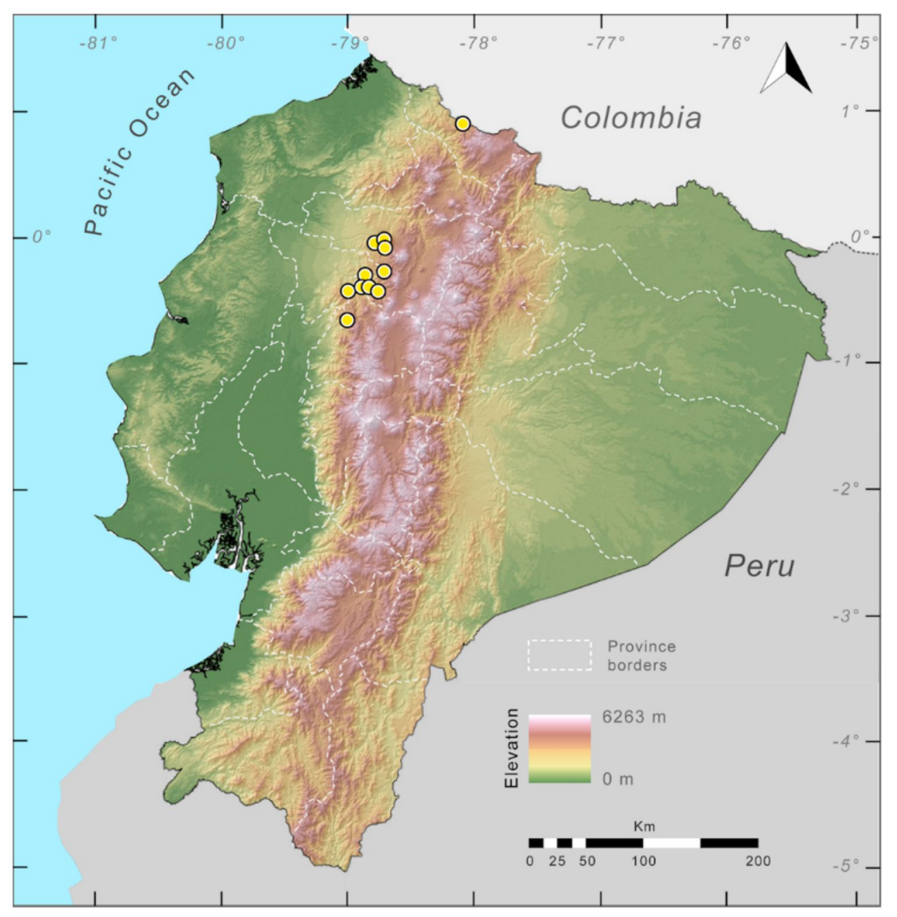

Figure 153. Distribution of Nymphargus grandisonae in Ecuador (yellow dots).

Conservation status: Nymphargus grandisonae is listed as a Least Concern species by the IUCN [261] and Arteaga et al. [87]. The species tolerates a certain level of forest disturbance. In Ecuador, there are several recent reports of N. grandisonae in Chiriboga, Reserva Río Guajalito, Reserva Las Gralarias, Tandayapa, Tandapi, and Reserva Otonga. At Reserva Las Gralarias, this glassfrog is infected by the chytrid fungus Batrachochytrium dendrobatidis, but populations have not shown evidence of drastic declines and the species is fairly common in the area [92]. Experimental studies have shown that tadpoles of $N$. grandisonae are susceptible to introduced trout, by having a higher mortality and changing its morphology [123]. We consider that the Least Concern conservation status is adequate.

Evolutionary relationships (Figure 136): Nymphargus grandisonae is sister to a clade formed by N. mariae and N. colomai sp. nov.

Taxonomic remarks: The name "Centrolenella grandisonae" was misapplied by Lynch and Duellman [22], who confused N. grandisonae with Centrolene lynchi. Duellman [127] provided a detailed description of these two species. There are reports [257] of N. grandisonae at Reserva Buenaventura (El Oro province, Ecuador) that, most likely, represent a new species (Paul Szekely, Diego F. Cisneros-Heredia, pers. comm.) 
Specimens examined: Nymphargus grandisonae: Ecuador: Provincia de Carchi: Quebrada Naranjo, near Maldonado (0.9 N, $78.1 \mathrm{~W} ; 1410 \mathrm{~m})$, KU 178168-69. Provincia de Cotopaxi: Reserva Otonga (0.4189 S, $79.004 \mathrm{~W} ; 1800 \mathrm{~m})$, QCAZ 20718, 20725, 11683; $18.2 \mathrm{~km}$ on the Quillotuña-Pucayacu road (0.6784 S, 79.01564 W), QCAZ 40388. Provincia de Pichincha: $3.5 \mathrm{~km} \mathrm{NE}$ of Mindo (0.0322 S, $78.761 \mathrm{~W}, 1340 \mathrm{~m})$, KU 164686-90; Quebrada Zapadores, 5 km ESE of Chiriboga on Chiriboga-Quito road (0.2375 S, 78.735278 W; 2010 m), QCAZ 16288; near Tandapi (0.4164 S, 78.7989 W; 1520 m), KU 180319-22; 5 km Won the Tandapi-Atenas road (0.3954 S, 78.7989 W; ca. 1700 m), QCAZ 14292-93, 17744, 17753-58; 25.7 km ENE La Palma on La Palma-Chiriboga road, $1820 \mathrm{~m}$, MCZ 93587; 2 km E Tandapi, (0.4258 S, 78.7853 W; 1550 m), MCZ 93023-26, 97848-51, USNM 211211; 1 km SW Tandayapa (0.033 S, 78.7667; 1640 m), MCZ 97847, USNM 211214; 2.9 km SW Tandayapa on Tandayapa-Mindo road (0.05 S, 78.783 W; $1820 \mathrm{~m})$, USNM 211212-13; $5.1 \mathrm{~km}$ SE Tandayapa on Tandayapa-Nono road (0.033 S, $78.7167 \mathrm{~W} ; 1850 \mathrm{~m})$, USNM 211215; Reserva Las Gralarias, Five-frog Creek (0.03098 S, 78.70853 W; 2150 m), MZUTI 430-31. Provincia de Santo Domingo de los Tsáchilas: 4 km NE Dos Ríos (0.30278 S, 78.8678 W; $1140 \mathrm{~m}$ ), KU 164670-85; $1 \mathrm{~km}$ W of Río Faisanes and its intersection with Chiriboga-La Palma road (0.3035 S, 78.869 W), QCAZ 15364.

Localities from the literature: Nymphargus grandisonae: Colombia: Serranía de los Paraguas (Boquerón; 04 $44.2^{\prime} \mathrm{N}, 76^{\circ} 18.3^{\prime} \mathrm{W}, 2000 \mathrm{~m}$ ) [260]. Ecuador:

Nymphargus griffithsi (Goin, 1961 [97]; Figures 154-157).

Cochranella griffithsi Goin, 1961 [97]. Holotype: BM 1940.2.20.4.

Type locality: "Río Saloya, Ecuador, 4000 feet".

Centrolenella griffithsi-Goin, 1964 [187].

Cochranella griffithsi-Ruiz-Carranza and Lynch, 1991 [6].

Nymphargus griffithsi_Cisneros-Heredia and McDiarmid, 2007 [17].

Common names: English: Griffiths' Glassfrog. Spanish: Rana de Cristal de Griffiths.

Etymology: The specific epithet honors Dr. Ivor Griffiths, of Birkbeck College, London, in recognition of his contributions to the understanding of relationships among frogs [97].

Identification: Among glassfrogs found on the Pacific slope of the Andes, Nymphargus griffithsi can be distinguished by having a uniformly green dorsum with small dark flecks (Figure 154), and by lacking webbing between fingers. The species also lacks humeral spines, although enlarged humeral crests are apparent in some specimens (Figure 155). Only two species, N. buenaventura, a species restricted to southwestern Ecuador (Reserva Buenaventura, Provincia de El Oro), and N. lasgralarias, from Reserva Las Gralarias (Pichincha Province), can be confused with N. griffithsi, and no distinctive morphological traits distinguish among these species. However, N. buenaventura is slightly smaller and has a green dorsum with yellow spots, whereas populations of $N$. griffithsi lack these yellow spots and have dark flecks on the dorsum (see Taxonomic Remarks). The most reliable traits to differentiate between $N$. lasgralarias and $N$. griffithsi are the calls; $N$. griffithsi produces a single tonal or multi-pulsed (i.e., two or more pulses) call, while the calls of N. lasgralarias are always pulsed. Also, Nymphargus griffithsi emits its advertisement call as a single note, whereas N. lasgralarias emits its calls singly or in a series. In addition, $N$. lasgralarias has shorter call duration than $N$. griffithsi (call duration in $N$. lasgralarias $=0.016-0.044 \mathrm{~s}$; call duration in $N$. griffithsi $=0.103-0.148 \mathrm{~s}$ ) [88]

Diagnosis: (1) Vomers lacking teeth; (2) snout truncated in dorsal view and truncated to protruding in profile; (3) lower half of the tympanic annulus evident, oriented dorsolaterally with dorsoventral inclination; tympanic membrane pigmented as surrounding skin; supratympanic fold absent or very weak; (4) dorsal skin slightly shagreen; (5) pair of enlarged subcloacal warts; (6) upper half of ventral parietal peritoneum white, posterior half transparent (condition P2); white pericardium, all 
other peritonea clear (condition V1); (7) liver tetralobed; hepatic peritoneum transparent (condition H0); (8) humeral spines absent, although enlarged humeral crests are apparent in some specimens (Figure 155); (9) hand webbing absent; (10) foot about two-thirds webbed: I $\left(2^{-}-2^{+}\right)-\left(2^{+}-2^{1 / 4}\right)$ II $\left(1^{+}-1^{2 / 3}\right)-\left(2^{1 / 2}-3^{-}\right)$III $\left(1^{1 / 2}-1^{2 / 3}\right)-\left(2^{1 / 3}-3^{-}\right)$IV $\left(2^{1 / 3}-3^{-}\right)-\left(1^{1 / 2}-2^{-}\right)$V (Figure 155); (11) ulnar and tarsal folds enameled and low; (12) concealed prepollex; nuptial pad Type I in adult males; (13) Finger I shorter than Finger II; (14) disc of Finger III 20.5\%-26.5\% of eye diameter; (15) in life, dorsum varies from uniform green to green with small dark flecks; bones green; (16) in ethanol, dorsal surfaces lavender with small dark marks; (17) iris background white to cream beige with brown to black punctuations; (18) fingers and toes lacking melanophores, except some on Toes IV and V; (19) males call from the upper side of leaves overhanging streams; call tonal and composed by single note with a duration of $0.103-0.148 \mathrm{~s}$, and a dominant frequency at 3790-4307 Hz; (20) males show dangling fighting behavior; (21) eggs deposited on tips of leaves overhanging streams; short-term maternal care present; parental care by males absent; (22) tadpoles unknown; (23) small body size; in adult males, SVL 22.5-24.2 mm ( $\bar{X}=23.0 \pm 0.7, n=5)$; SVL adult females unknown.

Color in life (Figure 154): Dorsum varies from uniformly green to green with small dark flecks. Ventral surfaces greenish white. Bones green. Iris from white to cream beige, with brown to black punctuations forming thin reticulation; in some individuals, a yellow hue is visible around pupil.

\section{N. griffithsi}

A

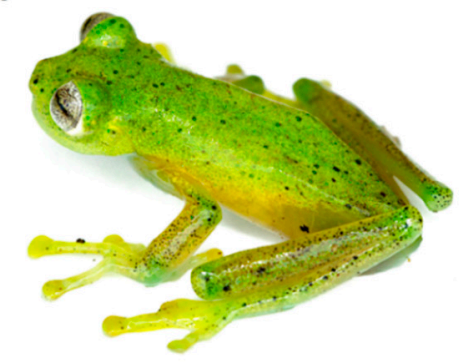

B

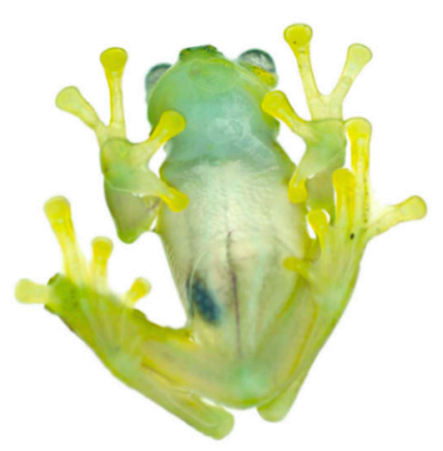

\section{N. lasgralarias}

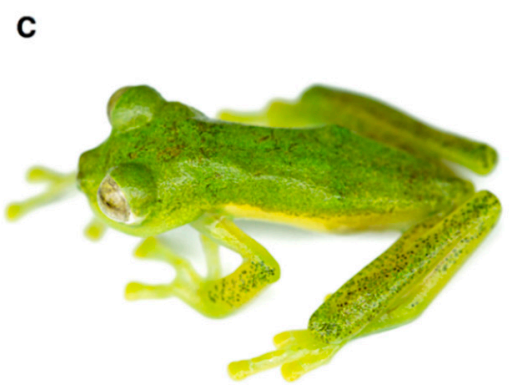

D

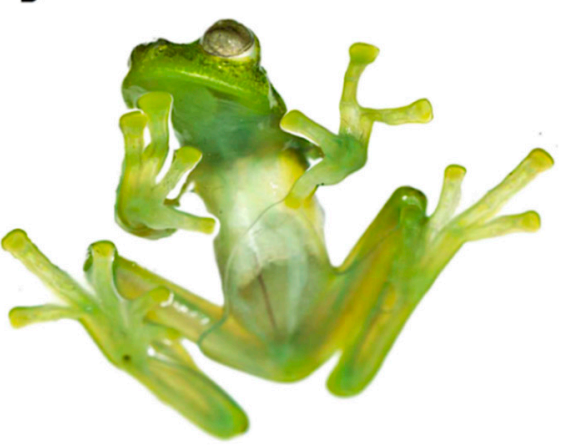

Figure 154. (A,B) Nymphargus griffithisi in life, MZUTI 099. (C,D) Nymphargus lasgralarias in life, MZUTI 094. Photos of both species from Reserva Las Gralarias, 2175-2200 m, Pichincha province, Ecuador. Photos by Carl R. Hutter. 


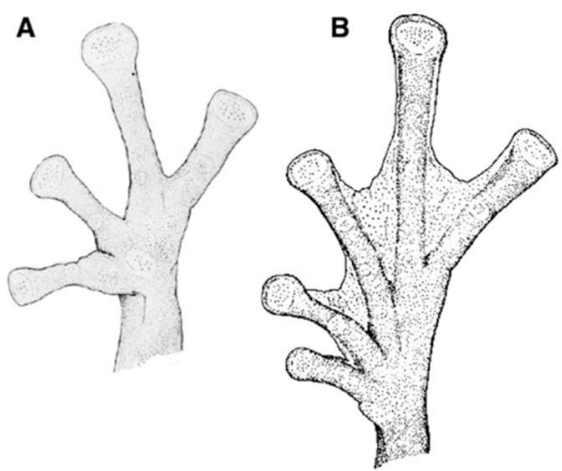

C
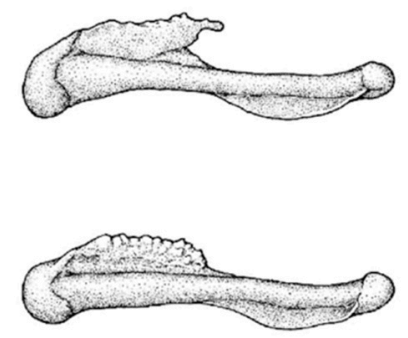

Figure 155. Nymphargus griffithisi. (A) Hand in ventral view, KU 118040. (B) Foot in ventral view, KU 118040. (C) Ventral humeral crests ((Top): KU 288992; (Bottom): KU 188148). (A,B) Modified from Lynch and Duellman [22]. (C) Modified from Guayasamin et al. [1].

Color in ethanol: Dorsal surfaces lavender with small dark marks. Anterior half to two-thirds of parietal peritoneum white, posterior part translucent; pericardium white; most visceral peritonea clear, except for white peritoneum covering renal capsules.

Biology and ecology: During the rainy season (December-April), at night, Nymphargus griffithsi is active on vegetation $50-900 \mathrm{~cm}$ above streams, waterfalls, and small rivers in primary and secondary cloud forests [5,87]. Reproductive activity peaks in February-April. Males are highly territorial and engage in aggressive interactions with conspecifics; when fighting, males have been observed dangling upside-down venter to venter holding onto a branch with their hind legs [5]. Females lay clutches of 14-22 eggs on leaves overhanging fast-flowing water. These later expand into a hanging gelatinous mass upon absorption of water; eventually, tadpoles hatch and fall into the stream below [87]. At Reserva Las Gralarias, N. griffithsi has been observed at Five-frog Creek, Heloderma Creek, Hercules Creek, and Kathy's Creek [88,92]. Short-term parental care is provided by females; no parental care is provided by males [25].

Call (Figure 156): The information presented below is from Hutter and Guayasamin (2012). The call of $N$. griffithsi is a tonal call, produced at a rate of $1.1-1.9$ calls per minute (mean $=1.6 \pm 0.4$ ). The call is composed by a single note with a duration of $0.103-0.148 \mathrm{~s}$ (mean $=0.122 \pm 0.009$ ) and a dominant frequency at $3790-4307 \mathrm{~Hz}($ mean $=4107 \mathrm{~Hz} ; \pm 105.5 \mathrm{~Hz})$.

Tadpole: Not described.

Distribution (Figure 157): Although Nymphargus griffithsi has been reported in Ecuador and Colombia [22], herein we restrict its distribution to Ecuador, specifically, to localities in Pichincha, Santo Domingo de los Tsáchilas, and Cotopaxi provinces, at elevations between $1220-2430 \mathrm{~m}$. Other populations that have been previously identified as $N$. griffithsi require further taxonomic evaluation. 
N. griffithsi
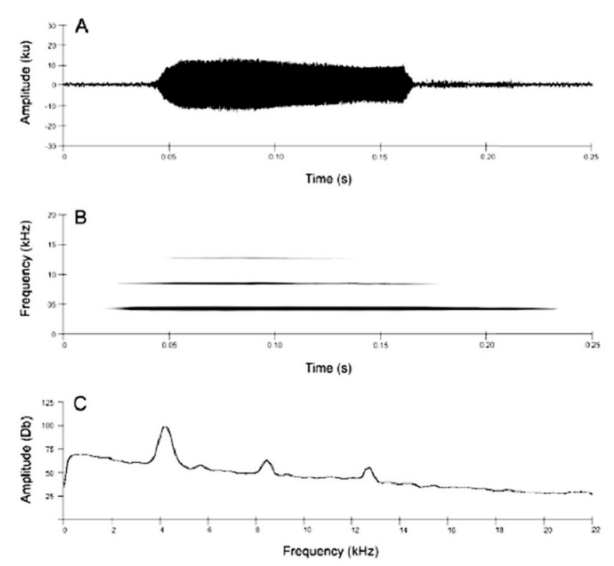

N. lasgralarias
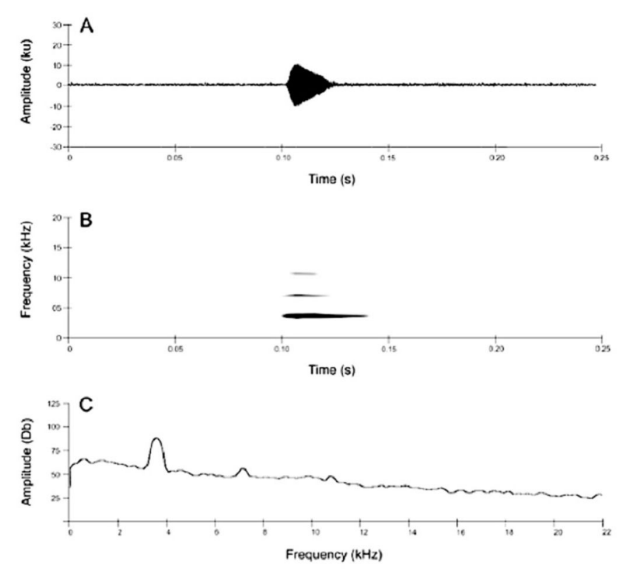

Figure 156. Advertisement call of Nymphargus griffithisi and N. lasgralarias. (A) Oscillogram. (B) Audiospectrogram. (C) Power spectrum. Modified from Hutter and Guayasamin [88].

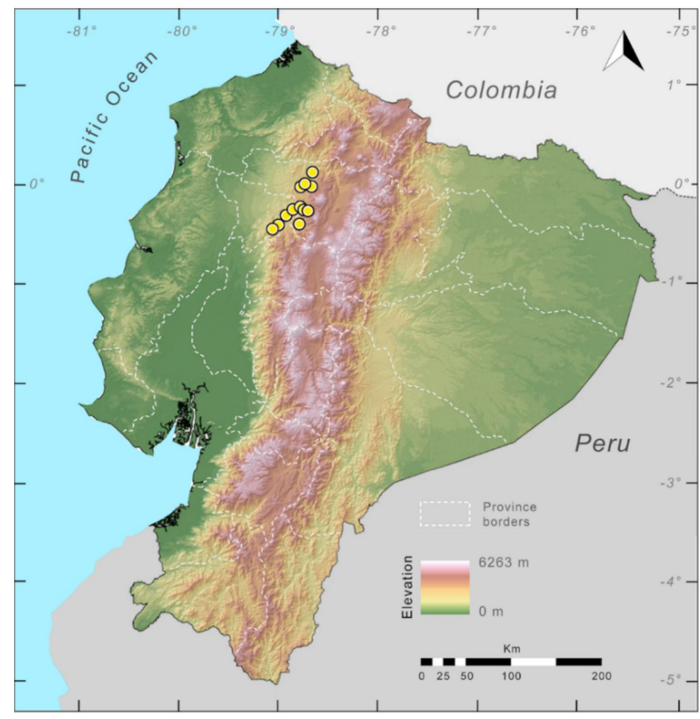

Figure 157. Distribution of Nymphargus griffithsi in Ecuador (yellow dots).

Conservation status: Globally, N. griffithsi is listed by the IUCN as Least Concern [263]. Recent records in Ecuador come from Reserva Las Gralarias, Reserva Río Guajalito, Reserva Otonga, La Favorita Station, and near the town of Chiriboga. At Reserva Las Gralarias, the species is not infected by the chytrid fungus Batrachochytrium dendrobatidis $(n=5)$ [92]. Given the more restricted distribution of the species, N. griffithsi should be considered as Endangered, following IUCN criteria B2a, B2(iii).

Evolutionary relationships (Figure 136): Nymphargus griffithsi and N. lasgralarias are sister taxa.

Taxonomic remarks: Several populations previously assigned to N. griffithsi (see Specimens examined) require further evaluation. Vocalization studies on Colombian populations assigned to N. griffithsi also suggest that several species are concealed under this name [264]. Paratypes of Centrolenella scirtetes seem to correspond to N. griffithsi (see Taxonomic remarks of Centrolene lynchi).

Specimens examined: Nymphargus griffithsi, Ecuador: Provincia de Cotopaxi: $11.5 \mathrm{~km} \mathrm{~W}$ of Pilaló (0.94815 ${ }^{\circ}$ S, $\left.78.989633^{\circ} \mathrm{W} ; 1500 \mathrm{~m}\right)$, QCAZ 34113; Provincia de Pichincha: Río Saloya, $1219 \mathrm{~m}, \mathrm{BMNH}$ 1940.2.20.4 (holotype), BMNH 1940.2.20.3 (paratype); $\mathrm{km} 14$ on the San Juan de Chillogallo-Chiriboga road $\left(0.275895^{\circ} \mathrm{S}, 78.721647^{\circ} \mathrm{W} ; 2120 \mathrm{~m}\right)$, QCAZ $29531 ; \mathrm{km} 16$ on the San Juan de Chillogallo-Chiriboga road $\left(0.278161^{\circ} \mathrm{S}, 78.706067^{\circ} \mathrm{W} ; 2430 \mathrm{~m}\right)$, QCAZ 29524-30; La Victoria $\left(0.16285^{\circ} \mathrm{S}, 77.909667^{\circ} \mathrm{W} ; 2104 \mathrm{~m}\right)$, QCAZ 24801; Tandapi (0.416388 S , $78.7988^{\circ}$ W), QCAZ 351, KU 118009-20; Reserva Las Gralarias “Hercules Giant 


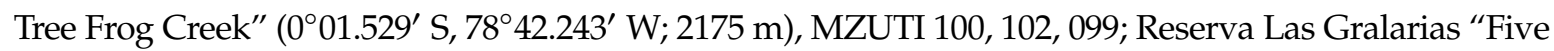
Frog Creek" (001.870' S, 7842.358' W; 2150 m), MZUTI 101; Reserva Las Gralarias "Heloderma Creek" $\left(0^{\circ} 01.245^{\prime} \mathrm{S}, 78^{\circ} 42.370^{\prime} \mathrm{W} ; 2200 \mathrm{~m}\right)$, MZUTI 098; $1 \mathrm{~km}$ SW San Ignacio $\left(0.44861^{\circ} \mathrm{S}, 78.74777^{\circ} \mathrm{W} ; 1920\right.$ $\mathrm{m}), \mathrm{KU}$ 178108-21; $3.5 \mathrm{NE}$ Mindo $\left(0.03222^{\circ} \mathrm{S}, 78.76138^{\circ} \mathrm{W} ; 1340 \mathrm{~m}\right), \mathrm{KU}$ 164564-76; $5 \mathrm{~km}$ ESE Chiriboga $\left(0.245277^{\circ} \mathrm{S}, 78.7261^{\circ} \mathrm{W} ; 2010 \mathrm{~m}\right), \mathrm{KU}$ 164519-37; $5.6 \mathrm{~km}$ SE Tandayapa $\left(0.0333^{\circ} \mathrm{S}, 78.7166^{\circ} \mathrm{W} ; 1910 \mathrm{~m}\right)$, KU 202792. Provincia de Santo Domingo de los Tsáchilas: $14 \mathrm{~km} \mathrm{~W}$ of Chiriboga $\left(0.26527778^{\circ} \mathrm{S}, 78.847778^{\circ} \mathrm{W}\right.$; 1960 m), KU 164544-63; 4 km W Chiriboga ( $\left(0.24277^{\circ} \mathrm{S}, 78.7855^{\circ} ; 2120 \mathrm{~m}\right), \mathrm{KU} 142649$.

Nymphargus aff. griffithsi. Ecuador: Provincia Imbabura: $23.2 \mathrm{~km} \mathrm{~W}$ of Apuela, Cordillera de Intag $\left(0.2666^{\circ} \mathrm{N}, 78.6^{\circ} \mathrm{W} ; 2190 \mathrm{~m}\right), \mathrm{KU} 178122-36$; San Antonio de Cuellaje, Finca de Estuardo Ayala (0.4775 N, 78.56263 W), QCAZ 42164. Provincia de Carchi: Chilma Bajo (0.86472 N, 78.04972 W; $2071 \mathrm{~m})$, QCAZ 40176-77; 9.9. $\mathrm{km}$ E of Maldonado on the Maldonado-Tulcán road $\left(0.83472^{\circ} \mathrm{N}, 78.051388^{\circ} \mathrm{W} ; 2130 \mathrm{~m}\right)$, QCAZ 12572; $\mathrm{km} 5$ on the Chilma Bajo-El Placer road $\left(0.85705^{\circ} \mathrm{N}, 78.032476^{\circ} \mathrm{W} ; 2222 \mathrm{~m}\right)$, QCAZ 39992, 39994; ca. 5 km W La Gruel (0.916667 N, 78.1333 W; 2340 m), KU 202784-91, 202796, 202801.

Nymphargus humboldti new species Guayasamin, Cisneros-Heredia, McDiarmid, Hutter (Figures 158 and 159).

http://zoobank.org/urn:lsid:zoobank.org:act:AD71F7CC-0718-449E-88DC-0A64302D9855.

Common names: English: Humboldt's Glassfrog. Spanish: Rana de cristal de Humboldt.

Etymology: The specific epithet humboldti honors Alexander von Humboldt for his unparalleled contributions to biogeography, integrative perspective of the sciences and arts, humanism, and also for his devotion towards mountains.

Holotype: ZSFQ 0388, adult male, collected from Volcán Sumaco $\left(0.61387^{\circ} \mathrm{S}, 77.590^{\circ} \mathrm{W} ; 1738 \mathrm{~m}\right)$, Napo Province, Ecuador, by Jose Vieira on 11 September 2018.

Paratopotypes: QCAZ 9402, adult male collected by Juan M. Guayasamin on 19 February 1996; QCAZ 41071, 41073-74, 41077-78, 41081-82, 41150-51, 41314-15, adult males and females, collected by Elicio Tapia and Raúl E. Ruíz on 20-30 March 2009.

Paratypes: QCAZ 45712-16, 45730, 47511-14, adult males and females, collected by Elicio Tapia from Río Yana Challuwa Yaku (1.26764 S, 78.04797 W; 1800-2400 m), Reserva Comunitaria Ankaku, Pastaza Province.

Generic placement: The new species is placed in the clade Nymphargus (sensu Guayasamin et al. [1]) based on morphological and molecular data. All species in Nymphargus share an absence of webbing between Fingers I-III and absence or reduced webbing between Fingers III and IV; additionally, males lack humeral spines (except N. grandisonae). Nymphargus humboldti sp. nov. also has these traits. Molecular analyses of mitochondrial genes (12S, 16S, ND1) unambiguously place the new species in the clade Nymphargus (Figure 16).

Identification: Among glassfrogs that inhabit the Amazonian slopes of the Andes and the Amazonian lowlands, Nymphargus humboldti sp. nov. (Figure 158) is distinguished by having a green dorsum with small yellow spots and moderate body size (male SVL 23.3-25.2 mm; female SVL 24.3-25.9 mm), and lacking hand webbing and humeral spines. Nymphargus humboldti sp. nov. is most similar to $N$. siren, which is smaller (SVL in males, 19.8-22.6 mm; in females, 22.5-23.3 mm). Other species with a similar dorsal color pattern include Espadarana audax, Nymphargus cariticommatus, N. siren, Rulyrana flavopunctata, R. mcdiarmidi, and Teratohyla midas. Differences among these species include the presence of hand webbing between Fingers III and IV in E. audax, R. flavopunctata, R. mcdiarmidi, and T. midas (absent in N. humboldti sp. nov.), white digestive tract in T. midas (opaque in N. humboldti sp. nov.), and humeral spine in males in E. audax (absent in N. humboldti sp. nov.). Nymphargus cariticommatus differs by having white renal peritoneum and white esophagus (transparent renal pericardium and 
opaque esophagus in N. humboldti sp. nov.) and less foot webbing. Two additional species endemic to Colombia, N. luminosus and N. spilotus, can be confused with N. humboldti sp. nov. Both species are conspicuously larger than $N$. humboldti sp. nov. ( $N$. luminosus, male SVL = 27.8-30.0 mm, female $\mathrm{SVL}=32.7 \mathrm{~mm}$; N. spilotus, male SVL = 25.3-26.4 mm, female SVL = 27.6-28.5 mm); also, N. luminosus in only found on the Pacific flank of the Andes in Colombia, whereas N. spilotus is only know from its type locality (Rancho Quemado, Corregimiento Florencia, Departamento de Caldas) on the eastern slope of Cordillera Central.

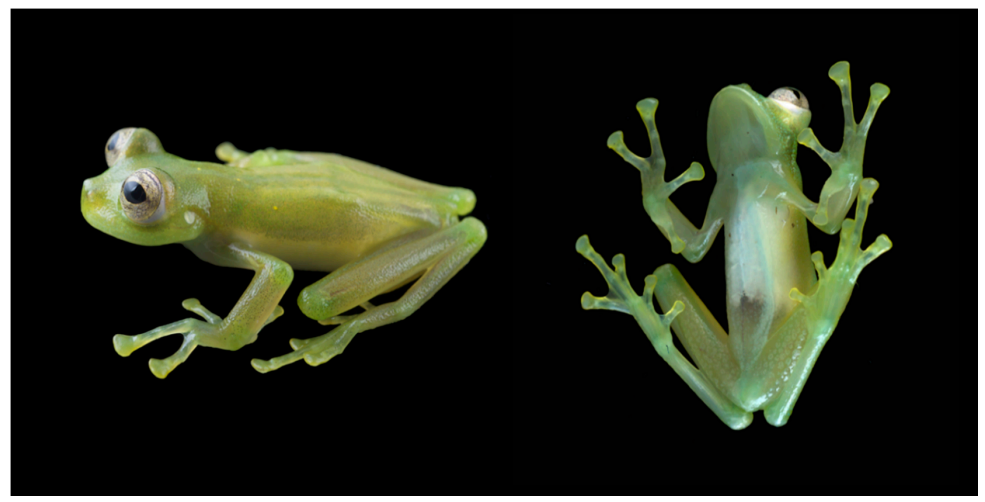

Figure 158. Nymphargus humboldti sp. nov. in life. Male from Río Yana Challuwa, Pastaza province, Ecuador, QCAZ 47514, paratype. Photos by Luis A. Coloma.

Diagnosis: (1) Vomers with edentate dentigerous process; (2) snout truncated to bluntly rounded in lateral profile; truncated in dorsal view; (3) tympanum oriented almost vertically, with slight lateral and posterior inclinations, its diameter about $20 \%-27 \%$ of eye diameter; upper fourth of tympanic annulus obscured by supratympanic fold; tympanic membrane pigmented as surrounding skin; (4) dorsal skin shagreen, with minute spicules in males; (5) venter areolate; pair of enlarged subcloacal warts; (6) white parietal peritoneum covering anterior $50 \%-60 \%$ of venter (condition P2); white pericardium; translucent peritonea covering intestines, stomach, kidneys, gall and urinary bladders (condition V1); (7) liver tetralobed, covered by transparent peritoneum (condition H0); (8) humeral spines absent; (9) webbing absent between inner fingers, absent or basal between Fingers III and IV; webbing formula III $\left(3^{-}-3\right)-\left(2^{2 / 3}-3^{-}\right)$IV; (10) feet about two-thirds webbed; webbing formula: I $\left(2^{-}-2\right)-\left(2^{+}-2^{1 / 4}\right)$ II $\left(1^{+}-1^{1 / 2}\right)-\left(2^{+}-2^{1 / 2}\right)$ III $\left(1^{+}-1^{1 / 4}\right)-\left(2^{1 / 4}-3^{+}\right)$IV $\left(2^{1 / 2}-3^{-}\right)-\left(1^{2 / 3}-2^{-}\right) \mathrm{V} ;(11)$ ulnar and tarsal folds present, low; (12) concealed prepollex; in males, nuptial pad Type I; (13) Finger I about same length as Finger II (Finger I length $94 \%-102 \%$ of Finger II); (14) disc width of Finger III about 50\%-55\% of eye diameter; (15) in life, dorsum green with yellow spots (Figure 158); bones green; (16) in preservative, dorsum lavender with small white spots; (18) melanophores usually lacking from dorsal surfaces of fingers and toes, except for few on Toe V; (19) males call from upper surfaces of leaves; call unknown; (20) fighting behavior unknown; (21) egg deposition site unknown; parental care unknown; (22) tadpoles unknown; (23) small body size; in males, SVL 23.3-25.2 mm $(\bar{X}=24.3 \pm 0.684, n=13)$; in females, SVL 25.5-27.4 mm $(n=3)$.

Description of holotype: Adult male, SVL $24.9 \mathrm{~mm}$. Head slightly wider than long (head length $98 \%$ of head width); snout truncated in dorsal and lateral profiles; canthus rostralis indistinct, slightly concave; loreal region slightly concave; lips slightly flared; nostril protuberant, closer to tip of snout than to eye, directed frontolaterally; internarial area barely depressed. Eyes large, directed anterolaterally at about a $50^{\circ}$ angle; transverse diameter of disc of Finger III 53\% eye diameter. Supratympanic fold low, obscuring upper portion of tympanic annulus; tympanum oriented mostly vertically, but with slight posterolateral inclination; tympanic membrane transparent, its upper half pigmented as surrounding skin. Dentigerous processes of vomer low, situated transversely between choanae, lacking teeth; choanae large, longitudinally rectangular; tongue ovoid, with ventral posterior fourth not attached (free) to floor of mouth, posterior margin notched; vocal slits extending posterolaterally from a point about midway along lateral margin of tongue) to angle of jaws. Humeral spine absent. Low ulnar fold evident on external ventrolateral margin 
of arm; inner ulnar fold absent; relative lengths of fingers: III > IV > II > I; webbing absent between Fingers I, II, and III, basal between Fingers III and IV, webbing formula III $3^{-}-2^{2 / 3}$ IV; discs expanded, nearly elliptical; disc pads nearly triangular in shape; subarticular tubercles small, round, simple; supernumerary tubercles absent; palmar tubercle elliptical, simple; nuptial pad large (Type I), ovoid, granular, extending from ventrolateral base to dorsal surface of Finger I, covering proximal half of Finger I. Length of tibia 58\% SVL; low inner tarsal fold evident; outer tarsal fold absent; two-thirds webbed; webbing formula of foot: I $2-2^{+}$II $1^{+}-2^{1 / 4}$ III $1^{+}-3^{+}$IV $3^{-}-2^{-} \mathrm{V}$; discs on toes round to elliptical; disc on Toe IV narrower than disc on Finger III; disc pads triangular; inner metatarsal tubercle large, ovoid; outer metatarsal tubercle round, barely evident; subarticular tubercles small, round; supernumerary tubercles absent. Skin on dorsal surfaces of head, body, and lateral surface of head and flanks shagreen with numerous minute spinules; throat smooth; belly and lower flanks areolate; cloacal opening directed posteriorly at upper level of thighs; cloacal ornamentation absent. Two enlarged tubercles below the level of vent.

Coloration of the holotype in life (Figure 158): Green dorsum with small yellow spots; upper lip white. Anterior $60 \%$ of venter white, posterior portion transparent. Bones green. Iris greyish cream with slight yellow hue and fine black reticulations; yellow circumpupilary ring.

Coloration of the holotype in ethanol: Dorsal surfaces of head, body, and limbs lavender with small white spots; white upper lip. Anterior $60 \%$ of ventral parietal peritoneum white. Heart covered by white pericardium; translucent peritonea on gall and urinary bladders; iridophores absent from digestive tract, liver, and kidneys.

Measurements of holotype (mm): Nymphargus humboldti sp. nov., adult male, ZSFQ 0388: $\mathrm{SVL}=24.9$, head length $=8.1$, head width $=8.3$, eye-nostril $=1.9$, nostril-snout $=1.1, \mathrm{IOD}=2.6$, upper eyelid width $=2.3$, eye diameter $=3.5$, tympanum diameter $=0.8$, tibia $=14.5$, foot length $=$ 11.5 , radio-ulna length $=5.5$, hand $=8.4$, Finger I length $=4.9$, Finger II length $=5.2$, disc of Finger III width $=0.9$

Biology and ecology: At Río Yana Challuwa Yaku, Nymphargus humboldti sp. nov. was found in sympatry with $N$. anomalus. During the night, males were calling from the upper surfaces of leaves near a fast-flowing stream. Parental care is unknown.

Call: Not described.

Tadpole: Not described.

Distribution (Figure 159): Nymphargus humboldti sp. nov. is known from few localities on the Amazonian slopes of the Ecuadorian Andes at elevations between 1770 and $2400 \mathrm{~m}$.

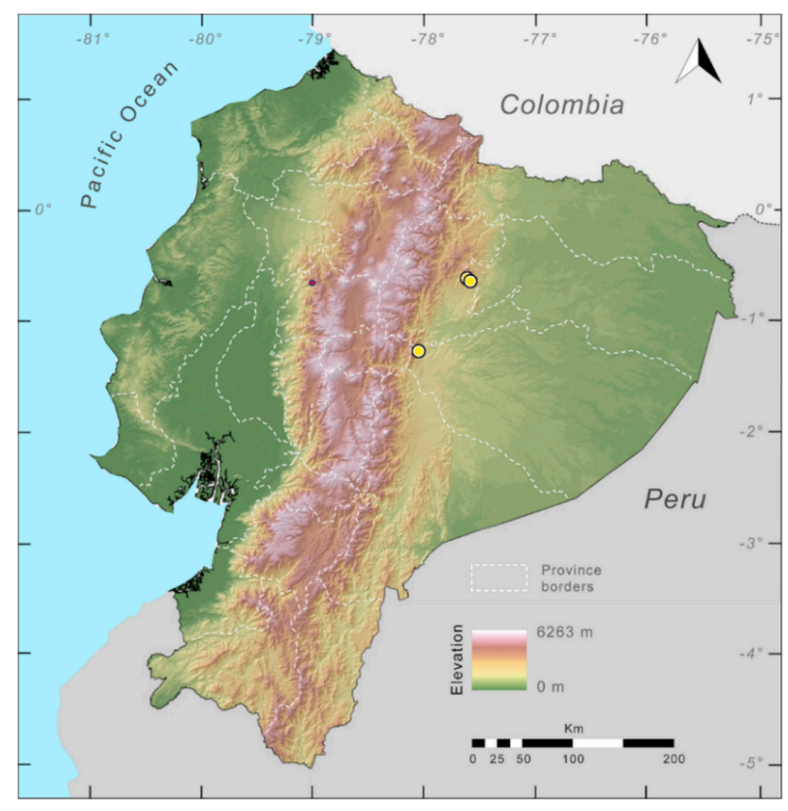

Figure 159. Distribution of Nymphargus humboldti sp. nov. in Ecuador (yellow dots). 
Conservation status: Following IUCN criteria, we suggest placing Nymphargus humboldti sp. nov. in the Data Deficient category.

Evolutionary relationships (Figure 136): Nymphargus humboldti sp. nov. is sister to N. siren.

Nymphargus lasgralarias Hutter and Guayasamin, 2012 [88] (Figures 154 and 160-162).

Nymphargus lasgralarias Hutter and Guayasamin, 2012 [88]. Holotype: MZUTI 096.

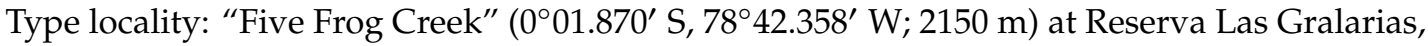

Pichincha province, Ecuador".

Common names: English: Las Gralarias Glassfrog. Spanish: Rana de Cristal de Las Gralarias.

Etymology: The epithet lasgralarias refers to the type locality of the species, Reserva Las Gralarias. The species was dedicated to the reserve and the team of people, led by Dr. Jane Lyons, for their efforts to conserve Ecuadorian cloud forests [88].

Identification: Among Nymphargus species found on the Pacific versant of the Andes of Ecuador, $N$. lasgralarias can only be confused with N. buenaventura and N. griffithsi. Dorsal texture and color pattern readily separate $N$. buenaventura, which, in life, has a light-green dorsum with warts corresponding to pale yellow spots, whereas the dorsum of N. lasgralarias is homogenously green and lacks warts. Additionally, N. buenaventura is smaller (male SVL in N. lasgralarias = 24.6-26.5 $\mathrm{mm}$; male SVL in N. buenaventura $=20.9-22.4 \mathrm{~mm}$ ). Nymphargus lasgralarias is most similar to $N$. griffithsi. The two species differ in the following traits: (i) Dorsal color pattern: Homogenously green in N. lasgralarias; green with very small black spots in N. griffithsi (Figure 154); (ii) body size: Male SVL in $N$. lasgralarias $=24.6-26.5 \mathrm{~mm}$, whereas male SVL in N.griffithsi $=22.5-24.2 \mathrm{~mm}$; and call: Short, pulsed note lasting $0.016-0.044 \mathrm{~s}$ in N. lasgralarias; long tonal note lasting 0.103-0.148 s in N. griffithsi. Two Colombian species from the Pacific slopes of the Andes, N. cristinae [255] and N. prasinus [120], can also be confused with $N$. lasgralarias. Nymphargus lasgralarias is distinguished from N. cristinae by being smaller (male SVL in N. lasgralarias $=24.6-26.5 \mathrm{~mm}$; male SVL in N. cristinae $=26.0-31.1 \mathrm{~mm}$ ), having a snout that is truncated in dorsal view and protruding in lateral view (subacuminate in dorsal view, truncated in lateral view in N. cristinae; see Ruiz-Carranza and Lynch [255]), and lacking palmar supernumerary tubercles (supernumerary small, abundant in N. cristinae). Nymphargus prasinus shares the same color pattern as N. lasgralarias, but is recognized by having a round snout in dorsal view (truncated N. lasgralarias), five to seven teeth on each process of the vomer (teeth absent in N. gralarias), and being considerably larger (male SVL 33.0-34.5 mm; $n=3$ ) [88].

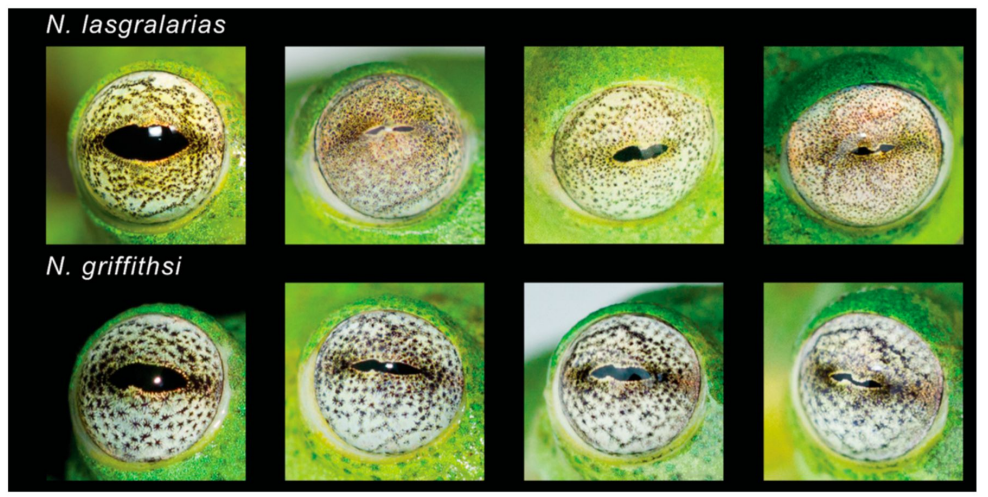

Figure 160. (Top Row): Iris of Nymphargus lasgralarias. (Bottom Row): Iris of N. griffithsi. Modified from Hutter and Guayasamin [88]. 
Characterization. (1) Vomerine teeth absent; (2) snout truncated in dorsal profile, protruding in lateral profile; (3) tympanum small; supratympanic fold present; tympanic membrane translucent, pigmented only on its upper half; (4) skin texture finely shagreen, with microspiculations; (5) ventral skin areolate, with pair of large subcloacal warts; cloaca surrounded by low warts; (6) upper half of ventral parietal peritoneum covered by iridophores (condition P2), all other peritonea translucent, except for thin layer of iridophores covering heart and renal capsules (condition V1); (7) liver lobed, lacking iridophores (condition H0); (8) humeral spines absent; (9) webbing absent between fingers; (10) foot about half webbed; webbing formula: I $\left(2-2^{-}\right)-\left(2^{+}-2^{1 / 2}\right)$ II $\left(2-2^{-}\right)-\left(3^{-}-3\right)$ III $\left(2^{-}-2\right)-\left(3^{-}-3\right)$ IV $\left(3-3^{+}\right)-2$ V; (11) ulnar and tarsal folds low, barely evident; (12) nuptial pad Type I; concealed prepollex; (13) first finger slightly shorter than second; (14) eye diameter larger than width of disc on Finger III; (15) in life: Green dorsum, lacking spots; (16) in preservative: Dorsum pale lavender; (17) iris golden yellow, with numerous small black spots; weakly reticulate; (18) hands and feet yellowish green; melanophores absent from fingers and toes or, when present, restricted to dorsal surfaces of Finger IV and Toes IV and V; (19) males call from upper side of leaves along streams; vocalizations emitted in series of one to five calls; each call pulsed, with a duration of 0.016-0.044 s, and non-modulated dominant frequency at 3618-3963 Hz; (20) fighting behavior unknown; (21) short-term maternal care present; parental care by males absent; (22) egg clutches deposited on upper surface of leaves at terminal margin, transitioning to hanging as eggs develop; (23) tadpoles unknown; (24) SVL in adult males 24.6-26.5 mm (mean = 25.3 $\pm 0.7368 ; n=7)$; in females 26.3-27.2 $\mathrm{mm}(n=2)$.

Color in life (Figure 154, Figure 160, Figure 161): Dorsum light green, lacking dark spots; flanks yellowish white; bones green; fingers and toes yellow with a faint green tint. Venter white anteriorly and translucent posteriorly. Iris background golden with numerous dark spots and very light reticulation [88].

Color in ethanol: Dorsal surfaces of head and body are cream; fingers and toes cream. Upper half of ventral parietal peritoneum covered by iridophores (white), all other peritonea translucent, except for thin layer of iridophores covering heart and renal capsules [88].

Biology and ecology: The following information is taken from Hutter and Guayasamin [88]. Nymphargus lasgralarias inhabits small, permanent streams (ca. $3 \mathrm{~m}$ width) within primary montane forest with minimal disturbance. The species is active during the night and emits advertisement calls from the tops of small-sized ferns, small leaves, and long palm leaves, 1-9 $\mathrm{m}$ above the stream. Fighting behavior is unknown, but the description by Duellman and Savitzky [5] could apply to $N$. lasgralarias as well. Small clutches (12-36 eggs per mass; $n=23$ ) are deposited on the upper surface of a leaf near its terminal margin, and transition into hanging masses as the eggs develop (Figure 160). Tadpoles are unknown. At Reserva Las Gralarias, the species has been found at Ballux Creek, Five-frog Creek, Heloderma Creek, Hercules Creek, Chalguayacu Creek, Kathy's Creek, and Lucy's Creek. Nymphargus lasgralarias occurs sympatrically with six other centrolenid species: Centrolene ballux, C. heloderma, C. lynchi, C. peristicta, Nymphargus grandisonae, and N. griffithsi. Reproductive activity was recorded between April 5 and July 1 2011, but increased dramatically at the end of April and peaked in the middle of May [88]. Females provide short-term parental care; male parental care is absent [25].
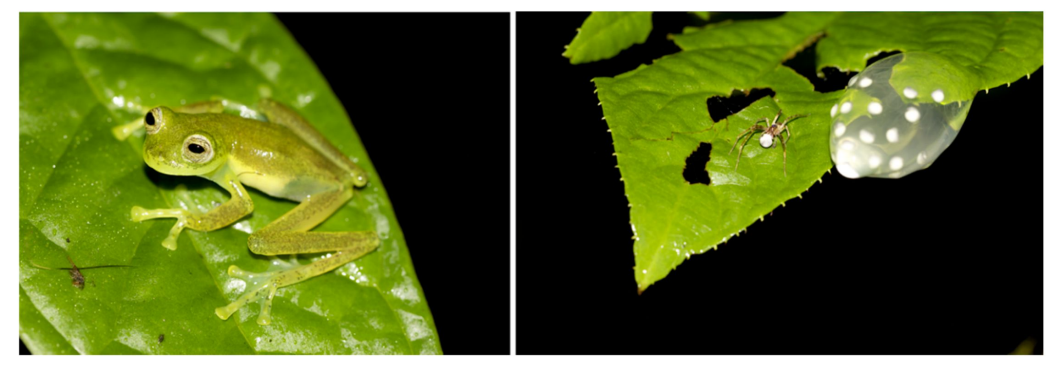

Figure 161. Nymphargus lasgralarias from Reserva Las Gralarias, Pichincha province, Ecuador. (Top): Adult male. (Bottom): Spider (Ctenidae) preying on egg clutch. Photos by Jaime Culebras. 
Call (Figure 156): Males emit calls during the night, from the tops of small-sized ferns, small leaves, and long palm leaves, 1-6 m above the stream. Calls are pulsed and emitted in series (one to four calls per call series; mean $=2.7 \pm 0.7$ calls). Five-call series are emitted sporadically. Each series has duration of $0.033-2.541 \mathrm{~s}$ (mean $=1.529 \pm 0.597 \mathrm{~s}$ ) and an interval of 8.6-78.6 s (mean $33.8 \pm 18.4 \mathrm{~s}$ ) between series, with an interval of $0.088-1.513 \mathrm{~s}$ (mean $=0.873 \pm 0.205 \mathrm{~s}$ ) between calls within a series. The call repetition rate is 2.0-9.9 (5.5 \pm 2.7$)$ calls per minute ( $n=6$ individuals), each call sounding like a "tick" or "click"; call duration is $0.0160-0.0440 \mathrm{~s}$ (mean $=0.0257 \pm 0.0058 ; n=119)$ and dominant frequency is at $3445-3962 \mathrm{~Hz}$ (mean $=3691 \pm 131.9 \mathrm{~Hz}$ ) [88].

Tadpole: Not described.

Distribution (Figure 157): N lasgralarias is known from localities on the western slope of the Ecuadorian Andes at elevations between 1850-2300 m. Specifically, it has been found within the limits of the Pichincha and Cotopaxi provinces ([87,88], this work). Individuals that resemble N. lasgralarias, but are genetically different, are found in northern Ecuador (see Specimens examined).

Conservation status: N. lasgralarias has not been evaluated by the IUCN. Main threats are habitat destruction and fragmentation due to agriculture and cattle, introduced species (trout), infectious diseases (Batrachochytrium dendrobatidis), and climate change. At Reserva Las Gralarias, the species is infected by the chytrid fungus $B$. dendrobatidis, but no recent declines have been observed [92]. Following IUCN criteria (B2a, biii, biv), we suggest considering the species as Endangered.

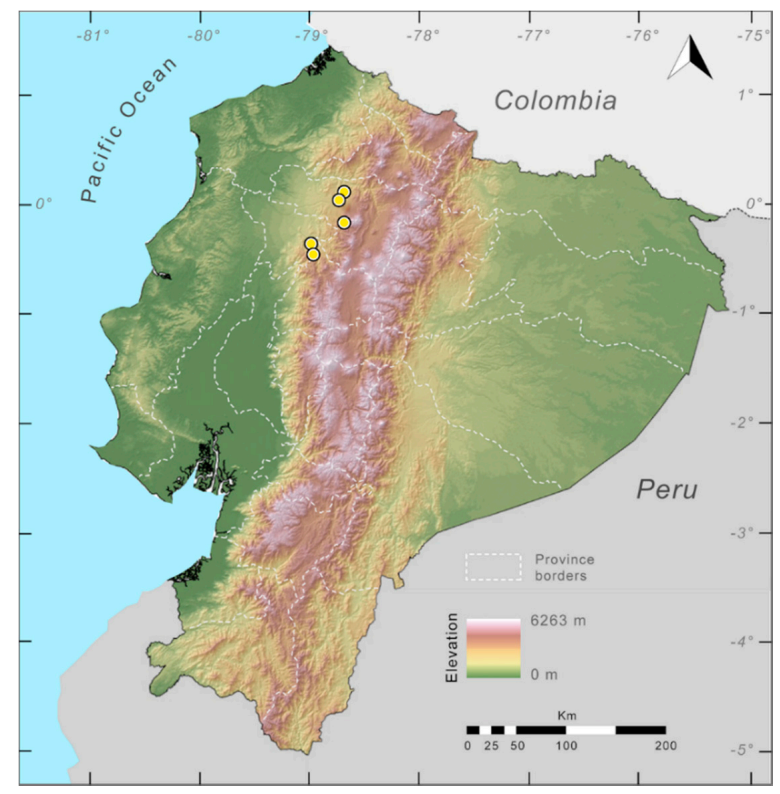

Figure 162. Distribution of Nymphargus lasgralarias in Ecuador (yellow dots).

Evolutionary relationships (Figure 136): N. lasgralarias and N. griffithsi are sister taxa.

Specimens examined: Nymphargus lasgralarias: Ecuador: Provincia de Cotopaxi: Bosque Integral Otonga (0.55 S, 79.46667 W; 2000 m), QCAZ 13115; Reserva Otonga (0.676 S, 76.397 W; 1950 m), QCAZ 11689-90. Provincia Imbabura: Provincia de Pichincha: Five Frog Creek $\left(0^{\circ} 01.870^{\prime} \mathrm{S}, 78^{\circ} 42.358^{\prime} \mathrm{W} ; 2150 \mathrm{~m}\right)$ at Reserva Las Gralarias, MZUTI 096 (holotype), MZUTI 091-095, 097; Kathy's Creek ( $0^{\circ} 01.398^{\prime}$ S, 78 43.772' W; 2000 m), Reserva Las Gralarias, MZUTI 091-095; Hercules Giant Tree Frog Creek $\left(0^{\circ} 01.529^{\prime} \mathrm{S}, 78^{\circ} 42.243^{\prime} \mathrm{W} ; 2175 \mathrm{~m}\right)$, Reserva Las Gralarias, MZUTI 097; Nanegal Grande (0.1167 N, 78.6667 W; 2300 m), QCAZ 46012; 9 km SE Tandayapa (0.01667 S, 78.6833 W; 2160 m), KU 164577-87.

Nymphargus aff. lasgralarias: Ecuador: Provincia de Imbabura: $23.2 \mathrm{~km} \mathrm{~W}$ of Apuela, Cordillera de Intag (0.2666 N, 78.6 W; 2190 m), KU 178122-36; San Antonio de Cuellaje, Finca de Estuardo Ayala (0.4775 N, 78.56263 W), QCAZ 42164; Santa Rosa, Reserva Alto Chocó (0.36939 N, 78.44942 W; 2104 m), QCAZ 31768. 
Nymphargus laurae Cisneros-Heredia and McDiarmid, 2007 [17] (Figures 163 and 164).

Nymphargus laurae Cisneros-Heredia and McDiarmid, 2007 [17]. Holotype: USNM 288453.

Type locality: “Loreto, Upper Rio Napo (=Loreto region, near the town of Loreto) (ca. $77^{\circ} 20^{\prime}$ S, $00^{\circ} 40^{\prime} \mathrm{W}$, ca. $500 \mathrm{~m}$ elevation), lower slopes of the Sumaco Volcano, on the Cordillera Oriental, eastern slopes of the Andes, Provincia de Orellana, República del Ecuador".

Common names: English: Laura's Glassfrog. Spanish: Rana de cristal de Laura.

Etymology: The specific epithet is a patronym for Laura Heredia, DFCH's grandmother, for her support of Diego's interest in animals and science [17].

Identification: Nymphargus laurae can be distinguished from most centrolenids by the presence of dorsal ocelli (a trait shared only with N. anomalus, N. lindae sp. nov., N. cochranae, and N. ignotus), two papillae on each toe except Toe V (Figure 163), and relatively small size (SVL = $19.9 \mathrm{~mm}$ in male holotype). Nymphargus anomalus differs by having smaller and more abundant ocelli, and dark spots and punctuations amidst the ocelli. Nymphargus lindae sp. nov. differs from N. laurae mainly by being larger (in N. lindae sp. nov., male SVL = 23.0-26.3 mm; female SVL = 27.2-27.8 mm), having vomerine teeth (absent in N. laurae), and lacking papillae on toe discs. Nymphargus ignotus differs by having, in life, a tan dorsal coloration, with smaller and more abundant ocelli, and by being larger (22.3-25.4 mm SVL in males of N. ignota); further, N. ignotus is known only from western Colombia around $1900 \mathrm{~m}$, whereas N. laurae is known from the slopes of Volcán Sumaco, on the Amazonian slopes of the Andes. Nymphargus laurae is very similar to N. cochranae; both species share a similar color pattern and are likely to be sympatric; N. cochranae however differs by having much smaller ocelli, no ocelli on forearms and shanks, and larger body size (male N. cochranae SVL $=23.8-26.7 \mathrm{~mm}$ ), and lacking papillae on the toes. See Taxonomic Remarks.

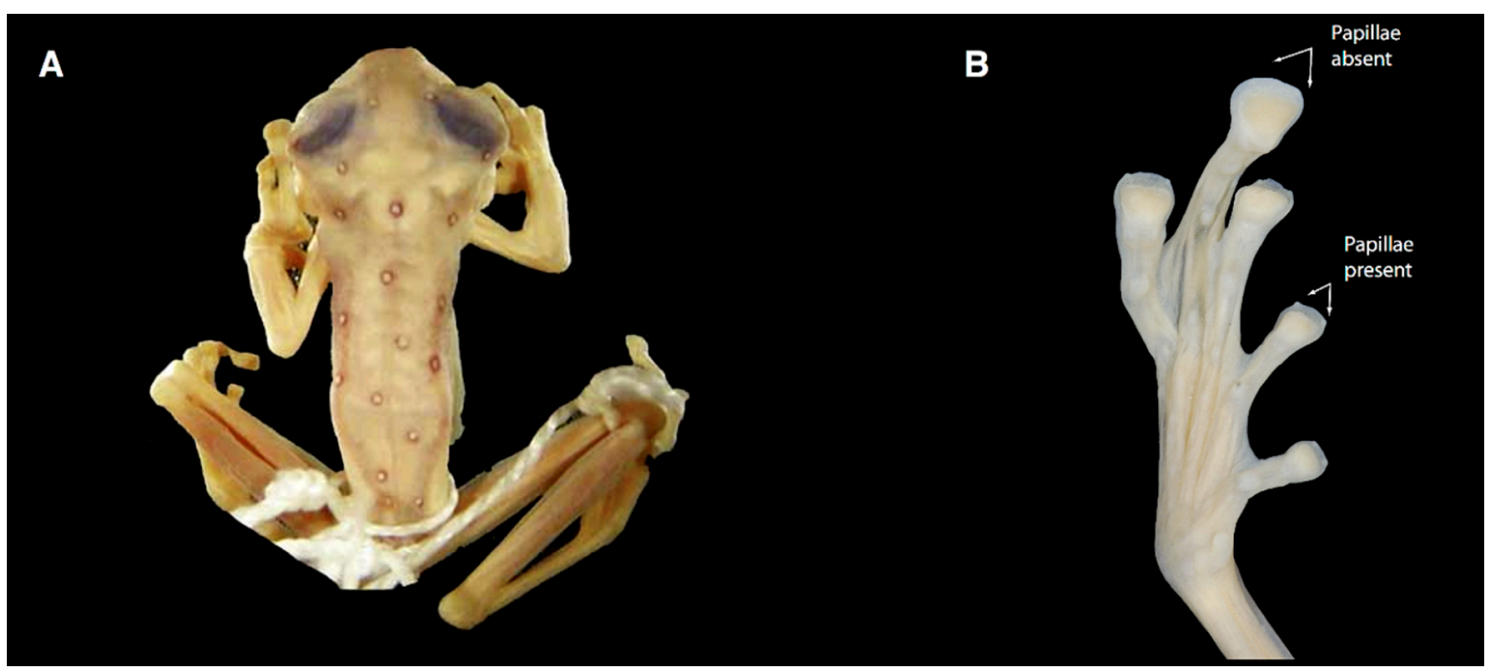

Figure 163. Nymphargus laurae in preservative, USNM 288453, from Ecuador, lower slopes of Volcán Sumaco. (A) Dorsal view of holotype. (B) Ventral view of foot; note presence of two papillae on each toe disc, except Toe IV. Photos by James Poindexter. 
Diagnosis: The following traits characterize N. laurae: (1) Vomerine teeth absent; (2) snout truncated in dorsal and profile views; nostrils slightly elevated producing a slight depression in the internarial area; loreal region concave; (3) tympanic annulus evident, oriented dorsolaterally with dorsal inclination; weak supratympanic fold from behind eye to insertion of arm; (4) dorsal skin slightly shagreen with elevated warts corresponding to ocelli, and scattered spicules; (5) ventral skin granular; pair of large, round, flat subcloacal warts; other cloacal ornamentation absent; (6) parietal peritoneum white, covering anterior two-thirds of abdomen (condition P2); white pericardium; all other peritonea clear (condition V1); (7) liver lobed, hepatic peritoneum clear (condition H0); (8) humeral spine absent; (9) webbing basal between Fingers I, II and III, outer fingers III $2^{2 / 3}-2^{1 / 2}$ IV; (10) webbing on feet I $2^{-}-2^{+}$II $1^{1 / 2}-2^{+}$III $1^{+}-2^{1 / 2}$ IV $2^{1 / 2}-1^{1 / 2} \mathrm{~V}$; (11) no dermal folds or tubercles on hands, forearms, feet, or tarsi; (12) unpigmented nuptial pad Type I; concealed prepollex; (13) second finger longer than first; (14) eye diameter greater than width of disc on Finger III; (15) color in life, green with yellow spots surrounded by black ocelli; (16) color in preservative, dorsal surfaces tan cream with dark, reddish-lavender ocelli; (17) iris coloration in life unknown; (18) melanophores absent on fingers and toes; (19) calling site and call unknown; (20) fighting behavior unknown; (21) egg deposition site and parental care unknown; (22) tadpole unknown; (23) minute body size; SVL in male holotype $19.9 \mathrm{~mm}$; females unknown.

Color in life: Green dorsum with black ocelli with yellow center [17].

Color in ethanol (Figure 163): Dorsal surfaces cream-colored with minute reddish-lavender melanophores appearing as punctuations and forming a reddish -lavender shadow on sides of body. Dark reddish-lavender ocelli on head and body, the center of each encircles a cream-colored wart. Venter cream. Parietal peritoneum with iridophores; white pericardium; all other peritonea clear [17].

Biology and ecology: Almost no information is available for Nymphargus laurae. The type locality is within the Foothill Evergreen forests. Parental care is unknown.

Call: Not described.

Tadpole: Not described.

Distribution (Figure 164): Nymphargus laurae only is known from its type locality, near the town of Loreto, lower slopes of the Sumaco Volcano (ca. $77^{\circ} 20^{\prime} \mathrm{S}, 00^{\circ} 40^{\prime} \mathrm{W}$; ca. $500 \mathrm{~m}$ ), Ecuador [17], within the Amazonian Tropical Rainforest ecoregion. 


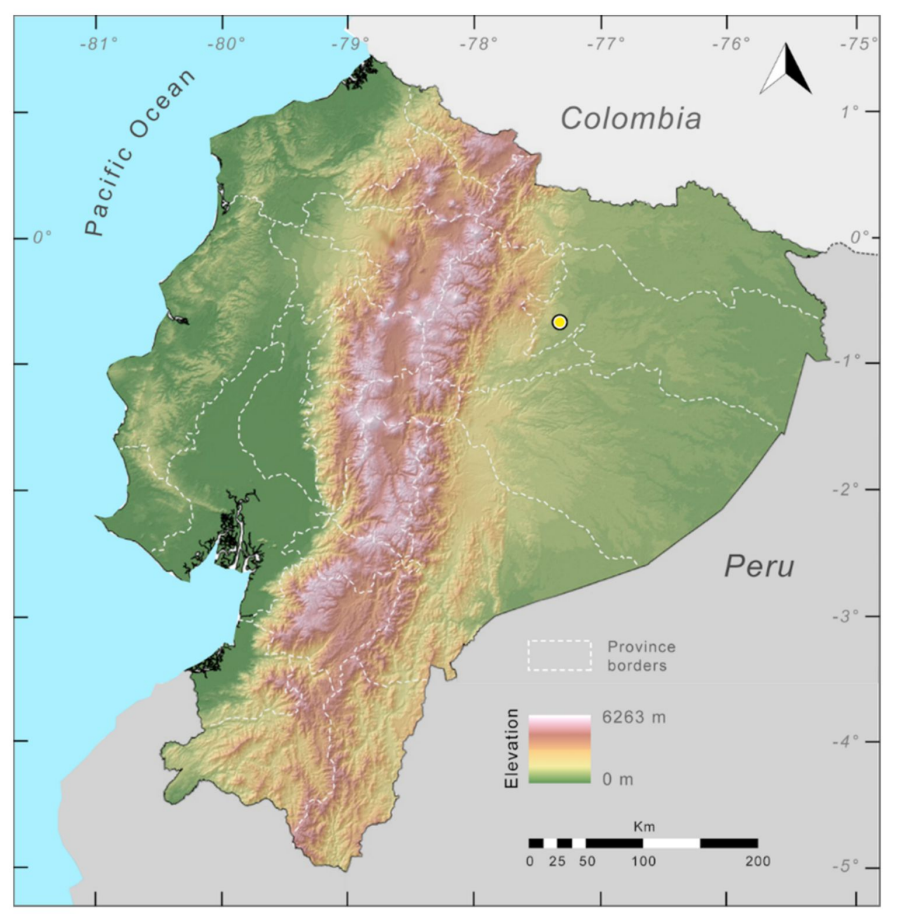

Figure 164. Distribution of Nymphargus laurae in Ecuador (yellow dot).

Conservation status: Nymphargus laurae is classified as Critically Endangered by the IUCN [265]; however, given that its type locality has a degree of uncertainty (collected in 1955 from the general area of "Loreto, Upper Rio Napo") and that the species is known from a single specimen, we consider that the category of Data Deficient is more appropriate.

Evolutionary relationships: It is likely that Nymphargus laurae is a close relative of N. cochranae and N. lindae sp. nov., given their similar morphologies and color patterns.

Taxonomic Remarks: The description of Nymphargus laurae was based on a single specimen and, therefore, intraspecific variation is unknown. Given that this species shares a number of traits (general morphology, webbing, color pattern) with N. cochranae, a relatively abundant species on the lower slopes of Volcán Sumaco (nearby the type locality of N. laurae), we are presented with two possibilities: (i) The holotype of N. laurae represents an anomalous individual of N. cochranae, or (ii) N. laurae is a valid species, that might occur in sympatry with $N$. cochranae. Also, N. laurae is very similar to N. lindae sp. nov.; although, the two species are geographically distant (N. lindae sp. nov. is only known from Cordillera del Cóndor, whereas N. laurae is known from the lower slopes of the Volcán Sumaco); the two taxa differ in body size, vomerine teeth, and papillae on toes (see Diagnosis). As mentioned above, at the moment, it is impossible to determine the extent of intraspecific variation in N. laurae.

Specimens examined: Nymphargus laurae: Ecuador: Provincia de Orellana: Loreto region, near the town of Loreto, lower slopes of Volcán Sumaco (ca. $77^{\circ} 20^{\prime} \mathrm{S}, 00^{\circ} 40^{\prime} \mathrm{W}$, ca. $500 \mathrm{~m}$ ), on the Cordillera Oriental, USNM 288453. 
Nymphargus lindae new species Guayasamin (Figures 165 and 166).

http://zoobank.org/urn:lsid:zoobank.org:act:A8E08511-149C-4DA3-8F74-57C04C7CC302

Common names: English: Linda's Glassfrog. Spanish: Rana de Cristal de Linda.

Etymology: The specific epithet honors Linda Trueb, one of the most influential amphibian systematist of our days. Linda, as the curator of the herpetological collection of the University of Kansas, has led one of the most prolific and solid research group on amphibian biology, mentoring numerous students (including JMG). Her work on the evolution of skeletal diversity, ontogeny, and scientific illustration is outstanding.

Holotype: QCAZ 41572, adult male, collected from Miazi Alto (4.25044 S, 78.61356 W; $1200 \mathrm{~m})$, Cordillera del Cóndor, Provincia de Zamora Chinchipe, Ecuador, by Juan M. Guayasamin and Elicio Tapia on 8 April 2009.

Paratopotypes: QCAZ 41562-71, 41573-74, 41587, 41594, 41597, 41599, 41644-47, 41654-56, 41658, 42446, adult males and females collected by Juan M. Guayasamin, Elicio Tapia, Silvia Aldás, and Holger Braun on 8-12 April 2009.

Generic placement: The new species is placed in the clade Nymphargus (sensu Guayasamin et al. [1]) based on morphological and molecular data. All species in Nymphargus share an absence of webbing between Fingers I-III and an absence or reduced webbing between Fingers III and IV; additionally, males lack humeral spines (except N. grandisonae). Nymphargus lindae sp. nov. has the aforementioned traits. Molecular analyses of mitochondrial genes (12S, 16S, ND1) unambiguously place the new species in the clade Nymphargus (Figure 16).

Identification: Nymphargus lindae sp. nov. can be distinguished from most other glassfrogs by having, in life, a green dorsum with dark lavender to black ocelli enclosing yellow to orange spots (Figure 165), and lacking webbing between fingers. Nymphargus lindae sp. nov. is most similar to other glassfrogs with dorsal ocellated patterns (N. anomalus, N. cochranae, N. ignotus, N. laurae, N. ocellatus). Nymphargus anomalus differs by having, in life, a pale brown dorsum and scattered black and lavender flecks between ocelli (green dorsum lacking flecks in N. lindae sp. nov.); N. ignotus has a brown dorsum and occurs on the Pacific slopes of the Andes, whereas N. lindae sp. nov. has a green dorsum and is restricted to the Amazonian slopes of the Cordillera del Cóndor; N. ocellatus has a dorsal color pattern of large dark rings that, in life, have greenish-white centers (smaller ocelli with yellow to orange centers in $N$. lindae sp. nov.); $N$. laurae, known from a single adult male, is smaller (SVL $=19.7 \mathrm{~mm}$ in $N$. laurae; male SVL $=23.0-26.3 \mathrm{~mm}$ in $N$. lindae sp. nov.), has pointed papillae in Toes I-IV (absent in N. lindae sp. nov.), and no teeth on the vomers (present in N. lindae sp. nov.; see Taxonomic Remarks). Nymphargus lindae sp. nov. differs from its sister species, N. cochranae, by the relative size of ocelli (minute in N. cochranae and conspicuously larger in N. lindae sp. nov.) and female body size (N. cochranae, $\mathrm{SVL}=27.8-30.3 \mathrm{~mm}$; N. lindae sp. nov., SVL 27.2-27.8 mm).

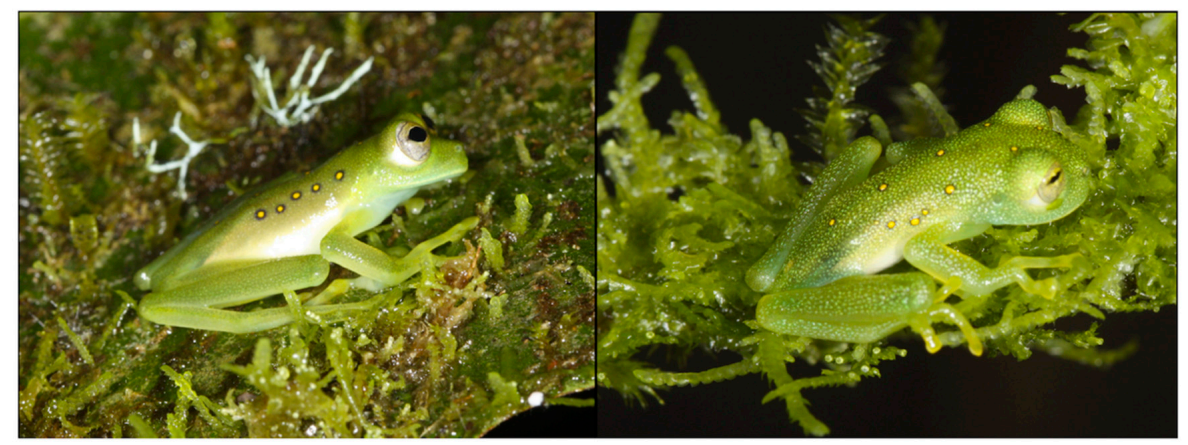

Figure 165. Nymphargus lindae sp. nov. in life. (Left): Adult female, paratype, QCAZ 41597. (Right): Male, also part of the type series. Photos taken at the type locality by Juan M. Guayasamin. 
Diagnosis: (1) Dentigerous process of the vomer with two to four teeth; (2) snout truncated to bluntly rounded in lateral profile; truncated in dorsal view; (3) tympanum oriented almost vertically, with slight lateral and posterior inclinations, its diameter about $20 \%-26 \%$ of eye diameter; upper fourth of tympanic annulus obscured by supratympanic fold; tympanic membrane pigmented as surrounding skin; (4) dorsal skin shagreen, with minute spicules in males; (5) venter areolate; pair of enlarged subcloacal warts; (6) white parietal peritoneum covering about anterior $60 \%$ of venter (condition P3); white pericardium; translucent peritonea covering intestines, stomach, kidneys, gall and urinary bladders (condition V1); (7) liver tetralobed, covered by transparent peritoneum (condition H0); (8) humeral spines absent; (9) webbing absent between inner fingers, absent or basal between Fingers III and IV (Figure 165); webbing formula III $\left(2^{4 / 5}-3^{-}\right)-\left(2^{3 / 4}-3^{-}\right)$IV; (10) feet about two-thirds webbed (Figure 165); webbing formula: I $2^{-}-\left(2^{1 / 4}-2^{1 / 3}\right) \operatorname{II}\left(1^{1 / 4}-1^{1 / 3}\right)-\left(2^{1 / 4}-2^{1 / 3}\right) \mathrm{III}\left(1^{1 / 4}-1^{1 / 3}\right)-\left(2^{2 / 3}-3^{-}\right)$ IV $\left(2-2^{+}\right)-2^{-}$V; (11) ulnar and tarsal folds present, low; (12) concealed prepollex; in males, nuptial pad Type I; (13) Finger I about same length as Finger II or slightly shorter (Finger I length $94 \%-100 \%$ of Finger II); (14) disc of Finger III width about $46 \%-50 \%$ of eye diameter; (15) in life, dorsum green with dark lavender to black ocelli enclosing yellow to orange spots (Figure 165); bones green; (16) in preservative, dorsum lavender with black ocelli with white centers; (17) iris white with slight pale yellow hue and thin black reticulation; (18) melanophores usually lacking from dorsal surfaces of fingers and toes, except for few on Toe V; (19) males call from the upper surfaces of leaves; call unknown; (20) fighting behavior unknown; (21) egg deposition site unknown; parental care unknown; (22) tadpoles unknown; (23) small to medium body size; in males, SVL 23.0-26.3 $\mathrm{mm}(\overline{\mathrm{X}}=25.1 \pm 0.848$, $n=12)$; in females, SVL $27.2-27.8 \mathrm{~mm}(n=2)$.

Description of holotype: Adult male, SVL $25.8 \mathrm{~mm}$. Head slightly wider than long (head length $95 \%$ of head width); snout truncated in dorsal and lateral profiles; canthus rostralis indistinct, slightly concave; loreal region slightly concave; lips slightly flared; nostril protuberant, closer to tip of snout than to eye, directed frontolaterally; internarial area barely depressed. Eyes large, directed anterolaterally at an angle $\sim 50^{\circ}$; transverse diameter of disc of Finger III $49 \%$ eye diameter. Supratympanic fold low, obscuring upper portion of tympanic annulus; tympanum oriented mostly vertically, but with slight posterolateral inclination; tympanic membrane translucent, pigmented as surrounding skin. Dentigerous process of vomer low, situated transversely between choanae, with three teeth; choanae large, longitudinally rectangular; tongue ovoid, with ventral posterior fourth not attached to floor of mouth and posterior margin notched; vocal slits extending posterolaterally from about the lateral margin of tongue (at about half the length of tongue) to angle of jaws. Humeral spine absent. Low ulnar folds evident on external and internal ventrolateral margins of arm; relative lengths of fingers: III $>$ IV $>$ II $>$ I; webbing absent between Fingers I-III, basal between Fingers III and IV, webbing formula III $3^{-}-2^{3 / 4} \mathrm{IV}$; discs expanded, nearly elliptical; disc pads nearly triangular shaped; subarticular tubercles small, round, simple; low supernumerary tubercles; palmar tubercle elliptical, simple; nuptial pad large (Type I), ovoid, granular, extending from ventrolateral base to dorsal surface of Finger I, covering proximal half of Finger I. Length of tibia 59\% SVL; low inner tarsal fold evident; outer tarsal fold absent; foot two-thirds webbed; webbing formula of foot: I $2^{-}-2^{1 / 3}$ II $1^{1 / 4}-2^{1 / 3}$ III $1^{1 / 3}-2^{2 / 3}$ IV $3^{-}-2^{-}$ V; discs on toes round to elliptical, lacking papillae; disc on Toe IV narrower that disc on Finger III; disc pads triangular; inner metatarsal tubercle large, ovoid; outer metatarsal tubercle not evident; subarticular tubercles small, round; supernumerary tubercles low. Skin on dorsal surfaces of head, body, and lateral surface of head and flanks shagreen with numerous minute spinules; throat smooth; belly and lower flanks areolate; cloacal opening directed posteriorly at upper level of thighs; cloacal ornamentation absent. Ventral surface of thighs with pair of enlarged tubercles.

Coloration of the holotype in life (Figure 165): Green dorsum with dark lavender to black ocelli enclosing yellow to orange spots. Upper lip white. Anteriorly, about $60 \%$ of ventral parietal peritoneum white, posterior portion translucent. Bones green. Iris white with slight pale-yellow hue and thin black reticulation. 
Coloration of the holotype in ethanol: Dorsal surfaces of head, body, and limbs lavender with dark lavender ocelli encircling white spots. Anterior $60 \%$ of the ventral parietal peritoneum white. Heart covered by white pericardium; translucent peritonea covering gall and urinary bladders; iridophores absent from digestive tract, liver, and kidneys.

Measurements of holotype (mm): Nymphargus lindae, adult male, QCAZ 41572: SVL $=25.8$, head length $=7.9$, head width $=8.3$, eye-nostril $=1.9$, nostril-snout $=0.8, \mathrm{IOD}=2.4$, upper eyelid width $=2.5$, eye diameter $=3.5$, tympanum diameter $=0.85$, tibia $=15.1$, foot length $=11.9$, radio-ulna length $=5.5$, hand length $=8.1$, Finger I length $=5.2$, Finger II length $=5.4$, disc of Finger III width $=1.7$.

Biology and ecology: Nymphargus lindae sp. nov. is the most abundant species in streams at Miazi Alto, Cordillera del Cóndor. Males were observed calling on leaves and branches about $30-400 \mathrm{~cm}$ above a stream. An amplectant pair and two additional males were observed fighting on a branch; males that were not in amplexus continuously approached the amplectant male and tried to push him away with kicks. Parental care is unknown.

Call: Not described.

Tadpole: Not described.

Distribution (Figure 166): Nymphargus lindae sp. nov. is only known from the type locality, Miazi Alto (4.25044 ${ }^{\circ}$ S, $78.61356^{\circ}$ W; $1200 \mathrm{~m}$ ), at Cordillera del Cóndor, Provincia de Zamora-Chinchipe, Ecuador. It inhabits the Eastern Foothill Forest ecoregion.

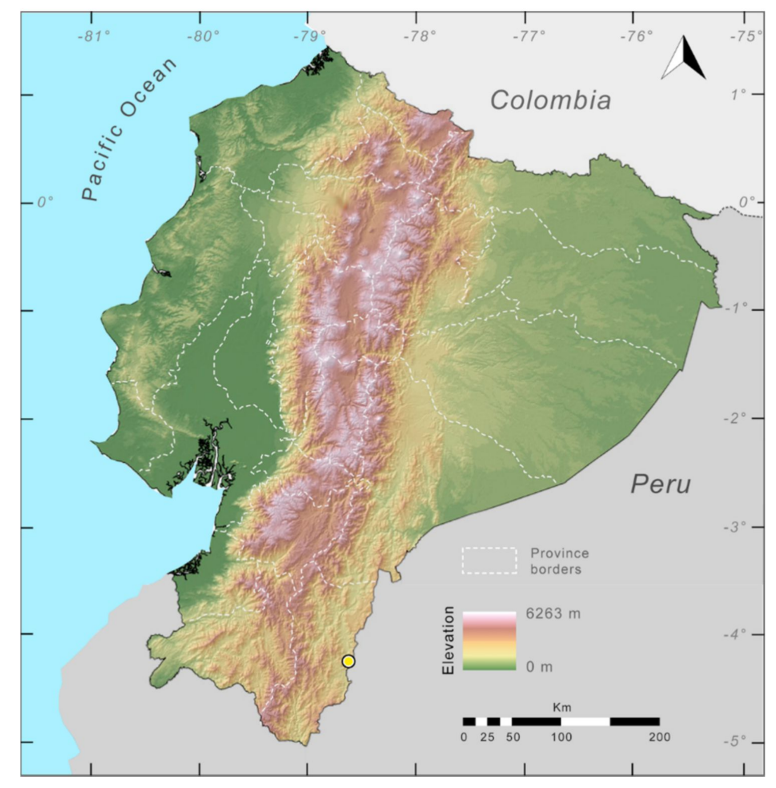

Figure 166. Distribution of Nymphargus lindae sp. nov. in Ecuador (yellow dot).

Conservation status: We suggest placing Nymphargus lindae sp. nov. in the Endangered category, following IUCN criteria B2a, B2(iii). The main threats for the species in Cordillera del Cóndor are habitat destruction and contamination associated with mining activities.

Evolutionary relationships (Figure 136): Nymphargus lindae sp. nov. is sister to N. cochranae.

Taxonomic Remarks: Nymphargus lindae sp. nov. is similar to N. laurae. Although the two species are geographically distant ( $N$. lindae sp. nov. is endemic to the isolated Cordillera del Cóndor, whereas $N$. laurae is endemic to the lower slopes of Volcán Sumaco, nearby the town of Loreto), differences between these taxa are limited (body size, vomerine teeth, papillae on toes; see Diagnosis). Since $N$. laurae was described based on a single specimen, it is impossible to determine its intraspecific variation. Additional samples from Volcán Sumaco that correspond to the description of $N$. laurae need to be examined to support or refute the validity of the specific status of the two species. 
Nymphargus mariae (Duellman and Toft, 1979 [266]; Figures 167-169).

Centrolenella mariae Duellman and Toft, 1979 [266]. Holotype: KU 174713.

Type locality: "Serranía de Sira, \pm 1550 m, Departamento Huánuco, Perú".

Cochranella mariae-Ruiz-Carranza and Lynch, 1991 [6]; Cisneros-Heredia and McDiarmid, 2006 [267].

Centrolene mariae-Duellman and Schulte, 1993 [174].

Nymphargus mariae—Guayasamin, Castroviejo-Fisher, Trueb, Ayarzagüena, Rada, and Vilà, 2009 [1].

Centrolenella puyoensis Flores and McDiarmid, 1989 [268]. Holotype: MCZ 91187. Type locality: "1.0 km W Puyo, Provincia de Pastaza, Ecuador, between 1000-1050 m elevation".

Synonymy by Cisneros-Heredia \& Guayasamin, 2014 [175].

Cochranella puyoensis-Ruiz-Carranza and Lynch, 1991 [6].

Centrolene puyoense—Stuart, Hoffmann, Chanson, Cox, Berridge, Ramani, and Young, 2008 [269].

Nymphargus puyoensis—Guayasamin, Castroviejo-Fisher, Trueb, Ayarzagüena, Rada, and Vilà, 2009 [1].

Common names: English: María's Glassfrog. Spanish: Rana de Cristal de María.

Etymology: The specific epithet is a patronym for María Koepcke, who devoted her life to biological exploration in Peru [266].

Identification: Nymphargus mariae can be distinguished from most glassfrogs by having, in life, a green dorsum with relatively large yellow-green spots, a white parietal peritoneum covering the anterior half of the venter, and by lacking humeral spines and webbing between fingers (Figure 167). Rulyrana flavopunctata, T. midas, N. cariticommatus, N. humboldti sp. nov., and N. siren have a similar color pattern, but the yellow spots are conspicuously larger in N. mariae. Two species, Sachatamia albomaculata and "Centrolene" medemi, also have large yellow spots on the dorsum, but S. albomaculata has webbing between Fingers III and IV and inhabits the Pacific lowlands (N. mariae lacks hand webbing and is found on the Amazonian slopes of the Andes and Amazonian lowlands). Also, "C." medemi is larger than N. mariae ("C." medemi: SVL 25.5-30.8 mm in adult males, 34.7-44.3 mm in adult females; N. mariae: SVL 23.4-30.2 $\mathrm{mm}$ in males, SVL 25.1-32.8 $\mathrm{mm}$ in females), has more webbing between Fingers III and $\mathrm{IV}$, and males have humeral spines.

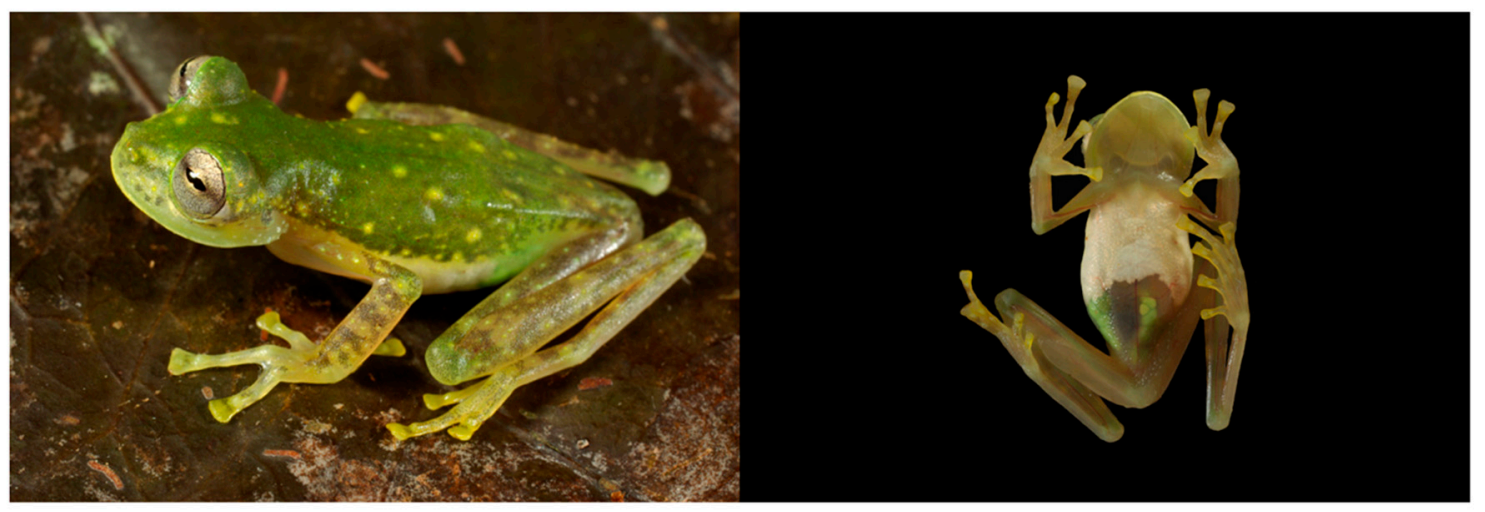

Figure 167. Nymphargus mariae in life. Adult female, QCAZ 37923, from a stream tributary of Río Lliquino, Pastaza province, Ecuador. Photos by Martín Bustamante.

Diagnosis: (1) Vomerine teeth present, each vomer with three to four teeth; (2) snout truncated in dorsal aspect, round in lateral profile (Figure 168); (3) tympanum oriented dorsolaterally, with slight posterior inclination, its diameter about $32 \%-35 \%$ of eye diameter; tympanic annulus visible, low supratympanic fold evident, tympanic membrane partially pigmented and clearly differentiated 
from surrounding skin; (4) dorsum shagreen with spiculated flat warts corresponding to light spots; (5) venter areolate; pair of enlarged subcloacal warts (Figure 6); (6) white lining on the anterior $40 \%$ of the ventral parietal peritoneum (condition P2); translucent peritonea covering intestines, stomach, gall bladder, and urinary bladder (condition V1); (7) liver tetralobed, covered by transparent peritoneum (condition H0); (8) humeral spines absent; (9) webbing absent between Fingers I, II, and III, and reduced or absent between outer fingers, III $\left(3^{-}-3\right)-\left(2^{1 / 3}-2^{2 / 3}\right)$ IV (Figure 168); (10) webbing formula on foot: I $\left(2-2^{-}\right)-\left(2^{1 / 3}-2^{1 / 2}\right)$ II $1^{1 / 2}-2^{-} 2^{2 / 3}$ III $\left(1^{1 / 3}-1^{2 / 3}\right)-2^{2 / 3}$ IV $\left(2^{+}-3^{-}\right)-\left(1^{2 / 3}-2^{-}\right)$V; (11) ulnar fold low; inner and outer tarsal folds low and thin; (12) concealed prepollex; nuptial pad Type I; (13) Finger I about same length as Finger II; (14) disc of Finger III narrow, about 34\%-38\% of eye diameter; (15) in life, dorsum green to dark green with minute and relatively large yellow-green spots; bones green; (16) in preservative, dorsum dark lavender with minute and large cream spots; (17) iris greyish cream with transverse brown bar and fine dark grey reticulations; pale yellow circumpupilar ring; (18) melanophores absent from Fingers I and II, and Toes I, II, and III; few present on Finger III; numerous on Finger IV and Toes IV and V; (19) males call from the upper side of leaves; call consists of a single note with a duration of $0.015-0.018 \mathrm{~s}$; time between calls is $1.733-1.940 \mathrm{~s}$; dominant frequency is at 3234-4299 Hz; (20) fighting behavior unknown; (21) egg deposition site and parental care unknown; (22) tadpoles unknown; (23) medium body size; in males, SVL 22.4-31.7 $\mathrm{mm}(\overline{\mathrm{X}}=26.3 \pm 2.866, n=7)$; in females, SVL $25.1-30.1 \mathrm{~mm}(\overline{\mathrm{X}}=28.3 \pm 2.347, n=4)$.

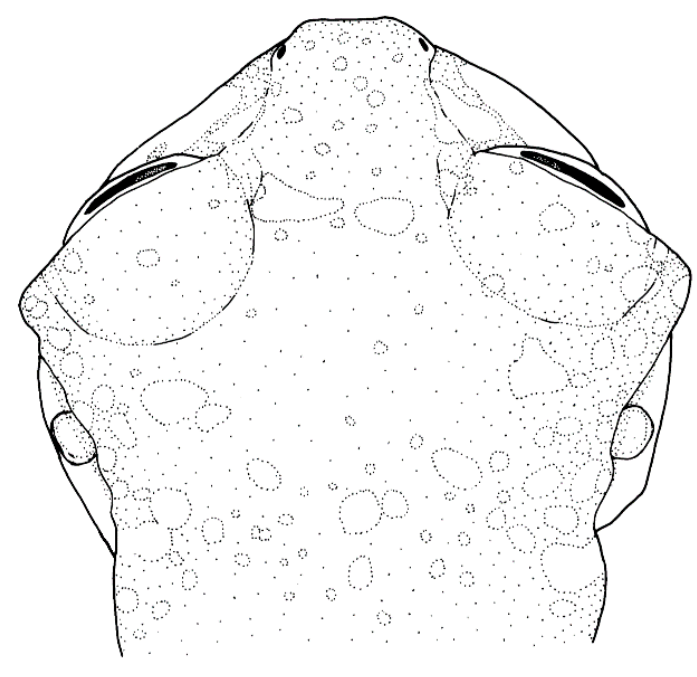

(A)

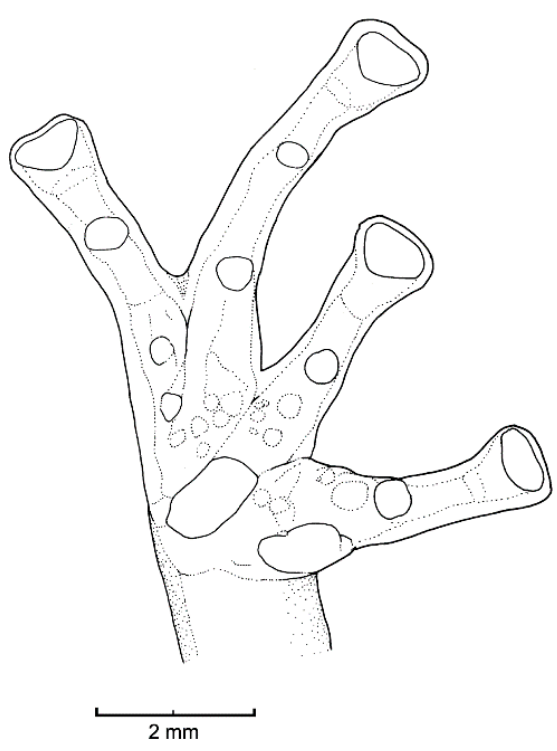

(B)

Figure 168. Nymphargus mariae, holotype, female, KU 174713. (A) Head in lateral view. (B) Hand in ventral view. Illustrations by Juan M. Guayasamin.

Color in life (Figure 167): Dorsal surfaces green to dark green, with minute and large yellow spots. Anterior half of venter white, posterior part translucent. Iris greyish cream with transverse brown bar and fine dark grey reticulations; pale yellow circumpupilar ring.

Color in ethanol: Dorsum lavender to dark lavender, with minute and large cream spots; iridophores on anterior $40 \%$ of the ventral parietal peritoneum; white pericardium; clear hepatic peritoneum; translucent peritoneum covering intestines, stomach, gall bladder, and urinary bladder.

Biology and ecology: Nymphargus mariae is active during the night. Species found the type locality of N. puyoensis included Boana cinerascens, Pristimantis conspicillatus, P. diadematus, P. lacrimosus, P. lathanites, P. martiae, and P. quaquaversus [268]. Parental care is unknown.

Call: Males call from the upper surfaces of leaves. The following call description is based on a recording of one male of Nymphargus mariae made by Diego Paucar on 22 February 2008 at stream 
tributary of Río Lliquino (1.72553 S, 78.98058 W; 400 m), Provincia de Pastaza, Ecuador. The call consists of a single non-frequency modulated note. Each call has a duration of $0.015-0.018 \mathrm{~s}(n=3)$; time between calls is $1.733-1.940 \mathrm{~s}$. Dominant frequency is at $3234-4299 \mathrm{~Hz}$; a first harmonic is visible at $7178-7928 \mathrm{~Hz}$, and a second harmonic is visible at $10767-11714 \mathrm{~Hz}$.

Tadpole: Not described.

Distribution (Figure 169): Nymphargus mariae is known from several localities on the Amazonian slopes of the Cordillera Oriental of the Ecuadorian Andes at elevations between 400 and $1078 \mathrm{~m}$ ([176,266-268], this work). In Ecuador, the potential distribution of the species is $28,298 \mathrm{~km}^{2}$.

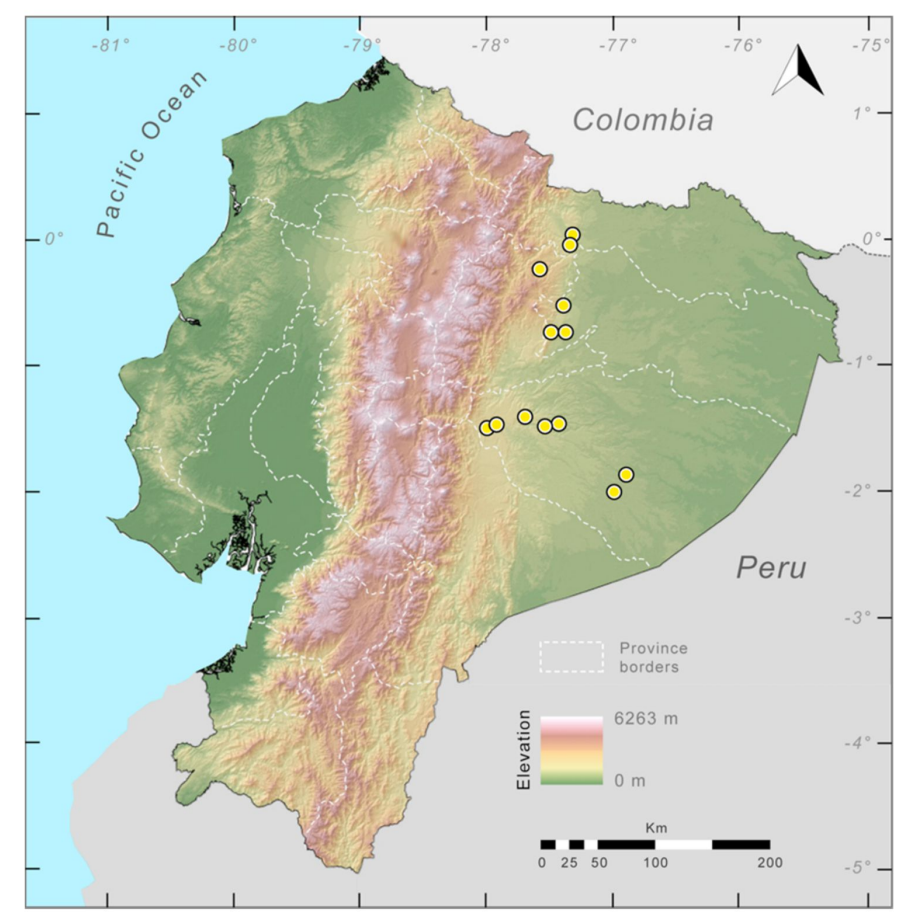

Figure 169. Distribution of Nymphargus mariae in Ecuador (yellow spots).

Conservation status: Globally, Nymphargus mariae is listed as Least Concern by the IUCN [270]. We agree with this conservation status.

Evolutionary relationships (Figure 136): Nymphargus mariae is sister to N. colomai sp. nov.

Specimens examined: Nymphargus mariae: Ecuador: Provincia de Pastaza: $1 \mathrm{~km}$ W Puyo (1.4833 S, 78.0 W; 1000-1050 m), MCZ 91187; Andean foothills in the Upper Bobonaza River Basin (ca. 2.0 S, 77.0 W), USNM 291298; stream tributary of Río Lliquino (1.72553 S, 78.98058 W; 400 m), QCAZ 37932; near Villano (1.47445 S, 77.53529 W; 440 m), QCAZ 39293; Sacha Yacu (1.39519 S, 77.72946 W; 1078 m), MZUTI 183. Provincia de Napo: ca. $45 \mathrm{~km}$ E of Narupa (ca. $0.729 \mathrm{~S}, 77.374 \mathrm{~W}$; ca. $800 \mathrm{~m}$ ), on the Hollín-Loreto road, DFCH-USFQ D285; Provincia de Orellana: Reserva Río Bigal (0.52525 S, 77.41785 W; 930 m), QCAZ 48529; Río Huataracu (ca. 0.729 S, 77.374; ca. $800 \mathrm{~m}$ ), ca. $70 \mathrm{~km}$ E of Hollín, on the Hollín-Loreto road, QCAZ 7104, 7499; Provincia de Sucumbíos: Lumbaqui (ca. 0.05 N, 77.333 W; ca. 500 m). Peru: Departamento de Huánuco: Serranía de Sira (ca. 9.367 S, 74.75 W; 1550 m), KU 174713.

Localities from the literature: Nymphargus mariae: Ecuador: Provincia de Pastaza: Río Pucayacu (1.942 S, 77.042 W) [253]; Conambo (1.86197 S, 76.906 W; 337 m) [176]; 1 km W of Puyo (1.493 S, 78.026 W; 1000-1050 m) [253]; Río Lliquino (1.41486 S, 77.54047 W; 380 m) [176]. Provincia de Napo: Río Putuyacu, 45 km E of Narupa (0.734 S, 77.49 W; 800 m) [176,253]. Provincia de Orellana: Río Huataraco (1.46986 S, 77.92477 W; 347 m) [176]. Provincia de Sucumbíos: Río Verde (0.23786 S, 77.576 W; 726 m) [176]; Lumbaqui (0.04675 S, 77. 34358 W; $515 \mathrm{~m})$ [176]. 
Nymphargus manduriacu Guayasamin, Cisneros-Heredia, Vieira, Kohn, Gavilanes, Lynch, Hamilton, and Maynard, 2019 [21] (Figures 170-173).

Nymphargus manduriacu Guayasamin, Cisneros-Heredia, Vieira, Kohn, Gavilanes, Lynch, Hamilton, and Maynard, 2019 [21]. Holotype: ZSFQ 0466, by original designation.

Type locality: "Reserva Río Manduriacu $\left(0.310755^{\circ} \mathrm{N}, 78.8569^{\circ} \mathrm{W} ; 1,215 \mathrm{~m}\right)$, Provincia de Imbabura, República del Ecuador".

Common names: English: Manduriacu glassfrog. Spanish: Rana de Cristal de Manduriacu.

Etymology: The specific epithet "manduriacu" refers to the type locality of the species, Río Manduriacu Reserve, Ecuador, a conservation area managed by Fundación EcoMinga (https: //ecomingafoundation.wordpress.com/) [21].

Identification: Nymphargus manduriacu is easily differentiated from most glassfrogs by lacking webbing between inner fingers (Figure 171) and having, in life, a greyish-green dorsum with numerous yellow spots, which sometimes are surrounded by an ill-defined black ring (i.e., false ocelli; Figure 170). On the Pacific slopes of the Ecuadorian and Colombian Andes, similar species include the following: N. buenaventura, N. ignotus, N. spilotus, and N. luminosus. Nymphargus buenaventura has a light green dorsum with diffuse pale yellow spots; $N$. ignotus exhibits a pale tan to olive-brown dorsum with black ocelli surrounding orange or yellow spots; N. luminosus has a green dorsum with numerous yellow spots; finally, N. spilotus has an olive green back with small yellow spots [21].
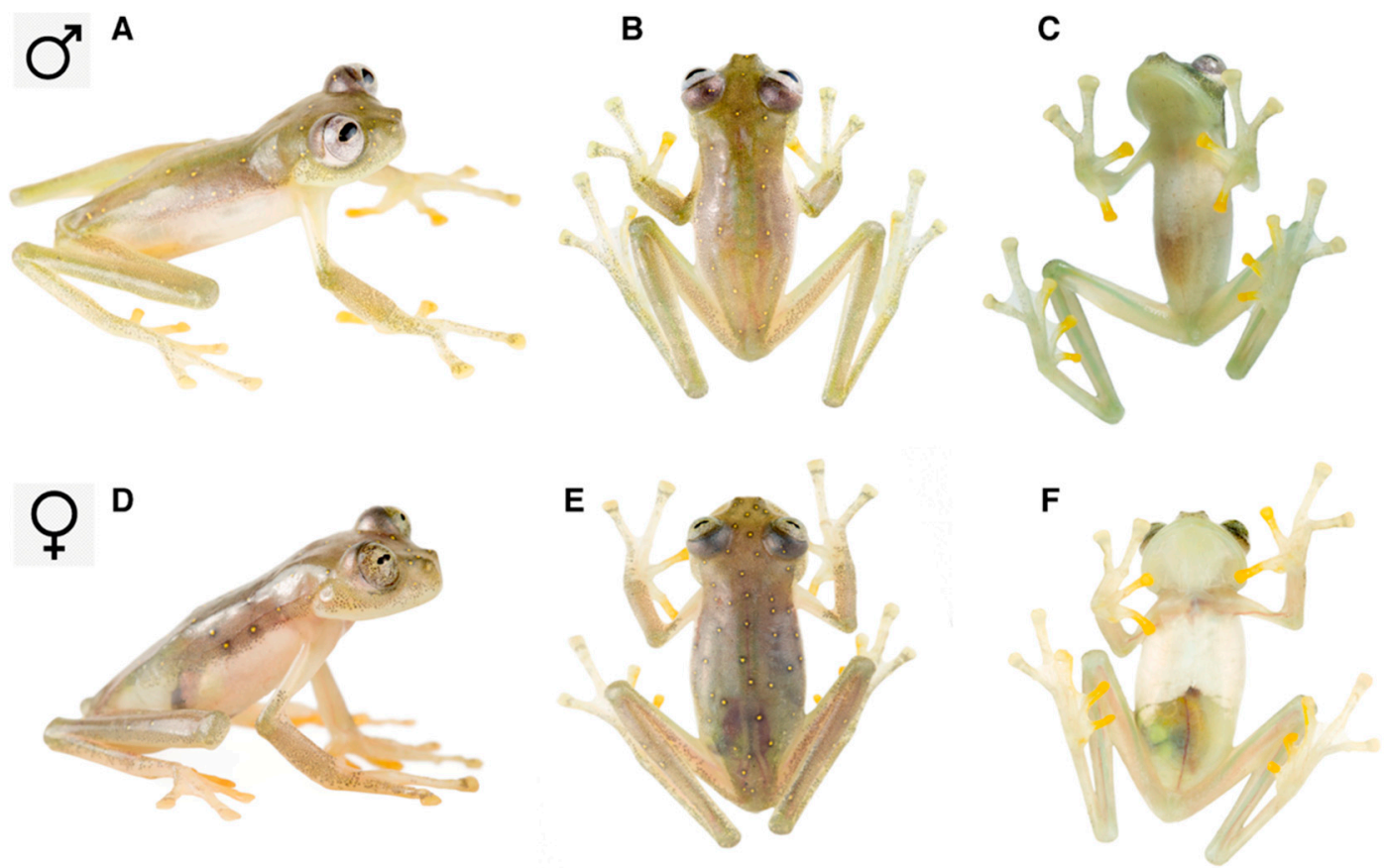

Figure 170. Nymphargus manduriacu in life from Reserva Río Manduriacu, Imbabura province. (A-C) Adult male, ZSFQ 0466. (D-F) Adult female, ZSFQ 0462. Photos by Jose Vieira/Tropical Herping. Obtained from Guayasamin et al. [194].

Diagnosis: Nymphargus manduriacu exhibits the following combination of traits: (1) Dentigerous process of vomer low or absent, lacking vomerine teeth; (2) snout truncated in dorsal view, and truncated to slight rounded in lateral view; (3) tympanic annulus barely evident, lower three-fourths visible, tympanic membrane colored as dorsal skin, supratympanic fold present; (4) dorsal skin shagreen, with microspicules in adult males; (5) ventral skin granular, subcloacal area with two large subcloacal warts; (6) parietal peritoneum white, iridophores covering one-third to one-half parietal peritoneum (conditions P2 or P3); pericardium white (i.e., covered by iridophores), all other visceral peritonea 
clear (condition V1); (7) liver lobed and hepatic peritoneum clear (lacking iridophore layer, condition H0); (8) adult males lacking humeral spines; (9) webbing between Fingers I, II, and III absent, basal between Fingers III and IV (Figure 171); (10) toe webbing basal between Toes I and II, III $1^{\frac{1}{2}}-\left(2^{\frac{1}{2}}-3^{-}\right)$III $\left(1^{1 / 3}-1^{\frac{1}{2}}\right)-\left(3-3^{-}\right)$IV $\left(3-3^{-}\right)-\left(1^{\frac{1}{2}}-2^{-}\right) \mathrm{V}$; (11) lacking dermal ornamentations in the form of tubercles, folds, or fringes on hands, arms, feet, or legs; (12) nuptial excrescences Type I and VI; concealed prepollex; (13) Finger I slightly longer than Finger II; (14) diameter of eye larger than width of disc on Finger III; (15) color in life, greyish green to olive green with yellow spots, which, sometimes, are surrounded an ill-defined black ring (i.e., false ocelli); bones green; (16) color in preservative, lavender dorsum with cream spots; (17) iris coloration in life: Light grey with thin grey reticulations and pale yellow hue around pupil; (18) melanophores present and abundant along Fingers III and IV, less dense on Finger II, and rarely present on Finger I; furthermore, present and abundant along Toes IV and V, less dense on Toe III, only at the base of Toes I and II; (19) males call from upper side of leaves; advertisement call is a high-pitched "chirp", with a single, pulsed note with a duration of 0.093-0.118 s $(\bar{X}=0.10 \pm 0.007$; $n=10)$ and a dominant frequency at $4052-4447 \mathrm{~Hz}(\overline{\mathrm{X}}=4267.7 \pm 118.3)$; (20) fighting behavior unknown; (21) egg masses deposited on upper side of leaves, clutch size 15-32 $(n=4)$; no long-term parental care provided by either males or females; (22) tadpoles undescribed; (23) SVL in adult males 24.0-25.7 mm $(n=3)$, and in an adult female $28.8 \mathrm{~mm}$.
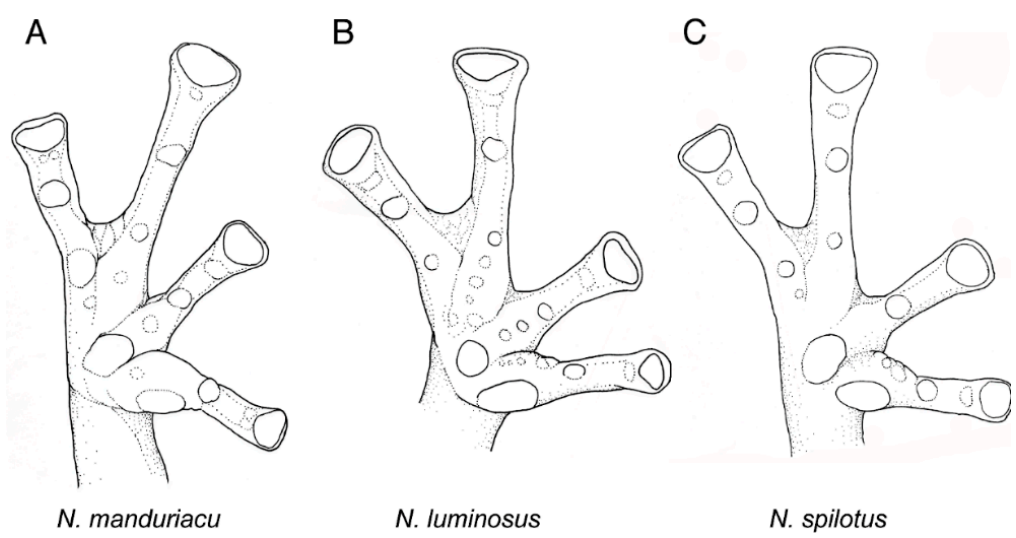

Figure 171. Hand webbing of Nymphargus manduriacu and similar species. (A) N. manduriacu, ZSFQ 0463, adult male, paratype. (B) N. luminosus, ICN 15930, adult female, holotype. (C) N. spilotus, ICN 35255, adult female, holotype. Modified from Guayasamin et al. [194].

Color in life (Figure 170): Dorsal surfaces greyish green to olive green with yellow spots, with melanophores concentrated around yellow spots, sometimes looking like false ocelli. Upper lip unpigmented. Inner fingers and toes with yellowish hue. Anterior half of ventral parietal peritoneum white, posterior portion translucent. Green bones. Iris light grey with thin, dark grey reticulations and pale-yellow hue around pupil [21].

Color in ethanol: Dorsal surfaces of body and limbs grey lavender with small white spots. Parietal peritoneum white, iridophores covering one-third to one-half parietal peritoneum. Heart white (covered by iridophores); all other visceral peritonea unpigmented [21].

Biology and ecology: Nymphargus manduriacu has only been found at Río Manduriacu Reserve and, although the reserve has been visited several times, $N$. manduriacu was only regularly detected during February 2018, with the site experiencing particularly heavy rains on a daily basis [21].

Call (Figure 172): The advertising call was described by Guayasamin et al. [21], as follows. Each call is a high-pitched "chirp" that consists of a single note with a duration of 0.093-0.118 s $(\bar{X}=0.10 \pm 0.007 ; n=10)$. Notes are clearly pulsed ( $8-12$ pulses per note; $\bar{X}=10.33 \pm 1.366)$. In each call, there is a slight increase in the dominant frequency with time; the dominant frequency is at $4052-4447 \mathrm{~Hz}(\bar{X}=4268 \pm 118.3)$. Time between calls is 3.9-8.6 s $(\bar{X}=5.72 \pm 1.82)$. 


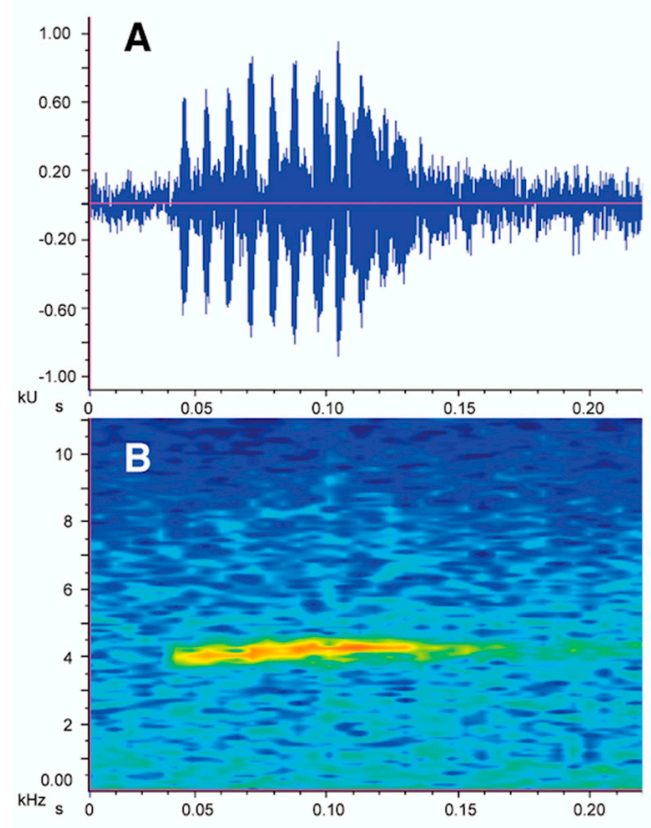

Figure 172. Call of Nymphargus manduriacu, LBE-C-042, from Reserva Río Manduriacu. (A) Oscillogram. (B) Audio-spectrogram. Obtained from Guayasamin et al. [21].

Tadpole: Not described.

Distribution (Figure 173): Nymphargus manduriacu is known from a few streams within the Río Manduriacu Reserve $\left(0.31^{\circ} \mathrm{N}, 78.85^{\circ} \mathrm{W} ; 1215-1242 \mathrm{~m}\right)$, Imbabura province, Ecuador [21].

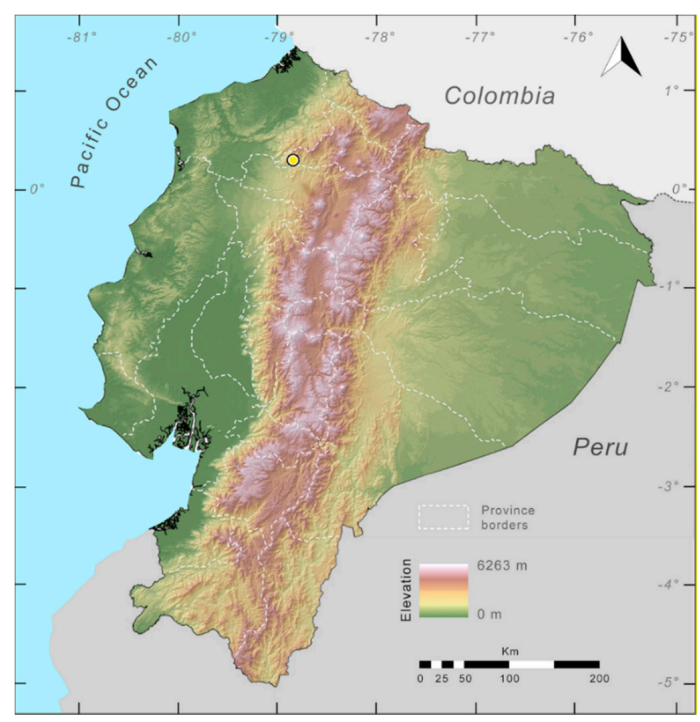

Figure 173. Distribution of Nymphargus manduriacu in Ecuador (yellow dot).

Conservation status: Guayasamin et al. [21] suggest placing the species in the Critically Endangered. At Río Manduriacu Reserve (the only known locality of the species), mining has become one the most dangerous threat to biodiversity, especially to species with restricted distributions.

Evolutionary relationships: N. manduriacu was inferred as sister to N. balionotus [21].

Specimens examined: Ecuador: Imbabura province: Reserva Río Manduriacu $\left(0.310^{\circ} \mathrm{N}, 78.857^{\circ} \mathrm{W}\right.$; 1215-1230 m), ZSFQ 0462-66 (type series). 
Nymphargus megacheirus (Lynch and Duellman, 1973 [22]; Figures 174-176).

Centrolenella megacheira Lynch and Duellman, 1973 [22]. Holotype: KU 143245.

Type locality: "16.5 km NNE of Santa Rosa, 1700 m, on Quito-Lago Agrio road, Provincia Napo, Ecuador".

Cochranella megacheira-Ruiz-Carranza and Lynch, 1991 [6].

Nymphargus megacheirus - Cisneros-Heredia and McDiarmid, 2007 [17].

Common names: English: Large-handed Glassfrog. Spanish: Rana de Cristal de manos grandes. Etymology: The specific epithet is from the Greek words megas, meaning large, and cheiros, meaning hand; the name is used to refer to the exceedingly large hands of the species [22].

Identification: Nymphargus megacheirus can be distinguished from other glassfrogs by its green dorsum with small blue to black spots (Figure 174), relatively large size (adult males, SVL 26.8-31.5 mm; adult females, SVL 31.2-32.9 mm), basal or no webbing among fingers (Figure 175), and lack of humeral spines. On the Amazonian slopes of the Ecuadorian Andes, only N. cochranae has similar characteristics; however, N. cochranae has small dark ocelli enclosing orange dots on the dorsum (Figure 140), whereas N. megacheirus has solid dark spots (Figure 174). Nymphargus megacheirus has a similar dorsal coloration and hand-webbing pattern as $N$. garciae, but the two species have allopatric distributions with N. garciae inhabiting higher elevations (1900-2700 m) than N. megacheirus (1300-1740 m). Additionally, N. megacheirus is slightly larger than $N$. garciae ( $N$. garciae, SVL 25.1-29.9 mm in adult males: SVL 25.9-28.4 $\mathrm{mm}$ in adult females).

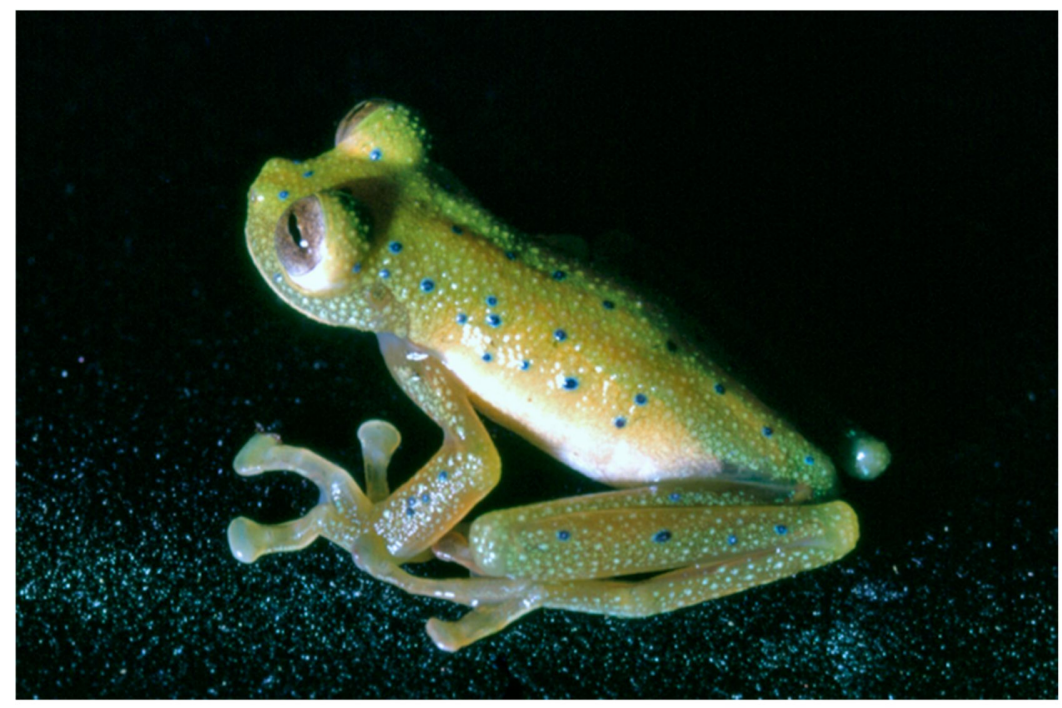

Figure 174. Nymphargus megacheirus in life. Adult male, holotype, KU 143245. Photo by W. E. Duellman.

Diagnosis: (1) Vomers lacking teeth; (2) snout truncated in dorsal and lateral profiles (Figure 175); (3) tympanum relatively small, its diameter $18.8 \%-25.4 \%$ eye diameter, dorsal border of tympanic annulus covered by supratympanic fold, tympanic membrane pigmented as surrounding skin; (4) dorsal skin of males shagreen to pustular, shagreen in females; numerous spicules present in males; in females, spicules present only on head, tympanic region, and limbs; (5) skin of venter areolate; pair of enlarged subcloacal warts; (6) anterior two-thirds to three-fourths of venter covered by white parietal peritoneum, posterior portion transparent (condition $\mathrm{P} 3$ ); white pericardium; translucent peritoneum covering intestines, stomach, testes, kidneys, gall bladder, and urinary bladder (condition V1); (7) liver tetralobed, two large ventral lobes partially covering two smaller lobes; hepatic peritoneum transparent (condition H0); (8) humeral spines absent; (9) hand webbing absent between inner finger, absent or basal between outer fingers (Figure 175), webbing formula: III $\left(2^{1 / 2}-3\right)-\left(2^{1 / 2}-3\right) \mathrm{IV}$; (10) foot about one-half webbed: I 
$\left(2-2^{-}\right)-\left(2^{+}-2^{1 / 2}\right)$ II $\left(1-1^{2 / 3}\right)-\left(2^{1 / 2}-2^{2 / 3}\right)$ III $\left(1^{+}-1^{3 / 4}\right)-\left(2^{1 / 2}-3^{-}\right)$IV $\left(2^{1 / 2}-3^{-}\right)-\left(1^{1 / 2}-2^{-}\right)$V; (11) ulnar fold conspicuous; tarsal folds low; (12) concealed prepollex; in males, nuptial pad Type I; (13) Finger I usually slightly shorter than Finger II (Finger I 88.9\%-101.3\% length of Finger II); (14) disc of Finger III relatively large, $49.7 \%-59.0 \%$ eye diameter; (15) in life, dorsum green with blue to black dots (Figure 174); bones green; (16) in ethanol, dorsal surfaces lavender with small dark purple dots; (17) iris greyish bronze with thin black reticulation; (18) dorsal surfaces of fingers and toes lacking melanophores; (19) males call from upper side of leaves overhanging streams; calls unknown; (20) fighting behavior unknown; (21) eggs deposition site and parental care unknown; (22) tadpoles unknown; (23) medium body size; in adult males, SVL $26.8-31.5 \mathrm{~mm}(\bar{X}=28.3 \pm 0.902, n=29)$; in adult females, SVL $31.2-32.9 \mathrm{~mm}$ $(\bar{X}=32.3 \pm 0.7805, n=4)$.

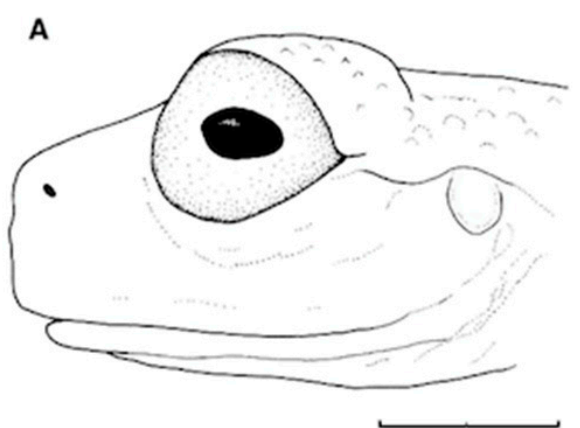

B

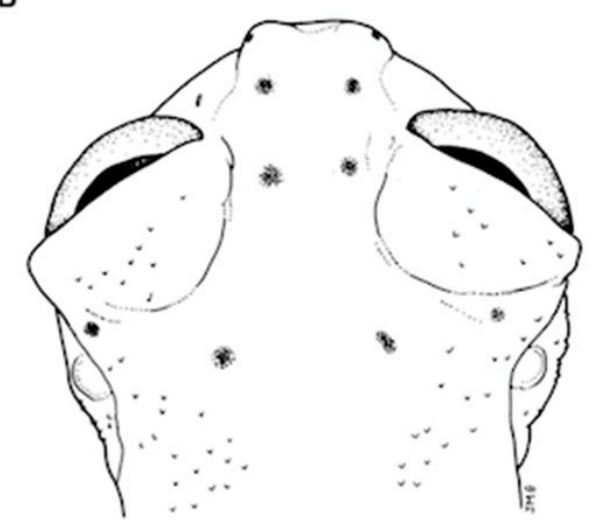

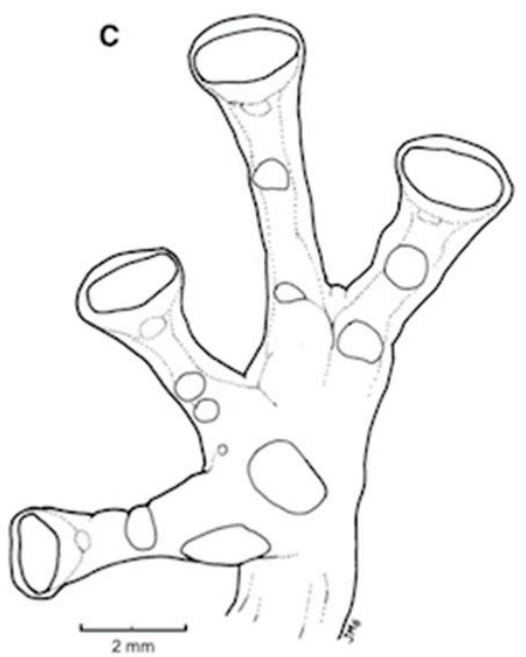

Figure 175. Nymphargus megacheirus, KU 143269. (A) Head in lateral view. (B) Head in dorsal view.

(C) Hand in ventral view. Illustrations by Juan M. Guayasamin.

Color in ethanol: Dorsal surfaces of head, body, forelimbs, and hind limbs lavender with small, round, black spots [22]. White lining covering pericardium and nearly two-thirds of anterior ventral parietal peritoneum. Liver, intestines, stomach, testes, kidneys, gall bladder, and urinary bladder lack iridophores.

Biology and ecology: Nymphargus megacheirus is active at night. During the reproductive season, males were calling from the upper surfaces of leaves overhanging fast-moving streams in cloud forest at the type locality (16.5 km NNE of Santa Rosa) in October 1971; Espadarana audax, Centrolene pipilata, and N. siren were also found there. At the Río Azuela, N. anomalus, N. siren, Hyalinobatrachium pellucidum, and C. pipilata occurred along the same streams with Nymphargus megacheirus [22]. Parental care is unknown.

Call: Not described.

Tadpole: Not described. 
Distribution (Figure 176): Nymphargus megacheirus is endemic to the Amazonian slope of the Andes of Ecuador and Colombia at elevations between 1300 and $1750 \mathrm{~m}$ ([22,101], this work). In Ecuador, this species has been reported from the provinces of Napo and Sucumbíos (Specimens Examined). The habitat of the species in Ecuador is within the Eastern Montane Forest region.

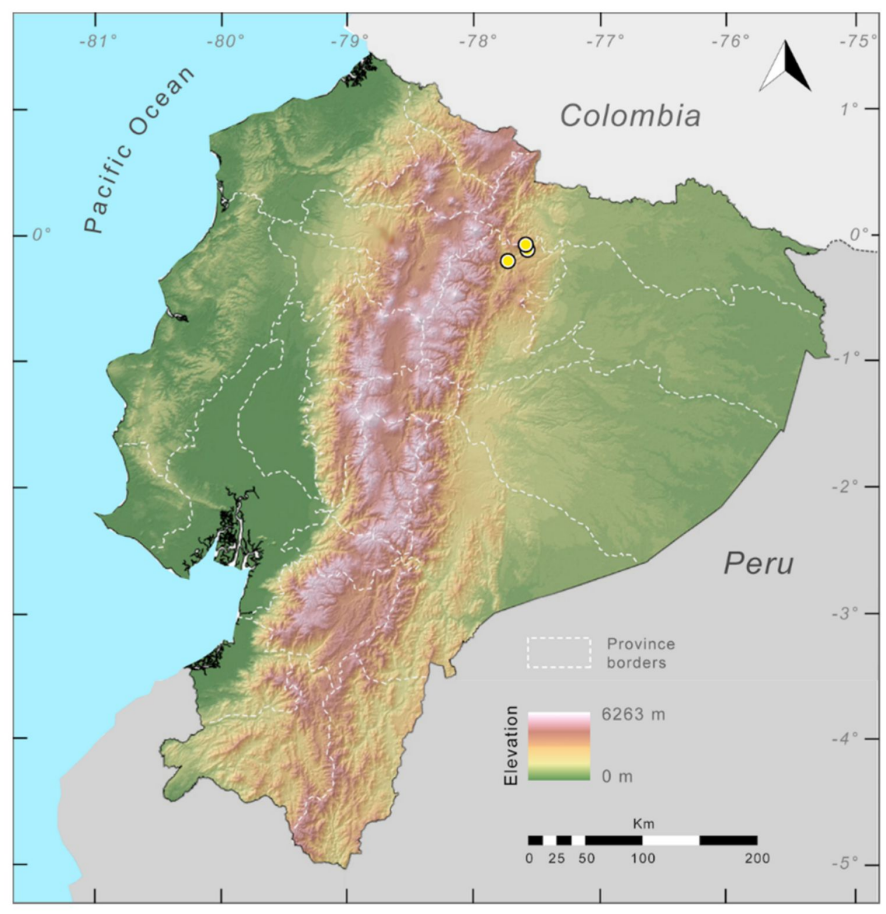

Figure 176. Distribution of Nymphargus megacheirus in Ecuador (yellow dots).

Color in life (Figure 174): Dorsal surfaces green with small blue to black spots. Ventral surfaces mostly white, except for translucent posterior third of venter. Upper lip and ulnar folds white. Bones green. Iris greyish bronze [22].

Conservation status: Globally listed as Endangered by the IUCN [271]. The last records of Nymphargus megacheirus correspond to specimens collected at Río Azuela and Río Salado on 24 February 1979 (USNM 286700-01, RWM, pers. obs. [17]). Surveys at Río Azuela have failed to find additional individuals [91]. Then, considering its limited distribution and lack of recent records, we suggest that the species should be considered as Critically Endangered.

Evolutionary relationships (Figure 136): With the current taxon and gene sampling, Nymphargus megacheirus is sister to N. anomalus.

Specimens examined: Nymphargus megacheirus: Ecuador: Provincia de Napo: $16.5 \mathrm{~km}$ NNE Santa Rosa (0.21861 S, 77.7319 W, 1700 m), KU 143245-72; $14.7 \mathrm{~km}$ (by road) NE of Río Salado (0.12889 S, $77.6083 \mathrm{~W}, 1300 \mathrm{~m})$, USNM 286701; 2 km SSW Río Reventador (0.1 S, 77.6 W, 1700 m), KU 164614; Provincia de Sucumbios: Río Azuela (0.1167 S, 77.6167 W, 1740 m), KU 143273-77, 166329; Rio Azuela, where river crosses Quito road (0.1166 S, 77.6166 W, $1700 \mathrm{~m}$.), USNM 286700. Colombia: Departamento de Putumayo: 10.3 km W El Pepino (1.05 N, 76.9559 W, 1300 m), KU 169664-65. 
Nymphargus posadae (Ruiz-Carranza and Lynch, 1995 [255]; Figures 177-179).

Cochranella posadae Ruiz-Carranza and Lynch, 1995 [255]. Holotype: ICN 11307.

Type locality: “Departamento de Cauca, municipio de Inzá, Km 61 carretera Popayán a Inzá,

vertiente oriental Cordillera Central, $2^{\circ} 34^{\prime}$ latitud, $76^{\circ} 4^{\prime} \mathrm{W}$ de Greenwich, $2800 \mathrm{~m}$ ",

Colombia.

Nymphargus posadae—Cisneros-Heredia and McDiarmid 2007 [17].

Common names: English: Posada's Glassfrog. Spanish: Rana de Cristal de Posada.

Etymology: The specific epithet honors Dr. Andrés Posada Arango, for his work in the fields of zoology, botany, education, and conservation biology in Colombia [255].

Identification: Among glassfrogs that inhabit the Amazonian slopes of the Ecuadorian Andes, Nymphargus posadae is unique by having a green dorsum with small greenish-white warts (Figure 177), a slightly sloping snout in lateral profile, and by lacking webbing between fingers. The only species that could be confused with N. posadae is Centrolene buckleyi, which has humeral spines in adult males (humeral spines absent in N. posadae).

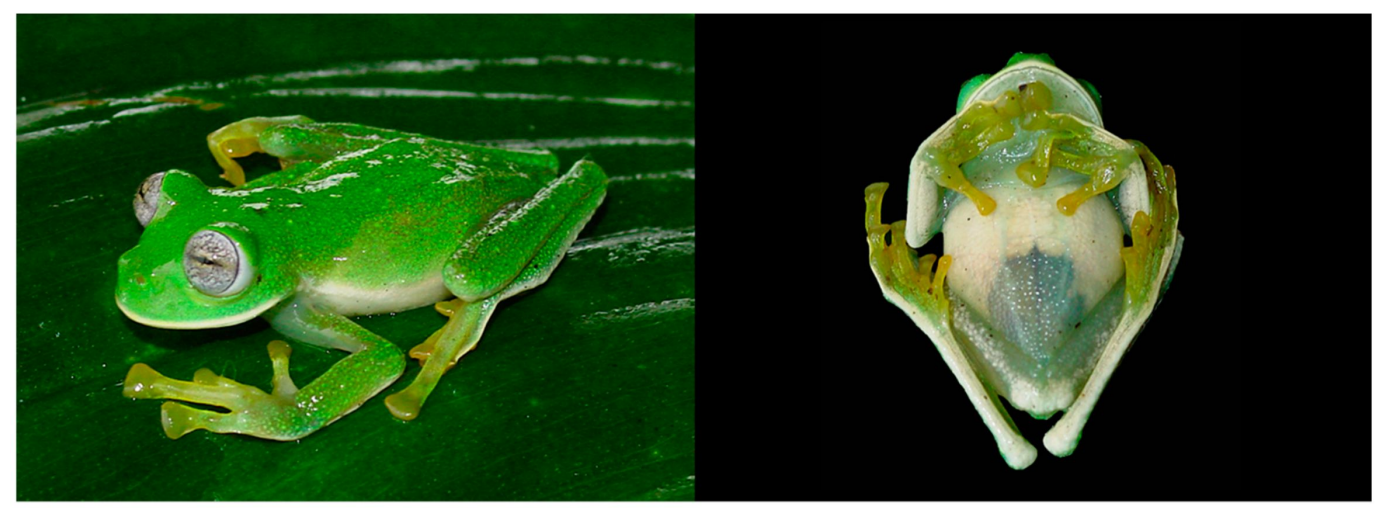

Figure 177. Nymphargus posadae in life. Adult male from Yanayacu Biological Station, $2100 \mathrm{~m}$, Napo province, Ecuador, QCAZ 25090. Photos by Martín Bustamante.

Diagnosis: (1) Vomers with edentate dentigerous process; (2) snout truncated to round in dorsal aspect, and truncated to slightly sloping in lateral profile (Figure 178); (3) tympanum almost indistinguishable; small when visible, its diameter $21.2 \%-26.5 \%$ of eye diameter; tympanic membrane not differentiated from surrounding skin; supratympanic fold present; (4) dorsal skin covered with numerous small warts and some scattered larger warts; no spicules visible; (5) ventral skin areolate; pair of enlarged subcloacal warts; (6) white parietal peritoneum covering anterior $50 \%-60 \%$ of venter (condition P2); white pericardium; no iridophores in peritonea covering intestines, stomach, and kidneys; translucent peritoneum around gall and urinary bladders (condition V1); (7) liver lobate, covered by transparent peritoneum (condition H0); (8) humeral spines absent; (9) webbing between fingers absent or greatly reduced; webbing formula: III $\left(2^{3 / 4}-3^{-}\right)-\left(2^{2 / 3}-2^{3 / 4}\right) \mathrm{IV} ;(10)$ feet about two-thirds webbed; webbing formula: I $\left(2^{-}-2\right)-\left(2^{+}-2^{1 / 4}\right) \mathrm{II}\left(1^{1 / 3}-1^{1 / 2}\right)-\left(2^{1 / 3}-2^{3 / 4}\right) \mathrm{III} 1^{1 / 2}-\left(2^{2 / 3}-2^{3 / 4}\right)$ IV ( $\left.2^{3 / 4}-3\right)-2^{-} \mathrm{V}$; (11) ulnar and tarsal folds low or absent; (12) concealed prepollex; in males, nuptial pad Type I; (13) Finger II longer than Finger I (Finger I length 92.2\%-95.7\% of Finger II); (14) disc width of Finger III about $49.3 \%-52.9 \%$ of eye diameter; (15) in life, dorsum green with small greenish-white warts; bones green; (16) in preservative, dorsum lavender with small white dots; (17) iris white with thin dark grey reticulations; (18) dorsal surfaces of fingers and toes lacking melanophores, except for proximal portion of Toes IV and V; (19) males call from upper surfaces of leaves; calls unknown; (20) fighting behavior unknown; (21) eggs deposition site and parental care unknown; (22) tadpole unknown; (23) large body size; male SVL 30.7-34.1 mm ( $\bar{X}=32.3, n=6)$; female SVL 30.2-33.3 mm $(\overline{\mathrm{X}}=31.4, n=4)$. 
A

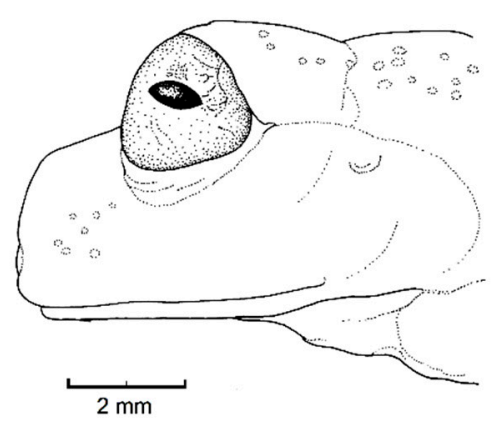

B

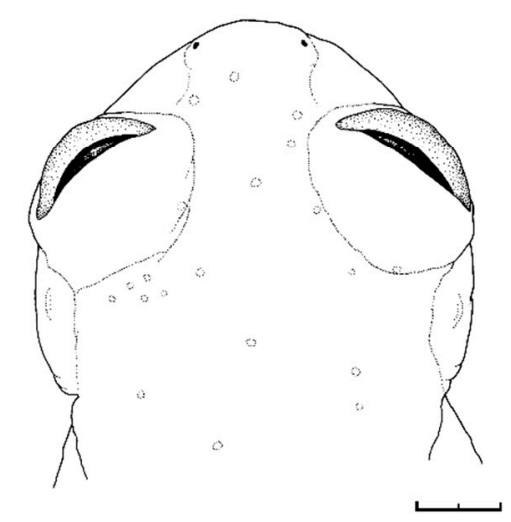

C
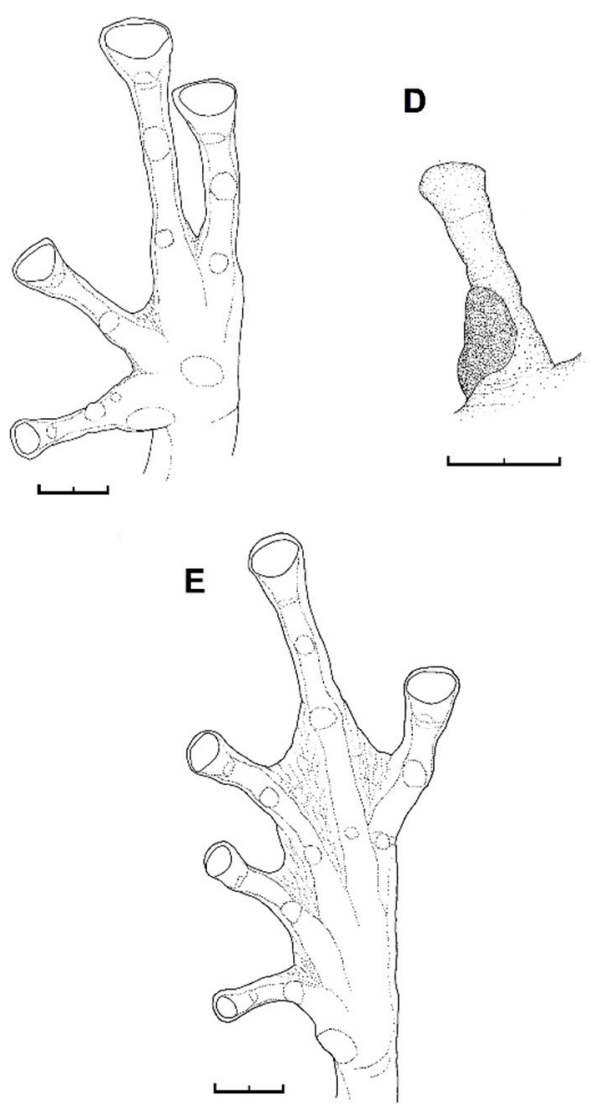

Figure 178. Nymphargus posadae, adult males from Yanayacu Biological Station, Napo province, Ecuador. (A) Head in lateral view, QCAZ 26023. (B) Head in dorsal view, QCAZ 26023. (C) Hand in ventral view, QCAZ 25090. (D) Finger I in dorsal view, QCAZ 26023. (E) Foot in ventral view, QCAZ 26023. Modified from Guayasamin et al. [20].

Color in life (Figure 177): The following description corresponds to individuals from Yanayacu Biological Station [20]. Dorsal surfaces of head, body, and limbs bright green with small, scattered, greenish-white warts. Upper lip white; lower lip with thin white border. Ventrolateral border of arm, Finger IV, tarsus, and Toe V white. Cloacal region with numerous small, white warts. White parietal peritoneum covering about anterior half of venter. Iris white with thin dark grey reticulations.

Color in ethanol: Dorsal surfaces of head, body, and limbs lavender with some larger warts being bluish white. Upper lip white; thin white line evident on lower lip. Ventrolateral border of arm, Finger IV, tarsus, and Toe V white. Ventral surfaces of forearm and tarsus completely covered with white in two specimens (QCAZ 25090 and 26022). Dorsally, Fingers I and II and Toes I, II, and III unpigmented: Some pigmentation visible on Fingers III and IV and Toes IV and V. Cloacal region with several white warts. In adult males, nuptial pad cream (Type I). Parietal peritoneum white anteriorly, covering approximately $50 \%-60 \%$ of venter. Pericardium silver white. No iridophores on the hepatic peritoneum, digestive tract, or kidneys ([20], this work).

Variation: Males from Yanayacu Biological Station are smaller (SVL $=30.7-31.9, n=3)$ than those from Colombian localities (SVL $=32.7-34.1 \mathrm{~mm}, n=3$ ) [20,255].

Biology and ecology: In Colombia, the species was observed on vegetation and rocks along a creek [255]. Carranza and Lynch [255] reported that the eggs have a pigmented animal pole (dark brown) and unpigmented vegetal pole (cream). Unfortunately, they did not mention where the eggs were deposited. In Ecuador, three individuals were collected during three years of inventory work at 
Yanayacu; all frogs were found calling on the same night (12 June 2003), on ferns $110-220 \mathrm{~cm}$ above a stream. Males call from the upper surfaces of leaves [20]. Parental care is unknown.

Call: Not described.

Tadpole: Not described.

Distribution (Figure 179): In Colombia, Nymphargus posadae is known from the Caldas, Cauca, and Huila departments on the eastern flank of the Central Cordillera of the Andes, between 1100 and $2800 \mathrm{~m}$ [255]. In Ecuador, the species has been reported from localities on the Amazonian slopes of the Andes at elevations of $1750-2100 \mathrm{~m}([17,20]$, this work). Nymphargus posadae is also present in Peru (Cordillera del Cóndor) [272].

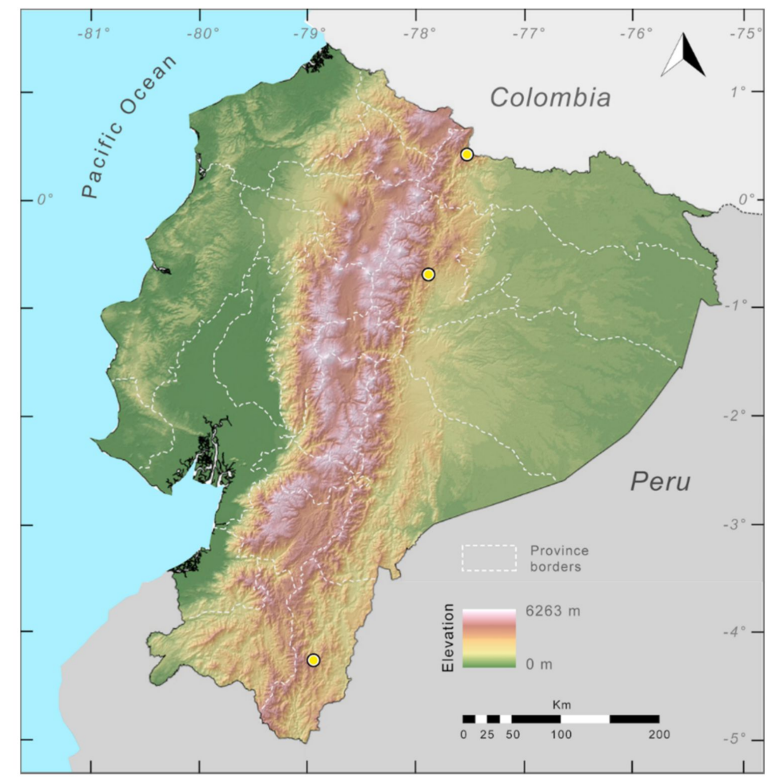

Figure 179. Distribution of Nymphargus posadae in Ecuador (yellow dots).

Conservation status: Globally, Nymphargus posadae is considered as Least Concern by the IUCN [273]. The species has a relatively large distribution and it is found within several protected areas. Thus, we agree with the current conservation assessment.

Evolutionary relationships (Figure 136): Given the current taxon and gene sampling, Nymphargus posadae is sister to N. pluvialis.

Specimens examined: Nymphargus posadae: Colombia: Departamento de Huila: $6.2 \mathrm{~km}$ NW of San José de Isnos, $1940 \mathrm{~m}$. Ecuador: Provincia de Napo: Yanayacu Biological Station $\left(0^{\circ} 41^{\prime} \mathrm{S}, 77^{\circ} 53^{\prime} \mathrm{W}\right.$; 2100 m), QCAZ 25090, 26022-23. Provincia de Zamora Chinchipe: tributary of Río Jambue, ca. $15 \mathrm{~km}$ S from Zamora (ca. $4^{\circ} 14^{\prime}$ S, 78 57' W; 1750 m). Provincia de Sucumbíos: Río Chingual, ca. $3 \mathrm{~km} \mathrm{~N}$ of Sebundoy, ca. $20 \mathrm{~km} \mathrm{~N}$ of La Bonita (ca. $0^{\circ} 26^{\prime} \mathrm{S}, 77^{\circ} 32^{\prime} \mathrm{W}$; $1890 \mathrm{~m}$ ), USNM 288464-65. Peru: Cordillera del Cóndor (ca. $05^{\circ} 25^{\prime} 16.5^{\prime \prime} \mathrm{S}, 78^{\circ} 35^{\prime} 23.2^{\prime \prime} \mathrm{W} ; 1890 \mathrm{~m}$ ). 
Nymphargus siren (Lynch and Duellman, 1973 [22]; Figures 180-182).

Centrolenella siren Lynch and Duellman, 1973 [22]. Holotype: KU 146610.

Type locality: "small tributary of the Río Salado, about $1 \mathrm{~km}$ upstream from the Río Coca, 1410 m, Provincia Napo, Ecuador."

Cochranella siren-Ruiz-Carranza and Lynch, 1991 [6].

emphNymphargus siren-Cisneros-Heredia and McDiarmid, 2007 [17].

Common names: English: Siren Glassfrog. Spanish: Rana de Cristal sirena.

Etymology: In Greek mythology, sirens were bird-women, who by their sweet singing enticed seafarers to destruction; the name is used in allusion to the calls of these frogs that entice biologists to the nocturnal perils of streams [22].

Identification: Among glassfrogs that inhabit the Amazonian slopes of the Ecuadorian Andes, Nymphargus siren (Figure 180) is distinguished by having a green dorsum with small yellow spots, a partially white venter, small size (male SVL $<22.6 \mathrm{~mm}$; female SVL $<23.3 \mathrm{~mm}$ ), and lacking humeral spines. Similar species from eastern Ecuador include Espadarana audax, Nymphargus humboldti sp. nov., Rulyrana flavopunctata, and Teratohyla midas. Differences among these species include the presence of humeral spines in adult males of E. audax (humeral spines absent in N. siren), moderate webbing between Fingers III and IV in E. audax and R. flavopunctata (webbing absent in N. siren and basal in T. midas), and the white peritoneal covering of the digestive tract of $T$. midas (digestive tract opaque or translucent in N. siren, E. audax, and R. flavopunctata). Nymphargus humboldti sp. nov. and $N$. siren have non-overlapping body sizes ( $N$. humboldti sp. nov., male SVL = 23.3-25.2 mm; female SVL $=24.3-25.9 \mathrm{~mm})$.

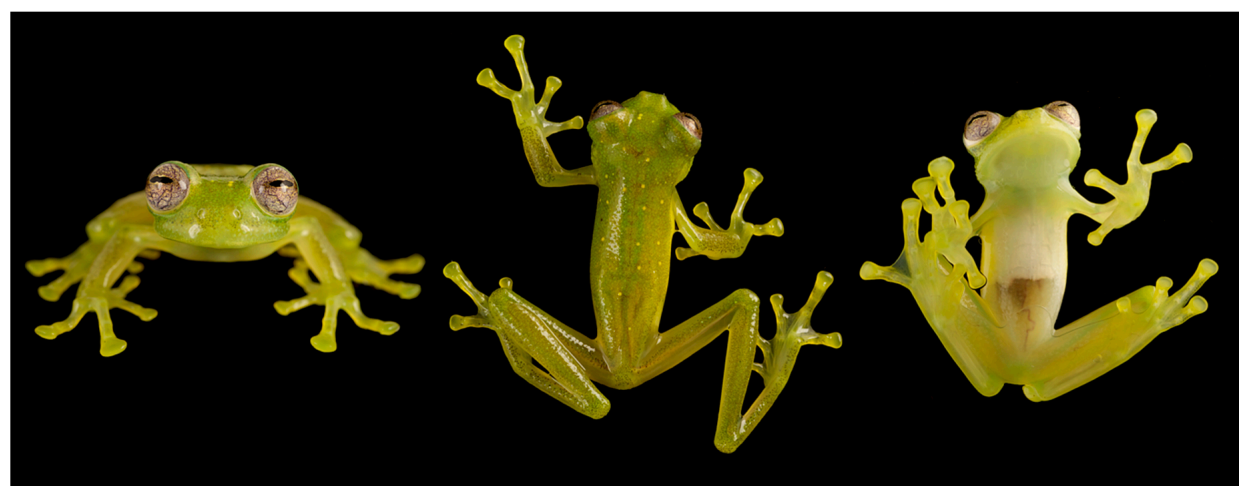

Figure 180. Nymphargus siren in life. Individual (MZUTI 774) from creek on the Oyacachi-El Chaco trail, 1878 m, Napo province, Ecuador. Photos by Luis A. Coloma.

Diagnosis: (1) Vomers with edentate dentigerous process; (2) snout usually truncated in dorsal aspect; truncated to slightly protruding in lateral profile (Figure 181), (3) tympanum oriented almost vertically, with slight lateral and posterior inclinations, its diameter about $20.5 \%-30.5 \%$ of eye diameter; upper fourth of tympanic annulus obscured by supratympanic fold; tympanic membrane clearly differentiated from surrounding skin; (4) dorsal skin shagreen, usually with spicules in males; (5) pair of enlarged subcloacal warts; (6) white parietal peritoneum covering anterior half of venter (condition P2); white pericardium; translucent to opaque peritonea covering intestines, stomach, and kidneys; translucent peritoneum around gall and urinary bladders (condition V1); (7) liver lobate, covered by transparent peritoneum (condition $\mathrm{H0}$ ); (8) humeral spines absent; (9) webbing absent between inner fingers, absent or basal between outer fingers (Figure 181); webbing formula IV $\left(2^{2 / 3}-3\right)-\left(2^{1 / 4}-2^{3 / 4}\right)$ $\mathrm{V}$; (10) feet about two-thirds webbed; webbing formula: I $\left(2^{-}-2\right)-\left(2^{+}-2^{1 / 2}\right)$ II $\left(1^{1 / 4}-1^{1 / 2}\right)-\left(2^{1 / 2}-3^{-}\right)$III $\left(1^{+}-2^{-}\right)-\left(2^{3 / 4}-3^{-}\right)$IV $\left(3^{-}-3\right)-\left(2^{-}-2\right) \mathrm{V} ;(11)$ ulnar fold absent; external tarsal fold absent; low inner tarsal fold evident; (12) concealed prepollex; in males, nuptial pad Type I; (13) Finger II slightly longer 
than Finger I (Finger I length $91.5 \%-99.6 \%$ of Finger II); (14) disc of Finger III width about $43.3 \%-58.5 \%$ of eye diameter; (15) in life, dorsum green with small yellow spots (Figure 180); bones green; (16) in preservative, dorsum lavender with small white spots; (17) iris, in life, whitish cream, with a yellow hue around pupil and fine, dark grey reticulations; (18) melanophores absent from dorsal surfaces of fingers and toes, except for few on Toe V; (19) males call from upper surface of leaves, call unknown; (20) fighting behavior unknown; (21) egg deposition site and parental care unknown; (22) tadpoles unknown; (23) minute body size; males, SVL 19.8-22.6 mm ( $\bar{X}=20.9 \pm 0.931, n=24)$; females, SVL 22.5-23.3 $\mathrm{mm}(n=2)$.

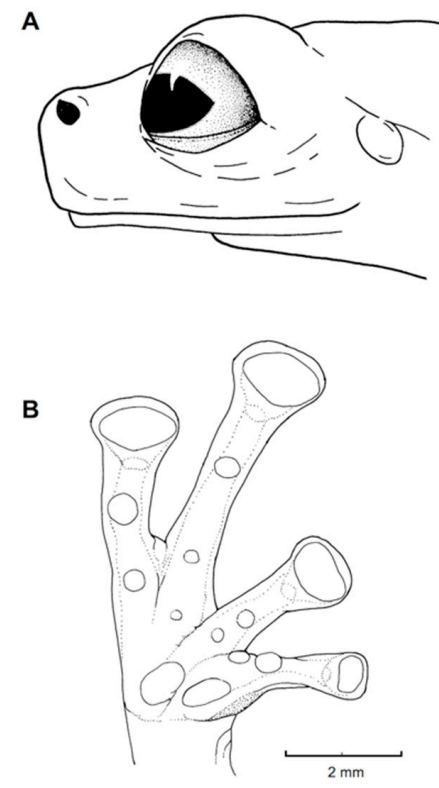

Figure 181. Nymphargus siren, KU 146610. (A) Head in lateral view. (B) Hand in ventral view. Illustrations by Juan M. Guayasamin.

Color in life (Figure 180): Green dorsum with small yellow spots, which are narrowly bordered by black in some individuals [22]. Anterior half of venter white, posterior half transparent. Bones green. Iris whitish cream, with yellow hue around pupil and fine, dark grey reticulations.

Color in ethanol: Dorsal surfaces of head, body, and limbs light to dark lavender with small white spots. Anterior half of ventral parietal peritoneum white; posterior half translucent. Translucent peritonea covering gall and urinary bladders. Iridophores absent from digestive tract, liver, and kidneys.

Variation: Spicules are absent in a few males (KU 164636, 297290). As noted, the presence of spicules may be a reflection of reproductive activity. Two males (KU 178199, 297292) lack yellow spots on the dorsum.

Biology and ecology: Relatively large numbers of individuals of Nymphargus siren, including calling males, were observed at the type locality on 7 April 1972 (13 individuals) and again on 18 March 1975 (15 individuals; WED's field notes). Many specimens were also noted at $3.2 \mathrm{~km}$ NNE Oritoyacu on 15 July 1977 (21 individuals; John D. Lynch's field notes). Males call from the upper surfaces of leaves (WED field notes, 7 April 1972). Parental care is unknown.

Call (Figure 182): We analyzed 14 notes from two individuals (MZUTI 765, 775). The typical advertisement call is short and is composed by a single note. Note duration is $20-42$ (mean $=24$, $\mathrm{SD}=7$ ) ms. Notes are generally pulsed and have one to three (mean $=2.2, \mathrm{SD}=0.6$ ) amplitude peaks, where the first peak is more pronounced that the others. Notes have their peak amplitude in the first $50 \%$ of the note (relative peak time: Range $=0.0595-0.1751$, mean $=0.123, \mathrm{SD}=0.032$ ). Pulses within a note have a rate of $24-130$ (mean $=86, \mathrm{SD}=23$ ) pulses per second. The dominant frequency of a note measured at peak amplitude is $4737-6029$ (mean $=4977, \mathrm{SD}=323$ ) $\mathrm{Hz}$ and is contained within 
the fundamental frequency. The fundamental frequency has a lower limit of 4651-5943 (mean $=4842$, $\mathrm{SD}=331) \mathrm{Hz}$ and a higher limit of 4823-6115 (mean = 5088, SD = 318) Hz.

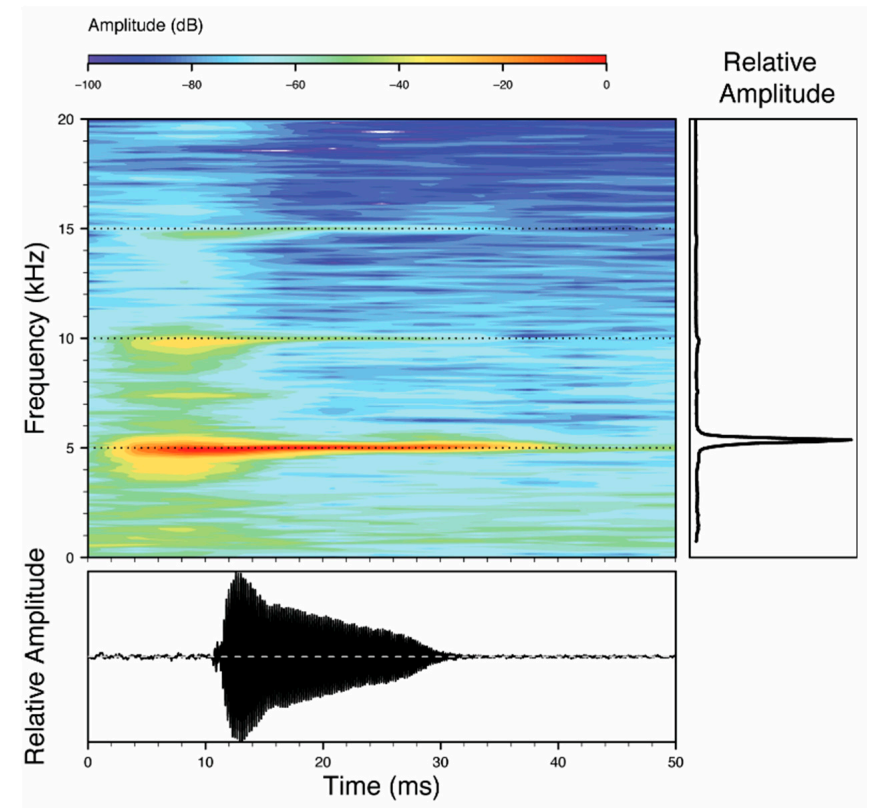

Figure 182. Call of Nymphargus siren, MZUTI 765, recorded at trail between Oyacachi and El Chaco, $1645 \mathrm{~m}$, Napo province, Ecuador. Air temperature $=15^{\circ} \mathrm{C}$.

Tadpole: Not described.

Distribution (Figure 183): Nymphargus siren inhabits the cloud forests of the Amazonian slopes of the Ecuadorian and Colombian Andes at elevations between 1410 and $2000 \mathrm{~m}$ ([22,176], this work). In Ecuador, the species has been reported from the provinces of Napo and Sucumbíos. Rodríguez et al. [274] reported N. siren from Peru (Departamento Ayacucho), but we consider this report to be based on a misidentification and restrict the distribution of N. siren to Colombia and Ecuador. In Ecuador, the potential distribution of the species is $3881 \mathrm{~km}^{2}$ within the Eastern Montane Forest region.

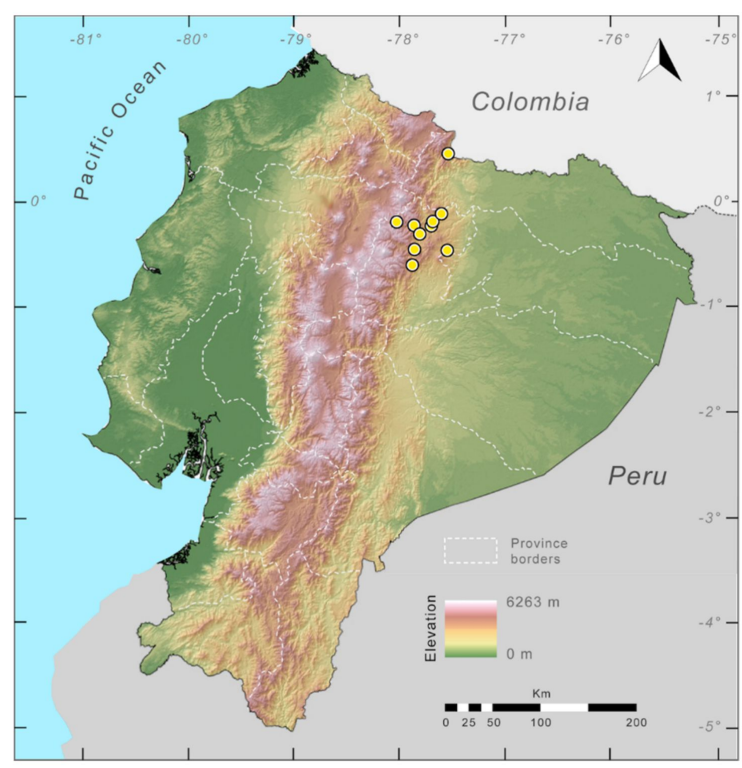

Figure 183. Distribution of Nymphargus siren in Ecuador (yellow dots). 
Conservation status: Nymphargus siren is listed as Vulnerable by the IUCN because the extent of its occurrence is less than $20,000 \mathrm{~km}^{2}$, its distribution is severely fragmented, and the extent and quality of its habitat continues to decline [275]. No data are available on the population demography of the species nor on its susceptibility to chytridiomycosis, climate change, and/or changes on UV radiation. Recent records of N. siren are from the Río Azuela (March 2000) [91], Yanayacu Biological Station (April 2008) [125], and the Oyacachi-El Chaco trail (May 2012; JMG pers. obs.). The population status of the species at localities where it was historically abundant (e.g., Río Salado; $3.2 \mathrm{~km}$ NNE Oritoyacu) is unknown. We maintain its conservation category.

Evolutionary relationships (Figure 136): Nymphargus siren and N. humboldti sp. nov. are sister species.

Remarks: Although Lynch and Duellman [22] mentioned that some individuals have up to two teeth on the dentigerous process of the vomer, all the specimens examined by us had edentate vomers.

Specimens examined: Nymphargus siren: Ecuador: Provincia de Napo: Yanayacu Biological Station, $2100 \mathrm{~m}$, QCAZ 37971, 37975; tributary of the Río Salado, about $1 \mathrm{~km}$ upstream from the Río Coca (0.19167 S, 77.6997 W; 1410 m), KU 146610 (holotype), KU 146611-23 (paratypes), 164635-49, 178191-206, 146610-23, QCAZ 14425, 30975, 30977-80; Baeza (0.46795 S, 77.567 W; 1650 m), KU 190020-21; 16.5 km NNE Santa Rosa (0.2186 S, 77.732 W; 1700 m), KU 143288-89, 143291, 143293-94; 3.2 km NEE Oritoyacu (0.4597 S, 77.867 W; 1910 m), KU 178170-90; Oyacachi-El Chaco trail at elevations between 1645-1800 m, MZUTI 765-776. Provincia de Sucumbíos: Río Azuela (0.11667 S; 77.6167 W, 1740 m), QCAZ 15263, 15266, KU 143295-97, 155499-501; Colombia: Putumayo: 35 km SE of San Francisco, 1950 m, KU 169668-69.

Nymphargus sucre Guayasamin, 2013 [276] (Figures 184-186).

Nymphargus sucre Guayasamin, 2013 [276]. Holotype: MZUTI 1421.

Type locality: "creek on the Plan de Milagro-Gualaceo road ( $3.0077^{\circ}$ S, $78.53318^{\circ}$ W; $\left.2159 \mathrm{~m}\right)$, Provincia Morona Santiago, Ecuador."

Common names: English: Sucre's glassfrog. Spanish: Rana de Cristal de Sucre.

Etymology: The specific epithet is a noun in apposition and honors Antonio José de Sucre, who, with Simón Bolívar, led the independence of most Andean countries (Bolivia, Colombia, Ecuador, Peru, and Venezuela) from Spain. The epithet also makes reference to the national currency of Ecuador between 1884 and 2000; the Sucre disappeared in the year 2000, when it was replaced by the US dollar after a disastrous economic policy that affected millions of Ecuadorians. As an analogy, the current destruction of habitats in southeastern Ecuador (as in many other regions) is likely to drive many species to extinction if activities such as mining, oil extraction, road building, cattle, and agriculture are promoted irresponsibly, and without assessing their effect on megadiverse areas and endangered species [276].

Identification: Nymphargus sucre is distinguished from most glassfrogs by having, in life, a brownish-yellow dorsal surface with yellow spots (Figure 184), and lacking webbing between the fingers. Nymphargus sucre is most similar to four other species that lack the typical green dorsal coloration of centrolenids (N. anomalus, N. colomai sp. nov., N. ignotus, and N. rosada; Figure 185). Nymphargus anomalus and N. ignotus differ from N. sucre mainly by having, in life, a pale tan to brown dorsum with black ocelli (ocelli absent in N. sucre) and lacking yellow spots. Nymphargus rosada is distinguished by its pink coloration in life with yellowish orange spots on the dorsum (brownish-yellow dorsum with yellow spots in N. sucre) and by being larger with non-overlapping SVL in adult males $(\mathrm{SVL}=24.9-28.3$ in male N. rosada [133]; $\mathrm{SVL}=21.6-22.3 \mathrm{~mm}$ in male N. sucre). Finally, N. colomai sp. nov. differs by having numerous diffuse yellow spots on the dorsum (fewer and well-defined spots in 
N. sucre), and a white iris with a contrasting horizontal black stripe (iris lacking horizontal stripe and having a yellow hue around the pupil in N. sucre [276]; Figure 185).

Other species that may have yellowish-green dorsal patterns and could be confused with N. sucre are $N$. armatus, $N$. oreonympha, $N$. nephelophila, and $N$. ruizi. These four species are readily distinguished from N. sucre by having black dorsal spots and lacking yellow spots. Additionally, adult males of N. armatus have nuptial pads with a Type III morphology, whereas N. sucre has a Type I morphology. Adult males of N. oreonympha, N. nephelophila, N. armatus, and N. ruizi are larger (SVL 22.6-24.1 mm, SVL 24.0-26.3 mm, SVL 23.3-24.8 mm, SVL 24.3-26.4 mm, respectively $[154,277,278]$ than males of N. sucre (SVL 21.6-22.3 mm). Finally, N. spilotus, an endemic to the eastern slope of the Cordillera Central of Colombia, has a dorsal pattern that resembles that of $N$. sucre (with yellow spots), but is a considerably larger species (adult male SVL $=25.3-26.4 \mathrm{~mm}$; female SVL $=27.6-28.5 \mathrm{~mm}$ [133]) and has prominent vomerine teeth (absent in N. sucre [276]).

A

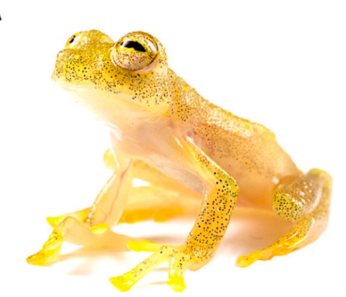

C

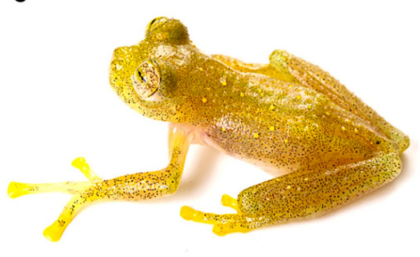

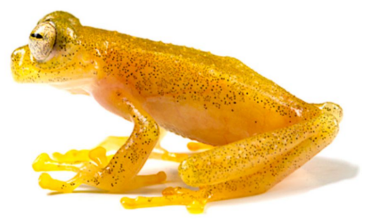

D

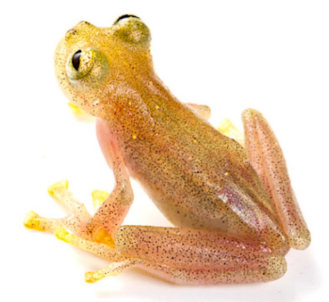

Figure 184. Nymphargus sucre in life. (A-C) Adult male, holotype, MZUTI 1421. (D) Adult female, MZUTI 1422. Photos by Alejandro Arteaga/Tropical Herping. Obtained from Guayasamin [276].

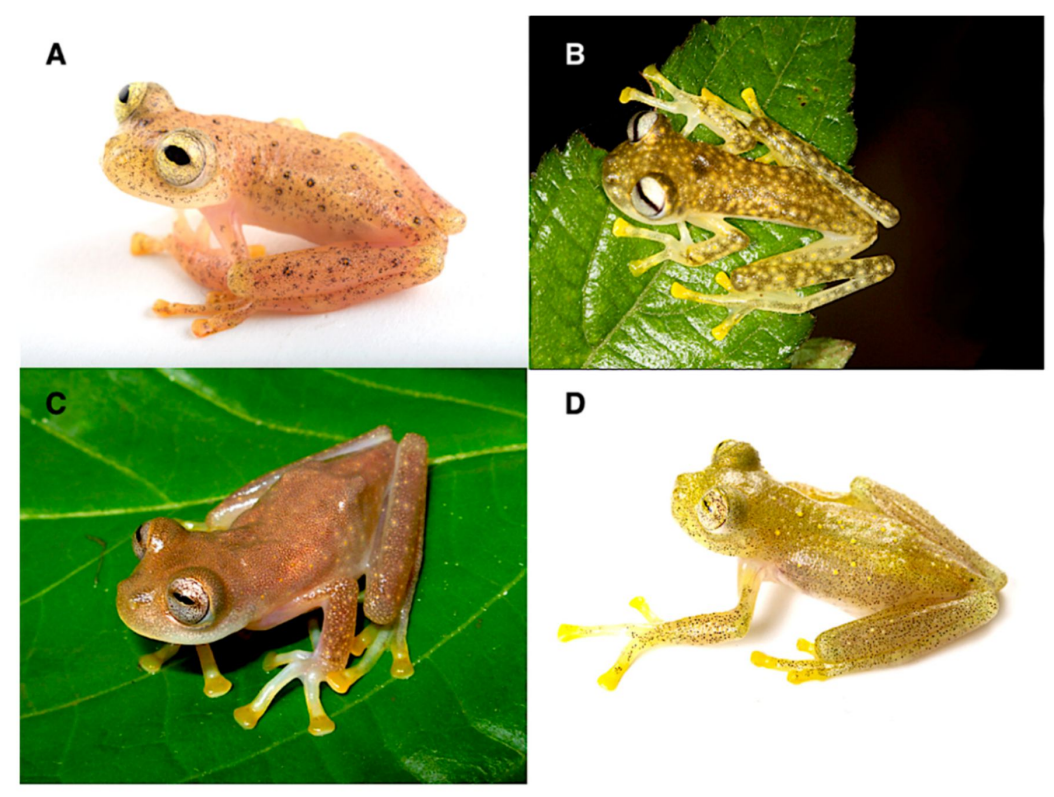

Figure 185. Glassfrog species similar to Nymphargus sucre [276]. (A) Nymphargus anomalus, QCAZ 47507; photo by Luis A. Coloma. (B) N. colomai sp. nov., QCAZ 41590; photo by Juan M. Guayasamin. (C) N. rosada, photo by M. Rivera. (D) N. sucre, MZUTI 1421; photo by A. Arteaga/Tropical Herping. 
Diagnosis: (1) Dentigerous process of the vomer present, but lacking teeth; (2) snout truncated in lateral and dorsal views; (3) tympanum visible without magnification, oriented almost vertically, with slight lateral and posterior inclinations, its diameter about $23 \%-26 \%$ of eye diameter; upper fourth of tympanic annulus obscured by supratympanic fold; tympanic membrane translucent, but with melanophores like those on surrounding skin; (4) dorsal skin shagreen, with numerous minute spicules in males; (5) venter areolate; pair of enlarged subcloacal warts; (6) white parietal peritoneum covering about anterior half of venter (condition P2); white pericardium; translucent peritonea covering intestines, stomach, kidneys, gall and urinary bladders (condition V1); (7) liver trilobed, covered by transparent peritoneum (condition H0); (8) humeral spines absent; (9) webbing absent between inner fingers, basal between Fingers III and IV; webbing formula III $\left(2^{3 / 4}-3^{-}\right)-\left(2^{1 / 2}-2^{3 / 4}\right)$ IV; (10) feet about two-thirds webbed; webbing formula: I $\left(2-2^{-}\right)-2^{+}$II $\left(1^{+}-1^{1 / 3}\right)-\left(2^{+}-2^{1 / 3}\right)$ III $\left(1-1^{1 / 2}\right)-\left(2^{1 / 3}-2^{1 / 2}\right)$ IV $\left(2^{2 / 3}-3^{-}\right)-2^{-} \mathrm{V} ;(11)$ ulnar and tarsal folds present, but low and inconspicuous, lacking pigmentation; (12) concealed prepollex; in males, nuptial pad Type I; (13) Finger I slightly shorter than Finger II (Finger I length $93 \%-96 \%$ of Finger II); (14) disc width of Finger III about 37\%-53\% of eye diameter; (15) in life, dorsum brownish yellow with yellow spots; color of bones unknown; (16) in preservative, dorsum grey lavender with small white or unpigmented spots; (17) iris white with minute dark spots, thin reticulation, and yellow hue around pupil; (18) dorsal surfaces of fingers and toes lacking melanophores, except for few on Fingers III and IV, and Toes III, IV, and V; (19) males call from the upper surfaces of leaves; call unknown; (20) fighting behavior unknown; (21) egg deposition site and parental care unknown; (22) tadpoles unknown; (23) medium body size; males, SVL 21.6-22.3 mm $(n=2)$; female, SVL $24.3 \mathrm{~mm}(n=1)$.

Color in life (Figure 184): Brownish-yellow dorsum with small yellow spots; dorsum of the holotype with a greenish hue. Upper lip unpigmented. Anterior half of ventral parietal peritoneum white, posterior portion translucent. Color of bones unknown. Iris white with minute dark spots, thin reticulation, and yellow hue around pupil [276].

Color in ethanol: Dorsal surfaces of head, body, and limbs grey lavender with small white or unpigmented spots. Anterior half of ventral parietal peritoneum white. Heart covered by white pericardium; translucent peritonea covering gall and urinary bladders; iridophores absent from digestive tract, liver, and kidneys. Observations on internal anatomy were based on specimen MZUTI 1421 [276].

Biology and ecology: During the night, males of Nymphargus sucre were observed calling on leaves at 90-130 cm above a stream on 6 June 2012. Only one other species of glassfrog (N. cariticommatus) was found at the same stream [276]. Parental care is unknown.

Call: Not described.

Tadpole: Not described.

Distribution (Figure 186): Nymphargus sucre is only known from the type locality, a creek on the Plan de Milagro-Gualaceo road ( $3.0077^{\circ}$ S, $78.53318^{\circ}$ W; 2140-2160 m), Morona Santiago province, Ecuador [276].

Conservation status: Nymphargus sucre has not been evaluated by the IUCN. Because of habitat loss and mining, we suggest that the species should be considered as Critically Endangered, following IUCN criteria B1, B2a,b(iii).

Evolutionary relationships (Figure 136): Nymphargus sucre is sister to N. cariticommatus. 


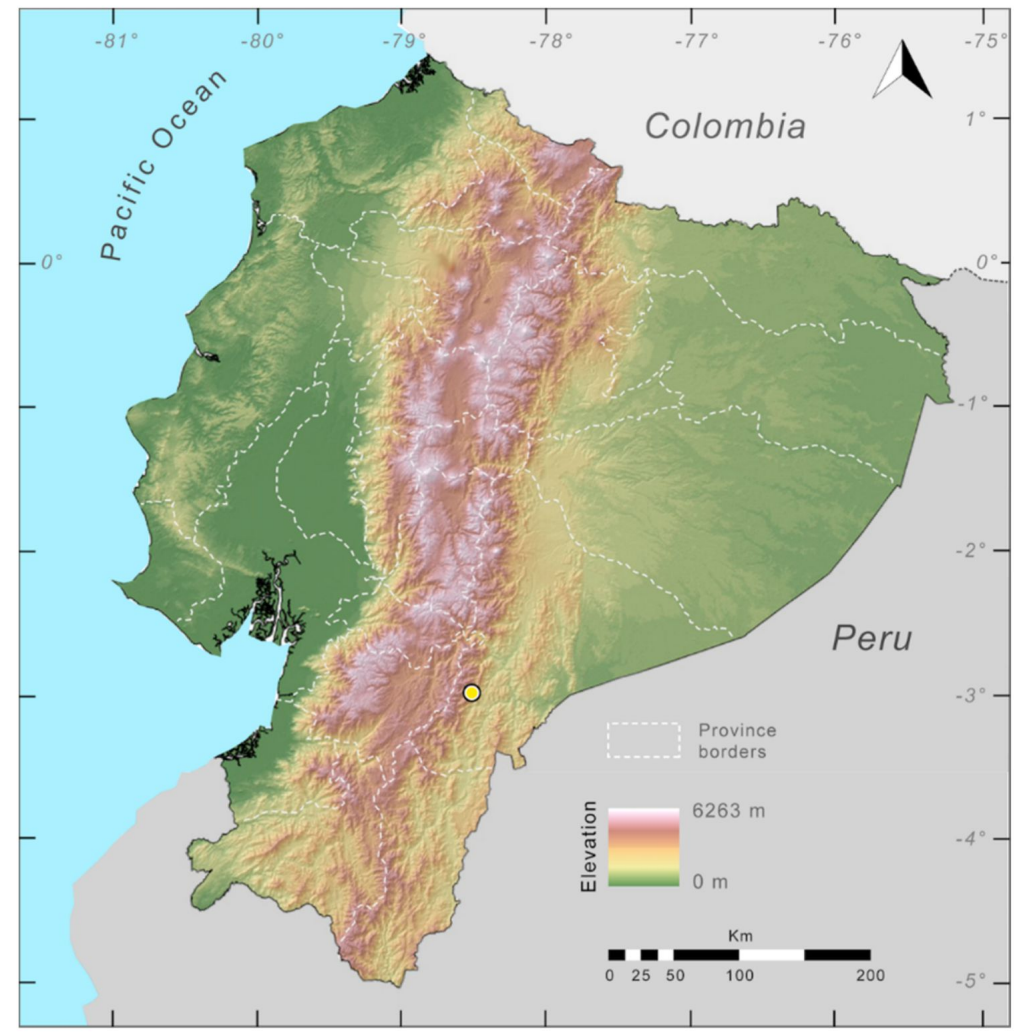

Figure 186. Distribution of Nymphargus sucre in Ecuador (yellow dot).

Specimens examined: Nymphargus sucre: Ecuador: Morona Santiago province: Plan de

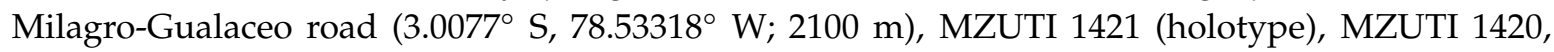
1421 (paratypes).

Nymphargus wileyi (Guayasamin, Bustamante, Almeida-Reinoso, Funk, 2006 [20]; Figures 187-189).

Cochranella wileyi Guayasamin, Bustamante, Almeida-Reinoso, Funk, 2006 [20]. Holotype: QCAZ 26028.

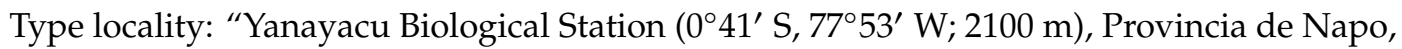
Ecuador."

Nymphargus wileyi_Cisneros-Heredia and McDiarmid, 2007 [17].

Common names: English: Wiley's Glassfrog. Spanish: Rana de Cristal de Wiley.

Etymology: The specific name is a noun in the genitive case and a patronym for Edward O. Wiley, for his influential work on the development of phylogenetic systematics and use of the evolutionary species concept [20]. 
Identification: Nymphargus wileyi differs from most species of glassfrogs by having a uniform green dorsum (Figure 187), white renal peritoneum, and by lacking any webbing between the fingers. On the Amazonian slopes of the Andes, only N. cariticommatus can be confused with N. wileyi. The differences between these two species are subtle; $N$. wileyi has a uniform dorsum (dorsum with small yellow dots in N. cariticommatus) and has a faint layer of iridophores covering the anterior portion of the esophagus (white peritoneum covering most of the esophagus in N. cariticommatus). The only other species with a uniform green dorsum on the Amazonian slopes of the Andes is Espadarana durrellorum, which differs by having webbing between Fingers III and IV, and a humeral spine in males.

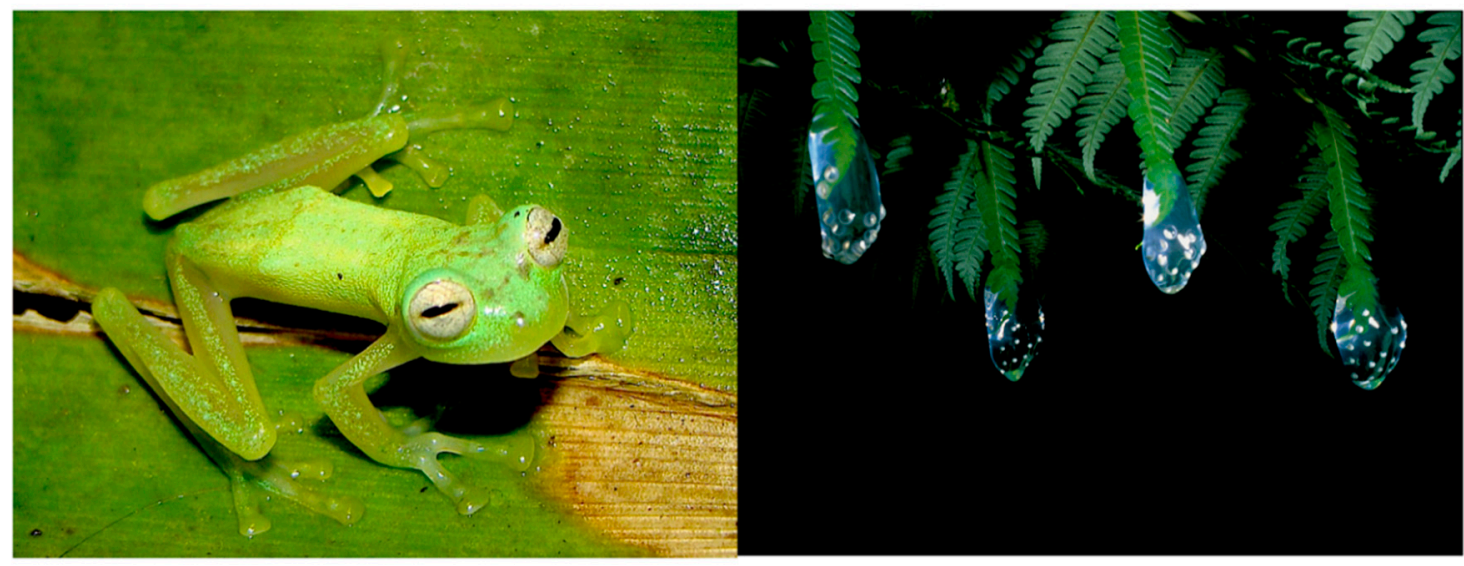

Figure 187. Nymphargus wileyi in life. (Left): Adult male from Yanayacu Biological Station, Napo province, QCAZ 37972. (Right): Egg clutches of N. wileyi at Yanayacu Biological Station. Photos by Martín Bustamante.

Diagnosis: (1) Vomers lacking teeth; (2) snout truncated in dorsal aspect, truncated to protruding in lateral profile (Figure 188); (3) tympanum oriented almost vertically, with slight posterior and lateral inclinations, its diameter $31.4 \%-37.8 \%$ of eye diameter; tympanic annulus visible anteroventrally, tympanic membrane unpigmented and clearly differentiated from surrounding skin; (4) dorsal surfaces of males and females shagreen, with small spicules evident in males; (5) venter areolate; pair of enlarged subcloacal warts (Figure 15); (6) anterior $40 \%-60 \%$ of ventral parietal peritoneum white, posterior portion transparent (condition P2); white pericardium; translucent to opaque peritoneum covering intestines, stomach, testes, gall bladder, and urinary bladder; peritoneum around kidneys white with unpigmented spots (condition V1); (7) liver tetralobed, covered by transparent peritoneum (condition H0); (8) humeral spines absent; (9) webbing absent between inner fingers; webbing reduced between outer fingers, III $3^{-}-2^{2 / 3}$ IV; (10) concealed prepollex; in males, nuptial pad Type I; (11) Finger II slightly longer than Finger I (Finger I 92\%-97\% of Finger II); (12) ulnar fold low or absent; inner tarsal low and thin, outer tarsal fold absent; (13) webbing formula on foot I $2-2^{1 / 3}$ II $\left(1^{1 / 3}-1^{2 / 3}\right)-\left(2^{1 / 2}-3^{-}\right)$III $\left(1^{+}-2^{-}\right)-\left(2^{2 / 3}-3^{-}\right)$ IV $\left(3^{-}-3\right)-\left(2^{-}-2\right)$ V (Figure 188); (14) disc of Finger III of moderate size, about $50 \%-60 \%$ of eye diameter; (15) in life, dorsum pale green; bones green; (16) in preservative, dorsum uniform pale lavender; (17) iris coppery white with black reticulation; (18) fingers and toes lacking melanophores on dorsal surfaces; (19) males call from the upper sides of leaves; call unknown; (20) fighting behavior unknown; (21) females deposit eggs on upper surface of leaves near streams (Figure 187); short-term maternal care unknown; prolonged parental care absent; (22) tadpoles undescribed; (23) small body size; males, SVL $24.0-26.2 \mathrm{~mm}(\bar{X}=24.6 ; n=5) ; 27.1 \mathrm{~mm}$ in one female. 
A

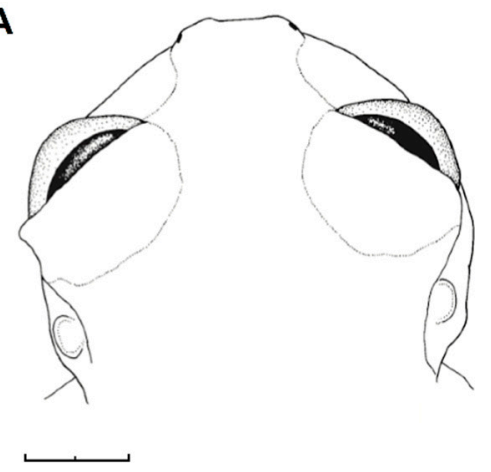

B

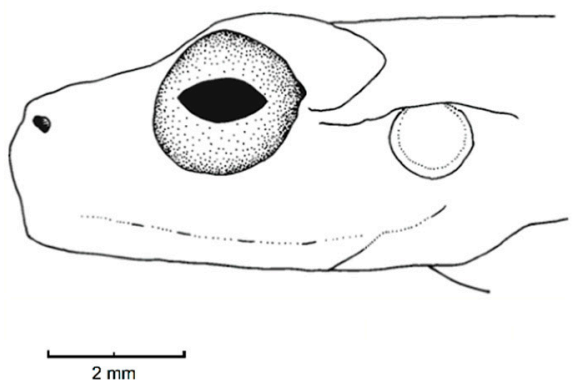

C

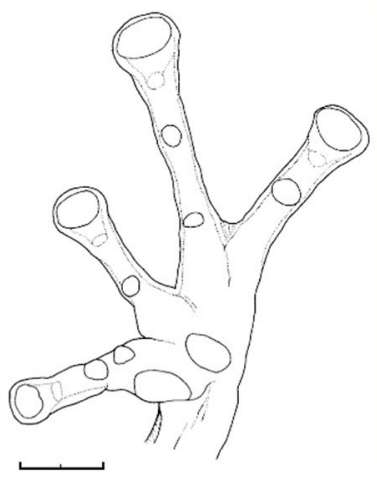

D

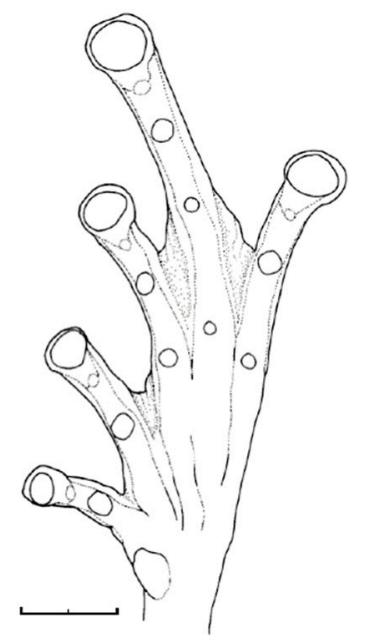

Figure 188. Nymphargus wileyi. (A) Head in dorsal view, QCAZ 26029. (B) Head in lateral view, QCAZ 26029. (C) Hand in ventral view, QCAZ 26028. (D) Foot in ventral view, QCAZ 26028. Modified from Guayasamin et al. [20].

Color in life (Figure 187): Dorsal surfaces pale green, lacking spots; lower venter transparent; parietal peritoneum white, covering anterior part of abdomen (heart not visible); iris coppery white with black reticulation; bones green [20].

Color in ethanol: Dorsal surfaces of head, body, and limbs pale lavender; upper lip white; dorsally, all fingers, Toes I-III, and most of Toe IV unpigmented; cloacal region mostly unpigmented, except for few minute white flecks. Cream nuptial pad on Finger I. Ventral parietal peritoneum white anteriorly, pericardium white, hepatic peritoneum clear, visceral peritoneum opaque, peritoneum around kidneys white with unpigmented spots (dissected specimens: QCAZ 26029-30) [20].

Biology and ecology: Nymphargus wileyi is a nocturnal species that seems to be restricted to primary forest. Individuals have been found at night on leaves $120-220 \mathrm{~cm}$ above streams (five males) or above the ground (one female). Males call from the upper surfaces of leaves; males are territorial and are usually found near egg clutches, which are on the tip of leaves; distances between egg clutches and males can be as close as $20 \mathrm{~cm}$ (Figure 187). Males were never observed on the same leaf as the egg clutch; also, several egg clutches had no male nearby; these observations suggest that prolonged parental care is absent [20]. Short-term maternal care is unknown. Clutches are deposited on the dorsal surface of leaves near their tips (Figure 187). The number of eggs per clutch varies from $19-28(\bar{X}=22$; $n=17$ ); eggs and embryos in early developmental stages are whitish [20].

Call: Not described.

Tadpole: Not described.

Distribution (Figure 189): Nymphargus wileyi is known only from the type locality (Yanayacu Biological Station, $2100 \mathrm{~m}$ ) on the Amazonian slopes of the Cordillera Oriental of the Ecuadorian Andes [20]. The habitat of the species is within the Eastern Montane Forest region. 


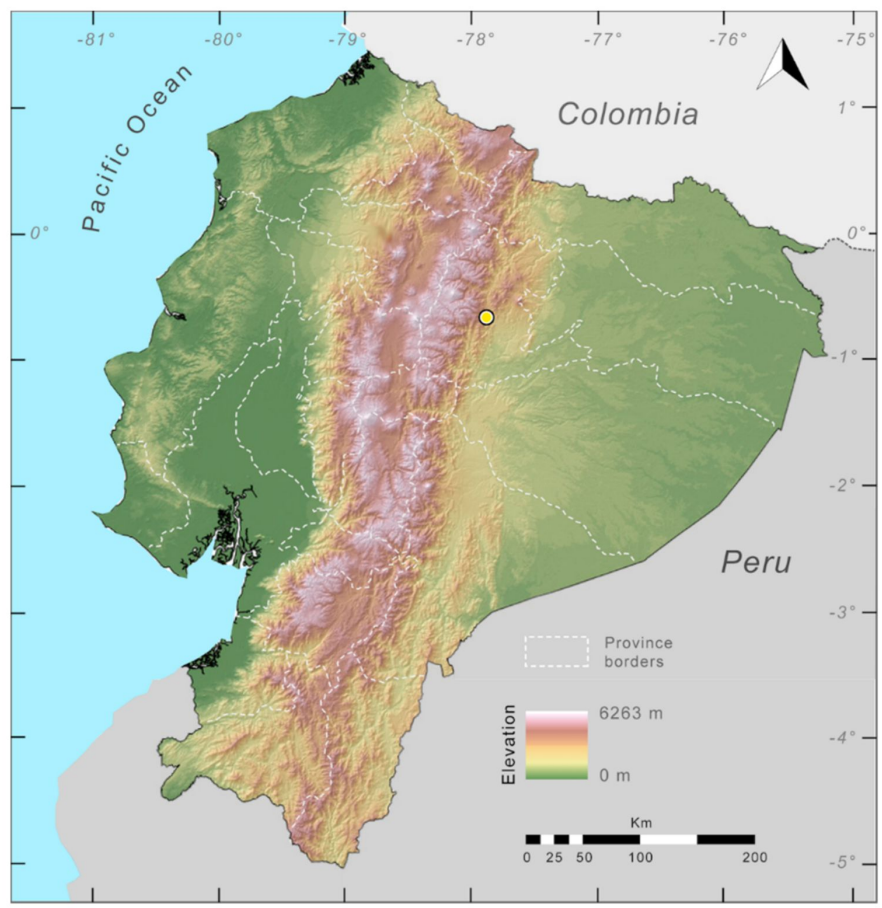

Figure 189. Distribution of Nymphargus wileyi in Ecuador (yellow dot).

Conservation status: Nymphargus wileyi is listed as Data Deficient by the IUCN [279]. We consider this category appropriate.

Evolutionary relationships (Figure 136): Nymphargus wileyi is sister to a clade formed by N. sucre and N. cariticommatus. These three species are found on the Amazonian slopes of the Andes.

Taxonomic Remarks: Only one discrete morphological character separates Nymphargus wileyi from N. cariticommatus, the absence of pale spots in N. wileyi. Also, in preserved material, the esophageal peritoneum of $N$. cariticommatus is more pronounced and extensive than in N. wileyi, in which the iridophores are restricted to the anterior portion of the esophageal peritoneum. Surprisingly, the two species, although closely related, are not sister to each other (Figure 136).

Specimens examined: Nymphargus wileyi: Ecuador: Provincia de Napo: Yanayacu Biological

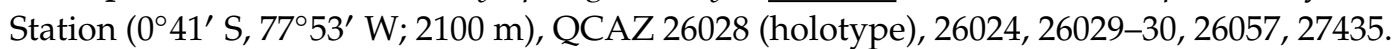

Genus Rulyrana Guayasamin, Castroviejo-Fisher, Trueb, Ayarzagüena, Rada, and Vilà, 2009 [1].

Etymology: The name Rulyrana honours Pedro Ruiz-Carranzat and John D. Lynch (Instituto de Ciencias Naturales, Universidad Nacional de Colombia), who have contributed enormously to the understanding of anuran diversity, biology, and evolution. Together, Pedro and John made an outstanding effort to describe the amphibian diversity of Colombia, producing a series of glassfrog papers $[6,26,27$, $101,110,113,129,133,154,246,255,277]$ that includes the description of the genus Hyalinobatrachium and numerous species. The name Rulyrana is femine in gender and comes from an arbitrary association of the two first letters of Ruiz and Lynch (Ruly) and the word rana (=frog). Ruly also is the nickname of JMG's good friend and colleague Martín Bustamante, whose work on biodiversity, conservation, and even sportive indoctrination, is remarkable ([1], this work). 
Rulyrana flavopunctata (Lynch and Duellman, 1973 [22]; Figures 190-194).

Centrolenella flavopunctata Lynch and Duellman, 1973 [22]. Holotype: KU 121048.

Type locality: "Mera, Provincia Pastaza, Ecuador."

Cochranella flavopunctata-Ruiz-Carranza and Lynch, 1991 [6].

Rulyrana flavopunctata-Guayasamin, Castroviejo-Fisher, Trueb, Ayarzagüena, Rada, and Vilà, 2009 [1].

Common names: English: Yellow-spotted Glassfrog. Spanish: Rana de Cristal de Puntos Amarillos.

Etymology: The specific name is a combination of the Latin flavus, meaning golden yellow, and punctatus, meaning dotted, and is used in reference to the dorsal coloration of the species [22].

Identification: Among glassfrogs that inhabit the Amazonian slopes of the Ecuadorian Andes, Rulyrana flavopunctata is distinguished by having a green to dark green dorsum with small yellow spots (Figure 190), a partially white venter, small to moderate body size (male SVL 21.0-23.9 mm; female SVL 24.0-27.4 mm), extensive webbing between Fingers III and IV, and lacking humeral spines. Species with a similar color pattern from eastern Ecuador include Espadarana audax, Nymphargus siren, N. humboldti sp. nov., N. mariae, R. mcdiarmidi, and Teratohyla midas. None of the species in the genus Nymphargus has webbing between Fingers III and IV; males of Espadarana audax have humeral spines; T. midas has very few yellow spots on the upper flanks and a white digestive tract; and R. mcdiarmidi has a slightly larger body size (male SVL 22.8-26.9 mm, female SVL 25.4-30.2 mm) and warts on its dorsum (absent in R. flavopunctata). The differences between R. flavopunctata and R. mcdiarmidi are subtle and more work is necessary to verify the validly of the specific status of the latter. See Taxonomic Remarks.

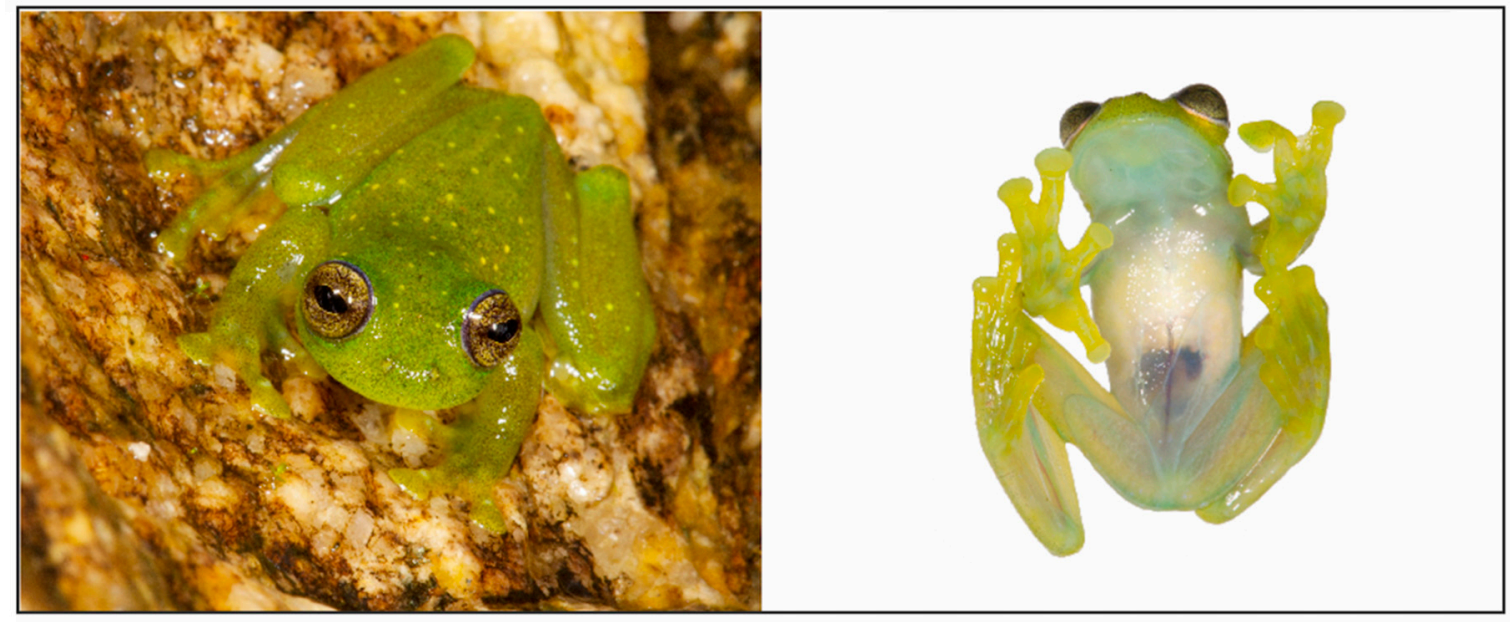

Figure 190. Rulyrana flavopunctata in life. Ecuador, Napo province, Cordillera de los Guacamayos, 1564 m, MZUTI 1250 (left), 1260 (right). Photos by Eduardo Toral.

Diagnosis: (1) Teeth on vomers present or absent; each vomer with zero to three teeth; (2) snout usually rounded in dorsal and lateral views; (3) tympanum visible, its diameter $27.9 \%-38.7 \%$ of eye diameter; supratympanic fold low; (4) dorsal skin shagreen; males with spicules; (5) skin of venter areolate; pair of slightly enlarged subcloacal warts; (6) anterior half of ventral parietal peritoneum white, posterior half translucent (condition P2); pericardium white; peritonea covering intestines, stomach, and kidneys lacking iridophores; urinary bladder transparent (condition V1); (7) lobed liver lacking iridophores (condition H0); (8) humeral spines absent; (9) webbing between Fingers I and II absent or basal, moderate between Fingers II and III, extensive between Fingers III and IV; webbing formula for outer fingers: II $\left(1^{1 / 2}-2^{-}\right)-\left(3-3^{+}\right)$III $\left(1^{1 / 3}-2^{-}\right)-\left(1^{+}-1^{1 / 2}\right)$ IV; $(10)$ feet about three-fourths webbed; webbing formula: I $\left(0^{+}-1\right)-\left(1-1^{3 / 4}\right) \mathrm{II}\left(0^{+}-1\right)-\left(0^{+}-2\right) \mathrm{III}\left(0^{+}-1\right)-\left(1^{1 / 3}-2^{+}\right) \mathrm{IV}$ 
$\left(2^{-}-2^{+}\right)-\left(0^{+}-1\right) \mathrm{V}$ (Figure 191); (11) ulnar fold low or absent; inner tarsal fold low, short; outer tarsal fold absent; (12) concealed prepollex; in males, nuptial pad Type I; (13) Finger I about same length as Finger II (Finger I length $95.5 \%-104.0 \%$ of Finger II); (14) disc of Finger III relatively large, its width $47.7 \%-67.0 \%$ of eye diameter; (15) in life, dorsum green to dark green with well-defined yellow spots; bones green; (16) in preservative, dorsum dark lavender to slate grey with small white to cream spots; (17) iris pale greyish white, with or without golden tint, with dark grey or brown flecks or fine reticulation; (18) dorsal surfaces of fingers and toes usually with melanophores, but some individuals lack melanophores on Finger I or on Fingers I and II; (19) males call from the upper side of leaves or rocks; call unknown; (20) fighting behavior unknown; (21) egg clutches placed on rock walls; parental unknown; (22) tadpoles unknown; (23) small body size in adult males, SVL 21.0-23.9 mm $(\bar{X}=22.1 \pm$ $0.834, n=10)$; in adult females, SVL 24.0-27.4 $\mathrm{mm}(\overline{\mathrm{X}}=25.3 \pm 1.207, n=6)$.
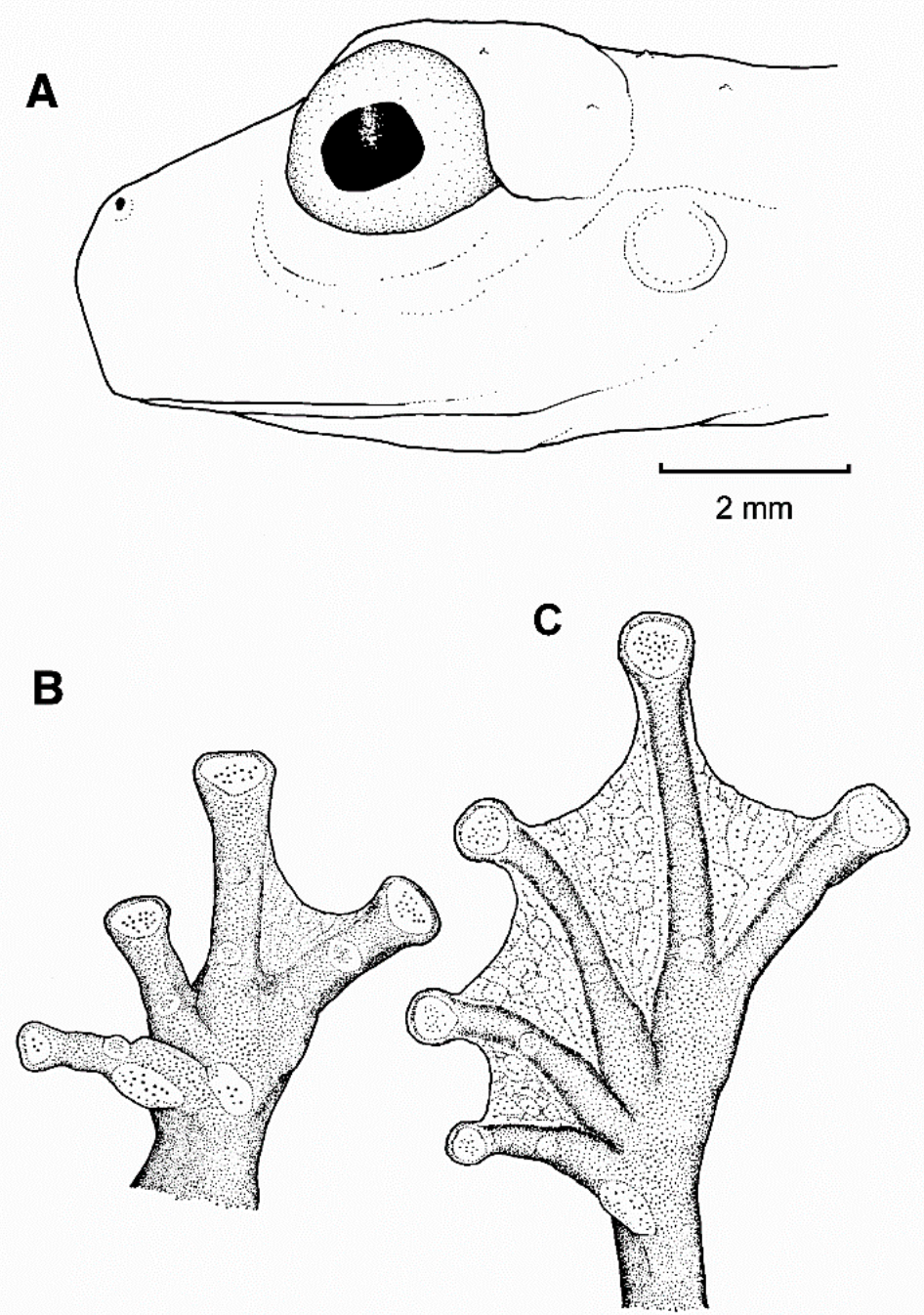

Figure 191. Rulyrana flavopunctata. (A) Head in lateral view, holotype, adult male, KU 121046. (B) Hand in ventral view, KU 121050. (C) Foot in ventral view, KU 121048. (B,C) Modified from Lynch and Duellman [22]. 
Color in life (Figure 190): Conspicuous variation has been observed in dorsal and ventral coloration. Dorsal surfaces of head and body vary from green to very dark green, with small yellow spots. Anterior half of ventral parietal peritoneum white; posterior half usually translucent, but some individuals have a milky colored peritoneum. Iris pale greyish white to brown, with yellow tint, with dark grey or brown flecks or fine reticulation ([22], this work). At one locality (Río Tayuntza), individuals showed considerable variation in dorsal coloration, from green to almost black, with yellow spots, indicating that intraspecific variation in this species is not necessarily associated with geography.

Color in ethanol: Dorsal surfaces of head, body, and limbs dark lavender to slate grey, with small white or cream spots usually corresponding to warts. Internal organs lacking iridophores, except for heart that is covered by white pericardium.

Biology and ecology: Most individuals were found in a deep ravine where males were perched on small herbs in the spray-zone of a small waterfall. At several small streams between Mera and the Río Alpayacu, males were calling from the upper sides of leaves on 2, 14, and 24 July 1968 [22]. At Río Tayuntza (Morona Santiago province, Ecuador) egg clutches of $R$. flavopunctata were found on rock walls during the rainy season [280] (Figure 192). Parental care is unknown.
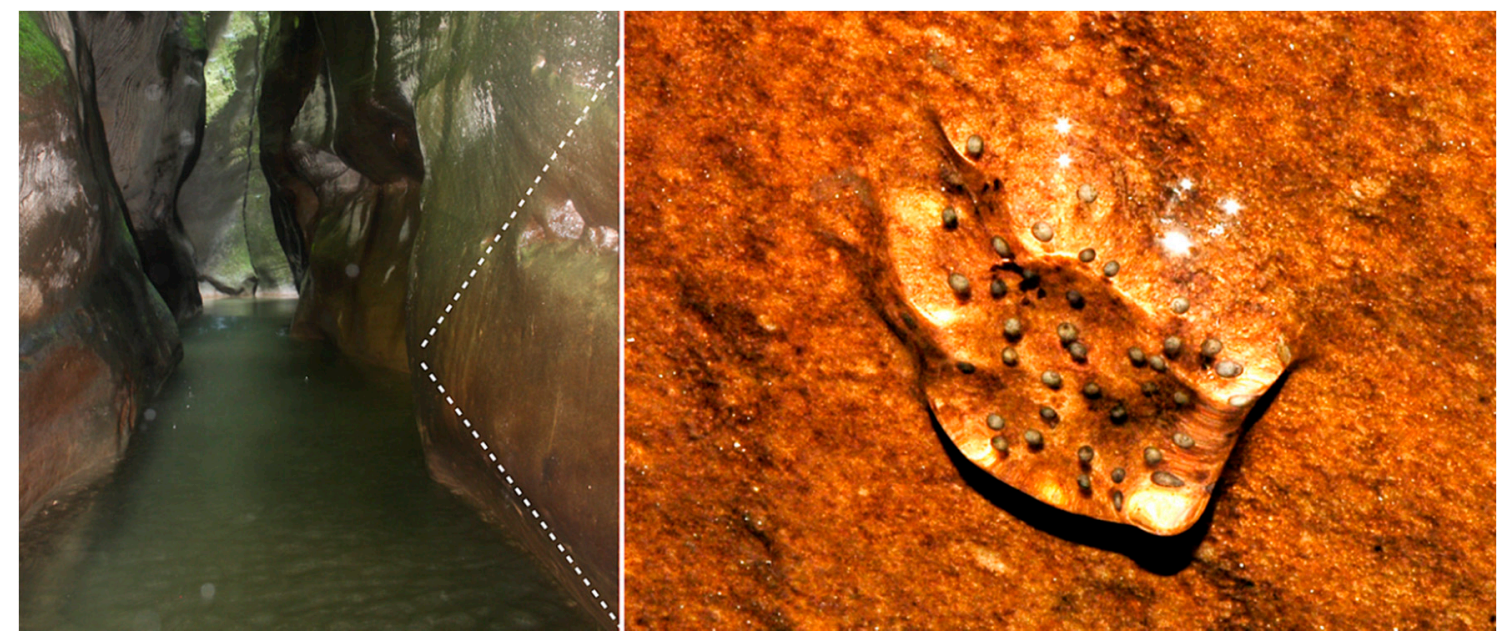

Figure 192. (Left): Habitat of a glassfrog tentatively assigned to Rulyrana flavopunctata or R. mcdiarmidi. (Right): Egg clutch of the rock walls of the river. Locality: Río Tayuntza, Cuevas de los Tayos, Río Tayuntza, Morona Santiago province, Ecuador. Photos by Octavio Jiménez-Robles (Left) and Ignacio de la Riva (Right). Modified from Jiménez-Robles et al. [280].

Call (Figure 193): We analyzed 85 notes contained within 13 calls from two individuals (MZUTI $1476,1684)$. Each call is composed by a single short note that has a duration of 3-8 (mean $=4, S D=1)$ ms. Notes are clearly pulsed; the first pulse of each note has the highest amplitude. Pulses within a note have a rate of $125-333$ (mean $=262, \mathrm{SD}=55$ ) pulses per second. The dominant frequency of a note measured at peak amplitude is $5857-7580$ (mean $=6931, \mathrm{SD}=472) \mathrm{Hz}$ and is contained within the fundamental frequency. The fundamental frequency has a lower limit of 5685-7149 (mean $=6648$, $\mathrm{SD}=447) \mathrm{Hz}$ and a higher limit of 6115-7924 (mean = 7382, SD = 491) Hz. 


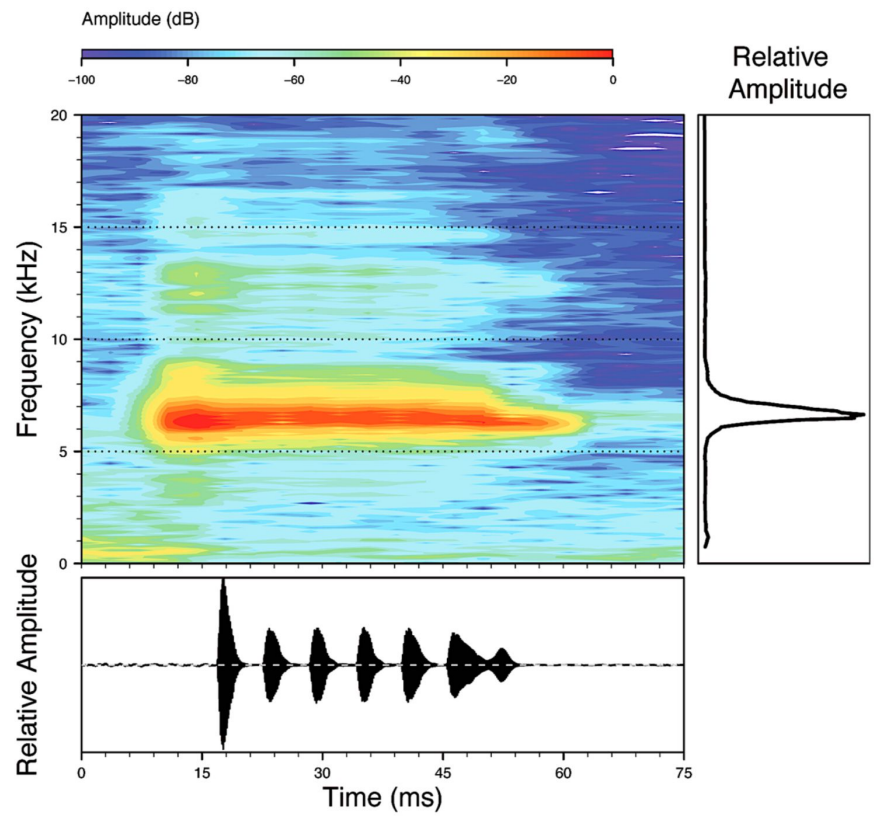

Figure 193. Call of Rulyrana flavopunctata, MZUTI 1684, recorded at Quebrada Pangayaku, 1645 m, Napo province, Ecuador. Air temperature $=19.4^{\circ} \mathrm{C}$.

Tadpole: Not described.

Distribution (Figure 194): Rulyrana flavopunctata is known from the Amazonian slopes of the Andes of Colombia and Ecuador at elevations between 300 and $1715 \mathrm{~m}$ ([22,101,281], this work). In Ecuador, this species has been recorded from localities in the provinces of Napo, Morona Santiago, Pastaza, Sucumbíos, and Tungurahua, at elevations between 720 and $1715 \mathrm{~m}$ (Specimens examined). In Ecuador, the potential distribution of the species is $16,369 \mathrm{~km}^{2}$ within the Eastern Foothill Forest and Eastern Montane Forest regions.

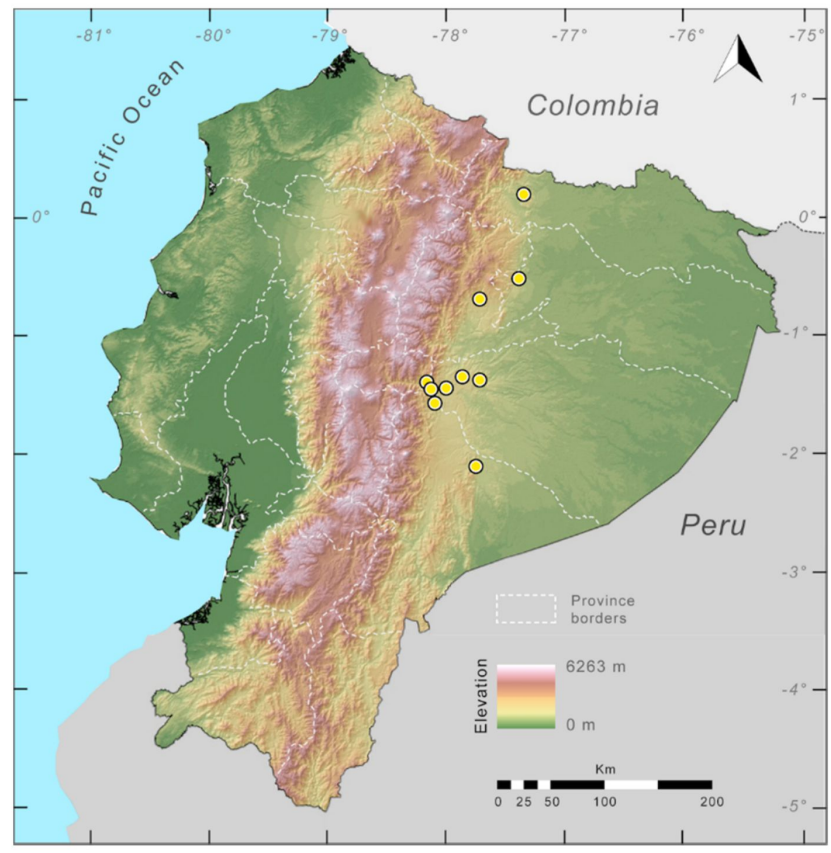

Figure 194. Distribution of Rulyrana flavopunctata in Ecuador (yellow dots). 
Conservation status: Globally, Rulyrana flavopunctata is listed as Least Concern by the IUCN [281]. In Ecuador, there are several recent reports of the species, including: Parroquia Teniente Hugo Ortíz (30 March 2007), $7.6 \mathrm{~km} \mathrm{~W}$ of 9 de Octubre (August 2006), 6.8 km N of Limón (21 April 2004), and Río Tayuntza (April 2011), Cordillera de los Guacamayos (April 2012), Quebrada el Plancón (March 2012), Río Hollín (August 2012), Quebrada Pangayacu (August 2012), lower slopes of Volcán Sumaco (February 2012, 2018), Narupa (June 2018). We agree with its current conservation status.

Evolutionary relationships (Figure 195): According to our molecular phylogeny, Rulyrana flavopunctata and R. mcdiarmidi are genetically indistinguishable.

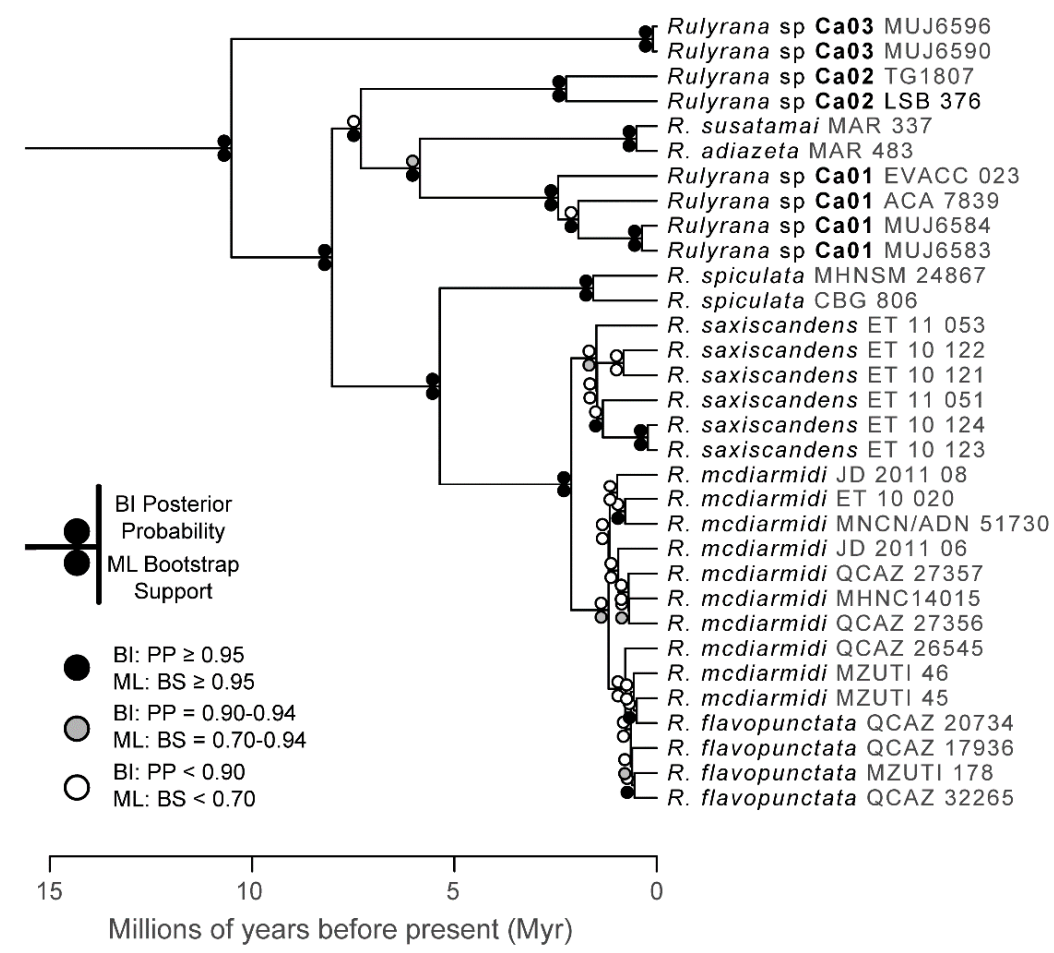

Figure 195. Evolutionary relationships of species in the glassfrog genus Rulyrana. The trees were inferred using maximum likelihood and Bayesian criteria.

Taxonomic Remarks: Morphological differences between Rulyrana flavopunctata and R. mcdiarmidi are subtle (body size, skin texture, color pattern), and the two species are genetically indistinguishable (Figure 195). It is possible that R. mcdiarmidi represents a geographic variation of R. flavopunctata or that the two species have recently diverged. Information on call variation and other traits are necessary to resolve the species status of $R$. mcdiarmidi.

Specimens examined: Ecuador: Provincia Morona Santiago: Río Tayuntza, Cuevas de los Tayos (02.1106 ${ }^{\circ}, 77.75185^{\circ}$ W; 700 m). Provincia Napo: Río Hollín (0.69583 S; 77.730277 W; 1190 m), QCAZ 22360-62; Reserva Narupa (0.6848 S, 77.742 W, 1170-1228 m), ZSFQ 0374-79. Provincia Pastaza: tributary of Río Rivadeneira $\left(1.3604^{\circ} \mathrm{S}, 77.86534^{\circ} \mathrm{W}\right)$, SC 34963; $9.5 \mathrm{~km} \mathrm{NW}$ Mera (1.4 S, $\left.78.166667 \mathrm{~W} ; 1270 \mathrm{~m}\right)$, KU 178094; Mera (1.466667 S, 78.13331 W; 1100 m), KU 121041-46, 121049-51, 178093; Río Alpayacu, 1 km E Mera (1.466667 S, 78.08333 W; 1080 m), KU 121047; near Río Rivadeneira (1.144307 S, 77.99667 W; 982 m), QCAZ 20734-35; km 6 on San Ramón-El Triunfo road (1.35998 S, 77.86564 W; 875 m), QCAZ 37911, 33269; Sacha Yacu (1.39519 S, 77.72946 W; 1078 m), MZUTI 176. Provincia Sucumbíos: Bermejo No. 4, 15 km ENE Umbaqui (0.1833 N, 77.366667 W; 720 m), KU 123224.

Localities from the literature: Rulyrana flavopunctata: Ecuador: Provincia de Napo: San José Abajo, on the eastern slope of Volcán Sumaco (00³2' S, 77²4' W; 700-1000 m), AMNH 22187. Provincia de Pastaza: 13 km WSW Puyo (ca. $1^{\circ} 34^{\prime}$ S, 78 $06^{\prime}$ W; 1000 m), TCWC 24032 [22]. 
Rulyrana mcdiarmidi (Cisneros-Heredia, Venegas, Rada, and Schulte 2008 [272];

Figures 196 and 197).

Cochranella mcdiarmidi Cisneros-Heredia, Venegas, Rada, and Schulte, 2008 [272]. Holotype: DFCH-USFQ D132.

Type locality: "small rivulet tributary of the Jambue River, ca. $6 \mathrm{~km} \mathrm{~S}$ from Zamora (ca. $04^{\circ} 03^{\prime} \mathrm{S}$, $78^{\circ} 56^{\prime} \mathrm{W}, 1150 \mathrm{~m}$ ), on the western slope of Contrafuerte de Tzunantza, Cordillera Oriental, eastern slopes of the Andes, Provincia de Zamora Chinchipe, República del Ecuador".

Rulyrana mcdiarmidi-Guayasamin, Castroviejo-Fisher, Ayarzagüena, Trueb, Rada, and Vilà, 2009 [1].

Common names: English: McDiarmid's Glassfrog. Spanish: Rana de Cristal de McDiarmid.

Etymology: The specific epithet honors Dr. Roy McDiarmid, in recognition of his contributions to the understanding of Neotropical herpetology [272].

Identification: Rulyrana mcdiarmidi can be distinguished from all other glassfrogs by having a moderate-sized body (male SVL 22.8-26.9 mm; female SVL 25.4-30.2 mm), green dorsum with diverse darker shadows and pale yellow to green spots (Figure 170), dorsal skin with warts, ventral parietal peritoneum completely white or with posterior portion translucent, thick ulnar folds, and extensive hand and foot webbing. Among centrolenids from the eastern slopes of the Andes, species with a similar color pattern include Espadarana audax, Nymphargus siren, N. humboldti sp. nov., N. mariae, R. flavopunctata, and Teratohyla midas. None of the species in the genus Nymphargus has webbing between Fingers III and IV; males of Espadarana audax have humeral spines; T. midas has very few yellow spots on the upper flanks and a white digestive tract; $R$. flavopunctata differs by being slightly smaller (male SVL 21.0-23.9 mm; female SVL 24.0-27.4 mm), having yellow dorsal spots, and lacking dorsal warts. See Taxonomic Remarks.

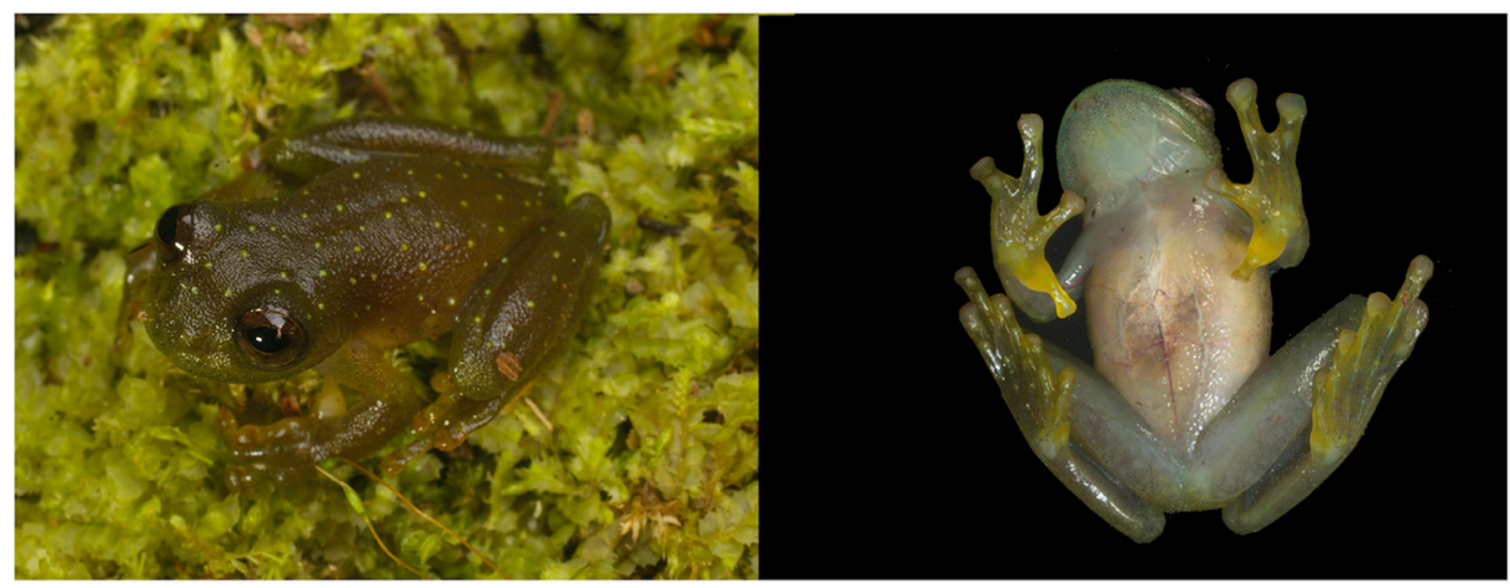

Figure 196. Rulyrana mcdiarmidi in life. Adult (QCAZ 32265) from $7.6 \mathrm{~km} \mathrm{~W}$ of 9 de Octubre, $1715 \mathrm{~m}$, Morona Santiago province, Ecuador. Photos by Martín Bustamante. 
Diagnosis: (1) Vomerine teeth present; (2) snout rounded to subtruncated in dorsal and lateral views; (3) tympanic annulus evident, oriented dorsolaterally; weak supratympanic fold; (4) dorsal skin smooth to shagreen, with numerous warts; (5) ventral skin coarsely granular; subcloacal area coarsely granular, with abundant low, flat warts; other cloacal ornamentation absent; (6) ventral parietal peritoneum white, iridophores covering entirely or almost entirely abdomen to level of groin (condition P4); pericardium white, all other visceral peritonea clear (condition V1); (7) liver lobed, lacking iridophores (condition H0); (8) humeral spine absent; (9) webbing absent between Fingers I and II, basal between II and III, moderate to extensive between outer fingers; webbing formula: II $1^{1 / 2}-3^{+}$III $\left(1^{1 / 2}-2^{-}\right)-\left(1^{-}-1^{+}\right)$IV; $(10)$ webbing on feet extensive, webbing formula: I $\left(1^{-}-1\right)-\left(1^{+}-1^{1 / 3}\right)$ II $\left(0^{+}-1\right)-\left(1^{1 / 3}-1^{2 / 3}\right)$ III $\left(1-1^{-}\right)-\left(1^{2 / 3}-2^{+}\right)$IV $2^{-}-\left(0^{+}-1\right) \mathrm{V}$; (11) thick, non-enameled, non-crenulated ulnar fold; low, short inner tarsal fold; (12) nuptial excrescences Type I in adult males; concealed prepollex; (13) first finger slightly shorter than second; (14) eye diameter larger than width of disc on Finger III; (15) in life, dorsum dark olive green with creamy yellow or light yellowish orange or light green spots, bones green; (16) color in preservative, dorsal surfaces tan grey, pale brown, or greyish lavender with diffuse light tan spots; (17) in life, iris olive brown to brown with thin dark reticulations; (18) abundant melanophores widespread on all fingers and toes; (19) males call from rocks along streams and waterfalls; call unknown; (20) fighting behavior unknown; (21) egg clutches unknown, parental care unknown; (22) tadpoles unknown; (23) small to medium body size; SVL in adult males 22.8-26.9 mm ( $\overline{\mathrm{X}}=24.5 \pm 1.139 ; n=11)$, and in adult females $25.4-30.2 \mathrm{~mm}(\overline{\mathrm{X}}=28.0 \pm 1.384 ; n=13)$.

Color in life (Figure 196): Olive green dorsum with darker suffusions and yellowish cream, orange, or green spots; males with smaller dorsal spots than females. Venter yellowish cream. Iris olive brown to brown with fine dark reticulations. Green bones [272].

Color in ethanol: Dorsal surfaces grey or greyish lavender with light spots. Venter cream. Parietal peritoneum entirely covered by iridophores to level of groin; pericardium white, all other peritonea lack white lining [272].

Biology and ecology: Natural history information on Rulyrana mcdiarmidi is scarce. It is nocturnal and males call from rocks in the spray zone of small waterfalls in Foothill Evergreen forests. Parental care is unknown [272].

Call: Not described.

Tadpole: Not described.

Distribution (Figure 197): Rulyrana mcdiarmidi is known from localities in southeastern Ecuador (Morona Santiago and Zamora Chinchipe provinces) and one in northeastern Peru (Departamento de Cajamarca) at elevations between 1150 and $1500 \mathrm{~m}$ ([272], this work). In Ecuador, the potential distribution of the species is $19,002 \mathrm{~km}^{2}$. 


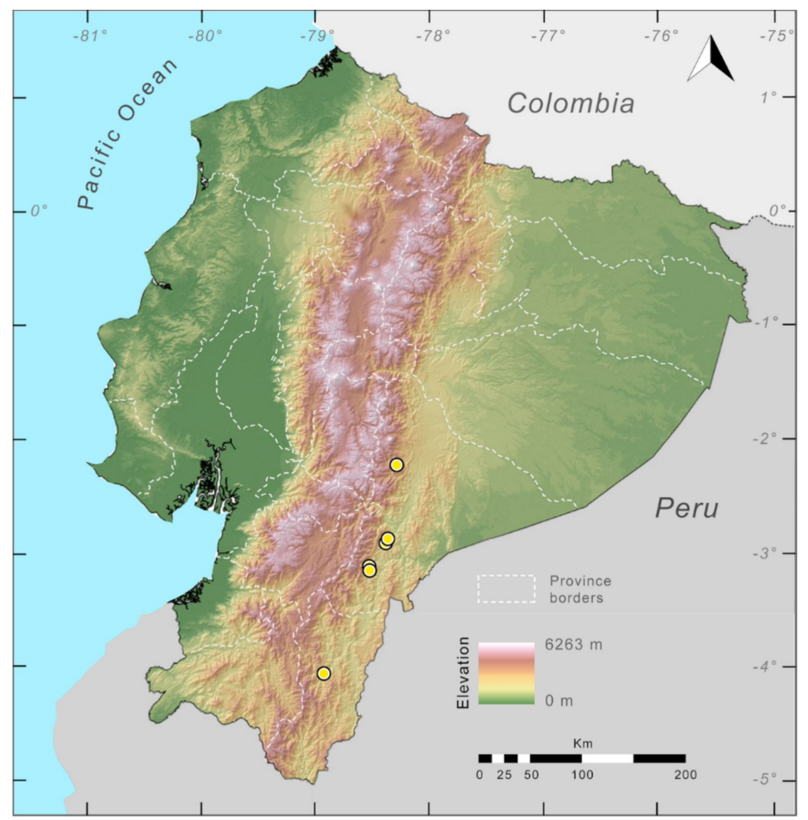

Figure 197. Distribution of Rulyrana mcdiarmidi in Ecuador (yellow dots).

Conservation status: Rulyrana mcdiarmidi is considered as Data Deficient by the IUCN [282]. Given the distribution of the species and the current threats if faces (i.e., habitat fragmentation, contamination by mining), we suggest that it should be considered as Vulnerable, following IUCN criteria following IUCN criteria B1, B2a, B2biii.

Evolutionary relationships (Figure 195): Rulyrana mcdiarmidi and R. flavopunctata are genetically indistinguishable. The clade mcdiarmidi + flavopunctata is sister to $R$. saxiscandens.

Taxonomic remarks: Morphological differences between Rulyrana flavopunctata and R. mcdiarmidi are subtle (body size, skin texture, color pattern), and the two species are not separated genetically (Figure 195). Therefore, it is possible that R. mcdiarmidi represents a geographic variant of $R$. flavopunctata, or that the two species have recently diverged. Information on call variation and ecological requirements are necessary to resolve the species status of $R$. mcdiarmidi.

Specimens examined: Rulyrana mcdiarmidi: Ecuador: Provincia de Zamora Chinchipe: small rivulet tributary of the Jambue River, ca. $6 \mathrm{~km} \mathrm{~S}$ from Zamora (ca. $04^{\circ} 03^{\prime} \mathrm{S}, 78^{\circ} 56^{\prime} \mathrm{W}, 1150 \mathrm{~m}$ ), on the western slope of Contrafuerte de Tzunantza, Cordillera Oriental, eastern slopes of the Andes, DFCH-USFQ D132; $\mathrm{km} 90$ of the Gualaceo-Indanza-Cochay road, ca. $1 \mathrm{~km} \mathrm{SW}$ of Conchay (ca. $03^{\circ} 06^{\prime} \mathrm{S}, 78^{\circ} 25^{\prime} \mathrm{W}$; 1100 m), DFCH-USFQ AL15. Provincia de Morona Santiago: Río Napinaza, 6.8 km N of Limón (2.92278 S, $78.407 \mathrm{~W} ; 985 \mathrm{~m})$, QCAZ 27356-58; $7.6 \mathrm{~km} \mathrm{~W}$ of 9 de Octubre on the 9 de Octubre-Guamote road (2.225 S, 78.2904 W; 1715 m), QCAZ 32265; 2.2 km S of San Juan Bosco (3.10612 S, 79.52515 W; $1013 \mathrm{~m})$, QCAZ 26443; $4.8 \mathrm{~km} \mathrm{~N}$ of Rosario (2.8858 S, $78.38804 \mathrm{~W} ; 841 \mathrm{~m}$ ), QCAZ 26484; $3.1 \mathrm{~km} \mathrm{~S}$ of San Juan Bosco (3.1467 S, 78.53559 W; 1278 m), QCAZ 26426. Peru: Departamento de Cajamarca: Provincia de Jaen: stream tributary of the Río Chinchipe (ca. $05^{\circ} 25^{\prime} 16.5^{\prime \prime}$ S, $78^{\circ} 35^{\prime} 23.2^{\prime \prime} \mathrm{W} ; 1250 \mathrm{~m}$ ), extreme southwestern slope of the Cordillera del Condor, MUSM 26322-4. 
Genus Sachatamia Guayasamin, Castroviejo-Fisher, Trueb, Ayarzagüena, Rada, and Vilà, 2009 [1].

Etymology: The generic name Sachatamia comes from the Kichwa words sacha, meaning forest, and tamia, meaning rain, and refers to the tropical rainforest occupied by the species in this genus; Sachatamia is feminine in gender [1].

Sachatamia albomaculata (Taylor, 1949 [145]; Figures 198-200).

Centrolenella albomaculata Taylor, 1949 [145]. Holotype: KU 23814.

Type locality: "Los Diamantes, one mile south of Guápiles (Cantón de Pococí, Provincia Limón), Costa Rica."

Cochranella albomaculata-Taylor, 1951 [15].

Sachatamia albomaculata-Guayasamin, Castroviejo-Fisher, Trueb, Ayarzagüena, Rada, and Vilà, 2009 [1].

Common names: English: Cascade Glassfrog [24], White-spotted glassfrog. Spanish: Rana de Cristal de Cascada [24], Rana de cristal de puntos blancos.

Etymology: The specific epithet albomaculata is a combination of the Latin words albus (=white) and macula (=spot, stain, mark) and refers to the dorsal color pattern of the species.

Identification: Sachatamia albomaculata is the only glassfrog on the Pacific versant of the Andes that has, in life, a green dorsum with minute and large yellow spots (Figure 198), relative extensive webbing between Fingers III and IV (Figure 199), and lacks humeral spines. Sachatamia punctulata seems to fall within the variation of S. albomaculata (see Taxonomic Remarks).

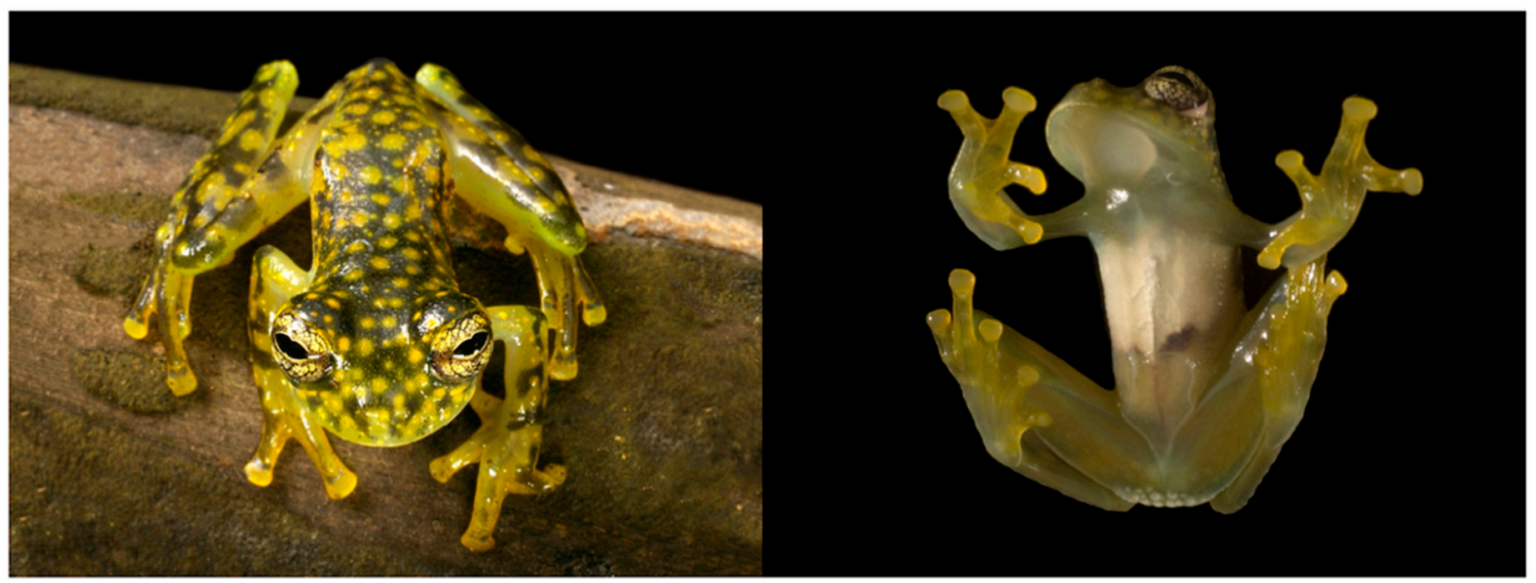

Figure 198. Sachatamia albomaculata in life, adult male, QCAZ 40816. Ecuador: Imbabura: near Lita, ca. $500 \mathrm{~m}$. Photos by M. Bustamante (left) and Luis A. Coloma (right).

Diagnosis: (1) Teeth on dentigerous process of the vomer present, each process bearing four to six teeth; (2) snout round to truncated in dorsal profile, and mostly truncated in lateral profile (Figure 199); (3) tympanum evident, its diameter $25.7 \%-34.2 \%$ of eye diameter, dorsal border of tympanic annulus covered by supratympanic fold, tympanic membrane clearly differentiated from surrounding skin; (4) dorsal skin of males and females shagreen, spicules present in males; (5) skin on venter areolate; pair of enlarged subcloacal warts, which are more evident in females; (6) anterior half of ventral parietal peritoneum covered by white iridophores, posterior half transparent (condition P2); white pericardium; translucent peritoneum covering intestines, stomach, testes, kidneys, gall bladder, and urinary bladder (condition V1); (7) liver tetralobed, two large ventral lobes covering two smaller lobes; 
hepatic peritoneum transparent (condition H0); (8) humeral spines absent; (9) no webbing between Fingers I and II; webbing between other fingers as follows: II $\left(1^{1 / 3}-2^{+}\right)-\left(3-3^{1 / 2}\right) \operatorname{III}\left(1^{1 / 3}-2\right)-\left(1^{1 / 3}-1^{3 / 4}\right)$ IV; (10) foot webbing extensive: I 1 - $\left(1^{3 / 4}-2\right)$ II $\left(0^{+}-1\right)-\left(2-2^{+}\right)$III $\left(1^{-}-1^{1 / 4}\right)-\left(2^{-}-2^{+}\right)$IV $\left(2^{-}-2^{+}\right)-\left(1-1^{+}\right)$ $\mathrm{V}$; (11) ulnar and tarsal folds low; (12) concealed prepollex; in males, nuptial pad Type I; (13) Finger I about same length as Finger II (Finger I 96.5\%-103.9\% length of Finger II); (14) disc of Finger III of moderate size, $41.9 \%-45.0 \%$ of eye diameter; (15) in life, dorsum green with small and large yellow spots; bones green; (16) in ethanol, dorsal surfaces of head, body, and limbs dark lavender with small and large whitish cream spots; venter cream; (17) iris silvery white to yellow with black reticulation; (18) melanophores usually present on dorsal surfaces of outer fingers and toes; (19) males call from the upper surfaces of leaves and rocks along streams and in spray zone of waterfalls; calls consists of a rapid high-pitched single note, "tik", with a duration of 0.001-0.002 s; the dominant frequency is at 6.1-7.1 kHz; (20) fighting behavior unknown; (21) eggs deposited on the upper surfaces of leaves or on rocks; short-term maternal care present; prolonged parental care absent; (22) tadpoles with flattened body; dark brown with violet tint dorsally; venter translucent, with few pigment spots laterally; upper jaw smoothly curved, lower jaw V-shaped; labial tooth row formula 1-2/3; (23) small body size, SVL of adult males 22.1-24.7 $\mathrm{mm}(\overline{\mathrm{X}}=23.6 \pm 0.920, n=7)$; SVL of adult females $26.7-29.0 \mathrm{~mm}(\overline{\mathrm{X}}=27.9 \pm 0.891$, $n=6)$.

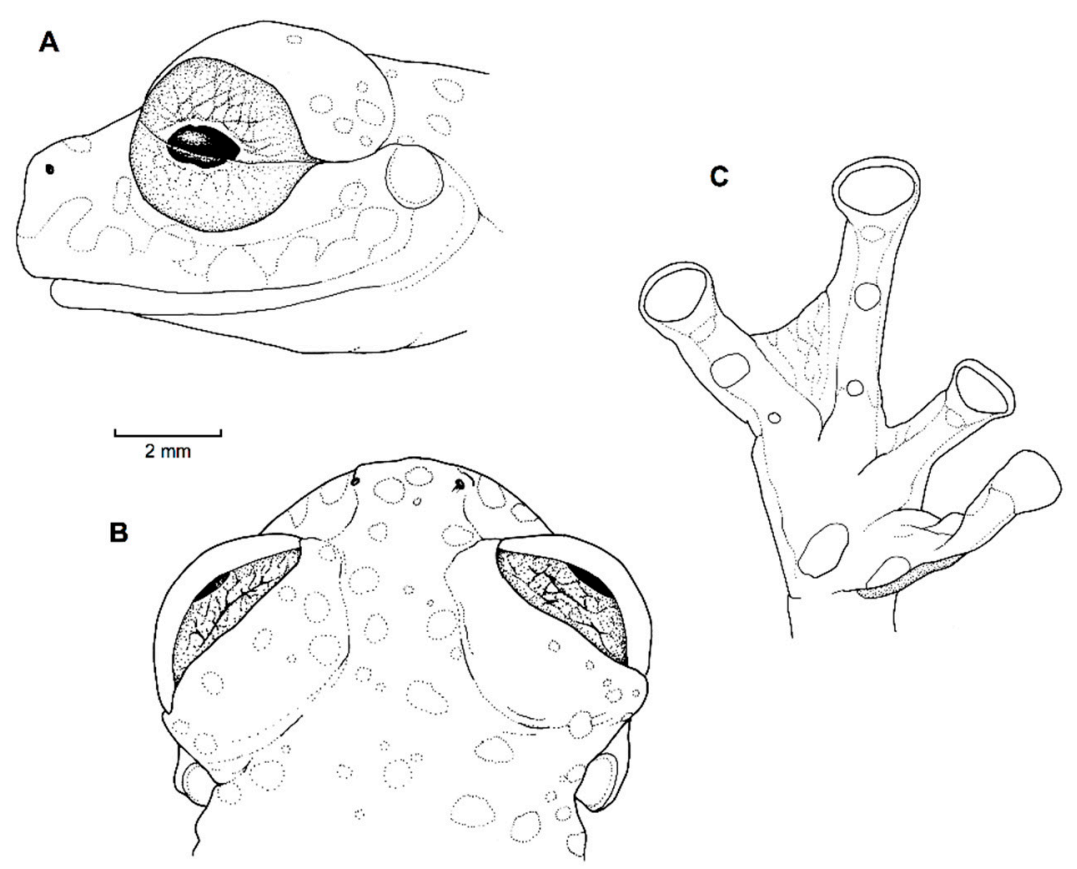

Figure 199. Sachatamia albomaculata, adult male, QCAZ 4325. (A) Head in lateral view. (B) Head in dorsal view. (C) Hand in ventral view. Illustrations Juan M. Guayasamin.

Color in life (Figure 198): In Central American, two clearly different color patterns have been reported, one with a green dorsum and small yellow spots; see photographs in AmphibiaWeb [283], McCranie and Wilson (81:plate 10), Savage 2002 (142:plate 198), Kubicki (24:118), and the other with small and large yellow spots (24:114). The holotype of the species, as well as Ecuadorian populations of the species, exhibit the latter coloration pattern. The venter is white on the anterior half and transparent posteriorly. The bones are green. The iris varies from white to yellow with dark reticulations.

Color in ethanol: Dorsal surfaces of head, body, and limbs lavender, with small whitish cream spots or with small and large spots. White lining covers pericardium and anterior half of ventral parietal peritoneum. Liver, intestines, stomach, testes, kidneys, and gall and urinary bladders covered by translucent peritonea. 
Biology and ecology: On the night of 1 March 1994, a male and a female (QCAZ 4324-25) were found in amplexus on a leaf about $180 \mathrm{~cm}$ above a stream (6 km E of Lita). At a Reserve of the Universidad de la Paz (Costa Rica), Sachatamia albomaculata was abundant in most of the smaller creeks that feed into the upper Río Jaris basin [284]. During the wet season, males and egg clutches were found throughout the stream channel and females deposited their eggs on the upper surfaces of leaves hanging over the water. At the beginning of the dry seasons (December 2001 and 2002), they noted a shift in the reproductive behavior and oviposition sites of this species. A large aggregation of males and egg clutches ( $n=53$; December 2002) were found on rocks in the splash area of two waterfalls; calling males and two egg clutches were also seen on a large boulder in the Jaris river. These observations suggested that in some areas $S$. albomaculata uses wet splash zones to prolong breeding during part of the dry season. The karyotype of Sachatamia albomaculata is $2 \mathrm{~N}=20$ [153]. Females provide short-term parental care; prolonged parental care absent [25].

Call: Males typically call from the upper surfaces of leaves but have also been seen calling from plants growing on the trunks of fallen trees crossing streams, from vegetation and branches growing along rocky riparian walls and from rocky surfaces along the streams ([24,148], RWM, pers. obs.). The call consists of a rapid high-pitched single note, "tik"; the average note duration of the call is $0.001-0.002 \mathrm{~s}$; the dominant frequency is $6.1-7.1 \mathrm{kHz}$ [24].

Egg masses and tadpoles: In the oviduct and shortly after laying, the eggs are black-and-white $[24,148]$. In Costa Rica, during the wet season, females deposit eggs on the upper surface of riparian vegetation; during the dry season, egg clutches are deposited in the splash area of waterfalls [284]. The eggs are distinctive in that a space without eggs often occurs in the center of the mass ([24], RWM, pers. obs.). Egg clutches have 37-81 eggs (mean $=57 \pm 18$ ) [147]. The tadpole of S. albomaculata was described in detail by Hoffmann [147] and we present a summary of his description below. Embryos in stage 22 are tan in color, whereas hatchlings at stage 25 are dark greyish brown, a coloration that extends to the flanks of the body and onto the venter. Ventral coloration is lighter because of the yellow yolk visible through the skin. The larvae of this species are among the most densely pigmented centrolenids in Costa Rica. While hatchlings are consuming their yolk reserve, the oral disc remains incomplete. More developed tadpoles (stages 25-37) have the typical dorsoventrally compressed body shape, which, together with the larvae of S. ilex and T. spinosa, are the most compressed of Costa Rican centrolenids. The oral disc is very similar to that of S. ilex; it is not emarginate and has a single row of $24-40$ marginal papillae with a distinctly broad anterior labium (dorsal gap), a trait that is also present in S. ilex; broad dorsal gap; papillae are often flattened, irregular, and sometimes absent. The upper jaw is smoothly curved, and the lower jaw is broad and V-shaped. The LTRF probably is 2(2)/3 but most tadpoles lack the A-1 tooth row; if present, the A-2 is short and consists mostly of a few teeth in short rows along the lateral margins of the upper jaw. Three ridges are evident on the lower labium and all or some of them bear teeth [147]. Whether these irregularities in the labial tooth rows result from laboratory rearing or are typical of the species remains to be demonstrated.

Distribution (Figure 200): Sachatamia albomaculata is known from humid lowlands and premontane slopes from north-central Honduras to western Colombia and Ecuador at elevations between 20 and $1500 \mathrm{~m}$ ([130,148,160], this work). In Ecuador, this species has been reported from the provinces of Esmeraldas and Imbabura at elevations below $700 \mathrm{~m}$. In Ecuador, the potential distribution of the species is $22,608 \mathrm{~km}^{2}$ within the Chocoan Tropical Forest and the Western Foothill Forest regions. 


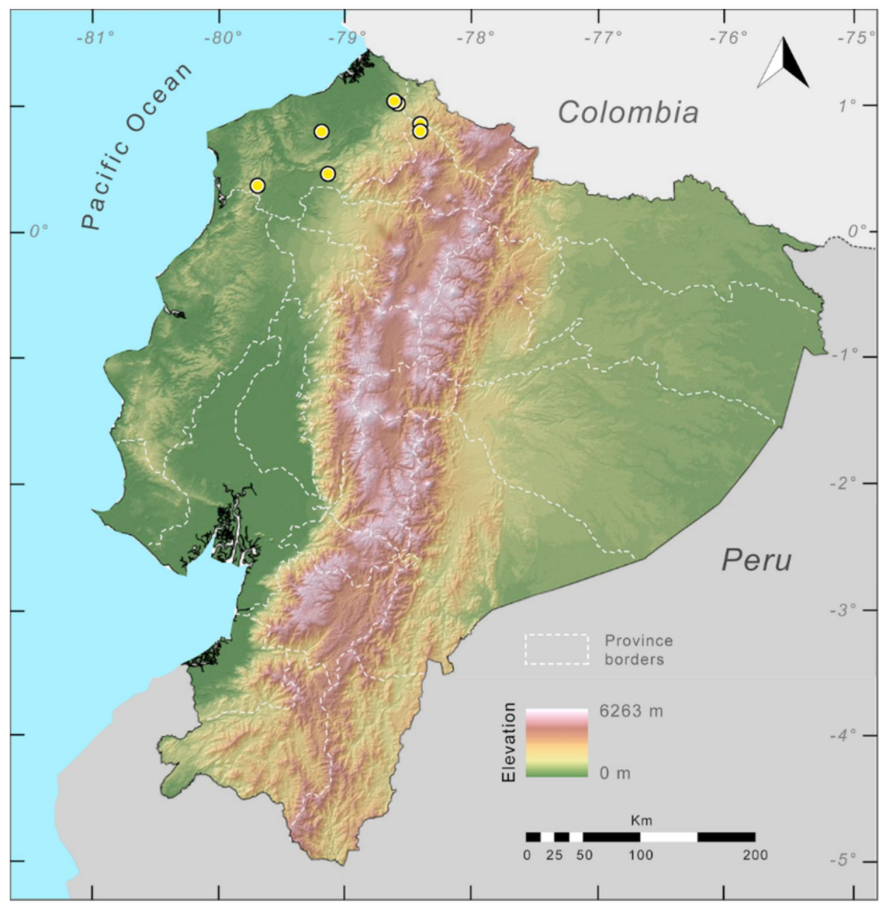

Figure 200. Distribution of Sachatamia albomaculata in Ecuador (yellow dots).

Conservation status: Listed as Least Concern by the IUCN in view of its wide distribution and presumed large population [285]. In Ecuador, the species is known mainly from a few reports in the Chocó, an area with the highest deforestation rate (because of oil palm and wood extraction) and spreading mining. We suggest that the species should be considered as Endangered in Ecuador, following IUCN criteria A2, B2a, B2(iii).

Evolutionary relationships (Figure 195): Sachatamia albomaculata is sister to a clade formed by S. punctulata + S. electrops.

Taxonomic Remarks: S. albomaculata, as currently defined, has two clear dorsal color patterns: (a) Dorsum with small yellow spots, (b) dorsum with small and large yellow spots (see Color in life section). Two scenarios can explain the observed polymorphism: Two or more species occur within what is now recognized as $S$. albomaculata, or S. albomaculata has a natural polymorphic coloration. To test the two hypotheses, it is necessary to plot the occurrence of the patterns, document variation and possible sympatry, and obtain acoustic data and molecular samples of the different color patterns for comparative analyses. It would also be worth obtaining samples from the Colombian species S. punctulata, which has a color pattern identical to pattern (a) of S. albomaculata.

Specimens examined: Sachatamia albomaculata: Colombia: Departamento de Antioquia: Dabeiba, Río Amparradó, Quebrada Iotó, 805 m, ICN 10685-87. Costa Rica: Limón: Los Diamantes, one mile south of Guápiles, KU 23814 (holotype). Ecuador: Provincia de Imbabura: $6 \mathrm{~km}$ SE of Lita $\left(0^{\circ} 47^{\prime} 41^{\prime \prime} \mathrm{N}\right.$, $78^{\circ} 25^{\prime} 43^{\prime \prime}$ W), QCAZ 4324-25. Provincia de Esmeraldas: Estero Vicente, an affluent of the Río San Miguel $\left.0^{\circ} 47^{\prime} 32^{\prime \prime} \mathrm{N}, 79^{\circ} 11^{\prime} 52^{\prime \prime} \mathrm{W}, 225-275 \mathrm{~m}\right)$, QCAZ 11369-70; Reserva Biológica Canandé $\left(0^{\circ} 27^{\prime} 4^{\prime \prime} \mathrm{N}\right.$, $\left.79^{\circ} 08^{\prime} 45^{\prime \prime} \mathrm{W}, 700 \mathrm{~m}\right)$, MECN 2618-19; $2.1 \mathrm{~km}$ E of Durango (1.02477 N, 78.61746 W; $284 \mathrm{~m}$ ), QCAZ $32172-73 ; 5 \mathrm{~km}$ E of Lita, on the Lita-Ibarra road (0.84773 N, $78.42175 \mathrm{~W})$, QCAZ 40816; Reserva Itapoa $\left(0.513^{\circ} \mathrm{N}, 79.134^{\circ} \mathrm{W}, 321 \mathrm{~m}\right)$, MZUTI 3013.

Localities from the literature: Sachatamia albomaculata: Ecuador: Provincia de Esmeraldas: Estación Biológica Bilsa $(0.359 \mathrm{~N}, 79.701 \mathrm{~W})$ [160]. 
Sachatamia ilex (Savage, 1967 [202]; Figures 201-203).

Centrolenella ilex Savage, 1967 [202]. Holotype: LACM 25205.

Type locality: "Costa Rica: Provincia de Limón: Cantón de Limón: Alta Talamanca: 16 km SW

Amubri, on Río Lari, 300 m"; corrected to 14 km SW Amubri, Río Lari, Cantón de

Talamanca, Provincia de Limón, $300 \mathrm{~m}$ by Savage, 1974 [183].

Centrolene ilex-Ruiz-Carranza and Lynch, 1991 [6].

Sachatamia ilex —Guayasamin, Castroviejo-Fisher, Trueb, Ayarzagüena, Rada, and Vilà, 2009 [1].

Common names: English: Holly's Glassfrog. Spanish: Rana de Cristal de Holly, Rana de Cristal Fantasma.

Etymology: The specific name ilex honors Priscilla Hollister "Holly" Starrett (Ilex is the genus of the holly trees), for her contributions to centrolenid systematics [202].

Identification: Sachatamia ilex is distinguished from other glassfrogs by having, in life, a uniform dark green dorsum, a white to pale yellow or greenish-yellow iris with thick and contrasting black reticulations (Figure 201), and a moderate body size (male SVL 27.0-29.0 mm; female SVL 28.0-34.0 mm). Adult males have a pointed humeral spine (Figure 201) that is embedded in the arm musculature (not easily visible externally). Sachatamia ilex closely resembles spotless populations of Espadarana prosoblepon (Figure 95) and E. callistomma (Figure 89), the males of which have externally visible humeral spines; most individuals of E. prosoblepon lack the thick black reticulation of the iris that is evident in S. ilex. Other species with uniform green dorsal coloration that could be confused with S. ilex are "Cochranella" prasina, which lacks webbing between Fingers II, III, and IV (present in S. ilex), and Teratohyla spinosa, which is much smaller in body size (SVL $<21 \mathrm{~mm}$ ) and lacks humeral spines.

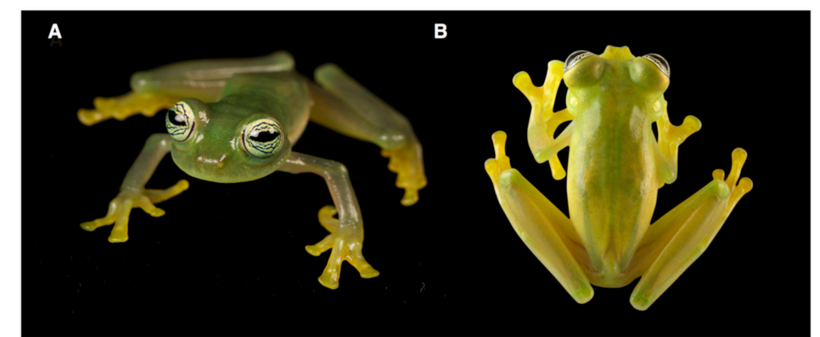

C

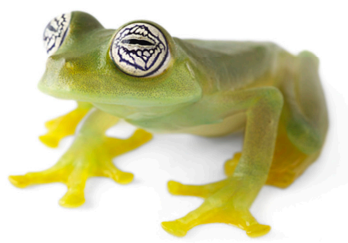

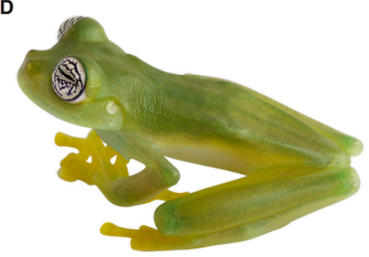

Figure 201. Sachatamia ilex in life. (A,B) Adult male, Alto Tambo, Esmeraldas province, $620 \mathrm{~m}, \mathrm{QCAZ}$ 47193. (C) Adult male, Alto Tambo-El Placer, Esmeraldas province, 706 m, QCAZ 48338. (D) Adult male, Alto Tambo-El Placer, Esmeraldas province, not collected. Photos by L. A. Coloma.

Diagnosis: (1) Each dentigerous process of the vomer bearing three to five teeth; (2) snout truncated in dorsal and lateral profiles; (3) tympanum oriented almost vertically, relatively small, its diameter $26.1 \%-28.7 \%$ of eye diameter; supratympanic fold conspicuous, covering dorsal margin of tympanic annulus; tympanic membrane pigmented, but clearly differentiated from surrounding skin; (4) dorsal surfaces of males and females smooth to shagreen, lacking spicules; (5) venter areolate; lacking pair of enlarged subcloacal warts; (6) anterior two-thirds of ventral parietal peritoneum white, posterior third transparent (condition P3); white pericardium; translucent peritoneum covering intestines, stomach, kidneys, testes, gall bladder, and urinary bladder (condition V1); (7) liver tetralobed, covered by transparent peritoneum (condition H0); (8) in males, humeral spines present, but embedded in arm 
musculature; (9) webbing absent between Fingers I and II, reduced between Fingers II and III, extensive between III and IV; webbing formula II $\left(1^{1 / 2}-2^{-}\right)-\left(3^{+}-3^{1 / 4}\right)$ III $\left(1^{1 / 3}-2\right)-\left(1^{+}-1^{1 / 3}\right)$ IV; $(10)$ webbing formula on foot I $\left(1-1^{1 / 4}\right)-\left(1^{1 / 2}-2^{-}\right)$II $\left(1-1^{+}\right)-\left(1^{3 / 4}-2\right)$ III $\left(1-1^{+}\right)-\left(2^{-}-2^{+}\right)$IV $\left(1^{1 / 2}-2^{+}\right)-\left(1-1^{+}\right)$V; (11) ulnar fold absent or low and inconspicuous; inner tarsal fold low, short; outer tarsal fold absent; (12) concealed prepollex; in males, nuptial pad Type I; (13) Finger I slightly shorter or about same length as Finger II (Finger I 97.2\%-100.0\% of Finger II); (14) disc of Finger III relatively narrow, its width about $34.0 \%-45.9 \%$ of eye diameter; (15) in life, dorsum uniform green; upper lip white; bones green; (16) in preservative, dorsum uniform lavender; (17) iris, in life, silvery white to greenish yellow with thick, contrasting black reticulation; (18) melanophores usually present on fingers and toes, except sometimes absent from Toes IV and V; (19) males call from upper sides of leaves near streams; each call is frequency modulated and consists of a single note with a duration of $0.077-0.086 \mathrm{~s}$; dominant frequency starts at $6562-6937 \mathrm{~Hz}$, rises to $7406-7500 \mathrm{~Hz}$, and drops to $6562-6843 \mathrm{~Hz}$; (20) males fight upside down, grasping one another venter to venter; (21) brown eggs deposited on upper side of leaves; parental care unknown; (22) tadpoles with flattened body shape; blackish brown dorsal coloration, venter translucent; upper jaw in form of broad arch; lower jaw V-shaped; labial tooth row formula 0/2-3; (23) medium body size; SVL of adult males 27.0-29.0 mm; SVL of adult females 28.0-35.0 mm.

A

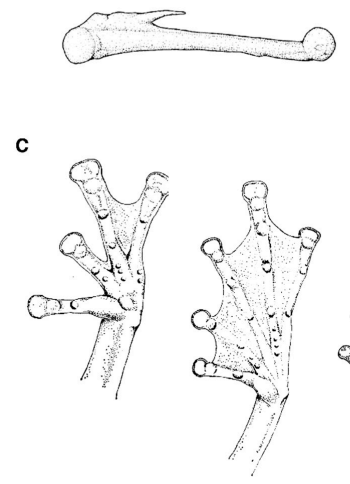

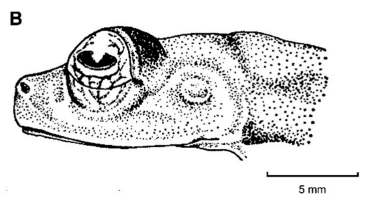$$
\text { D }
$$

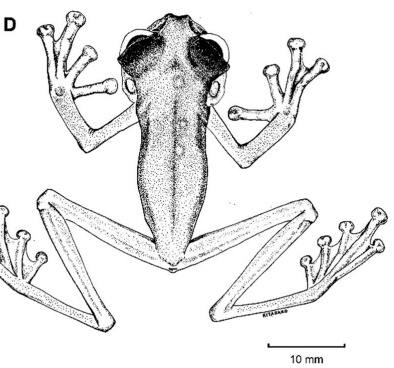

Figure 202. Sachatamia ilex. (A) Humeral spine of adult male, LACM 72910, not to scale. (B) Head in lateral, paratype. (C) Hand (left) and foot (right) in ventral view, paratype, not to scale. (D) Dorsal view of paratype. (A) Modified from Guayasamin et al. [1]. (B-D) Modified from Savage [202].

Color in life (Figure 201): Dorsum uniform dark green; throat and venter cream white; dull yellow hands and feet; upper lip with thin white line. White parietal peritoneum covers anterior two-thirds of venter; clear visceral and hepatic peritonea. Bones green. Iris silvery white to greenish yellow with thick, contrasting black reticulations.

Color in ethanol: Dorsal surfaces of head and body uniform lavender, although faint cream spots might be visible in some individuals [202]; limbs creamy lavender dorsally; margin of upper lip white or cream. White parietal peritoneum covering anterior two-thirds of venter; pericardium white; clear peritoneum covering liver, intestines, stomach, kidneys, and urinary bladder. In males, nuptial pad creamy white.

Biology and ecology: Nocturnal and arboreal. On 10 November 1999, at Hacienda La Joya (northwestern Ecuador), one male was calling, and two females were gravid, suggesting reproductive activity [130]. Kubicki [24] described and illustrated the combat behavior of Sachatamia ilex as follows: Males hang vertically from vegetation by the tips of their toes and grasp each other chest to chest in a type of arm lock; males may hang in this position for several minutes to hours, and try to dislodge the other male's feet, so that he loses grip of the vegetation. During this behavior, the two males produce softer preep calls. Parental care is unknown. 
Call: The following call description is based on a recording of one male of Sachatamia ilex made by Elicio Tapia on 17 May 2010 at Reserva Otokiki $\left(0.91104^{\circ}\right.$ N, 78.57369 ${ }^{\circ}$ W; 706 m), Provincia de Esmeraldas, Ecuador. Males call from the upper surfaces of leaves. Ten calls where emitted during a five-minute interval; the call consists of a single, pulsed note; the note ends with a series of pulses the amplitude of which is conspicuously lower than the pulses at the beginning of the note. Each note has a duration of $0.077-0.086 \mathrm{~s}(\overline{\mathrm{X}}=0.08 \pm 0.033, n=6)$. The note is frequency modulated; the dominant frequency at the beginning of the note (pulsed section) is at $6562-6937 \mathrm{~Hz}(\bar{X}=6640 \pm 150.2, n=6)$; during the tonal section of the note, the dominant frequency increases to $7406-7500 \mathrm{~Hz}(\bar{X}=7422 \pm 38.4$, $n=6)$; finally, it drops to $6562-6843 \mathrm{~Hz}(\overline{\mathrm{X}}=6718 \pm 128.0, n=6)$. The maximum value of the dominant frequency is always during the first pulsed section of the note.

Egg masses and tadpoles: Brown eggs are deposited as a single layer on the upper leaf surface of plants overhanging streams; sometimes a mass has a slight hole in the center, resembling a doughnut, because they might rotate around from the middle while laying eggs; egg clutches have 12-25 eggs [24]. Species of Drosophila have been observed to parasitize egg clutches of S. ilex [147]. The tadpole description presented below is a summary obtained from Hoffmann [147]. When hatching, larvae have a dark greyish-brown dorsal coloration; the body is nearly circular in cross-section with a length of about $12 \mathrm{~mm}$; it is longer than other Costa Rican centrolenid hatchlings. In tadpoles that are living off their yolk reserves, oral discs are incomplete. As development continues (Gosner stages 28-40) the body becomes flattened and a dense dorsal pigmentation develops, giving them a blackish-brown ground tone; there is a slightly violet coloration because of the vascularized underlying organs. Lateral body pigmentation decreases ventrally, and the tail coloration is the same as the dorsum, decreasing gradually towards its ventral side. The snout is rounded in dorsal view and acutely angled in lateral view. The anteroventral oral disc has marginal papillae only on the lateral and ventral margins; the anterior labium forms the upper lip and is uniformly broad; the disc is not emarginate. Because of the lack of an anterior disc area, the labial tooth rows A-1 and A-2 are absent. P-1 is usually completely developed, P-2 is shorter not always completely developed, and P-3 lacks teeth or has very few of them [147].

Distribution (Figure 203): Sachatamia ilex is known from localities in eastern Nicaragua, Costa Rica, western Panama, western Colombia, and western Ecuador at elevations from sea level up to $1420 \mathrm{~m}([130,148,217,284,285]$, this work). In Ecuador, Sachatamia ilex has been found in Esmeraldas and Pichincha provinces at elevations between 150 and $800 \mathrm{~m}$ ([130], this work). In Ecuador, the potential distribution of the species is $12,669 \mathrm{~km}^{2}$ within the Chocoan Tropical Forest and the Western Foothill Forest regions.

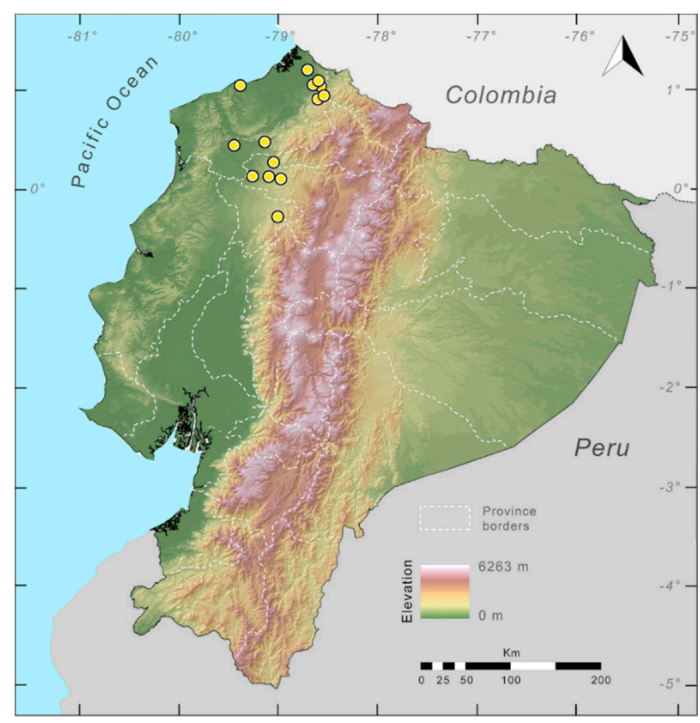

Figure 203. Distribution of Sachatamia ilex in Ecuador (yellow dots). 
Conservation status: Sachatamia ilex is globally listed as Least Concern [285]. Kubicki (2007) mentioned that $S$. ilex is fairly common in much of its range along the Caribbean drainage in Costa Rica. In Ecuador, habitat reduction is a serious threat for this and other species that inhabit the Chocó Ecoregion; thus, at the local level, we suggest that the species should be considered as Endangered, following IUCN criteria B2a, B2(iii).

Evolutionary relationships (Figure 204): Molecular evidence places Sachatamia ilex and S. orejuela as sister species.

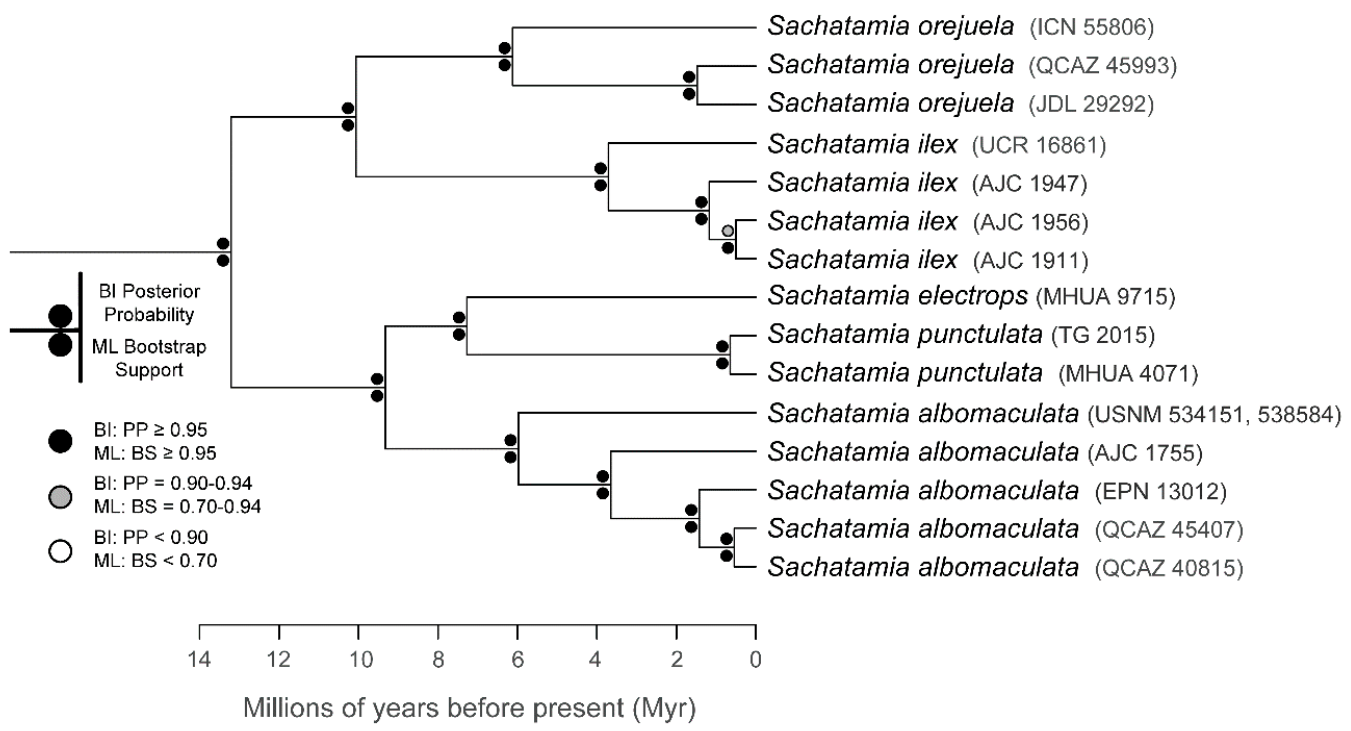

Figure 204. Evolutionary relationships of species in the glassfrog genus Sachatamia. The trees were inferred using maximum likelihood and Bayesian criteria.

Specimens examined: Sachatamia ilex: Colombia: Departamento de Antioquia: Dabeiba, Río Amparradó, Quebrada Iotó, 805 m, ICN 10625-29, 10630 (C\&S), 10631-32. Costa Rica: Provincia de Limón: Costa Rican Amphibian Research Center, UCR 16861. Ecuador: Provincia de Esmeraldas: Reserva Biológica Canandé $\left(0.45^{\circ} \mathrm{N}, 79.14^{\circ} \mathrm{W}, 700 \mathrm{~m}\right)$, MECN 2620-26; Río Tululbí $\left(1.0634^{\circ} \mathrm{N}, 78.59397^{\circ} \mathrm{W}\right.$,

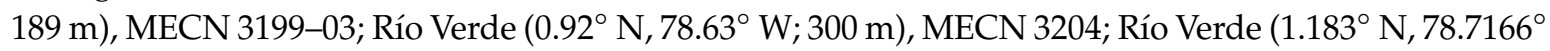
W; 300 m), MECN 3199; recinto Ventanas $\left(0.89816^{\circ} \mathrm{N}, 78.6175^{\circ}\right.$ W. $\left.200 \mathrm{~m}\right)$, MECN 3204; Reserva Otokiki $\left(0.91104^{\circ} \mathrm{N}, 78.57369^{\circ} \mathrm{W} ; 706 \mathrm{~m}\right)$, QCAZ $48338 ; 4 \mathrm{~km} \mathrm{~N}$ of Durango $\left(1.44307^{\circ} \mathrm{N}, 77.99667^{\circ} \mathrm{W} ; 253 \mathrm{~m}\right)$, QCAZ 33325; Río La Carolina (0.70449 ${ }^{\circ} \mathrm{N}, 78.20115^{\circ} \mathrm{W}$; $\left.500 \mathrm{~m}\right)$, QCAZ 35363; $2.1 \mathrm{~km}$ E Durango $\left(1.02477^{\circ} \mathrm{N}, 78.61746^{\circ} \mathrm{W} ; 284 \mathrm{~m}\right)$, QCAZ 32158; $4 \mathrm{~km} \mathrm{~W}$ Durango $\left(1.02348^{\circ} \mathrm{N}, 78.19296^{\circ} \mathrm{W} ; 238 \mathrm{~m}\right)$, QCAZ 33057. Provincia de Santo Domingo de los Tsáchilas: $4 \mathrm{~km}$ NW La Florida, Finca Gloria $\left(0.25694^{\circ} \mathrm{N}\right.$, 79.0538 W; 896 m), QCAZ 19881; La Florida, near Alluriquín $\left(0.2836^{\circ} \mathrm{N}, 79.0188^{\circ} \mathrm{W}\right)$, QCAZ 13055. Provincia de Pichincha: Puerto Quito $\left(0.1167^{\circ} \mathrm{N}, 79.2667^{\circ} \mathrm{W} ; 150 \mathrm{~m}\right)$, KU 221613; Hacienda La Joya, $\mathrm{km} 109$ of the Calacalí-Nanegalito-P.V. Maldonado Road, next to the town of San Vicente de Andoas $\left(0.083^{\circ} \mathrm{N}, 78.983^{\circ} \mathrm{W} ; 750-800 \mathrm{~m}\right)$, DFCH-USFQ D260-61; near Pedro Vicente Maldonado $\left(0.10421^{\circ} \mathrm{N}\right.$, 79.10279 W; 544 m), QCAZ 35429. Panama: Comarca San Blas: Camp Summit, 400 m, KU 116464. 
Sachatamia orejuela (Duellman and Burrowes, 1989 [86]; Figures 205 and 206).

Centrolenella orejuela Duellman and Burrowes, 1989 [86]. Holotype: KU 145081.

Type locality: "between El Tambo and La Costa, 800 m, Departamento de Cauca, Colombia."

Cochranella orejuela-Ruiz-Carranza and Lynch, 1991 [6].

"Cochranella" orejuela—Guayasamin, Castroviejo-Fisher, Trueb, Ayarzagüena, Rada, and Vilà, 2009 [1].

Sachatamia orejuela-Twomey, Delia, and Castroviejo-Fisher, 2014 [19].

Teratohyla sornozai-Cisneros-Heredia, Yánez-Muñoz, and Ortega-Andrade, 2009 [286].

Synonymy by Cisneros-Heredia, Yánez-Muñoz, and Ortega-Andrade, 2010 [287].

Common names: English: Orejuela's Glassfrog. Spanish: Rana de Cristal de Orejuela.

Etymology: The specific name orejuela is a patronym for the Orejuela family (Jorge, Anamaría, and Tomás), who, at the time when the study was conducted, resided, and administered the Reserva La Planada, Colombia [86].

Identification: Sachatamia orejuela is mainly recognized by having a uniformly olive-green dorsum (Figure 205). In the Pacific versant of the Andes, only the following species have a uniformly green dorsum: Nymphargus prasinus, Sachatamia ilex, S. orejuela, Teratohyla spinosa, and some populations of E. prosoblepon. From these species, Sachatamia orejuela is distinguished by the absence of humeral spines (spines present in males of E. prosoblepon and S. ilex), relatively large body size (SVL 27.3-33.8 $\mathrm{mm}$ in S. orejuela; SVL $<22.0 \mathrm{~mm}$ in T. spinosa), and extensive webbing between Fingers III and IV (webbing absent or basal in Nymphargus prasinus). Additionally, S. orejuela is found in a very specific microhabitat, on rocks nearby waterfalls.

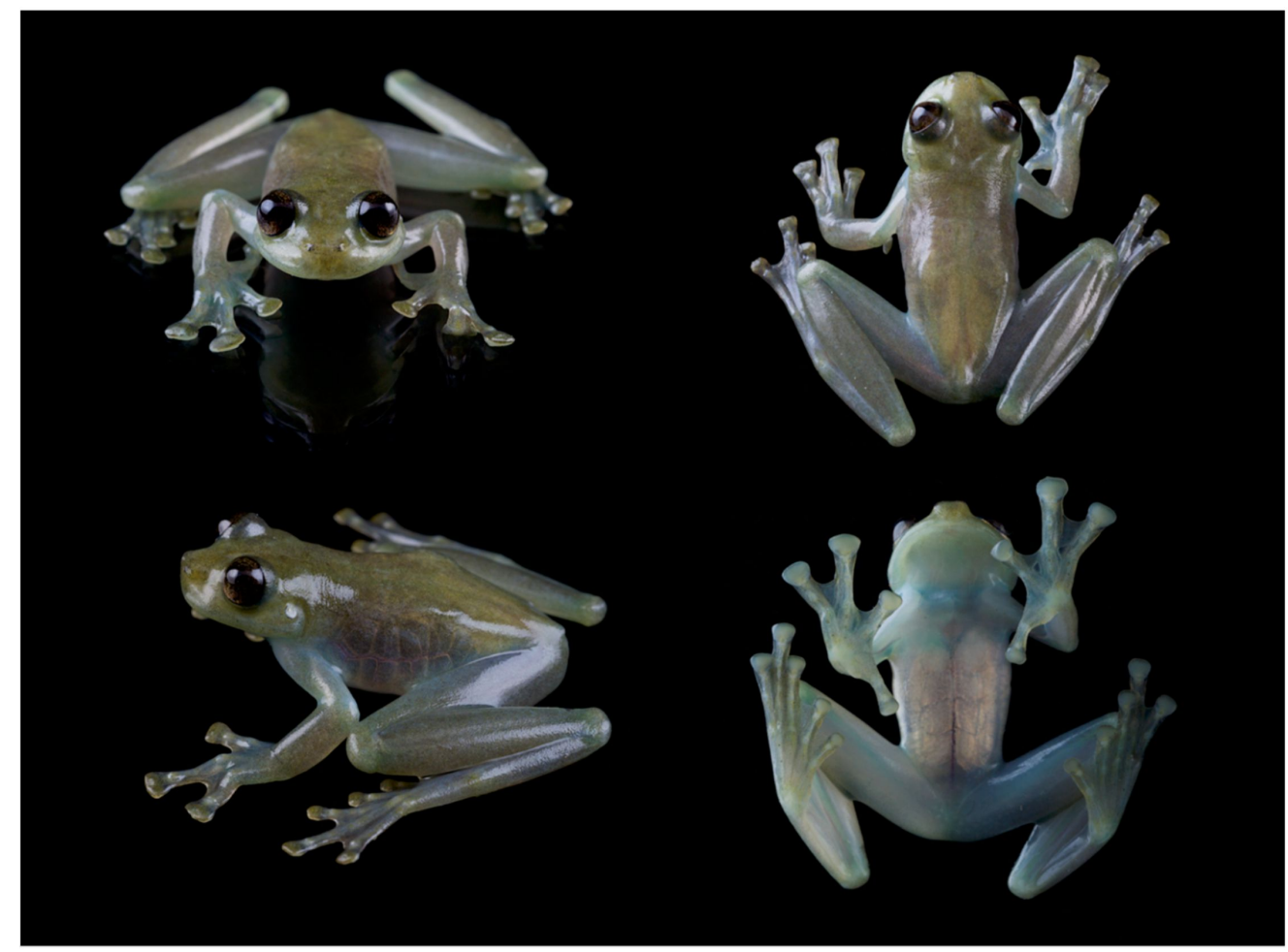

Figure 205. Sachatamia orejuela in life. Adult male, QCAZ 45993. Locality near Río Aguas Verdes, 670 m, Imbabura province, Ecuador. Photos by Luis A. Coloma. 
Diagnosis: (1) Each vomer with two to five teeth; (2) snout truncated in dorsal aspect, slightly protruding in lateral profile; (3) tympanum small, visible, its diameter $18.5 \%-25.6 \%$ of eye diameter; tympanic membrane pigmented as surrounding skin; supratympanic fold conspicuous; (4) dorsal surfaces finely shagreen, with small spicules evident in sexually active males; (5) ventral surfaces of body areolate; pair of enlarged subcloacal warts absent; in males, cloacal region with minute spinules; (6) anterior half of the parietal peritoneum white (condition P2); white pericardium, translucent visceral peritoneum (condition V1); (7) tetralobed liver covered by transparent peritoneum (condition $\mathrm{H} 0$ ); (8) humeral spines absent; (9) webbing between Fingers I and II basal, moderate between Fingers II and III, and extensive between Fingers III and IV; webbing formula for fingers: II $\left(1-1^{1 / 2}\right)-\left(3^{-}-3^{+}\right)$ III $\left(1^{+}-2^{-}\right)-\left(1-1^{+}\right)$IV; (10) webbing on foot extensive: I $0^{+}-\left(1^{-}-1\right)$ II $0^{+}-\left(0^{+}-1\right)$ III $0^{+}-\left(0^{+}-1\right)$ IV $\left(1^{1 / 3}-1^{1 / 2}\right)-0 \mathrm{~V}$; (11) ulnar and tarsal folds absent; (12) nuptial pad Type I, concealed prepollex; (13) Finger I slightly longer than Finger II (Finger II about 95\%-98\% length of Finger I); (14) disc of Finger III large, its width about $62 \%-70 \%$ of eye diameter; (15) in life, dorsum uniform dark olive green; (16) in preservative, dorsum uniform dull grey; (17) iris, in life, dark grey with yellow ring around pupil; (18) melanophores on dorsal surfaces of all fingers and toes; (19) males call from rocks along or within streams; call unknown; (20) fighting behavior unknown; (21) eggs deposition site unknown; parental care unknown; (22) tadpoles unknown; (23) medium body size; SVL 27.3-28.3 $\mathrm{mm}(n=3)$ in males; 29.6-33.8 $\mathrm{mm}(n=6)$ in females.

Color in life (Figure 205): Uniform dark olive-green dorsum, greyish green flanks; throat translucent, with light green hue; venter whitish cream. Bones green. Iris dark grey to brown ([86], this work).

Color in ethanol: Dorsum, including hands, feet, and webbing dull grey [86]. Anterior half of venter cream white, posterior half translucent; white pericardium, translucent visceral peritonea, and transparent hepatic peritoneum (liver brown).

Biology and ecology: During the night, Sachatamia orejuela is mostly found on rocks along steep stream banks or within the stream in the spray zone of cascades ([86,288], this work). As other species adapted to spray zones (e.g., Centrolene geckoidea, C. paezorum, "Centrolene" petrophilum, "Centrolene" medemi), hand and foot webbing in Sachatamia orejuela is relatively extensive when compared to glassfrogs not found in this microhabitat. Spiders of the genus Clubiona have been observed to prey on juveniles of S. orejuela [289]. Parental care is unknown.

Call: Not described.

Tadpole: Not described.

Distribution (Figure 206): Sachatamia orejuela is known from four localities in southern Colombia and four localities in northern Ecuador ([86,101,288,290], this work). All localities are on the Pacific flank of the Andean Cordillera Occidental at elevations between 500 and 1250 m, within the Eastern Foothill Forest region. In Ecuador, the potential distribution of the species is $27,514 \mathrm{~km}^{2}$.

Conservation status: Sachatamia orejuela is classified as Least Concern by the IUCN [291]. However, in Ecuador, the habitat of the species is fragmented and threatened by logging and mining. We suggest that the species should be considered as Endangered, following IUCN criteria B2a, B2(iii).

Evolutionary relationships (Figure 204): Sachatamia orejuela and S. ilex are inferred as sister species. Herein, we modify the phylogenetic definition of the genus Sachatamia [1] as follows: Sachatamia is the clade stemming from the most recent common ancestor of Centrolenella albomaculata Taylor 1949 [145], and Cochranella orejuela Duellman and Burrowes 1989 [86]. 
Taxonomic Remarks: Teratohyla sornozai was synonymized with Sachatamia orejuela by Cisneros-Heredia et al. [287]. Examination of the type series of T. sornozai showed that all differences that separated it from S. orejuela were expressions of ontogenetic and intraspecific variation of the later.

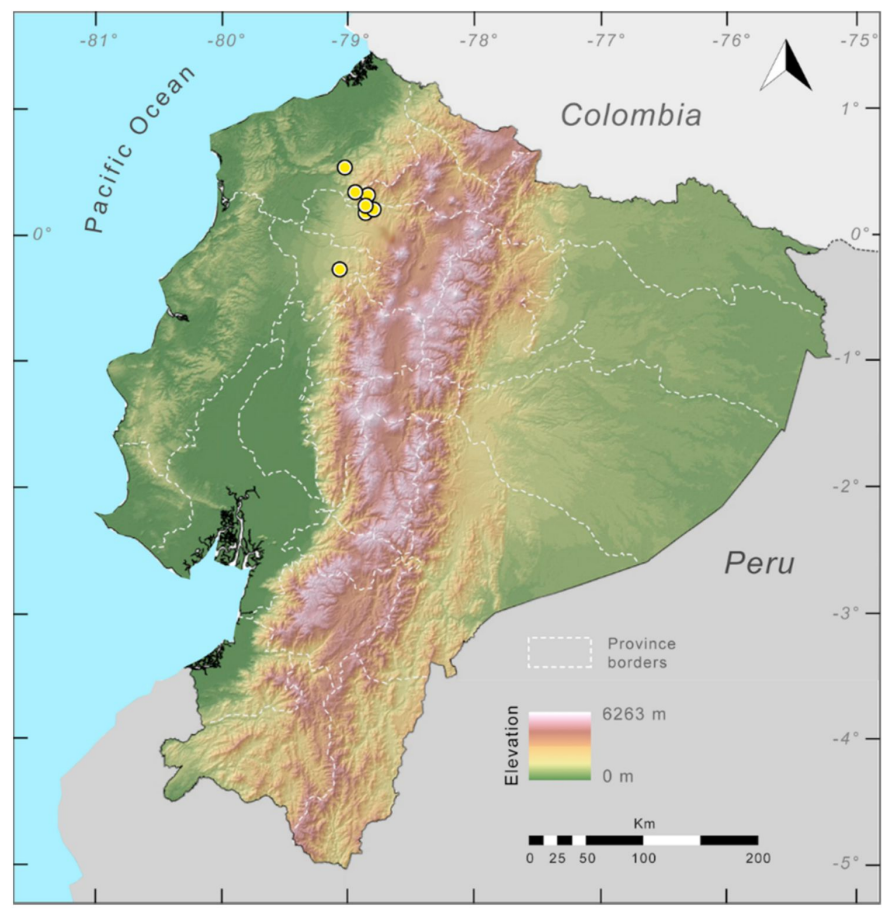

Figure 206. Distribution of Sachatamia orejuela in Ecuador (yellow dots).

Specimens examined: Sachatamia orejuela: Colombia: Departamento de Cauca: between El Tambo and La Costa, $800 \mathrm{~m}, \mathrm{KU} 145081$ (holotype), 145080 (paratype). Ecuador: Provincia de Esmeraldas: Reserva Biológica Canandé (0.5299 N, 79.0354 S; 550 m), DHMECN 2634. Provincia de Imbabura: Zona de amortiguamiento de Reserva Cotacachi Cayapas, near Río Aguas Verdes $\left(0.331010^{\circ} \mathrm{N}, 78.93152^{\circ} \mathrm{W}\right.$; 670 m), QCAZ 45993; Reserva Río Manduriacu (0.3108 N, 78.8576 S; 1230 m), JMG 1581. Provincia de Pichincha: Bosque Protector Mashpi $\left(00^{\circ} 10^{\prime} 2.34^{\prime \prime}\right.$ N 7852'2.32" W; $\left.1200 \mathrm{~m}\right)$, DHMECN 04309; Río Chalpi $\left(00^{\circ} 13^{\prime} 32.38^{\prime \prime} \mathrm{N} 78^{\circ} 51^{\prime} 28.87^{\prime \prime} \mathrm{W}\right.$; $\left.615 \mathrm{~m}\right)$, DHMECN 04551; Río Anope $\left(00^{\circ} 12^{\prime} 45.54^{\prime \prime} \mathrm{N}\right.$ $78^{\circ} 48^{\prime} 58.34^{\prime \prime} \mathrm{W} ; 1080 \mathrm{~m}$ ), in the surroundings of the town of Saguangal, DHMECN 04552. Provincia de Santo Domingo de los Tsáchilas: Trail within Hotel Tinalandia (0.2727 S, 79.079 W), QCAZ 45452.

Localities from the Literature: Colombia: Departamento de Nariño: Pialapí, 1250 m, IND-AN 1520-21, LP248 [86]; Departamento Valle del Cauca: Campo Alegre (IUCN, 2010). Ecuador: Provincia de Esmeraldas: Reserva Biológica Canandé (0.306 N, 79.138 W; 550 m), DHMECN 2634. Provincia de Pichincha: Bosque Protector Mashpi (0.167 N, 78.867 W; 550 m), DHMECN 4308. Provincia de Imbabura: Stream tributary of Río Naranjal (0.351 N, 78.917 W; 750 m), DHMECN 3522 ([286] as Teratohyla sornozai). 
Genus Teratohyla Taylor 1951 [15].

Etymology: The generic name Teratohyla is derived from the Greek teras, meaning monster, marvel or wonder, and the word Hyla, traditionally associated with treefrogs. The origin of the frog name Hyla is based on the mythological Greek boy Hylas and, although the boy's name is masculine, it has been unambiguously treated as feminine by amphibian systematists [292].

Teratohyla amelie (Cisneros-Heredia and Meza-Ramos, 2007 [253]; Figures 207-209).

Cochranella amelie Cisneros-Heredia and Meza-Ramos, 2007 [253]. Holotype: DHMECN 3066. Type locality: "Comunidad de Oglán, Cantón Arajuno, Provincia de Pastaza, República del Ecuador ( $01^{\circ} 18^{\prime} 65^{\prime \prime} \mathrm{S}, 77^{\circ} 42^{\prime} 41^{\prime \prime} \mathrm{W}, 600$ m elevation)."

Teratohyla amelie - Guayasamin, Castroviejo-Fisher, Trueb, Ayarzagüena, Rada, and Vilà, 2009 [1].

Common names: English: Amelie's Glassfrog. Spanish: Rana de Cristal de Amelie.

Etymology: The specific name is for Amelie, protagonist of the movie "Le Fabuleux Destin d'Amélie Poulain", a movie where little details play an important role in the achievement of joie de vivre; like the important role that glassfrogs and all amphibians and reptiles play in the health of our planet. [253].

Identification: Teratohyla amelie differs from most species inhabiting the Amazonian lowlands and Amazonian slopes of the Andes by having a completely transparent ventral parietal peritoneum (Figure 207). In Ecuador, only species in the genus Hyalinobatrachium and Chimerella mariaelenae share the transparent parietal peritoneum character. Chimerella mariaelenae differs from T. amelie by having a green dorsum with many dark lavender punctuations and scattered larger dark spots in life (dorsum uniform green in T. amelie). Also, adult males of $C$. mariaelenae have a small humeral spine (absent in T. amelie). Teratohyla amelie differs from all species in the genus Hyalinobatrachium (characteristics in parentheses) by having a uniform green dorsum in life that turns lavender in preservative (green dorsum with small yellow spots in life; cream in preservative), by depositing its egg clutches on the upper surfaces of leaves (underside of leaves), and by having a Type I nuptial pad (TypeV pad in most Hyalinobatrachium). Two other species that are not found in Ecuador, T. pulverata and Vitreorana antisthenesi, also have a transparent ventral peritoneum and deposit eggs on the upper surfaces of leaves. Teratohyla pulverata, however, is restricted to Central America and areas west of the Andes (T. amelie is endemic to Amazonian lowlands of Ecuador and Peru), and differs from $T$. amelie by having a sloping snout in lateral view and a green dorsum with white spots in life. The Venezuelan $V$. antisthenesi can be differentiated from $T$. amelie by the presence of vomerine teeth, a green dorsum with light spots, and being larger (21.4-26.2 mm SVL in adult males of $V$. antisthenesi [106]). Teratohyla midas is also found on the Amazonian lowlands, but it has yellow dorsal spots and a venter that is white anteriorly and transparent posteriorly.

Diagnosis: (1) Vomerine teeth absent; (2) snout truncated in dorsal view and rounded in lateral view; (3) tympanic annulus evident, oriented dorsolaterally with posterior inclination; very weak supratympanic fold above the tympanum; (4) dorsal skin shagreen; (5) ventral and subcloacal surfaces granular, pair of enlarged subcloacal warts; (6) parietal peritoneum completely transparent (lacking iridophores, condition P0), all visceral peritonea covered with iridophores (condition V5); (7) liver white, bulbous (condition H2); (8) humeral spine absent; (9) webbing on hand absent between Fingers I and II, moderate to extensive between outer fingers: II $\left(1-1^{+}\right)-\left(3-3^{+}\right) \mathrm{III}\left(1^{1 / 2}-2^{-}\right)-\left(1-1^{1 / 2}\right) \mathrm{IV} ;(10)$ webbing on feet extensive: I (0-1)-(1/2-2- II $\left(1^{-}-1\right)-2^{-}$III $\left(1^{-}-1^{+}\right)-\left(2^{-}-2^{1 / 4}\right)$ IV $\left(2^{-}-2^{1 / 3}\right)-\left(0^{-}-1^{-}\right) \mathrm{V}$; (11) low non-enameled ulnar fold; low non-enameled inner tarsal fold; (12) nuptial excrescences present, Type I; concealed prepollex; (13) first finger longer than second, (14) eye diameter larger than width of disc on Finger III; (15) color in life, uniform green to bluish-green dorsally; (16) in preservative, dorsal 
surfaces uniform lavender; (17) in life, iris cream brown; (18) numerous melanophores on all fingers and toes; (19) males call from upper sides of leaves; each call consists of single note with three or four pulses; dominant frequency at $4984-7085 \mathrm{~Hz}$, reaching maximum frequency at $5906-6023 \mathrm{~Hz}$; (20) fighting behavior unknown; (21) egg clutches deposited in single layer on upper surfaces of leaves next to streams; males call from tops of leaves next to their clutches; parental care unknown; (22) tadpoles unknown; (23) minute body size; SVL in adult males $18.1-19.3 \mathrm{~mm}(\overline{\mathrm{X}}=18.8 \pm 0.47 ; n=6)$; females unknown.

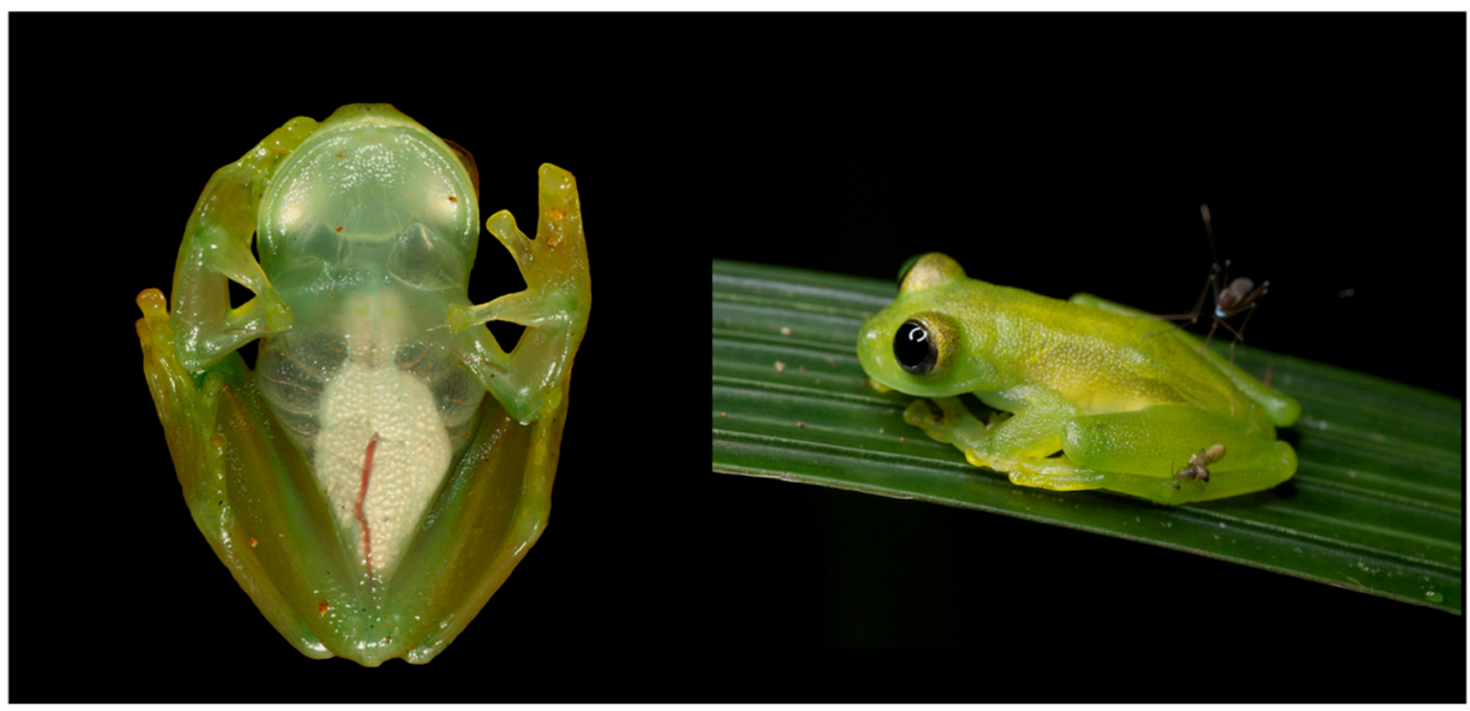

Figure 207. Teratohyla amelie in life. (Left): Adult male, QCAZ 37920, Ecuador, Pastaza province, stream tributary of Río Lliquino, $350 \mathrm{~m}$ (photo by Martín Bustamante). (Right): Adult male, QCAZ 47204, Ecuador, Pastaza province, Reserva Ecológica Río Anzu, 1200 m. Photo by Lucas Bustamante/Tropical Herping.

Color in life (Figure 207): Uniform green to bluish-green dorsum, lacking flecks or spots. Greenish throat, other ventral surfaces transparent. White heart and viscera visible ventrally. Green bones. Iris cream brown.

Color in ethanol: Dorsal surfaces uniformly lavender. Ventral surfaces cream. Ventral parietal peritoneum without iridophores. Iridophores covering heart, digestive tract, and liver.

Biology and ecology: Teratohyla amelie is a recently described species and little is known about its natural history. It is nocturnal and males call from and pairs deposit single layer clutches on the upper surfaces of Heliconia leaves about $80 \mathrm{~cm}$ above small streams in pristine Lowland Evergreen forests. Parental care is unknown.

Call (Figure 208): The description provided below is based on a recording obtained by Diego Paucar at a tributary of Río Lliquino (1.45295 S; $77.443^{\circ} \mathrm{W}, 350 \mathrm{~m}$; QCAZ 38779), Provincia Pastaza, Ecuador, on 15 May 2008. Calls are emitted every 10-30 s ( $\bar{X}=17.8 \mathrm{~s} \pm 7.55, n=8)$. Each call consists of a single pulsed note that lasts $0.011-0.014 \mathrm{~s}(\overline{\mathrm{X}}=0.013 \pm 0.001, n=10)$; each call has three to four pulses $(\bar{X}=3.5 \pm 0.515, n=10)$. The dominant frequency is between $4984-7085 \mathrm{~Hz}(n=10)$, with its maximum frequency at $5906-6023 \mathrm{~Hz}$; a first harmonic is visible at $10,923-12,474 \mathrm{~Hz}(n=10)$; a second harmonic is visible at $16,815-19,120 \mathrm{~Hz}(n=10)$. 


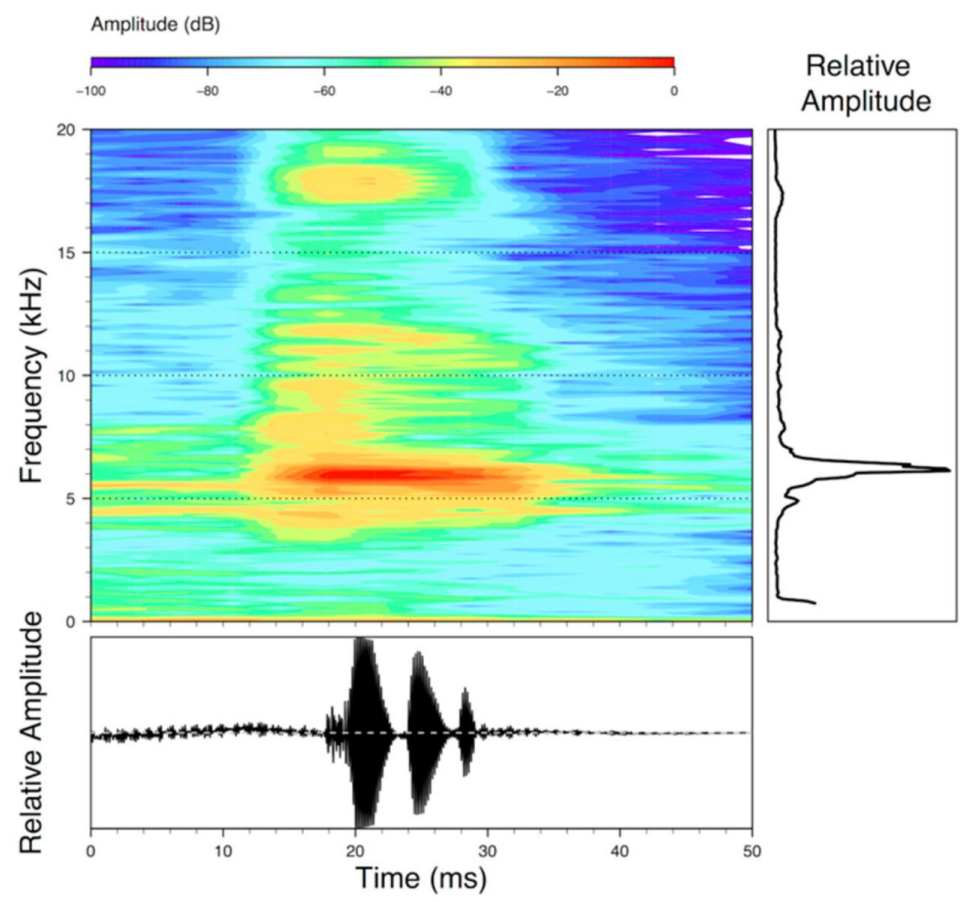

Figure 208. Call of Teratohyla amelie (QCAZ 38779) from a tributary of Río Lliquino $\left(1.45295^{\circ} \mathrm{S} ; 77.443^{\circ} \mathrm{W}\right.$, 350 m; QCAZ 38779), Provincia Pastaza, Ecuador.

Tadpole: Not described.

Distribution (Figure 209): Teratohyla amelie is known from a few localities in the foothills and Amazonian lowlands of Ecuador and Peru at elevations between 350 and $1037 \mathrm{~m}$ ([19,176,253], this work). In Ecuador, it has been found at only five localities, all within Pastaza Province. In Peru, T. amelie is known from a single locality: $\mathrm{Km} 10$ from Quincemil towards Puerto Maldonado $\left(13^{\circ} 12^{\prime} 03.6^{\prime \prime} \mathrm{S}\right.$; $70^{\circ} 40^{\prime} 28.9^{\prime \prime} \mathrm{W} ; 572 \mathrm{~m}$ ) [19]. In Ecuador, the potential distribution of the species is $24,852 \mathrm{~km}^{2}$.

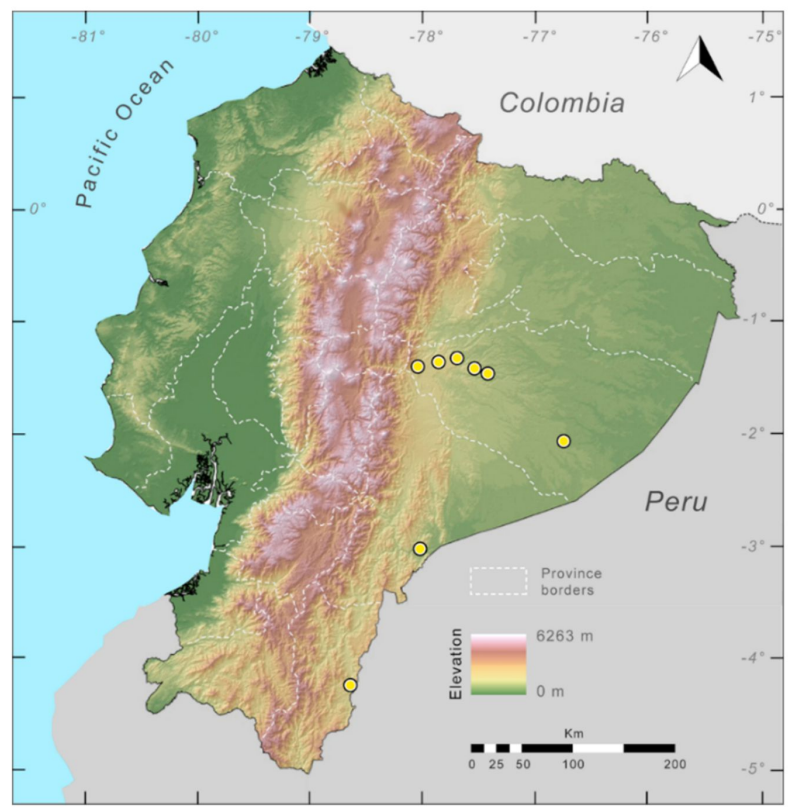

Figure 209. Distribution of Teratohyla amelie in Ecuador (yellow dots). 
Conservation status: Teratohyla amelie is classified as Data Deficient by the IUCN [293]. However, the distribution of the species is much broader than previously recorded. Thus, we suggest that this species should considered as Least Concern.

Evolutionary relationships (Figures 16 and 210): Teratohyla amelie is the sister species to T. pulverata [2]. Given the lowland distributions of these two species-T. amelie east of the Andes and T. pulverata from west of the Andes-the most likely mechanism of speciation is vicariance through the uplift of the Andes.

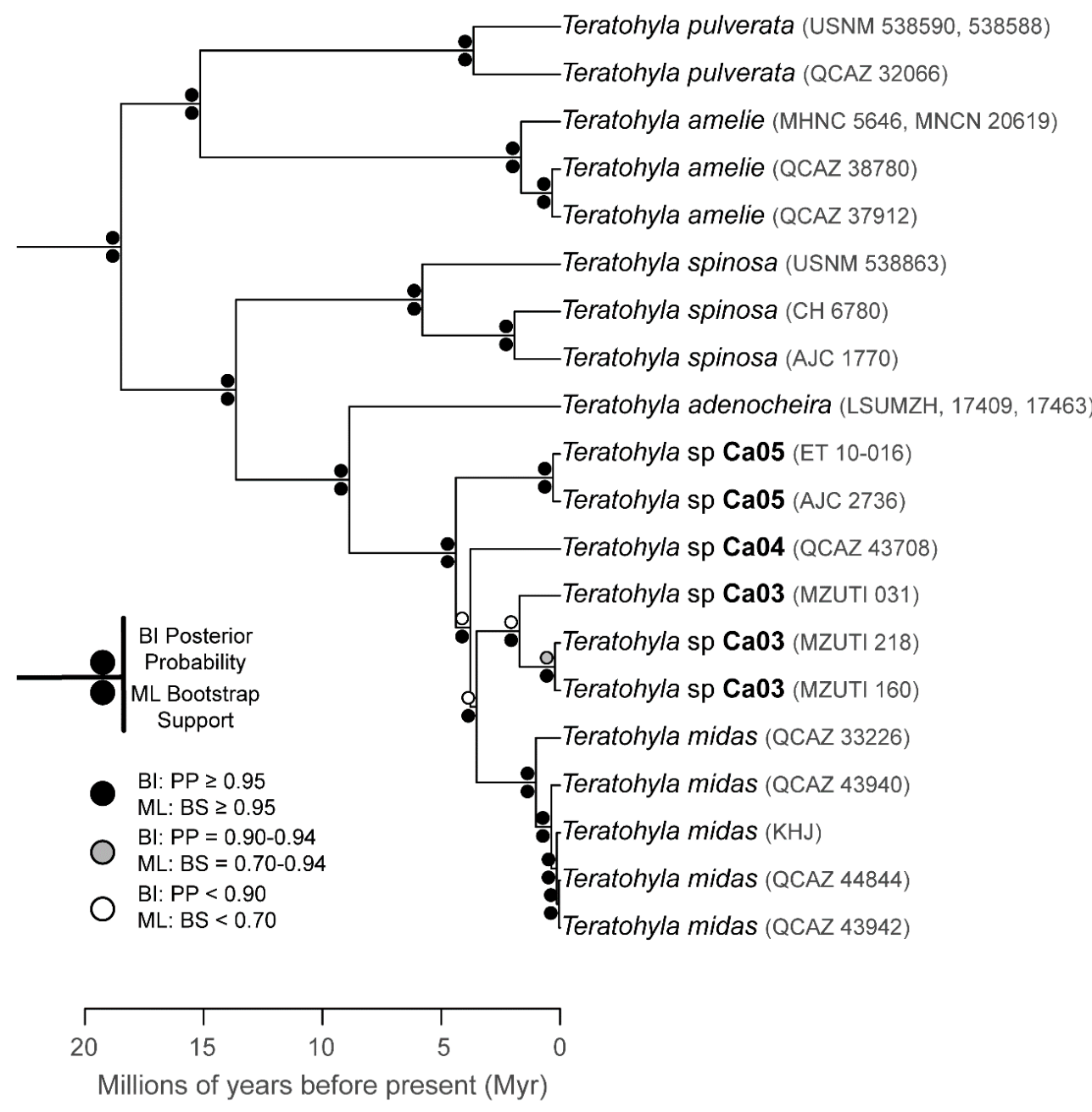

Figure 210. Evolutionary relationships of species in the glassfrog genus Teratohyla. The trees were inferred using maximum likelihood and Bayesian criteria.

Specimens examined: Teratohyla amelie: Ecuador: Provincia de Pastaza: Comunidad de Oglán $\left(1.318^{\circ} \mathrm{S}, 77.711^{\circ} \mathrm{W}, 600 \mathrm{~m}\right)$, DHMECN 3066, 3591; Tributary of Río Lliquino (1.45295 $\mathrm{S} ; 77.443^{\circ}$ W; 350 m), QCAZ 37920-21, 38779; tributary of Río Rivadeneira (1,3604 ${ }^{\circ}$ S, $\left.77.86534^{\circ} \mathrm{W}\right)$, QCAZ 48734; Reserva Ecológica Río Anzu (1.40608 S; $78.0479^{\circ}$ W; 1037 m), QCAZ 47204; Reserva Ecológica Shanca Arajuno, Río Shanca Arajuno (1.35998 S; 77.86564 W; 850-875 m), QCAZ 37912-13; Curintza $\left(2.05747^{\circ} \mathrm{S}, 76.751^{\circ} \mathrm{W}\right)$, DHMECN 4372.

Photographic records: Ecuador: Zamora Chinchipe province: Reserva Natural Maycu $\left(4.24859^{\circ} \mathrm{S}\right.$, 78.6574 ${ }^{\circ}$ W), QCAZ 66821. Morona Santiago province: Kimm (3.0146 ${ }^{\circ}$ S, $78.0354^{\circ}$ W), QCAZ 73545 [294]. 
Teratohyla midas (Lynch and Duellman, 1973 [22]; Figures 211-214).

Centrolenella midas Lynch and Duellman, 1973 [22]. Holotype: KU 123219.

Type locality: "Santa Cecilia, 340 m, Provincia Napo (Sucumbíos), Ecuador".

Cochranella midas-Ruiz-Carranza and Lynch, 1991 [6].

Teratohyla midas_Guayasamin, Castroviejo-Fisher, Trueb, Ayarzagüena, Rada, and Vilà, 2009 [1].

Common names: English: Midas' Glassfrog. Spanish: Rana de Cristal Midas.

Etymology: The specific name Midas is that of a king in Greek mythology, at whose touch everything turned to gold. The epithet is associated with Río Aguarico (=rich water), near the type locality of the species, in reference to gold found in the river, and in allusion to the gold flecks on the frogs [22].

Identification: Among glassfrogs that inhabit the Amazonian lowlands of Ecuador, Teratohyla midas is unique by having a green dorsum with a few small yellow dots that are usually concentrated on the upper flanks (Figure 211); other important diagnostic traits include a white digestive tract, small body size (male SVL $<22.5 \mathrm{~mm}$ ), and the absence of humeral spines. Other species with similar dorsal coloration that inhabit the Amazonian slopes of the Andes are Nymphargus cariticommatus, N. siren, $N$. humboldti sp. nov., and Rulyrana flavopunctata. All these species have numerous yellow spots uniformly distributed on the dorsum (limited to the upper flanks of the body in T. midas). Also, none of these species have a white digestive tract, and species of Nymphargus have less hand webbing than T. midas.

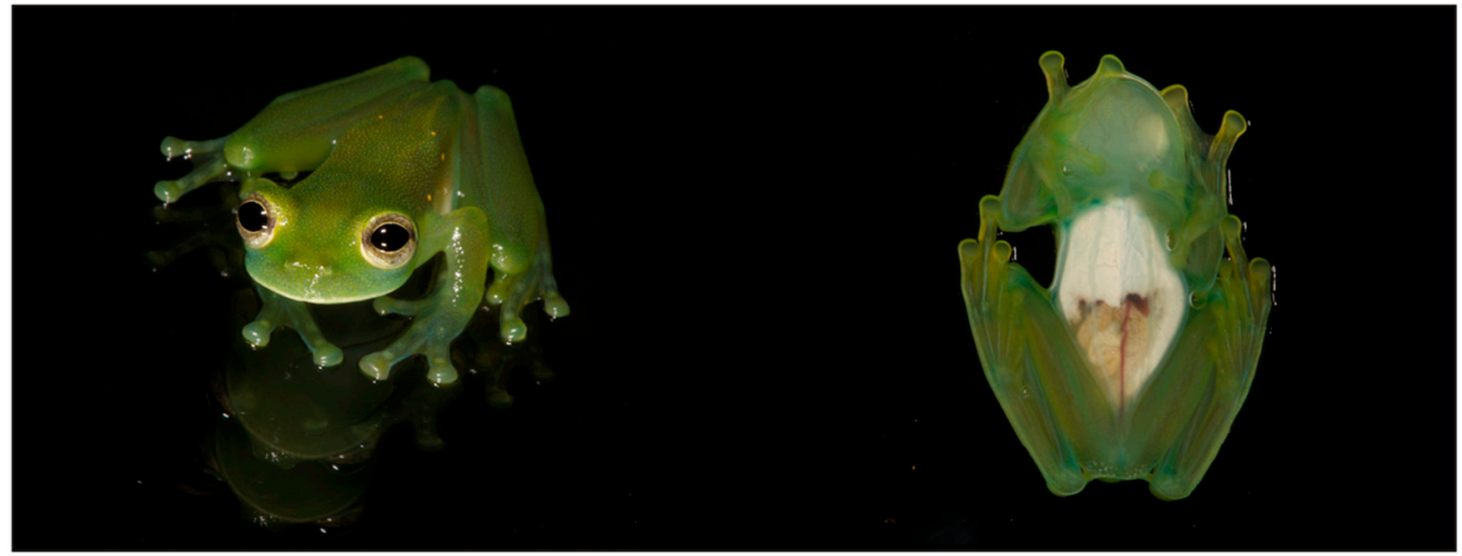

Figure 211. Teratohyla midas in life. Adult male from stream near Tena, $708 \mathrm{~m}$, MZUTI 1621. Photos by Eduardo Toral.

Diagnosis: (1) Vomers with dentigerous process bearing zero to four teeth; (2) snout truncated in dorsal aspect; truncated to bluntly rounded in lateral profile (Figure 212); (3) tympanum moderate, oriented almost vertically, with slight lateral and posterior inclinations, its diameter $29.1 \%-36.3 \%$ of eye diameter; only upper border of tympanic annulus obscured by supratympanic fold; tympanic membrane clearly differentiated from surrounding skin; (4) dorsal skin smooth; males with minute spicules visible only under magnification $(\times 250)$; (5) venter areolate; pair of enlarged subcloacal warts; (6) white parietal peritoneum covering anterior $40 \%-50 \%$ of venter (condition P2); white pericardium and gastrointestinal peritoneum; translucent peritonea on liver and gall and urinary bladders (condition V2); (7) liver lobate, covered by transparent peritoneum (condition H0); (8) humeral spines absent; (9) webbing absent between Fingers I and II, reduced between Fingers II and III, and moderate between outer fingers (Figure 212); formula: II $\left(2^{-}-2\right)-\left(3-3^{1 / 3}\right)$ III $\left(2^{-}-2^{+}\right)-\left(1^{3 / 4}-2\right) \mathrm{IV} ;(10)$ feet about two-thirds webbed; webbing formula: I $\left(1-1^{+}\right)-\left(2-2^{+}\right)$II $\left(1-1^{+}\right)-\left(2-2^{+}\right)$III $\left(1^{-}-1^{+}\right)-\left(2-2^{+}\right)$IV $\left(2-2^{+}\right)-1$ V; (11) ulnar and tarsal folds absent; (12) concealed prepollex; in males, nuptial pad Type I; (13) Finger I slightly longer than Finger II (Finger II length $94.1 \%-98.4 \%$ of Finger I); (14) width of disc of Finger 
III about $34.4 \%-39.7 \%$ of eye diameter; (15) in life, dorsum green with few small yellow dots usually concentrated on flanks; bones green; (16) in preservative, dorsum lavender with small white dots; (17) iris, in life, silvery white with pale yellow hue, faint brown horizontal stripe, and grey reticulations; yellow ring around pupil; (18) melanophores usually covering fingers and toes; (19) males call from the upper surfaces of leaves; call consists of a series of three notes; each note is $0.15-0.16 \mathrm{~s}$ in length, with a dominant frequency of 7030-7060 Hz; (20) fighting behavior unknown; (21) eggs deposited on the upper side of leaves along streams; short-term maternal care present; prolonged parental care absent; (22) tadpoles unknown; (23) minute body size; in males, SVL 19.0-22.5 $\mathrm{mm}(\overline{\mathrm{X}}=19.9 \pm 1.346, n=8)$; in females, SVL 20.9-26.8 $\mathrm{mm}(\overline{\mathrm{X}}=23.0 \pm 2.135, n=8)$.

B

A
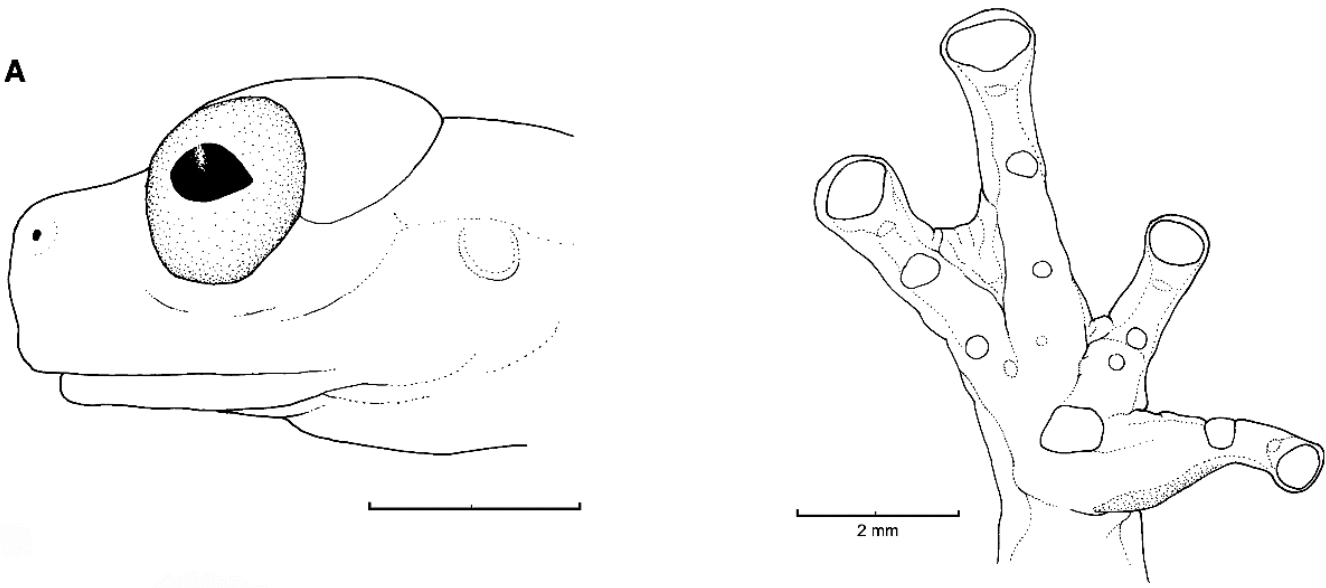

Figure 212. Teratohyla midas, QCAZ 33226. (A) Head in lateral view. (B) Hand in ventral view.

Illustrations by Juan M. Guayasamin.

Color in life (Figure 211): Dorsum green with few small yellow spots on upper flanks. White upper lip. Venter white anteriorly and transparent posteriorly. Iris silvery white with pale yellow hue, faint brown stripe, and thin grey reticulations. Green bones.

Color in ethanol: Dorsal surfaces of head, body, and limbs cream lavender to lavender. Anterior half of the venter cream white, posterior half cream with some translucence. Digestive tract white (with iridophores).

Variation: Two paratypes (females KU 107026, 150622) lack yellow spots on the dorsum. Additionally, these individuals were the largest females examined (SVL $=26.8$ and $25.4 \mathrm{~mm}$, respectively). When excluding them from the summary statistics for the female body size, the values change as following: SVL $=20.9-23.8 \mathrm{~mm}(\bar{X}=21.95 \pm 1.009, n=6)$. Teeth on the dentigerous process of the vomer are always present in females; vomerine teeth are less evident or absent in males.

Biology and ecology: This species has been found throughout the year on leaves of herbs, shrubs, and trees along small rivulets in the Amazonian rainforest ([22,139], this work). At Santa Cecilia, Teratohyla midas is sympatric with Hyalinobatrachium munozorum and Cochranella resplendens [22]. Diaz-Ricaurte et al. [295] provide a description of the amplexus, oviposition, and parental care behaviors in the species. The observed female laid 27 eggs that, after fertilization, were covered by the female for almost an hour (brooding).

Call (Figure 213): The following description is based on a call of Teratohyla midas (LBE-C-036), recorded at the Boanamo community, $240 \mathrm{~m}$, Orellana province, Ecuador, by Morley Read. Calls are emitted in series; 16 calls were recorded in a 3-min period. Time between calls is 10.2-15.1 s (mean $=13.02 \pm 1.732$ ). Each call is short and composed by a single note, which has a duration of $0.073-0.092 \mathrm{~s}$ (mean $=0.082 \pm 0.007)$. Notes usually have three or four well-differentiated pulses $($ mean $=3.14 \pm 0.378)$. The dominant frequency measure at its peak is $7210-7390 \mathrm{~Hz}($ mean $=7285 \pm 60.4)$. 
Calls are similar to those reported by Twomey et al. [19] for Peruvian populations of the species, although they report a dominant frequency at $6760-7060 \mathrm{~Hz}$.

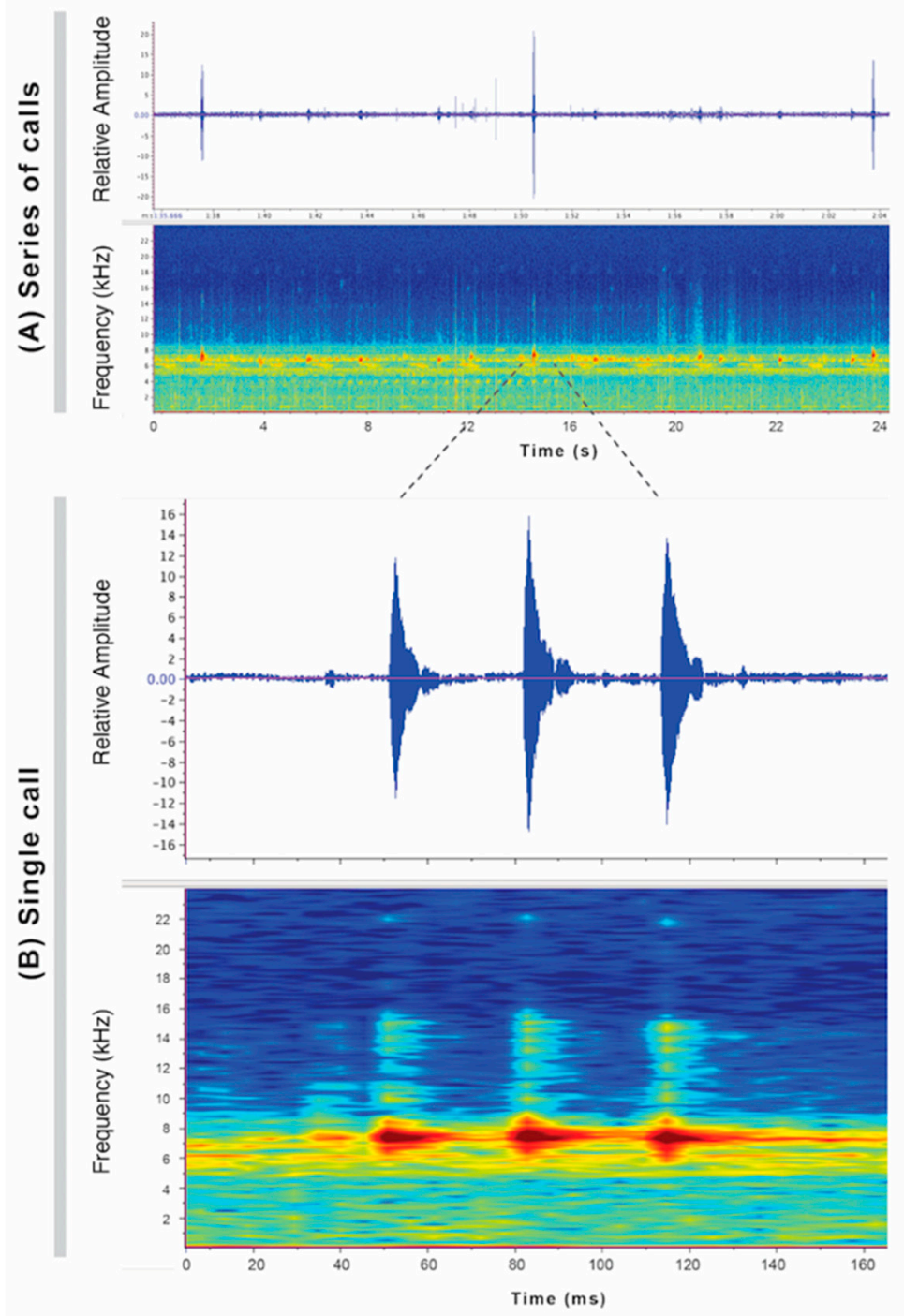

Figure 213. Calls of Teratohyla midas, LBE-C-036, recorded at Boanamo community, $240 \mathrm{~m}$, Orellana province, Ecuador, by Morley Read. (A) Call series: fragment showing 3 calls. (B) Single call.

Tadpole: Not described.

Distribution (Figure 214): T. midas has been reported from the Amazonian lowlands (<940 m) of Ecuador, Peru, and Brazil, and is likely to be present in Colombia and Bolivia $([17,19,22,139,229,296]$, this work). In Ecuador, T. midas localities are at elevation of 190-930 m, with a potential distribution of $51,794 \mathrm{~km}^{2}$ within the Amazonian Tropical Rainforest and the Eastern Foothill Forest regions. 


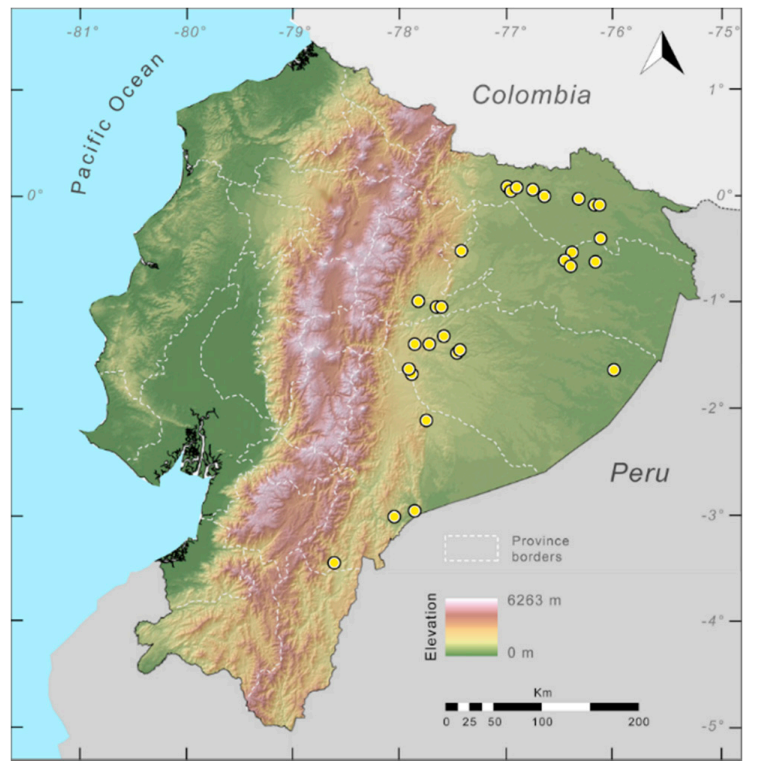

Figure 214. Distribution of Teratohyla midas in Ecuador (yellow dots).

Conservation status: Globally, Teratohyla midas is listed as Least Concern by the IUCN [297]. In Ecuador, the species has a broad distribution; thus, we agree with the current conservation status.

Evolutionary relationships (Figure 210): Teratohyla midas, as currently recognized, is the sister species of T. adenocheira. However, there is considerable genetic structure within Teratohyla midas and it might represent a species a complex.

Specimens examined: Teratohyla midas: Ecuador: Provincia de Morona Santiago: Río Kusutka (02.111 ${ }^{\circ}$ S, $\left.77.73897^{\circ} \mathrm{W} ; 650 \mathrm{~m}\right)$, nearby Wisui Biological Station, MZUTI 031. Provincia de Napo: Puerto Misahualli (1.033 S, 77.667 W; 400 m), QCAZ 20001-02; S side of Río Napo, 6.5 km ESE Puerto Misahualli at La Cruz Blanca in Jatun Sacha Biological Reserve (1.05 S, 77.6 W; 395 m), QCAZ 9038-44; Tena, near airport (0.985 S, 77.825 W; 550 m), QCAZ 8819-21. Provincia de Orellana: stream nearEstación Científica Yasuní (0.667 S, 76.4 W; 230-240 m), QCAZ 22876, 23895; Estación Científica Yasuní, near the bird observation tower $\left(0.67491^{\circ} \mathrm{S}, 76.39834^{\circ} \mathrm{W}\right)$, QCAZ 19316; Río Napo, Añangu (0.52492 ${ }^{\circ} \mathrm{S}$, $\left.76.38445^{\circ} \mathrm{W} ; 255 \mathrm{~m}\right)$, QCAZ 43939-44; Tiputini Biodiversity Station (0.6167 $\left.\mathrm{S}, 76.167^{\circ} \mathrm{W} ; 190-270 \mathrm{~m}\right)$, DFCH-D102; km 37-38 on the Pompeya-Iro road (ca. 0.6 S, 76.45 W), QCAZ 17311-12, 17314-16. Provincia de Pastaza: Pomona (1.6833 S, 77.883 W; 930 m), QCAZ 33225-26; Estación Hola Vida near Pomona (1.6284 ${ }^{\circ}$ S, $77.9095^{\circ}$ W; 837 m), QCAZ 33225-26; Parroquia Teniente Hugo Ortíz (1.37 S, 77.955

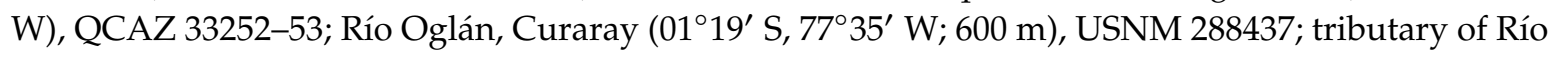
Lliquino (1.18183 $\left.{ }^{\circ} \mathrm{S}, 77.47879^{\circ} \mathrm{W} ; 400 \mathrm{~m}\right)$, QCAZ 37933-34; tributary of Río Lliquino, Villano B Camp

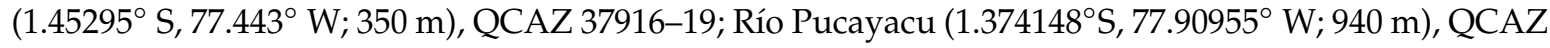
33252-53. Provincia de Sucumbíos: Río Pañayacu (0.40667 S, 76.113 W; 210 m), QCAZ 20329; Monte Tour (0.0315 S, 76.321 W; 290 m); near Lago Agrio (0.0847 S, 76.8828 W; 370 m), KU 125334; Pozo Peña Blanca, E of Dureno and near Pacayacu (0.0001 S, 76.648 W; 260 m), QCAZ 6385; Puerto Bolívar (0.0886 S, 76.142 W; 240 m), QCAZ 28134, 28137; Puerto Libre (0.061 N, 76.75 W; 280 m), KU 123220-23; Estación Científica PUCE at the Reserva de Producción Faunística Cuyabeno (0.083 S, 76.166 W; 220 m), QCAZ 6015; Río Conejo, 2 km N of Santa Cecilia (0.097778 N, 76.99 W), KU 153256; Santa Cecilia (0.05 N, 76.9667 W; 340 m), KU 105283, 107026, 123219, 146625, 150622-23, 152487, 158518.

Photographic records: Teratohyla midas: Ecuador: Morona Santiago province: Kimm, $5 \mathrm{~km} \mathrm{NW}$ airline distance from Santiago (3.0149 S, 78.0356 W), QCAZ 73554 [294]. Road Peñas-Shaimi, 2.8 Km E of Río Yaupi by road (2.9663 S, 77.84682 W), QCAZ 73546-47 [294]. Orellana province: Reserva Río Bigal $\left(0.532913^{\circ} \mathrm{S}, 77.423228^{\circ} \mathrm{W} ; 981 \mathrm{~m}\right)$, photo by Morley Read. Pastaza province: Lorocachi (1.625259 S, 75.99035 W), QCAZ 56024 [294]. 
Teratohyla pulverata (Peters, 1873 [298]; Figures 215-217).

Hyla pulverata Peters, 1873 [298]. Holotype: ZMB 7842, according to Duellman, 1977 [118]. Type locality: "Chiriqui", Panama; at the time of the description "Chiriqui" included both Atlantic and Pacific versants of extreme western Panama, according to Myers, 1982 [299]. Centrolene pulveratum-Dunn, 1931 [236].

Centrolenella pulveratum-Taylor, 1949 [145].

Cochranella pulverata-Taylor, 1951 [15].

Cochranella petersi-Goin, 1961 [97]. Type locality: "Rio Durango, N. W. Ecuador". Placed in synonymy by Guayasamin, Cisneros-Heredia, and Castroviejo-Fisher, 2008 [300].

Centrolenella petersi-Goin, 1964 [187].

Centrolenella pulverata-Savage, 1967 [202].

Hyalinobatrachium pulveratum -Ruiz-Carranza and Lynch, 1991 [6].

Hyalinobatrachium petersi-Ruiz-Carranza and Lynch, 1998 [27].

Teratohyla pulverata—Guayasamin, Castroviejo-Fisher, Trueb, Ayarzagüena, Rada, and Vilà, 2009 [1].

Common names: English: Dusty Glassfrog [24]. Spanish: Rana de Cristal polvosa [24].

Etymology: The specific name comes from the Latin pulvereus, meaning dusty, and refers to the minute white spots on the dorsum of the species.

Identification: Among glassfrogs that inhabit the Chocoan forest of Ecuador, Teratohyla pulverata is unique by having a green dorsum with small white spots, completely transparent ventral parietal peritoneum (Figure 215), white hepatic and gastrointestinal peritonea, a sloping snout in lateral profile, and by lacking humeral spines. Only species in the genus Hyalinobatrachium could be confused with T. pulverata; however, T. pulverata has green bones (white in Hyalinobatrachium), deposits eggs on the upper sides of leaves (undersides of leaves in Hyalinobatrachium), and has conspicuous teeth on the vomers (teeth absent in Hyalinobatrachium).

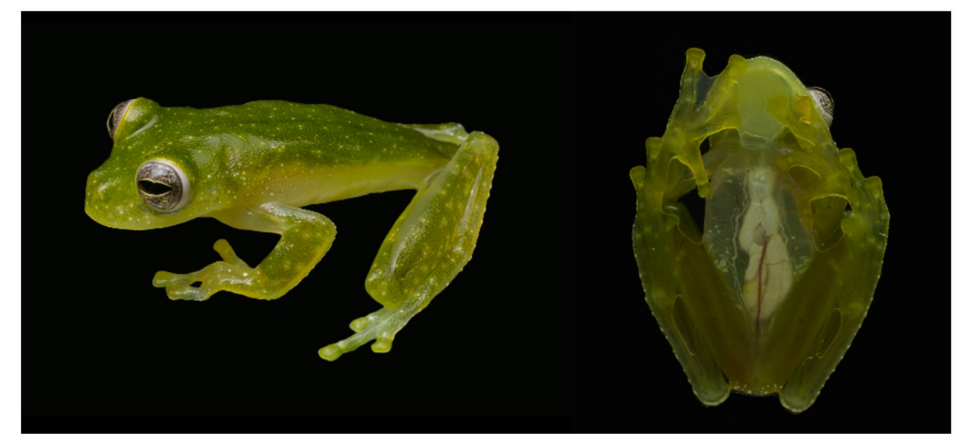

Figure 215. Teratohyla pulverata in life. Individual (QCAZ 32224) from Silanche, Pichincha province. Photos by Luis A. Coloma.

Diagnosis: Teratohyla pulverata exhibits the following traits: (1) Dentigerous process of the vomer with two to four teeth; (2) snout rounded in dorsal view, sloping in lateral profile (Figure 216); (3) tympanum visible, relatively small, its diameter $20.2 \%-23.3 \%$ of eye diameter; tympanic annulus visible except for upper border covered by supratympanic fold; tympanic membrane differentiated and translucent, pigmented as surrounding skin; (4) dorsal surfaces shagreen; males with small spicules (only visible under magnification); (5) ventral surfaces granular, lacking pair of enlarged subcloacal warts; (6) ventral parietal peritoneum completely transparent (condition P0); pericardium and gastrointestinal peritoneum white (condition V2); (7) white, bulbous liver (i.e., covered by iridophores; condition H2); (8) humeral spines absent; (9) webbing between Fingers I and II absent or basal; webbing formula: II $\left(1^{+}-1^{1 / 3}\right)-\left(2^{4 / 5}-3^{-}\right)$III $\left(1^{1 / 3}-1^{2 / 3}\right)-\left(1^{+}-2^{-}\right)$IV; (10) feet about two-thirds webbed; webbing formula: 
I $\left(1^{-}-1\right)-\left(1^{2 / 3}-2^{-}\right)$II $\left(1^{-}-1\right)-\left(1^{3 / 4}-2^{-}\right)$III $\left(1-1^{+}\right)-\left(1^{2 / 3}-2^{+}\right)$IV $\left(2^{-}-2^{+}\right)-\left(1^{-}-1^{+}\right)$V; (11) metacarpal, ulnar, metatarsal, and tarsal enameled folds present, with low, enameled tubercles; (12) nuptial pad Type I in adult males; concealed prepollex; (13) Fingers I and II about same length (Finger II length 98\%-103\% of Finger I length); (14) disc of Finger III small, its width $20.1 \%-23.5 \%$ of eye diameter; (15) in life, dorsum green with white flecks and dots; bones green; (16) in preservative, dorsum cream to light lavender with unpigmented or white flecks and dots; (17) iris greyish white with thin dark grey reticulations and minute yellow flecks; yellow to cream circumpupilary ring borders the pupil; (18) melanophores partially covering dorsal surface of Finger IV, absent from Fingers I-III; (19) males call from upper side of leaves; call emitted as series of three notes (each note $=0.05 \mathrm{~s}$ ), dominant frequency at 5600-6200 Hz; (20) fighting behavior unknown; (21) egg masses deposited on upper side of leaves; short-term maternal care present; prolonged parental care absent; (22) in tadpoles, tooth row formula 2/3; A-2 tooth row is widely separated in the center; (23) small body size; adult males, SVL 22.0-24.5 mm ( $n=13)$; adult females, SVL 25.3-28.3 mm $(n=5)$.
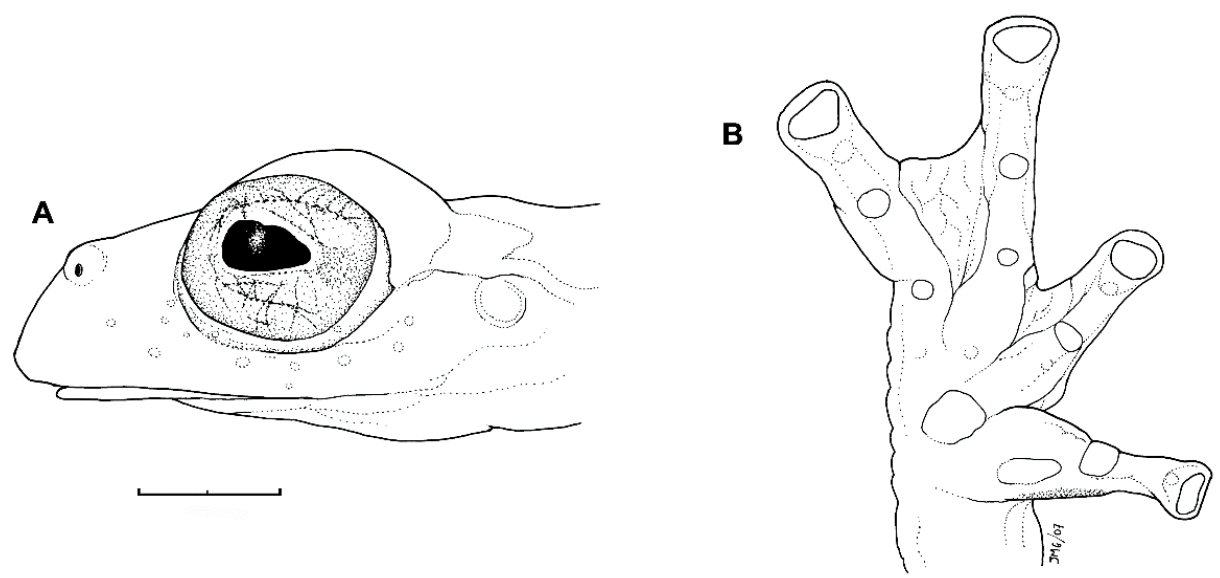

Figure 216. Teratohyla pulverata, QCAZ 32066. (A) Head in lateral view. (B) Hand in ventral view. Scale bar $=2 \mathrm{~mm}$. Illustrations by Juan M. Guayasamin.

Color in life (Figure 215): Dorsal surfaces of head and body green with small, white dots. Dorsally, limbs green with pale yellow spots, with white centers. Upper lip white; small white dots visible below eye. Ulnar and tarsal folds with low, white tubercles. Cloacal region with numerous small, white warts. Parietal peritoneum transparent (all internal organs visible ventrally). White peritonea covering heart, liver, digestive tract, testes, and gall bladder. Transparent peritonea covering urinary bladder and kidneys. Iris grey white with thin dark grey reticulations and minute yellow flecks; thin yellow line around pupil.

Color in ethanol: Dorsal surfaces of head, body, and limbs cream with numerous minute lavender flecks and lacking white iridophores, which are visible in life. Upper lip white; small white spots visible below eye. Low tubercles on ulnar and tarsal folds white, although this coloration is often lost after years of preservation (e.g., KU 116493). Cloacal region with several white warts. Internal organs that are covered by white peritonea in life remain white in preservative (i.e., heart, liver, digestive tract, testes, and gall bladder).

Biology and ecology: As in all centrolenid frogs, the reproductive activity of Teratohyla pulverata is in vegetation along streams. In Ecuador, T. pulverata was found sympatrically with Espadarana prosoblepon and H. fleischmanni in Estero Aguacate, and with Sachatamia ilex, S. albomaculata, E. prosoblepon, and H. aureoguttatum in Río Bogotá [199]. Delia et al. [25] experimentally demonstrated that short-term brooding provided by females of $T$. pulverata greatly impacts the survival of clutches. This form of parental care reduces mortality associated to dehydration, predation, and fungal infection [25]. 
Call: Males of Teratohyla pulverata call from the upper surfaces of leaves [24]. The call of is a quick high-pitched "tik", normally repeated several times with roughly a second pause between calls [24]. The dominant frequency is at $5.7-6.2 \mathrm{kHz}[149,150]$.

Egg masses: The following information was mostly obtained from Hawley [301]. Unlike other glassfrog egg clutches, the jelly surface is crenulated [17]. The eggs have a yellowish-green coloration and are deposited in a single layer on the upper surface of leaves. The coloration persists for the first five days of development, then changes to pink over the next five days, and lastly to darker shades of red during the remainder of development. The number of eggs per clutch is $23-57$ eggs $(n=62)$. Development from oviposition until the last egg hatched was 6-24 days. There was a positive correlation between hatching and nocturnal rainfall. Survivorship per clutch was $85 \% \pm 4 \%(n=59)$; $42 \%$ percent of clutches hatched without embryonic mortality. Mortality in embryos was caused mainly by flooding ( $5 \%$ or 128 eggs). Desiccation caused mortality in July and August, whereas flooding produced mortality in September. Hatching in embryos in clutches with high mortality is earlier than embryos in clutches with low mortality, perhaps as a response to avoid fungal infection on decaying embryos or predation. Delia et al. [25] reported that clutches contain 59 eggs $( \pm 7.5, n=50)$.

Tadpole: The tadpole of Teratohyla pulverata was described by Hoffmann [302]; herein, we present a summary of his description. The ecomorphological guild of the tadpole is exotroph, lotic, and burrower. When hatching (Gosner Stage 24-25) tadpoles have a dark reddish coloration due to the dorsal star-like pigmentation spots and the reddish visceral and muscular system. Young larvae have a nearly circular shape in cross-section, whereas later larval stages change to a typical flat shape. The LTRF is $2 / 3$; the A-2 row had a wide gap; P-3 is slightly shorter than the equal sized P-1 and P-2. The upper jaw sheath forms a smooth arc and has a pointed serration. The lower jaw sheath is smooth and V-shaped. Marginal papillae are present on both sides of the oral disc; the papillae are arranged in a single row but have a wide dorsal gap on the anterior labium. The eye position is dorsal.

Distribution (Figure 217): Teratohyla pulverata is known from the humid lowlands on the Atlantic versant from north-central Honduras, and on the Pacific slope from southwestern Costa Rica up to $960 \mathrm{~m}$; it is also known from the lowland forest on the western slopes of the Andes of Colombia and Ecuador at elevations below $400 \mathrm{~m}([84,101,148,198,199,300,303]$, this work). In Ecuador, this species is known from localities in the provinces of Esmeraldas and Pichincha at elevations below $400 \mathrm{~m}$ (Specimens Examined). In Ecuador, the potential distribution of the species is $25,146 \mathrm{~km}^{2}$ within the Chocoan Tropical Forest region.

Conservation status: Globally, Teratohyla pulverata is listed as Least Concern by the IUCN [304]. Major threats for species inhabiting the Chocó Ecoregion are contamination associated to mining and deforestation because of agriculture (mainly oil palm) and pasture lands. In Ecuador, because of the mentioned threats, we suggest that the species should be considered as Endangered, following IUCN criteria B2a, B2(iii).

Evolutionary relationships (Figure 210): Guayasamin et al. [1] mentioned that the placement of Teratohyla pulverata in the genus Teratohyla is supported by a dataset that includes nuclear and mitochondrial genes, and the combined nuclear genes. They also mentioned that the topology recovered by one particular mitochondrial gene (ND1) strongly supports a clade composed of Vitreorana castroviejoi $+V$. antisthenesi $+T$. pulverata. Most genetic data at hand favor a sister relationship between T. pulverata and T. amelie ([2,3,19], this work). Given the lowland distributions of these two species-T. amelie east of the Andes and T. pulverata from west of the Andes-the most likely mechanism of speciation is vicariance through the uplift of the Andes. 


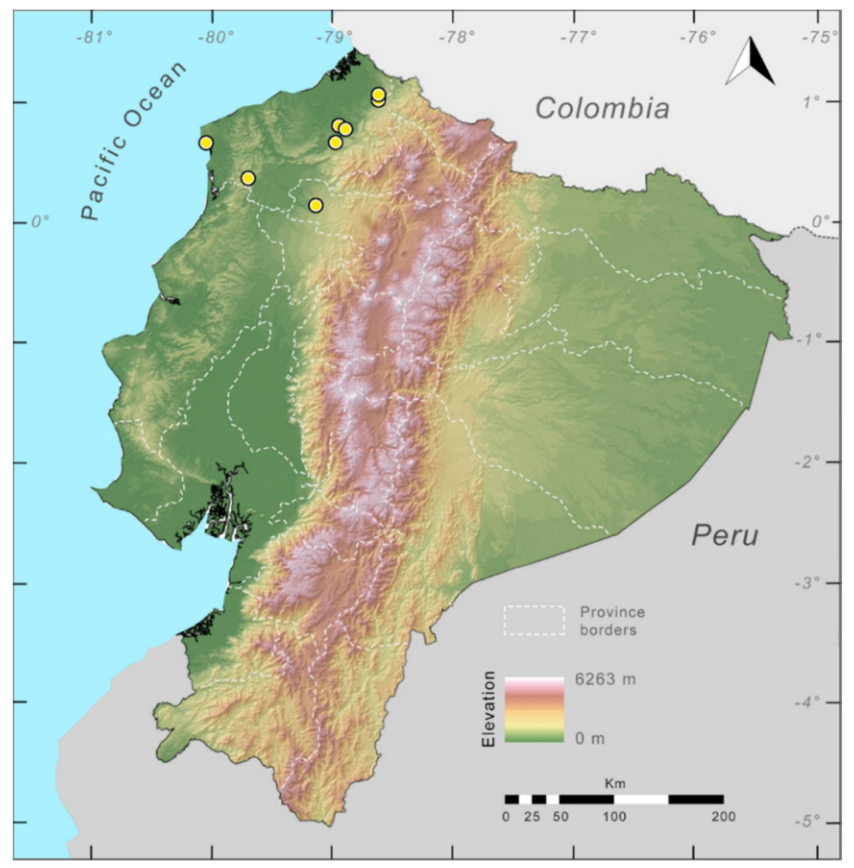

Figure 217. Distribution of Teratohyla pulverata in Ecuador (yellow dots).

Remarks: From our observations, it is evident that iridophores (white iridophores) are usually maintained in preserved specimens during long periods of time. For example, the specimen KU 85476 was collected on August 1964 and still maintains the white colorations in most of its internal organs (only a portion of the digestive tract has lost the iridophores and now is cream). However, small amounts of iridophores are diffused in ethanol. In Teratohyla pulverata, the white dots on the dorsal surfaces and ulnar and tarsal folds are not visible in some preserved specimens. Given the importance of the presence/absence of iridophores in centrolenid taxonomy, it is important that researchers take the time to carefully record and photograph the coloration in life.

Specimens examined: Teratohyla pulverata: Costa Rica: Puntarenas: Rincón de Osa, UCR 17417, USNM 219379-87. Ecuador: Provincia de Esmeraldas: Río Durango (1.04186 $\left.{ }^{\circ} \mathrm{N}, 78.62405^{\circ} \mathrm{W} ; 243 \mathrm{~m}\right)$, BM 1902.5.27.24 (holotype of H. petersi), BM 1902.5.27.25, QCAZ 32066, QCAZ 45414, DHMECN

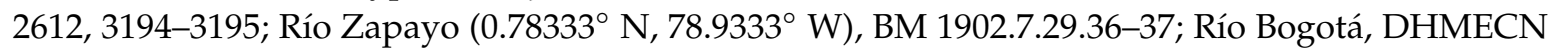
3194-95; Reserva Ecológica Cotacachi-Cayapas, Charco Vicente, 60 m, QCAZ 11367-68; Estero Aguacate (00 $\left.39^{\prime} \mathrm{N}, 80^{\circ} 03^{\prime} \mathrm{W} ; 10-64 \mathrm{~m}\right)$, Parroquia San Francisco del Cabo, DHMECN 3194-95. Provincia de Pichincha: Silanche $\left(0.1333^{\circ} \mathrm{N}, 79.1333^{\circ} \mathrm{W} ; 400 \mathrm{~m}\right)$, QCAZ 32224. Nicaragua: Matagalpa: Finca Tepeyac, $10.5 \mathrm{~km} \mathrm{~N}$ and $9.0 \mathrm{~km}$ E of Matagalpa, $960 \mathrm{~m}$, KU 85476. Panama: Coclé: Quebrada Guabalito, Palmarazo, Parque Nacional Omar Torrijos, CH 5122; Darién: Río Jaque, 1.5 km above Río Imamado, 50 m, KU 116493. Honduras: Olancho, USNM 342214-21. 
Teratohyla spinosa (Taylor 1949 [145]; Figures 218-221).

Centrolenella spinosa Taylor, 1949 [145]. Holotype: KU 23809.

Type locality: "Los Diamantes, one mile south of Guápiles, (Cantón de Pococí, Provincia de

Limón,) Costa Rica". Savage, 1974 [183], commented on the type locality.

Teratohyla spinosa-Taylor, 1951 [15].

Cochranella siren-Ruiz-Carranza and Lynch, 1991 [6].

Teratohyla spinosa-Guayasamin, Castroviejo-Fisher, Trueb, Ayarzagüena, Rada, Vilà, 2009 [1].

Common names: English: Dwarf Glassfrog [24], Minute Spiny Glassfrog. Spanish: Rana de Cristal Enana [24], Rana de Cristal espinosa.

Etymology: The specific name comes from the Latin spina, meaning thorn, and refers to the spine-like prepollex that is evident next to the thumb (Figure 12).

Identification: Among glassfrogs that inhabit the lowlands of western Ecuador (Chocó Ecoregion), Teratohyla spinosa is unique in having a uniform green dorsum, a white to yellowish-white iris with contrasting black reticulations (Figure 218), small size (SVL $<21.0 \mathrm{~mm}$ ), and lacking humeral spines. Also, this species is exceptional by having a spine (prepollex) that is clearly separated from Finger I (Figures 12 and 219).

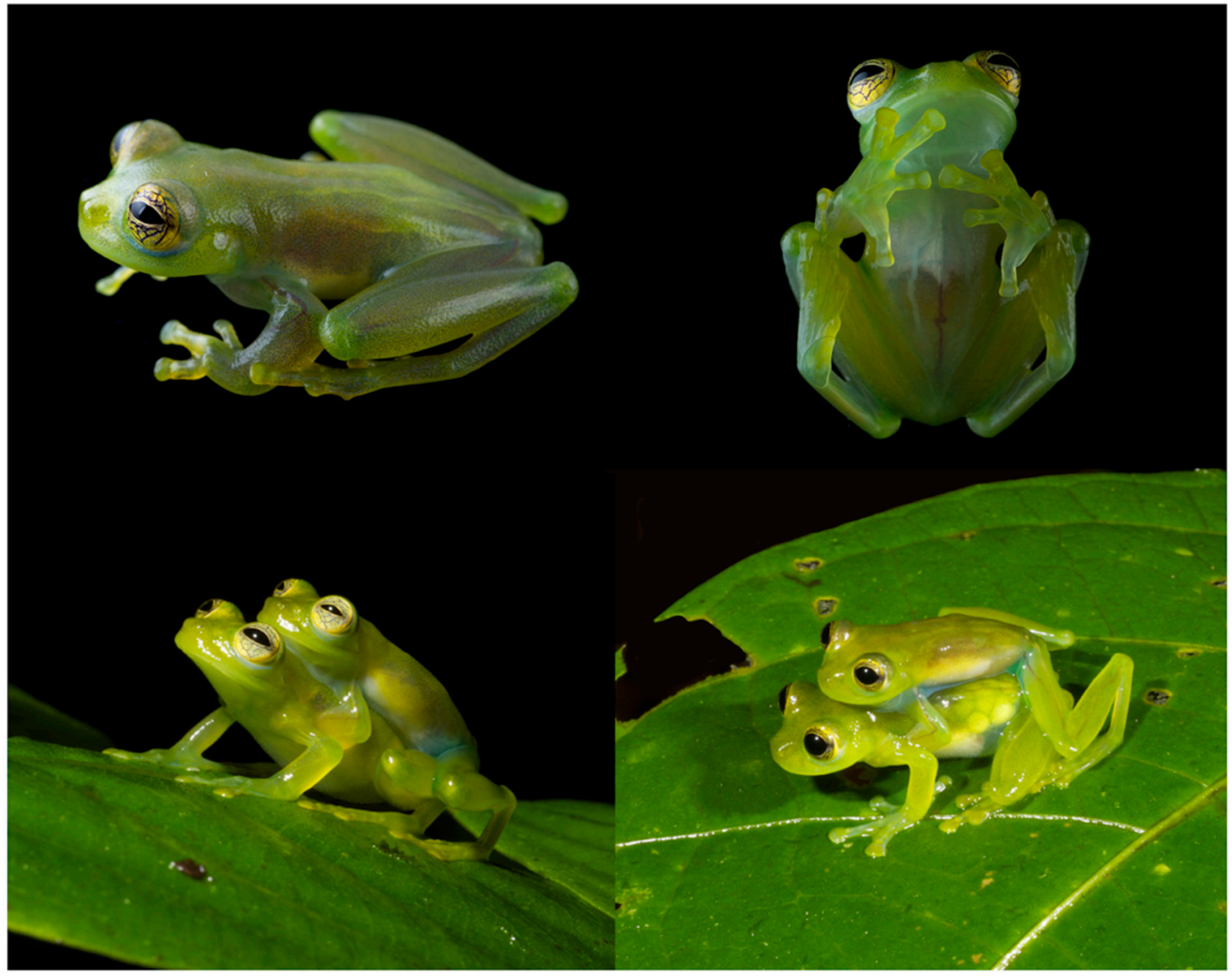

Figure 218. Teratohyla spinosa in life. (Top row): Adult male from Durango, Esmeraldas province, QCAZ 45410. (Bottom row): Amplectant pair from Reserva Otokiki, Esmeraldas province, Ecuador. Photos by Luis A. Coloma.

Diagnosis: (1) Vomers with dentigerous process that bear or lack teeth; (2) snout truncated in dorsal aspect; truncated to slightly protruding in lateral profile (Figure 219); (3) tympanum with pronounced lateral inclination, its diameter about $23.5 \%-32.0 \%$ of eye diameter; upper border of 
tympanic annulus obscured by supratympanic fold; tympanic membrane clearly differentiated from surrounding skin; (4) dorsal skin smooth, lacking spicules; (5) ventral skin smooth to slightly areolate; lacking pair of enlarged subcloacal warts; (6) white parietal peritoneum covering anterior $50 \%-60 \%$ of venter (condition P3); white pericardium; no iridophores in peritonea covering intestines, stomach, and kidneys; translucent peritoneum around gall and urinary bladders (condition V1); (7) liver lobate, covered by transparent peritoneum (condition H0); (8) humeral spines absent; (9) webbing absent between Fingers I and II, reduced between Fingers II and III, and extensive between Fingers III and IV (Figure 219); formula: II $\left(1^{2 / 3}-2^{-}\right)-\left(3^{+}-3^{1 / 4}\right)$ III $\left(2^{-}-2\right)-\left(1^{+}-1^{2 / 3}\right)$ IV; (10) distinct prepollex; in males, nuptial pad Type I (see Remarks); (11) Finger I slightly longer than Finger II (Finger II length $90.1 \%-92.5 \%$ of Finger I); (12) ulnar fold low; tarsal folds absents; (13) feet with relatively extensive webbing; formula: I $1-\left(2^{-}-2\right)$ II $\left(1^{-}-1\right)-\left(2^{-}-2^{+}\right)$III $\left(1^{+}-1^{1 / 2}\right)-\left(2^{+}-2^{1 / 2}\right)$ IV $\left(2^{-}-2^{1 / 2}\right)-\left(1^{-}-1\right)$ V; (14) width of Finger III disc about $33.1 \%-40.4 \%$ of eye diameter; (15) in life, dorsum uniform green; bones green; (16) in preservative, dorsum creamy lavender; (17) in life, iris white to yellowish white, with black contrasting reticulations; (18) melanophores present only on dorsal surfaces of Finger IV (and sometimes Finger III) and Toes IV and V; (19) males call from the upper surfaces of leaves; each call consists of one to three pulsed notes; the dominant frequency is at $6469-6937 \mathrm{~Hz}$; (20) fighting behavior unknown; (21) eggs deposited on the underside of leaves; short-term maternal care present; prolonged parental care absent; (22) oral apparatus of tadpoles with tooth row formula 0/0; (23) minute body size; in males, SVL 18.0-19.7 mm ( $\bar{X}=19.0 \pm 0.525, n=10)$; in females, SVL 19.7-20.7 mm $(n=3)$.

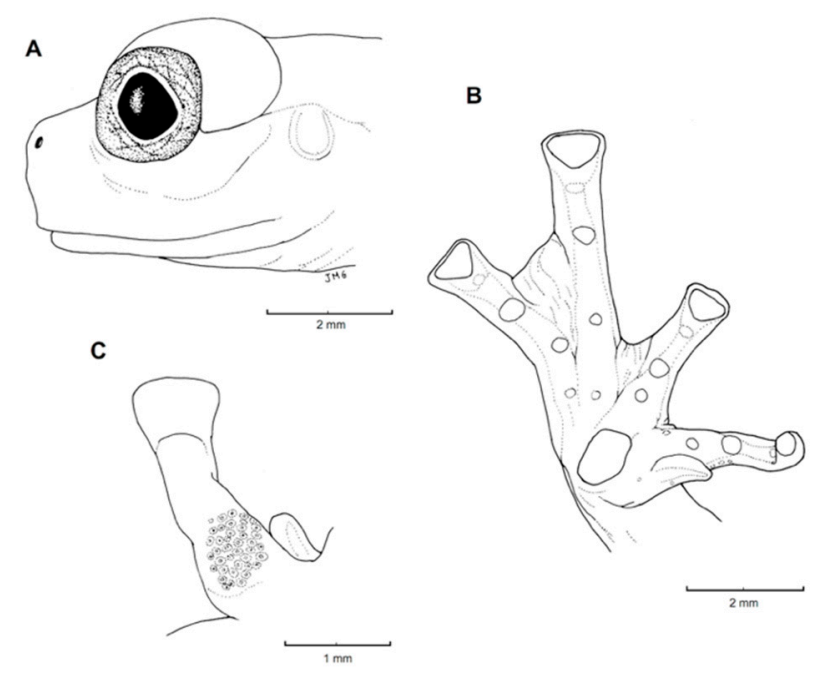

Figure 219. Teratohyla spinosa, adult male. (A) Head in lateral view, QCAZ 31321. (B) Hand in ventral view, KU 164668. (C) Finger I in dorsal view, QCAZ 10450; note nuptial pad and prepollical spine. Illustrations by Juan M. Guayasamin.

Color in life (Figure 218): Yellowish-green dorsum. Anterior half of venter white, posterior part transparent. Green bones. Iris silvery white to yellowish white, with marked black reticulations.

Color in ethanol: Dorsal surfaces of head, body, and limbs cream with light lavender hue. Anterior half of venter white, posterior part translucent. Translucent peritonea covering gall and urinary bladders. Iridophores absent from digestive tract, liver, and kidneys.

Biology and ecology: In Ecuador, Teratohyla spinosa has been found breeding along streams near San Francisco de Bogotá (25 May 2006) and Alto Tambo (April 2010). Individuals were active during the night; several males were calling and amplectant pairs were observed. Females provide short-term parental care, whereas any form of prolonged parental care is absent [25].

Call (Figure 220): Males call from the upper surfaces of leaves. Ibáñez et al. [197] described the call as a series of harsh "creep-creeps" followed by a considerable pause, with a dominant frequency at $6.8-7.2 \mathrm{kHz}$. The description provided below is based on a recording obtained by JMG at Reserva 
Otokiki $\left(0.91104^{\circ} \mathrm{N}, 78.57369^{\circ} \mathrm{W} ; 706 \mathrm{~m}\right)$, Esmeraldas province, Ecuador. Calls are emitted every 12-35 $\mathrm{s}$; each call usually has two notes (range $=1-3$ notes, $\bar{X}=1.92 \pm 0.515, n=12$; Figure 220); calls with one note have a duration of $0.124-0.139 \mathrm{~s}(n=2)$; calls with two notes last $0.431-0.594 \mathrm{~s}(\overline{\mathrm{X}}=0.545 \pm 0.067$, $n=9)$; a single three-note call had a duration of $0.793 \mathrm{~s}$. Notes are pulsed, with $5-15$ pulses per note $(\bar{X}=7.87 \pm 2.096, n=23)$. The dominant frequency is at $6469-6937 \mathrm{~Hz}(\overline{\mathrm{X}}=6664 \pm 129.2, n=12)$; a first harmonic is visible at $12,843-13,687 \mathrm{~Hz}(\overline{\mathrm{X}}=13351 \pm 305.6, n=12)$; a second harmonic is sometimes visible at $19,312-20,812 \mathrm{~Hz}(\overline{\mathrm{X}}=20039 \pm 9885, n=8)$.

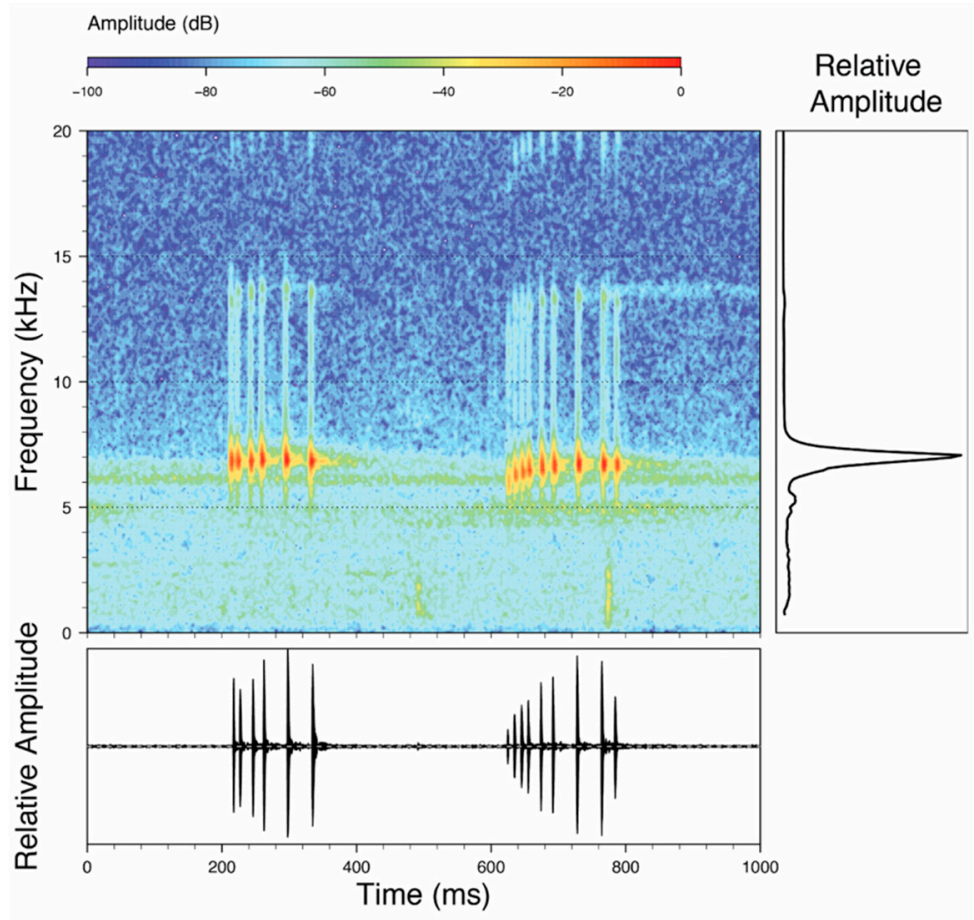

Figure 220. Call of Teratohyla spinosa, LBE-C-002, recorded at Reserva Otokiki, 706 m, Esmeraldas province, Ecuador.

Egg masses and tadpoles: Egg masses are attached on the underside of the leaves near their margins and 0.5 to $2.5 \mathrm{~m}$ above the water and sometimes over the shore $[24,146,147]$. When laid, the eggs of Teratohyla spinosa are greenish white; the embryos are initially yellow and become darker during development, reaching a dark grey, brownish, or reddish-tan color at hatching $[24,146,147]$. Egg masses contain 15-25 eggs, with each egg and associated capsule measuring 5-7 mm in diameter; clutch mass is small, measuring about $21 \times 25 \times 7 \mathrm{~mm}[24,146,147]$. The following description of the tadpole is primarily derived from Savage [148], but with some modifications (RWM, pers. obs.). Tiny on hatching, total length about $11 \mathrm{~mm}$ at stage 25; body elongated, depressed; mouth ventral; nares and crescent-shaped eyes dorsal; midlateral, posterior, sinistral spiracle; vent tube median; tail long with rounded tip; caudal fins reduced. Oral disc complete, moderate, with single row of marginal papillae (21-45) laterally and ventrally, wide dorsal gap above mouth; LTRF probably 2/3, but when rows are present, rows of teeth are weaker and sometimes irregular; A-1 row often not evident [147]; A-2 usually present, but often visible only as traces of teeth on the lateral extremes of the tooth ridge; jaw sheaths robust and well developed, upper broadly arched and lower one v-shaped, both with sharp serrations along their entire lengths. Body and tail greyish brown dorsally, lighter ventrally; bright yellow yolk mass colors posterior half of the body and covers the liver and intestine; tail musculature mostly brown except pale area anteroventrally; fins are opaquely transparent with scattered dark spots. Starrett [146] and Hoffmann [147] also provided descriptions of the tadpoles. Starrett mentioned that her specimens lacked labial teeth and suggested that possibly this species does not develop labial teeth. Savage [148] considered her specimens to be anomalous and possibly the result of raising the tadpoles 
in captivity. Hoffmann agreed, but also noted how variable the tooth rows were in his specimens, which also were lab-raised. A better understanding of the nature of the labial teeth will only become available with the examination of field collected larvae of T. spinosa.

Distribution (Figure 221): Teratohyla spinosa is distributed from eastern Honduras, through Nicaragua, Costa Rica, and Panama in Central America [84,134,145,148,305-308]. In South America, it is found in the Chocó Ecoregion of Colombia south to Río Palenque in Ecuador [86,101,134]. In Ecuador, the species has been reported from the provinces of Esmeraldas, Pichincha, and Los Ríos at elevations below $700 \mathrm{~m}$. In Ecuador, the potential distribution of the species is $38,671 \mathrm{~km}^{2}$, within the Chocoan Tropical Forest and the Western Foothill Forest regions.

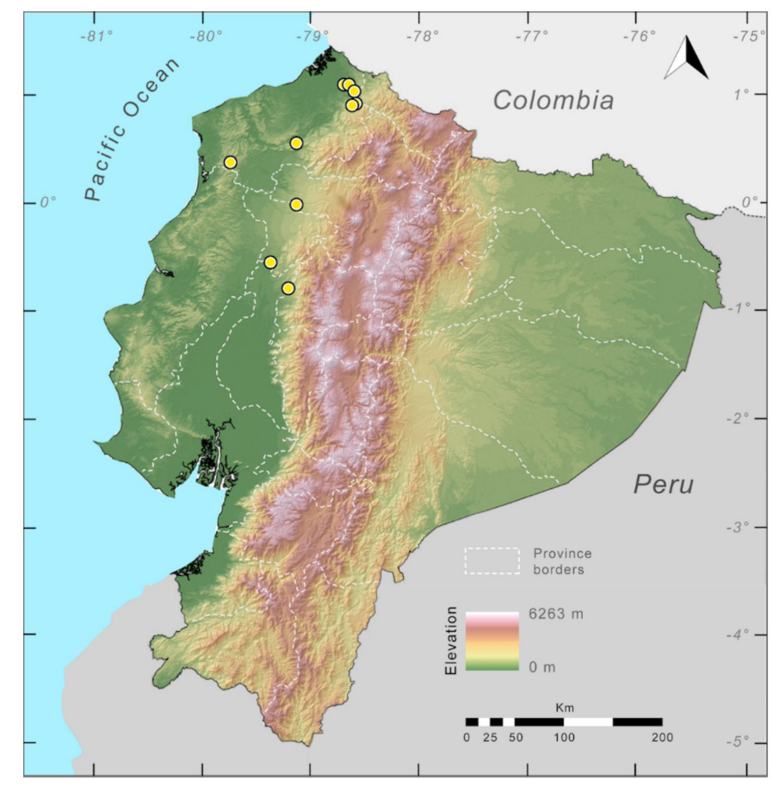

Figure 221. Distribution of Teratohyla spinosa in Ecuador (yellow dots).

Conservation status: Globally, Teratohyla spinosa is listed as Least Concern by the IUCN [309]. In Ecuador, the habitat of the species (Chocó) is continuously being fragmented by logging activity and habitat transformation towards oil palm plantations; therefore, we suggest that the species should be considered as Endangered, following IUCN criteria B2a, B2(iii).

Evolutionary relationships (Figure 210): Teratohyla spinosa is sister species to a clade formed by T. midas + T. adenocheira. Teratohyla spinosa is found in the Chocó, whereas T. midas and T. adenocheira are endemic to the Amazon basin. The most like speciation mechanism that separated T. spinosa from its closest relatives is vicariance through the uplift of the Andes.

Specimens examined: Teratohyla spinosa: Ecuador: Provincia de Cotopaxi: $6 \mathrm{~km}$ W of Guasaganda $\left(0.797^{\circ} \mathrm{S}, 79.212^{\circ} \mathrm{W}\right)$, QCAZ 6809. Provincia de Esmeraldas: $2 \mathrm{~km}$ E of San Francisco de Bogotá, on the San Francisco-Durango road $\left(1.08585^{\circ} \mathrm{N}, 78.68575^{\circ} \mathrm{W} ; 77 \mathrm{~m}\right)$, QCAZ 32124-25; $1.3 \mathrm{~km}$ E of San Francisco de Bogotá, on the San Francisco-Durango road (1.0888 $\left.\mathrm{N}, 78.69563^{\circ} \mathrm{W}\right)$, QCAZ 32138; near Durango $\left(1.07934^{\circ} \mathrm{N}, 78.66954^{\circ} \mathrm{W} ; 74 \mathrm{~m}\right)$, QCAZ 31321; $4 \mathrm{~km} \mathrm{~N}$ of Durango $\left(1.44307^{\circ} \mathrm{N}, 77.99667^{\circ} \mathrm{W} ; 253 \mathrm{~m}\right)$, QCAZ 33319; Bosque Integral Otokiki $\left(0.91241^{\circ} \mathrm{N}, 78.58092^{\circ} \mathrm{W} ; 700 \mathrm{~m}\right), \mathrm{QCAZ} 48283 ; 7 \mathrm{~km} \mathrm{~N}$ of Durango in the Durango-San Lorenzo road (1.07934 $\left.{ }^{\circ} \mathrm{N}, 78.66954^{\circ} \mathrm{W} ; 74 \mathrm{~m}\right), \mathrm{QCAZ}^{\circ} 1321$. Provincia Los Ríos: Estación Biológica Río Palenque $\left(0.55^{\circ} \mathrm{S}, 79.3667^{\circ} \mathrm{W} ; 220 \mathrm{~m}\right), \mathrm{KU}$ 164663-68. Provincia Pichincha: Río Blanco, Río Yambi (0001' S, $79^{\circ} 08^{\prime} \mathrm{W}$; ca. 700 m), USNM 288443.

Localities from the literature: Ecuador: Provincia de Esmeraldas: Estación Biológica Bilsa (0.36667 N, 79.750 W), Reserva Ecológica Mache Chindul [310].

Photographic record: Ecuador: Provincia de Esmeraldas: Reserva Tesoro Escondido (0.5337 N, 79.1445 W), QCAZ 65398 [294]. 
Vitreorana ritae (Lutz in Lutz and Kloss, 1952 [311]; Figures 222-226).

Centrolene ritae Lutz in Lutz and Kloss, 1952 [311]. Holotype at MNRJ, now lost. Neotype: MCZ A96522.

Type locality: "headwaters of Río Caiwima, a tributary of the Río Amayaca-Yacu, ca. $70 \mathrm{~km}$ NNE Puerto Nariño, Amazonas, Colombia (approximately $3^{\circ} 20^{\prime} \mathrm{S}, 70^{\circ} 20^{\prime} \mathrm{W}$ )" Cisneros-Heredia, 2013 [312].

Centrolenella oyampiensis Lescure, 1975 [313]. Holotype: MNHNP 1973.1673. Type locality: "village Zidok (Haut-Oyapock), Guyane française". Placed in synonymy by CisnerosHeredia, 2013 [312].

Cochranella oyampiensis-Ruiz-Carranza and Lynch 1991 [6].

Centrolenella ametarsia Flores, 1987 [314]. Holotype: MCZ 96522. Type locality: "the headwaters of Río Caiwima, a tributary of the Río Amaca-Yacu, ca. $70 \mathrm{~km}$ NNE Puerto Nariño,

Amazonas, Colombia (approximately $3^{\circ} 20^{\prime} \mathrm{S}, 70^{\circ} 20^{\prime} \mathrm{W}$ )". Placed in synonymy by CisnerosHeredia, 2013 [312].

Cochranella ametarsia-Ruiz-Carranza and Lynch 1991 [6].

Vitreorana oyampiensis—Guayasamin, Castroviejo-Fisher, Trueb, Ayarzagüena, Rada, and Vilà, 2009 [1].

"Cochranella" ritae—Guayasamin, Castroviejo-Fisher, Trueb, Ayarzagüena, Rada, and Vilà, 2009 [1].

Vitreorana ritae-Cisneros-Heredia, 2013 [312].

Common names: English: Rita's Glassfrog. Spanish: Rana de Cristal de Rita.

Etymology: The name Vitreorana has its origin in the Latin words vitreum, meaning glass, and rana, meaning frog. The name refers to the total or partial ventral transparency of these frogs [1]. The specific name ritae is a patronym to Rita Kloss, assistant of Bertha Lutz.

Identification: Among glassfrogs, Vitreorana ritae is unique by having a green dorsum with small black spots (Figure 222), a small size $(\leq 24 \mathrm{~mm})$, white gastrointestinal peritoneum, and a distinct prepollex (Figure 12). The only glassfrog that could be confused with $V$. ritae is $V$. helenae, which differs by having a yellow iris (greyish white with a fine dark reticulation in $V$. ritae), light greenish-yellow dorsum with dark punctuations (green with dark punctuations in V. ritae; Figure 222), and a mostly white hepatic peritoneum (hepatic peritoneum mostly transparent, showing the brown liver, except for some iridophores on the upper border in $V$. ritae [300].

Diagnosis: Vitreorana ritae has the following combination of traits: (1) Dentigerous process of vomer with one tooth or lacking teeth; (2) snout rounded in dorsal and lateral views (Figure 223); (3) tympanum visible, moderate in size, its diameter $25.8 \%-35.4 \%$ of eye diameter; tympanic annulus visible except for upper border covered by supratympanic fold; tympanic membrane differentiated and translucent, pigmented as surrounding skin; (4) dorsal surfaces shagreen; spinules absent; (5) ventral surfaces granular, pair of enlarged subcloacal warts; (6) anterior $25 \%-40 \%$ of ventral parietal peritoneum white, posterior portion transparent (condition P2-P3); pericardium and gastrointestinal peritoneum white (condition V2); (7) lobed liver covered by transparent peritoneum, except for anterior border that may be covered by thin layer of iridophores (condition H0); (8) humeral spines absent; (9) webbing between Fingers I-III absent, moderate between Fingers III and IV (Figure 223); webbing formula: III $\left(2^{-}-2^{1 / 3}\right)-\left(1^{+}-2^{-}\right)$IV; $(10)$ webbing between toes moderate; webbing formula: I $1-\left(2^{-}-2\right)$ II $\left(1-1^{+}\right)-\left(2-2^{1 / 4}\right)$ III $\left(1^{+}-1^{1 / 2}\right)-2^{+}$IV $\left(2-2^{1 / 3}\right)-1 \mathrm{~V}$; (11) low ulnar fold, lacking iridophores; low inner tarsal fold present, lacking iridophores; outer tarsal fold absent; (12) nuptial pad of males Type I; distinct prepollex; (13) Finger I slightly longer than Finger II (Finger II length $84 \%-92 \%$ of Finger I); (14) disc of Finger III moderate, its width $31.0 \%-42.3 \%$ of eye diameter; (15) in life, dorsum green with small dark spots (Figure 222); bones green; (16) in preservative, dorsum lavender with dark spots; (17) iris greyish white with thin dark reticulation; (18) melanophores covering dorsal surfaces of 
Fingers III and IV; (19) males call from the upper side of leaves; single and double note advertisement call of $0.10-0.15$ s duration, dominant frequency at 4640-5160 Hz; (20) fighting behavior unknown; (21) eggs deposited on upper or underside of leaves; short-term maternal care present; prolonged parental care absent; (22) tadpoles at stage 25 with labial tooth row formula 0/1-2; oral disc small and ventral with one row of large marginal papillae laterally and posteriorly; upper jaw sheath wide and robust, lower jaw sheath wide, V-shaped; dorsum reddish brown, venter whitish, tail muscle reddish and tail fins transparent (Figure 224); (23) minute body size; adult male SVL 17.1-20.1 mm ( $\bar{X}=18.8 \pm 1.250, n$ = 6); two adult females SVL 19.8-19.9 mm; Lima et al. [315] provided the following data for the species in central Amazonia: SVL in males 17-21 mm, in females 21-24 mm.

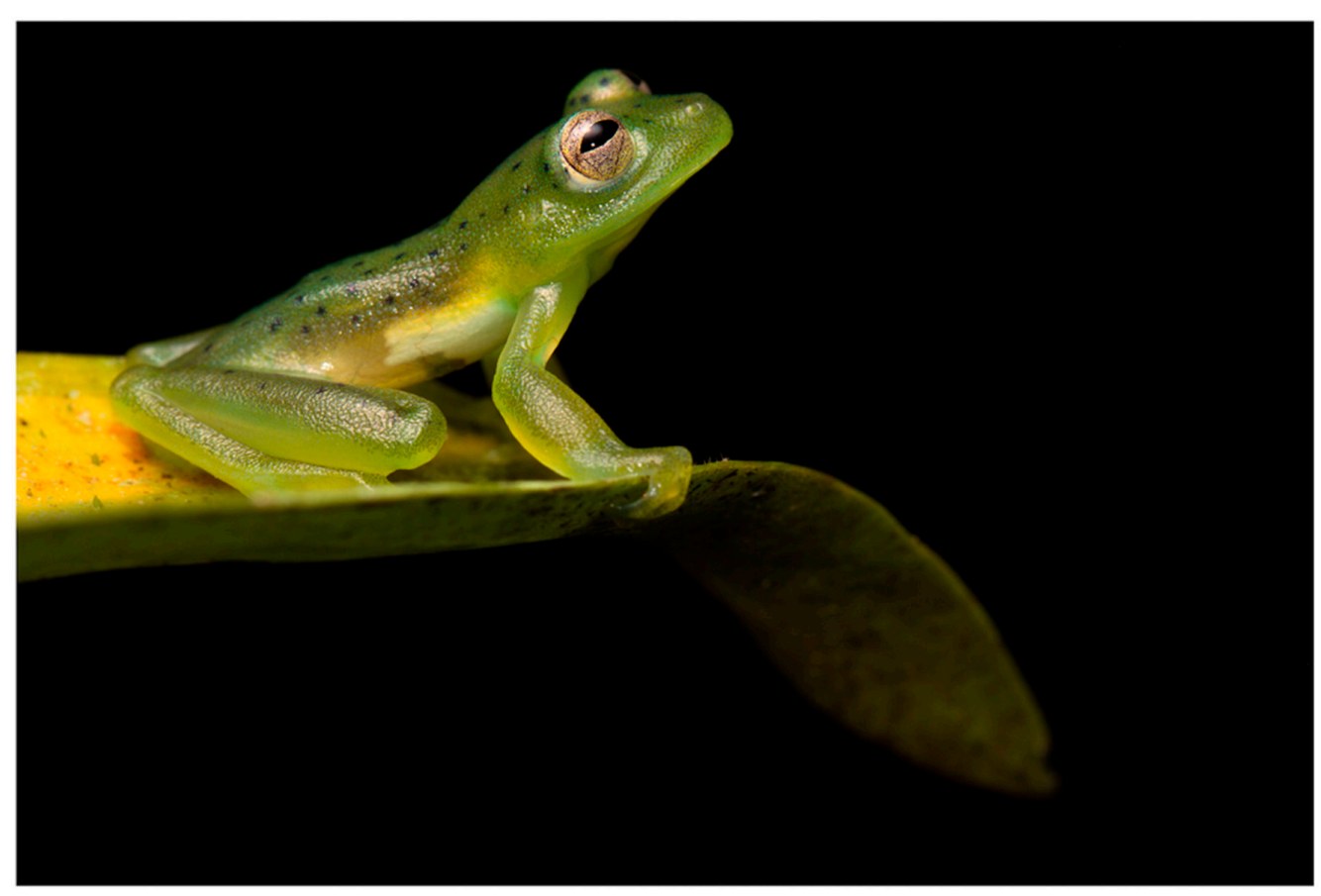

Figure 222. Vitreorana ritae from Yasuní National Park, Ecuador. Photo by Jaime Culebras.
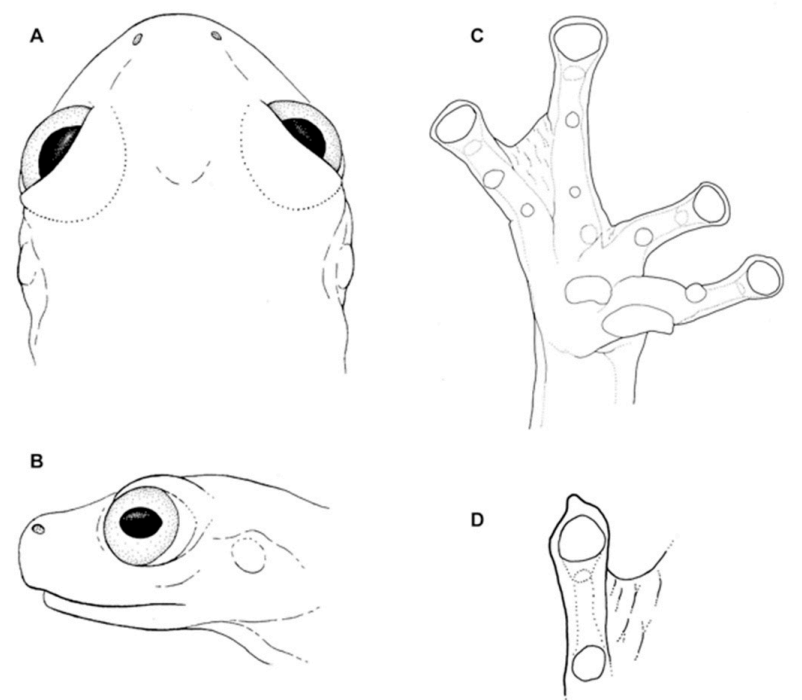

Figure 223. Vitreorana ritae. (A) Head in dorsal view, MCZ 96522. (B) Head in lateral view, MCZ 96522. (C) Hand in ventral view, with exposed prepollex, ICN 50847. (D) Toe I in ventral view, with papilla at tip. Not drawn to scale. (A,B) Modified from Flores [314]; (C,D) by Juan M. Guayasamin. 
Color in life (Figure 222): Green dorsum with small dark blue to black spots. Green bones. Iris greyish white with thin dark reticulation. Venter white anteriorly, turning transparent posteriorly; white digestive tract.

Color in ethanol: Dorsum lavender with small dark lavender spots. Color of parietal and visceral peritonea variable; holotype and one Colombian specimen (ICN 50847) with transparent parietal and visceral peritonea. Two specimens (ICN 50846, QCAZ 28138) with white parietal peritoneum on anterior half of venter, and white peritoneum on intestines and stomach. We consider that the white lining has been dissolved in the holotype and ICN 50847, but it is equally possible that Vitreorana ritae is polymorphic for the presence of white lining on the parietal and visceral peritonea. It may also be possible that the species is a composite of more than one species.

Biology and ecology: During the night, Vitreorana ritae has been found on vegetation, about 1-5 $\mathrm{m}$ above streams, and on the trunk of a Ceiba, about $7 \mathrm{~m}$ above the ground [300,314]. At Reserva Florestal Adolpho Ducke in Manaus, Amazonas, Brazil, breeding individuals and clutches of $V$. ritae were observed on vegetation above small streams in forests [300]. Adults were found throughout the year, and vocalizations were heard throughout the night and were more common between January and May (from the middle to the end of the rainy season). Short-term maternal care is present, whereas any form of prolonged parental care is absent [25].

Egg masses and tadpoles (Figure 224): The information shown below is from Menin et al. [316]. At Reserva Florestal Adolpho Ducke, Amazonas, Brazil, clutches were deposited on the upper $(n=4)$ or undersides $(n=2)$ of leaves hanging over a stream, from 0.5 to $1 \mathrm{~m}$ above water surface. Mean clutch size was 16 eggs $(n=4$; range 12-18). The eggs were green and deposited in a single layer with adhered jelly capsules. Tadpoles were green while in the egg capsules but became reddish brown with transparent tail after hatching. Tadpoles from a single clutch raised in the laboratory hatched at Gosner's [191] stage 24. Tadpoles were found buried in the leaf litter along the edges of slow-flowing streams. The description below is based on eleven tadpoles at stage 25. In life, dorsum reddish brown, venter whitish, tail muscle reddish and tail fins transparent. In preserved specimens, dorsum transparent with dark melanophores, venter whitish with melanophores on posterior part and tail translucent with melanophores on tail musculature. Body elongate and depressed in lateral view, and rectangular and elongate in dorsal view. Body and tail $27 \%-28 \%$ and $72 \%-73 \%$ of total length, respectively. Body wider than deep; maximum body width behind eyes. Snout broad and truncated in dorsal and ventral views and flattened in lateral view. Eyes small, close together, and facing dorsolaterally. Interorbital distance six times larger than maximum eye diameter. Narial openings small, nearer snout than eyes. Spiracle single, short, sinistral, positioned on longitudinal axis of body and directed posteriorly. Vent tube short, positioned along ventral midline and attached directly to ventral fin. Tail musculature robust; caudal fins low, similar in height, deeper than the robust caudal musculature only on the posterior one-third of the tail. Dorsal fin originates at tail-body junction and increases in depth throughout the first third of the tail, and then gradually decreases to a rounded tip. Ventral fin originating on the tail musculature, slightly arched, and maintaining the same height throughout the distal two-thirds of the tail. Tail tip rounded. Oral disc small and ventral (Figure 224), bordered laterally and posteriorly by one row of large marginal papillae with pointed tips. Marginal papillae on posterior border larger than lateral ones. Labial tooth row formula (LTRF) 0/1-2. All labial tooth rows nearly the same length. Upper jaw sheath wide and robust; lower jaw sheath wide, V-shaped; both hardly serrated. 
A

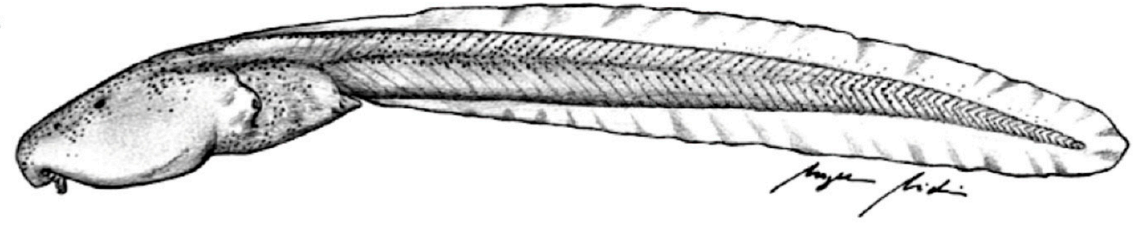

B
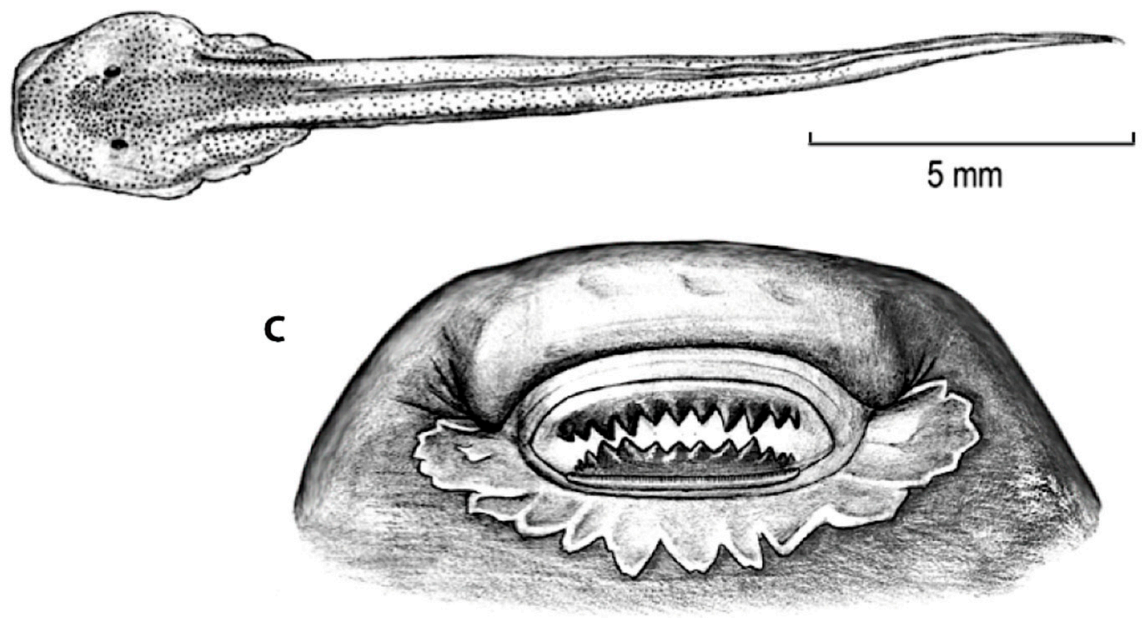

$1 \mathrm{~mm}$

Figure 224. Tadpole of Vitreorana ritae at Gosner stage 25. (A) Lateral view. (B) Dorsal view. (C) Oral disc. Modified from Menin et al. [316].

Call (Figure 225): At central Amazonia of Brazil, males of Vitreorana ritae were observed calling on vegetation above streams, about 0.5 to $3 \mathrm{~m}$ high on leaves of aquatic or stream side plants $(n=20)$ [316]. Herein we report a call obtained by Morley Read at Boanamo community (LBE-C-039; $240 \mathrm{~m}$ ) and Shiripuno Lodge (LBE-C-039; $250 \mathrm{~m}$ ), Orellana province, Ecuador. We analyzed 31 notes contained within 10 calls from two individuals. The typical advertisement call is relatively short (range $=288-1095 \mathrm{~ms}$, mean $=685.2 \mathrm{~ms}, \mathrm{SD}=280.1 \mathrm{~ms})$ and contains two to five notes per call $($ mean $=3.3, \mathrm{SD}=1.1)$. Each note has a duration of $61-122($ mean $=76, \mathrm{SD}=16.3) \mathrm{ms}$. Notes are strongly pulsed and have $10-19$ (mean $=13.7, \mathrm{SD}=2$ ) amplitude peaks throughout the note, whereby some pulses are difficult to delimit because of a lower amplitude. Pulses within a note have a rate of 131-224 (mean $=171, \mathrm{SD}=24)$ pulses per second. Notes have their peak amplitude in the last $50 \%$ of the note (relative peak time: Range $=0.4425-0.8815$, mean $=0.719$, $\mathrm{SD}=0.106$ ), where the amplitude increases from a lower to a higher amplitude at the end of the note. The dominant frequency of a note measured at peak amplitude is $4688-5344$ (mean $=5044, \mathrm{SD}=182$ ) $\mathrm{Hz}$ and is contained within the fundamental frequency. The fundamental frequency has a lower limit of $4312-4875$ (mean $=4605$, $\mathrm{SD}=164) \mathrm{Hz}$ and a higher limit of 4969-6029 (mean = 5284, SD =229) Hz. The call described for the Ecuadorian populations matches the general information provided by Zimmerman and Bogart [317] for Brazilian populations. 


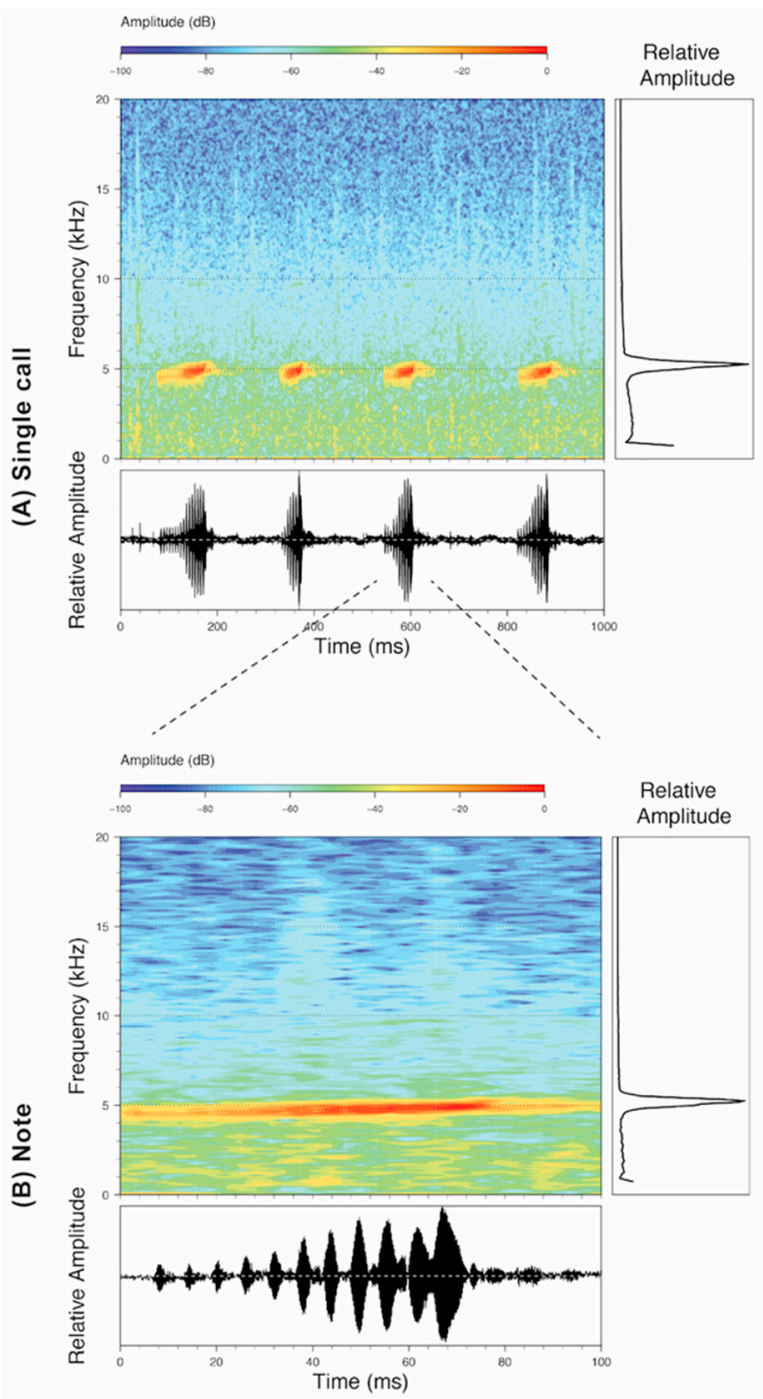

Figure 225. Calls of Vitreorana ritae, LBE-C-039, recorded by Morley Read at Boanamo Community, $240 \mathrm{~m}$, Orellana province, Ecuador. (A) A single call with four notes. (B) A single note.

Distribution (Figure 226): Vitreorana ritae is found from the Guianas across western Amazonia [17,222,229,300,313-316,318]. In Ecuador, the species has been reported from five localities in the provinces of Orellana and Sucumbíos at elevations below $260 \mathrm{~m}$ (Specimens Examined). In Ecuador, the potential distribution of the species is $42,600 \mathrm{~km}^{2}$ within the Amazonian Tropical Rainforest region.

Conservation status: Vitreorana ritae is listed as Data Deficient by the IUCN [297]. This species is known only from a handful of localities but is likely to occur more widely in the Amazon basin. Further surveys with emphasis on sampling bromeliads may provide a better understanding of the population dynamics of this species [166,319]. Given the broad distribution of the species in the Amazon basin, we suggest that it should be placed in the Least Concern category.

Evolutionary relationships (Figure 227): Vitreorana ritae is sister to V. helenae.

Taxonomic remarks: Cisneros-Heredia [312] placed C. ametarsia and C. oyampiensis under the synonymy of $C$. ritae, arguing that several of the traits described by Lutz [311] were misinterpreted and that Lutz's description of apparently "large size" of the discs of C. ritae was misrepresentative. We adopt the change proposed by Cisneros-Heredia [312] but note that new material of ritae from its type locality ("Benjamin Constant, Alto Solimões", Estado do Amazonas, Brazil) will provided a definitive solution to any taxonomic uncertainty. 


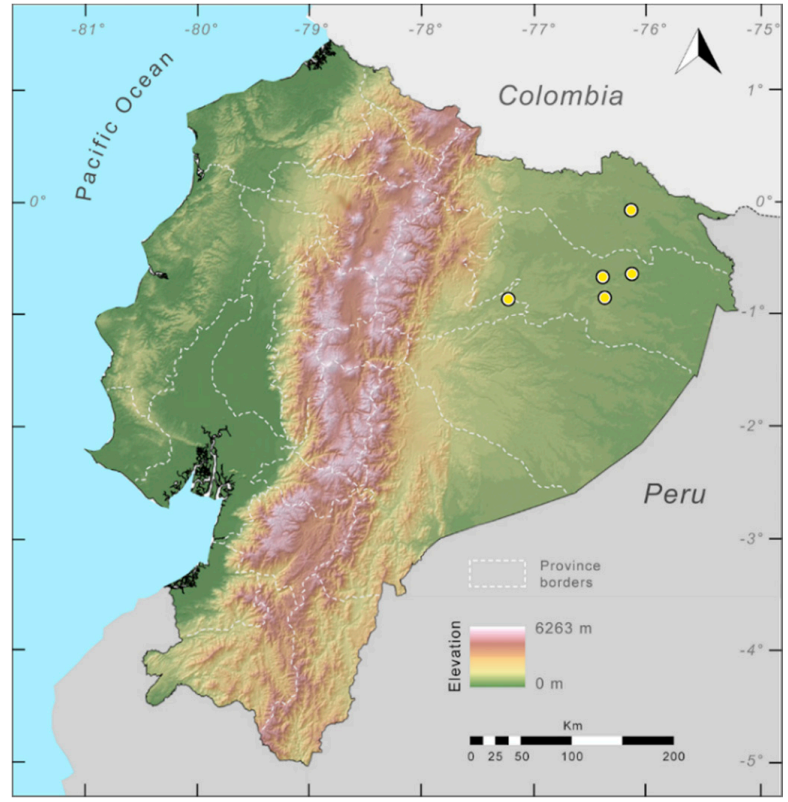

Figure 226. Distribution of Teratohyla ritae in Ecuador (yellow dots).

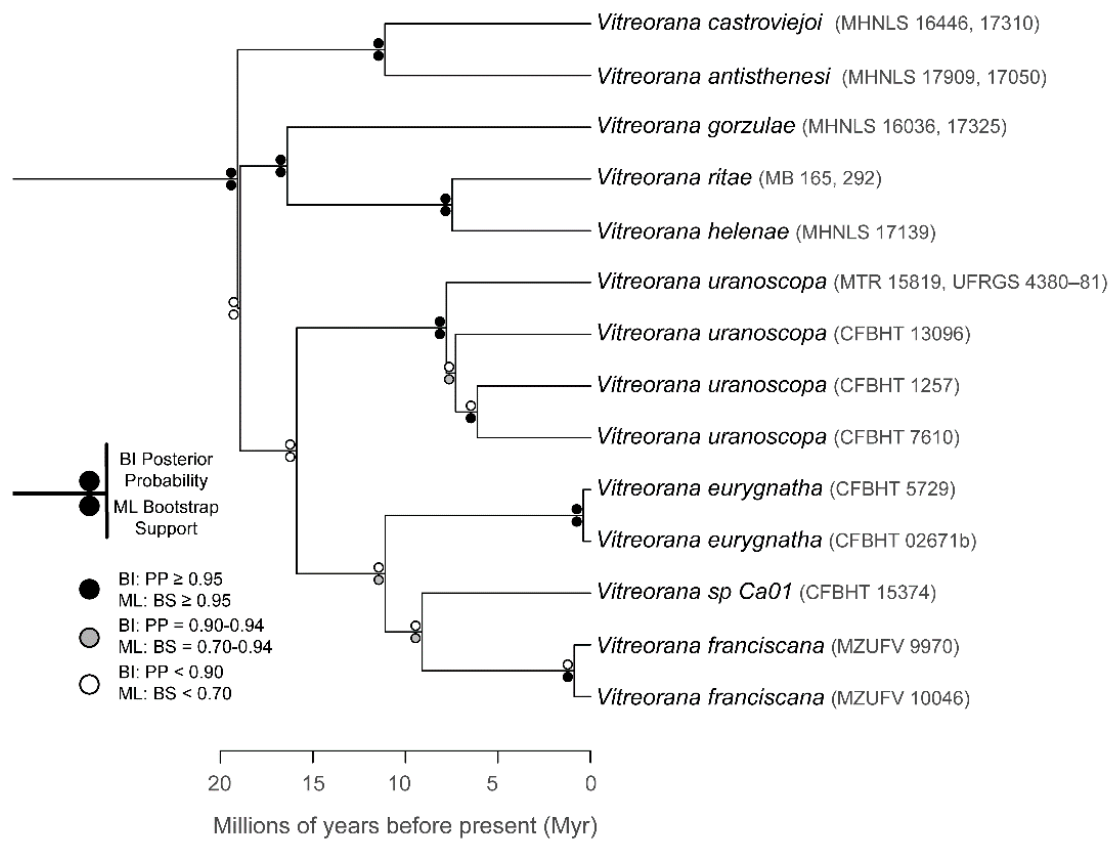

Figure 227. Evolutionary relationships of species in the glassfrog genus Vitreorana. The tree was inferred using maximum likelihood and Bayesian criteria.

Specimens examined: Teratohyla ritae: Colombia: Departamento de Amazonas: headwaters of Río Caiwima, tributary of the Río Amayaca-Yacu, MCZ A-96522 (holotype of C. ametarsia, neotype of V. ritae); Leticia, ICN 50846-47, ICN (JDL 24472). Ecuador: Provincia de Orellana: Río Yasuní, 200 km upstream from Río Napo $\left(0.85^{\circ} \mathrm{S}, 76.383^{\circ} \mathrm{W} ; 200 \mathrm{~m}\right)$, KU 175216; Tiputini Biodiversity Station $\left(0.65^{\circ} \mathrm{S}\right.$, $76.13^{\circ}$ W; 210 m), DFCH-USFQ D162; Estación Científica Yasuní PUCE, 240 m, QCAZ 16652; Yasuní, $\mathrm{km} 8$ on the Pompeya-Iro road, $260 \mathrm{~m}$, QCAZ 22709. Provincia de Sucumbíos: Puerto Bolívar $\left(0.09^{\circ}\right.$ S, $\left.76.14^{\circ} \mathrm{W} ; 240 \mathrm{~m}\right), 260 \mathrm{~m}$, QCAZ 28138. 


\section{Discussion}

\subsection{Evolutionary Relationships of Glassfrogs and Other Anurans}

Historically, glassfrogs have been thought to be closely related to hylids [93,94,298,320-324], although Jiménez de la Espada [83] considered Centrolene geckoidea to be a Neotropical representative of Rhacophorus, and Taylor [15] believed the South African heleophrynid frogs and glassfrogs were closely related. Noble, as early as 1931 [321], suggested a close affinity between glassfrogs and Allophryne ruthveni, which he described as a "toothless Centrolenella". The hypothesis by Noble has been supported by molecular and morphological studies [2,8,11-14,325-328], but see Haas [329], and by now it is well established that Allophrynidae is the sister family of Centrolenidae.

\subsection{Evolutionary Relationships and Generic Placement within Centrolenidae}

The molecular evolutionary trees of glassfrogs, constructed since 2008, have been accompanied by a reinterpretation of the systematics, biogeography, richness patterns, behavior, and speciation of the group $([1,3,19]$, this work). Continuous and collaborative efforts have allowed a better taxon and gene sampling, increasing the accuracy of the inference of evolutionary relationships [330-340].

Our phylogenetic sampling includes $75 \%$ of the described diversity of Centrolenidae and all but three ("Centrolene" medemi, Nymphargus buenaventura, N. laurae) of the known Ecuadorian species. All genera are supported and congruent with the taxonomy proposed by Guayasamin et al. [1]. Thus, recognized genera within Centrolenidae are stable and meet the stability criteria described by Guayasamin et al. [1] and Vences et al. [341]. However, relationships among genera are not fully resolved and further genetic data are necessary. At the species level, relationships are stable and well supported in most cases, allowing straightforward generic placement and facilitating recognition of cryptic species. Among Ecuadorian species, only one species, "Centrolene" medemi, still has an uncertain generic placement. A full species list of Centrolenidae and their current generic placement is provided in Table S1.

\subsection{Biogeography}

Our divergence dating results show that Centrolenidae and Allophrynidae separated from each other 25-55 Mya, and centrolenids started to diversify about 25-41 Mya, which are slightly older ages than previous estimates [3]. The most recent estimate of divergence times found an age of $\sim 45 \mathrm{Mya}$ for the split between Centrolenidae and Allophrynidae [328]. The geographic origin of glassfrogs is placed, unambiguously, in South America, originating at mid-elevations or climatically similar habitats $[3,28]$. From there, glassfrogs have dispersed into Central America multiple times [2,3]. Notably, the lowland clades (e.g., Hyalinobatrachium, Teratohyla) have colonized Central America, whereas Andean clades with high levels of species richness (e.g., Nymphargus, Centrolene) are completely absent from Central America [3]. This is likely in part due to climatic-niche conservatism constraining centrolenids from dispersing to lowland regions from the Andes [3,28].

Even though glassfrog diversity thrives in the Andes (Figures 228 and 229), the specific ancestral biogeographic region of centrolenid origins is ambiguous [3]; what we do know, however, is that the most common recent ancestor inhabited mid-elevation mountains (1000-2000 m), and that lower and higher elevation habitats were colonized more recently [3,28]. Also, the Andes facilitated an explosion of species that is best explained by greater time (ancient cradle or montane museum hypothesis; or time-for-speciation effect more generally) rather than faster diversification at mid-elevations (montane species pump), despite the recently of the major Andean uplift [3,28,342]. At a broad scale, speciation within the Andes is produced, mainly, by a combination of landscape heterogeneity (e.g., with both longitudinal and transversal barriers) and climatic-niche conservatism in species [28]. There are several examples of niche conservatism at the generic level; most species of Centrolene, Nymphargus, Celsiella, and Ikakogi are restricted to mountains, whereas others such as Hyalinobatrachium, Vitreorana, and Cochranella are more prevalent in lowlands. 
Elevational distribution of glassfrogs in the Pacific lowlands and Andean slopes of Ecuador

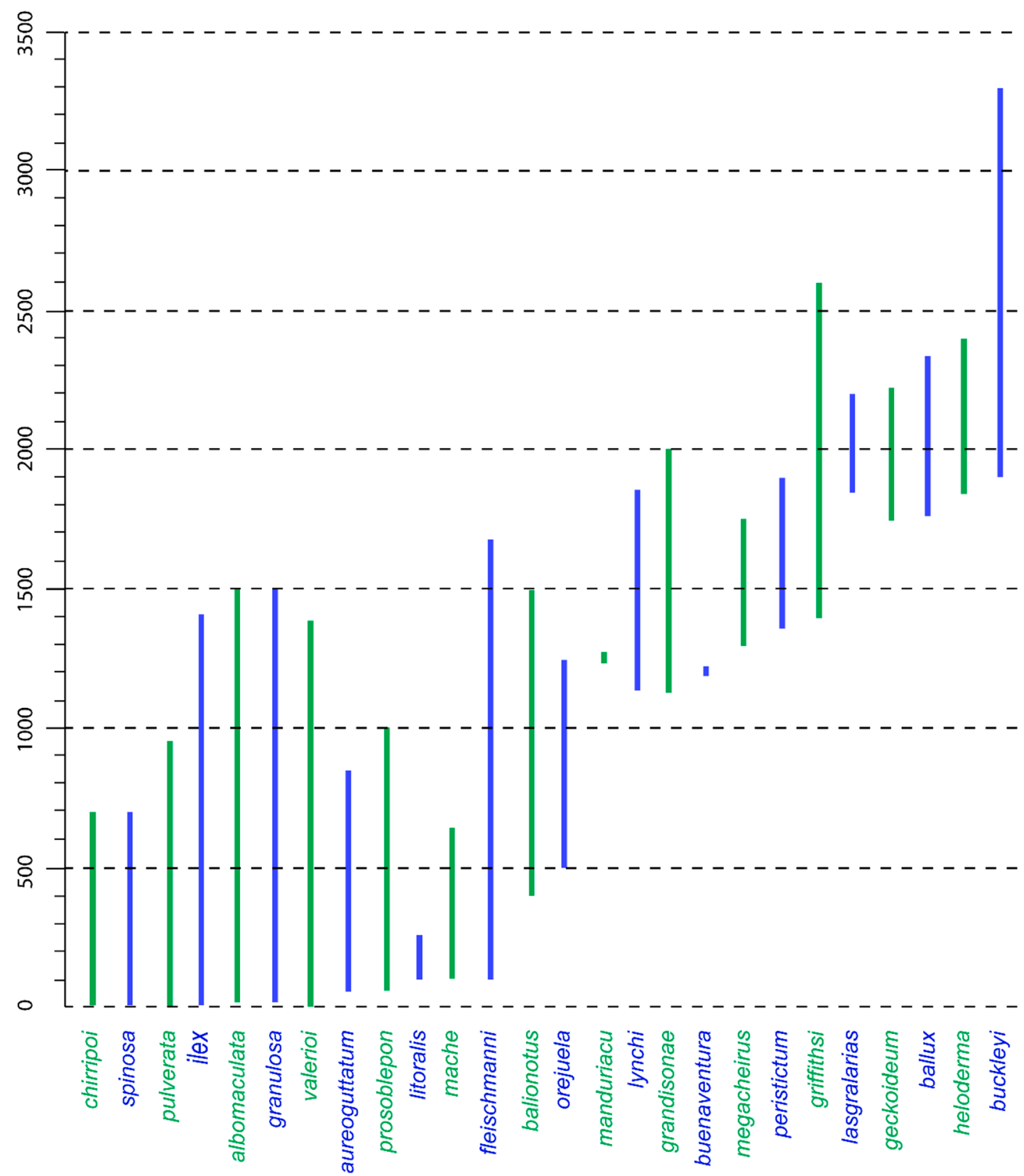

Figure 228. Elevational distribution of glassfrogs found on the Pacific lowlands and western slopes of the Ecuadorian Andes. 


\section{Elevational distribution of glassfrogs in the Amazonian lowlands and slopes of Ecuador}

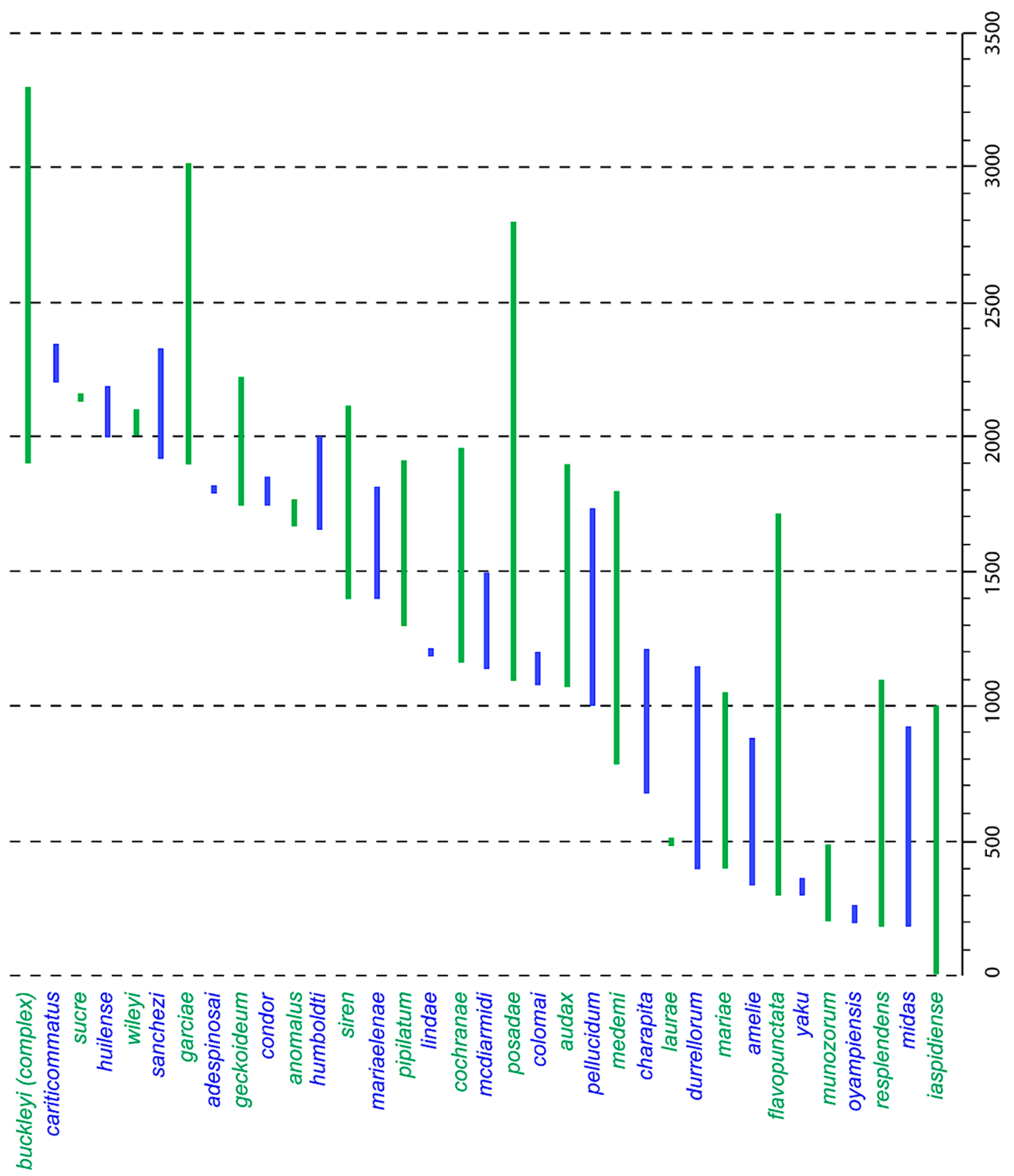

Figure 229. Elevational distribution of glassfrogs on the Amazonian lowlands and Amazonian slopes of the Ecuadorian Andes.

Glassfrogs have shown to be successful, in terms of species numbers, mostly in tropical montane areas (Figures 230 and 231). There is a clear reduction of species richness as latitude increases, with low temperature and low precipitation being the most likely limiting factors. These two variables also explain the absence (or near absence) of glassfrogs in dry or highly seasonal areas (Cerrado, Llanos, Chaco) and high-elevation regions within the tropics (e.g., Páramo; Figures 230-232).

In Ecuador, glassfrogs also reach their diversity peak in cloud and montane forests (Figure 232). They have a moderate species richness in the Choco and Amazonian Rainforest and are completely absent from xeric and dry areas of southwestern Ecuador, although they can be found in semideciduous 
forests (Figure 232). Below, we describe the patterns and diversification mechanisms that are prevalent in Centrolenidae.

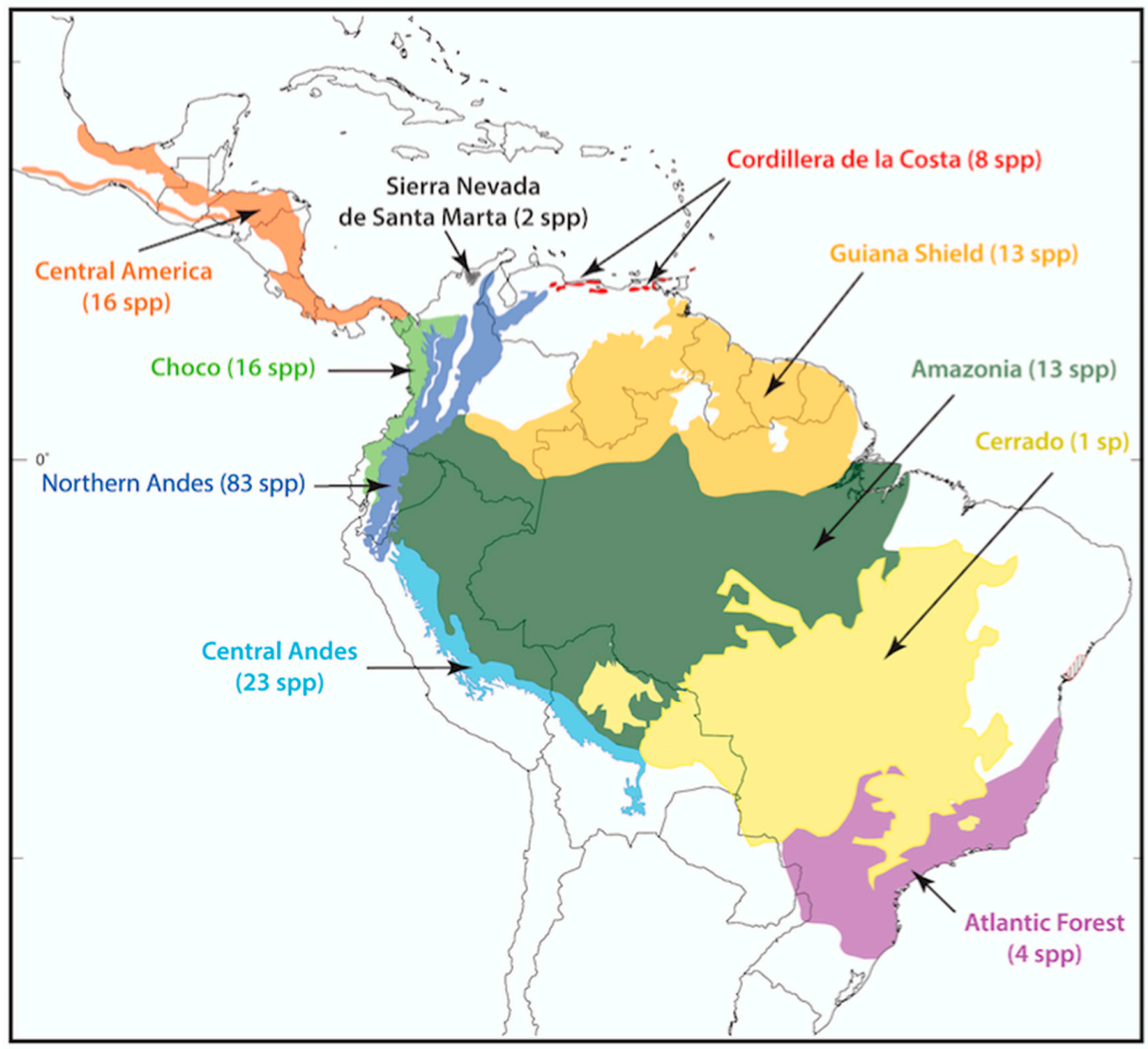

Figure 230. Biogeographical regions in the Neotropics (sensu Duellman [343]). Each region is followed by its number of glassfrog species. Note that one particular species can occur in more than one biogeographic area. Modified from Castroviejo-Fisher et al. [3].

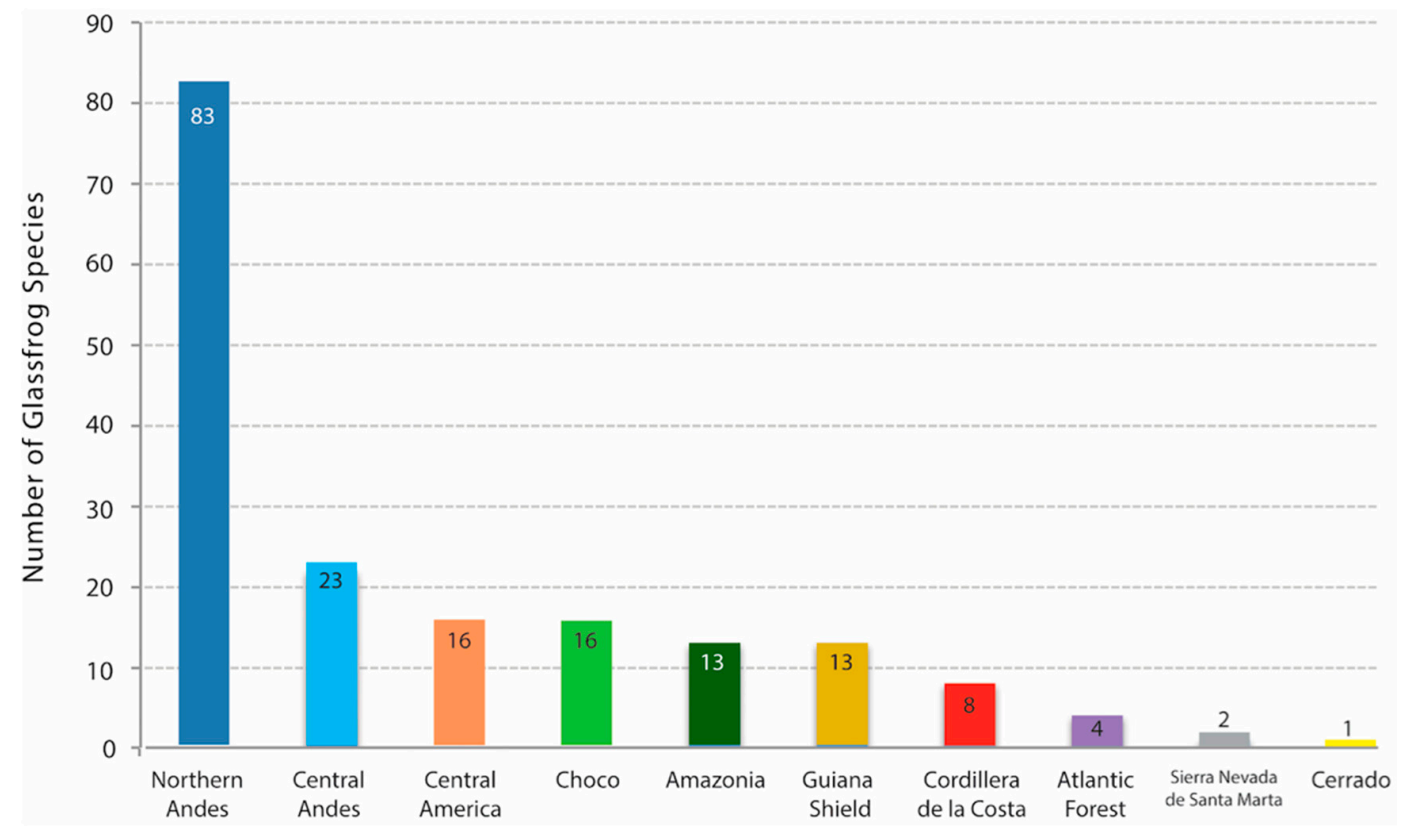

Figure 231. Species richness of glassfrogs per biogeographic region in the Neotropics. 


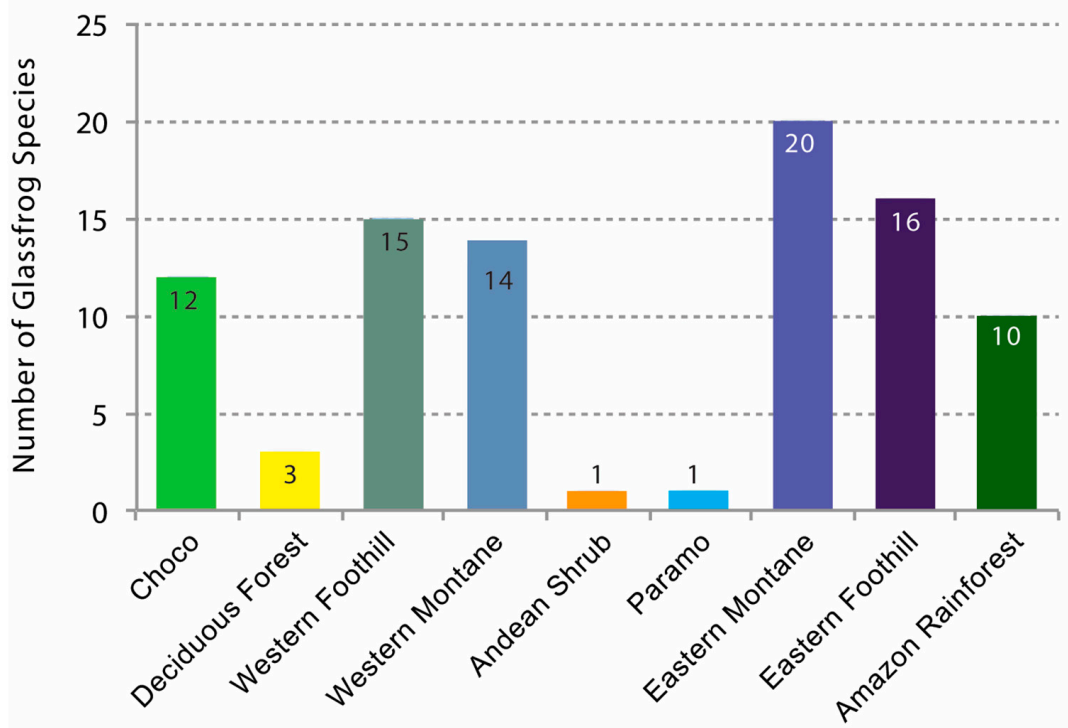

Figure 232. Species richness of glassfrogs per biogeographic region in Ecuador.

\subsection{Speciation}

Speciation reflects the interactions among several biotic, abiotic, and historical events that have operated over various temporal and spatial scales. Most models that attempt to explain population divergence assume a role of geography (e.g., allopatry, parapatry) combined with niche conservatism or divergence to generate species [344-346]. For example, the linearity of the Andes results in elongate geographical ranges and reduces potential contact and gene flow among parapatric populations [347,348] (Figure 233). Pleistocene glaciations have produced recurrent fragmentation, isolation, and reconnection of montane forests and their faunas [349-353], but see Bush and Oliveira [354]. Species that today occupy the lowlands of the Chocó and Amazon ecoregions may had been separated by the uplift of the Andes, creating the opportunity for large-scale, co-occurring allopatric speciation.

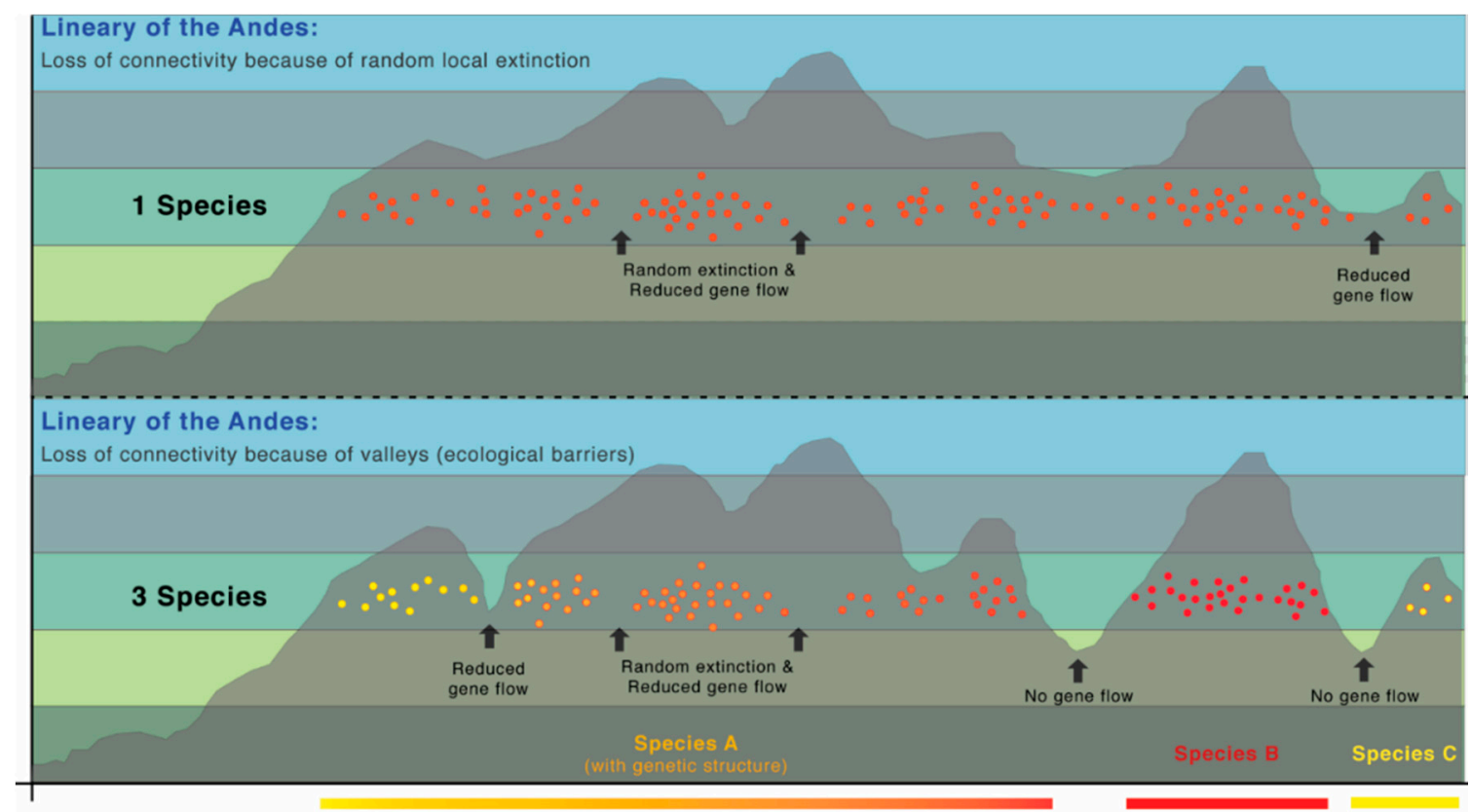

Figure 233. Speciation modes. Effect of the linearity of the Andes in diversification processes. Modified from Guayasamin et al. [194]. 
Speciation may or may not be coupled with an ecological shift (Figure 234). The tendency of populations to retain their ancestral ecological niche and failing to adapt to the new environmental conditions facilitates lineage divergence when ecological barriers are present [344-356]. Recent studies demonstrate that closely related centrolenid species have, in most cases, similar abiotic ecological niches and that elevational shifts are rare in the family $[3,28]$ (Figure 233). Then, lineage divergence in glassfrogs seems to be driven mostly by allopatric speciation coupled with niche conservatism [28]. There are, however, clear exceptions where clades are adapted to very different climates, meaning that niche divergence has occurred at least a few times (e.g., Hyalinobatrachium is mostly a lowland clade, whereas Centrolene and Nymphargus are montane clades). The relevance of niche conservatism in glassfrog diversification is at odds with studies that predicted and showed that, in amphibians, the primary causes of speciation were adaptation to climates (elevated regions vs. lowland regions) coupled with fragmentation of the once contiguous lowlands; in other words, allopatric speciation with ecological evolution $[357,358]$ (Figure 234).

\section{(i) Ecological Speciation (Species A, B)}
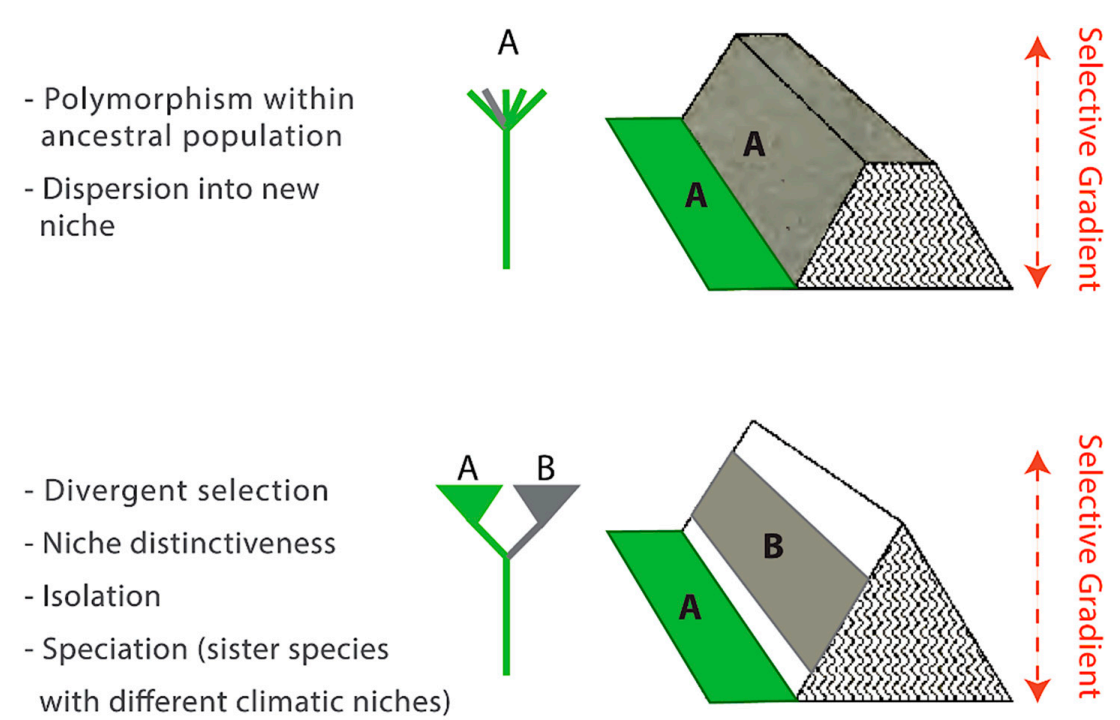

(ii) Non-ecological Speciation (Species B, C)

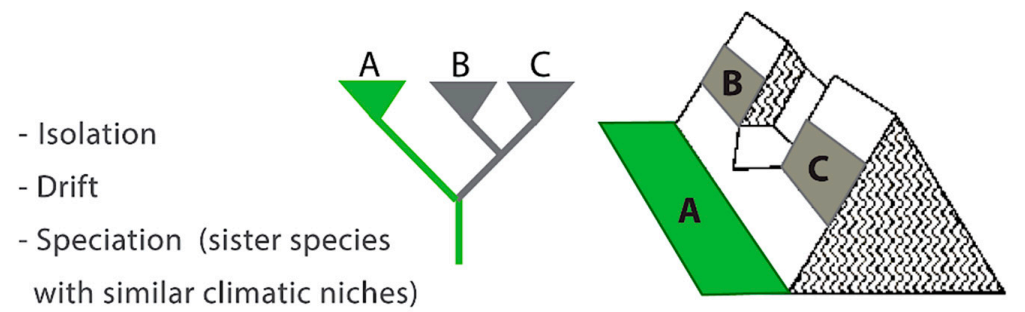

Figure 234. Speciation modes. (i) Ecological speciation in elevational gradients. (ii) Non-ecological speciation in the same elevational band.

Giving that our phylogeny includes the most complete taxon sampling so far, we are presented with the opportunity to search for specific lineages that match the different scenarios that explain tropical diversity. We acknowledge that many more species of glassfrogs remain to be discovered, changing the topology that is the backbone of our interpretations; however, we expect that these variations will be relatively minor and that the general patterns of speciation will hold. Also, we work under the assumption that geography is a primary player in the process of speciation and that closely related species are likely to be geographically nearby; this assumption is supported by the relatively 
low vagility that amphibians have in relation to other vertebrates [259,359-362], and that speciation is likely to produce sister species that are found nearby (allopatry), adjacent (parapatry), or in the same place (sympatry) [345,363]. Thus, below, we summarize the speciation hypotheses that are relevant for the Ecuadorian Andes and lowlands and include the examples that fit these scenarios.

- Allopatric speciation of lowland species mediated by the uplift of the Andes. Within glassfrogs, there are some examples where sister species inhabit the Chocoan and Amazonian lowlands: (i) Teratohyla amelie + T. pulverata, (ii) T. spinosa $+($ T. midas + T. adenocheira), (iii) Cochranella granulosa and C. resplendens, (iv) Hyalinobatrachium muiraquitan $+(H$. fleischmanni $+H$. tatayoi). The most parsimonious speciation mechanism that explains this pattern is allopatric (vicariant) speciation coupled with niche conservatism (i.e., non-ecological speciation), the vicariant event being the uplift of the Andes.

- Allopatric speciation facilitated by the linearity of mountain ranges (Figures 233 and 234). This is the most prevalent speciation mode in centrolenids. In this case, allopatric (vicariant) speciation is coupled with niche conservatism (i.e., non-ecological speciation), but the geographic barriers are, usually, river valleys or depressions. The linearity and complexity of the Andes is, likely, one of the major allopatric speciation forces behind the diversity of Nymphargus and Centrolene, genera that present conspicuous niche conservatism [28] (Figure 235). The linearity of the Andes results in species with elongated geographical ranges that reduces opportunities for contact and gene flow among parapatric populations [347,348,364]. Also, contact between populations is further restricted by the presence of deep river canyons that transect the Andes and thereby facilitate allopatric speciation [347]. On the Amazonian slope of the Ecuadorian Andes, such river canyons include, potentially, the following: Quijos, Pastaza, Paute, Zamora, and Nangaritza (Figure 236). On the Pacific slopes of the Andes, rivers that potentially disrupt gene flow are Mira, Guayllabamba, Chanchán, and Jubones [365-370] (Figure 236). Most sister species within the Andean Centrolene and Nymphargus fit into this speciation pattern. Similarly, sister glassfrog species in Celsiella (C. revocata + C. vozmedianoi) and Vitreorana (V.antisthenesi $+V$. castroviejoi), distributed in the elongated Cordillera de la Costa in Venezuela, are another example of speciation facilitated by the linearity of a mountain chain and, in this particular case, the effect of the Unare Depression.

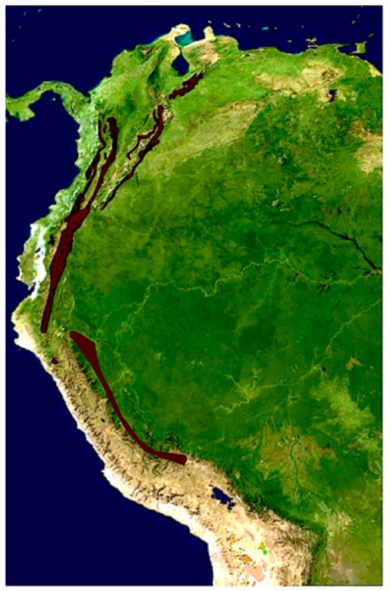

Centrolene

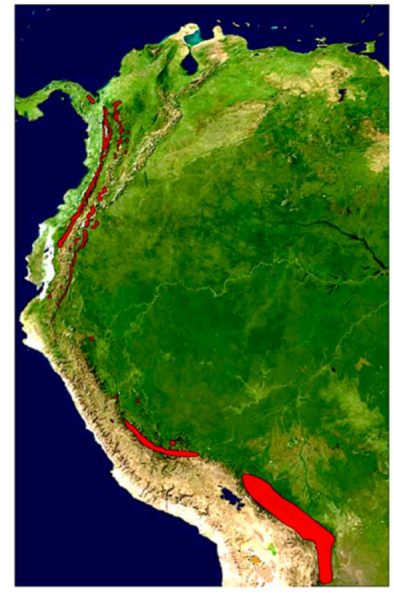

Nymphargus

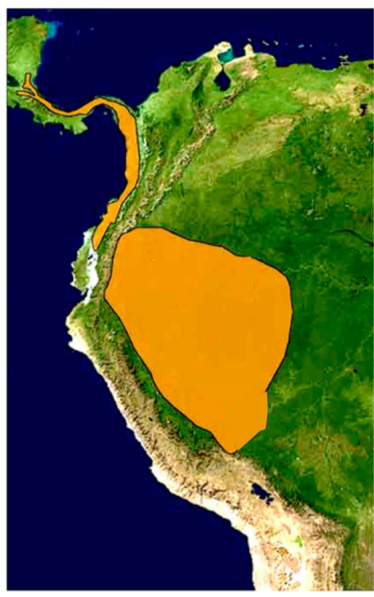

Hyalinobatrachium

Figure 235. Niche conservatism in glassfrogs at the generic level (modified from Guayasamin et al. [1]). Note that distribution of genera is restricted to particular biogeographic regions, suggesting that closely related species have similar climatic requirements. Number of species per genera are as follows: Centrolene $=24$, Nymphargus $=41$, Hyalinobatrachium $=32$. 


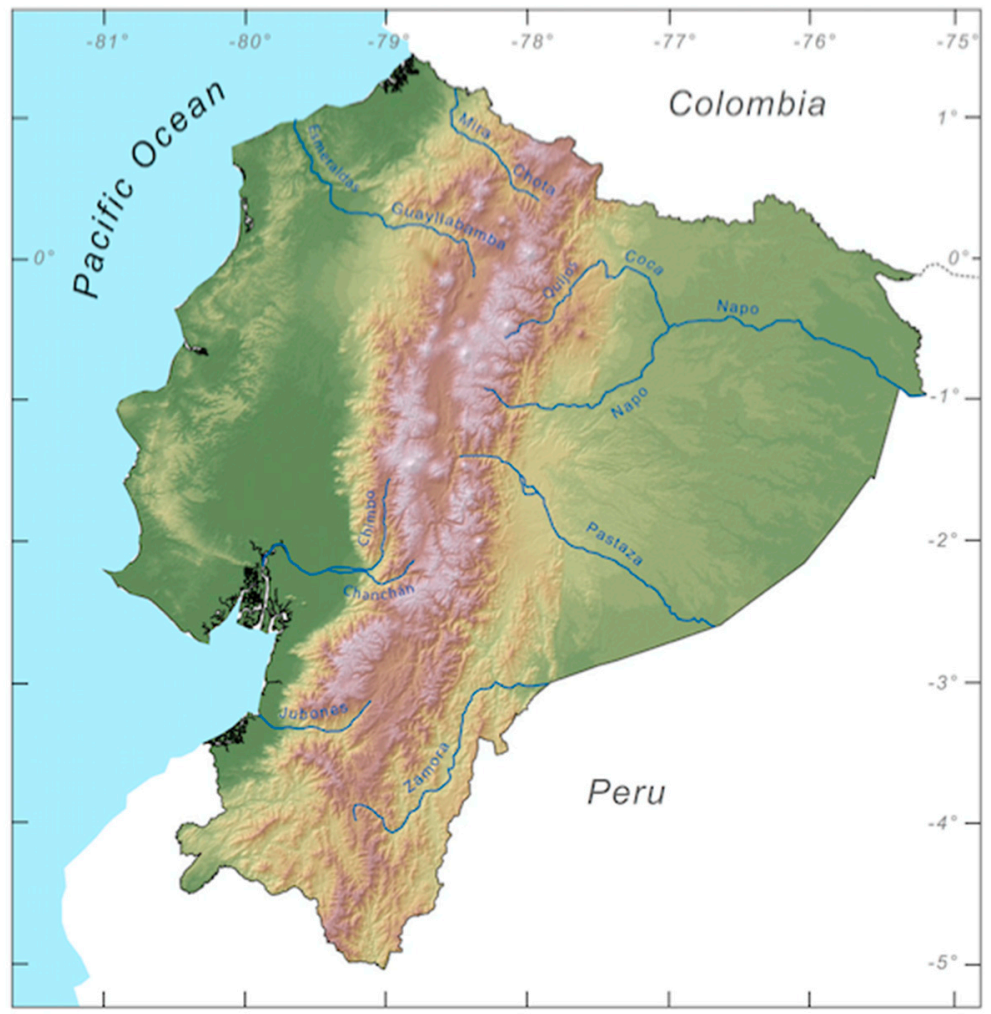

Figure 236. Potential river valleys that promote speciation in Ecuador.

- Speciation along elevational gradients (Figure 234). Speciation involving adaptation to new climates (i.e., ecological speciation) has been hypothesized as a major generator of diversity in amphibians [357] (Figure 234). Ancestral reconstructions suggest that glassfrogs originated at mid-elevations or climatically similar habitats, and that the lowlands and higher elevation habitats were colonized more recently [28]. Within Andean clades, few species have shifted towards the lowlands (e.g., Nymphargus mariae, Centrolene durrellorum), and only two species, Centrolene buckleyi and C. venezuelensis, reach elevations above $3000 \mathrm{~m}$. Similarly, within mainly lowland clades, few taxa have been able to speciate in the Andes (e.g., Hyalinobatrachium pellucidum). Thus, the data at hand strongly suggest that niche shifts in centrolenids are rare [28] and that clades tend to radiate within the same climatic regimes (e.g., Centrolene and Nymphargus in the highlands; Teratohyla and Hyalinobatrachium in the lowlands).

- Sympatric speciation. Examples of sympatric speciation are rare and, in most cases, difficult to test [345]. Within Centrolenidae, there are very few cases of sister species that are found in sympatry; some such examples include: (i) Nymphargus griffithsi + N. lasgralarias, and (ii) N. cariticommatus + N. sucre. The possibility of sympatric speciation in glassfrogs remains to be tested and contrasted with other plausible scenarios (i.e., that species originated in allopatry, and that the current sympatry is a consequence of subsequent range expansions and secondary contact).

\subsection{Pending Taxonomic Problems and Candidate Species}

We have identified a total of 24 candidate species (Table S6), as well as numerous pending taxonomic problems, which we describe below:

- Centrolene buckleyi: Different sources of evidence (i.e., genetic, acoustic) suggest that $C$. buckleyi, as currently defined, is a species complex [2,20,98]. We find three lineages (Centrolene sp. Ca02, C. sp. Ca04, and C. sp. Ca05) that are morphologically similar to C. buckleyi. None of these candidate species are sister to populations from the neotype locality of $C$. buckleyi. The extensive distribution of C. buckleyi in the high Andes of Colombia and Ecuador provide multiple opportunities for 
isolation and speciation. A taxonomic evaluation of this species complex is greatly needed, especially in the face of population declines that seem to have affected this species [91,103].

- Centrolene peristicta: Giving the striking morphological similarity and phylogenetic proximity between $C$. peristicta and C. antioquiensis, it is possible that they represent a single evolutionary lineage. Call analysis is critical to assess this possibility.

- Espadarana prosoblepon: Within Centrolenidae, this species has the broadest latitudinal range. Also, it has considerable variation in terms of color pattern and body size. Historically, several species (Hylella puncticrus, Hylella parabambae, Hyla ocellifera) have been recognized in what is now accepted as a single species, E. prosoblepon. The most similar species in Ecuador, E. callistomma, is not reciprocally monophyletic with specimens identified as E. prosoblepon. This might be the result of incorrect identification, hybridization, or introgression. However, as mentioned above, calls of E. prosoblepon and E. callistomma are different. Espadarana prosoblepon may also represent a species complex that requires subdivision.

- Hyalinobatrachium munozorum: We identify one candidate species related to H. munozorum in Ecuador (H. sp. Ca02). Species in the genus Hyalinobatrachium share several morphological traits, sometimes making species recognition difficult. Accordingly, more life history information including data on calls, patterns of parental care, and tadpole morphology, together with denser sampling for genetic data are critical for species identifications and to uncover any cryptic diversity [231,232].

- Nymphargus garciae, N. nephelophilus, and N. oreonympha: Given the morphological similarity among these three species, we recommend their revision and consideration of the possibility that they represent a single species. Currently, molecular data are available only for N. garciae.

- Nymphargus griffithsi: Cryptic species are likely hidden in N. griffithsi as we identify three candidate species with strong morphological similarity (N. sp. Ca01, N. sp. Ca02, N. sp. Ca03). We recommend an evaluation of $N$. griffithsi across its entire range, including populations of N. buenaventura.

- Nymphargus laurae: Nymphargus laurae is morphologically similar to N. lindae sp. nov. and $N$. cochranae. Differences among these taxa are difficult to assess because N. laurae was described based on a single specimen; additionally, some of the diagnostic traits could be the result of prolonged preservation (e.g., reduction of body size) [371]. The taxonomic resolution of this problem requires collecting more specimens from the type locality of $N$. laurae (slopes of Volcán Sumaco).

- Rulyrana flavopunctata and R. mcdiarmidi: Genetic data show that these two species are not reciprocally monophyletic. This is a pattern expected in early diverging species but could also indicate that the two species actually represent a single evolutionary species with geographic variation. Analyses of calls and other life history data are needed to validate or reject the validity of R. mcdiarmidi.

- Sachatamia albomaculata: As currently defined, this species has two clearly differentiated dorsal color patterns: (i) Dorsum with small yellow spots and (ii) dorsum with small and large yellow spots. This variation could correspond to two taxa or represent natural intraspecific polymorphism. Additionally, S. punctulata has a color pattern identical to pattern (i) of S. albomaculata. Clearly, more detailed work is needed.

- Teratohyla midas: We identify a candidate species in T. midas (T. sp. Ca03), which has substantial genetic differentiation from T. midas from near the type locality. However, the species may have substantial genetic differentiation or population structure. In terms of morphology and DNA data, T. midas is very similar to T. adenocheira. Both species have a small body size, similar color pattern, and inhabit the Amazonian lowlands $(<1000 \mathrm{~m})$. The most conspicuous difference between these species is the density of dorsal yellow spots; T. adenocheira has numerous dots, whereas T. midas has very few that are restricted to the upper flanks [372]. We recommend a reassessment of the geographic variation of T. midas and the validity of T. adenocheira. 


\subsection{Evolution of Translucency, Parental Care, and Humeral Spines}

Translucency: The widespread occurrence of translucency in glassfrogs is puzzling. A recent study (Barnett et al. 2020) [373] found that perceived luminance of glassfrogs changes depending on the immediate background, a change that is more pronounced on the legs, suggesting that camouflage is through edge diffusion. The strategy of disrupting the typical frog body outline might be even more efficient in species that exhibit complete ventral translucency and where internal organs are covered by reflective iridophores (Figures $13 \mathrm{~A}$ and 102). It has also been shown that the dorsal green coloration in glassfrogs has similar reflective properties as photosynthetic leaves [374], also supporting the relevance of camouflage as an antipredatory mechanism. The venters of all glassfrogs are partially or completely transparent; therefore, it is reasonable to assume that this feature appeared in the ancestor of the clade. Also, complete ventral transparency has evolved multiple independent times within Centrolenidae (e.g., Hyalinobatrachium, Chimerella, Vitreorana).

Parental care: Until very recently, parental care in glassfrogs was considered to be rare and, when present, provided exclusively by males [4,17]. However, Delia et al. [25], based on detailed observations of 40 species, demonstrated that parental care is widespread in Centrolenidae (Table 8). In species thought to lack parental care, Delia et al. [25] observed that, just after oviposition and fertilization, females exhibit a short brooding behavior; this behavior significantly reduces embryonic mortality (experimentally tested in Cochranella granulosa and Teratohyla pulverata). Even though we still lack information on parental care for most glassfrogs species, the results by Delia et al. [25] have produced a major shift in what we thought we knew about parental behavior in this frog family. Ancestral reconstructions suggest that the most recent common ancestor of glassfrogs exhibited a short, female-only parental care, from which some species (mostly Hyalinobatrachium and some Centrolene) have evolved prolonged, male-only parental care [25]. Additionally, the repeated evolution of complex male care is always associated with reductions in egg jelly and changes in oviposition sites [375]. Female mate choice and the evolution of parental care is an area of glassfrog biology that still needs further research.

Table 8. Parental care in glassfrogs. Short-term maternal care = immediately after oviposition, female provides brooding to egg clutch for several hours; after this initial brooding, clutches remain unattended. Prolonged male care $=$ male provides parental care to egg clutch for several days. Prolonged maternal care $=$ female provides parental care to egg clutch for several days. Each type of parental care is coded as Absent (0), Present (1), or Unknown (?). Terminology and data are summarized from Delia et al. [25].

\begin{tabular}{ccccc}
\hline Species & $\begin{array}{c}\text { Short-Term } \\
\text { Maternal Care }\end{array}$ & $\begin{array}{c}\text { Prolonged } \\
\text { Male Care }\end{array}$ & $\begin{array}{c}\text { Prolonged } \\
\text { Maternal Care }\end{array}$ & Source \\
\hline Centrolene antioquiensis & $?$ & 1 & 0 & Delia et al. [25] \\
\hline Centrolene ballux & $?$ & 0 & 0 & Delia et al. [25] \\
\hline Centrolene buckleyi & 1 & 0 & 0 & Delia et al. [25] \\
\hline Centrolene daidalea & 0 & 1 & 0 & Cardozo-Urdaneta \& Señaris \\
[376], Delia et al. [25]
\end{tabular}


Table 8. Cont.

\begin{tabular}{|c|c|c|c|c|}
\hline Species & $\begin{array}{l}\text { Short-Term } \\
\text { Maternal Care }\end{array}$ & $\begin{array}{l}\text { Prolonged } \\
\text { Male Care }\end{array}$ & $\begin{array}{c}\text { Prolonged } \\
\text { Maternal Care }\end{array}$ & Source \\
\hline \multicolumn{5}{|c|}{ Subfamily: Centroleninae } \\
\hline Centrolene sanchezi & $?$ & 0 & 0 & Delia et al. [25] \\
\hline Centrolene savagei & 0 & 1 & 0 & $\begin{array}{l}\text { Vargas-Salinas et al. [378], } \\
\text { Delia et al. [25] }\end{array}$ \\
\hline Chimerella corleone & $?$ & 0 & 0 & Delia et al. [25] \\
\hline Chimerella mariaelenae & 1 & 0 & 0 & Delia et al. [25] \\
\hline Cochranella erminea & $?$ & 0 & 0 & Delia et al. [25] \\
\hline Cochranella euknemos & 1 & 0 & 0 & Delia et al. [25] \\
\hline Cochranella granulosa & 1 & 0 & 0 & Delia et al. [25] \\
\hline Cochranella guayasamini & $?$ & 0 & 0 & Delia et al. [25] \\
\hline Cochranella resplendens & 1 & 0 & 0 & Delia et al. [25] \\
\hline Espadarana andina & $?$ & 0 & 0 & Cabanzo-Olarte et al. [379] \\
\hline Espadarana audax & 1 & 0 & 0 & Delia et al. [25] \\
\hline Espadarana prosoblepon & 1 & 0 & 0 & Jacobson [188], Delia et al. [25] \\
\hline Nymphargus grandisonae & 1 & 0 & 0 & Delia et al. [25] \\
\hline Nymphargus griffithsi & 1 & 0 & 0 & Delia et al. [25] \\
\hline Nymphargus lasgralarias & 1 & 0 & 0 & Delia et al. [25] \\
\hline Nymphargus ignotus & $?$ & 0 & 0 & Restrepo \& Naranjo [380] \\
\hline Nymphargus wileyi & $?$ & 0 & 0 & Delia et al. [25] \\
\hline Sachatamia albomaculata & 1 & 0 & 0 & Delia et al. [25] \\
\hline Sachatamia punctulata & $?$ & 0 & 0 & Delia et al. [25] \\
\hline Teratohyla midas & 1 & 0 & 0 & $\begin{array}{l}\text { Diaz-Ricaurte et al. [295], } \\
\text { Delia et al. [25] }\end{array}$ \\
\hline Teratohyla pulverata & 1 & 0 & 0 & Delia et al. [25] \\
\hline Teratohyla spinosa & 1 & 0 & 0 & Delia et al. [25] \\
\hline Vitreorana aff. eurygnatha & $?$ & 0 & 0 & Gouveia et al. [381] \\
\hline Vitreorana ritae & 1 & 0 & 0 & Delia et al. [25] \\
\hline \multicolumn{5}{|c|}{ Subfamily: Hyalinobatrachinae } \\
\hline Celsiella vozmedianoi & $?$ & 1 & 0 & Señaris \& Ayarzagüena [106] \\
\hline $\begin{array}{l}\text { Hyalinobatrachium } \\
\text { aureoguttatum }\end{array}$ & 0 & 1 & 0 & $\begin{array}{l}\text { Valencia-Aguilar et al. [196], } \\
\text { Delia et al. [25] }\end{array}$ \\
\hline Hyalinobatrachium chirripoi & 0 & 1 & 0 & Delia et al. [25] \\
\hline $\begin{array}{l}\text { Hyalinobatrachium } \\
\text { colymbiphyllum }\end{array}$ & 0 & 1 & 0 & McDiarmid [4], Delia et al. [25] \\
\hline $\begin{array}{l}\text { Hyalinobatrachium } \\
\text { fleischmanni }\end{array}$ & 0 & 1 & 0 & $\begin{array}{c}\text { Greer \& Wells [213], Jacobson } \\
\text { [195], Hayes [189], } \\
\text { Delia et al. [25] }\end{array}$ \\
\hline Hyalinobatrachium mondolfii & $?$ & 1 & 0 & Delia et al. [25] \\
\hline Hyalinobatrachium orientale & 0 & 1 & 0 & Lehtinen et al. [382] \\
\hline Hyalinobatrachium pallidum & $?$ & 1 & 0 & $\begin{array}{l}\text { Cardozo-Urdaneta \& } \\
\text { Señaris [376] }\end{array}$ \\
\hline $\begin{array}{l}\text { Hyalinobatrachium } \\
\text { pellucidum }\end{array}$ & 0 & 1 & 0 & Delia et al. [25] \\
\hline $\begin{array}{l}\text { Hyalinobatrachium } \\
\text { talamancae }\end{array}$ & 0 & 1 & 0 & Delia et al. [25] \\
\hline
\end{tabular}


Table 8. Cont.

\begin{tabular}{ccccc}
\hline Species & $\begin{array}{c}\text { Short-Term } \\
\text { Maternal Care }\end{array}$ & $\begin{array}{c}\text { Prolonged } \\
\text { Male Care }\end{array}$ & $\begin{array}{c}\text { Prolonged } \\
\text { Maternal Care }\end{array}$ & Source \\
\hline $\begin{array}{c}\text { Subfamily: Centroleninae } \\
\text { Hyalinobatrachium valerioi }\end{array}$ & 0 & 1 & 0 & $\begin{array}{c}\text { McDiarmid [4] Vockenhuber } \\
\text { et al. [239,383], Delia et al. [25] }\end{array}$ \\
\hline $\begin{array}{c}\text { Hyalinobatrachium } \\
\text { vireovittatum }\end{array}$ & $?$ & 1 & 0 & Hayes [189] \\
\hline Ikakogi tayrona & 0 & 0 & 1 & $\begin{array}{c}\text { Bravo-Valencia \& Delia [47], } \\
\text { Delia et al. [25] }\end{array}$ \\
\hline
\end{tabular}

Humeral spines: Male glassfrogs are highly territorial and they have evolved very unique behaviors and structures that are specifically associated to male-to-male combats (Table 9). The most conspicuous morphological trait that males use during fights are humeral spines [52,103], which are bony processes that project from each humeral bone (Figure 14), and that are present only in males of several glassfrog species (see Guayasamin et al. [1]). Although humeral spines are a rarity among amphibians, they have evolved multiple independent times in Centrolenidae [2], suggesting that they provide a selective advantage. Armaments (i.e., humeral spines) in glassfrogs probably only allow males to obtain or defend a territory [52,103], and most likely have no direct role in attracting females, which presumably choose a mate based on the quality of his territory, and acoustic and behavioral displays.

Table 9. Centrolenid species in which combat behavior has been documented, coded by the type of combat behaviors: Primitive: Combat in axillary amplexus-like position or wrestling on the leaves; derived: Combat dangling by hind limbs; both: Primitive and derived. Modified from Rojas-Runjaic and Cabello [384].

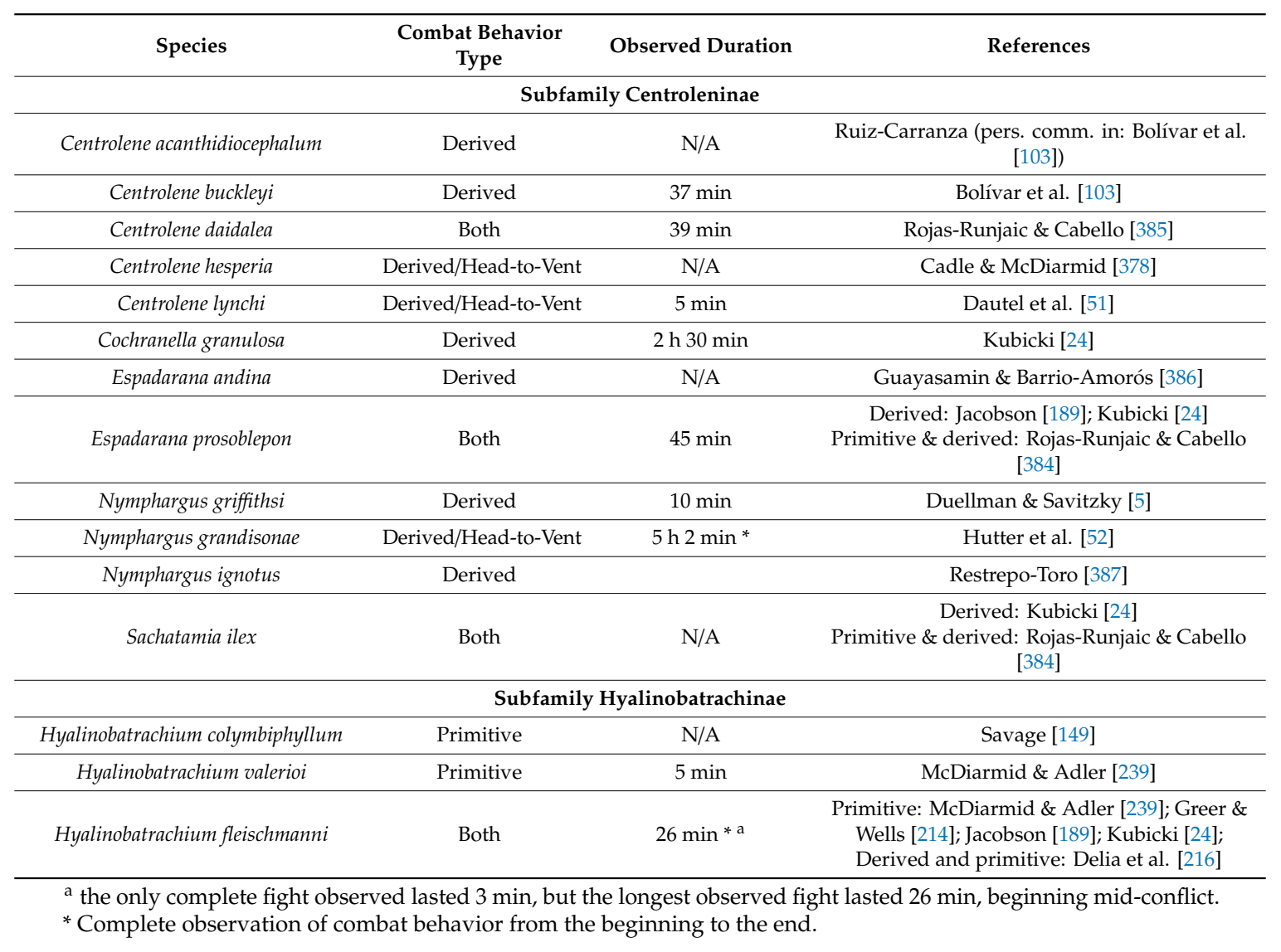




\section{Conservation}

Evaluating the conservation status and conservation needs of amphibian species is extremely challenging. Traditional threats (e.g., habitat destruction, water contamination, pesticides) and the emergence of novel factors (e.g., climate change, introduced species, and emerging diseases) need to be combined when developing conservation strategies $[23,76,124,270]$. With all these considerations in mind, we present our evaluation of the conservation of each Ecuadorian glassfrog in Table S7. The most endangered species are: Centrolene buckleyi, C. charapita, C. geckoidea, C. medemi, C. pipilata, Cochranella mache, Nymphargus balionotus, N. manduriacu, N. megacheirus, and N. sucre (Table S7) and, therefore, are most likely to go extinct because of any of the aforementioned variables. Additionally, numerous species are Data Deficient (Table S7) and urgently require additional research.

The most conspicuous and immediate threat to glassfrog conservation is habitat destruction, which is rampant in the Chocó ecoregion (Esmeraldas Province) and also on the northwestern slopes of the Andes (Figure 18). The Chocó suffers the highest deforestation rate in Ecuador, thus, affecting all the species that occur there. Five Chocoan glassfrogs (H. fleischmanni, C. geckoidea, T. pulverata, T. spinosa, Cochranella mache) have more than half of their potential distribution affected by human activities (Table S4).

Habitat preservation is the most effective mechanism to protect diversity. However, we first need to identify the areas that should be prioritized for such actions. As a first approach, it is clear that both at the South American and Ecuadorian scales, mountain ranges harbor the highest density of species and, also, species that tend to have small distributions. Also, as shown in Figure 230, the Northern Andes are, by far, the most important biogeographic regions in terms of glassfrog species richness. Then, any effort directed towards the conservation of Andean forests will greatly benefit glassfrogs.

In Ecuador, more specifically, when the potential distributions of all glassfrog species are combined, we are able to identify areas with both high diversity and low human disturbance that are not included in the current system of protected areas of Ecuador (Figure 237). Based on this information, specifically, we recommend: (i) The implementation of a biological corridor between the National Parks of Cayambe-Coca and Sumaco, (ii) creation of a new protected area in the lower montane evergreen forest of the western Andes in Pichincha Province, and (iii) protection of the endemic Chocoan forest (threatened mainly by wood extraction and palm plantations). The aforementioned conservation actions agree with the recommendations produced by broader studies [76,388], in terms of the areas that need to be protected in Ecuador given the current threats and biodiversity patterns (Figures 238 and 239).

Other conservation actions should be directed towards species that are known from few localities that lie within areas that are (or will be) affected by human activities; this is the case, for example, for Centrolene condor, species endemic to the Cordillera del Cóndor, where hundreds of hectares have been conceded for mining activities [389]. A similar situation applies to N. manduriacu, known from a single locality (Reserva Río Manduriacu) that is concessioned for mining [21].

One of the novel threats to amphibian diversity worldwide is the disease caused by the fungus Batrachochytrium dendrobatidis (Bd), known as chytridiomycosis [23,390,391]. Chytridiomycosis has been implicated in the extinction of numerous Andean species, mainly harlequin toads (Atelopus) [31,33,392]. In Ecuador, ecological modeling predicts that the highest suitability for chytridiomycosis is in the Andes, at elevations above $2000 \mathrm{~m}$ [393]. The impact of the disease on Ecuadorian glassfrogs has not been assessed, but preliminary studies show that $B d$ has a relatively high prevalence in several species of Andean glassfrogs [92]. Because of the absence of long-term monitoring of amphibian populations in Ecuador, there is no certainty of the effect of $B d$ on most amphibians, but in places where $B d$ is present, it is possible that all vulnerable species are already extinct. Glassfrogs that persist in spite of infections are probably resistant to the disease or are exposed to a less-pathogenic strains of the fungus [93]. The disappearance of species such as Nymphargus balionotus and Centrolene geckoidea from relatively pristine areas may be related to chytridiomycosis. 


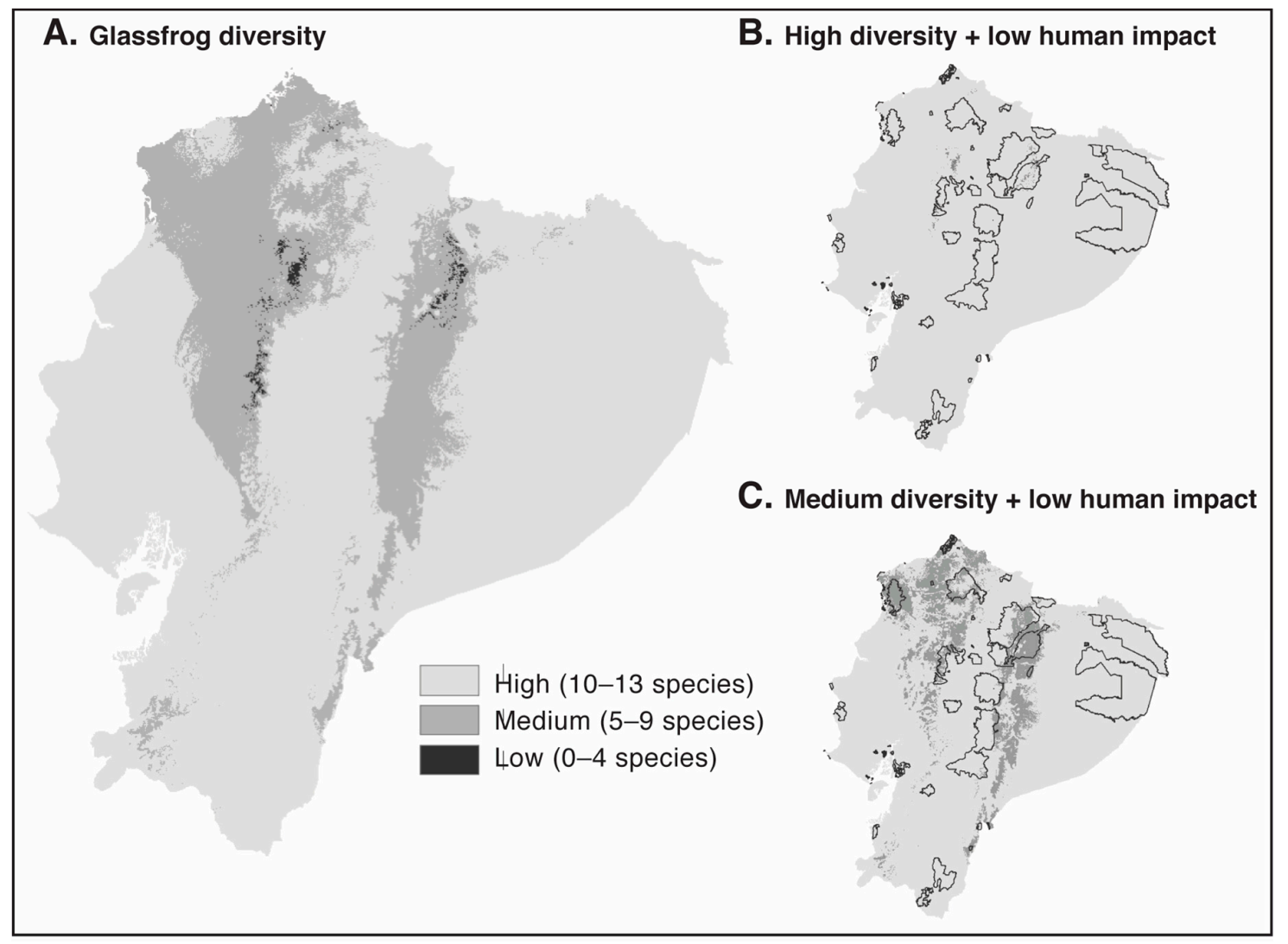

Figure 237. Glassfrog species diversity in Ecuador. (A) Species diversity simplified into three categories: High, medium, and low. (B) Map showing protected areas in Ecuador and, in dark, regions that combine high glassfrog diversity and low impact by human activities. (C) Map showing protected areas in Ecuador and, in dark, regions with both medium diversity and low impact by human activities.

Another specific conservation threat to Andean species that depend on rivers and streams is the introduced rainbow trout, Oncorhynchus mykiss [124,394]. Laboratory experiments on the interaction of this exotic fish and tadpoles of the red-spotted glassfrog (Nymphargus grandisonae) show that trout prey on tadpoles and that its presence results in an increased mortality and phenotypic change [124]. Most likely, similar effects are produced on other amphibian species with aquatic larvae. Given that the rainbow trout has been introduced into most Ecuadorian Andean rivers and lakes, the only option to reduce its impact is to start eradication programs, at least in protected areas and wherever the trout might be threatening endangered amphibians [124]. Other studies suggest that climate change, chytridiomycosis, and their synergetic effects, likely represent the major threats that amphibians face in Ecuador [393] and worldwide [395].

Finally, climate change represents one of the most challenging conservations phenomenon for biodiversity, given its global scale and potentially large effect even on species that are found in relatively pristine areas. It has been shown that the same variables that explain the high levels of tropical diversity (e.g., narrow thermal tolerance and low dispersal) also make tropical species more vulnerable to rapid thermal change [396]. The thermal breath of tropical amphibians is poorly known, but it can be correlated with their elevational distribution; glassfrogs show, in general, a narrow elevational range $($ mean $=653 \mathrm{~m} \pm 526 ; n=150$ species; Table S1), meaning that their optimal thermal niches are only available at very restricted elevations. The survival of a species depends, then, on its ability to disperse at a pace fast enough to find itself in a suitable climatic environment. Dispersion will also depend on factors that are extrinsic to the organism, such as habitat continuity. In areas where fragmentation is severe, species will not be able to shift their distributional ranges. From a conservation perspective, it is critical to have areas with elevational gradients and both terrestrial and riparian corridors to allow 
species' movements. Alternatively, in fragmented landscapes, assisted dispersal might represent a necessary conservation action [396].
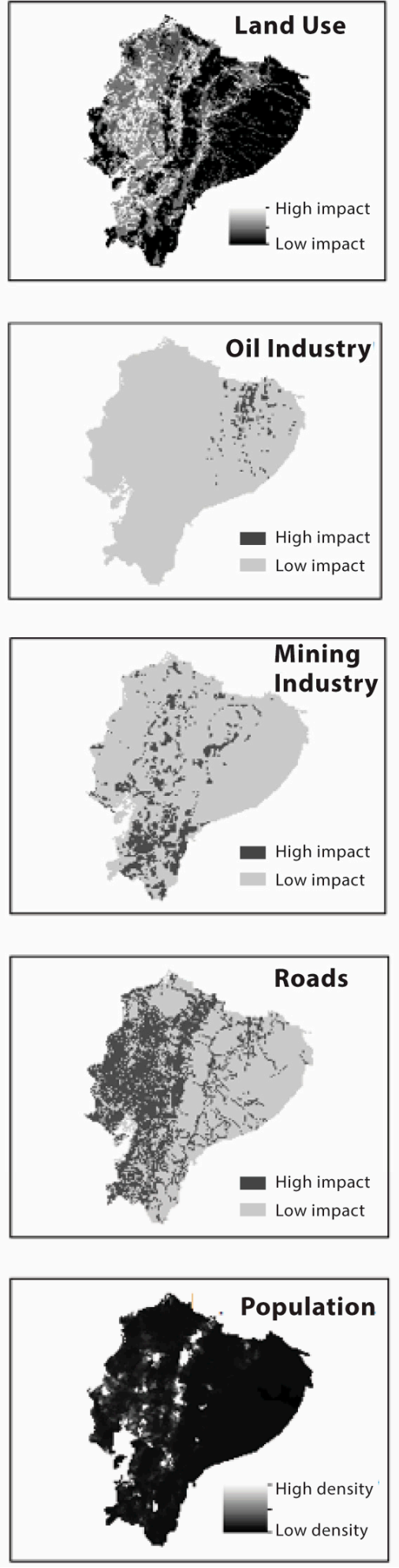

Figure 238. Human impact on ecosystems of Ecuador.

\section{Human Impact in Ecuador}

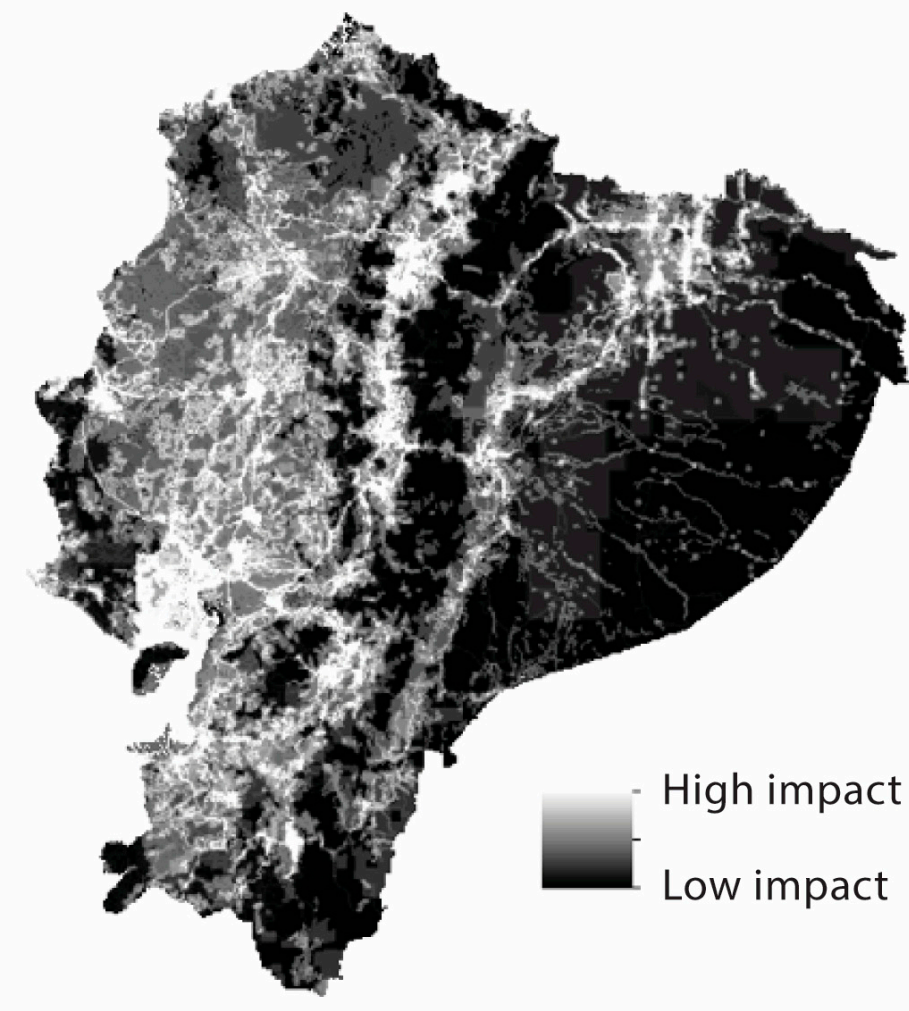


(A) Environmental Risk

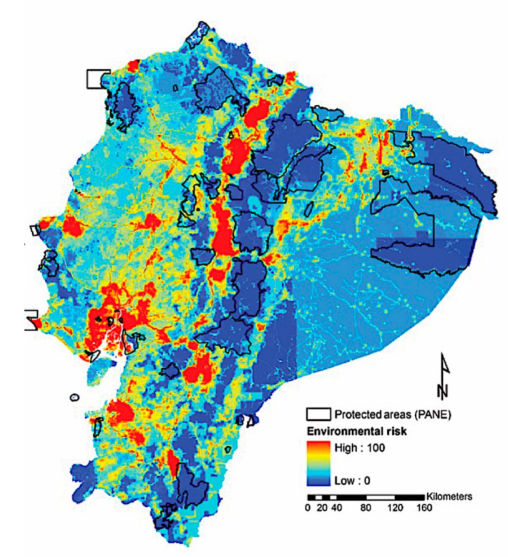

(B) Conservation Priorities

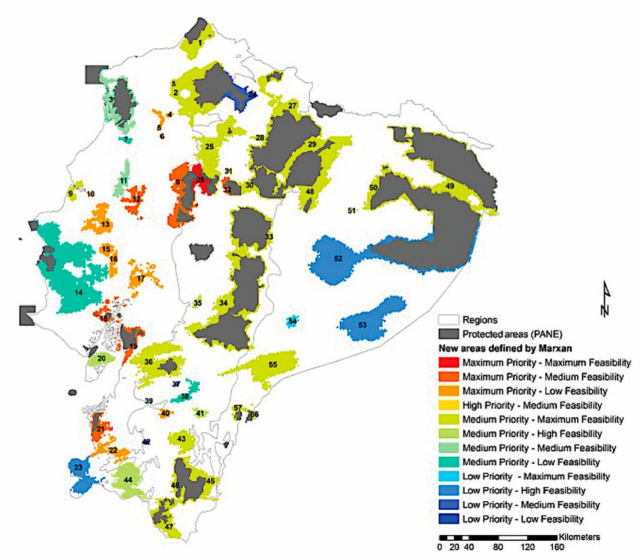

Figure 239. Environmental risk and conservation priorities in Ecuador. (A) Environmental risk surface for continental Ecuador. This surface takes into account information on roads, human population density, airports, dams, agriculture and husbandry, and oil and mining industry [73]. (B) Conservation priorities in Ecuador; this map was constructed using the potential distribution of 809 species (amphibians, birds, mammals, plants), combined with feasibility of conservation [73].

The alternative solution for species is to adapt to the novel climatic conditions associated with anthropogenic climate change; however, rates of climatic niche change among populations of plants and animals are dramatically slower than projected rates of future climate change. This means that, most likely, populations may not be able to change their climatic niches rapidly enough to keep pace with changing conditions as global climate warms, with dispersal being the only venue to avoid extinction [397,398].

Supplementary Materials: The following are available online at http://www.mdpi.com/1424-2818/12/6/222/s1, Table S1: Taxonomy, biogeographic distribution, and elevation of all recognized species of glassfrogs, Table S2: Taxon and genetic markers used in this study. Sequences generated in previous studies were downloaded from GenBank. Newly generated sequences are in bold blue, Table S3: Summary statistics for each marker used in the phylogenetic analyses, Table S4: Potential distribution of glassfrog species in Ecuador, with percentage affected by human activities, Table S5: Area Under Curve (AUC) values for potential distribution models, Table S6: Candidate species recognized in this study, Table S7: Conservation status of Ecuadorian glassfrogs.

Author Contributions: J.M.G. and D.F.C.-H. conceived the study; J.M.G. wrote the manuscript, with contributions from all authors; J.M.G., D.F.C.-H., P.P., R.W.M., and C.R.H. collected the data; J.M.G., C.R.H., and P.P. analyzed the data; J.M.G. and C.R.H. rendered all figures and tables. All authors have read and agreed to the published version of the manuscript.

Funding: JMG's research was supported by the National Science Foundation (DEB-1046408, DEB-1045960, DEB-1045991DEB-0608011, EF-0334928, DEB-1046408); Secretaría Nacional de Educación Superior, Ciencia, Tecnología e Innovación de Ecuador (PIC-08-0000470); Partnerships for Enhanced Engagement in Research Science [grant number P1-108]; JRS Biodiversity Foundation; the American Philosophical Society through the Lewis and Clark Fund for Exploration and Field Research; IUCN-Save Our Species; Pontificia Universidad Católica del Ecuador; Mashpi Biodiversity Reserve, Panorama Society Grant and Harris Scholarship Award of the University of Kansas Natural History Museum; Universidad Tecnológica Indoamérica; and Universidad San Francisco de Quito (Collaboration Grants 11164, 16871; COCIBA Grants 5521, 5467, 16808). DFCH's research was supported by María Elena Heredia, Laura Heredia, the Smithsonian Women's Committee, the 2002 Research Training Program, National Museum of Natural History, Smithsonian Institution, Tiputini Biodiversity Station, Instituto de Ecología Aplicada ECOLAP-USFQ, Río Guajalito Protected Forest, Mashpi Protected Forest/Metropolitan Tourists, Fundación Futuro, the Global Amphibian Assessment, Conservation International, the Atelopus Initiative, the Research Analysis Network for Neotropical Amphibians (RANA, supported by the National Science Foundation DEB-0130273), the Russel E. Train Education for Nature Program, World Wildlife Fund WWF, Programa "Becas de Excelencia", Secretaría de Educación Superior, Ciencia, Tecnología e Innovación (SENESCYT), Ecuador, and Universidad San Francisco de Quito USFQ (Chancellor grants, COCIBA grants, Collaboration grants, projects HUBI ID 34, 36, 39, 48, 1057, 7703, 12253, 13524, 16953). Work by JMG and DFCH was supported by "Proyecto Descubre Napo", an initiative of Universidad San Francisco de Quito in association with Wildlife Conservation Society and funded by the Gordon and Betty Moore Foundation as part of the project: WCS Consolidating Conservation of Critical Landscapes (mosaics) in the Andes. 
Acknowledgments: This study took a very long time to write and review; it was supposed to be part of JMG'S $\mathrm{PhD}$ dissertation but, instead, it took 12 additional years of punctuated work and the creative input of all coauthors, mainly CRH. There are numerous people to thank and, for sure, we will forget to mention some (we apologize in advance). This article was greatly improved by discussions with Santiago Castroviejo-Fisher, Marco Rada, Jesse Delia, Alessandro Catenazzi, Rudolf von May, Annabelle Wang, Elisa Bonaccorso, and three anonymous reviewers. We are grateful to the many individuals and institutions who provided specimens, tissues, calls, photos, and information included in this study: Luis A. Coloma, Ítalo Tapia (Centro Jambatu), Linda Trueb, William E. Duellman, John E. Simmons, Rafe Brown (University of Kansas), Alejandro Arteaga, Lucas Bustamante, Jose Vieira (Tropical Herping), John D. Lynch (ICN), James A. Poindexter, Ron Heyer, Addison Wynn (USNM), Darrel Frost, Charles W. Myers, Charles J. Cole, Linda S. Ford (AMNH), Jeff Streicher, David Gower and Mark Wilkinson (BMNH), James Hanken and José Rosado (MCZ), Chris Funk (Colorado State University), Ivan Ineich, Roger Bour, and Jean-Christophe de Massary (MNHN); Janalee Caldwell and Laurie Vitt (OMNH), Santiago Castroviejo-Fisher, Marco Rada (Pontificia Universidad Católica do Rio Grande do Sul), Taran Grant (Universidade de São Paulo), Jane Lyons (Reserva Las Gralarias), Marco M. Reyes (Fundación Óscar Efrén Reyes), Kelly Zamudio (Cornell University), Mario Yánez-Muñoz (INABIO), Brian Kubicki (Costa Rican Amphibian Research Center), Santiago Ron (QCAZ), Ana Almendáriz (EPN), Jean-Marc Touzet and Ana María Velasco (FHGO), Carolina Reyes-Puig, Emilia Peñaherrera and David Brito (ZSFQ), Mauricio Ortega-Andrade (Ikiam) and Andrew J. Crawford (Smithsonian Research Tropical Institute, Panama). For assistance and comments during the development of this project, we extend our sincere gratitude mainly to Luis A. Coloma, Martín R. Bustamante, Elisa Bonaccorso, Santiago Castroviejo-Fisher, and Marco Rada. We also thank Alejandro Arteaga, Lucas Bustamante, Eduardo Toral, Gabriela Gavilanes, Nathalia Valencia, Carolina Reyes-Puig, Diego Páez-Moscoso, Andrea Encalada, Ítalo Tapia, Nicolás Peñafiel, Diana Flores, Gabriela Nicholls, Gene Schupp, Henry Imba, Esteban Suárez, César Barrio-Amorós, Mario Yánez-Muñoz, Jonathan Guillemot, Mark Mulligan, Susana Cárdenas, Jesse Delia, Janeth Lessmann, Jeffrey Arellano, David Brito, Emilia Peñaherrera, Ana Nicole Acosta, Gabriel Muñoz, Ernesto Villacís, Katiuska Valarezo, María Olga Borja, Sebastián Cruz, María Elena Heredia, Andrés León-Reyes, Wendy Loor, Pablo Melo, Carolina Proaño, Daniel Proaño, Geovanna Robayo, Javier Robayo, Mayer Rodríguez, and Tomi Sugahara for their help in numerous ways (discussions, fieldwork, labwork, photography). Several friends and colleagues contributed photographs for this article; their names are listed in the figure captions, but we would like to explicitly thank Luis Coloma, Alejandro Arteaga, Jose Vieira, Lucas Bustamante, Jesse Delia, and Jaime Culebras. Research permits in Ecuador were issued by the Ministerio del Ambiente (\#033-IC-FAU-DNBAPVS/MA, \#56-IC-FAU/FLO-DPN/MA, \#05-2013-IC-FAU-DPAP-MA, MAE-DNB-CM-2015-0017). JMG thanks John D. Lynch, Angela Suárez, Celsa Señaris, Chris Funk, Cameron Ghalambor, and Cesar Barrio-Amorós for their hospitality during visits to Colombia, Venezuela, and United States. DFCH is grateful to George R. Zug, W. Ronald Heyer, Robert P. Reynolds, Kenneth A. Tighe, Steve W. Gotte, Carole C. Baldwin, and Mary Sangrey for their support at the USNM, to Julian Faivovich, Taran Grant, Anita Peñaherrera, Jean-Marc Touzet, Claudia Torres-Gastello, Juana Suarez, Jeff Streicher, and Leonardo Zurita for their support during his visits to New York, Paris, Lima, and London; and to David Romo, Consuelo Barriga de Romo, Kelly Swing, Vlastimil Zak, Francisco Vintimilla, Carlos Burneo, Carolina Proaño, Ana Sevilla, and Roque Sevilla for their support for fieldwork. Juan Manuel dedicates this study to Nina and Elisa.

Conflicts of Interest: The authors declere no conflict of interest.

\section{References}

1. Guayasamin, J.M.; Castroviejo-Fisher, S.; Trueb, L.; Ayarzagüena, J.; Rada, M.; Vilà, C. Phylogenetic systematics of glassfrogs (Amphibia: Centrolenidae) and their sister taxon Allophryne ruthveni. Zootaxa 2009, 2100, 1-97. [CrossRef]

2. Guayasamin, J.M.; Castroviejo-Fisher, S.; Ayarzagüena, J.; Trueb, L.; Vilà, C. Phylogenetic relationships of glassfrogs (Centrolenidae) based on mitochondrial and nuclear genes. Mol. Phylogenet. Evol. 2008, 48, 574-595. [CrossRef]

3. Castroviejo-Fisher, S.; Guayasamin, J.M.; Gonzalez-Voyer, A.; Vilà, C. Neotropical diversification seen through glassfrogs. J. Biogeogr. 2014, 41, 66-80. [CrossRef]

4. McDiarmid, R.W. Evolution of parental care in frogs. In The Development of Behavior: Comparative and Evolutionary Aspects; Burghardt, G.M., Bekoff, M., Eds.; Garland STPM Press: New York, NY, USA, 1978; pp. 127-147.

5. Duellman, W.E.; Savitzky, A.H. Aggressive behavior in a centrolenid frog, with comments on territoriality in anurans. Herpetologica 1976, 32, 401-404.

6. Ruiz-Carranza, P.M.; Lynch, J.D. Ranas Centrolenidae de Colombia I. Propuesta de una nueva clasificación genérica. Lozania 1991, 57, 1-30.

7. Hayes, M.P.; Starrett, P.H. Notes on a collection of centrolenid frogs from the Colombian Chocó. Bull. South. Calif. Acad. Sci. 1980, 79, 89-96. 
8. Wiens, J.J.; Fetzner, J.W.; Parkinson, C.L.; Reeder, T.W. Hylid frog phylogeny and sampling strategies for speciose clades. Syst. Biol. 2005, 54,719-748. [CrossRef] [PubMed]

9. Guayasamin, J.M.; Trueb, L. A new species of glassfrog (Anura: Centrolenidae) from the lowlands of northwestern Ecuador, with comments on centrolenid osteology. Zootaxa 2007, 27-45. [CrossRef]

10. Darst, C.R.; Cannatella, D.C. Novel relationships among hyloid frogs inferred from $12 \mathrm{~S}$ and $16 \mathrm{~S}$ mitochondrial DNA sequences. Mol. Phylogenet. Evol. 2004, 31, 462-475. [CrossRef] [PubMed]

11. Faivovich, J.; Haddad, C.F.B.; Garcia, P.C.A.; Frost, D.R.; Campbell, J.A.; Wheeler, W.C. Systematic review of the frog family Hylidae, with special reference to Hylinae: Phylogenetic analysis and taxonomic revision. Bull. Am. Mus. Nat. Hist. 2005, 294, 1-240. [CrossRef]

12. Frost, D.R.; Grant, T.; Faivovich, J.; Bain, R.H.; Haas, A.; Haddad, C.F.B.; de Sa, R.O.; Channing, A.; Wilkinson, M.; Donnellan, S.C.; et al. The amphibian tree of life. Bull. Am. Mus. Nat. Hist. 2006, 297, 1-370. [CrossRef]

13. Grant, T.; Frost, D.R.; Caldwell, J.P.; Gagliardo, R.; Haddad, C.F.B.; Kok, P.J.R.; Means, D.B.; Noonan, B.P.; Schargel, W.F.; Wheeler, W.C. Phylogenetic systematics of Dart-poison frogs and their relatives (Amphibia: Athesphatanura: Dendrobatidae). Bull. Am. Mus. Nat. Hist. 2006, 299, 1-262. [CrossRef]

14. Pyron, R.A.; Wiens, J.J. A large-scale phylogeny of Amphibia including over 2800 species, and a revised classification of advanced frogs, salamanders, and caecilians. Mol. Phylogenet. Evol. 2011, 61, 543-583. [CrossRef]

15. Taylor, E.H. Two new genera and a new family of tropical American frogs. Proc. Biol. Soc. Wash. 1951, 64, 33-40.

16. Sanchiz, B.; De la Riva, I. Remarks on the tarsus of centrolenid frogs (Amphibia: Anura). Graellsia 1993, 49, 115-117.

17. Cisneros-Heredia, D.F.; McDiarmid, R.W. Revision of the characters of Centrolenidae (Amphibia: Anura: Athesphatanura), with comments on its taxonomy and the description of new taxa of glassfrogs. Zootaxa 2007, 1572, 1-82. [CrossRef]

18. Castroviejo-Fisher, S.; Vilà, C.; Ayarzagüena, J.; Blanc, M.; Ernst, R. Species diversity of Hyalinobatrachium glassfrogs (Amphibia: Centrolenidae) from the Guiana Shield, with the description of two new species. Zootaxa 2011, 3132, 1-55. [CrossRef]

19. Twomey, E.M.; Delia, J.; Castroviejo-Fisher, S. A review of northern Peruvian glassfrogs (Centrolenidae), with the description of four new remarkable species. Zootaxa 2014, 3851, 1-87. [CrossRef]

20. Guayasamin, J.M.; Bustamante, M.R.; Almeida-Reinoso, D.; Funk, W.C. Glass frogs (Centrolenidae) of Yanayacu Biological Station, Ecuador, with the description of a new species and comments on centrolenid systematics. Zool. J. Linn. Soc. 2006, 147, 489-513. [CrossRef]

21. Guayasamin, J.M.; Cisneros-Heredia, D.F.; Vieira, J.; Kohn, S.; Gavilanes, G.; Lynch, R.L.; Hamilton, P.S.; Maynard, R.J. A new glassfrog (Centrolenidae) from the Chocó-Andean Río Manduriacu Reserve, Ecuador, endangered by mining. PeerJ 2019, 7, e6400. [CrossRef]

22. Lynch, J.D.; Duellman, W.E. A review of the centrolenid frogs of Ecuador, with descriptions of new species. Occas. Pap. Mus. Nat. Hist. 1973, 16, 1-66.

23. Lips, K.R.; Brem, F.; Brenes, R.; Reeve, J.D.; Alford, R.A.; Voyles, J.; Collins, J.P. Emerging infectious disease and the loss of biodiversity in a Neotropical amphibian community. Proc. Natl. Acad. Sci. USA 2006, 103, 3165-3170. [CrossRef]

24. Kubicki, B. Ranas de vidrio de Costa Rica/Glass frogs of Costa Rica; Editorial INBio: Santo Domingo de Heredia, Costa Rica, 2007; 304p.

25. Delia, J.; Bravo-Valencia, L.; Warkentin, K.M. Patterns of parental care in Neotropical glassfrogs: Fieldwork alters hypotheses of sex-role evolution. J. Evol. Biol. 2017, 30, 898-914. [CrossRef]

26. Ruiz-Carranza, P.M.; Lynch, J.D. Ranas Centrolenidae de Colombia VIII. Cuatro nuevas especies de Centrolene de la Cordillera Central. Lozania 1995, 65, 1-16.

27. Ruiz-Carranza, P.M.; Lynch, J.D. Ranas Centrolenidae de Colombia XI. Nuevas especies de ranas de cristal del genero Hyalinobatrachium. Rev. Acad. Colomb. Cienc. Exact. Fís. Nat. 1998, 22, 571-586.

28. Hutter, C.R.; Guayasamin, J.M.; Wiens, J.J. Explaining Andean megadiversity: The evolutionary and ecological causes of glassfrog elevational richness patterns. Biol. Lett. 2013, 16, 1135-1144. [CrossRef] 
29. Vieites, D.R.; Wollenberg, K.C.; Andreone, F.; Köhler, J.; Glaw, F.; Vences, M. Vast underestimation of Madagascar's biodiversity evidenced by an integrative amphibian inventory. Proc. Natl. Acad. Sci. USA 2009, 106, 8267-8272. [CrossRef]

30. Stuart, S.N.; Chanson, J.S.; Cox, N.A.; Young, B.E.; Rodrigues, A.S.; Fischman, D.L.; Waller, R.W. Status and trends of amphibian declines and extinctions worldwide. Science 2004, 306, 1783-1786. [CrossRef]

31. La Marca, E.; Lips, K.R.; Lötters, S.; Puschendorf, R.; Ibañez, R.; Rueda-Almonacid, J.V.; Schulte, R.; Marty, C.; Castro, F.; Manzanilla-Puppo, J.; et al. Catastrophic population declines and extinctions in neotropical harlequin frogs (Bufonidae: Atelopus). Biotropica 2005, 37, 190-201. [CrossRef]

32. Wake, D.B.; Vradenburg, V.T. Are we in the midst of the sixth mass extinction? A view from the world of amphibians. Proc. Natl. Acad. Sci. USA 2009, 105, 11466-11473. [CrossRef]

33. Scheele, B.C.; Pasmans, F.; Berger, L.; Skerratt, L.F.; Martel, A.; Beukema, W.; Acevedo, A.A.; Burrowes, P.A.; Carvalho, T.; Catenazzi, A.; et al. Amphibian fungal panzootic causes catastrophic and ongoing loss of biodiversity. Science 2019, 363, 1459-1463. [CrossRef] [PubMed]

34. Simpson, G.G. The species concept. Evolution 1951, 5, 285-298. [CrossRef]

35. Simpson, G.G. Principles of Animal Taxonomy; Columbia University Press: New York, NY, USA, 1961.

36. Wiley, E.O. The evolutionary species concept reconsidered. Syst. Zool. 1978, 27, 17-26. [CrossRef]

37. De Queiroz, K. Ernst Mayr and the modern concept of species. Proc. Natl. Acad. Sci. USA 2005, 102, 6600-6607. [CrossRef]

38. De Queiroz, K. Species concepts and species delimitation. Syst. Biol. 2007, 56, 879-886. [CrossRef]

39. Dayrat, B. Towards integrative taxonomy. Biol. J. Linn. Soc. 2005, 85, 407-415. [CrossRef]

40. Padial, J.M.; Miralles, A.; De la Riva, I.; Vences, M. The integrative future of taxonomy. Front. Zool. 2010, 7, 16. [CrossRef]

41. Alberch, P.; Gale, E. A developmental analysis of an evolutionary trend: Digital reduction in amphibians. Evolution 1985, 39, 8-23. [CrossRef]

42. Fabrezi, M.; Alberch, P. The carpal elements of anurans. Herpetologica 1996, 52, 188-204.

43. Shubin, N.; Alberch, P. A Morphogenetic approach on the origin and basic organization of the tetrapod limb. In Evolutionary Biology; Hecht, M., Wallace, B., Prance, G., Eds.; Plenum Press: New York, NY, USA, 1986; pp. 319-387.

44. Savage, J.M.; Heyer, W.R. Variation and distibution in the tree-frog genus Phyllomedusa in Costa Rica, Central America. Beiträge Zur Neotropischen Fauna 1967, 5, 111-131. [CrossRef]

45. McDiarmid, R.W.; Altig, R. (Eds.) Tadpoles: The Biology of Anuran Larvae; The University of Chicago Press: Chicago, IL, USA, 1999; 444p.

46. Flores, G. A new Centrolenella (Anura) from Ecuador, with comments on nuptial pads and prepollical spines in Centrolenella. J. Herpetol. 1985, 19, 313-320. [CrossRef]

47. Bravo-Valencia, L.; Delia, J. Maternal care in a glassfrog: Care function and commitment to offspring in Ikakogi tayrona. Behav. Ecol. Sociobiol. 2016, 70, 41-48. [CrossRef]

48. Sueur, J.; Aubin, T.; Simonis, C. Seewave, a free modular tool for sound analysis and synthesis. Bioacoustics 2008, 18, 213-226. [CrossRef]

49. Cocroft, R.B.; Ryan, M.J. Patterns of advertisement call evolution in toads and chorus frogs. Anim. Behav. 1995, 49, 283-303. [CrossRef]

50. Dautel, N.; Salgado Maldonado, A.L.; Abuza, R.; Imba, H.; Griffin, K.; Guayasamin, J.M. Advertisement and combat calls of the glass frog Centrolene lynchi (Anura: Centrolenidae), with notes on combat and reproductive behavior. Phyllomedusa 2011, 10, 31-43. [CrossRef]

51. Hutter, C.R.; Escobar-Lasso, S.; Rojas-Morales, J.A.; Gutiérrez-Cárdenas, P.D.A.; Imba, H.; Guayasamin, J.M. The territoriality, vocalizations and aggressive interactions of the red-spotted glassfrog, Nymphargus grandisonae, Cochran and Goin, 1970 (Anura: Centrolenidae). J. Nat. Hist. 2013, 47, 3011-3032. [CrossRef]

52. Köhler, J.; Jansen, M.; Rodríguez, A.; Kok, P.R.J.; Toledo, L.F.; Emmrich, E.; Glaw, F.; Haddad, C.F.B.; Rödel, M.R.; Vences, M. The use of bioacoustics in anuran taxonomy: Theory, terminology, methods and recommendations for best practice. Zootaxa 2017, 4251, 1-124. [CrossRef]

53. Perl, R.B.; Nagy, Z.T.; Sonet, G.; Glaw, F.; Wollenberg, K.C.; Vences, M. DNA barcoding Madagascar's amphibian fauna. Amphib. Reptil. 2014, 10, 15685381-00002942. [CrossRef]

54. Felsenstein, J. Cases in which parsimony or compatibility methods will be positively misleading. Syst. Zool. 1978, 27, 401-410. [CrossRef] 
55. Felsenstein, J. Inferring Phylogenies; Sinauer Associates: Sunderland, MA, USA, 2004.

56. Jin, L.; Nei, M. Limitations of the evolutionary parsimony method of phylogenetic analysis. Mol. Biol. Evol. 1990, 7, 82-102.

57. Katoh, K.; Standley, D.M. MAFFT multiple sequence alignment software version 7, improvements in performance and usability. Mol. Biol. Evol. 2013, 30, 772-780. [CrossRef] [PubMed]

58. Nguyen, L.T.; Schmidt, H.A.; von Haeseler, A.; Minh, B.Q. IQ-TREE: A fast and effective stochastic algorithm for estimating maximum-likelihood phylogenies. Mol. Biol. Evol. 2015, 32, 268-274. [CrossRef] [PubMed]

59. Kalyaanamoorthy, S.; Minh, B.Q.; Wong, T.K.; von Haeseler, A.; Jermiin, L.S. ModelFinder: Fast model selection for accurate phylogenetic estimates. Nat. Methods 2017, 14, 587. [CrossRef] [PubMed]

60. Minh, B.Q.; Nguyen, M.A.T.; von Haeseler, A. Ultrafast approximation for phylogenetic bootstrap. Mol. Biol. Evol. 2013, 30, 1188-1195. [CrossRef]

61. Bouckaert, R.; Heled, J.; Kühnert, D.; Vaughan, T.; Wu, C.H.; Xie, D.; Drummond, A.J. BEAST 2, a software platform for Bayesian evolutionary analysis. Plos Comput. Biol. 2014, 10, e1003537. [CrossRef]

62. Hutter, C.R.; Lambert, S.M.; Wiens, J.J. Rapid diversification and time explain amphibian richness at different scales in the Tropical Andes, Earth's most biodiverse hotspot. Am. Nat. 2017, 190, 828-843. [CrossRef]

63. Rambaut, A.; Drummond, A.J. Tracer v1.4. 2007. Available online: http://beast.bio.ed.ac.uk/Tracer (accessed on 14 August 2019).

64. IUCN. IUCN Red List Categories and Criteria: Version 3.1; IUCN Species Survival Commission; IUCN: Gland, Switzerland; Cambridge, UK, 2001.

65. Sierra, R.; Cerón, C.; Palacios, W.; Valencia, R. Propuesta Preliminar de un Sistema de Clasificación de Vegetación Para el Ecuador Continental; Proyecto INEFAN/GEF-BIRF y ECOCIENCIA: Quito, Ecuador, 1999.

66. Ron, S.R.; Guayasamin, J.M.; Menéndez-Guerrero, P. Biodiversity and Conservation Status of Ecuadorian Amphibians. In Amphibian Biology; Part 2; Heatwole, H., Barrio-Amoros, C.L., Wilkinson, H.W., Eds.; Surrey Beatty \& Soons PTY Limited: Baulkham Hills, Australia, 2011; Volume 9, pp. 129-170.

67. Cerón, C.; Palacios, W.; Valencia, R.; Sierra, R. Las formaciones naturales de la Costa del Ecuador. In Propuesta Preliminar de un Sistema de Clasificación de Vegetación para el Ecuador Continental; Sierra, R., Ed.; Proyecto INEFAN/GEF-BIRF y EcoCiencia: Quito, Ecuador, 1999; pp. 55-73.

68. Palacios, W.; Cerón, C.; Valencia, R.; Sierra, R. Las formaciones naturales de la Amazonía del Ecuador. In Propuesta Preliminar de un Sistema de Clasificación de Vegetación para el Ecuador Continental; Sierra, R., Ed.; Proyecto INEFAN/GEF-BIRF y EcoCiencia: Quito, Ecuador, 1999; pp. 109-117.

69. Valencia, R.; Cerón, C.; Palacios, W.; Sierra, R. Las formaciones naturales de la Sierra del Ecuador. In Propuesta Preliminar de un Sistema de Clasificación de la Vegetación para el Ecuador Continental; Sierra, R., Ed.; Proyecto INEFAN/GEF-BIRF y EcoCiencia: Quito, Ecuador, 1999; pp. 79-108. 194p.

70. Valencia, R.; Foster, R.B.; Villa, G.; Condit, R.; Svenning, J.C.; Hernández, C.; Romoleroux, K.; Losos, E.; Magård, E.; Balslev, H. The especies distributions and local hábitat variation in the Amazon: Large forest plot in Eastern Ecuador. J. Ecol. 2004, 92, 214-229. [CrossRef]

71. Ridgely, R.S.; Greenfield, P.J. The Birds of Ecuador; Cornell University Press: Ithaca, NY, USA, 2001.

72. Bass, M.S.; Finer, M.; Jenkins, C.N.; Kreft, H.; Cisneros-Heredia, D.F.; McCracken, S.F.; Pitman, N.C.A.; English, P.H.; Swing, K.; Villa, G.; et al. Global conservation significance of Ecuador's Yasuní National Park. PLoS ONE 2010, 5, e8767. [CrossRef]

73. Lessmann, J.; Muñoz, J.; Bonaccorso, E. Maximizing species conservation in continental Ecuador: A case of systematic conservation planning for biodiverse regions. Ecol. Evol. 2014, 4, 2410-2422. [CrossRef]

74. Jarnevich, C.S.; Stohlgren, T.J.; Kumar, S.; Morisette, J.T.; Holcombe, T.R. Caveats for correlative species distribution modeling. Ecol. Inform. 2015, 29, 6-15. [CrossRef]

75. Radosavljevic, A.; Anderson, R. Making better Maxent models of species distributions: Complexity, overfitting and evaluation. J. Biogeogr. 2014, 41, 629-643. [CrossRef]

76. Hijmans, R.J.; Cameron, S.E.; Parra, J.L.; Jones, P.G.; Jarvis, A. Very high resolution interpolated climate surfaces for global land areas. Int. J. Climatol. 2005, 25, 1965-1978. [CrossRef]

77. Phillips, S.J.; Anderson, R.P.; Schapire, R.E. Maximum entropy modeling of species geographic distributions. Ecol. Model. 2006, 190, 231-259. [CrossRef]

78. Phillips, S.J.; Dudík, M. Modeling of species distributions with Maxent: New extensions and a comprehensive evaluation. Ecography 2008, 31, 161-175. [CrossRef] 
79. Graham, C.H.; Hijmans, R.J. A comparison of methods for mapping species ranges and species richness. Glob. Ecol. Biogeogr. 2006, 15, 578-587. [CrossRef]

80. Elith, J.; Leathwick, J. Predicting species distributions from museum and herbarium records using multiresponse models fitted with multivariate adaptive regression splines. Divers. Distrib. 2007, 13, 265-275. [CrossRef]

81. Liu, C.; Berry, P.M.; Dawson, T.P.; Pearson, R.G. Selecting thresholds of occurrence in the prediction of species distributions. Ecography 2005, 28, 385-393. [CrossRef]

82. Jiménez-Valverde, A.; Lobo, J.M. Threshold criteria for conversion of species presence to either-or presence-absence. Acta Oecologica 2007, 31, 361-369. [CrossRef]

83. Jiménez de la Espada, M. Nuevos batracios americanos. An. De La Soc. Española De Hist. Nat. 1872, 1, 85-88.

84. McCranie, J.R.; Wilson, L.D. The Amphibians of Honduras; Society for the Study of Amphibians and Reptiles: Ithaca, NY, USA, 2002; 625p.

85. Barrio-Amorós, C.L.; Rojas-Runjaic, F.J.M.; Señaris, J.C. Catalogue of the amphibians of Venezuela: Illustrated and annotated species list, distribution, and conservation. Amphib. Reptile Conserv. 2019, 13, 1-198.

86. Duellman, W.E.; Burrowes, P.A. New species of frogs, Centrolenella, from the Pacific Versant of Ecuador and Southern Colombia. Univ. Kans. Mus. Nat. Hist. Occas. Pap. 1989, 132, 1-14.

87. Arteaga, A.; Bustamante, L.; Guayasamin, J.M. The Amphibians and Reptiles of Mindo: Life in the Cloudforest; Universidad Tecnológica Indoamérica: Quito, Ecuador, 2013.

88. Hutter, C.R.; Guayasamin, J.M. A new cryptic species of glassfrog (Centrolenidae: Nymphargus) from Reserva Las Gralarias, Ecuador. Zootaxa 2012, 3257, 1-21. [CrossRef]

89. Márquez, R.; De la Riva, I.; Bosch, J. Advertisement calls of three glass frogs from the Andean forests (Amphibia: Anura: Centrolenidae). Herpetol. J. 1996, 6, 97-99.

90. Cisneros-Heredia, D.F.; Wild, E.; Reyes, J.P.; Coloma, L.A.; Gutierrez, P.; Ron, S.R.; Bolívar, W. The IUCN Red List of Threatened Species. Cent. Ballux. 2019, e.T54907A85877221. [CrossRef]

91. Bustamante, M.R.; Ron, S.R.; Coloma, L.A. Cambios en la diversidad en siete comunidades de anuros en los Andes de Ecuador. Biotropica 2005, 37, 180-189. [CrossRef]

92. Guayasamin, J.M.; Mendoza, A.M.; Longo, A.V.; Zamudio, K.R.; Bonaccorso, E. High prevalence of Batrachochytrium dendrobatidis in an Andean frog community (Reserva Las Gralarias, Ecuador). Amphib. Reptile Conserv. 2014, 8, 33-44.

93. Boulenger, G.A. Catalogue of the Batrachia Salientia s. Ecaudata in the collection of the British Museum; Trustees, British Museum (Natural History): London, UK, 1882; 495p.

94. Noble, G.K. Two new batrachians from Colombia. Bull. Am. Mus. Nat. Hist. 1920, 42, 441-446.

95. Rivero, J.A. Salientia of Venezuela. Bull. Mus. Comp. Zool. 1961, 126, 1-207.

96. Cochran, D.M.; Goin, C.J. Frogs of Colombia; United States National Museum Bulletin, Smithsonian Institution Press: Washington, DC, USA, 1970; 655p.

97. Goin, C.J. Three new centrolenid frogs from Ecuador. Zool. Anz. 1961, 166, 95-104.

98. Amador, L.; Parada, A.; D'Elía, G.; Guayasamin, J.M. Uncovering hidden specific diversity of Andean glassfrogs of the Centrolene buckleyi species complex (Anura: Centrolenidae). PeerJ 2018, 6, e5856. [CrossRef]

99. ICZN. International Code of Zoological Nomenclature. In The International Trust for Zoological Nomenclature, 4th ed.; ICZN: London, UK, 1999; 306p.

100. Bolívar-G, W.; Grant, T.; Osorio, L.A. Combat behavior in Centrolene buckleyi and other centrolenid frogs. Alytes 1999, 16, 77-83.

101. Ruiz-Carranza, P.M.; Ardila-Robayo, M.C.; Lynch, J.D. Lista actualizada de la fauna de Amphibia de Colombia. Rev. Acad. Colomb. Cienc. Exact. Fís. Nat. 1996, 20,365-415.

102. Duellman, W.E.; Wild, E.R. Anuran amphibians from the Cordillera de Huancabamba, northern Peru: Systematics, ecology, and biogeography. Occas. Pap. Mus. Nat. Hist. Univ. Kans. 1993, 157, 1-53.

103. Guayasamin, J.M. The IUCN Red List of Threatened Species. Cent. Buckleyi. 2010, e.T54908A11220443. [CrossRef]

104. Myers, C.W.; Donnelly, M.A. A tepui herpetofauna on a granitic mountain (Tamacuari) in the borderland between Venezuela and Brazil: Report from the Phipps Tapirapecó Expedition. Am. Mus. Novit. 1997, 3213, 1-71.

105. Rivero, J.A. Los Centrolénidos de Venezuela. Mem. De La Soc. De Cienc. Nat. La Salle 1968, 28, 301-334. 
106. Señaris, J.C.; Ayarzegüena, J. Revisión taxonómica de la Familia Centrolenidae (Amphibia; Anura) de Venezuela; Publicaciones del Comité Español del Programa Hombre y Biosfera—Red IberoMaB de la UNESCO: Sevilla, Spain, 2005; 337p.

107. Cisneros-Heredia, D.F.; Morales-Mite, M. A new species of glassfrog from elfin forests of the Cordillera del Cóndor, southeastern Ecuador. Herpetozoa 2008, 21, 49-56.

108. Almendáriz, A.; Batallas, D. Nuevos datos sobre la distribución, historia natural y el canto de Centrolene condor Cisneros-Heredia y Morales-Mite 2008 (Amphibia: Anura: Centrolenidae). Rev. Politécnica 2012, 30, 42-53.

109. Cisneros-Heredia, D.; Angulo, A. The IUCN Red List of Threatened Species 2009. Cent. Condor 2009, e.T158474A5200524. [CrossRef]

110. Ruiz-Carranza, P.M.; Hernández-Camacho, J.; Ardila-Robayo, M.C. Una nueva especie colombiana del género Centrolene Jiménez de la Espada 1872 (Amphibia: Anura) y redefinición del género. Caldasia 1986, 15, 431-444.

111. Rueda-Almonacid, J.V. Estudio anatómico y relaciones sistemáticas de Centrolene geckoideum (Salientia: Anura: Centrolenidae). Trianea 1994, 5, 133-187.

112. Grant, T.; Bolívar, G.W.; Castro, F. The advertisement call of Centrolene geckoideum. J. Herpetol. 1998, 32, $452-455$. [CrossRef]

113. Lynch, J.D.; Ruiz-Carranza, P.M.; Rueda, J.V. Notes on the distribution and reproductive biology of Centrolene geckoideum Jimenez de la Espada in Colombia and Ecuador (Amphibia: Centrolenidae). Stud. Neotrop. Fauna Environ. 1983, 18, 239-243. [CrossRef]

114. Goodman, D.E.; Goin, C.J. The Habitat of Centrolene geckoideum in Ecuador. Herpetologica 1970, $26,276$.

115. Cisneros-Heredia, D.F.; Yánez-Muñoz, M.H. A new species of glassfrog (Centrolenidae) from the southern Andean foothills on the west Ecuadorian region. South Am. J. Herpetol. 2007, 2, 1-10. [CrossRef]

116. Cisneros-Heredia, D.F.; Yánez-Muñoz, M. Amphibia, Anura, Centrolenidae, Centrolene balionotum, Centrolene geckoideum, and Cochranella cariticommata: Distribution extension, new provincial records, Ecuador. Check List 2007, 3, 39-42. [CrossRef]

117. Cisneros-Heredia, D.F.; Wild, E.; Gonzalez Duran, G.A.; Reyes, J.P.; Coloma, L.A.; Yánez-Muñoz, M.; Rivera, M.; Gutierrez, P.; Ron, S.R.; Bolívar, W. The IUCN Red List of Threatened Species 2019. Cent. Geckoideum 2019, e.T54911A85877414. [CrossRef]

118. Duellman, W.E. Liste der rezenten Amphibien und Reptilien: Hylidae, Centrolenidae, Pseudidae. Das Tierreich 1977, 95, 1-225.

119. González-Fernández, J.E. Anfibios colectados por la Comisión Científica del Pacífico (entre 1862 y 1865) conservados en el Museo Nacional de Ciencias Naturales de Madrid. Graellsia 2006, 62, 111-158. [CrossRef]

120. Duellman, W.E. Three new species of centrolenid frogs from the Pacific versant of Ecuador and Colombia. Univ. Kans. Mus. Nat. Hist. Occas. Pap. 1981, 88, 1-9.

121. Krynak, K.L.; Wessels, D.G.; Imba, S.M.; Lyons, J.A.; Guayasamin, J.M. Newly discovered population of Bumpy Glassfrog, Centrolene heloderma (Duellman, 1981), with discussion of threats to population persistence. Check List 2018, 14, 261. [CrossRef]

122. Mejía, D.; Cisneros-Heredia, D.F.; Gómez, D.; Vargas-Salinas, F.; Chaves Portilla, G.; Gonzalez Duran, G.A.; Coloma, L.A.; Rada, M.; Gutierrez, P.; Bernal, M.H.; et al. The IUCN Red List of Threatened Species 2019. Cent. Heloderma 2019, e.T54916A85878225. [CrossRef]

123. Martín-Torrijos, L.; Sandoval-Sierra, J.V.; Diéguez-Uribeondo, J.; Bosch, J.; Muñoz, J.; Guayasamin, J.M. Rainbow Trout (Oncorhynchus mykiss) threaten Andean amphibians. Neotrop. Biodivers. 2016, 2, $26-36$. [CrossRef]

124. Mendoza, Á.; Wild, E.; Delia, J.; Lynch, J.; Bravo, L.; Rada, M. The IUCN Red List of Threatened Species 2019. Cent. Huilense 2019, e.T54918A49363441. [CrossRef]

125. Guayasamin, J.M.; Funk, W.C. The amphibian community at Yanayacu Biological Station, Ecuador, with a comparison of vertical microhabitat use among Pristimantis species and the description of a new species of the Pristimantis myersi group. Zootaxa 2009, 2220, 41-66. [CrossRef]

126. Coloma, L.A.; Ron, S.; Wild, E.; Cisneros-Heredia, D. The IUCN Red List of Threatened Species 2004. Cent. Lynchi 2004, e.T54924A11225650. [CrossRef]

127. Duellman, W.E. The identity of Centrolenella grandisonae Cochran and Goin (Anura, Centrolenidae). Trans. Kans. Acad. Sci. 1980, 83, 26-32. [CrossRef]

128. Suárez-Mayorga, A.M. Lista preliminar de la fauna Amphibia presente en el transecto la Montañita-Alto de Gabinete, Caqutá, Colombia. Rev. Acad. Colomb. Cienc. Exact. Fís. Nat. 1999, 23, 395-405. 
129. Ruiz-Carranza, P.M.; Lynch, J.D. Ranas Centrolenidae de Colombia II. Nuevas especies de Centrolene de la Cordillera Oriental y Sierra Nevada de Santa Marta. Lozania 1991, 58, 1-26.

130. Guayasamin, J.M.; Cisneros-Heredia, D.F.; Yánez-Muñoz, M.H.; Bustamante, M.R. Notes on geographic distribution. Amphibia, Centrolenidae, Centrolene ilex, Centrolene litorale, Centrolene medemi, Cochranella albomaculata, Cochranella ametarsia: Range extensions and new country records. Check List 2006, 2, 24-25. [CrossRef]

131. Lynch, J.; Renjifo, J.; Rada, M.; Bolívar, W. The IUCN Red List of Threatened Species 2019. Cent. Medemi 2019, e.T54926A49364088. [CrossRef]

132. Salgado, A.L.; Guayasamin, J.M. Parental care and reproductive behavior of the minute dappled glassfrog (Centrolenidae: Centrolene peristictum). South Am. J. Herpetol. 2018, 13, 211-220. [CrossRef]

133. Ruiz-Carranza, P.M.; Lynch, J.D. Ranas Centrolenidae de Colombia, X. Los centrolénidos de un perfil del flanco oriental de la Cordillera Central en el Departamento de Caldas. Rev. Acad. Colomb. Cienc. Exact. Fís. Nat. 1997, 21, 541-553.

134. Cisneros-Heredia, D.F.; McDiarmid, R.W. Amphibia, Centrolenidae, Centrolene peristictum, Centrolene prosoblepon, Cochranella cochranae, Cochranella midas, Cochranella resplendens, Cochranella spinosa, Hyalinobatrachium munozorum: Range extensions and new provincial records. Check List 2005, 1, 18-22. [CrossRef]

135. Cisneros-Heredia, D.F.; Wild, E.; Lynch, J.; Mueses-Cisneros, J.J.; Reyes, J.P.; Coloma, L.A.; Gutierrez, P.; Ron, S.R. The IUCN Red List of Threatened Species 2019. Cent. Peristictum 2019, e.T54931A85879425. [CrossRef]

136. Cisneros-Heredia, D.F.; Reyes, J.P.; Coloma, L.A.; Yánez-Muñoz, M.; Ron, S.R. The IUCN Red List of Threatened Species 2019. Cent. Pipilatum 2019, e.T54933A98643479. [CrossRef]

137. Wild, E.R. Two new species of centrolenid frogs from the Amazonian slope of the Cordillera-Oriental, Ecuador. J. Herpetol. 1994, 28, 299-310. [CrossRef]

138. Lynch, J.; Rueda-Almonacid, J.V. The IUCN Red List of Threatened Species 2019. Cent. Sanchezi 2019, e.T54939A49365296. [CrossRef]

139. Cisneros-Heredia, D.F.; McDiarmid, R.W. A new species of the genus Centrolene (Amphibia: Anura: Centrolenidae) from Ecuador with comments on the taxonomy and biogeography of Glassfrogs. Zootaxa 2006, 1344, 1-32.

140. Terán-Valdez, A.; Guayasamin, J.M. The tadpole of the glassfrog Chimerella mariaelenae (Anura: Centrolenidae). CienciAmérica 2014, 3, 17-22.

141. Cisneros-Heredia, D.F. Amphibia, Anura, Centrolenidae, Chimerella mariaelenae (Cisneros-Heredia and McDiarmid, 2006), Rulyrana flavopunctata (Lynch and Duellman, 1973), Teratohyla pulverata (Peters, 1873), and Teratohyla spinosa (Taylor, 1949): Historical records, distribution extension and new provincial record in Ecuador. Check List 2009, 5, 912-916.

142. Cisneros-Heredia, D.F.; Guayasamin, J.M. Amphibia, Anura: Centrolenidae, Centrolene mariaelenae: Distribution extension, Ecuador. Check List 2006, 2, 93-95. [CrossRef]

143. Catenazzi, A.; Venegas, P.J. Anfibios y reptiles/Amphibians and reptiles. Rapid Biol. Soc. Invent. Rep. 2012, 24, 106-117. (in Spanish); 260-271 (in English).

144. Catenazzi, A.; Cisneros-Heredia, D.F.; Sánchez, J.; Brito, J.; Szekely, P.; Betancourt, R. The IUCN Red List of Threatened Species 2018. Chimerella Mariaelenae 2018, e.T135968A516500. [CrossRef]

145. Taylor, E.H. Costa Rican frogs of the genera Centrolene and Centrolenella. Univ. Kans. Sci. Bull. 1949, 33, 257-270. [CrossRef]

146. Starrett, P.H. Descriptions of tadpoles of Middle American frogs. Misc. Publ. Mus. Zool. Univ. Mich. 1960, 110, 1-37.

147. Hoffmann, H. The glass frog tadpoles of Costa Rica (Anura: Centrolenidae): A study of morphology. Abh. Der Senckenberg Ges. Für Nat. 2010, 567, 1-78.

148. Savage, J.M. The Amphibians and Reptiles of Costa Rica: A Herpetofauna Between Two Continents, Between Two Seas; The University of Chicago Press: Chicago, IL, USA; London, UK, 2002; 934p.

149. Savage, J.M.; Starrett, P.H. A new fringe-limbed tree-frog (family Centrolenidae) from lower Central America. Copeia 1967, 604-609. [CrossRef] 
150. Ibáñez, D.R.; Rand, A.S.; Jaramillo, A. Los Anfibios del Monumento Natural Barro Colorado, Parque Nacional Soberanía y Áreas Adyacentes; Mizrachi, E., Pujol, S.A., Eds.; Fundación Natura, Smithsonian Tropical Research Institute: Santa Fe, Bogota, Colombia, 1999.

151. Culebras, J.; Angiolani-Larrea, F.N.; Tinajero-Romero, J.; Pellet, C.; Yeager, J. First record and notable range extension of the glass frog Cochranella granulosa (Taylor, 1949) (Anura, Centrolenidae) found in Ecuador. Herpetol. Notes 2020, 13, 353-355.

152. Solís, F.; Ibáñez, R.; Jaramillo, C.; Chaves, G.; Savage, J.; Cruz, G.; Wilson, L.D.; Köhler, G.; Kubicki, B.; Sunyer, J. The IUCN Red List of Threatened Species 2010. Cochranella Granulosa 2010, e.T54964A11232691. [CrossRef]

153. Duellman, W.E. Additional studies of chromosomes of anurans amphibians. Syst. Zool. 1967, 16, $38-43$. [CrossRef] [PubMed]

154. Ruiz-Carranza, P.M.; Lynch, J.D. Ranas centrolenidos de Colombia. IX. Dos nuevas especies del suroeste de Colombia. Lozania 1996, 68, 1-11.

155. Frost, D.R. Amphibian Species of the World: An Online Reference, Version 3.0; Museum of Natural History: New York, NY, USA, 2004. Available online: http://research.amnh.org/vz/herpetology/amphibia/American (accessed on 12 November 2019).

156. Cisneros-Heredia, D.F.; Morales, M.; Rada, M.; Pinto-Erazo, M.; Yánez-Muñoz, M.; Calderón, M.; Ortega-Andrade, M.; Bejarano-Muñoz, P.; Grant, T. The IUCN Red List of Threatened Species 2019. Cochranella Litoralis 2019, e.T54923A49367704. [CrossRef]

157. Guayasamin, J.M.; Bonaccorso, E. A new species of glass frog (Centrolenidae: Cochranella) from the lowlands of northwestern Ecuador, with comments on the Cochranella granulosa group. Herpetologica 2004, 60, 485-494. [CrossRef]

158. Cisneros-Heredia, D.F.; Delia, J.; Yánez-Muñoz, M.H.; Ortega-Andrade,H.M. Natural history and intraspecific variation of the Ecuadorian Blue Glassfrog Cochranella mache Guayasamin \& Bonaccorso, 2004 (Anura: Centrolenidae). Herpetozoa 2008, 2, 57-66.

159. Ortega-Andrade, H.M.; Rojas-Soto, O.; Paucar, C. Novel data on the ecology of Cochranella mache (Anura: Centrolenidae) and the importance of protected Areas for this Critically Endangered glassfrog in the Neotropics. PLOS ONE 2013, 8. [CrossRef]

160. Ortega-Andrade, H.M.; Bermingham, J.; Aulestia, C.; Paucar, C. Herpetofauna of the Bilsa Biological Station, province of Esmeraldas, Ecuador. Check List 2010, 6, 119-154. [CrossRef]

161. Jaramillo-Martinez, A.F.; Valencia-Z, A.; Cardona, V.E.; Castro-Herrera, F.; Cisneros-Heredia, D.F. Range extension of Cochranella mache Guayasamin and Bonaccorso, 2004 (Anura: Centrolenidae) with comments on the distribution of C. euknemos (Savage and Starrett, 1967) in Colombia. Herpetol. Notes 2015, 8, 161-163.

162. Guayasamin, J.M. Cochranella mache. In IUCN 2013. IUCN Red List of Threatened Species. Version 2013.1. 2006. Available online: www.iucnredlist.org (accessed on 26 September 2013).

163. Cisneros-Heredia, D.F.; Delia, J.; Yánez-Muñoz, M.H.; Ortega-Andrade, H.M. Endemic Ecuadorian glassfrog Cochranella mache is critically endangered because of habitat loss. Oryx 2009, 44, 114-117. [CrossRef]

164. Aguayo, R.; Harvey, M.B. A new glassfrog of the Cochranella granulosa group (Anura: Centrolenidae) from a Bolivian cloud forest. Herpetologica 2006, 62, 323-330. [CrossRef]

165. Duellman, W.E. The biology of an Equatorial herpetofauna in Amazonian Ecuador. Misc. Publ. Mus. Nat. Hist. Univ. Kans. 1978, 65, 1-352.

166. Guayasamin, J.M.; Ron, S.R.; Cisneros-Heredia, D.F.; Lamar, W. A new species of frog of the Eleutherodactylus lacrimosus assemblage (Leptodactylidae) from the Western Amazon Basin, with comments on the utility of canopy surveys in lowland rainforest. Herpetologica 2006, 62, 191-202. [CrossRef]

167. Terán-Valdez, A.; Guayasamin, J.M.; Coloma, L.A. Description of the tadpole of Cochranella resplendens and redescription of the tadpole of Hyalinobatrachium aureoguttatum (Anura, Centrolenidae). Phyllomedusa 2009, 8, 105-124. [CrossRef]

168. Mijares-Urrutia, A. Una nueva especie de rana arborícola (Amphibia: Hylidae) de un bosque nublado del oeste de Venezuela. Rev. Bras. de Biol. 1998, 58, 659-663. [CrossRef]

169. Rada, M.; Rueda-Almonacid, J.V.; Velásquez-Álvarez, A.A.; Sánchez-Pacheco, S.J. Descripción de las larvas de dos centrolénidos (Anura: Centrolenidae) del noroccidente de la Cordillera Oriental, Colombia. Pap. Avulsos Zool. 2007, 47, 259-272. [CrossRef] 
170. Noonan, B.; Bonett, R. A new species of Hyalinobatrachium (Anura: Centrolenidae) from the highlands of Guyana. J. Herpetol. 2003, 37, 91-97. [CrossRef]

171. Twomey, E.M.; Brown, J.L. Range extension: Cochranella resplendens. Herpetol. Rev. 2005, 36, 1.

172. Molina-Zuluaga, C.; Cano, E.; Restrepo, A.; Rada, M.; Daza, J.M. Out of Amazonia: The unexpected trans-Andean distribution of Cochranella resplendens (Lynchy and Duellman, 1978) (Anura: Centrolenidae). Zootaxa 2017, 4238, 268-274. [CrossRef]

173. Cisneros-Heredia, D.F.; Brown, J. The IUCN Red List of Threatened Species 2018. Cochranella Resplendens 2018, e.T54985A54458254. [CrossRef]

174. Duellman, W.E.; Schulte, R. New species of centrolenid frogs from northern Peru. Univ. Kans. Mus. Nat. Hist. Occas. Pap. 1993, 155, 1-33.

175. Cisneros-Heredia, D.F.; Guayasamin, J.M. Notes on the taxonomy of some glassfrogs from the Andes of Peru and Ecuador (Amphibia: Centrolenidae). Pap. Avulsos Zool. 2014, 54, 161-168. [CrossRef]

176. Yánez-Muñoz, M.H.; Meza-Ramos, P.; Ortega-Andrade, H.M.; Mueses-Cisneros, J.J.; Reyes-Puig, M.; Reyes-Puig, J.P.; Durán, J.C. Nuevos datos de distribución de ranas de cristal (Amphibia: Centrolenidae) en el oriente de Ecuador, con comentarios sobre la diversidad en la región. Avances en Ciencias e Ingenierías 2010, 3, 33-40. [CrossRef]

177. Mueses-Cisneros, J.J.; Brito, J.; Sánchez, J.; Szekely, P.; Betancourt, R. The IUCN Red List of Threatened Species 2018. Espadarana Audax 2018, e.T78163103A78162747. [CrossRef]

178. Ospina-Sarria, J.J.; Bolívar-G, W.; Mendez-Narvaez, J. Amphibia, Anura, Centrolenidae, Espadarana callistomma (Guayasamin and Trueb, 2007): First country records from Colombia. Check List 2010, 6, 244-245. [CrossRef]

179. Cisneros-Heredia, D.F.; Guayasamin, J.; Rada, M. The IUCN Red List of Threatened Species 2019. Espadarana Callistomma 2019, e.T135738A85908349. [CrossRef]

180. Cisneros-Heredia, D.F. A new species of glassfrog of the genus Centrolene from the foothills of Cordillera Oriental of Ecuador (Anura: Centrolenidae). Herpetozoa 2007, 20, 27-34.

181. Cisneros-Heredia, D.F.; Brito, J.; Sánchez, J.; Yánez-Muñoz, M.; Szekely, P.; Betancourt, R. The IUCN Red List of Threatened Species 2019. Espadarana Durrellorum 2019, e.T135835A98657065. [CrossRef]

182. Boettger, O. Katalog der Batrachier-Sammlung im Museum der Naturforschenden Gesellschaft in Frankfurt am Main; Knauer: Frankfurt am Main, Germany, 1892.

183. Savage, J.M. Type localities for species of amphibians and reptiles described from Costa Rica. Rev. De Biol. Trop. San José 1974, 22, 71-122.

184. Boulenger, G.A. Descriptions of new batrachians collected by Mr. C.F. Underwood in Costa Rica. Ann. Mag. Nat. Hist. Lond. 1896, 18, 340-342. [CrossRef]

185. Günther, A.C.L.G. Reptilia and Batrachia. Part 166. Biol. Cent. Am. 1901, 7, 269-292.

186. Noble, G.K. Some Neotropical batrachians preserved in the United States National Museum with a note on the secondary sexual characters of these and other amphibians. Proc. Biol. Soc. Wash. 1924, 37, 65-72.

187. Goin, C.J. Distribution and synonymy of Centrolenella fleischmanni in northern South America. Herpetologica 1964, 20, 1-8.

188. Jacobson, S.K. Reproductive behavior and male mating success in two species of glass frogs (Centrolenidae). Herpetologica 1985, 41, 396-404.

189. Hayes, M.P. A study of clutch attendance in the Neotropical frog Centrolenella fleischmanni (Anura: Centrolenidae). Ph.D. Thesis, University of Miami, Coral Gables, FL, USA, 1991, Unpublished.

190. McCaffery, R.; Lips, K. Survival and abundance in males of the glass frog Espadarana (Centrolene) prosoblepon in central Panama. J. Herpetol. 2013, 47, 162-168. [CrossRef]

191. Gosner, K.L. A simplified table for staging anuran embryos and larvae with notes on identification. Herpetologica 1960, 16, 183-190.

192. Kubicki, B.; Bolaños, F.; Chaves, G.; Solís, F.; Ibáñez, R.; Coloma, L.A.; Ron, S.R.; Wild, E.; Cisneros-Heredia, D.F.; Renjifo, J. The IUCN Red List of Threatened Species 2010. Espadarana Prosoblepon 2010, e.T54934A11228804. [CrossRef]

193. Eaton, T.H. An anatomical study of a neotropical tree frog, Centrolene prosoblepon (Salientia: Centrolenidae). Univ. Kans. Sci. Bull. 1958, 39, 459-472.

194. Guayasamin, J.M.; Vieira, J.; Glor, R.E.; Hutter, C.R. A new glassfrog (Centrolenidae: Hyalinobatrachium) from the Topo river basin, Amazonian slopes of the Andes of Ecuador. Amphib. Reptile Conserv. 2019, 13, 133-144 e194. 
195. Barrera-Rodríguez, M.; Ruiz-Carranza, P.M. Una nueva especie del género Centrolenella Noble 1920 (Amphibia: Anura: Centrolenidae) de la Cordillera Occidental de Colombia. Trianea 1989, 3, 77-84.

196. Valencia-Aguilar, A.; Castro-Herrera, F.; Ramírez-Pinilla, M.P. Microhabitats for oviposition and male clutch attendance in Hyalinobatrachium aureoguttatum (Anura: Centrolenidae). Copeia 2012, 2012, 722-731. [CrossRef]

197. Ibáñez, D.R.; Jaramillo, F.E.; Jaramillo, A. Ampliación del ámbito de distribución y descripción del renacuajo de la rana de cristal Hyalinobatrachium aureoguttatum (Anura: Centrolenidae). Rev. Acad. Colomb. Cienc. Exact. Fís. Nat. 1999, 23, 293-298.

198. Acosta-Galvis, A.R. Ranas, Salamandras y Caecilias (Tetrapoda: Amphibia) de Colombia. Biota Colomb. 2000, 1, 289-319.

199. Bustamante, M.R.; Cisneros-Heredia, D.F.; Yánez-Muñoz, M.H.; Ortega-Andrade, H.M.; Guayasamin, J.M. Amphibia, Centrolenidae, Cochranella pulverata, Hyalinobatrachium aureoguttatum: Distribution extension, Ecuador. Check List 2007, 3, 271-276. [CrossRef]

200. Solís, F.; Ibáñez, R.; Jaramillo, C.; Fuenmayor, Q.; Castro, F.; Grant, T. The IUCN Red List of Threatened Species 2010. Hyalinobatrachium Aureoguttatum 2010, e.T55003A11234997. [CrossRef]

201. Taylor, E.H. Notes on Costa Rican Centrolenidae with descriptions of new forms. Univ. Kans. Sci. Bull. 1958, 39, 41-68.

202. Savage, J.M. A new tree-frog (Centrolenidae) from Costa Rica. Copeia 1967, 1967, 325-331. [CrossRef]

203. McCranie, J.R.; Wilson, L.D. Two new species of centrolenid frogs of the genus Hyalinobatrachium from eastern Honduras. J. Herpetol. 1997, 31, 10-16. [CrossRef]

204. Kubicki, B. Rediscovery of Hyalinobatrachium chirripoi (Anura: Centrolenidae) in southeastern Costa Rica. Rev. Biol. Trop. 2004, 215-218. [CrossRef]

205. Solís, F.; Ibáñez, R.; Chaves, G.; Savage, J.M.; Jaramillo, C.; Fuenmayor, Q.; Castro, F.; Grant, T.; Wild, E.R.; Kubicki, B. The IUCN Red List of Threatened Species 2008. Hyalinobatrachium Chirripoi 2008, e.T55006A11235906. [CrossRef]

206. Boettger, O. Ein neuer Laubfrosch aus Costa Rica. Berichte der Senckenbergischen Naturforschenden Gesellschaft in Frankfurt am Main. 1893, Volume 1893, pp. 251-252. Available online: https://www. biodiversitylibrary.org/itemdetails/33793 (accessed on 29 December 2019).

207. Mertens, R. Die herpetologische Sektion des Natur-Museums und Forschungs-Institutes Senckenberg in Frankfurt a. M. nebst einem Verzeichnis ihrer Typen. Senckenbergiana Biol. 1967, 48, 1-106.

208. Cope, E.D. Third addition to a knowledge of the Batrachia and Reptilia of Costa Rica. Proc. Acad. Nat. Sci. USA 1894, 46, 194-206.

209. Starrett, P.H.; Savage, J.M. The systematic status and distribution of Costa Rican glass-frogs, genus Centrolenella (Family Centrolenidae), with description of a new species. Bull. South. Calif. Acad. Sci. 1973, 72, 57-78.

210. Boulenger, G.A. Reptilia and Batrachia (1894). Zool. Rec. 1895, 31, 1-44.

211. Taylor, E.H. New tailless Amphibia from Mexico. Univ. Kans. Sci. Bull. 1942, 28, 67-89.

212. Mendoza, A.M.; Bolívar-García, W.; Vásquez-Domínguez, E.; Ibánez, R.; Parra-Olea, G. The role of Central American barriers in shaping the evolutionary history of the northernmost glassfrog, Hyalinobatrachium fleischmanni (Anura: Centrolenidae). Peer] 2019, 7, e6115. [CrossRef]

213. Greer, B.J.; Wells, K.D. Territorial and reproductive behavior of the tropical American frog Centrolenella fleischmanni. Herpetologica 1980, 36, 318-326.

214. Villa, J. Biology of a Neotropical glass frog, Centrolenella fleischmanni (Boettger), with special references to its frogfly associates. Milwaukee Public Mus. Contrib. Biol. Geol. 1984, 21, 1-17.

215. Delia, J.; Cisneros-Heredia, D.F.; Whitney, J.; Murrieta-Galindo, R. Observations on the reproductive behavior of a Neotropical Glassfrog, Hyalinobatrachium fleischmanni (Anura: Centrolenidae). South Am. J. Herpetol. 2010, 5, 1-12. [CrossRef]

216. McDiarmid, R.W. Glass frog romance along a tropical stream. TerraLos Angeles Cty. Mus. Nat. Hist. 1975, 13, 14-18.

217. Frost, D.R. Amphibian Species of the World: An Online Reference, Version 6.0; Museum of Natural History: New York, NY, USA, 2019. Available online: http://research.amnh.org/vz/herpetology/amphibia/American (accessed on 12 November 2019).

218. Cruz, F.K.; Urgiles, V.L.; Sánchez-Nivicela, J.C.; Siddons, D.C.; Cisneros-Heredia, D.F. Southernmost records of Hyalinobatrachium fleischmanni (Anura: Centrolenidae). Check List 2017, 13, 67-70. [CrossRef] 
219. Coloma, L.A.; Ron, S.R.; Wild, E.R.; Cisneros-Heredia, D.F.; Solís, F.; Ibáñez, R.; Santos-Barrera, G.; Kubicki, B. The IUCN Red List of Threatened Species 2010. Hyalinobatrachium Fleischmanni 2010, e.T55014A11238651. [CrossRef]

220. Ayarzagüena, J. Los Centrolenidos de la Guayana Venezolana; Publicaciones de la Asociación de Amigos de Doñana: Sevilla, Spain, 1992; Volume 1, pp. 1-46.

221. Duellman, W.E. Amphibian species of the world: Additions and corrections. Univ. Kans. Publ. Mus. Nat. Hist. 1993, 21, 1-372.

222. Lescure, J.; Marty, C. Atlas des Amphibiens de Guyane; Muséum National d'Histore Naturelle: Paris, France, 2001; 388p.

223. Yánez-Muñoz, M.H.; Pérez-Peña, P.; Cisneros-Heredia, D.F. New country records of Hyalinobatrachium iaspidiense (Amphibia, Anura, Centrolenidae) from the Amazonian lowlands of Ecuador and Peru. Herpetol. Notes 2009, 2, 49-52.

224. Barrio-Amorós, C.L.; Brewer-Carias, C. Herpetological results of the 2002 expedition to Sarisariñama, a tepui in Venezuelan Guayana, with the description of five new species. Zootaxa 2008, 1942, 1-68. [CrossRef]

225. Guayasamin, J.M.; North, S. Amphibia, Centrolenidae, Hyalinobatrachium iaspidiense: Distribution extension. Check List 2009, 5, 526-529. [CrossRef]

226. Cordeiro-Duarte, A.C.; Sanaiotti, T.M.; Duarte, E.L.C.; Pereira, O. Geographic Distribution. Hyalinobatrachium nouraguensis. Herpetol. Rev. 2002, 33, 220.

227. Caldwell, J.P.; Shepard, D.B. Frogs of the Lower Cristalino River Area. In Amphibians and Reptiles of the Lower Cristalino River Region of the Southern Amazon; Vitt, L.J., Caldwell, J.P., Colli, G.R., França, F.G.R., Shepard, D.B., Eds.; Norman, Sam Noble Oklahoma Museum of Natural History: Norman, OK, USA, 2005. Available online: http://www.omnh.ou.edu/personnel/herpetology/vitt/Cerrado/Cristalino/index.htm (accessed on 12 September 2019).

228. Ernst, R.; Rödel, M.O.; Arjoon, D. On the cutting edge-The anuran fauna of the Mabura Hill Forest Reserve, Central Guyana. Salamandra 2005, 41, 179-194.

229. Kok, P.J.R.; Castroviejo-Fisher, S. Glassfrogs (Anura: Centrolenidae) of Kaieteur National Park, Guyana, with notes on the distribution and taxonomy of some species of the family in the Guiana Shield. Zootaxa 2008, 1680, 25-53. [CrossRef]

230. La Marca, E.; Señaris, C. The IUCN Red List of Threatened Species. Hyalinobatrachium Iaspidiense 2004, e.T55018A11239792. [CrossRef]

231. Castroviejo-Fisher, S.; Padial, J.M.; Chaparro, J.C.; Aguayo, R.; De la Riva, I. A new species of Hyalinobatrachium (Anura: Centrolenidae) from the Amazonian slopes of the central Andes, with comments on the diversity of the genus in the area. Zootaxa 2009, 2143, 24-44. [CrossRef]

232. Castroviejo-Fisher, S.; Moravec, J.; Aparicio, J.; Guerrero-Reinhards, M.; Calderón, G. DNA taxonomy reveals two new species records of Hyalinobatrachium (Anura: Centrolenidae) for Bolivia. Zootaxa 2011, 2798, 64-68. [CrossRef]

233. Cisneros-Heredia, D.F.; McDiarmid, R.W. Primer registro de Hyalinobatrachium ruedai (Amphibia: Centrolenidae) en Ecuador, con notas sobre otras especies congenéricas. Herpetotropicos 2006, 3, 21-28.

234. Rodríguez, L.; Martinez, J.L.; Coloma, L.A.; Ron, S.R.; Cisneros-Heredia, D.F.; Angulo, A.; Icochea, J.; Acosta, A. The IUCN Red List of Threatened Species 2010. Hyalinobatrachium Munozorum 2010, e.T195860A115339384. [CrossRef]

235. Angulo, A.; Cisneros-Heredia, D.F.; Icochea, M.J.; Martinez, J.L.; Jungfer, K.; Rodriguez, L.; Coloma, L.A.; Ron, S.R.; Sinsch, U.; Arizabal, W. The IUCN Red List of Threatened Species 2014. Hyalinobatrachium Pellucidum 2014, e.T47255219A47255232. [CrossRef]

236. Dunn, E.R. New frogs from Panama and Costa Rica. Occas. Pap. Boston Soc. Nat. Hist. 1931, 5, $385-401$.

237. Hayes, M.P. Predation on the adults and prehatching stages of glass frogs (Centrolenidae). Biotropica 1989, 15, 74-76. [CrossRef]

238. McDiarmid, R.W.; Adler, K. Notes on the territorial and vocal behaviour of Neotropical frogs of the genus Centrolenella. Herpetologica 1974, 30, 75-78.

239. Vockenhuber, E.A.; Hödl, W.; Amézquita, A. Glassy fathers do matter: Egg attendance enhances embryonic survivorship in the glass frog Hyalinobatrachium valerioi. J. Herpetol. 2009, 43, 340-344. [CrossRef] 
240. Solís, F.; Ibáñez, R.; Chaves, G.; Savage, J.M.; Bolaños, F.; Kubicki, B.; Jaramillo, C.; Fuenmayor, Q.; Coloma, L.A.; Ron, S.R.; et al. The IUCN Red List of Threatened Species 2008. Hyalinobatrachium Valerioi 2008, e.T55036A11243874. [CrossRef]

241. Guayasamin, J.M.; Cisneros-Heredia, D.F.; Maynard, R.J.; Lynch, R.L.; Culebras, J.; Hamilton, P.S. A marvelous new glassfrog (Centrolenidae, Hyalinobatrachium) from Amazonian Ecuador. ZooKeys 2017, 673, 1-20. [CrossRef] [PubMed]

242. Maynard, R.J.; Aall, N.C.; Saenz, D.; Hamilton, P.S.; Kwiatkowski, M.A. Road-edge effects on herpetofauna in a lowland Amazonian rainforest. Trop. Conserv. Sci. 2016, 9, 264-290. [CrossRef]

243. Coloma, L.A.; Ron, S. The IUCN Red List of Threatened Species. Nymphargus Anomalus 2004, e.T54946A11230785. [CrossRef]

244. Lynch, J.D. A new ocellated frog (Centrolenidae) from western Colombia. Proc. Biol. Soc. Wash. 1990, 103, 35-38.

245. Bolívar-G, W.; Coloma, L.A.; Ron, S.R.; Cisneros-Heredia, D.F.; Lynch, J.D.; Wild, E.R. The IUCN Red List of Threatened Species. Cochranella Balionota 2004, e.T54948A11231013. [CrossRef]

246. Lynch, J.D.; Ruiz-Carranza, P.M. A remarkable new centrolenid frog from Colombia with a review of nuptial excrescences in the family. Herpetologica 1996, 52, 525-535.

247. Yánez-Muñoz, M.H.; Sánchez, J.C.; López, K.; Rea, S.E.; Meza-Ramos, P.; Oyagata, C.L.A.; Guerrero, P. Ampliaciones del rango de distribución de algunas especies de anfibios y reptiles en el suroccidente de Ecuador. Av. En Cienc. E Ing. 2014, 6, B2-B5.

248. Cisneros-Heredia, D.F. The IUCN Red List of Threatened Species. Nymphargus Buenaventura 2008, e.T135767A4198831. [CrossRef]

249. Coloma, L.A.; Ron, S.R.; Almeida, D. The IUCN Red List of Threatened Species 2004. Nymphargus Cariticommatus 2004, e.T54950A11231356. [CrossRef]

250. Salaman, P.G.W.; Donegan, T.M. (Eds.) Colombia '98 expedition to Serranía de los Churumbelos: Preliminary Report. Fund. Proaves 1998, 1, 1-46.

251. Coloma, L.A.; Ron, S.R.; Almeida, D. The IUCN Red List of Threatened Species 2010. Nymphargus Cochranae 2010, e.T54954A11231957. [CrossRef]

252. Guayasamin, J.M.; Tapia, E.; Aldas, S.; Deichmann, J. Anfibios y Reptiles de los Tepuyes de la Cuenca Alta del Río Nangaritza, Cordillera del Cóndor. In Evaluación Ecológica Rápida de la Biodiversidad de los Tepuyes de la Cuenca Alta del Río Nangaritza, Cordillera del Cóndor, Ecuador; Guayasamin, J.M., Bonaccorso, E., Eds.; Conservación Internacional: Quito, Ecuador, 2011; pp. 56-61.

253. Cisneros-Heredia, D.F.; Meza-Ramos, P. An enigmatic new species of glassfrog (Amphibia: Anura: Centrolenidae) from the Amazonian Andean slopes of Ecuador. Zootaxa 2007, 1485, 33-41. [CrossRef]

254. Almendáriz, A.; Simmons, J.E.; Vaca-Guerrero, J.; Brito, J. Overview of the herpetofauna of the unexplored Cordillera del Cóndor of Ecuador. Amphibian Reptile Conserv. 2014, 8, 45-64.

255. Ruiz-Carranza, P.M.; Lynch, J.D. Ranas Centrolenidae de Colombia, V. Cuatro nuevas especies de Cochranella de la Cordillera Central. Lozania 1995, 62, 1-24.

256. Quevedo, A.; Mejía, D.; Gómez, D.; Vargas-Salinas, F.; Gonzalez Duran, G.A.; Lynch, J.; Bernal, M.H.; Gutierrez, P.; Bolívar, W. The IUCN Red List of Threatened Species 2019. Nymphargus Garciae 2019, e.T54962A85873982. [CrossRef]

257. Sorokin, A.; Steigerwald, E. Interspecific combat between Nymphargus aff. grandisonae and Espadarana prosoblepon (Anura, Centrolenidae). Herpetol. Notes 2017, 10, 283-285.

258. Bogert, C.M. The influence of sound on the behavior of amphibians and reptiles. In Animal Sounds and Communication. American Institute of Biological Sciences Publication No. 7; Lanyon, W.E., Tavolga, W.N., Eds.; Intelligencer Printing Company: Washington, DC, USA, 1960; pp. 137-320.

259. Duellman, W.E.; Trueb, L. Biology of Amphibians; The Johns Hopkins University Press: Baltimore, Maryland; London, UK, 1994.

260. Ospina-Sarria, J.J.; Bolívar, W.; Mendez-Narvaez, J.; Burbano-Yandi, C. The tadpole of Nymphargus grandisonae (Anura: Centrolenidae) from Valle del Cauca, Colombia. South Am. J. Herpetol. 2011, 6, 79-86. [CrossRef]

261. Bolívar-G, W.; Coloma, L.A.; Ron, S.R.; Cisneros-Heredia, D.F.; Wild, E.R. The IUCN Red List of Threatened Species. Nymphargus Grandisonae 2004, e.T54914A11222520. [CrossRef]

262. Vanegas-Guerrero, J.; Ramírez-Castaño, V.A.; Guevara-Molina, S.C. Nymphargus grandisonae (Cochran y Goin 1970). Catálogo de Anfibios y Reptiles de Colombia 2014, 2, 51-55. 
263. Mejía, D.; Gómez, D.; Vargas-Salinas, F.; Gonzalez Duran, G.A.; Coloma, L.A.; Bernal, M.H.; Rada, M.; Yánez-Muñoz, M.; Gutierrez, P.; Ron, S.R.; et al. The IUCN Red List of Threatened Species 2018. Nymphargus Griffithsi 2018, e.T54965A85873493. [CrossRef]

264. Arcila-Pérez, L.F.; Rios-Soto, J.A.; Montilla, S.O.; Londoño-Guarnizo, C.A.; Vargas-Salinas, F. Vocalization and natural history in populations of a glassfrog assigned to Nymphargus griffithsi in the Central Andes of Colombia. Herpetol. Rev. 2017, 48, 275-280.

265. Cisneros-Heredia, D.F. The IUCN Red List of Threatened Species. Nymphargus Laurae 2008, e.T135996A4223953. [CrossRef]

266. Duellman, W.E.; Toft, C.A. Anurans from Serranía de Sira, Amazonian Perú: Taxonomy and biogeography. Herpetologica 1979, 35, 60-70.

267. Cisneros-Heredia, D.F.; McDiarmid, R.W. Review of the taxonomy and conservation status of the Ecuadorian glassfrog Centrolenella puyoensis Flores \& McDiarmid (Amphibia: Anura: Centrolenidae). Zootaxa 2006, 1361, 21-31.

268. Flores, G.; McDiarmid, R.W. Two new species of South American Centrolenella (Anura: Centrolenidae) related to C. Mariae. Herpetol. 1989, 45, 401-411.

269. Stuart, S.N.; Hoffmann, M.; Chanson, J.S.; Cox, N.A.; Berridge, R.J.; Ramani, P.; Young, B.E. (Eds.) Threatened Amphibians of the World; Lynx Editions: Barcelona, Spain; International Union for the Conservation of Nature: Gland, Switzerland; Conservation International: Arlington, VA, USA, 2008.

270. Cisneros-Heredia, D.F.; Ortega-Andrade, M.; Bejarano-Muñoz, P. The IUCN Red List of Threatened Species. Nymphargus Mariae 2018, e.T88380390A89226232. [CrossRef]

271. Bolívar, W.; Coloma, L.A.; Ron, S.; Almendáriz, A.; Grant, T. The IUCN Red List of Threatened Species 2004. Nymphargus Megacheirus 2004, e.T54969A11233360. [CrossRef]

272. Cisneros-Heredia, D.F.; Venegas, P.J.; Rada, M.; Schulte, R. A new species of glassfrog (Anura: Centrolenidae) from the foothill Andean forests of Ecuador and Peru. Herpetologica 2008, 64, 341-353. [CrossRef]

273. Guerrero, J.A.; Mueses-Cisneros, J.J.; Brito, J.; Guayasamin, J.; Sánchez, J.; Szekely, P.; Betancourt, R.; Castroviejo-Fisher, S. The IUCN Red List of Threatened Species. Nymphargus Posadae 2018, e.T54981A85874598. [CrossRef]

274. Rodríguez, L.O.; Córdova, J.; Icochea, J. Lista preliminar de los anfibios del Perú. Publicaciones Museo Historia Natural Universidad Nacional Mayor San Marcos 1993, 45, 1-22.

275. Coloma, L.A.; Ron, S.R.; Cisneros-Heredia, D.F. The IUCN Red List of Threatened Species 2010. Nymphargus Siren 2010, e.T54992A11226688. [CrossRef]

276. Guayasamin, J.M. A new yellow species of glassfrog (Centrolenidae: Nymphargus) from the Amazonian slopes of the Ecuadorian Andes. Zootaxa 2013, 3651, 193-200. [CrossRef] [PubMed]

277. Ruiz-Carranza, P.M.; Lynch, J.D. Ranas Centrolenidae de Colombia IV. Nuevas especies de Cochranella del grupo ocellata de la Cordillera Oriental. Lozania 1991, 60, 1-13.

278. Lynch, J.D. A new centrolenid frog from the Andes of western Colombia. Rev. Acad. Colomb. Cienc. Exact. Fís. Nat. 1993, 18, 567-569.

279. Guayasamin, J.M. The IUCN Red List of Threatened Species. Nymphargus Wileyi 2008, e.T135864A4213232. [CrossRef]

280. Jiménez-Robles, O.; de la Riva, I.; Guayasamin, J.M. Rulyrana flavopunctata (Yellow-spotted Cochran Frog): Reproduction. Herpetol. Rev. 2015, 46, 238-239.

281. Castro, F.; Rueda, J.V.; Bolívar-G, W.; Estupinan, R.A.; Almendáriz, A. The IUCN Red List of Threatened Species. Rulyrana Flavopunctata 2004, e.T54961A11219097. [CrossRef]

282. Cisneros-Heredia, D.; Angulo, A. The IUCN Red List of Threatened Species. Rulyrana Mcdiarmidi 2009, e.T158475A5200698. [CrossRef]

283. AmphibiaWeb. Information on Amphibian Biology and ConservationBerkeley, California: AmphibiaWeb. Available online: http://amphibiaweb.org/ (accessed on 30 September 2019).

284. Puschendorf, R.; Kubicki, B.; Ryan, M.; Vaughan, C. Cochranella albomaculata (NCN). Reproduction. Herpetol. Rev. 2004, 35, 52.

285. Solís, F.; Ibáñez, R.; Chaves, G.; Savage, J.M.; Jaramillo, C.; Fuenmayor, Q.; Castro, F.; Grant, T.; Wild, E.R.; Kubiki, B.; et al. Iucn Red List Threat. Species. Sachatamia Albomaculata 2010, e.T54944A11230494. [CrossRef] 
286. Cisneros-Heredia, D.F.; Yánez-Muñoz, M.H.; Ortega-Andrade, H.M. Description of a new species of Teratohyla Taylor (Amphibia: Athesphatanura: Centrolenidae) from north-western Ecuador. Zootaxa 2009, 2227, $53-62$. [CrossRef]

287. Cisneros-Heredia, D.F.; Yánez-Muñoz, H.M.; Ortega-Andrade, H.M. Teratohyla sornozai Cisneros-Heredia, Yánez-Muñoz y Ortega-Andrade es un sinónimo junior de Rulyrana orejuela Duellman y Burrowes (Amphibia, Anura, Centrolenidae). Av. En Cienc. E Ing. 2010, 3, B3-B4. [CrossRef]

288. Yánez-Muñoz, M.H.; Cisneros-Heredia, D.F. Amphibia, Anura, Centrolenidae, Cochranella orejuela, first country record from Ecuador. Check List 2008, 4, 50-54. [CrossRef]

289. Almeida-Reinoso, D.; Coloma, L.A. Natural History Notes: Rulyrana orejuela (Orejuela glass frog). Predation. Herpetol. Rev. 2012, 43, 126.

290. Guevara-Molina, S.C.; Rada, M. Sachatamia orejuela. Catálogo de Anfibios y Reptiles de Colombia 2018, 4, 68-72.

291. Castro, F.; Gonzalez Duran, G.A.; Lynch, J.; Grant, T. The IUCN Red List of Threatened Species 2019. Sachatamia Orejuela 2019, e.T54976A49367802. [CrossRef]

292. Myers, C.W.; Stothers, R.B. The myth of Hylas revisited: The frog name Hyla and other commentary on Specimen medicum (1768) of J.N. Laurenti, the "father of herpetology". Arch. Nat. History Lond. 2006, 33, 241-266. [CrossRef]

293. Cisneros-Heredia, D.F. The IUCN Red List of Threatened Species 2008. Teratohyla Amelie 2008, e.T135771A4199328. [CrossRef]

294. Ron, S.R.; Merino-Viteri, A.; Ortiz, D.A. Anfibios del Ecuador; Version 2019.0.; Pontificia Universidad Católica del Ecuador: Museo de Zoología, Córdoba, Argentina, 2019. Available online: https://bioweb.bio/faunaweb/ amphibiaweb (accessed on 5 March 2020).

295. Diaz-Ricaurte, J.; Molina, E.; Guevara, C.; Díaz-Morales, R. Teratohyla midas (Santa Cecilia Cochran Frog). Reproductive behavior. Herpetol. Rev. 2016, 47, 12-13.

296. Araújo, K.d.C.; Pansonato, A.; de Oliveira, R.H.; Morais, D.H.; de Carvalho, V.T.; Ávila, R.W. Advertisement call and new distribution records from Brazil of Teratohyla midas (Lynch \& Duellman, 1973) (Anura, Centrolenidae). Check List 2018, 14, 303-308.

297. Rodríguez, L.; Martinez, J.L.; Azevedo-Ramos, C.; Coloma, L.A.; Ron, S.R. The IUCN Red List of Threatened Species 2004. Teratohyla Midas 2004, e.T54971A11219321. [CrossRef]

298. Peters, W.C.H. Über eine neue Schildkrötenart, Kinosternon Effeldtii und einige andere neue oder weniger bekannte Amphibien. Mon. der Königlich Preuss. Akad. der Wiss. zu Berl. 1873, 603-618.

299. Myers, C.W. Spotted poison frogs: Descriptions of three new Dendrobates from western Amazonia, and resurrection of a lost species from "Chiriqui". Am. Mus. Novit. 1982, 2721, 1-23.

300. Guayasamin, J.M.; Cisneros-Heredia, D.F.; Castroviejo-Fisher, S. Taxonomic identity of Cochranella petersi Goin, 1961 and Centrolenella ametarsia Flores, 1987. Zootaxa 2008, 1815, 25-34. [CrossRef]

301. Hawley, T.J. Embryonic development and mortality in Hyalinobatrachium pulveratum (Anura: Centrolenidae) of south-western Costa Rica. J. Trop. Ecol. 2006, 22, 731-734. [CrossRef]

302. Hoffmann, H. Description of the previously unknown tadpole of Hyalinobatrachium pulveratum (Anura: Centrolenidae). Rev. De Biol. Trop. 2004, 52, 219-228. [CrossRef]

303. Köhler, G. Anfibios y Reptiles de Nicaragua; Herpeton: Offenbach, Germany, 2001.

304. Solís, F.; Ibáñez, R.; Castro, F.; Grant, T.; Acosta-Galvis, A.; Kubicki, B. The IUCN Red List of Threatened Species. Teratohyla Pulverata 2010, e.T55030A11242870. [CrossRef]

305. Ibáñez, D.R.; Solís, F.A.; Jaramillo, C.A.; Rand, A.S. An overview of the herpetology of Panama. In Mesoamerican Herpetology: Systematics, Zoogeography and Conservation; Johnson, J.D., Webb, R.G., Flores-Villela, O.A., Eds.; The University of Texas at El Paso: El Paso, TX, USA, 2000; pp. 159-170.

306. Sunyer, J.; Köhler, G. New country and departmental records of herpetofauna in Nicaragua. Salamandra 2007, 43, 57-62.

307. Sunyer, J.; Páiz, G.; Dehling, D.M.; Köhler, G. A collection of amphibians from Río San Juan, southeastern Nicaragua. Herpetol. Notes 2009, 2, 189-202.

308. Köhler, G. Amphibians of Central America; Herpeton: Offenbach, Germany, 2011.

309. Coloma, L.A.; Ron, S.R.; Wild, E.; Cisneros-Heredia, D.; Solís, F.; Ibáñez, R.; Jaramillo, C.; Chaves, G.; Savage, J.; Cruz, G.; et al. The IUCN Red List of Threatened Species 2010. Teratohyla Spinosa 2010, e.T54996A11227658. [CrossRef] 
310. Jongsma, G.F.M.; Hedley, R.W.; Duraes, R.; Karubian, J. Amphibian diversity and species composition in relation to habitat type and alteration in the Mache-Chindul Reserve, northwest Ecuador. Herpetologica 2014, 70, 34-46. [CrossRef]

311. Lutz, B.; Kloss, G.R. Anfíbios anuros do alto Solimões e Rio Negro. Apontamentos sôbre algumas formas e suas vicariantes. Memórias do Instituto Oswaldo Cruz. Rio de Jan. 1952, 50, 625-678. [CrossRef]

312. Cisneros-Heredia, D.F. Centrolene ritae Lutz is a senior synonym of Cochranella oyampiensis Lescure and Cochranella ametarsia Flores (Anura: Centrolenidae). ACI Avances en Ciencias e Ingenierías 2013, 5, B1-B4. [CrossRef]

313. Lescure, J. Contribution a l'étude des amphibiens de Guyane Francaise. V. Les centrolenidae. Bull. Soc. Zool. Fr. 1975, 100, 385-394.

314. Flores, G. A new Centrolenella from the Amazonian Lowlands of Colombia. J. Herpetol. 1987, 21, $185-190$. [CrossRef]

315. Lima, A.P.; Magnusson, W.E.; Menin, M.; Erdtmann, L.K.; Rodrigues, D.J.; Keller, C.; Hödl, W. Guia de Sapos da Reserva Adolfdo Ducke, Amazônia Central; Áttema Design Editorial: Manaus, Brazil, 2006.

316. Menin, M.; Lima, A.; Rodriguez, D. The tadpole of Vitreorana oyampiensis (Anura: Centrolenidae) in Central Amazonia, Brazil. Zootaxa 2009, 2203, 65-68. [CrossRef]

317. Zimmerman, B.L.; Bogart, J.P. Vocalizations of primary forest frog species in the central Amazon. Acta Amaz. 1984, 14, 473-519. [CrossRef]

318. Muñoz-Saravia, A.; Aguayo-Vedia, C.R. Sobre la presencia de Vitreorana oyampiensis (Lescure, 1975) (Amphibia: Centrolenidae) en Bolivia. Cuad. Herpetol. 2009, 23, 97-99.

319. McCracken, S.F.; Forstner, M.R.J. Bromeliad patch sampling technique for canopy herpetofauna in neotropical forests. Herpetol. Rev. 2008, 39, 170-174.

320. Lynch, J.D. The transition from archaic to advanced frogs. In Evolutionary Biology of the Anurans: Contemporary Research on Major Problems; Vial, J.L., Ed.; University of Missouri Press: Columbia, NY, USA, 1973.

321. Noble, G.K. The Biology of the Amphibia; McGraw-Hill: New York, NY, USA, 1931; pp. 133-182, 577p.

322. Duellman, W.E. On the classification of frogs. Occas. Pap. Mus. Nat. Hist. Univ. Kans. 1975, 42, 1-14.

323. Duellman, W.E. Hylid Frogs of Middle America, 2nd ed.; Society for the Study of Amphibians and Reptiles, Contributions to Herpetology: Lawrence, KS, USA, 2001; No. 18.

324. Ford, L.S.; Cannatella, D.C. The major clades of frogs. Herpetol. Monogr. 1993, 7, 94-117. [CrossRef]

325. Austin, J.D.; Lougheed, S.C.; Tanner, K.; Chek, A.A.; Bogart, J.P.; Boag, P.T. A molecular perspective on the evolutionary affinities of an enigmatic neotropical frog, Allophryne ruthveni. Zool. J. Linn. Soc. 2002, 134, 335-346. [CrossRef]

326. Burton, T. Muscles of the pes of hylid frogs. J. Morphol. 2004, 260, 209-233. [CrossRef] [PubMed]

327. Pyron, R.A. Biogeographic analysis reveals ancient continental vicariance and recent oceanic dispersal in amphibians. Syst. Biol. 2014, 63, 779-797. [CrossRef] [PubMed]

328. Feng, Y.J.; Blackburn, D.C.; Liang, D.; Hillis, D.M.; Wake, D.B.; Cannatella, D.C.; Zhang, P. Phylogenomics reveals rapid, simultaneous diversification of three major clades of Gondwanan frogs at the Cretaceous-Paleogene boundary. Proc. Natl. Acad. Sci. USA 2017, 114, E5864-E5870. [CrossRef] [PubMed]

329. Haas, A. The phylogeny of frogs as inferred from primarily larval characters. Cladistics 2003, 19, $23-89$.

330. Wiley, E.O. Phylogenetics: The Theory and Practice of Phylogenetic Systematics; John Wiley and Sons: New York, NY, USA, 1981.

331. Lecointre, G.; Philippe, H.; Van Le, H.L.; Le Guyader, H. Species sampling has a major impact on phylogenetic inference. Mol. Phylogenetics Evol. 1993, 2, 205-224. [CrossRef]

332. Hillis, D.M. Inferring complex phylogenies. Nature 1996, 383, 130-131. [CrossRef]

333. Hillis, D.M. Taxonomic sampling, phylogenetic accuracy, and investigator bias. Syst. Biol. 1998, 47, 3-8. [CrossRef]

334. Rannala, B.; Huelsenbeck, J.P.; Yang, Z.; Nielsen, R. Taxon sampling and the accuracy of large phylogenies. Syst. Biol. 1998, 47, 702-710. [CrossRef]

335. Zwickl, D.J.; Hillis, D.M. Increased taxon sampling greatly reduces phylogenetic error. Syst. Biol. 2002, 51, 588-598. [CrossRef] [PubMed]

336. Pollock, D.D.; Zwickl, D.J.; McGuire, J.A.; Hillis, D.M. Increased taxon sampling is advantageous for phylogenetic inference. Syst. Biol. 2002, 51, 664-671. [CrossRef] [PubMed] 
337. Poe, S. Evaluation of the strategy of long-branch subdivision to improve the accuracy of phylogenetic methods. Syst. Biol. 2003, 52, 423-428. [CrossRef] [PubMed]

338. Rokas, A.; Carroll, S.B. More genes or more taxa? The relative contribution of gene number and taxon number to phylogenetic accuracy. Mol. Biol. Evol. 2005, 22, 1337-1344. [CrossRef]

339. Heath, T.A.; Zwickl, D.J.; Kim, J.; Hillis, D.M. Taxon sampling affects inferences of macroevolutionary processes from phylogenetic trees. Syst. Biol. 2008, 57, 160-166. [CrossRef]

340. Heath, T.A.; Hedtke, S.M.; Hillis, D.M. Taxon sampling and the accuracy of phylogenetic analyses. J. Syst. Evol. 2008, 46, 239-257.

341. Vences, M.; Guayasamin, J.M.; Miralles, A.; de La Riva, I. To name or not to name: Criteria to promote economy of change in Linnaean classification schemes. Zootaxa 2013, 3636, 201-244. [CrossRef]

342. Hoorn, C.; Wesselingh, F.P.; Ter Steege, H.; Bermudez, M.A.; Mora, A.; Sevink, J.; Jaramillo, C. Amazonia through time: Andean uplift, climate change, landscape evolution, and biodiversity. Science 2010, 330, 927-931. [CrossRef]

343. Duellman, W.E. Distribution Patterns of Amphibians in South America. In Patterns of Distribution of Amphibians: A Global Perspective; Duellman, W.E., Ed.; The Johns Hopkins University Press: Baltimore, MD, USA, 1999; pp. 255-328.

344. Peterson, A.T.; Soberon, J.; Sanchez-Cordero, V. Conservatism of ecological niches in evolutionary time. Science 1999, 285, 1265-1267. [CrossRef]

345. Coyne, J.A.; Orr, H.A. Speciation; Sinauer Associates, Inc.: Sunderland, MA, USA, 2004.

346. Wiens, J.J. Speciation and ecology revisited: Phylogenetic niche conservatism and the origin of species. Evolution 2004, 58, 193-197. [CrossRef]

347. Remsen, J.V. High incidence of "leapfrog" pattern of geographic variation in Andean birds: Implications for the speciation process. Science 1984, 224, 171-173. [CrossRef] [PubMed]

348. Graves, G.R. Linearity of geographic range and its possible effect on the population structure of Andean birds. Auk 1988, 105, 47-52. [CrossRef]

349. Vuilleumier, F. Pleistocene speciation in birds living in the high tropical Andes. Nature 1969, 223, 1179-1180. [CrossRef]

350. Haffer, J. Avian Speciation in Tropical South America; Nutall Ornithological Club: Cambridge, MA, USA, 1974.

351. Hackett, S.J. Molecular systematics and zoogeography of flowerpiercers in the Diglossa baritula complex. Auk 1995, 112, 156-170. [CrossRef]

352. Behling, H.; Hooghiemstra, H. Holocene Amazon rainforest-savanna dynamics and climatic implications: High-resolution pollen record from Laguna Loma Linda in eastern Colombia. J. Quat. Sci. 2000, 15, 687-695. [CrossRef]

353. Bonaccorso, E.; Koch, I.; Peterson, A.T. Pleistocene fragmentation of Amazonian species' ranges. Divers. Distrib. 2006, 8, 157-164. [CrossRef]

354. Bush, M.B.; de Oliveira, P.E. The rise and fall of the refugial hypothesis of Amazonian speciation: A paleoecological perspective. Biota Neotrop. 2006, 6, 1-17. [CrossRef]

355. Wiens, J.J.; Graham, C.H. Niche conservatism: Integrating evolution, ecology, and conservation biology. Ann. Rev. Ecol. Evol. Syst. 2005, 36, 519-539. [CrossRef]

356. Losos, J.B. Phylogenetic niche conservatism, phylogenetic signal and the relationship between phylogenetic relatedness and ecological similarity among species. Ecol. Lett. 2009, 11, 995-1003. [CrossRef]

357. Lynch, J.D.; Duellman, W.E. Frogs of the genus Eleutherodactylus in western Ecuador: Systematics, ecology, and biogeography. Univ. Kans. Nat. Hist. Mus. Spec. Publ. 1997, 23, 1-236.

358. Graham, C.H.; Ron, S.R.; Santos, J.C.; Schneider, C.J.; Moritiz, C. Integrating phylogenetics and environmental niche models to explore speciation mechanisms in dendrobatid frogs. Evolution 2004, 58, 1781-1793. [CrossRef] [PubMed]

359. Martof, B.S. Home range and movements of the green frog, Rana clamitans. Ecology 1953, 34, 529-543. [CrossRef]

360. Dole, J.W. Spring movements of leopard frogs, Rana pipiens Schreber, in Northern Michigan. Am. Midl. Nat. 1967, 78, 167-181. [CrossRef]

361. Dole, J.W. Dispersal of recently metamorphosed leopard frogs, Rana pipiens. Copeia 1971, 2, $221-228$. [CrossRef] 
362. Berven, K.A.; Grudzien, T.A. Dispersal in the wood frog (Rana sylvatica): Implications for genetic population structure. Evolution 1990, 22, 2047-2056.

363. Lynch, J.D. The gauge of speciation: On the frequencies of modes of speciation. In Speciation and Its Consequences; Otte, D., Endler, J.A., Eds.; Sinauer Associates: Sunderland, MA, USA, 1989; pp. 527-556.

364. Graves, G.R. Elevational correlates of speciation and intraspecific geographic variation in plumage in Andean forest birds. Auk 1985, 102, 556-579. [CrossRef]

365. Krabbe, N. Arid valleys as dispersal barriers to high-Andean forest birds in Ecuador. Cotinga 2008, 29, 28-30.

366. Guayasamin, J.M.; Bonaccorso, E.; Duellman, W.E.; Coloma, L.A. Genetic differentiation in the nearly extinct harlequin toads (Bufonidae: Atelopus), with emphasis on the Atelopus ignescens and A. bomolochos species complexes. Zootaxa 2010, 2574, 55-68. [CrossRef]

367. Guayasamin, J.M.; Krynak, T.; Krynak, K.; Culebras, J.; Hutter, C.R. Phenotypic plasticity raises questions for taxonomically important traits: A remarkable new Andean rainfrog (Pristimantis) with the ability to change skin texture. Zool. J. Linn. Soc. 2015, 173, 913-928. [CrossRef]

368. Guayasamin, J.M.; Hutter, C.R.; Tapia, E.E.; Culebras, J.; Peñafiel, N.; Pyron, R.A.; Arteaga, A. Diversification of the rainfrog Pristimantis ornatissimus in the lowlands and Andean foothills of Ecuador. PLoS ONE 2017, 12, e0172615. [CrossRef]

369. Hutter, C.R.; Guayasamin, J.M. Cryptic diversity concealed in the Andean cloud forests: Two new species of rainfrogs (Pristimantis) uncovered by molecular and bioacoustic data. Neotrop. Biodivers. 2015, 1, 36-59. [CrossRef]

370. Prieto-Torres, D.A.; Cuervo, A.M.; Bonaccorso, E. On geographic barriers and Pleistocene glaciations: Tracing the diversification of the Russet-crowned Warbler (Myiothlypis coronata) along the Andes. PLoS ONE 2018, 13, e0191598. [CrossRef] [PubMed]

371. Deichmann, J.; Boundy, J.; Williamson, G.B. Anuran artifacts of preservation: 27 years later. Phyllomedusa 2009, 8, 51-58. [CrossRef]

372. Harvey, M.B.; Noonan, B.P. Bolivian glass frogs (Anura: Centrolenidae) with a descrition of a new species from Amazonia. Proc. Biol. Soc. Wash. 2005, 118, 428-441. [CrossRef]

373. Barnett, J.B.; Michalis, C.; Anderson, H.M.; McEwen, B.L.; Yeager, J.; Pruitt, J.N.; Scott-Samuel, N.E.; Cuthill, I.C. Imperfect transparency and camouflage in glass frogs. Proc. Natl. Acad. Sci. USA 2020, 201919417. [CrossRef]

374. Schwalm, P.A.; Starrett, P.H.; McDiarmid, R.W. Infrared reflectance in leaf-sitting neotropical frogs. Science 1977, 196, 1225-1226. [CrossRef]

375. Delia, J.; Bravo-Valencia, L.; Warkentin, K.M. The evolution of extended parental care in glassfrogs: Do egg-clutch phenotypes mediate coevolution between the sexes? Ecol. Monogr. 2020. [CrossRef]

376. Cardozo-Urdaneta, A.; Señaris, J.C. Vocalización y biología reproductiva de las ranas de cristal Hyalinobatrachium pallidum y Centrolene daidaleum (Anura, Centrolenidae) en la sierra de Perijá, Venezuela. Mem. De La Fund. La Salle De Cienc. Nat. 2012, 70, 87-105.

377. Cadle, J.E.; McDiarmid, R.W. Two new species of Centrolenella (Anura: Centrolenidae) from northwestern Peru. Proc. Biol. Soc. Wash. 1990, 103, 746-768.

378. Vargas-Salinas, F.; Quintero-Ángel, A.; Osorio-Domínguez, D.; Rojas-Morales, J.A.; Escobar-Lasso, S.; Gutiérrez-Cárdenas, P.D.A.; Amézquita, A. Breeding and parental behaviour in the glass frog Centrolene savagei (Anura: Centrolenidae). J. Nat. Hist. 2014, 48, 1689-1705. [CrossRef]

379. Cabanzo-Olarte, L.C.; Ramírez-Pinilla, M.P.; Serrano-Cardozo, V.H. Oviposition, site preference, and evaluation of male clutch attendance in Espadarana andina (Anura: Centrolenidae). J. Herpetol. 2013, 47, 314-320. [CrossRef]

380. Restrepo, J.H.; Naranjo, L.G. Ecología reproductiva de una población de Cochranella ignota (Anura: Centrolenidae). Rev. Acad. Colomb. Cienc. Exact. Fís. Nat. 1999, 23, 49-60.

381. Gouveia, S.F.; Faria, R.G.; da Rocha, P.A. Local distribution and notes on reproduction of Vitreorana aff. eurygnatha (Anura: Centrolenidae) from Sergipe, Northeastern Brazil. Herpetol. Bull. 2012, 120, 16-21.

382. Lehtinen, R.M.; Green, S.E.; Pringle, J.L. Impacts of paternal care and seasonal change on offspring survival: A multiseason experimental study of a Caribbean frog. Ethology 2014, 120, 400-409. [CrossRef]

383. Vockenhuber, E.A.; Hödl, W.; Karpfen, U. Reproductive behavior of the glass frog Hyalinobatrachium valerioi (Anura: Centrolenidae) at the tropical stream Quebrada Negra (La Gamba, Costa Rica). Stapfia 2008, 88, 335-348. 
384. Guayasamin, J.M.; Barrio-Amorós, C. Combat behavior in Centrolene andinum (Rivero, 1968) (Anura: Centrolenidae). Salamandra 2005, 41, 153-155.

385. Rojas-Runjaic, F.J.; Cabello, P. Centrolene daidaleum (Ruiz-Carranza \& Lynch, 1991)(Anura, Centrolenidae): A glassfrog with primitive and derived combat behavior. Zootaxa 2011, 2833, 60-64.

386. Restrepo-Toro, J.H. Ecología conductual de una Rana arbórea Neotropical. Bachelor's Thesis, Universidad del Valle, Cali, Colombia, 1996.

387. Cuesta, F.; Peralvo, M.; Merino-Viteri, A.; Bustamante, M.; Baquero, F.; Freile, J.F.; Muriel, P.; Torres-Carvajal, O. Priority areas for biodiversity conservation in mainland Ecuador. Neotrop. Biodivers. 2017, 3, 93-106. [CrossRef]

388. Vandegrift, R.; Thomas, D.C.; Roy, B.A.; Levy, M. The Extent of Recent Mining Concessions in Ecuador; Rainforest Information Center: Nimbin, NSW, Australia, 2018.

389. Berger, L.; Speare, R.; Daszak, P.; Green, D.E.; Cunningham, A.A.; Goggin, C.L.; Slocombe, R.; Ragan, M.A.; Hyatt, A.D.; McDonald, K.R. Chytridiomycosis causes amphibian mortality associated with population declines in the rain forests of Australia and Central America. Proc. Natl. Acad. Sci. USA 1998, 95, 9031-9036. [CrossRef]

390. Bonaccorso, E.; Guayasamin, J.M.; Méndez, D.; Speare, R. Chytridomycosis as a possible cause of population declines in Atelopus cruciger (Anura: Bufonidae). Herpetol. Rev. 2003, 34, 331-334.

391. Scheele, B.C.; Pasmans, F.; Skerratt, L.F.; Berger, L.; Martel, A.; Beukema, W.; Acevedo, A.A.; Burrowes, P.A.; Carvalho, T.; Catenazzi, A.; et al. Response to comment on "Amphibian fungal panzootic causes catastrophic and ongoing loss of biodiversity". Science 2020, 367, eaay2905. [CrossRef] [PubMed]

392. Menéndez-Guerrero, P.A.; Graham, C.H. Evaluating multiple causes of amphibian declines of Ecuador using geographical quantitative analyses. Ecography 2013, 36, 756-769. [CrossRef]

393. Vimos, D.J.; Encalada, A.C.; Ríos-Touma, B.; Suárez, E.; Prat, N. Effects of exotic trout on benthic communities in high-Andean tropical streams. Freshw. Sci. 2015, 34, 770-783. [CrossRef]

394. Krynak, K.L.; Wessels, D.G.; Imba, S.M.; Krynak, T.J.; Snyder, E.B.; Lyons, J.A.; Guayasamin, J.M. Call survey indicates rainbow trout farming alters glassfrog community composition in the Andes of Ecuador. Amphib. Reptile Conserv. 2020, 14, e234.

395. Polato, N.R.; Gill, B.A.; Shah, A.A.; Gray, M.M.; Casner, K.L.; Barthelet, A.; Messer, P.W.; Simmons, M.P.; Guayasamin, J.M.; Encalada, A.C.; et al. Narrow thermal tolerance and low dispersal drive higher speciation in tropical mountains. Proc. Natl. Acad. Sci. USA 2018, 115, 12471-12476. [CrossRef] [PubMed]

396. Hoegh-Guldberg, O.; Hughes, L.; McIntyre, S.; Lindenmayer, D.B.; Parmesan, C.; Possingham, H.P.; Thomas, C.D. Assisted colonization and rapid climate change. Science 2008, 321, 345-346. [CrossRef] [PubMed]

397. Quintero, I.; Wiens, J.J. Rates of projected climate change dramatically exceed past rates of climatic niche evolution among vertebrate species. Ecol. Lett. 2013, 16, 1095-1103. [CrossRef]

398. Jezkova, T.; Wiens, J.J. Rates of change in climatic niches in plant and animal populations are much slower than projected climate change. Proc. R. Soc. B 2016, 283, 20162104. [CrossRef]

(C) 2020 by the authors. Licensee MDPI, Basel, Switzerland. This article is an open access article distributed under the terms and conditions of the Creative Commons Attribution (CC BY) license (http://creativecommons.org/licenses/by/4.0/). 